\title{
AN EVOLUTIONARY BASIS FOR POLLINATION EGOLOGY
}

S. C. WILLEMSTEIN

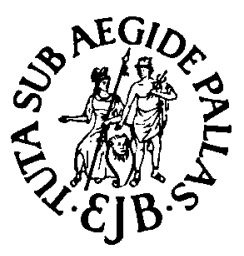

E. J. BRILL / LEIDEN UNIVERSITY PRESS LEIDEN 1987 
Published with financial support from the Netherlands Organization for the Advancement of Pure Research (Z.W.O.)

Published in cooperation with the Leiden University Press, Leiden

\section{Library of Congress Cataloging-in-Publication Data}

Willemstein, S. C.

An evolutionary basis for pollination ecology.

(Leiden botanical series, ISSN 0169-8508; v. 10)

Bibliography: p.

Includes index.

1. Insects-Evolution. 2. Insects-Food.

3. Insects-Ecology. 4. Pollination. 5. Plants-

Evolution. 6. Botany-Ecology. I. Title. II. Series.

QL468.7.W55 $1987 \quad$ 582'.056 87-12833

ISBN 90-04-08457-6 (pbk.)

ISSN 0169-8508

ISBN 9004084576

(C) Copyright 1987 by E.J. Brill, Leiden, The Netherlands

All rights reserved. No part of this book may be reproduced or translated in any form, by print, photoprint, microfilm, microfiche or any other means without written permission from the publisher

PRINTED IN THE NETHERLANDS BY E. J. BRILL. 
Aan Els

Voor Nicolette en Eveline 


\section{PREFACE}

Apart from the persons mentioned in the acknowledgements at page 364 (maximum of acknowledgements allowed for the thesis version of this study), I would like to thank:

Prof. Dr. J. T. Wiebes (Rijksmuseum van Natuurlijke Historie en Geologie en Mineralogie, Leyden) and Prof. Dr. C. Kalkman (Rijksherbarium, Leyden) for their lasting support;

Prof. Dr. St. Vogel (Institut für Spezielle Botanik, Johannes Gutenberg Universität, Mainz) and Dr. M. C. F. Proctor (Department of Biology, University of Exeter) for critically reading the manuscript, and in stimulating discussions providing important suggestions for completing this study.

S.C.W. 


\section{GONTENTS}

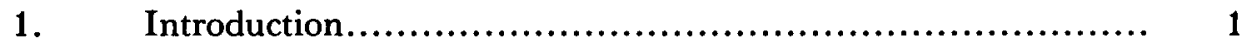

2. Methodology and terms...................................... 4

3. Materials and techniques, co-authored by M. ZANDEE......... 10

4. Short descriptions of the feeding-habits of the adult insects included in this study and of their relatives.................. 12

4.1. Coleoptera..................................................... 12

4.2. Hymenoptera .............................................. 21

4.3. Lepidoptera .............................................. 26

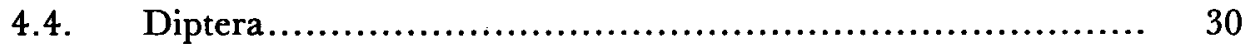

4.5. Other insect orders in which flower-visiting occurs........... 39

5. Correlation of the feeding-habits of the insects with their phylogeny and their fossil record................................... 41

5.1. Coleoptera............................................... 45

5.2. Hymenoptera ............................................. 64

5.3. Lepidoptera .............................................. 87

5.4. Diptera................................................ 95

5.5. Notes on the stratigraphical appearance of the families in which anthophily developed...................................... 108

6. Statistical analysis of the floral characters important to pollination ecology................................................. 110

6.1. Evaluation of the appearance of the anthophilous insect taxa. 110

6.2. Pollination types............................................ 112

6.2.1. The complex of facultative and obligatory pollination types... 112

6.2.2. Obligatory entomophilous pollination types.................... 118

6.3. Blossom-pollinator relationships........................... 125

6.4. Flower types............................................. 129

6.5. Blossom classes........................................... 133

6.6. Single flower as pollination unit........................... 141

6.7. Perianth developed or rudimentary........................... 146

6.8. Colours, co-authored by M. ZANDEE......................... 148

6.8.1. Analysis by $2 \times 2$ chi-square testing......................... 149

6.8.2. The interdependence among floral colours and visiting insect groups. An analysis by reciprocal averaging.................. 154 
6.8.3. Interdependences between floral colours and the taxa of lower rank within the insect groups............................... 165

6.9. Position of the anthers .................................. 179

6.10. Numbers of stamens per flower........................... 182

6.11. Position of the ovaries.................................... 188

6.12. Number of ovules per stigma............................. 193

6.13. Nectar presence and position............................... 199

6.14. Variation in time between receptivity and dehiscence.......... 204

6.14.1. Dichogamy ..................................................... 204

6.14.2. Homogamy.............................................. 219

6.15. Dicliny ................................................ 227

6.16. Concluding remarks: the transformation series within angiosperm flowers, derived from the insect-flower relationships....

7. Reconstruction of the evolutionary developments in pollination

7.1. A theoretical model of the earliest angiosperm flowers .........

7.1.1. General floral character states .................................

7.1.2. Survey of characters or character states of the earliest angiosperm flower.

7.2. Remarks on the origin of the Angiospermae.

7.3. Approximate dating of the flower-ecologically important apomorphies on basis of the fossil record and phylogeny of the insect taxa in which anthophily developed.....

7.4. Comparison of the fossil record of the Angiospermae and the fossil record and phylogeny of the insect taxa in which anthopily developed

7.4.1. Origin and early development............................. 292

7.4.2. Lower Cretaceous........................................... 293

7.4.3. Upper Cretaceous.......................................... 299

7.4.4. Tertiary ................................................. 319

7.4.5. Quaternary............................................. 340

7.4.6. Some remarks on the fossil record of the Angiospermae....... 342

7.5. Phases in the evolutionary development of angiosperm pollination

8. Summary and conclusions............................... 348

9. Prospects of research to evolutionary developments in pollina-

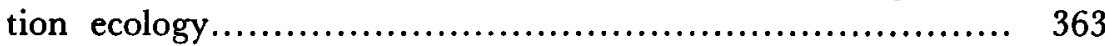

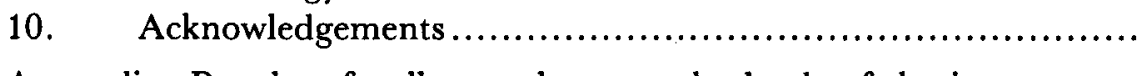
364

Appendix: Results of pollen analyses on the loads of the integuments and contents of the digestive tracts of Cetoniinae, Cerambycinae and Lepturinae.

References.................................................. 374

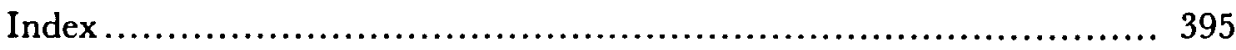




\section{INTRODUCTION}

Usually pollination ecology is narrative and in many cases even anecdotical, presenting case histories rather than generalizations. There are exceptions however, which are mainly presented in the form of text books, including syntheses of the relations of pollinators and flowers, as Müller (1873 and 1881), Loew (1895), Knuth (1898), Kirchner (1911), Knoll (1921 and 1956), Cammerloher (1931), Meeuse (1961), Kugler (1970), Proctor Yeo (1973), and Faegri \& Van der Pijl (1980). The syntheses in these books, however, are not connected with either the phylogeny of the pollinators or that of the angiosperms.

Evolutionary studies on pollinator-flower relationships are mainly restricted to taxa of lower rank, morphological features, phenology of plant communities, processes (isolating mechanisms; ethology of, mainly, higher bees; and other restricted items). Examples are: Daumann, 1935 (nectaries in the taxonomy of Iris), 1966 ("Pollenkitt", pollination mechanisms and phylogeny); Doyle, 1945 (developmental lines in pollination mechanisms in the Coniferales); Mayr, 1947 (ecological factors in evolution); Pennell, 1948 (relation between taxonomy and floral biology); Grant, 1949, 1963 (processes: pollination systems as isolating mechanisms; adaptations); Whitehouse, 1950 (incompatibility and angiosperm evolution); Heslop-Harrison, 1958 (ecological variation and angiosperm evolution); Faegri, 1965 (Proteaceae); Baker, 1966 (evolution of incompatibility systems in Plumbaginaceae); Grant, 1966 (floral colours and hummingbird flowers); Gottsberger, 1967, 1972 (Malvaceae), 1970 (Annonaceae), 1974 ("primitive" angiosperms); Grant \& Grant, 1965 (description of several evolutionary lines in the pollination of North American Polemoniaceae, regarding also the taxonomical relationships within the family), 1968 (hummingbirds and flowers); Van der Pijl, 1969 (evolutionary action of tropical animals on plant reproduction); Levin \& Anderson, 1970 (processes: competition for pollinators beween simultaneously flowering species); Kevan, 1972, 1972a (entomophilous pollination in the high arctic); Bell, 1971 (fine example of developmental processes in micro-evolution of some Apiaceae); Grinfeld, 1973 (anthophilous evolution of the Apoidea); Heywood (Ed.), 1973 (various examples of taxonomy and ecology); Gilbert \& Raven (Eds), 1975 (various examples of co-evolution of animals and plants); Frankie, 1975 (tropical phenology and pollinator-plant evolution); Dodson, 1975 (co-evolution of orchids and bees); Chase Raven, 1975 (evolutionary and ecological relationships in two Aquilegia species); Vogel, 1969, 1971, 1974, 
1984, 1986 (co-evolution of oil-producing flowers and oil-collecting bees); and many others. Interesting surveys can be expected from e.g. the extensive research on bumblebees and Pedicularis (e.g. Macior, 1968, etc.; and Kwak, 1979, etc, see references) and of Agaonidae and Ficus (see e.g. Wiebes, 1979, 1982 and his referring to e.g. Corner and Galil).

The main synopses have been given by Van der Pijl $(1960,1961)$ and Proctor (1978), based on a comparison of Recent ecosystemic conditions.

Some authors have included angiosperm phylogeny and fossil record in pollination ecological research, as Leppik (1957, 1957a, 1971 and 1974) for Rhododendron and Crepet et al. (1974) and Crepet (1979 and 1979a).

In case of an approach from plant systematics, the tracing of evolutionary lines (transformation series) is difficult, because the study of the phylogeny of the Angiospermae in the sense of Hennig (1966) is only at its very beginning, despite the several existing classification systems (Takhtajan, 1980; Cronquist, 1981; Dahlgren et al., 1981; Rouleau, 1981; Thorne, 1981). In actual systematics, first the phylogeny is described and it functions as a basis for the classification. Systematic zoology in this respect is ahead of taxonomical botany. This certainly will be due to the fact that morphological variation within angiosperm species is much more extensive than in animal species. But to my opinion it may also be a result of the fact that zoological systematists much earlier started to produce taxonomical monographs (subject of study a whole taxon) than did plant taxonomists. The latter mainly produced geographically restricted floras, which for practical reasons initially were more required than monographs of single taxa, because of the extensive economical importance of angiosperms, but in which in most cases only parts of taxa occur. And, last but not least, the inventarisation of seed plants of a region is much easier than that of insects.

Although the insect phylogeny in the sense of Hennig (1966) is much in development in recent times (see e.g. the many foot notes in the second edition of Hennig (1981)) the link with entomophilous pollination ecology has not yet been made on a more large scale. This may be due to the fact that up to now too few entomologists have shown interest in pollination ecology from a phylogenetic point of view. One of the few examples concerns the Agaonidae (see Wiebes, 1982)

It is, however, hopeful to notice that in the most recent surveys of the Angiospermae (as e.g. Cronquist, 1981) not only morphological character states, but also pollen ecological aspects are, at least, taken into account.

As has been stated above, the insufficient descriptions of evolutionary trends in pollination are mainly due to the imperfectly studied phylogeny of the Angiospermae, but also other facts may have hindered these descriptions. The main interest of pollination ecologists was in first instance drawn to the highlights of insect-flower relationships. In most cases these are highly 
developed temporary terminal points of evolutionary lines, and in many cases possibly the definite terminal points. It mainly will be the beauty of these cases which gave them such an important place in pollination ecology as a whole. These and other pollination systems are classified in the, each other excluding, pollination syndromes. These syndromes, however, refer to artificial groupings of taxonomically often unrelated angiosperms. Only when applied within the phylogeny of angiosperm taxa of lower rank, they will throw some light on the evolutionary developments of pollination. Besides, pollination syndromes only cover a part of the angiosperm flowers. Many non-specialized entomophilous flowers do not fit the syndromes, and consequently they were largely overlooked. In analysing the present state of pollination ecology it can be concluded that most evolutionary studies are limited to the pollination syndromes.

The absence of general descriptions of evolutionary trends in pollination ecology, based on the phylogenies of pollinators and angiosperms, has fascinated and challenged me to try and find out whether these transformation series can be described. To achieve this, the comparatively well-known phylogeny of insects and their extensive fossil record are taken as a starting point and are correlated with the Recent insect feeding-habits and insectflower relationships. This correlation results in flower-morphological transformation series, which can be dated by the fossil history of insects and comparison with the fossil history of angiosperms in its turn indicates floral developments and consequent developments in pollination ecology. 


\section{METHODOLOGY AND TERMS}

For the description of an evolutionary basis for pollination ecology the following tools are available:

a) insect phylogeny based on Recent comparative morphology and fossil history;

b) Recent feeding-habits of insects and their relationships with flowers (inclusive some aspects of insect ethology);

c) angiosperm phylogeny based on Recent comparative morphology and fossil history.

One of the main aids to indicate the sequence of developments is the fossil record. According to De Jong (1980) the stratigraphical appearance is a valid argument to decide whether a character state is plesio- or apomorphous. It, however, will be subject to constant change. The fossil record of angiosperm flowers is very poor; flowers are temporary parts of the plants and after blossom they drop off in whithered parts, which means that even in a habitat favourable for fossilization entire fossil flowers are extremely rare. The main exception is the amazingly rich middle Eocene Claiborne Formation of the U.S.A. (see Grepet, 1979), which provides a good flower-ecological picture of that period. Also in the middle Senonian fluviatile sands and clays from Scania, southern Sweden, several flower fossils are found which demonstrate the definite presence of some flower-ecologically important character states in the Upper Cretaceous (see Friis, 1983 and Friis \& Skarby, 1982). In contrast to the floral fossil history that of the adult insects (with their resistent chitinous exoskeleton) is very rich. The description of the evolutionary basis for flower ecology is mainly based on the fossil record of the insects. There are strong arguments for this approach, but it requires some explanation.

The nature of the co-evolution of anthophilous insects and entomophilous flowers

The evolutionary developments of pollination are essentially the result of coevolution of (anthophilous) insects and entomophilous flowers (except for developments towards anemogamy, hydrogamy and autogamy). The term coevolution denotes the complex of reciprocal adaptive developments favoured by the complex of reciprocal selective pressures, or reciprocal restrictions to variations. Starting from dystropic pollinators (compare e.g. the interesting publication of Vogel et al. (1984) on ornithophilous flowers pollinated by nonspecialized birds on the Canary Islands) the developments to allophilic, 
hemiphilic and euphilic flowers and allotropic, hemitropic (hemilectic) and eutropic (eulectic) pollinators respectively occur. In many cases it will be difficult to indicate whether the evolution of anthophilous insects is guided by the evolution of the angiosperm flowers, or vice versa. Both guidances will occur, but in general it can be stated that initially adult insects are less dependent on flowers or certain forms of flowers, than are entomophilous flowers on insects for (cross-)pollination. Many nectarivorous insects can e.g. also feed on nonfloral honey-dew; within anthophily long-tongued insects in many cases also can feed on short-tubed flowers. This difference in absoluteness of dependence is caused by the fact that insects are free-living organisms and plants in adult state are sessile, and means that the insects form an essential part of the environment of entomophilous flowers.

In the evolution of pollination this indicates that the developments of floral structures run (somewhat) after the developments in insect morphology; every new floral character state is dependent on the presence, i.e. established development, of corresponding elements of insect morphology. Within the variation of floral character states one of the extremes will succeed if corresponding extremes are present in the "environmental" insect morphology (e.g. lengths of corolla tubes and tongue-lenghts of anthophilous insects). Once succeeded, on the other hand selection in one of the extremes of the variation in insect morphology can occur (e.g. anthophilous insects with the longest tongues will meet less feeding-competition on the flowers with the longest corolla tubes than on those with shorter ones). Because initially floral evolution is more dependent on the morphological evolution of anthophilous insects than is the reverse, the stratigraphical presence of these insects may indicate the presence of corresponding floral structures, or the potential presence of them. The stratigraphical presence of floral structures more certainly indicate the presence of insect morphology, but as mentioned before, the fossil record of floral structures is very poor.

Using the phylogeny of anthophilous insects, based on the classification of taxa in which anthophily developed and their fossil record, requires the presupposition that these insects did not behave otherwise in earlier times in unchanged morphological conditions (e.g. Coleoptera in the Cretaceous had no wider visual sensitivity in the spectrum than they have now). This presupposition is the same as the doctrine of uniformitarianism as used in historical geology. In this study it will be regarded as "vertical" uniformitarianism (in the geological time scale); because the sample taken for the analysis of insectflower relationships is geographically limited to the central European area, the term "horizontal"' uniformitarianism will be also used (see next paragraph). 
Correlation of the Recent insect-flower relationships with the phylogeny of insect taxa in which anthophily developed

The least anecdotically compiled survey of flower visits of insects is that of Knuth (1898a, 1899) as far as it concerns the central European area.

A statistical analysis was carried out, correlating these insect visits to flowers with the floral morphology of central Europe, as described by Hegi (19061931, 1936 etc. and 1966 etc.) and listed by Ehrendorfer (1973). To correlate the results of this analysis with the fossil record of the insects, the results have to be considered world-wide (e.g. if the bees in central Europe appear to visit significantly more blue coloured flowers than do beetles, they are considered to do so also in other parts of the world), and this requires the presupposition of "horizontal" uniformitarianism (geographically over the world). The geographical restriction of the analysis means that not all insect-flower relationships are covered, which will appear in many examples. The statement of Faegri \& Van der Pijl (1980) that pollination ecology is too much based on the observations of the central European area (with, however, still the most detailedly known flora and insect fauna of the world) is avoided as much as possible: only the statistically significant results are taken into account.

The correlation of the results of the analysis of Recent insect-flower relationships requires a behavioural "vertical" uniformitarianism (in unchanged morphological conditions).

The phylogeny of the insects is largely based on the principles of phylogenetic systematics as introduced by Hennig (1966). This definition of classification in complexes of sister groups, applied on insect phylogeny (Hennig, 1969 and 1981) has the advantage of the predictive value of stratigraphical presence of insect taxa (the presence of a predictive theory can be considered one of the most important elements of good research programmes, see e.g. Lakatos, 1978): if a representative of a taxon is present in a stratum, demonstrating the presence of one or more synapomorphies, also representatives of the sister-group must have been present in the time corresponding with that stratum.

The results of this correlation are functionally directed developmental lines in floral morphology, or in other words a series of transformation series. E.g., the floral colours yellow and white were much earlier functional in attracting insects than were purple and blue, and therefore probably they were earlier present than the other ones, i.e. yellow and white can be considered plesiomorphous (primitive) floral colours and purple and blue apomorphous (advanced) ones in the evolution of angiosperm floral colours. Regarding the presuppositions stages in the transformation series can be dated by the stratigraphical appearance of the insect taxa in which anthophily developed. 
The phylogeny of the Angiospermae in the sense of Hennig (1966) ought to be based on the Recent morphology correlated with the fossil record. The first has not yet been worked out as detailed as that of the insects, or at least is less readily available, and thus the main component of correlation is that of the fossil record. It is possible that the dating of the transformation series on the basis of the stratigraphical appearance of the insect taxa in which anthophily developed, has to be changed by the stratigraphical appearance of angiosperm fossils (hypothetically) or flowers (definitely). This method of reasoning is called spiral reasoning (Hull, 1967, 1979) and is the result of reciprocal illumination (Hennig, 1966; see also e.g. Walker, 1974a).

A survey of the structure of this study is given in fig. 2-1, indicating the sources (with indications of secondary, i.e. derived from literature, and original, i.e. personal observations, statistical analyses and new combinations) and the way of reasoning. It is indicated that application of the results of this study on the phylogeny of the Angiospermae may provide a synergy effect (at any rate at the present state of knowledge of angiosperm phylogeny), i.e. comparison of the description of the evolution of pollination (transformation series, mainly based on insect phylogeny and fossil record) with the phylogeny and fossil record of the Angiospermae will give a result that reaches further than separate descriptions (continuing process of reciprocal illumination).

This study consists of a number of compilations, which are compared with each other. None of these compilations is complete, they merely give a survey of the present state of comparatively easily accessable knowledge, i.e. found in more general surveying articles. Together, however, they throw some light on the evolutionary developments in pollination ecology at a fairly high abstraction level. The general transformation series should be checked on their validity in angiosperm taxa of lower rank, also with regard to falsification. The latter may indicate interesting evolutionary potentials.

This study has to be considered no more than a first interim report towards the foundation of a more sound evolutionary basis for pollination ecology, throwing light on both the phylogeny of entomogamous angiosperms and on that of anthophilous insects.

\section{Some remarks on the terminology used in this study}

The flower is considered the reproductive structure of the Angiospermae and the term flower is not used for Gymnospermae.

In naming the pollination systems a distinction is made between the flower and the specimen or taxon. A flower can be entomophilous (in case of entomochory, there is no question of a flower anymore). Entomophily in a 


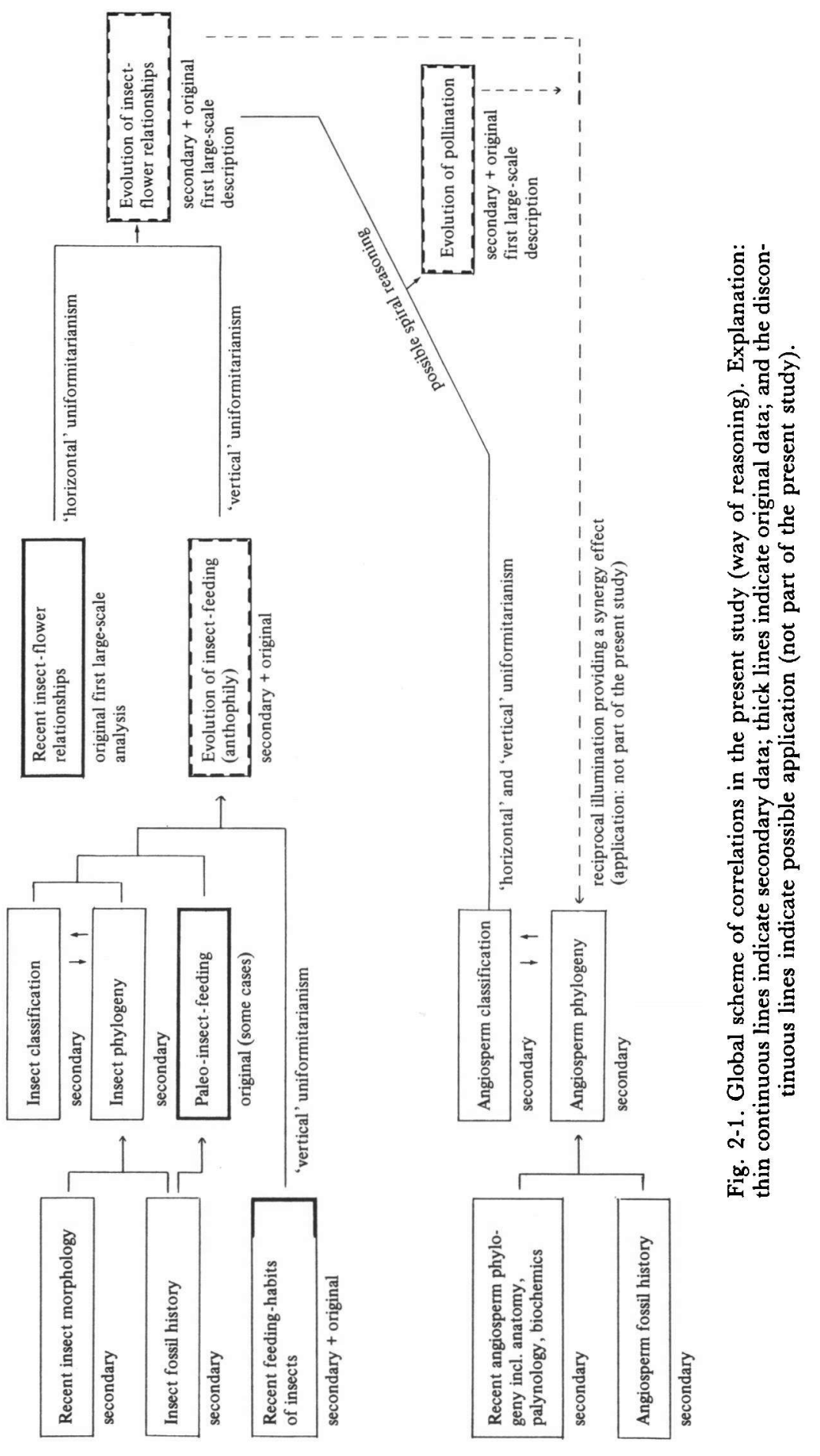


specimen or a taxon is possible, but may mean more insect-plant relationships. As example I will use here the relations of ants with plants: there may be question of myrmecochory, myrmecophylaxis, often combined with myrmecodomy and myrmecogamy (pollination by ants). In this study for the flower the termination -philous (not regarding possible cases of floral entomodomy, they are considered to be connected with the entomophily) and for specimens or taxa the termination -gamous is used in indicating the pollination system. 


\section{MATERIAL AND TECHNIQUES (co-authored by M. ZANDEE)}

As indicated in the previous chapter, the basic material for this study is the compilation of insect visits to flowers (whether or not leading to pollination) of Knuth (1898a and 1899), as far as it concerns the central European area. Although already very old, it still is the least anecdotically compiled survey readily available.

A data base was compiled as follows. Following Hegi (1906-1931; 1936, etc.; 1966, etc.) the central European angiosperm species were coded, and for each species flower-ecologically important character states (see chapter 6) were entered in the data base together with its insect visitors mentioned in Knuth (1898a and 1899). In order to obtain frequencies for visiting insect taxa suitable for statistic evaluation the presence of these taxa was scored at (sub)family level. Scoring for lower category levels resulted in data matrices with too many zero entries. However, in this study (except in section 6.8.2) only the main orders of flower-visiting insects are treated: Coleoptera, Diptera, Lepidoptera and Hymenoptera. The latter order was functionally divided, on the basis of degree of differences in anthophily, morphology and ethology, into Apoidea (bee families) and non-apoid Hymenoptera (wasps). The significance of these groups, with regard to the more detailed survey of the phylogeny and fossil record of the insect taxa in which anthophily developed is explained in section 6.1.

From the data base frequencies relating to the presence of flower-ecologically important characters, as mentioned in chapter 6 , were extracted within the following categories:

- species of which the flowers are suitable for pollination by the various insect groups (facultative and obligatory pollination types, see section 6.2.1);

- species of which the flowers can be classified in the pollination syndromes (obligatory pollination types, see section 6.2.2);

- species visited by the various insect groups (visited by Coleoptera, Diptera, etc., or not: Qualitative analysis);

- visits of different insect species within the group/taxon to the flowers, indicated as disposition of flower visits of the various insect groups/taxa referring to the character states (Quantitative analysis).

In the first three categories the units are the angiosperm species. In the latter the units are visits of different insect species, thus, including the range within the insect groups of preferences for, or interdependence with the character 
states. In the qualitative analysis the insect group whether ot not is interdependent with the character states; in the quantitative analysis also the taxa of lower rank within the insect groups have their impact in the interdependence of the insect group with the character states. The differences of the frequencies within the categories were pairwise evaluated by chi-square tests.

The a priori pairwise decomposition of large data matrices comprising frequency data destroys the statistical interdependency among samples necessary to perform a proper chi-square analysis. Therefore probability levels given for all null-hypotheses in the separate analyses are not interpreted as indicating strict statistical significance. They only serve as putative boundaries beyond which a meaningful biological interpretation of the observed differences is considered irrelevant or impossible. Considering the general question of linking biological with statistical significance this approach was mainly chosen for its ease of computation, while obtaining quick first glances of general tendencies.

In one instance, viz. the analysis of interdependency between floral colours and insect visits (sections 6.2 and 3), another approach was explored as well. Here the technique of reciprocal averaging (or correspondence analysis) was used to decompose the data matrix into independent aspects of variation among frequencies of insect visits to floral colours. In applying this technique the problem of statistical independency among samples does not occur because all samples are analyzed simultaneously. Ease of interpretation is accomplished by displaying the significant aspects of variation in a graphical manner by means of scattergrams. In these scattergrams both insect groups/taxa and plant character states (floral colours) are presented as dots in a two-dimensional space. Their associations can be conjectured by inspection of their mutual distances. One of the assumptions we make in applying this technique is that biological relevance coincides with statistical significance.

This study forms a general framework for future analyses of taxa of lower rank within the separate insect groups. One of these analyses will be that of the associations of various coleopteran taxa with the flower-ecologically important character states, and those will form the basis for the interpretation of extensive pollen analyses on the loads of the integuments (outside of the body) and contents of the digestive tracts of central European beetle specimens of the Cetoniinae (Scarabaeidae) and Lepturinae and Cerambycinae (both Cerambycidae). The results of the pollen analyses are compiled together with extensive records from literature and inquiry among coleopterologists in Willemstein (1978), and in this study they are used to illustrate the activities of these, mainly pollen-feeding beetles on flowers with various positions of the nectar and pollen flowers (see section 6.13) and a survey is given in the appendix. 


\section{SHORT DESCRIPTIONS OF THE FEEDING-HABITS OF THE ADULT INSECTS INCLUDED IN THIS STUDY AND OF THEIR RELATIVES}

The descriptions of the feeding-habits of the flower-visiting insects (imagines) recorded in Knuth (1898a, 1899) and of their relatives (as far as necessary for understanding the development of insect anthophily) are compiled from the main entomological handbooks (Richards \& Davies, 1977, and the various authors of the insect orders in C.S.I.R.O., 1970). For the central European region a very good survey of insect biology is found in Jacobs \& Renner (1974). In many cases, however, more specialized literature was studied.

The insect orders included in this study are Coleoptera, Diptera, Hymenoptera and Lepidoptera. The feeding-habits are described down to the family level. For families in which the feeding-habits vary, the feeding-habits are as far as possible described for the taxa of the highest rank in which no variation in feeding-habits was found. Finally the other insect orders in which flower-visiting occurs are shortly discussed.

To increase accessibility, the C.S.I.R.O. classification (1970) is followed here. It does not differ very much from that followed in Richards \& Davies (1977), but it is different from the classifications of the various groups in the next chapter. The phylogenetic classifications (as far as possible in the form of cladograms) are far from stable and with an increased, directed search for synapomorphies are continually subject to change. In the next chapter the phylogenetic classifications are necessary for better understanding the phylogeny of the anthophilous insects. In the present chapter a more practical classification seems more useful for pollination-ecologists.

In the search for the feeding-habits of insects included in this chapter, many times the qualification "not known" was encountered, particularly in the more general literature. This expression can only be used if the author is completely informed about the insects, literature and the activities of his/her colleages. This is usually not the case, particularly the latter; in my experience conducting an inquiry among colleages added very many new unpublished observations (see Willemstein, 1978). I will use the qualification "not found": in literature, in personal communication and, in case of really unknown, in nature.

\subsection{Coleoptera}

The feeding-habits of Coleoptera are very diverse, as appears from the general literature on beetles (Reitter, 1908, 1909, 1911, 1912 and 1916; 
Paulian, 1943; Auber, 1965, 1966; Freude et al., 1965, etc.; Britton, 1970; Burmeister, 1970; Evans, 1975). The classification followed here is in accordance with Britton (1970).

The records of flower visits refer to representatives of all series of the Polyphaga (see below). In the course of this chapter "included" means included in this study (i.e. in the records of Knuth, 1898a, 1899). The suborders Archostemata, Myxophaga and Adephaga are not included. In order, however, to complete the information on the feeding-habits of the Coleoptera and their possible implications in the development of coleopteran anthophily, they are shortly discussed at the end of this section.

\section{STAPHYLINIFORMIA}

All three superfamilies are included.

\section{Hydrophiloidea}

The only family included is that of the Hydrophilidae (see Lohse, 1971), represented by two terrestrial species. These are small to large beetles which live in decaying vegetable material, fungi and dung. In the Hydrophilidae no anthophilous species are found, as can also be stated for the other hydrophiloid families (Hydraenidae, Hydrochidae, Spercheidae and Georyssidae) which are all phytophagous. Sometimes Hydrophilidae (as e.g. Arcyon and Cryptopleurum) are attracted to the carrion-scenting spadices of Arum (Knoll, 1926).

\section{Histeroidea}

The only family included is that of the Histeridae (see Witzgall, 1971), represented by three species in this study. These are medium-sized beetles which mainly live on decaying vegetable material and on dead animals. Some species feed on saps exuded by trees. There are no genuine anthophilous species, as can also be stated for the other histeroid families, viz. Sphaeritidae (associated with fungi) and Syntellidae (feeding on the exudates of wounded trees) (Sharp, 1899).

It will be clear that Histeridae are attracted to carrion-scenting flowers. The records of Knuth (1899) are of visits to sapromyiogamous and/or coprocantharogamous Amorphophallus and Dracunculus.

\section{Staphylinoidea}

The families included are the Anisotomidae (with one species), Silphidae (with one species) and Staphylinidae (with 24 species). 
Anisotomidae or Liodidae (see Von Peez, 1971) are small to medium-sized beetles which feed on the mycelia of subterranean Ascomycetes.

Silphidae (see Freude, 1971) are represented by the large Necrophorus which feed on the dead bodies of small vertebrates and on fungi. Other silphid beetles are usually found on carrion and some are phytophagous. Silphidae sometimes are attracted to carrion-scenting flowers (Knoll, 1926).

Staphylinidae (see Lohse, 1964) are (very) small to (fairly) large beetles, mostly with short elytra. They mainly feed on decaying organic material, including dung, and many are predacious. In central Europe only the small representatives of the montane genera Eusphalerum (Anthobium auct. nec. Leach) (8 species included) and Anthophagus (one species included) are anthophilous and mainly feed on pollen. Other species sometimes visit flowers (some of Omalium). Eusphalerum has been reported feeding on pollen of the anemogamous Luzula nivea (Porsch, 1956). In some cases Staphylinidae are attracted to carrion-scenting flowers (Oxytelus, Platystethus, Atetha, Aleochara) (Knoll, 1926).

The other staphylinoid families are Limulodidae (myrmecophilous), Ptiliidae (feeding on decaying vegetable material and on fungi under bark; they are also found in carrion flowers as Araceae; Van der Pijl (1953) found them in Typhonium trilobatum), Dasyceridae, Leptinidae (both parasitic in nests), Scydmaenidae (predacious), Scaphidiidae (fungivorous) and Pselaphidae (myrmecophilous and predacious).

Conclusion: genuine anthophily is rare among the Staphyliniformia. It only occurs in the staphylinid subfamily Omaliinae (Eusphalerum, Philorinum and Anthophagus; the other genera are found under bark, on mosses and in vegetable litter). Sometimes Silphidae, Hydrophilidae and Staphylinidae are attracted to carrion-scenting flowers.

\section{SCARABAEIFORMIA}

The observations are based on medium-sized to large Scarabaeidae (Scarabaeoidea). It concerns the subfamilies Cetoniinae (9 species), Trichiinae (3 species), Hopliinae (two species), Rutelinae (one species) and Melolonthinae (two species).

Cetoniinae (Willemstein, 1978) and Trichiinae are to a large extent anthophilous, while Hopliinae, Rutelinae and Melolonthinae to a variable degree also feed on leaves and other extrafloral parts of the plants (see also Janssens, 1960 and Machatschke, 1969). Fuchs (1974) found increasing adaptation to pollen- and nectar-feeding in the series Melolontha, Phyllopertha, Hoplia, Tropinota, Potosia, Cetonia, Trichius, Valgus. From the bare maxillae in Melolontha (mainly feeding on leaves), the maxillae become more setose via the leaf- and 
nectar-/pollen-feeding Phyllopertha and Hoplia to Tropinota, until the maximum number of setae is reached in Potosia and Cetonia. In Trichius and Valgus the numbers of maxillar setae are lower, but the setae are spatulate. In the Dynastinae, Valginae and Glaphyrinae anthophily is also found. Beetles of the other scarabaeid subfamilies mostly feed on dung.

The other scarabaeoid families are non-anthophilous. Lucanidae feed on exudates of wounded trees, Passalidae on decaying wood, Trogidae on carrion and dung, Acanthoceridae are associated with rotting wood and are possibly partly myrmecophilous, and Geotrupidae mostly feed on dung.

Within the other scarabaeiform superfamily Dascilloidea anthophily is found in the Dascillidae. Of the other dascilloid families the feeding-habits could not be ascertained. Clambidae, at least, are partly myrmecophilous, Eucinetidae are associated with decaying wood and Helodidae are associated with vegetation near water and litter (Lohse, 1979e,f).

Conclusion: in the Scarabaeiformia genuine anthophily is definitely present. In the Scarabaeidae different degrees of anthophily are present and the Dascillidae are entirely anthophilous (see also Lohse, 1979d). The latter are adapted to pollen- and nectar-feeding, as is shown by the presence of setae at the tips of the labium. Some non-anthophilous Scarabaeidae are attracted to carrion-scenting flowers: Aphodius, Onthophagus, Caccobius (Knoll, 1926); Phaeochrous to Hydnora (Krikken, pers. comm. in Kuyten, 1978). Some cases of pollination by Cyclocephala are known for Nymphaea and Victoria (Prance \& Arias, 1975; Prance et al., 1975; Prance \& Anderson, 1976; Cramer et al., 1975). The pollen analytical research on the integument of Cetoniinae by Willemstein (1978) suggests a distinct role of the Cetoniinae in the pollination of many non-specialized, entomophilous flowers.

\section{ELATERIFORMIA}

The observations are based on the superfamilies Byrrhoidea, Buprestoidea, Elateroidea and Cantharoidea.

\section{Byrrhoidea}

The only family included is that of the Byrrhidae (three species) (see Paulus, 1979a). These are small to medium-sized beetles which live and feed on mosses. The other byrrhoid family Nosodendridae feed on exudates of wounded trees (Sharp, 1899; Paulus, 1979).

\section{Buprestoidea}

The only family is that of the Buprestidae ( 6 species included). These are small to large beetles which mainly feed on leaves, but also many species feed 
on pollen. There are many anthophilous species and they are said to prefer yellow flowers (Harde, 1979).

\section{Elateroidea}

The families included are the Elateridae (30 species), Eucnemidae (one species) and Trixagidae (one species).

Elateridae (see Lohse, 1979b) are medium-sized beetles which mostly are phytophagous. They are regular flower visitors and are frequently seen feeding on pollen.

Eucnemidae (see Lohse, 1979c) are small elaterid-like beetles which are mainly found on rotting wood.

Trixagidae (see Lohse, 1979h: Throscidae) much resemble the Eucnemidae and are often found on flowers.

The feeding-habits of the other (small) elateroid families Cerophytidae and Perothopidae were not found.

\section{Cantharoidea}

The families included are the Cantharidae (28 species) and Melyridae or Malachiidae (21 species). Knuth (1899) mentioned both families under Telephoridae.

Cantharidae are medium-sized beetles which often feed on flowers; many species prey on other insects on flowers (Evers, 1979; Lohse, 1979).

Melyridae (inclusive the former Dasytidae) are small to medium-sized beetles of which the pollen-feeding is described by Schicha (1967).

No records of feeding-habits were found for the other cantharoid families: Brachyspectridae, Telegeustidae, Karumiidae and Phengodidae. The winged males of the Drilidae are regular flower visitors (Geisthardt, 1979a). The same can be stated for the Homalisidae and Lycidae. Of the adult Lampyridae it is said that they do not feed. This is confirmed for the central European species by Geisthardt (1979).

The other elateriform superfamilies are the Dryopoidea and Rhipiceroidea. The former consists of mostly small, phytophagous beetles, of which many Dryopidae and Helminthidae (Elmidae) feed on algae (Steffan, 1979). For the Rhipiceroidea no feeding-habits were found.

Conclusion: many Elateriformia are anthophilous and they certainly do play a role in the pollination of non-specialized, entomophilous flowers. 


\section{BOSTRICHIFORMIA}

The observations are based on the superfamilies Dermestoidea and Bostrychoidea.

\section{Dermestoidea}

The only family included is that of the Dermestidae ( 12 species) (see Reitter, 1911; Lohse, $1979 \mathrm{~g}$ ). These are small to medium-sized beetles. The species included belong to the subfamily Anthreninae. They feed on pollen and nectar. The other dermestid species mainly feed on pollen and some (Dermestes) feed on dead animals and vegetable material. Dermestes also visits carrionscenting flowers such as Dracunculus (dystropic visitor).

The other dermestoid families are the Derodontidae (some species feeding on pollen), Thorictidae (myrmecophilous, associated with stored food) (Auber, 1966) and Sarothriidae (feeding-habits not found).

\section{Bostrychoidea}

The families included are the Anobiidae (two species) and Ptinidae (one species). In Knuth (1899) both families are included in Anthicidae.

Anobiidae (see Lohse, 1969) are small beetles which feed on dead wood (possibly on the fungi growing there) and pollen.

Ptinidae (see Lohse, 1969) are small beetles which are associated with stored food, dead insects, excrements, dry vegetable material, and many species are myrmecophilous. Some species also feed on pollen (Porsch, 1956). The species included, Ptinus dubius, lives on Pinus.

The other bostrychoid families are the Bostrychidae and Lyctidae. Both are associated with wood and starch-containing plant tissue (Cymorek, 1969 and 1969a).

Conclusion: anthophily in Bostrychiformia is mainly found in the Dermestidae (particularly Anthreninae) and to some degree also in Anobiidae and Ptinidae. Many dermestid and ptinid species also are attracted to carrionscenting flowers.

\section{CUCUJIFORMIA}

The superfamilies included are the Cleroidea, Cucujoidea, Chrysomeloidea and Curculionoidea. Only the Lymexyloidea are not included (the only family Lymexylidae is fungivorous). 


\section{Cleroidea}

The only family included is that of the Cleridae (two species). These mostly medium-sized beetles live under bark, preying on other insects, but they also frequently visit flowers (Lohse, 1979a).

The other cleroid families are the Trogossitidae (living on fungi and insects, under bark), Chaetosomatidae (no feeding-habits found) and Phloeophilidae (live under bark). Crowson (1954) includes the Melyridae (see Cantharoidea) in this superfamily.

\section{Cucujoidea}

The families included are the Nitidulidae (22 species), Cryptophagidae (four species), Phalacridae (three species), Coccinellidae (13 species), Lathridiidae (the two species in Knuth (1899) are included in Colydiidae), Tenebrionidae (one species), Lagriidae (one species), Alleculidae (5 species), Mordellidae (12 species), Oedemeridae (15 species), Meloidae (two species) and Anthicidae (two species).

Nitidulidae (see Spornkraft, 1967) are small beetles. They mostly are anthophilous and feed on nectar and pollen. Few species are resticted to particular plant species. Some species are found in fungi or in decaying animal material.

Cryptophagidae (see Lohse, 1967) are small, mainly fungivorous beetles. Many species, however, are anthophilous (as the species included).

Phalacridae (see Vogt, 1967) are small, partly anthophilous beetles.

Coccinellidae (see Fürsch, 1967; De Gunst, 1978; Hodek, 1973) are small to medium-sized beetles. Most species are entomophagous and only a minority is phytophagous. Anthophily is not found, and it may be very well possible that the beetles visit the flowers to prey on other small insects or their larvae.

Lathridiidae (see Von Peez, 1967) are very small, fungivorous beetles.

Tenebrionidae (see Kaszab, 1969) are small to large beetles. They mostly are omnivorous and sometimes feed on pollen (Kugler, 1970).

Lagriidae (see Kaszab, 1969a) are medium-sized, phytophagous beetles. Some species visit flowers.

Alleculidae (see Kaszab, 1969b), Mordellidae (see Ermisch, 1969) and Oedemeridae (see Kaszab, 1969c) are small to medium-sized, mainly anthophilous beetles. The mordellid Variimorda fasciata and Mordellistena pentas have spatulate maxillar setae (Fuchs, 1974). Species of the mordellid Anaspis have also been found in spadices of Arum (Knoll, 1926).

Meloidae (see Kaszab, 1969d) are medium-sized, phytophagous beetles. Only some species are anthophilous. In this family the most specialized nectarfeeding beetles are found. These are species of Nemognatha, with elongated 
maxillae that form a sucking-tube. The maxillae have spatulate setae (Fuchs, 1974). See Kugler (1979) for activities of this genus on Echinops ritro.

Anthicidae (see Kaszab, 1969e) are small beetles of which many species are anthophilous.

Other anthophilous cucujoid families are the Byturidae and Rhipiphoridae. The Languriidae (in comparison with their closest relatives, the Erotylidae, more elongated beetles which also feed on stems of herbaceous plants), Mycteridae (also associated with bark), Pyrochroidae (also associated with bark and also feeding on leaves), Melandryidae (frequenting dry and decaying wood and also feeding on fungi) and Scraptiidae (also feeding on decaying wood and fungi) are partly anthophilous.

Non-anthophilous Cucujoidea are the Rhizophagidae (associated with bark; particularly the larvae are rhizophagous), Sphindidae (feeding on fungi growing in wood), Passandridae (live in the tunnels of wood-boring insects, in which the larvae are predacious on insects or insect larvae), Cucujidae (most live under bark or in the tunnels of other insects; they are probably carnivorous although some species also feed on cereals), Silvanidae (partly phytophagous, often found under bark in association with Scolytidae; Coccidotrophus socialis and Eunausibius wheeleri live, along with their early stages, in the hollow leaf petioles of Tachigalia paniculata (Caesalpiniaceae) together with the mealy bug Pseudococcus bromeliae, whose honey-dew is sollicited by the beetles and their larvae (Wheeler, 1921)), Helotidae (phytophagous; according to Lewis in Sharp (1899) they are found feeding on the sap streaming from trees), Phycosecidae (coprophagous, predacious), Biphyllidae (associated with bark and feeding on fungi), Erotylidae (associated with decaying vegetable material and feeding on fungi), Cerylonidae (associated with bark and vegetable detritus), Corylophidae (living on rotting vegetation and decaying wood; some species are associated with Coccidae), Endomychidae (feeding on fungi growing on wood; some species are found in dung and vegetable refuse), Discolomidae (associated with bark), Merophysiidae (feeding on fungi), Aculagnathidae (myrmecophilous), Ciidae (feeding on fungi growing on bark or on rotting wood), Mycetophagidae (feeding on fungi and mouldy material, especially in connection with wood; species of the genus Berginus develop in flowers), Colydiidae (most species live under bark and feed on fungi, some species are myrmecophilous and some prey on the larvae of wood-boring insects), Zopheridae (associated with bark), Monommidae (associated with decaying wood), Tetratomidae (live on rotting wood, feeding on fungi), Elacatidae (live on decaying vegetable material), Inopeplidae (associated with bark), Salpingidae (associated with bark and mosses), Hemipeplidae (live together with their larvae under the leaf bases of palms; they feed on the leaves), Phytidae (associated with bark), Cephaloidae (phytophagous), Aderidae (associated with decaying wood and vegetable refuse). No feeding-habits were found for the (small) 
families Smicripidae, Protocucujidae, Hydrocopridae, Propalticidae (are said to occur under bark), Merycidae, Pterogeniidae, Perimylopidae, Cononotidae and Trictenotomidae (live in forests).

\section{Chrysomeloidea}

All three families are incuded.

Cerambycidae (48 species included) (see Caillol, 1914; Butovitsch, 1939; Harde, 1966; Von Demelt, 1966; Allenspach, 1973) are medium-sized to very large, slender beetles. Flower feeders are found in the Lepturinae, part of the Cerambycinae and in some of the Lamiinae. Within the Cerambycidae the modifications towards obligatory anthophily consist of an upwards-tilting of the head, which brings the mouth parts foreward, the development of the head behind the eyes to form an additional, neck-like region, transformation of the usually broad first segment of the thorax into a long and narrow segment, and a lengthening of the setae on the maxillae (Proctor \& Yeo, 1973). In Rhagium, Strangalia and Pachytodes spatulate setae occur on the maxillae (Fuchs, 1974). Most of the Lamiinae and some Cerambycinae are associated with bark (sometimes feeding on the soft bark of young shoots). Other cerambycid beetles also feed on leaves, young needles, exuding saps, fruits, roots and/or fungi. Many of the anthophilous species certainly play a role in the pollination of nonspecialized entomophilous flowers (see Willemstein, 1978).

Bruchidae (6 species included) (see Reitter, 1912) are small, phytophagous beetles. Most species also visit flowers.

Chrysomelidae (48 species included) (see Mohr, 1966) are small to mediumsized beetles which mainly feed on leaves. Many species also visit flowers and from the records of Knuth (1898b, 1899) and Harper (1957) some regularity in flower-visiting might appear in certain Cryptocephalinae and Donaciinae. Anthophily has also developed in the Galerucinae (Diabrotica) (Knuth, 1905).

\section{Curculionoidea}

The families included are the Anthribidae (two species) and the Curculionidae (44 species).

Anthribidae (see Reitter, 1916) are small to medium-sized beetles with various feeding-habits. Many species live under bark, on wood and on fungi. They are frequently seen on flowers.

Curculionidae (see Reitter, 1916) are small to medium-sized beetles which are phytophagous. They feed on leaves, roots, fruits, flowers and other plant tissues. Only very few species feed on pollen. The other families of the Curculionoidea are the Nemonychidae (partly associated with Gymnospermae: females of Cimberis and Diodyrrhynchus deposit eggs on the male cones of Pinus), 
Belidae (phytophagous), Oxycorynidae (partly associated with flowers (Oxycorynus), partly associated with palm fruits (Metroxena), Proterhinidae (Aglycyderidae) (associated with bark, dead wood; a species in New Zealand has been found associated with the tree fern Cyathea dealbata), Attelabidae (feeding on leaves; Allocorynus breed in the male cones of Cycas), Brenthidae (associated with wood), Apionidae (phytophagous and destructive on flowers).

Conclusion: anthophily in the Cucujiformia is wide-spread. In most families only a part is anthophilous. The anthophilous Cucujiformia certainly play a role in the pollination of non-specialized entomophilous flowers.

As mentioned above the suborders Archostemata, Myxophaga and Adephaga are not included. The Archostemata consist of the families Cupedidae and Micromalthidae. Both are associated with wood. The adults in many cases feed on pollen. Myxophaga are correlated with wet places, feeding on algae and mosses. The Adephaga mostly are carnivorous. Phytophagy is only known in few groups of the Carabidae. As far as I could find, it only occurs in the Omophrominae, Harpalinae (possibly nearly all species which feed on plants are omnivorous; Diachromus germanus feeds on pollen and seeds) and Zabrinae (mainly feeding on seeds) (Freude, 1976). The most pleisiomorphous Adephaga are the Rhysodidae, which are cupedid-like beetles that are associated with bark and decaying wood (Freude, 1971a).

\subsection{Hymenoptera}

Hymenoptera can be found in all kinds of situations. About 25,000 species, however, depend exclusively on angiosperm pollen and nectar as food source (Baker \& Hurd, 1968). Many sawflies feed on pollen and nectar and some are carnivorous. Many Hymenoptera are involved in pollination. A good survey of the feeding-habits of the Hymenoptera is found in Malyshev (1968) and Bischoff (1927) and some data can be found in Schmiedeknecht (1930) and Steinbach (1970). A good survey of the biology of the wasps is given by Evans \& Eberhard (1970). The classification used here is in accordance with that of Riek (1970).

\section{SYMPHYTA}

Apart from the Siricoidea (see at the end of the Symphyta) all superfamilies are included.

\section{Megalodontoidea}

The only family is that of the Megalodontidae (two species included). In Knuth (1899) they are included in Tenthredinidae. These are robustly built 
wasps with short mouth parts. They frequently visit flowers and feed on nectar and pollen. Megalodontes species have somewhat projected mouth parts.

\section{Tenthredinoidea}

The families included are the Tenthredinidae (89 species), Cimbicidae (two species) and Argidae (5 species). In Knuth (1899) these families are included in Tenthredinidae.

Tenthredinidae are medium-sized wasps. Many species frequent flowers and some are predacious on other insects. The flower-visiting species feed on nectar and pollen.

Cimbicidae are stout, often large, wasps which sometimes are encountered on flowers. They are associated with the plants on which their larvae live and it is remarkable that the genera, of which the larvae are associated with Gymnospermae, are characterized by more plesiomorphous morphological features than those, of which the larvae are associated with Angiospermae (see Malyshev, 1968).

Argidae are small to medium-sized wasps of which no feeding-habits were found. As regards their morphological features and the plants on which their larvae live, the same remark can be made as for the Cimbicidae (see Malyshev, 1968). The records of Knuth (1899) suggest at least some regular flowervisiting.

The other tenthredinoid families are the Blasticotomidae (in central Europe associated with ferns; feeding-habits not found), Diprionidae (Diprion is associated with Pinus; feeding-habits not found) and Pergidae (particularly the Euryinae are flower visitors).

\section{Xyeloidea}

The only family included is that of the Pamphiliidae (two species). In Knuth (1899) they are included in Tenthredinidae. They are stout, robustly built wasps with slightly elongated mouth parts. As regards their morphological features and the plants on which their larvae live, the same remark can be made as for the Cimbicidae and Argidae (see Malyshev, 1968). Most species are regular flower visitors.

The other xyeloid family is that of the Xyelidae. The Xyelinae are associated with the male cones of Pinus. They feed on pollen. Xyela julii larvae live on the male cones of Pinus, while the adults feed on pollen of the male catkins of Betula.

\section{Cephoidea}

The only family is Cephidae (8 species included). They are medium-sized, narrow-bodied wasps, which regularly visit flowers. 
The superfamily not included, the Siricoidea, consists of four families: Orussidae (associated with dry wood; feeding-habits not found), Xiphydriidae, Siricidae (both feed on the exuded sap of trees), and Syntexidae (no feedinghabits found).

Conclusion: among the Symphyta anthophily is common. The food sources on flowers are nectar and pollen. Xiphydriidae and Siricidae might also be attracted to nectar.

\section{APOCRITA}

Apart from the Megalyroidea, Trigonaloidea, Proctotrupoidea and Bethyloidea (see at the end of Apocrita) all superfamilies are included.

\section{Ichneumonoidea}

The families included are the Ichneumonidae (106 species) and Braconidae (12 species).

Ichneumonidae are small to large, slender wasps. They frequent flowers, particularly those of Apiaceae.

Braconidae are small to medium-sized, mostly glabrous wasps. They live on sweet liquids, including nectar.

The other ichneumonoid family is that of the Agriotypidae for which no feeding-habits were found.

\section{Evanioidea}

The only family included is that of the Gasteruptiidae (12 species). In Knuth (1899) they are included in Evaniidae. These are medium-sized wasps that feed on nectar.

The other evanioid families are the Evaniidae and Aulacidae. Both are associated with wood, but no proper feeding-habits were found.

\section{Cynipoidea}

The only family included is that of the Cynipidae (four species). They mostly are small wasps. A survey of flower-visits is given by Proctor \& Yeo (1973).

The other cynipoid families are the Liopteridae, Ibaliidae and Figitidae. For none feeding-habits were found. 


\section{Chalcidoidea}

The families included are the Eulophidae (two species), Chalcididae (5 species), Torymidae (one species) and Pteromalidae (two species). In Knuth (1899) these families are included in Chalcididae. They all are minute wasps. In many species the adults do not feed and only some species feed on nectar (see list of flower visits in Proctor \& Yeo (1973)) and other plant fluids. Some species feed on liquids of the host of the larvae.

The same variety of feeding-habits exists in the other chalcidoid families: Trichogrammatidae, Mymaridae, Eurytomidae and Encyrtidae. Particularly the chalcid Leucospinae are attracted to flowers. The Agaonidae are the pollinators of Ficus.

\section{Chrysidoidea}

The only family is that of the Chrysididae ( 45 species included). They are small to medium-sized, sparsely bristled wasps. Most species feed on nectar; some species have an elongated proboscis.

\section{Pompiloidea}

The only family included is that of the Pompilidae (44 species). Most are medium-sized wasps with very short mouth parts. They feed on exudates, including nectar.

For the other pompiloid family, Rhopalosomatidae, no feeding-habits were found.

\section{Scolioidea}

Except for the Plumariidae all families are included. In Knuth (1899) the Tiphiidae are taken together with the Scoliidae.

Scoliidae ( 6 species included) are mostly medium-sized, hairy wasps, which often feed on nectar.

Mutillidae ( 5 species included) are small to medium-sized wasps, often feeding on nectar.

Tiphiidae (5 species included) are medium-sized wasps which feed on nectar. Nectar or honey-dew appear to be necessary for the development of the eggs.

Sapygidae (two species included) are small to medium-sized wasps for which no feeding-habits were found.

For the Plumariidae no feeding-habits were found. 


\section{Vespoidea}

All families are included. In Knuth (1899) all families are taken together in the Vespidae.

Masaridae (one species included) are medium-sized, anthophilous, nectarand pollen-feeding wasps. They have a comparatively long proboscis. The pollen is collected between the setae of the frons and transported into the crop by the fore-legs.

Vespidae (14 species included) are medium-sized, omnivorous wasps. Some species have an elongated proboscis. The main vegetable food sources are ripe fruits and nectar.

Eumenidae (36 species included) are medium-sized, predacious wasps, which also visit flowers. The records of Knuth (1898a, 1899) suggest some nectar-feeding.

\section{Sphecoidea}

The only family included is that of the Sphecidae (143 species). They are small to large wasps. Many species frequent flowers, feeding on nectar. Sometimes the proboscis is somewhat elongated. Proctor \& Yeo (1973) conclude that these wasps probably are insignificant pollinators.

The other sphecoid family is that of the Ampulicidae. They are common on tree trunks; no proper feeding-habits were found.

\section{Apoidea}

Except the Fideliidae all families are included: Colletidae (37 species), Halictidae (119 species), Andrenidae (149 species), Melittidae (12 species), Megachilidae (125 species), Anthophoridae (54 species), and Apidae (46 species). They are all anthophilous bees and very important pollinators. In the above mentioned enumeration, very generally spoken, an increase of tongue length from Colletidae to Apidae is traceable. The longest tongues are found in the apid Bombinae. Kugler (1970) lists many tongue lengths of this superfamily.

The Fideliidae are megachilid-like bees.

\section{Formicoidea}

The only family is that of the Formicidae (17 species included). They are in many cases nectar thieves and only in some cases they are "legitimate" pollinators.

The other superfamilies of the Apocrita are the Megalyroidea (associated with dead wood), Trigonaloidea (associated with dead leaves, probably feeding 
on liquids of caterpillars, caught as food for their larvae), Proctotrupoidea and Bethyloidea (associated with herb foliage, bark and litter). No proper feedinghabits for these superfamilies were found.

Conclusion: in the Apocrita anthophily is common and wide-spread. It culminates in the winged, socially living taxa, that collect pollen and nectar as food for their offspring.

\subsection{Lepidoptera}

The evolution of the Lepidoptera was probably substantially directed by the development of the haustellum. It must have been associated directly with the development of the angiosperm flowers.

Except the Dacnonypha (see at the end of this section) all suborders are included (see below). The classification is in accordance with that of Common (1970).

\section{ZEUGLOPTERA}

The only family is that of the Micropterigidae (one species included). In Knuth (1899) they are included in Tineidae. These are small diurnal moths with dentate, functional mandibles. They frequent flowers and feed on pollen.

\section{MONOTRYSIA}

The only superfamily included is that of the Incurvarioidea.

\section{Incurvarioidea}

The only family included is that of the Incurvariidae (11 species). In Knuth (1899) they are included in Tineidae. These are small, diurnal moths with a short haustellum. The moths are often seen resting on flowers. The records of Knuth (1898a, 1899) suggest some nectar-feeding.

For the other incurvarioid families Prodoxidae (haustellum accompanied by maxillary tentacles), Heliozelidae (the central European Heliozela is found on Cornus), and Tischeriidae no proper feeding-habits were found. The famous Yucca moths belong to the Prodoxidae.

The other superfamilies of the Monotrysia are the Hepialoidea (Prototheoridae with a short haustellum; Palaeosetidae, without haustellum; Hepialidae, mainly crepuscular, haustellum very short or absent) and the minute Nepticuloidea ( = Stigmelloidea) (Nepticulidae (= Stigmellidae) with 
a very short or rudimentary haustellum and Opostegidae with a very short haustellum). For both superfamilies no feeding-habits were found.

\section{DITRYSIA}

The superfamilies included are the following.

\section{Tortricoidea}

The only family included is that of the Tortricidae ( 21 species). These are small to medium-sized, crepuscular to nocturnal moths with a short haustellum. No feeding-habits were found for this family. The records of Knuth (1898a, 1899) suggest some nectar-feeding.

For the other tortricoid family Phaloniidae ( = Cochylidae) (haustellum short or absent) the same must be stated.

\section{Tineoidea}

The families included are the Psychidae (one species) and Tineidae (6 species). In Knuth (1899) both are included in Tineidae.

Psychidae are small to medium-sized, diurnal to crepuscular moths with a rudimentary haustellum. Possibly no food is taken during adult life.

Tineidae are small moths with a more or less reduced haustellum. No feeding-habits were found for this family.

The other tineoid families are Pseudarbelidae, Arrhenophanidae, Lyonetiidae, Phyllocnistidae (all with a short haustellum) and Gracillariidae (crepuscular moths; some species with a long haustellum). No feeding-habits were found for these families.

\section{Yponomeutoidea}

The families included are the Aegeriidae (three species), Glyphipterigidae (three species), Douglasiidae (one species) and Yponomeutidae (three species). In Knuth (1899) these families are included in Tineidae.

Aegeriidae are small to medium-sized, diurnal, wasp-like moths with a naked haustellum. They visit flowers and can feed on nectar hovering before the flower.

Glyphipterigidae, Douglasiidae and the not included Heliodinidae are small, diurnal (only rarely crepuscular) moths with a short, naked haustellum. Some species visit flowers.

Yponomeutidae and the not included Epermeniidae are minute to mediumsized moths with a naked haustellum. Yponomeutidae have been observed 
feeding on the flowers of Senecio and Rhamnus (P. Kuyten, pers. comm.). For the Epermeniidae no feeding-habits were found.

\section{Gelechioidea}

The families included are the Coleophoridae (one species), Elachistidae (one species), Oecophoridae (one species) and Gelechiidae (two species). In Knuth (1899) these families are mentioned under Tineidae.

Coleophoridae, Elachistidae (crepuscular), Oecophoridae (crepuscular to nocturnal) and Gelechiidae are small to medium-sized moths with a short haustellum. No feeding-habits were found for these families.

The same must be stated for the other gelechioid families: Agonoxenidae, Scythridae, Ethmiidae (probably the same feeding-habits as Yponomeutidae), Timyridae, Cosmopterigidae, Metachandidae, Anomologidae, Pterolonchidae, Blastobasidae, Xyloryctidae, Stenomidae, Physoptilidae and Strepsimanidae. Only the diurnal Stathmopodidae feed on flowers.

\section{Zygaenoidea}

The only family included is that of the Zygaenidae (10 species). They are small to medium-sized, diurnal Lepidoptera with a well-developed haustellum. They frequent flowers to feed on nectar.

For the other zygaenoid families, Heterogynidae, Chrysopolomidae, Megalopygidae, Cyclotornidae, Epipyropidae, Limacodidae (haustellum absent) no feeding-habits were found.

\section{Pyraloidea}

The only family included is that of the Pyralidae ( 18 species). They mostly are medium-sized, crepuscular to nocturnal moths, some with a reduced haustellum. Some species visit flowers to feed on nectar.

For the pyraloid families Hyblaeidae (strong haustellum), Tineodidae (naked haustellum), Oxychirotidae (haustellum present) no feeding-habits were found. In the Thyrididae (well-developed haustellum) the central European Thyris fenestrella frequents the inflorescences of Sambucus and Apiaceae.

\section{Hesperioidea}

The only family included is that of the Hesperiidae (7 species). In Knuth (1899) they are included in Rhopalocera. They are medium-sized, diurnal butterflies (only some species are crepuscular) with a long haustellum. They frequently visit flowers.

The same can be stated for the other hesperioid family Megathymidae. 


\section{Papilionoidea}

The families included are the Papilionidae (8 species), Pieridae (16 species), Nymphalidae (22 species), Lycaenidae (16 species) and Erycinidae (one species). In Knuth (1899) these families are included in Rhopalocera.

All families mentioned are composed of sometimes small, but mostly medium-sized to large butterflies with a long, naked haustellum. The majority frequents flowers to feed on nectar. Many species, particularly in the Papilionidae, are also attracted to excrement. Heliconius (Nymphalidae: Heliconiinae) eats pollen and can digest it to support prolonged oviposition.

The other papilionoid family Libytheidae is closely related to the Nymphalidae.

\section{Geometroidea}

The only family included is that of the Geometridae (13 species). They are medium-sized to large, mostly crepuscular to nocturnal Lepidoptera with a naked, in some species reduced, haustellum. There are flower-visiting species.

Of the other geometroid families no feeding-habits were found for the Drepanidae (haustellum vestigial or absent), Thyatiridae (haustellum welldeveloped; Diloba caeruleocephala does not feed in adult state), Epiplemidae (haustellum present), Axiidae (haustellum present), Sematuridae (haustellum present). In Uraniidae (haustellum present) flower-visiting occurs.

\section{Sphingoidea}

The only family is that of the Sphingidae (21 species included). They are medium-sized to large, diurnal to nocturnal Lepidoptera with a strong, often very long haustellum. They frequent flowers to feed on nectar and many cases of pollination are known. They can also feed on nectar hovering before the flower.

\section{Noctuoidea}

The families included are the Lymantriidae (two species), Arctiidae (5 species) and Noctuidae (47 species). In Knuth (1899) Lymantriidae and Arctiidae are mentioned under Bombycidae.

Lymantriidae are small to large (mostly medium-sized), crepuscular to nocturnal Lepidoptera with the haustellum reduced or absent. No feeding-habits were found for this family.

Arctiidae are small to large (mostly medium-sized) Lepidoptera with a usually reduced haustellum. Most species are crepuscular to nocturnal, some 
species are diurnal. In central Europe Tyria jacobaeae visits flowers and some Litthosiinae feed on nectar.

Noctuidae are medium-sized to large Lepidoptera with a usually strong and long haustellum. Many species feed on nectar and cases of pollination are known. Some species are attracted to fermenting fruits.

For the other noctuoid families, the Amatidae (diurnal, haustellum present), Hypsidae (mostly nocturnal, haustellum present), Nolidae (mainly crepuscular, haustellum mostly well-developed) and Agaristidae (mainly diurnal, haustellum strong) no feeding-habits were found.

The other superfamilies of the Ditrysia are Cossoidea (the nocturnal Cossidae and Metarbelidae have a reduced haustellum; possibly the adults do not feed), Copromorphoidea (for Copromorphidae, Alucitidae and Carposinidae no feeding-habits were found; all three families have a naked haustellum), Castnioidea (the only family Castniidae consists of diurnal species with the haustellum reduced or present; some species frequent (tree) flowers to feed on nectar (Hannemann, 1968)), Calliduloidea (Callidulidae and Pterothysanidae are diurnal moths with a haustellum; no feeding-habits have been found), Bombycoidea (haustellum absent or more or less strongly reduced in Endromidae, Lasiocampidae, Anthelidae, Eupterotidae, Lacosomidae, Bombycidae, Lemoniidae, Saturniidae and Ratardidae; haustellum present in Brahmaeidae, Oxytenidae and Cercophanidae; haustellum strong in Carthaeidae; for these families no feeding-habits were found).

The suborder Dacnonypha has only one superfamily, the Eriocranioidea. This consists of five families (Richards \& Davies, 1977): Eriocraniidae (nonfunctional mandibulae, with a short haustellum), Mnesarchaeidae (rudimentary haustellum used as a sucking-organ), Neopseustidae (short haustellum), Agathiphagidae (with zeuglopteran mandibulae and a short haustellum) an Lophocoronidae. For these families no feeding-habits were found.

Conclusion: anthophily in the Lepidoptera is very common. The main food source on flowers is nectar for the species with a haustellum and pollen for the mandibulate species. Too little is known about the adults of the crepuscular and nocturnal species. It may be expected that many moths with a welldeveloped haustellum are flower visitors and play a role in pollination.

\subsection{Diptera}

Diptera mainly feed on liquid food: free water, products of decomposition of organic material, soluble solids, tissue fluids of other animals and nectar. 
Many Diptera are anthophilous. They mainly feed on nectar, but pollenfeeding also occurs. The method of pollen-feeding by flies is described by Müller (1881) (see also Proctor and Yeo, 1973). A good survey of dipteran biology is given by Oldroyd (1964). The classification followed here is in accordance with that of Colles \& McAlpine (1970).

\section{NEMATOCERA}

All series are included, see below.

\section{Tipulomorpha}

The only family included is that of the Tipulidae ( 8 species). These are medium-sized to large crane flies which feed on fluids, inclusive of nectar (Schlee, 1977). Tipulidae regularly visit flowers as is also mentioned by Parmenter (1952) and Proctor \& Yeo (1973). The latter describe and illustrate the mouth parts of Tipula and conclude that they are suited for mopping up exposed fluids.

The other tipulomorph families are the Trichoceridae and Ptychopteridae. The feeding-habits of the former were not found, the latter are flower visitors.

\section{Psychodomorpha}

Two species of the only western Palaearctic family Psychodidae are included. These are minute moth flies that feed on plant fluids, including nectar. The females of some genera of the subfamily Phlebotominae, however, feed by sucking blood from vertebrates. Not only mammals, but also birds and reptiles are used as hosts. Females of the species Phlebotomus minutus mainly feed on the blood of lizards and geckos. The males of the Phlebotominae often feed on nectar. The species mentioned in Knuth (1899) belong to the subfamily Psychodinae in which blood-feeding is extremely rare. Schlee (1977) observed Psychodidae feeding on nectar.

The feeding-habits of the other psychodomorph family Tanyderidae were not found. Because of their usually elongated mouth parts it is suggested that they have a tipulid-like biology. The imagines are mostly found together with Tipulidae in moist forest habitats.

\section{Culicomorpha}

The families included are the Culicidae (two species), Ceratopogonidae (7 species), Chironomidae (7 species) and Simuliidae (one species).

Culicidae are medium-sized, slender mosquitos, generally with an 
elongated, piercing proboscis. As far as adult feeding takes place, the males feed on fluids, including nectar (Schlee, 1977) (the females feed on blood). In several cases male Culicidae are regular flower visitors and can play a role in pollination. This has been demonstrated by Dexter (1913) for the orchid Habenaria obtusata, by Hocking (1960) and Kevan (1972) for several arctic flowers and by Brantjes \& Leemans (1976) for Silene otites. Corbet (1970) gave records of visits to Heracleum sphondylium.

Ceratopogonidae (in Knuth (1899) included in Chironomidae) are small, biting midges with mouth parts adapted for piercing. Most of the males and some females feed on plant fluids, including nectar. Females of Culicoides are often found in large numbers in Arum spadices. Daumann (1971) reported Atrichopogon, Dashyela and Forcipomyia as pollinators of Aristolochia clematitis.

Chironomidae are small to medium-sized, delicate midges. The adult insects have reduced mouth parts and, at any rate in some species of Chironomus, no food is taken by the imagines. Flower visits with nectar-feeding are recorded by Schlee (1977). Simuliidae are small, stoutly built black-flies with an elongated proboscis. Mainly the males feed on nectar (and other plant fluids) and might be regular flower visitors; the females mainly feed on the blood of vertebrates.

The other culicomorph families are the Dixidae (non-blood-feeding midges with short mouth parts) and Thaumaleidae (no feeding-habits found).

\section{Bibionomorpha}

The families included are the Anisopodidae (two species) (in Knuth (1899) included in Rhyphidae), Bibionidae (15 species), Cecidomyiidae (two species) and Mycetophilidae (12 species).

Anisopodidae are medium-sized, gnat-like flies. They have somewhat elongated mouth parts. Most species are crepuscular and nocturnal, only some are diurnal. They have been observed sitting on plants. Grensted (1946) gives a record of a visit to Heracleum sphondylium; Proctor \& Yeo (1973) suggest nectar-feeding.

Bibionidae are medium-sized, robust flies. They feed on plant fluids, honeydew and nectar. As demonstrated in Proctor \& Yeo (1973) they are regular flower visitors. The main food source is nectar, but Bibio pomonae is suggested to feed on pollen as well. Willis \& Burkil (1895-1908) recorded pollen-feeding by Bibionidae.

Cecidomyiidae are minute, delicate flies with short mouth parts. They feed on nectar and possibly are regular flower visitors.

Mycetophilidae are small to medium-sized fungus gnats. Many species visit flowers to feed on nectar and pollen. They are attracted by fungus-mimicking flowers (Vogel, 1973, 1978, 1978a). 
The other (mainly small) families of the Bibionomorpha may all have connections with flowers in some way. The males of the Blephariceridae (former Blepharoceridae) feed on nectar (the females are predacious, preying upon small Diptera) (Richards \& Davies, 1977). The feeding-habits of the Deuterophlebiidae (very closely related to the Blephariceridae) were not found. The same must be stated for the Pachyneuridae, Axymyiidae and Perissommatidae. Many species of the Scatopsidae visit umbelliform inflorescences to feed on nectar, while pollen-feeding may take place as well. About the feedinghabits of the Nymphomyiidae no records were found. The Sciaridae feed on fungi, but also visit flowers to feed on nectar.

Conclusion: within the Nematocera flower-visiting is common. Many families have regular flower visitors with consequent pollination possibilities. Possibly, in the Nematocera part of the pollinators of the many very small, nectar-containing, entomophilous flowers (micro-entomophily) are found. The knowledge of the feeding-habits may increase considerably when more observations are made on the many crepuscular and nocturnal species. The main food source of Nematocera on flowers is nectar, but some species also feed on pollen.

\section{BRACHYGERA}

The suborder Brachycera is divided into two divisions: Orthorrhapha and Cyclorrhapha. The first has the more plesiomorphous features.

\section{ORTHORRHAPHA}

All three superfamilies are included, see below.

\section{Tabanoidea}

The families included are the Rhagionidae (5 species) (in Knuth (1899) included in Leptidae), Tabanidae (13 species) and Stratiomyidae (20 species).

Rhagionidae are medium-sized flies. Many males and only some females feed on honey dew and plant fluids, including nectar (most females are predacious upon other insects, some are blood suckers).

Tabanidae are medium-sized to large flies with a strong proboscis. The males feed on nectar and honey dew. The females feed on blood, but in the absence of blood also on the liquids the males feed on. Stratiomyidae are medium-sized, anthophilous flies with a short fleshy proboscis. They feed on nectar and pollen.

Other anthophilous tabanoid families are the Pelecorhynchidae (the only 
plesiomorphous genus is Pelecorhynchus of which both the males and females are anthophilous on Leptospermum), Xylomyidae, Nemestrinidae (often with a long to very long proboscis) and Acroceridae (long-tongued, nectar-feeding flies; some short-tongued species probably do not feed in adult life). The other tabanoid families are the Coenomyiidae (feed on exudates of trees), Pantophthalmidae (probably as Coenomyiidae) and Xylophagidae (feed on exudates of trees).

\section{Asiloidea}

The families included are the Therevidae ( 5 species), Asilidae ( 8 species) and Bombyliidae (21 species).

Therevidae are medium-sized, bristly flies with a rather prominent proboscis. They are said to be predacious, but Jacobs \& Renner (1974) state that they also feed on flowers (see also Proctor \& Yeo, 1973), and dung.

Asilidae are medium-sized to very large, always bristly, flies with a firm proboscis. They are predacious on other insects, inclusive of honey bees and other anthophilous insects, which explains their presence on flowers.

Bombyliidae are medium-sized, bumblebee-like flies, usually with a very long proboscis. They are anthophilous, feed on nectar and are excellent pollinators.

The other asiloid families are the Scenopinidae (feeding on exposed liquids with their short proboscis), Apioceridae (anthophilous) and Mydaidae (mostly anthophilous; it is thought that at least some species are predacious).

\section{Empidoidea}

Both families are included, see below.

Empididae (36 species included) are minute to medium-sized, bristly flies with a horny proboscis adapted for piercing. Most species are predacious and feed on smaller arthropods. Particularly the Empidinae are anthophilous and feed on nectar.

Dolichopodidae (8 species included) are small, bristly flies with a short, fleshy proboscis. Most species are predacious, some feed on nectar.

Conclusion: anthophily is very common in the Orthorrhapha. Sometimes within a family it is combined with predacious feeding-habits. The main floral food source is nectar, although pollen-feeding is known in the Stratiomyidae and possibly also in the Xylomyidae. Except for the Asilidae, all families included to a greater or lesser extent visit flowers to feed on nectar and/or pollen. Coenomyiidae, Pantophthalmidae and Xylophagidae might also be attracted to nectar. 


\section{CYCLORRHAPHA}

This division has two series, Aschiza and Schizophora, which will be treated separately.

\section{ASCHIZA}

The observations in Knuth $(1898 \mathrm{a}, 1899)$ are based on all three superfamilies, see below.

\section{Lonchopteroidea}

The only family is that of the Lonchopteridae (two species included). They are small, slender, bristly flies. All species are anthophilous.

\section{Phoroidea}

The only family included is that of the Phoridae ( 5 species). These are minute flies, feeding on sap of decaying plant and animal material and nectar (for a survey, see Baumann, 1978). The other phoroid families are the Platypezidae and Sciadoceridae for which no feeding-habits were found.

\section{Syrphoidea}

Both families are included, see below.

Pipunculidae (two species included) are tiny, plumose to almost bare flies with an elongated proboscis. They are anthophilous and feed on nectar and honey-dew.

Syrphidae (198 species included) are medium-sized to fairly large flies with an elongated to long proboscis. They are anthophilous and feed on nectar and pollen. According to Van der Goot \& Grabandt (1970) possibly mainly the females feed on pollen. The proboscis of the Syrphidae varies in size, but can reach considerable lengths (up to $19 \mathrm{~mm}$ in Volucella zonaria (Kugler, 1970)). Syrphidae often feed on pollen flowers.

It can be stated that all Aschiza are anthophilous, possibly Platypezidae and Sciadoceridae excluded.

\section{SCHIZOPHORA}

Except for the Asteioidea (see at the end of the Schizophora) all superfamilies are included (see below). All families, except for the Conopidae, are treated as Muscidae by Knuth (1899). 


\section{Conopoidea}

The only family is that of the Conopidae (22 species included). These are more or less elongated, medium-sized, thinly plumose to almost glabrous flies. Most species are anthophilous and have a long proboscis.

\section{Tephritoidea}

The families included are the Otitidae (three species), Platystomatidae (two species) and Tephritidae (22 species).

Otitidae are small to medium-sized, predacious flies. The flower visits reported in Knuth $(1898 \mathrm{~b}, 1899)$ may be accidentally, or they prey in flowers on other insects.

Platystomatidae are small to medium-sized flies. Some species (as those of Rivellia) milk aphids for honey-dew. Sometimes they also feed on nectar.

Tephritidae are medium-sized flies of which some are anthophilous, feeding on nectar (Christenson \& Foote, 1960); other liquids are also used as food.

The other tephritoid families are the Richardiidae, Pyrgotidae (for both no feeding-habits were found) and Tachiniscidae (bumblebee-like flies which possibly are flower visitors).

\section{Micropezoidea}

The only family included is that of the Micropezidae (one species). They are small to medium-sized flies, which mostly are predacious.

For the other (small) micropezoid families Pseudomyzidae, Cypselosomatidae, Neriidae and Megamerinidae no feeding-habits were found.

\section{Tanypezoidea}

The families included are the Tanypezidae (one species) and Psilidae (three species). Both families consist of small to medium-sized, almost bare flies for which no feeding-habits were found. The same must be stated for the other tanypezoid families Nothybidae and Diopsidae. The latter probably feed on plant fluids, honey dew and nectar (see Oldroyd, 1964).

\section{Sciomyzoidea}

The families included are the Sepsidae (10 species), Dryomyzidae (four species), Sciomyzidae (5 species) and Lauxaniidae (5 species).

Sepsidae are small, somewhat ant-like flies. They are saprophagous and also 
frequent flowers. The mouth parts of Sepsis are illustrated in Proctor \& Yeo (1973). Sepsidae are frequently seen on the umbels of Apiaceae.

Dryomyzidae are rather large flies, which are saprophagous and also feed on nectar.

Sciomyzidae are medium-sized, predacious flies. The records in Knuth (1898b, 1899) suggest some nectar-feeding; however they may be preying on other insects on flowers.

Lauxaniidae are small to medium-sized anthophilous flies.

The other sciomyzoid families are the Helcomyzidae (living on sea shores), Ropalomeridae (associated with exudates of trees), Chamaemyiidae (feeding on honey-dew) and Celyphidae (no feeding-habits found)

\section{Heleomyzoidea}

The families included are the Coelopidae (three species), Heleomyzidae (two species) and Sphaeroceridae (7 species).

Coelopidae are small to medium-sized flies. They mainly live along the sea shore, but are also found inland where they frequently visit flowers.

Heleomyzidae are small to medium-sized flies with coprophagous feedinghabits. They also feed on exuded plant sap and on nectar.

Sphaeroceridae are small flies. They are mainly found on dung and are attracted to carrion-scenting flowers (Arum, Dracunculus) in which they may play a role in pollination.

The other heleomyzoid families are the Chyromyidae (mainly anthophilous) and Somatiidae (no feeding-habits found).

\section{Opomyzoidea}

The families included are the Lonchaeidae (one species), Piophilidae (one species), Opomyzidae (one species) and Agromyzidae (5 species).

Lonchaeidae are small flies, which are found on leaves, flowers and decaying vegetable material.

Piophilidae are small flies for which no feeding-habits were found.

Opomyzidae are small flies, which are found on grasses, but no proper feeding-habits were found.

Agromyzidae are small flies, which feed on plant saps, honey-dew and possibly also on nectar.

The other opomyzoid families are the Pallopteridae (associated with the heads of Asteraceae, but no proper feeding-habits were found), Neottiophilidae (anthophilous), Clusiidae (feed on fungi and carrion), Odiniidae (feed on exudates of trees), Fergusoninidae (associated with Eucalyptus, but no proper feeding-habits were found), Carnidae (some species feed on the blood 
of birds; most species, however, frequently visit flowers) and Acartophthalmidae (associated with carrion and decaying fungi).

\section{Drosophiloidea}

The families included are the Ephydridae ( 7 species), Drosophilidae (two species) and Chloropidae (13 species).

Ephydridae are minute flies which feed on carrion and decaying vegetable material. The records in Knuth $(1898 \mathrm{~b}, 1899)$ suggest some regularity in flower-visiting of Hydrellia. Schlee (1977) observed nectar-feeding.

Drosophilidae are small to medium-sized flies. They feed on plant juices, rotting wood and sometimes also on nectar. Some species are attracted to Arum spadices.

Chloropidae are minute to medium-sized flies. They feed on sweet liquids like honey-dew and nectar. They are important flower-visiting and pollinating flies (Proctor \& Yeo, 1973).

The other drosophiloid families are the Camellidae, Diastatidae, Curtonotidae (feeding-habits were found for none), Milichiidae (saprophagous and predacious; Vogel (1961) observed them in flowers of Ceropegia (deceit attraction) in which they deposit their eggs and afterwards feed on nectar, and Van der Pijl (1953) recorded them from Abroma), Cryptochaetidae (no feedinghabits found), Tethinidae (mainly found in the intertidal zone at sea shores), Canaceidae (as preceeding), Braulidae (associated with bee nests, no proper feeding-habits found).

\section{Muscoidea}

The families included are the Scatophagidae (8 species), Anthomyiidae (52 species), Muscidae (48 species), Calliphoridae (42 species), Sarcophagidae ( 7 species) and Tachinidae (41 species).

Scatophagidae are small to medium-sized, bristly flies. Most species are predacious. Possibly they mainly visit flowers to prey on other insects. Schlee (1977) observed nectar-feeding.

Anthomyiidae are small to medium-sized, bristly flies, which feed on pollen and nectar. They also feed on plant and animal fluids, and some species are predacious.

Muscidae are small to rather large, more or less bristly flies. Their feedinghabits are diverse and vary from predacious and blood-sucking, carrion- and dung-feeding to nectar- and pollen-feeding. Many species are regular flower visitors.

Calliphoridae and Sarcophagidae are medium-sized to large, bristly flies. 
They feed on carrion and dung, but also on sweet liquids such as honey-dew and nectar. On flowers they can also feed on pollen (Porsch, 1956).

Tachinidae are medium-sized to large, strongly bristled flies with an elongated proboscis. The proboscis of Siphona is illustrated in Proctor \& Yeo (1973). Although many species are found on carrion, dung and decaying vegetable material, most are regular flower visitors which feed on nectar.

The other muscoid families are the Mormotomyiidae (live on excrements), Gasterophilidae (no feeding in the adult stage) and Oestridae (no feeding in the adult stage, however, Sharp (1899) suggested feeding on animal secretions). The remaining families are ectoparasitic (Hippoboscidae, Streblidae and Nycteribiidae).

The superfamily not included is that of the Asteioidea. The Anthomyzidae are frequently associated with Araceae. The Periscelididae feed on the sap stream in plants and the same may be the case in the Asteiidae. For the Teratomyzidae and Aulacigastridae no feeding-habits were found.

Conclusion: anthophily in the Schizophora is common. It mostly concerns anthophily together with other feeding-habits. The main flower visitors are the Lauxaniidae, Chloropidae and some of the muscoid families. The main food source in flowers is nectar, but in many cases pollen is also eaten. Particularly the feeding-habits of the many minute to small flies should be studied in relation to their possible role in pollinating the many very small, entomophilous flowers. Ropalomeridae and Odiniidae might also be attracted to pollen. Sepsidae, Dryomyzidae, Clusiidae and Acartophthalmidae, like Sphaeroceridae and Anthomyzidae, might be attracted to carrion-scenting flowers.

\subsection{Other insect orders in which flower-visiting occurs}

Collembola are saprophagous or phytophagous insects which in many cases feed on pollen and fungal spores. Only very few cases of pollination by Collembola are known. The latter may be the case in Chrysosplenium oppositifolium (Burkill, 1897, see Proctor \& Yeo, 1973).

Adults of many species of the Plecoptera feed on lichens and unicellular algae, sometimes also on pollen and nectar. They have been seen on Caltha, Helianthemum, Achillea, Apiaceae and probably might play a role in the pollination of Listera ovata (Proctor \& Yeo, 1973).

The Dictyoptera mostly are occasional flower visitors, although in Brazil a species is known which exclusively feeds on nectar. Saltatorial Orthoptera may visit flowers (Schuster, 1974).

In the Hemiptera the Phymatidae are predacious and some species hide themselves in flowers in order to catch their prey, which come within reach. 
The Anthocoridae behave in the same way, but sometimes feed on nectar. The many phytophagous Hemiptera are injurious when visiting flowers. Apart from the Anthocoridae, flower-visiting also regularly occurs in Miridae. Both families may play some role in the pollination of flowers such as Asteraceae and Apiaceae.

The Thysanoptera mostly are injurious on flowers. However, some cases of pollination have been described. Taeniothrips ericae plays a role in the pollination of Calluna vulgaris, Erica tetralix and Hypochoeris radicata on the Faroes (Hagerup, 1950). Richards \& Davies (1977) mentioned that Thrips fuscipennis. T. major, T. flavus, Taeniothrips atratus and $T$. vulgatissimus congregate in large numbers on many different flowers, though their larvae feed on other plants. In this way they play a role in the pollination of e.g. Beta (Imms, 1957) and Dipterocarpaceae.

The Neuroptera often feed on nectar. Particularly the Raphidiidae are often found on flowers.

The Mecoptera are attracted to nectar (Panorpa) and like the Trichoptera are regularly seen feeding on it (particularly some species of the Leptoceridae).

Genuine anthophily, however, is very rare among these insect orders and pollination only occurs in some cases. Flower visits of insects belonging to other orders than those mentioned here, have to be considered as purely accidental events. 


\section{CORRELATION OF THE FEEDING-HABITS OF THE INSECTS WITH THEIR PHYLOGENY AND FOSSIL REGORD}

The correlation of the feeding-habits as compiled in chapter 4 with the phylogeny and fossil record of the insect taxa in which entomophily developed is carried out here. The approach is the most optimistic one: comparison of the Recent feeding-habits with the phylogeny and fossil record. With the present knowledge it is not possible to trace developments in the feeding-habits within the separate taxa. Only some pollen analyses on fossil insects are carried out up to now (Willemstein, 1978a and 1980), indicating that the insects in question must have been anthophilous to some degree. Because of the absence of more of these observations the correlation is speculative: the feeding-habits could only be compared with the presence of the taxa and in only some cases can they be based on studying the morphology of e.g. the mouth parts, as is the case in some fossils enclosed in amber. In the next sections only the general tendencies shown by the many specific theoretical correlations will be described.

With only few exceptions, the extant flower-visiting insects are classified in the Holometabola (Coleoptera, Hymenoptera, Diptera and Lepdidoptera). The monophyly of the Holometabola is accepted by Hennig (1981) and with him probably by the majority of the present-day entomologists. Kristensen (1975) noted that there is indeed little evidence for alternative views. The main synapomorphy, on which the monophyly of the Holometabola is based, is the type of metamorphosis (complete metamorphosis: the life-cycle incorporates the egg, a number of larval instars, differing considerably from the adult, pupal instars, and the imago). It has to be mentioned that the larval mouth parts and feeding-habits are often quite unlike those of the adults. Being aware of these differences is important for understanding the phylogeny of the Holometabola and thus for the development of insect-flower relationships within the Holometabola.

Within the Holometabola Kristensen (1975) recognized four monophyletic groups, viz., Coleoptera + Strepsiptera, Neuropteroidea (Megaloptera + Raphidioptera + Neuroptera), Hymenoptera and Mecopteroidea (Trichoptera + Lepidoptera + Mecoptera + Siphonaptera + Diptera), see fig. 5-1. This classification has been largely accepted by Königsmann (1976) and Hennig (1981). Of these insect groups, the Strepsiptera and Siphonaptera are of no importance for this study. The second larval instar and the apterous females of the Strep- 


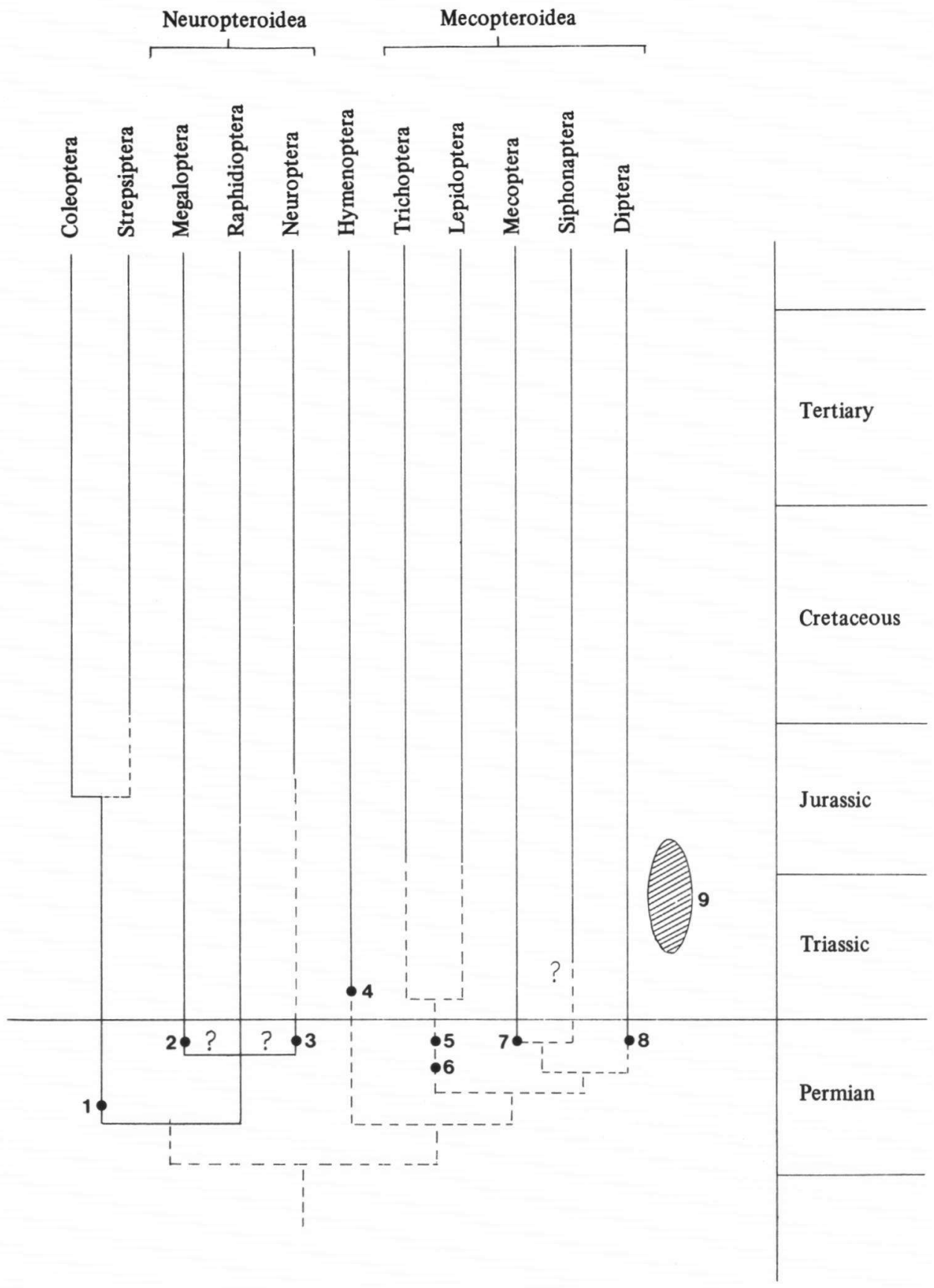

Fig. 5-1. Outline of the probable relationships within the Holometabola, after Kristensen (1975), Königsmann (1976) and Hennig (1969, 1981). 1. Tshekardocoleus; 2. Permosialis; 3. Palaeohemerobiidae; 4. Archexyela; 5. Microptysma; 6. Microptysmodes, Cladochorista; 7. Mecoptera from the Upper Permian of Australia; 8 and 9 Paratrichoptera. 
siptera are endoparasitic in other insects. The Strepsiptera are considered the sister-group of the Coleoptera (Kinzelbach, 1971) and therefore should form a relatively early development in the Holometabola. However, Crowson (1981) placed the origin of the Strepsiptera, as a sister-group of the Lymexylidae, in the Lower Cretaceous. The extant Siphonaptera are apterous ectoparasites on warm-blooded animals. If the earliest Siphonaptera had the same habits, they could not have evolved earlier than in the Triassic (presumed origin of the Mammalia and the Aves, see Romer (1966)) and not in the upper Permian at the latest as Hennig (1981) suggested. This means that a sistergroup relationship with the Mecoptera as a whole (Kristensen, 1975), as illustrated in fig. 5-1, is not probable, because this would indicate too an early origin of the Siphonaptera. Both the Strepsiptera and Siphonaptera are specialized insects which do not form any link with the development of anthophily in insects.

To understand the development of the feeding-habits of the Holometabola (larvae and adults), a hypothesis as to the feeding-habits of the earliest representatives has to be formulated. In the upper Permian rather great differences may already have existed between the feeding-habits of the four major holometabolan groups.

The earliest representatives of the Coleoptera most probably were fungivorous (and phytophagy may have evolved very early), those of the Neuropteroidea zoophagous, those of the Hymenoptera phytophagous and those of the Mecopteroidea phytophagous (with an early development towards zoophagy). It is difficult to accept either phytophagy or zoophagy as the original feeding-habit of the earliest Holometabola. More probable may be fungivory, saprophagy or a combination of both, as this is the most acceptable basis for the development of phytophagy as well as zoophagy. This hypothesis finds support in the probable development of the feeding-habits in the sistergroup of the Holometabola, i.e., the Paraneoptera. The relationships within the Paraneoptera are illustrated in fig. 5-2.

The extant Zoraptera are small insects that live under bark, in decaying wood, humus, etc. Both nymphs and adults feed on fungal spores and sometimes fragments of mites are found in their intestines. The extant Psocoptera (together with the Phthiraptera forming the Psocodea) live on foliage, on tree trunks, under bark, on weathered fences and palings on fungi and among the growths of algae and lichens. Adults and nymphs feed on unicellular algae, lichens, fungal hyphae, spores, fragments of plant tissue and fragments of insect tissue (saprophagy). The specialized feeding-habits of the Phthiraptera (feeding on skin surface debris and blood) are of later origin. The extant Thysanoptera are mainly phytophagous and fungivorous. The few species with predatory habits are found in the apomorphous Aeolothripidae (Mound et al., 1980). The same authors stated that in the Thysanoptera, fungus-feeding in 


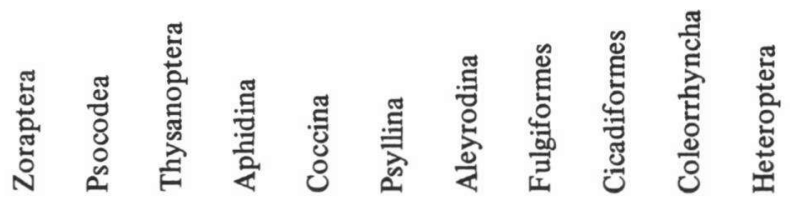

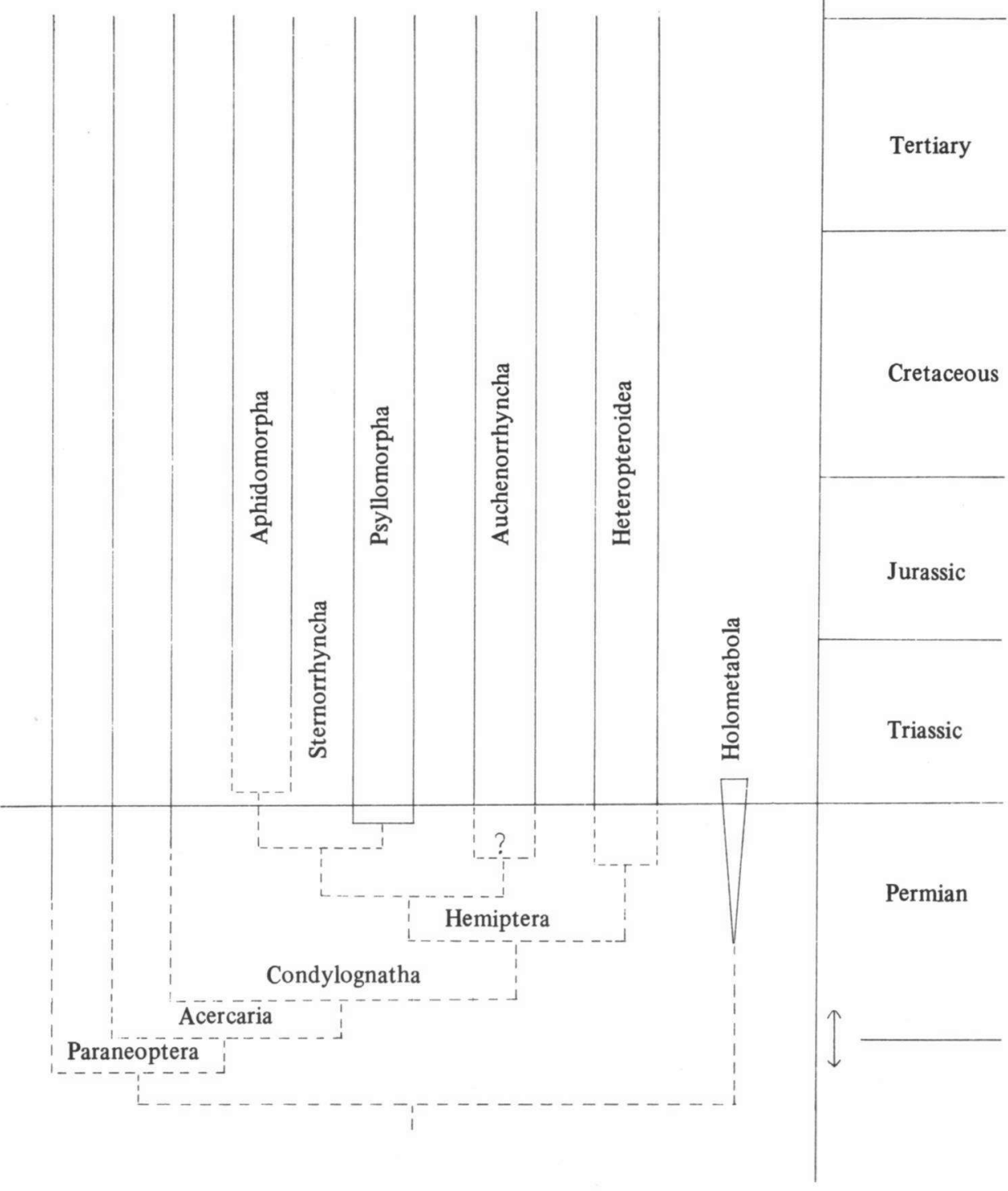

Fig. 5-2. Outline of the probable relationships within the Paraneoptera, based on Hennig (1969, 1981). 
litter is the plesiomorphous character state, while the apomorphous character states (in this sequence from plesio- to apomorphous) are: fungus-feeding under bark, phytophagous on leaves, phytophagous on flowers, and predatory. The last-mentioned feeding-habit may have originated from the fungusfeeding state already, since a direct change from phytophagy to predatory does not seem very probable, although phytophagy on flowers may form some basis for predatory habits on flower-visiting insects and other animals. Among the extant Hemiptera, the Sternorrhyncha and Auchenorrhyncha ( = Homoptera minus Coleorrhyncha) are phytophagous. Blood-sucking occurs besides phytophagy only in the Heteropteroidea.

All this makes it quite probable that saprophagy, fungivory or a combination of both in litter is the most plesiomorphous feeding-habit in the Paraneoptera. This in turn means that this way of feeding may also have occurred in the stem-group of the Paraneoptera and the Holometabola.

With the above-mentioned in mind, the idea of Tillyard (1926) (see also Hennig, 1981) that the larvae of the Holometabola originally lived in vegetable debris and similar substances, as do the modern Choristidae (Mecoptera), becomes highly probable. Because of the generally arid conditions in the Permian (and the late Carboniferous) (Schwarzbach, 1950) the (moist) environment of decaying organic material must have been a most suitable habitat for the larvae of the early Holometabola.

At this point it is possible to formulate a hypothesis on the habitat and feeding-habits of the larvae of the earliest Holometabola: they most probably lived in moist vegetable debris and other decaying substances, and their feeding-habits were saprophagous and/or fungivorous. The presence of lower fungi is already known from the Devonian and their presence in Carboniferous and Permian petrified woods has been demonstrated by Pirozynski (1976).

If the Holometabola, again, are compared with the Paraneoptera, there are also indications that the adults of the earliest Holometabola had the same feeding-habits as their larvae.

In this chapter it has repeatedly been suggested that insect taxa may have been anthophilous at the time of appearance of the Angiospermae. It is not possible to talk about the origin of the Angiospermae, because this may be (much) older than hitherto thought (see section 7.4). With the appearance is ment the stratigraphical appearance of angiosperm fossils in the Barremian-Aptian.

\subsection{Coleoptera}

The oldest fossils of coleopteran stock date from the uppermost division (Leonardien) of the lower Permian. These fossils show similarities to the Recent archostematan Ommadidae (Cupedidae-Ommadinae auct.), but they also have features foreign to modern Coleoptera e.g., some of the lower Per- 
mian fossils (as Tshekardocoleus) show a Megaloptera-like venation of the elytra. These are reasons for Crowson (1981) to use the name Protocoleoptera for the Coleoptera-like fossils of the lower Permian and he concluded that the Coleoptera arose in the Permian from the Megaloptera or Megaloptera-like ancestors. If the Coleoptera are from megalopteran ancestry, they would not be the sister-group of the Neuropteroidea. If they are from Megaloptera-like ancestry they can be, because Megaloptera-like characters or character states may well have been present in the stem-group of the Coleoptera and the Neuropteroidea. As long as the relationships within the Neuropteroidea are not clear, this problem remains unsolved.

The fossils of the Protocoleoptera are only adults and they provide no direct evidence about their habits. These have to be deduced by comparison with modern forms showing similar features. Most of the Protocoleoptera have a somewhat flattened habitus (e.g. Sylvacoleus), relatively short legs, nonprojecting coxae and short antennae inserted low down the sides of the head. In the Recent Coleoptera these features are common to the species which live under bark of (dead) trees. This makes it likely that this habitat was ancestral in the Coleoptera and the development of the elytra from the forewing may have been an adaptive feature for this habitat. In the period in which the Protocoleoptera occurred trees were present: tree ferns and the rise of Coniferae, e.g. Walchia species in the Rotliegendes, see Gothan \& Weyland (1973) and Maegdefrau (1968). There are no indications that the larvae of the Protocoleoptera lived in other habitats.

Because the mouth parts cannot be properly studied in the fossils of the Protocoleoptera, there is no direct evidence about their feeding-habits. In the Recent Coleoptera, the most plesiomorphous mouth parts (adult as well as lar$\mathrm{val}$ ) are found in some of the forms feeding on lower fungi, particularly those of the mould type. These fungi constitute a readily available food source (in the form of spores), they are associated with dead trees and they also occur in the crevices in the bark of living trees. Thus, a reasonable hypothesis is that fungi-feeding by adults and larvae is the ancestral type in the Coleoptera.

More Coleoptera-like fossils are known from the upper Permian, some of which show features more like modern Coleoptera. This is why Crowson (1981) used the name Archecoleoptera for the more Coleoptera-like insects from the upper Permian (the ancestral form of the Archecoleoptera still has to be found). In the sense of Hennig (1981) the Archecoleoptera could be regarded as predecessors of the Coleoptera. This means that the left part of fig. 5-1 (Coleoptera + Strepsiptera) can be refined to the outlines presented in fig. 5-3.

In the upper Permian the fossils of the Archecoleoptera show a considerable adaptive radiation (relatively large diversity of forms), but it is difficult to deduce the habits of the Archecoleoptera by comparison with the modern 


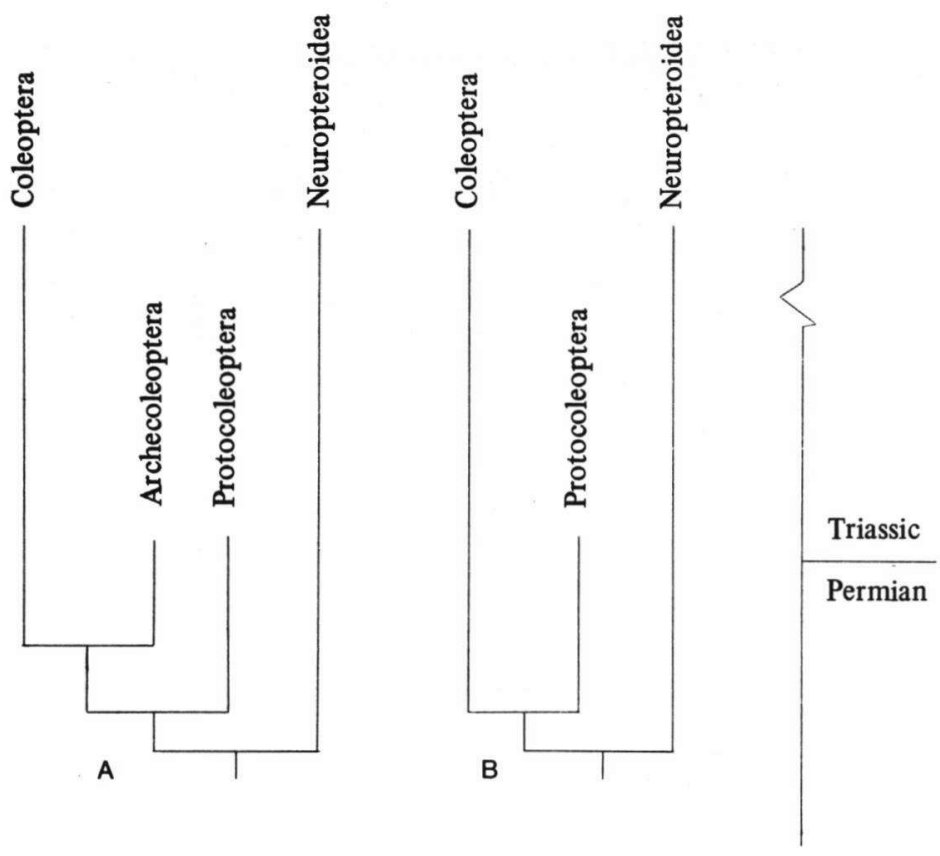

Fig. 5-3. Outlines of the probable relationships in the Coleoptera and their ancestors, after Crowson (1981): A. with the Archecoleoptera as a separate group; B. Archecoleoptera included in the Coleoptera.

Coleoptera. The habitats and feeding-habits were more diverse than in the Protocoleoptera. It is of interest for this study that one of the types of feedinghabits may well have been pollen-feeding, because the transformation of the mouth parts from fungi- to pollen- or spore-feeding is morphologically relatively simple.

During the Triassic, characters and character states suggestive to modern suborders begin to occur. In the middle and upper Triassic pieces of fossil wood have been found with unmistakable insect borings (Walker (1938): Arizona; Linck (1949): Keuper of Germany). These insect borings are associated with archostematan larvae and because the borings are of different types it can be suggested that the Archostemata had already diversified by then. If the association of wood-boring and archostematan larvae is correct, some suggestion as to the adult feeding-habits may be made by comparison with the modern Archostemata. In the adult stage most are flower visitors which feed on pollen, and it is possible that the adults of the Triassic Archostemata did the same. Pollen- or spore-feeding in Coleoptera, then, may have been established in the first half of the Triassic.

From the other coleopteran suborders (see fig. 5-4) the mainly predacious 


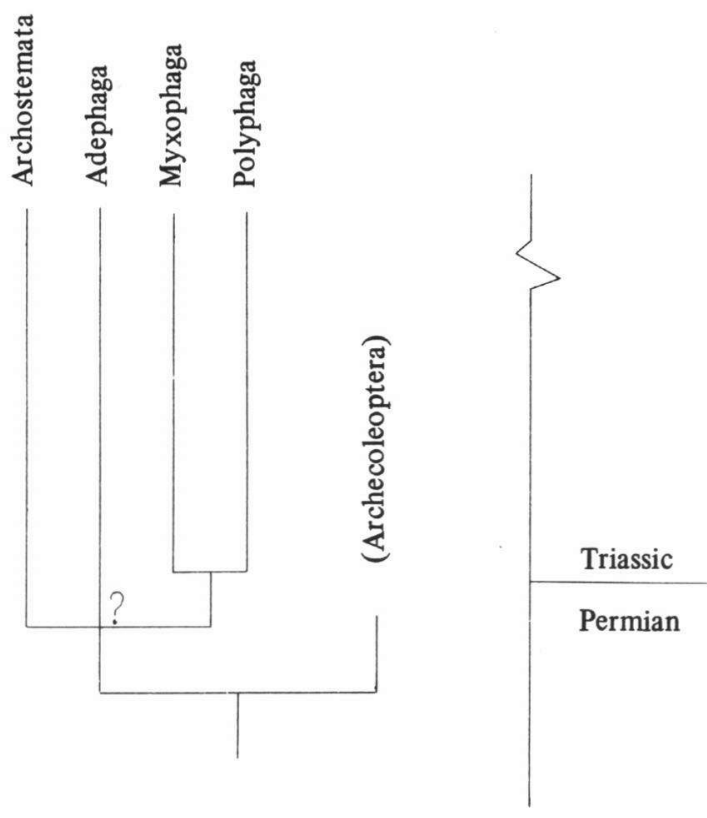

Fig. 5-4. Outline of the probable relationships of the suborders of the Coleoptera, after Crowson (1981).

Adephaga and the aquatic, algae-feeding Myxophaga are not important in this study, because they did not develop anthophily, and are left out of the discussion. There are clear indications that these suborders originated in the early Triassic. Next to what was said on the Archostemata, we have to follow the line of the Polyphaga. In the Triassic some features suggestive to the Polyphaga are to be seen, e.g. the Ademosynidae described by Ponomarenko (1969) from lower or middle Triassic deposits.

From the Jurassic deposits extensive fossil insect faunas are known and in all of them the Coleoptera are richly represented. During the Jurassic there were many changes in the biotic environment, e.g. the development of the Bennettitales towards their largest extension, which may have had a considerable impact on the development of pollen-feeding among the fungivorous or phytophagous Coleoptera.

Of the many fossils of Coleoptera from the lower Jurassic only a few have been studied in detail. Arnoldi and Zherichin (in Ponomarenko, 1977) described representatives of the archostematan Ommadidae, Tetraphaleridae, and certain adephagan types; there are indications that Hydraenidae and Elateridae-like forms occurred. Moreover it is possible that Scarabaeidae (Aphodiites and Opiselleipon) and Eucinetidae (Ooperiglyptus) did occur as well. It 


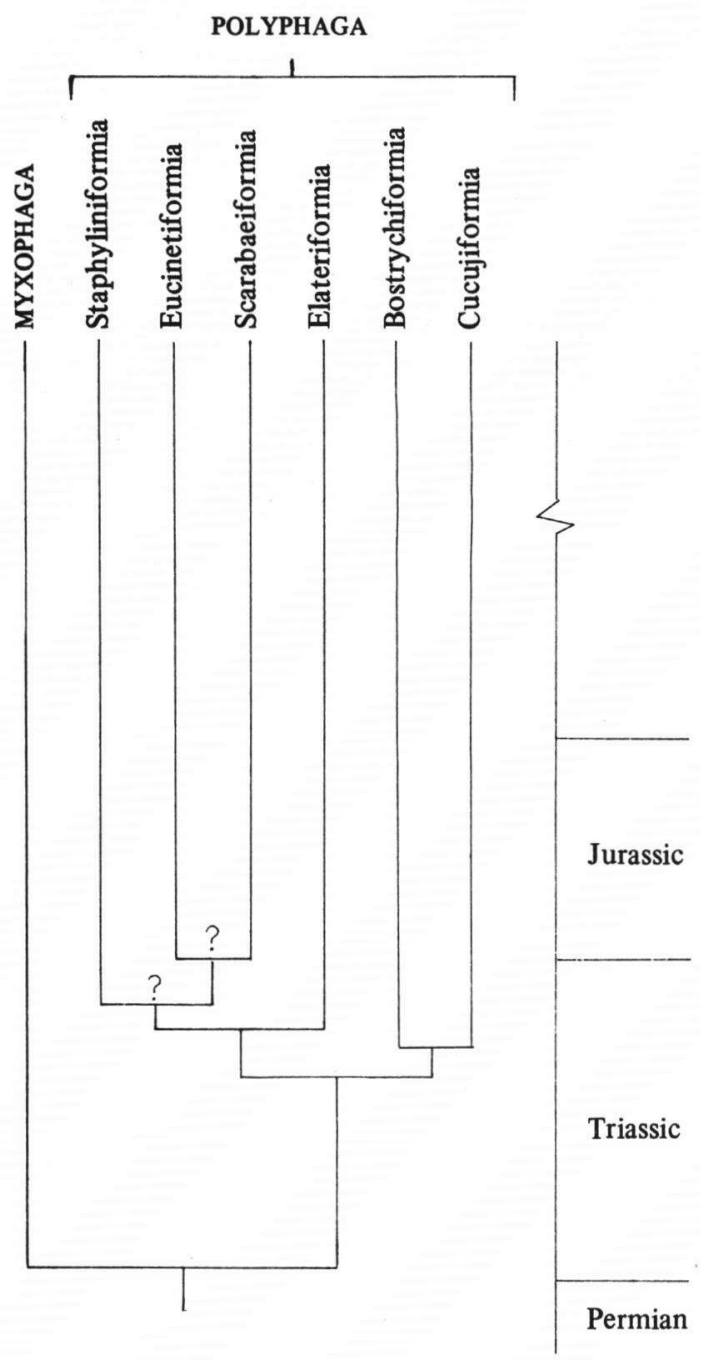

Fig. 5-5. Outline of the probable relationships of the series in the Polyphaga, after Crowson (1981).

is, then, probable that the series of the Polyphaga were already established and their origin may date from the upper Triassic (fig. 5-5).

From the middle Jurassic, fossils of the Coleoptera are not known in large quantities, but from the upper Jurassic numerous fossils have been recovered. It appears that during the Jurassic most superfamilies of the Coleoptera were established and that many of the extant families may already be recognized by the end of the Jurassic. A survey of the presumably established superfamilies 
and families in which anthophily developed is given in table 5-1 at the end of this section.

If we compare the families in this table with the descriptions of the feedinghabits in section 4.1 the following can be concluded. The adults of the Recent Cupedidae, Ommadidae and Tetraphaleridae (in contrast to Crowson (1981), Britton (1970) considered the Ommadidae as a subfamily of the Cupedidae) feed on pollen, so there may be indications that they also did so at the end of the Jurassic. Within the Staphyliniformia there are no reasons to believe that the Hydraenidae and Hydrophilidae had other feeding-habits than they have now (decaying vegetable material, fungi and excrements). The modern representatives of these families sometimes are found in carrion-scenting inflorescences of the Araceae. Whether the reproductive structures of the Bennettitales (and possibly other gymnosperm groups with hermaphroditic reproductive structures as well, see section 7.2) produced carrion scent or not, will never be known, but if they did, they could have attracted these beetles and many others. Crepet (1972) reported remains of possible insect injury to the microsporophylls of Cycadeoidea. Although scents may have played a role in attracting insects in the Jurassic, in the analyses in chapter 6 they are not included. The Histeridae may have fed in this time on decaying vegetable material and dead animals. In the Staphylinoidea the Scydmaenidae most probably were predacious or developing predacious feeding-habits and the Silphidae probably were coprophagous and may have been in some cases phytophagous. The Staphylinidae, for which Crowson (1981) indicated the middle Jurassic as the time of origin, probably were feeding on decaying vegetable material and predacious habits already may have been developed. Pollen-feeding in the Recent Staphylinidae mainly occurs in the Omaliinae. This subfamily shows some plesiomorphous features within the Staphylinidae (e.g. entire elytra in the Recent exotic genera Tanygnathus and Cameolium (Crowson, 1954) and in the females of the subgenus Abinothum of Eusphalerum (Lohse, 1964)). Association of pollen-feeding with these plesiomorphous features makes it probable that this way of feeding in the Staphylinidae occurred already at the end of the Jurassic. The Eucinetiformia (Crowson (1981) include the families Clambidae, Eucinetidae and Helodidae; Britton (1970) considered these families as belonging to the scarabaeiform Dascilloidea) are represented by the Helodidae which probably were associated with vegetation near water as are the Recent forms. In the Scarabaeiformia the Dascillidae may have fed on pollen, the Lucanidae probably were phytophagous and the Geotrupidae and Scarabaeidae may have been coprophagous. In the Elateriformia moss-feeding may have occurred in the Byrrhidae, algae-feeding and phytophagy in the Ptilodactylidae, phytophagy and pollen-feeding in the Buprestidae, probably phytophagous feeding-habits in the Artematopidae, and in addition to phytophagy also pollen-feeding in the Elateridae. In the 
Bostrychiformia association with wood and seeds may have occurred in the Bostrychidae and fungivory and pollen-feeding in the Anobiidae. In the Cucujiformia fungivory may have occurred in the Peltidae and Lymexyloidea, carnivory in the Cucujidae, fungivory in the Cavognathidae, pollen-feeding in the Mordellidae and omnivory with possible pollen-feeding in the Tenebrionidae. In the Chrysomeloidea both in the Cerambycidae and Bruchidae besides phytophagy also pollen-feeding may have occurred; the Chrysomelidae probably were phytophagous on stems and leaves. Chrysomelid pollen-feeding is not likely, because the subfamilies in which it in present times occurs with some regularity (Cryptocephalinae and Donaciinae) are comparatively advanced. There may be a chance that the more plesiomorphous Galerucinae had anthophilous habits in the Lower Cretaceous. In the Curculionoidea pollen-feeding may have occurred in the Nemonychidae (associated with Gymnospermae), Anthribidae (besides fungivory) and Oxycorinidae. There is only a minor chance that pollen-feeding occurred in the mainly phytophagous Curculionidae and Belidae.

From the Cretaceous fewer fossil Coleoptera are known than from the Jurassic, but they include for the first time fossils enclosed in fossil resins (amber), which permits more detailed morphological studies (mainly of the Coleoptera that live in the vicinity of stems and branches of the resinproducing trees). From the Lower Cretaceous, besides Coleoptera already known from the Jurassic Kara Tau-deposits, Scarabaeoidea of the more plesiomorphous types like Hybosoridae and Geotrupidae are known (Geotrupes, Proteroscarabaeus and Holcorobus), an apparent representative of the Helophorinae (Mesohelophorus) and a very probable representative of the Apionidae (Cretonanophyes). None of these families can be associated with flowers, except for the Apionidae, Recent forms of which are phytophagous and destructive to flowers. The Helophorinae are phytophagous and the Hybosoridae and Geotrupidae live on dung and carrion. The latter two within the Scarabaeoidea may form stepping-stones towards the development of anthophilous Scarabaeidae (see below).

In fossil, probably coniferous, wood of the Wealden, Blair (1943) found subcortical insect borings very similar to those made by the Recent Scolytidae, but Crowson (1981) suggested that they also could have been made by the larvae of the older Anthribidae- and Belidae-like forms, or may be even from noncurculionoid Coleoptera. Only the presence of the Anthribidae (see also the late Jurassic) would indicate probable flower-visiting.

In the Libanon amber (Schlee \& Dietrich, 1970) of the Aptian (Lower Cretaceous), Crowson (1981) identified a larva, resembling those of Micromalthus, a typical representative of the Scydmaenidae, a scarabaeoid type, two Elateridae, a representative of the Dermestidae, a clavicorn, possibly of 
the Pharaxonothini (Cryptophagidae) and two small Heteromera. The Recent Micromalthus feed on decaying wood, the extant Scydmaenidae are predacious, the scarabaeoid type shows features suggestive of termitophilous habits, the modern Elateridae are frequently visiting flowers, as do the Dermestidae and possibly the Pharaxonothini. Thus, besides the probable pollen-feeding families of the late Jurassic (table 5-1), there are indications that in the Lower Cretaceous anthophily was also present in the Cryptophagidae and Dermestidae.

From the late Cretaceous amber of the Taimyr Penninsula in Siberia Zherichin (in Arnoldi and Zherichin in Ponomarenko, 1977) described fossils of the Cerophytidae, Cleroidea, Lathridiidae and (probable) Atomariinae. Only the presence of the Cleroidea may indicate anthophily if this indeed refers to Cleridae. Recent Cerophytidae in all stages are associated with decaying wood and modern Lathridiidae and Atomariinae feed on fungi.

Most families of the Coleoptera became recognizable in the Tertiary. We will only consider the evolutionary history of the superfamilies in which anthophily developed. The Quaternary is not taken into account because during that period no important new developments have taken place in the Coleoptera. No further developments towards anthophily occurred after the Jurassic in the Archostemata, so we only have to deal with the polyphagan superfamilies. The probable relationships of the series and superfamilies within the Polyphaga are illustrated in fig. 5-6, only the superfamilies marked with an asterisk are treated here.

\section{STAPHYLINIFORMIA}

As described in section 4.1 anthophily in the Staphyliniformia has developed only in the Staphylinoidea, and there it is limited to the staphylinid Omaliinae. The relationships within the Staphylinoidea are not clear, thus in order to avoid too much speculation, only the Staphylinidae are considered.

As mentioned above, the pollen-feeding habits of the Omaliinae may have existed at the end of the Jurassic, derived from plesiomorphous staphylinid saprophagy and fungivory. These plesiomorphous feeding-habits can fit a sister-group relationship with the Eucinetiformia (Eucinetoidea). The latter are also in Recent times still saprophagous (only in the Clambidae this was specialized into myrmecophilous habits).

\section{SCARABAEIFORMIA}

Within the Scarabaeiformia anthophily has developed in both superfamilies Dascilloidea and Scarabaeoidea. The most favourable hypothesis of the origin 

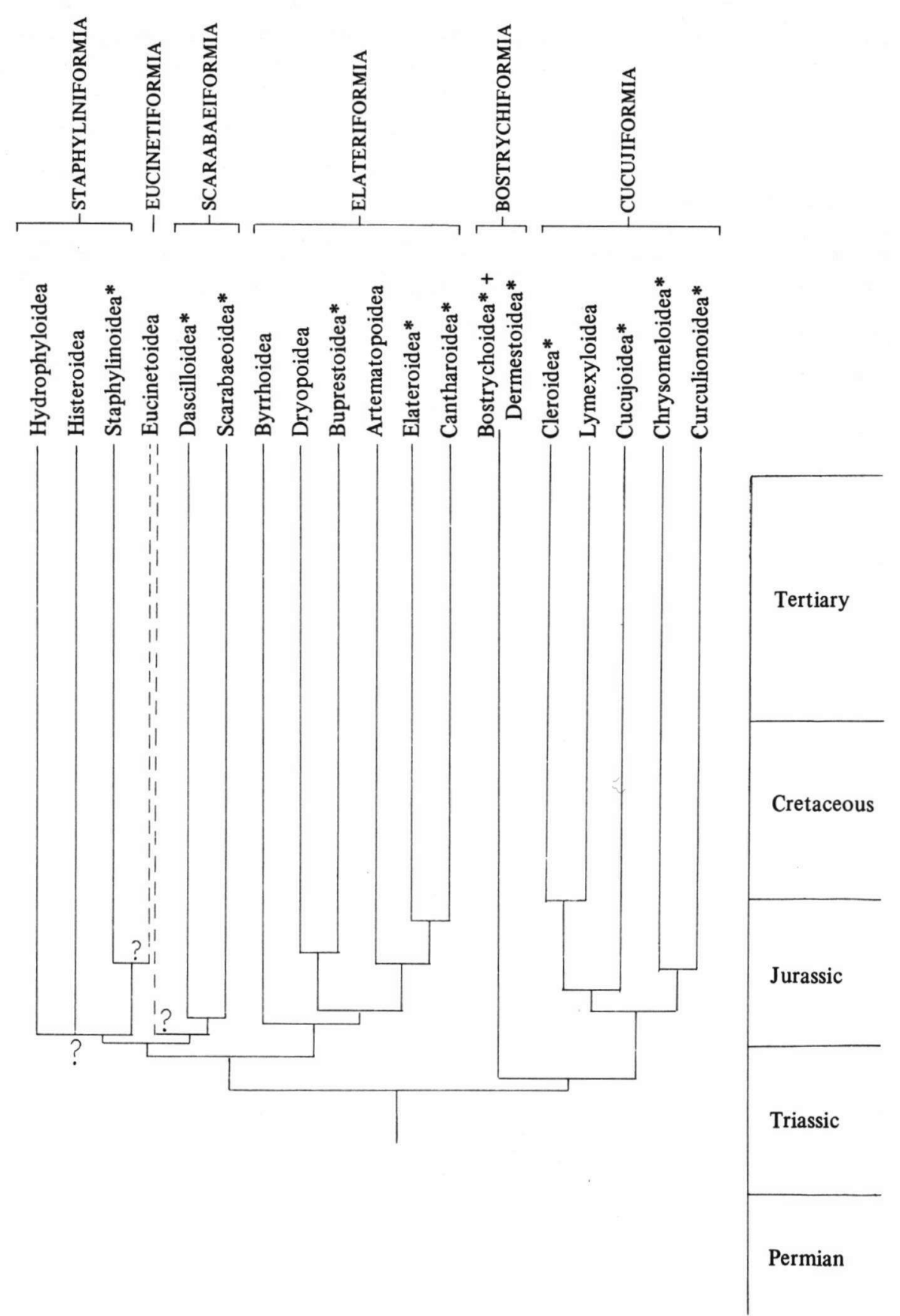

Fig. 5-6. Outline of the probable relationships of the superfamilies within the Polyphaga, after Crowson (1981). The superfamilies marked with an asterisk developed anthophily and are treated in the text. 
of the Scarabaeoidea is that they are derived from ancestors much alike the plesiomorphous sister-group, i.e., the Dascilloidea. The oldest fossils that can be attributed to the Dascilloidea are of the genus Mesodascilla from the late Jurassic Kara Tau deposits. The most plesiomorphous Scarabaeoidea probably had burrowing-habits and fed on fungi. This feeding-habit might well have been plesiomorphous in the early Dascilloidea as well, and formed the basis for the development of anthophily in many of the adults of the Recent Dascillidae. Here we see that a sister-group relationship of the Scarabaeiformia and the Eucinetiformia based on the type of feeding-habits is possible (see also in the Staphylinoidea).

The scarabaeoid fossils younger than the Cretaceous contribute little to the understanding of the phylogeny in the group. The scarce fossils found in the lower Oligocene of Chile (dung ball associated with the modern Scarabaeinae), the lower Eocene London Clay (Saprosites-like fossil belonging to the Aphodiinae; Balthasar (1963) mentioned that the Recent representatives of this genus are saprophagous), the Eocene brown coal deposits of Germany (Eophyllocerus, oldest pleurostict fossil attributed to the Melolonthinae) and the Baltic amber (Paleognathus belonging to the Lucanidae and species attributed to Aphodius) indicate that most of the modern types were already present in the first half of the Tertiary.

As has been mentioned in chapter 4.1 anthophily in the Scarabaeoidea only developed in the Scarabaeidae. The most plesiomorphous types of this family show affinities to the geotrupid types. The Geotrupidae feed on the dung of herbivores, thus on half-digested plant remains. This feeding-habit does not differ very much from feeding on decaying plant material (saprophagy) and probably was derived from it (Balthasar, 1963). The plesiomorphous saprophagy may have given rise to coprophagy (most Laprosticti) and on the other hand, via fungivory (among others the laprostict Ochodaeinae) to anthophily (in the Pleurosticti). The Pleurosticti are the most apomorphous Scarabaeidae. The Glaphyrinae have a pleurostict, Melolonthinae-like habitus, but the abdominal spiracles of the adults and the maxillary lobes of the larvae are of the laprostict type. Although there may be parallel adaptive development (the Glaphyrinae mainly have the same habits as most Pleurosticti), Crowson (1954) suggested that the Glaphyrinae might occupy the same sort of position in relation of the Laprosticti and the Pleurosticti as dipnoan fish have in relation to the bony fish and the amphibians.

The anthophily in the Pleurosticti may date from the origin of their most plesiomorphous representatives, i.e., the Melolonthinae. As we have seen above this subfamily is known from the Eocene (Eophyllocerus). The extensive anthophily in most of the other pleurostict subfamilies (Rutelinae, Cetoniinae, Dynastinae, Hopliinae, Valginae, Trichiinae) may have developed later in the Tertiary. Balthasar (1963) concluded that the Scarabaeidae must have had a 
stormy evolution during the Paleocene and the Eocene. Older anthophily within the Scarabaeidae may be found in the Glaphyrinae, but whether it was present at the time of appearance of the Angiospermae is questionable. It is known that Cetonia aurata feeds on the pollen of Pinus mugo (Willemstein, 1978) but indications that this feeding indeed may be considered plesiomorphous, require more research.

\section{ELATERIFORMIA}

Within the Elateriformia anthophily has developed in the superfamilies Buprestoidea, Elateroidea and to some degree in the Cantharoidea. In the Buprestoidea (only family Buprestidae) pollen-feeding may date from the middle or late Jurassic, derived from fungivory or algae-feeding (the latter being the feeding-habit of the more plesiomorphous representatives of the sistergroup, i.e. the Dryopoidea) and kept unchanged (besides some guiding by the evolutionary development of angiosperm flowers) up to Recent. Harde (1979) noted that the Buprestidae in Recent times mainly visit yellow flowers.

Within the Elateroidea pollen-feeding is mainly found in the Elateridae and Trixagidae. The relationships within the Elateroidea are not clear, so we only may state that the Elateridae may have had pollen-feeding habits from the middle or late Jurassic onwards. Fossils of the late Jurassic Kara Tau deposits have been attributed to the subfamilies Negastriinae and Cardiophorinae. The Recent representatives of the Negastriinae feed on decaying plant material near water and some visit flowers, e.g. species of Quasimus. The Cardiophorinae mainly feed on flowers.

The Cantharoidea are known from fossils in the Baltic amber (upper Eocene to lower/middle Oligocene) in many species of several families (Cantharidae, Lampyridae, Lycidae). This means that the main divisions within the Cantharoidea were already established at that time. The origin of the Cantharoidea is not clear from the fossil record, but since they form the sistergroup of the Elateroidea, they must have been present in the second half of the Jurassic. Because the more plesiomorphous Cantharoidea mainly visit flowers (Brachyspectridae, Homalisidae, Drilidae) pollen-feeding habits may have been present at the time of appearance of the Angiospermae. The Cantharidae and the Lycidae are apomorphous within the Cantharoidea and are of later origin, as are the predatory feeding-habits of the first. Cantharis tristis also feeds on the pollen of Picea excelsa (Knuth, 1899).

\section{BOSTRYCHIFORMIA}

Within the Bostrychiformia anthophily is mainly found in the Dermestoidea and only in some species of the Bostrychoidea pollen-feeding occurs. Of the 
Dermestoidea many fossils are found in the Baltic amber and they represent several subfamilies of the Dermestidae. Larsson (1978) recorded representatives of the Dermestinae (Dermestes), Anthreninae (Anthrenus), Attageninae (Attagenus), Megatominae (Globicornis) and Trinodinae (Trinodes). This means that the divisions within the Dermestidae were well-established in the first half of the Tertiary. The same can be said for the Bostrychoidea. The first bostrychoid fossil is known from the lower Eocene London Clay (anobiid Veneblesia collurium) and from the Baltic amber Larsson (1978) mentioned many species of the Anobiidae (representing both Recent central European subfamilies), some Bostrychidae, some Ptinidae and of the Lyctidae the genus Lyctus. The origin of the Bostrychiformia is much older than the Tertiary. Since they form the sister-group of the Cucujiformia, their origin has to be placed in the second half of the Triassic. Crowson et al. (1967) noted that the Dermestoidea will not be readily recognisable in Mesozoic fossils and it will be difficult to attribute fossil forms to the Bostrychoidea. Since the relationships of the families in both superfamilies are not very clear, it is difficult to date the separation of the Bostrychoidea and the Dermestoidea in the Jurassic, but it must have been completed before the Lower Cretaceous Aptian. A possible plesiomorphous type of pollen-feeding in the Ptinidae is that of Ptinus dubius on Picea excelsa (Knuth, 1899).

\section{CUCUJIFORMIA}

Within the Cucujiformia anthophily has developed in the Cleroidea, Cucujoidea, Chrysomeloidea and Curculionoidea.

Within the Cleroidea (Crowson (1954) included the Melyridae) the Trogossitidae are considered the most plesiomorphous. Part of their diet (in addition to other insects) consists of fungi. This fungivory may have given rise to the pollen- and nectar-feeding habits of the Cleridae (they also prey on other insects). The first cleroid fossil dates from the late Cretaceous and later fossils are known from the Baltic amber and include several species of the Trogossitidae, Cleridae and Melyridae. If the Melyridae are classified correctly here, then the anthophilous habits of the Cleroidea were well-established in the first half of the Tertiary. The origin of the cleroid anthophily will be very difficult to trace: here again, as Crowson et al. (1967) noted, the Cleroidea are not likely to be readily recognized in Mesozoic fossils. Because both Cleridae and Melyridae are considered to be more apomorphous Cleroidea, their origin may date from later than the upper Jurassic and there is only a minor chance that cleroid anthophily existed at the time of appearance of the Angiospermae. From Recent Melyridae it is known that Dasytes obscurus (in Britton (1970) Dasytidae), Haplocnemus pini and $H$. tarsalis feed on the pollen of Pinus sylvestris (Knuth, 1899). 
The Cucujoidea are pre-eminently beetles of the loose bark and dead trees and it is likely that some such habitat for them was ancestral. The plesiomorphous fungivory in the Cucujoidea is connected with these habitats and it may easily have given rise to pollen-feeding. Because of the large number of families in the Cucujoidea and their very imperfectly understood interrelationships we will only deal with the families in which anthophily developed.

The Cucujoidea evidently fall into two series, corresponding roughly to the old Clavicornia and Heteromera. The Clavicornia include the more plesiomorphous types of the Cucujoidea and it is possible that the Heteromera arose from fairly plesiomorphous clavicorn, e.g. Byturidae-like, types. The clavicorn families in which anthophily developed are the Nitidulidae, Cryptophagidae, Byturidae, Languriidae and Phalacridae.

The Nitidulidae are plesiomorphous Clavicornia, of which the first fossil is found in the upper Jurassic Kara Tau deposits. Nitidulid fossils in the Tertiary are mainly found in the Baltic amber, however, in relatively small numbers. It can be concluded that the early developed pollen-feeding of the Nitidulidae continued and differentiated (many of the Recent species are limited to particular plant species) during the Cretaceous and the Neozoic. The Nitidulidae may be connected with the Phalacridae by intermediate Smicripidae-like forms.

The Cryptophagidae are poorly represented in the Baltic amber (mainly by the small Atomaria). They have affinities to the Protocucujidae and Sphindidae on the one side and on the other towards the Languriidae and Erotylidae and possibly also to the Silvanidae. Only the Silvanidae are known from the Baltic amber (Silvanus and related forms). The cryptophagid anthophily (besides fungivory) may have existed during the Cretaceous from the Aptian Pharaxonotini onwards.

The Byturidae are not known from the Baltic amber. If they are connected with a basis for the Heteromera they must have been present before the end of the Jurassic, since the Heteromera were already well-established at that time. This would mean that byturid pollen-feeding habits probably were present at the time of appearance of the Angiospermae. The Languriidae are related to the Erotylidae and the Cryptophagidae. Although there are no fossils known from the Tertiary, the relationships indicate that languriid anthophily (besides phytophagy on leaves and the stems of herbaceous plants) did exist in the first half of the Tertiary.

The Phalacridae may be related with the Nitidulidae and include plesiomorphous cucujoid types. There are no fossils known, so the time of origin cannot be indicated, but in view of their relationship with the Nitidulidae they may have arisen early. This does not mean that their anthophilous and anthophagous feeding-habits did arise at the same time. Because the Recent Olibrus species develop in the heads of Asteraceae this may be of relatively late 
origin and the pollen- and nectar-feeding habits may have developed from the plesiomorphous fungivorous feeding-habits like those of Phalacrus.

Within the Heteromera more families have developed anthophily than in the Clavicornia. The Heteromera include the more apomorphous Cucujoidea. The families in which anthophily developed are the Tenebrionidae, Lagriidae, Alleculidae, Mycteridae, Pyrochroidae, Melandryidae, Scraptiidae, Mordellidae, Rhipiphoridae, Meloidae, Oedemeridae and Anthicidae.

The Tenebrionidae are of relatively early origin (upper Jurassic) and it will be no surprise that in the Baltic amber most of the central European tribes were well established: Boletophagini (Boletophagus), Diaperini, Helopini (Helopus), Opatrini, Adeliini (Laena), Triboliini (Palorus, Tribolium), Ulomini (Uloma). Besides omnivory the tenebrionid pollen-feeding may have existed throughout the Cretaceous and the Neozoic, although these beetles never became obligatory specialists in this field.

The Lagriidae are related to the Tenebrionidae. This means that they may be of early origin. The few fossils in the Baltic amber indicate the establishment of the subfamilies Lagriinae (Lagria) and Statirinae (Statira) in the first half of the Tertiary. The origin of their anthophily (besides phytophagy on herbaceous plants), derived from fungivory under bark, may date from sometime in the Cretaceous.

The Alleculidae are closely related to the Tenebrionidae and therefore probably of early origin. From the Baltic amber it appears that the subfamilies Alleculinae (Mycetochara, Mycetocharoides, Isomira, Allecula, Gonodera and Hymenalia) and Omophlinae (Cteniopus) were well established in the middle Tertiary. This means that the origin of the Alleculidae and their anthophily may be much earlier. Recent species Omophlus americanae is known to visit the male cones of Pinus sylvestris (Knuth, 1899).

The Mycteridae (with poorly developed anthophily) are probably related to the Oedemeridae, but no fossils are known. There are no indications about their evolution.

The Pyrochroidae are related with the Oedemeridae and perhaps with the Anthicidae and Phytidae. There is one fossil known from the Baltic amber (Palaeopyrochroa crowsoni). Because the Oedemeridae and Anthicidae are also definitely present in the Baltic amber it, can be concluded that pyrochroid anthophily may have occurred in the middle Tertiary.

The Melandryidae (or Serropalpidae) have affinities to the Tetratomidae and more or less to the Scraptiidae, Mordellidae and Rhipiphoridae. Many fossils are known from the Baltic amber. They demonstrate that the family was well-established in the middle Tertiary: Serropalpus, Anisoxya, Abdera, Abderina, Dircaea, Phloetrya. The Tetratomidae are also represented in the Baltic amber (Hallomenus). If the Melandryidae indeed are related to the Mordellidae they may be of relatively early origin. The fairly plesiomorphous Tetratomidae may 
also indicate a rather early origin. They may have been present in the Cretaceous, but whether or not their anthophily (as it occurs only in the Recent melandryid genus Osphya), derived from the fungivory (as it occurs in the majority of the family), was already present in the Cretaceous or early Tertiary cannot be established.

The Scraptiidae approach the anthicid group, but are still allied to the Melandryidae and Mordellidae. Their fossils are known from the Baltic amber in large series. Willemstein (1978a and 1980) demonstrated that an individual of the extinct species Scraptia pseudofusculosa (fossil in Baltic amber) visited Quercus flowers before it got stuck in the resin of Pinus. If the relationship with the Mordellidae is correct, scraptiid anthophily may already have existed in the Cretaceous. Whether it dates as far back as the appearance of the Angiospermae remains questionable.

The Mordellidae are more or less closely related to the Melandryidae, Scraptiidae and perhaps to the Rhipiphoridae. Their fossils are known from the Baltic amber (Mordella, Mordellistena). On or in a fossil of the Mordellidae in Baltic amber (because of the poor quality of the amber the identification below family level was not possible) Willemstein (1980) demonstrated rather coarsely reticulate tricolporate pollen that, in view of the pollen structure and sculpture, must have been produced by entomophilous flowers. As has been mentioned, the pollen-feeding habits of the Mordellidae may date from before the end of the Jurassic.

The Rhipiphoridae probably arose from Scraptiidae- or Mordellidae-like ancestors. Their fossils are known from the Baltic amber (Pelecotoma, Rhipiphorus, Rhipidius). Because of the relationship with the two families, they may originate from Cretaceous times. Whether their anthophily existed at the time of appearance of the Angiospermae remains questionable.

The Meloidae may be related to the Anthicidae. Only a few fossils are known from the Baltic amber, e.g. Lytta. Thus it is possible that the meloid anthophily existed in the middle Tertiary. Because of the imperfectly understood relationships of the Meloidae their time of origin remains unknown.

The precise affinities of the Oedemeridae are not clear. There may be relations to the Cononotidae and the Anthribidae. Crowson (1954) based the Cononotidae on the North American genus Cononotus and included the central European Agnathus that formerly was classified in the Lagriidae. The possible relationships of the Oedemeridae indicate a Tertiary or somewhat earlier origin. Fossils of Oedemera are known from the Baltic amber. In conclusion it can be said that oedemerid anthophily possibly existed in the first half of the Tertiary and may be of late Cretaceous origin.

The relationships of the Anthicidae within the Heteromera are not clear. Their fossils are known from the Baltic amber and it appears that the main 
tribes Notoxini and Anthicini were definitely present in the middle of the Tertiary. This means that the anthicid (facultative) anthophily was present at that time and possibly may be of late Cretaceous origin.

"The phylogeny of the chrysomeloid larvae presents an almost literal picture of climbing a tree. Beginning with the larvae living down in the fungusdecayed dead wood we can trace lines going up into scund dead wood, into the living timber, out into the twigs and ultimately the larvae appear living an exposed life on the topmost leaves; a side branche leads into the carpels and seeds and others into the roots"' (Crowson, 1954). The most plesiomorphous habitat of the chrysomeloid larvae is also inhabited by those of the plesiomorphous Cerambycidae (mainly Prioninae and Aseminae). The 'trunk' part is found in the intermediately advanced Cerambycidae (mainly Lepturinae, Cerambycinae and some of the Lamiinae). The twigs (and the stems of herbaceous plants) are inhabited by the larvae of the most apomorphous Cerambycidae (part of the Lamiinae) and some Chrysomelidae. Free-living of larvae occurs in the majority of the Chrysomelidae. The branch into the carpels and seeds is found in the Bruchidae and the branch into the roots is found in some Cerambycidae (not distinguishable as plesio- or apomorphous because it occurs in the subfamilies Prioninae, Lepturinae, Cerambycinae and Lamiinae) and some Chrysomelidae. Mostly the larvae feed on the material of the substrate they live on. As will appear below the feeding-habits of the adults mostly differ from those of the larvae, but they have devloped in about the same way: from saprophagy and fungivory lines are traceable to pollenand nectar-feeding, feeding on leaves, soft twigs and roots. The above mentioned survey illustrates that if the relationships within a taxon are correctly understood, evolutionary lines can also be traced in the feeding-habits, which in their turn complete the picture of its phylogeny.

The basic division of the cerambycid and chrysomelid lines probably took place before the end of the Jurassic and probably coincided with a division between their basic food plants into Coniferales and Cycadales. The cerambycid line was directed towards the Coniferales and the chrysomelid line towards the Cycadales.

The most plesiomorphous Cerambycidae are considered to be the Philinae and very near the basis are the Prioninae and Aseminae. This suggestion is supported by the Parandra-like fossil Parandrexis from the Jurassic (Malm) deposits of Turkestan. There is evidence that the Recent, mostly crepuscular adults of the Prioninae and Aseminae do not feed (Mjöberg, 1905; Craighead, 1923; Poloschenzeff, 1929 and 1931; Eckstein \& Butovitsch, 1931), so there are no indications about the feeding-habits of the early plesiomorphous Cerambycidae. The most plesiomorphous feeding-habit following saprophagy and fungivory may have been pollen-feeding on Coniferales. It is known that Rhagium bifasciatum (Lepturinae) visits the male strobili of Pinus cembra (Tepp- 
ner, pers. comm.; see Willemstein, 1978). The Prioninae may be related with the Anoploderminae (via Parandra-like forms) and thus the Anoploderminae may be rather plesiomorphous. It is not known whether and to what extent the Recent Anoploderminae are anthophilous. Of the exotic Disteniinae the relationships within the Cerambycidae are not clear; their Lepturinae-like mouth parts may indicate anthophilous feeding-habits. The Lepturinae can be considered a stepping-stone towards the Cerambycinae with connections to the Philinae, Prioninae, Disteniinae and Aseminae (and possibly with plesiomorphous Chrysomelidae). Crowson (1954) stated that "the mouth parts of typical Lepturinae seem to be adapted to the flower-feeding habits of most of them, a circumstance that might cast some doubt on the hypothesis (often advocated) that the Lepturinae are the ancestral group of the Cerambycidae, for flowering plants are a relatively young group geologically, not surely known from the beginning of the Cretaceous and the Cerambycinae are likely older than them". This is not a valid argument, because these mouth parts are adapted to feeding on pollen as well as on nectar, and before the origin of the Angiospermae there were many polliniferous plants. As suggested above, plesiomorphous pollen-feeding, also within the Lepturinae, must have been pollen-feeding on Gymnospermae. The mouth parts of the Lepturinae may indicate a series of feeding-habits: from plesiomorphous fungus-feeding (as we have seen above, mouth parts adapted to fungus-feeding may be considered preadapted to pollen-feeding) in some Lepturinae-like groups (extended in the asemine Liopini), via pollen- (and nectar-) feeding in the Lepturinae (extended in part of the Cerambycinae), towards fruit- and leaf-feeding in many Cerambycinae. In the Lépturinae a probably later development may be nectarfeeding. This may be illustrated by the observations that both Clytus arietis (Picard, 1929) and Strangalia quadrifasciata (Schoijen, 1916) feed on honey-dew. The relationships of the Aseminae are not clear; they may have affinities to the Prioninae and the Lepturinae. The Aseminae are exclusively associated with Coniferales. The Cerambycinae have connections with the Lepturinae: through Necydalis-like forms a transformationseries is tracable. Crowson (1954) did not give a direction to this series. As argued above it may well be directed from the Lepturinae towards the Cerambycinae. The Lamiinae are the most apomorphous Cerambycidae. Many adults are known to chew actively on soft bark, leaves and roots (Dorcadion). Some species frequent flowers.

Following this survey of the Cerambycidae, there are indications that both in the Lepturinae and in the Cerambycinae pollen-feeding was present at the time of appearance of the Angiospermae. From the Baltic amber many Aseminae, Lepturinae, Cerambycinae and Lamiinae are known.

The Bruchidae are more closely related to the Chrysomelidae than to the Cerambycidae (Crowson, 1954; Brandl, 1981). As we have seen, the division between the Bruchidae and the Chrysomelidae may have taken place before 


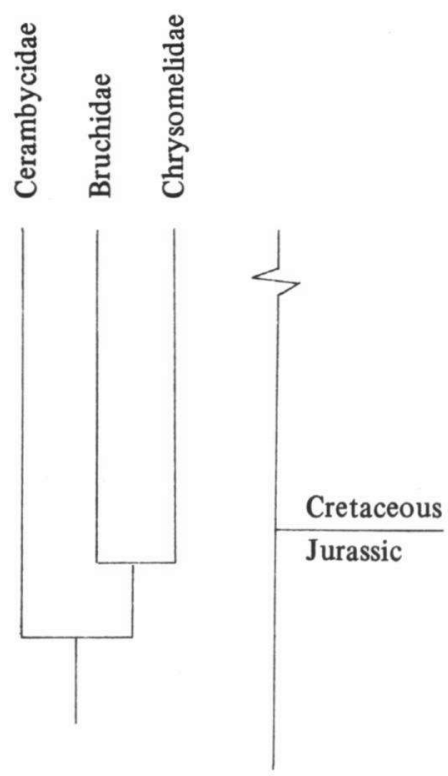

Fig. 5-7. Outline of the probable relationships within the Chrysomeloidea, after Crowson (1954).

the end of the Jurassic. The probable relationships within the Chrysomeloidea now can be illustrated (see fig. 5-7). All the Recent bruchid larvae feed on the seeds of Angiospermae, many species preferring Fabaceae. The adults take food from all kinds of non-specialized entomophilous flowers. In the Tertiary Bruchidae are known from the Baltic amber.

Within the Chrysomelidae some regular anthophily has developed in the subfamilies Donaciinae, Galerucinae and Cryptocephalinae. The Chrysomelidae are represented among the upper Jurassic Kara Tau fossils by the Proscelinae. They ressemble the Recent Aulacoscelinae (Aulacoscelis) and Sagrinae (Carpophagus) which are associated with the Cycadaceae. So there are indications that the earliest Chrysomelidae were associated with Cycadales. The feeding on Cycadales, then, is plesiomorphous in the Chrysomelidae. From the Eocene brown coal deposits of Germany, Haupt (1950) described Sagrinae, probable Donaciinae, Clytrinae, Cassidinae, Eumolpinae and Chrysomelinae. From the Baltic amber Hispinae and Halticinae were described (see Larsson, 1978). The Galerucinae may have occurred in Eocene deposits (Crowson, 1981). Among the fossils of the North American Paleocene very probable Donaciinae were found (occurring in conjunction with fossils of the Nymphaeaceae). Crowson (1954) considered it possible that the Galerucinae arose from Aulacoscelinae-like forms and that the Cryptocephalinae in all aspects are apomorphous Chrysomelidae. There are indica- 
tions that the flower-visiting of the Donaciinae is of comparatively late (about late Cretaceous) origin. Anthophily of the Galerucinae may have been present at the time of appearance of the Angiospermae and the pollen- and nectarfeeding habits of the Cryptocephalinae may be of early Tertiary origin.

Within the Curculionoidea anthophily has developed in the Anthribidae, scattered Nemonychidae, Oxycorinidae and Curculionidae, but mostly anthophily is accompanied by anthophagy.

The Nemonychidae are partly associated with Coniferales. The larvae of Cimberis and Diodyrrhynchus develop in the male cones of Pinus; the other genera develop in Angiospermae. The Nemonychidae are of pre-Cretaceous origin and the pollen-feeding habits of the adults may have existed during the Cretaceous and the Neozoic.

The Anthribidae probably are related to the Nemonychidae and of the same time of origin. Among the anthribid larvae a similar picture of climbing trees is found as in the Chrysomeloidea: borers in rotting wood (majority of the genera), fungus eaters (Holostilpna), borers in living stems (e.g. Sintor), seed eaters (Bruchela, Araecerus); from the saprophagous wood borers the predatory habits of Brachytarsus on Coccidae may have been derived. The adult Anthribidae have remained phytophagous, their plesiomorphous saprophagy and fungivory may have given rise to the combination of anthophily and anthophagy. As mentioned above, their anthophily may have been present at the time of origin of the Angiospermae and continued in the Cretaceous and the Neozoic. From the Baltic amber only a few fossils are known (Tropideres).

The Belidae are related with the Oxycorynidae and probably also with the Nemonychidae. They are partly associated with the Coniferales and partly with the Angiospermae. They may be of pre-Cretaceous origin and Belidaelike forms may have given rise to the Oxycorynidae. The Oxycorynidae are of upper Jurassic origin. The three Recent genera are associated with particular plant groups: Oxycorynus develops in the fleshy flowers of Prosopanche (Hydnoraceae); Metroxena has been recorded from palm fruits; the larvae of Allocorynus live in the male cones of the cycad Zamia. The pollen-feeding habits of the adults may date from the late Jurassic. The Oxycorynidae may have given rise to the Attelabidae by Allocorynus-like forms. The Atellabidae are phytophagous and probably of Cretaceous origin. The genus $\mathrm{Car}$ found in the Baltic amber may be linked with the oxycorynid Allocorynus.

The Brenthidae are connected with the more plesiomorphous forms of the Apionidae and thereby may be of relatively late origin (Cretaceous). The Apionidae may be regarded as forms intermediate between the Attelabidae and the Curculionidae. Fossils are known from the Baltic amber, thus their anthophagy may have been present in the middle Tertiary. The origin of the Apionidae may be Cretaceous.

The Curculionidae are of pre-Cretaceous origin and probably they form the 
sister-group of the Apionidae + Brenthidae ( + Attelabidae). Many Tertiary fossils are known and they demonstrate that almost all subfamilies were wellestablished in the early Tertiary. Recent Curculionidae are phytophagous: leaves, twigs, buds, flowers, seeds, stems, bark, dead and living wood, and roots are attacked. Some species partly feed on fungi and in only some scattered instances pollen-feeding occurs. Pollen-feeding may have derived from fungus-feeding on decaying wood and it may be relatively plesiomorphous. This means that pollen-feeding may be of relatively early origin in the Curculionidae and the presence of this feeding-habit at the time of the appearance of the Angiospermae may not be excluded.

A survey of the stratigraphical appearance of the (sub)families of the Coleoptera in which anthophily developed is given in table 5-1.

\subsection{Hymenoptera}

The Hymenoptera + Mecopteroidea form the sister-group of the complex Coleoptera (+ Strepsiptera) + Neuropteroidea. The characteristic fossil Tshekardocoleus (Protocoleoptera) of this complex is known from the lower Permian (Leonardien). This means that the stem-group of the Hymenoptera + Mecopteroidea dates at least from the lower Permian. It appears that in the upper Permian the main mecopteroid orders are present: the stem-group of the Trichoptera + Lepidoptera is represented by Microptysma, Microptysmodes and Cladochorista; Mecoptera are found in the upper Permian layers of Australia and some paratrichopteran types indicate the presence of plesiomorphous Diptera or their predecessors. Hymenopteran fossils are not known from the Permian, but since the Hymenoptera form the sister-group of the Mecopteroidea their origin must be at least in the middle or upper Permian. The classification of the Hymenoptera followed here, is that of Königsmann (1976, 1977, 1978 and 1978a). The cladograms are dated largely after Rasnicyn (1971, 1975 and 1980) (for a short survey, see Wootton, in press), regarding the critical notes in Königsmann (loc. cit.).

The oldest fossil of the Hymenoptera is found in the Triassic deposits of Queensland: Archexyela crosbyi (Riek, 1955) and it is attributed to the Xyelidae. This family is extant and the Recent representatives of the Xyelinae are associated with the male strobili of the Coniferales. The females deposit their eggs in the strobili and the hatched larvae develop feeding on pollen. The adults also feed on pollen (Xyela julii does so on the male catkins of Betula).

Malyshev (1968) did not consider the pollen-feeding of the larvae and the adults the most plesiomorphous feeding-habit in the Hymenoptera. He suggested that it was derived from saprophagy in the following way: "The soil of the warm, wet forests of the end of the Carboniferous and the beginning of the 


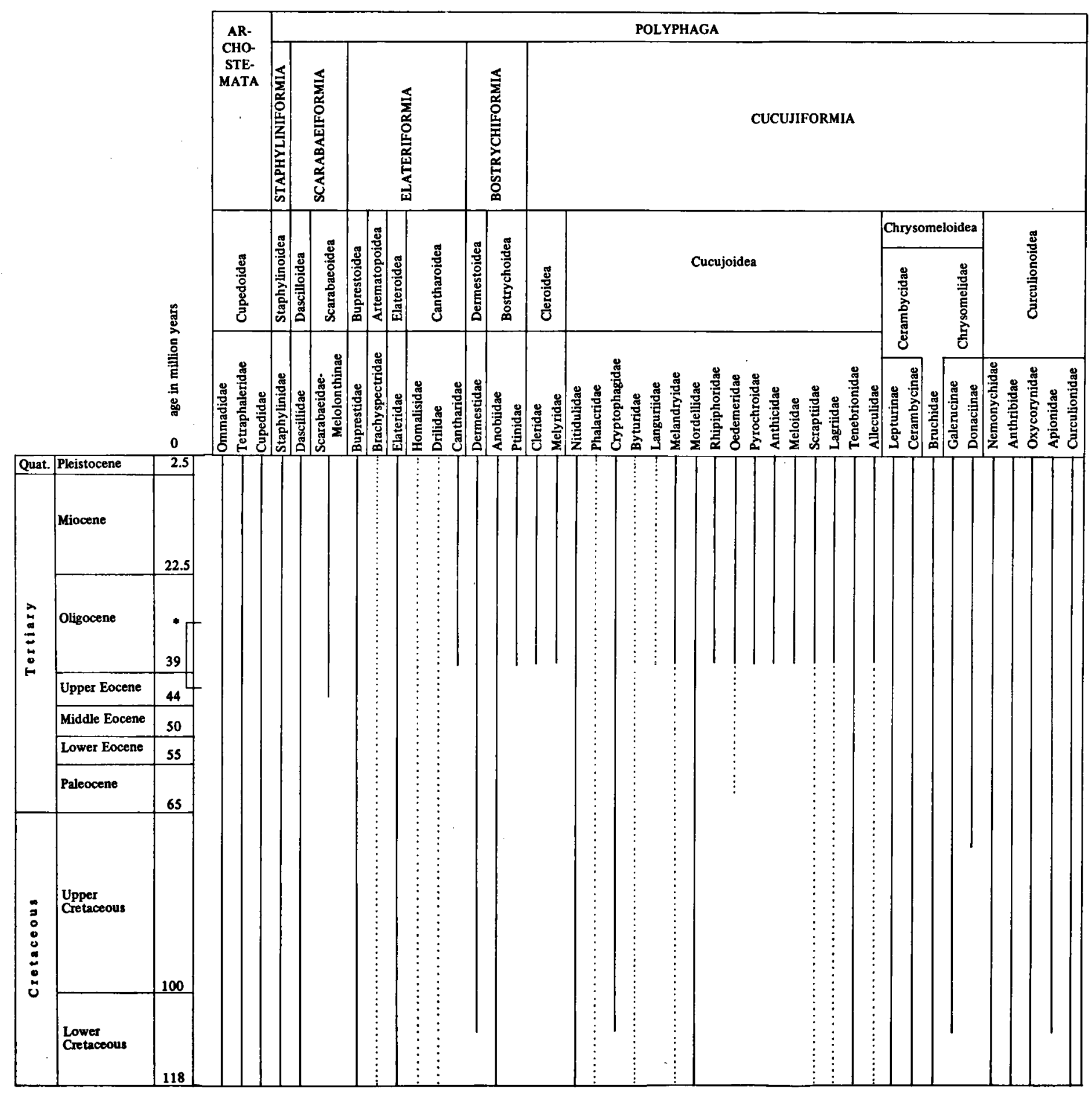

Table 5-1. Taxonomic arrangement of the stratigraphical appearance of the (sub)families of the Coleoptera in which anthophily developed. Explanation: continuous lines mean presence proved by fossils; dotted lines mean presence based on probable relationships. " indicates the period in which the Baltic amber was formed. 
Permian was covered not only with decaying remnants of various fern-like and gymnospermous plants, but also with a mass of fresh pollen and spores, falling from them in abundance to the ground, and in some cases formed a complete layer (Komarov, 1949, 1961). This mass of pollen, of higher food-value than the plant tissues producing it and more readily assimilated even by the primitive mouth apparatus, could easily become the principal item in the diet of larvae living in the forest bedding, not only in a state of decomposition but also in a fresh condition soon after falling from the plants". I do prefer to consider fungivory, as in the Coleoptera, as an intermediate stage in the development of feeding-habits between saprophagy and pollen-feeding. As in the Coleoptera mouth parts adapted to feeding on fungi and their spores can be considered preadapted to feeding on pollen. The forming of complete layers of pollen and spores falling from the vegetation must have been restricted and locally and therefore can hardly be a basis for future pollen-feeding. The fungi growing on the forest litter continually produce spores in quantities large enough to feed insect larvae in that habitat. Once specialized in fungivory the road to pollen-feeding was open. It is very well possible that the adult Hymenoptera already fed on pollen, while the larvae were still saprophagous and fungivorous.

The development of anthophily in the Hymenoptera is guided by the habits of the larvae and the maternal care for these. The most plesiomorphous hymenopteran larvae were free-living and actively feeding on decaying plant remains and fungi, whereas in the most apomorphous Hymenoptera the larvae are immobile and totally depending on the food collected (and processed) and brought to them by the adult females, or in case of many eusocial forms, by the workers. In the Apidae the larval food consists of honey and pollen and this forces the adults or workers to visit many flowers to collect nectar and pollen. This development culminated in the state-building Apis species that not only have to feed the larvae but, particularly in temperate regions, also have to build stocks for the hibernating adults. The stocks may not contain perishables and it is not surprising that nectar, with its high percentage of sugar, is the basis for the production of honey. These needs for large quantities of food made Apis mellifera the world's most important biotic pollen agent in the pollination of flowers. They are of such importance that, owing to the easy handling of their states, they were domesticated, not only for the production of honey, but also for pollination (see e.g. McGregor (1976) for a survey of the pollination requirements and practices for cultivated crop plants). Thus, in the description of anthophily in the Hymenoptera we emphatically have to trace the larval evolution and the evolutionary development of maternal care for the larvae. As regards the quantitative importance of the flower visits and their subsequent pollination, the evolution of social behaviour also has to be taken into account. 


\section{SYMPHYTA}

Königsmann (1977) noted that there are no synapomorphies to warrant the monophyly of the Symphyta, although they make the impression of close relationships by their habitus and behaviour. All common features are symplesiomorphies which they share with the ancestral Hymenoptera. A smaller group, viz. Symphyta minus Cephoidea (= Symphyta s.str.) can be considered monophyletic. The Cephoidea and the Apocrita have several synapomorphies and they can be considered the sister-group of the Symphyta s.str. These relationships and those within the Symphyta s.str. are illustrated in fig. 5-8.

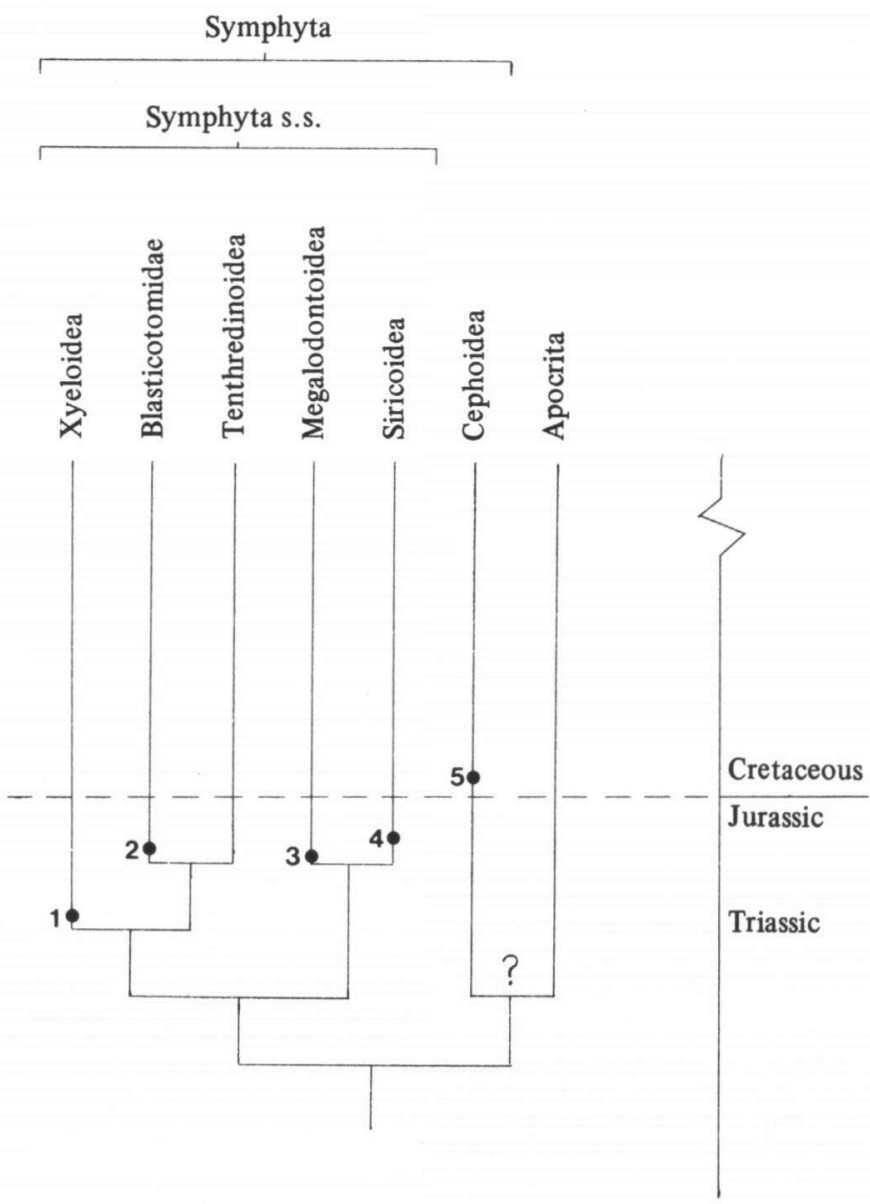

Fig. 5-8. Outline of the probable relationships within the Symphyta (s.str.), based on demonstrated synapomorphies, after Königsmann (1977). 1. Xyeloidea (upper Triassic); 2. Xyelotomidae (middle to upper Jurassic); 3. Parapamphilus; 4. Sinosirex, Pseudosiricidae, Anaxyelidae, Paroryssidae (middle to upper Jurassic); 5. Mesocephus (Lower Cretaceous). 
The synapomorphy on which the monophyly of the Symphyta s.str. is based is the presence of cenchri on the metathorax. These are raised bosses on the metanotum, which are connected with a scaly area on the underside of the forewings to keep them in place when at rest. This character may form an adaptation to the life on tree trunks, where the females deposit their eggs in the wood in crevices of bark and under bark, probably to enable the larvae to feed on fungi growing in the tunnels of the wood-boring larvae of Coleoptera, or on the larvae themselves (as do the larvae of the Siricoidea). Here we find that different insects may develop different structures for the same purpose. The possibility to fix the wings as an adaptation to the habitat of the tree trunks (living in the crevices of the bark and under bark) was reached by the Symphyta s.str. by the development of the cenchri, and by the Coleoptera by the development of the elytra. The Symphyta s.str., thus may have had ancestors living on tree trunks. Most of the families have left this habitat, but the cenchri remained and may be considered a 'ancestral' character. Comparison with the recent Symphyta s.str. indicates that many of the adults, except for the Siricoidea, already early fed on pollen.

In the larval life of the Symphyta s.str., Malyshev (1968) distinguished three stages: the archaic terrestrial phase (the females laid their eggs more or less haphazardly and showed no concern for them; the larvae emerging from these eggs led a wandering life and obtained their food by their own efforts, like, e.g. the larvae of the modern Mecoptera); the exophytic phase (the females laid their eggs on a food-containing substrate, possibly guided by their own feeding-habits; the larvae could move freely); the endophytic phase (the females deposited their eggs in the food-containing plant tissue and in this tissue the larvae could move actively in search for (more) food). The latter stage culminated in the formation of galls (tenthredinoid Nematinae: Pontia species), containing the food for the larvae; in the galls and the larvae became more immobile. Thus the first development towards the immobility of the hymenopteran larvae can already be followed in the Symphyta s.str. The adults did not yet show concern for their progeny, according to Königsmann (1977) possibly apart from the pending case of the Australian Perga lewisi (tenthredinoid Pergidae) which guards the eggs untill the hatched larvae begin to feed, and the instance of the South-American Dielocerus (tenthredinoid Argidae) that sit over and protect the larvae, which spin their cocoon under a common covering (Richards \& Davies, 1977). Neither the development towards immobile larvae, nor the evolution of the maternal care for the offspring in the Tenthredinoidea can be related to those in the Apocrita.

The Xyeloidea (only family Xyelidae) include the first known hymenopteran fossil (Archexyela crosbyi) dating from the Triassic. Many xyelid fossils are also known from the Jurassic. The larvae of the Recent Xyelidae live on woody plants. Those of the Xyelinae live in the male strobili of Coniferales 
and feed on pollen; those of the Macroxyelinae feed on the leaves of several Angiospermae (e.g. Juglandaceae, Ulmaceae); those of the Pleuronerinae bore in the young twigs of Coniferales, as probably do those of the Xyeliciinae. Taking them together with the xyelid ancestors, we here see a similar phylogeny as in the larvae of the Chrysomeloidea (see Coleoptera in section 5.1), viz. the picture of climbing a tree: as has been suggested above the common ancestor of the Symphyta s.str. lived on tree trunks and the larvae reached the male strobili, probably via fungivory (Xyelinae) and the uppermost young twigs and needles (Pleuronerinae and Xyeliciinae, and probably the predecessors of the Macroxyelinae which later shifted to the Angiospermae). Many of the adults of all subfamilies feed on pollen.

According to Königsmann (1977) the extinct Xyelotomidae of the middle and upper Jurassic are closely related to the predecessors of the Blasticotomidae. The Recent Blasticotomidae are associated with ferns and possibly the Xyelotomidae were the same. They are not important for potential anthophily, but they have to be mentioned here because they form the sistergroup of the Tenthredinoidea, of which no Jurassic fossils are known. They confirm the presence of the Tenthredinoidea in the middle and upper Jurassic.

Within the Tenthredinoidea some groups can be considered monophyletic, but the interrelationships are not clear. The Recent Argidae sometimes visit flowers. Malyshev (1968) noted that in the Argidae (like Benson (1945) did for the Pamphiliidae) the insects of which the larvae are associated with the Gymnospermae, show more plesiomorphous features than those of which the larvae are associated with the Angiospermae. Whether there is a distinct separation of these groups is not known, so there is no indication at all when the separation of the larval food plants occurred.

The Cimbicidae are plesiomorphous Tenthredinoidea and the same remark concerning the morphological features of the adults and the host plants of the larvae can be made as for the Argidae (see Malyshev, 1968). Here are indications of a considerable age and because of the fact that the Recent adults sometimes visit flowers, the possibility exists that cimbicid anthophily was present at the time of the appearance of the Angiospermae.

The Diprionidae are plesiomorphous Tenthredinoidea and the larval habitat is limited to the Coniferales. They may be of pre-Cretaceous origin, but whether the adults fed on pollen is not known. The monophyly of the Pergidae is not certain. The larvae show the plesiomorphous free-living mode of life, although the abdominal legs have disappeared in the Perginae. The food plants of the larvae are Angiospermae. This may mean that they are of comparatively recent age within the Tenthredinoidea.

Königsmann (1977) did not succeed in finding definite synapomorphies for the Tenthredinidae. The Recent larvae are associated with many different plants (both Gymnospermae and Angiospermae) and there are no indications 
whether these groups of food plants correspond to any classification within the family. Most adults of the Recent Tenthredinidae are regular flower visitors, but whether they were so at the time of the appearance of the Angiospermae is not known.

The Megalodontoidea were present in the upper Jurassic Kara Tau deposits. The fossil Parapamphilus can neither be attributed to the Megalodontidae nor to the Pamphiliidae and has to be inserted into their stem-group. The Xyelydidae from the upper Jurassic deposits of Kasachstan (Xyelya, Mesolyda, Strophandria and Prolyda) have to be considered to belong to the direct predecessors of the Pamphiliidae. This means that the separation between the Megalodontidae or their direct predecessors and the the direct predecessors of the Pamphiliidae was already established before the end of the Jurassic. The adults of both Recent families are regular flower visitors. The megalodontid and pamphiliid anthophily may have been present at the time of appearance of the Angiospermae.

The Siricoidea form the sister-group of the Megalodontoidea. Within the Siricoidea the Siricidae + Xiphydriidae form a good monophyletic group. They share no definite apomorphies with the Syntexidae (= Anaxyelidae) and/or the Orussidae, but monophyly of the families may be possible (Königsmann, 1977). The relationships of the Siricidae + Xiphydriidae on the one side and the Syntexidae and Orussidae on the other are not clear. The oldest fossils of the Siricoidea are found in the Jurassic Lias (Gigasiricidae, Sepulcidae and Myrmiciidae) but they are difficult to attribute to the modern families. Sinosirex gigantea (Sinosiridae) of the upper Jurassic or Lower Cretaceous of China is very similar to the Recent Siricidae. This means that the Siricidae and the Xiphydriidae (being sister-groups) probably were already present at the end of the Jurassic or the beginning of the Cretaceous. The Recent Siricidae and Xiphydriidae are known to feed on the sap exuded from trees and this, as in e.g. the Cetoniinae (Coleoptera) may be accompanied by nectar- (and pollen-) feeding. It is not very probable that they had anthophilous habits at the time of appearance of the Angiospermae.

The larvae of the Syntexidae ( = Anaxyelidae) are known from Coniferales and probably the adults are also associated with these plants. Many fossils are known from the upper Jurassic Kara Tau deposits and from the Lower Cretaceous of East Siberia.

The Orussidae are known from the middle Jurassic of Kasachstan (Paroryssidae which have to be attributed to the direct predecessors of the Orussidae). The larvae are parasites on other insect larvae. The Recent adults are found on dry wood.

The Cephoidea form together with the Apocrita the sister-group of the Symphyta s.str. This means that the stem-group of the Cephoidea + Apocrita was 
already present in the Triassic. The first fossil that can be attributed to the Cephoidea is Mesocephalus sibiricus from the Lower Cretaceous, and if the insertion of the Karavitidae into the direct predecessors of the Cephoidea is correct (synapomorphies, however, not yet found) then the latter were present in the upper Jurassic. The first certain cephoid fossils are found in the upper Eocene to lower/middle Oligocene, e.g. Cephus and Electrocephus stralendorffi were described from the Baltic amber. Because the Cephoidea form the sister-group of the Apocrita, the presence of the apocritan fossil species Mesaulacinus oviformis and Mesochelorus muchini in the Kara Tau deposits demonstrate the presence of the Cephoidea or their direct predecessors in the upper Jurassic. Because of the absence of the cenchri, the Cephoidea (only family Cephidae) might have been separated from the Symphyta s.str. or their direct predecessors before the stage of tree trunk-inhabiting. The Recent Cephidae deposit their eggs mostly in the stalks, stems or soft, young twigs of Angiospermae. The larvae often are injurious to corn crops (see e.g. Curtis, 1883). May be, in pre-angiosperm times, the cephoid larvae found their way to ferns in earlier times than did the Blasticotomidae, or they may have been specialized on the young twigs of Gymnospermae. The Recent adults frequently visit flowers and probably they did already do so at the time of the appearance of the Angiospermae.

\section{APOCRITA}

The relationships within the "Terebrantes" are by no means clear. The study by Königsmann (1978) has resulted in the outline given in fig. 5-9. Because of the many question marks regarding the phylogeny, the search for the probable origins of anthophily in the families of these insects mainly have to be based on the fossil record.

The families of the former Proctotrupoidea (Ceraphronoidea, Diapriidae s.lat., Pelecinidae, Monomachidae and the Heloridae s.lat.: Roproniidae, Proctotrupidae, Heloridae and Vanhorniidae) and the Stephanidae and Trigonalidae did not develop anthophilous feeding-habits. They mainly feed on liquids of animals (in some cases they feed on the fluids of the larval prey or host) and plants (in many instances they feed on sap of trees and occasionally on nectar, but the latter did not lead to regularity in flower-visiting). For the plesiomorphous Megalyridae (incl. Dinapsidae) it is unknown whether they developed anthophily. The superfamilies and families that did develop anthophily are marked with an asterisk in fig. 5-9 and they are treated below.

In the "Terebrantes" the larvae are mainly carnivorous, preying on the larvae of other insects. The most probable hypothesis for the origin of these feeding-habits is that they were derived directly from saprophagous feedinghabits in the following series: saprophagy, feeding on soft-bodied insect larvae living in decaying forest litter, feeding on more solid insect larvae living in the 


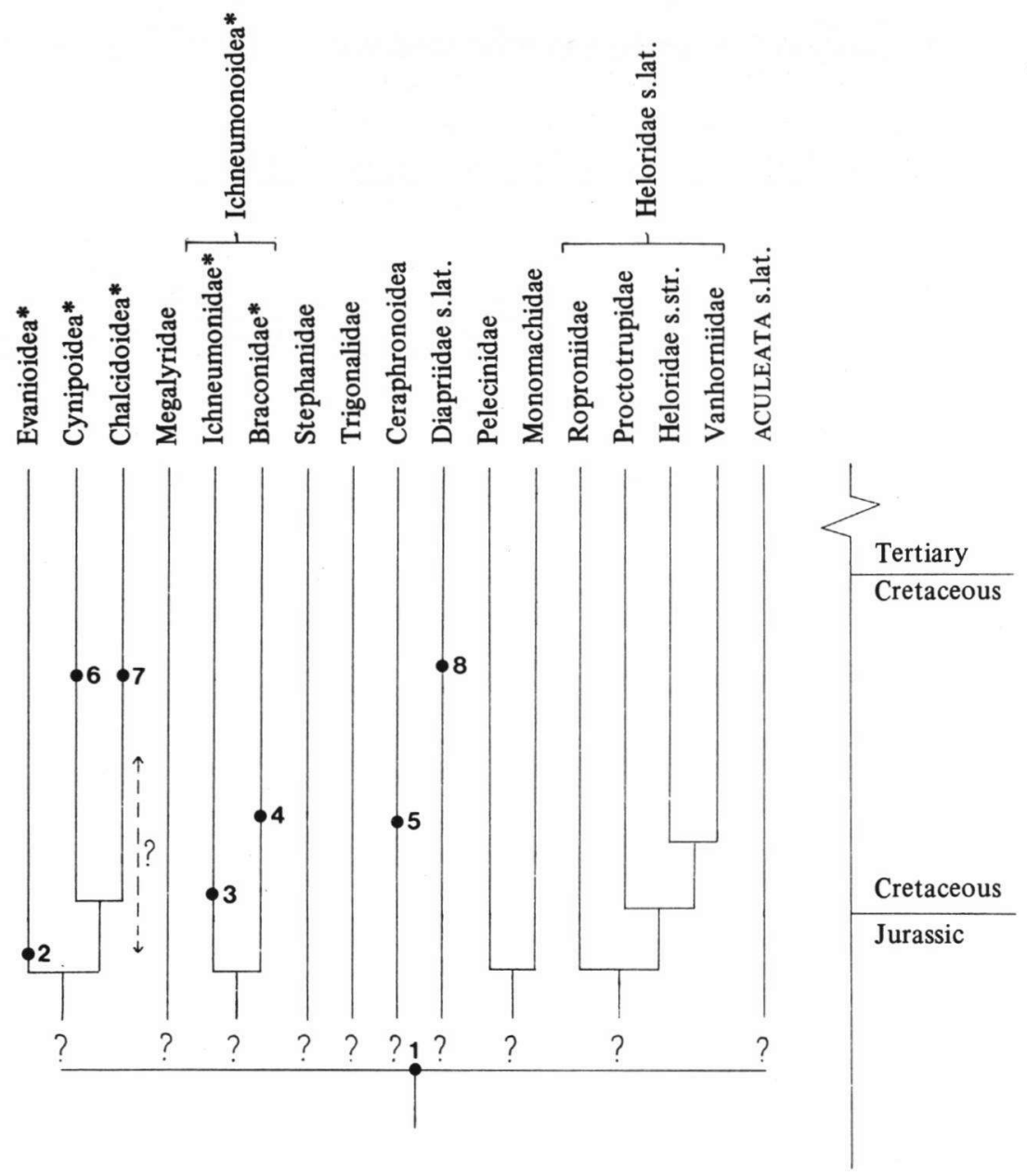

Fig. 5-9. Outline of the probable relationships within the "Terebrantes", after Königsmann (1978), based on demonstrated synapomorphies. 1. Mesoserphidae (Jurassic); 2. Praeaulacidae (upper Jurassic); 3. Tanychorella (Cretaceous); 4. Braconidae (Cretaceous); 5. Stigmaphronidae and Allocoditus (Cretaceous); 6. Cynipoidea (Upper Cretaceous); 7. Chalcidoidea (Upper Cretaceous); 8. Baryconus and Proteroscelio (Upper Cretaceous). The (super)families marked with an asterisk developed anthophily and are treated in the text.

wood of (dead) trees. A side-branch is formed by egg-parasitism and a very advanced development is hyperparasitism. The maternal care is restricted to finding a suitable larva or egg for oviposition. Within the monophyletic group Evanioidea + Cynipoidea + Chalcidoidea gall formation developed independently in the Cynipoidea and Chalcidoidea. Because the larvae of the Evanioidea (being the sister-group of the Cynipoidea + Chalcidoidea) are external parasites, or better predators, of other insect larvae, the zoophagy in the group 
Evanioidea + Cynipoidea + Chalcidoidea has to be considered plesiomorphous. The gall formation in the Cynipoidea and Chalcidoidea, then, is apomorphous. The mechanism of the change-over to gall formation is not clear. The change-over in maternal care consists of finding a suitable substratum from host larva or egg to plant tissue. In the chalcidoid Agaonidae the maternal care consists of active pollination of the female flowers of Ficus in some of which the eggs are deposited.

The Evanioidea are known from the upper Jurassic. From the Kara Tau deposits Rasnicyn (1972) described the genera Praeaulacus, Praeaulacinus, Praeaulacon, Praeaulacops, Praeaulacites, Aulacogaster, Evanigaster and Evaniops and brought them together in the family Praeaulacidae. Within the Evanioidea the most probable division into sister-groups is that in the Evaniidae and the Aulacidae + Gasteruptionidae (see fig. 5-10). The relationships of the Praeaulacidae with the extant families are not clear and as yet it seems reasonable to attribute them to the Evanioidea or their direct predecessors. The same must be stated for the upper Jurassic (Malm) fossil family Anomopterellidae and the extinct Upper Cretaceous Cretavaniidae and Kotujellidae. This means that the Evanioidea or their direct predecessors were present at the end of the Jurassic. The separation of the sister-groups Evaniidae and Aulacidae + Gasteruptionidae was established in the middle Tertiary: Evania and Brachygaster are known from the Baltic amber and they confirm the presence of the Evaniidae. This means that the Aulacidae + Gasteruptionidae or their stem-group were also present at that time. This is confirmed by the presence in the Baltic amber of Pristaulacus and Micraulacus which have to be attributed to the Aulacidae or their direct predecessors. Certain Aulacidae are present in the Miocene of North America (Aulacus and, still, Pristaulacus). Since the Aulacidae form the sister-group of the Gasteruptionidae (see fig. 5-10), the latter must have existed at the same time: Gasteruptionidae ( = Gasteruptiidae) or their direct predecessors must have been present in the middle Tertiary and certainly were so in the Miocene. Within the Evanioidea only the Gasteruptionidae developed regular flower-visiting and nectarivorous habits. For the adults of the other families no feeding-habits were found, but compared with the adaptation to anthophily of the mouth parts of the Gasteruptionidae, considered a synapomorphy by Königsmann (1978), the mouth parts of the other families are more plesiomorphous, probably suited for liquidfeeding or saprophagy. There are indications that evanioid anthophily is of late, probably middle, Tertiary origin and the main food source on flowers was nectar. Evanioid or -like anthophily at the time of appearance of the Angiospermae is highly questionable.

The Cynipoidea + Chalcidoidea form the sister-group of the Evanioidea, and thus, they, or their stem-group, must have been present in the upper Jurassic. The Cynipoidea or their direct predecessors are represented in the 


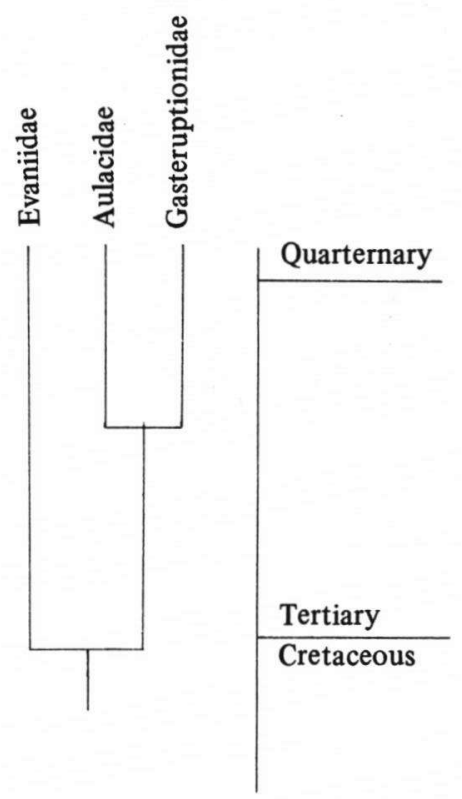

Fig. 5-10. Outline of the probable relationships within the Evanioidea, after Königsmann (1978), based on demonstrated synapomorphies.

Upper Cretaceous amber of Manitoba by Protimaspis. It is not clear whether this fossil species belongs to the Cynipoidea or the Cynipidae. Other cynipoid fossils are known from the Upper Gretaceous of North Siberia and in the Tertiary they are found in the Baltic amber and Oligocene and Miocene deposits. The relationships within the Cynipoidea are not clear. They developed some flower-visiting, nectarivorous habits, but it is not clear whether the Cynipoidea or the stem-group of the Cynipoidea + Chalcidoidea had anthophilous habits at the time of appearance of the Angiospermae.

The Chalcidoidea (inclusive of the Mymaridae and Leptofoenidae) form the sister-group of the Cynipoidea. The first Chalcidoidea were found in the Upper Cretaceous Canadian amber. Yoshimoto (1975) and Brues (1937) described species belonging to the Mymaridae, Trichogrammatidae and Tetracampidae or their direct predecessors from this amber. Many Chalcidoidea were also described from the upper Cretaceous of North Siberia (e.g. Mymaridae). In the Tertiary many fossils are known from the different types of amber and from Oligocene deposits (Rott). In the middle Tertiary (Baltic amber) most families are definitely present: Trichogrammatidae, Eulophidae, Mymaridae, Eurytomidae, Torymidae, Pteromalidae and Mymarommidae. Except for the Agaonidae, the monolectic pollinators of Ficus species, and the chalcidid Leucospinae which are attracted to floral and 
extrafloral nectaries, none of the Chalcidoidea developed definite anthophilous habits. They mainly feed on exposed plant fluids. The oldest agaonid fossil is Tetrapus mayri from the Miocene or lower to middle Oligocene deposits of Florissant (see Axelrod, 1954). It was found together with a leaf of Ficus. It is interesting to mention that the oldest Ficus type pollen dates from the middle Oligocene (Muller, 1981). This means that the agaonid anthophily originated around the middle of the Tertiary. No fossils are known of the Leucospinae, thus nothing can be said about the time of origin of their nectarivorous habits.

The Ichneumonoidea form a monophyletic group. The relationships with other superfamilies, however, are not clear. The oldest Ichneumonoidea-like fossils are the Ichneumonomimidae from the Lower Cretaceous Neocomian of Trans-Baykal and they most probably can be attributed to the direct predecessors of the Ichneumonoidea. From the same deposits Tanychorella has been described, which can be assigned to the direct predecessors of the Ichneumonidae. This means that they probably were already separated from the Braconidae or their direct predecessors in the Lower Cretaceous. The Recent adult Ichneumonidae are frequent flower-visitors and possibly their ancestors in the Lower Cretaceous were so too. The first fossil that can be attributed to the Ichneumonidae is Tanychora from the Upper Cretaceous of Trans-Baykal. Later, in the Tertiary many fossils are found, both in ambers (mainly Baltic) and in deposits (Oligocene of Rott and Miocene or lower to middle Oligocene of Florissant).

The Braconidae form the sister-group of the Ichneumonidae and thus they were present in the Neocomian. The first certain Braconidae or their direct predecessors date from the Upper Cretaceous (ambers from Canada and North Siberia). In the Tertiary many fossils are found in the Baltic amber and in the Oligocene deposits of Rott and the Miocene or lower to middle Oligocene of Florissant. It appears that the Braconidae were well-differentiated in the middle Tertiary: Larsson (1978) listed 18 subfamilies described from the Baltic amber. The Recent Braconidae mainly feed on plant fluids, inclusive of nectar.

\section{ACULEATA S.LAT.}

The relationships of the Aculeata s.lat. (= Sclerogibbidae + Bethyloidea + Aculeata s.str.) with the other groups of the Hymenoptera are not clear and also within the group many questions about the phylogeny remain. The study by Königsmann (1978a) resulted in the outline given in fig. 5-11. The relatively many incertainties, indicated by question marks, mean that in the Aculeata s.lat. (particularly for the older families), as in the "Terebrantes", the search for the origins of anthophily also mainly has to be based on the fossil record. 


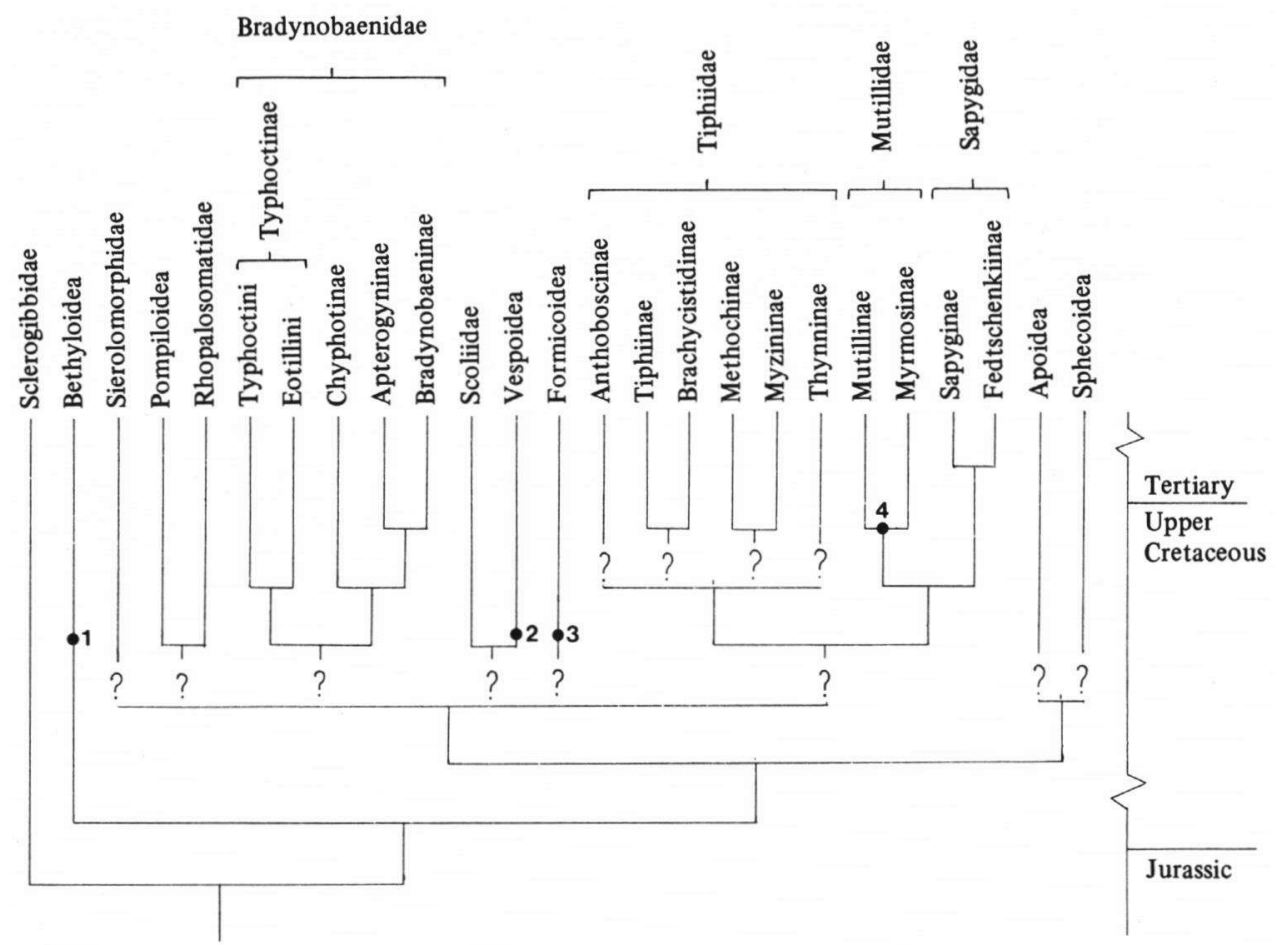

Fig. 5-11. Outline of the probable relationships within the Aculeata s.lat., after Königsmann (1978a), based on demonstrated synapomorphies. 1. Cretodryinus zherichini; 2. Curiosivespa curiosa and C. magna; 3. Sphecomyma freyi; 4. Cretavus sibiricus (all Upper Cretaceous).

The Aculeata s.lat. probably originated in the Jurassic and had their first adaptive radiation during the Cretaceous. The latter can be concluded from the many fossils known from the Upper Cretaceous, e.g. Cretavus, Sphecomyrma, Archisphex, Lisponema, Taimyrisphex, Pittoecus and Procleptes. Of special interest are the Baissodidae from the early Cretaceous of Baissa (Rasnicyn, 1975). Up to now this family, although clearly aculeate, cannot be related to one of the extant superfamilies. The Bethylonymidae, which have to be assigned to the stem-group of the Aculeata s. lat., but in which the aculeate synapomorphies are not yet fully developed, are known from the Jurassic of South Kasachstan and Trans-Baykal.

The Sclerogibbidae are a small family of small insects of which no fossils were found. Königsmann (1978a) considered them to be the sister-group of all other Aculeata s.lat. Brothers (1975) classified them with the Bethyloidea. The larvae are parasites of Embiidae, within the "colonies" of which (silken tunnels in which the Embiidae live) the apterous females also live. About the feeding-habits of the fully winged males no data were found. 
The Bethyloidea probably form the siter-group of the Aculeata s.str. (Sierolomorphidae, Pompiloidea and Rhopalosomatidae, Bradynobaenidae, Scoliidae and Vespoidea, Formicoidea, Tiphiidae, Mutillidae and Sapygidae, Apoidea and Sphecoidea). The first bethyloid fossil is Cretodryinus zherichini from the Upper Cretaceous amber of Jantardach. Many more fossils are known from the late Cretaceous and most of the amber fossils from this period are clearly attributable to extant families. This means that the differentiation within the Bethyloidea was established at the end of the Cretaceous. It implies that they radiated during the Cretaceous, but whether they were present at the time of appearance of the Angiospermae is not clear. Königsmann (1978a) included the Bethylidae, Loboscelidae, Embolemidae, Dryinidae, Chrysididae, Cleptidae, Scolebythidae and Plumariidae in the Bethyloidea. Their probable relationships are outlined in fig. 5-12.

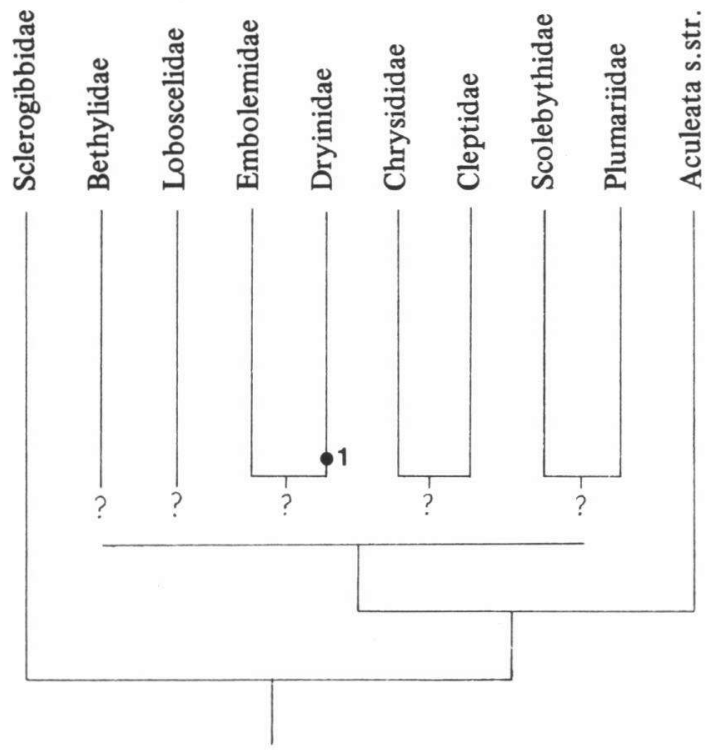

Fig. 5-12. Outline of the probable relationships within the Bethyloidea sensu Königsmann (1978a), based on demonstrated synapomorphies. 1. Cretodryinus zherichini (Upper Cretaceous)

The Bethylidae are the most plesiomorphous Bethyloidea. The larvae are ectoparasites of larvae of Coleoptera and Diptera. The females show some maternal care: they sometimes transport their larvae to a more suitable place. The females of many species feed on the sap of the host-larvae they catch for their offspring. As we have hypothesized before, this behaviour can easily provide a basis for feeding on the fluids of plants, honey dew and nectar. The oldest Bethylidae-like fossils are known from the Upper Cretaceous amber of 
Taimyr (Siberia), viz., Archepyris minutus and Celonophamia taimyria which have to be attributed to the Bethylidae or their direct predecessors.

The Loboscelidae (included in the Proctotrupoidea in Riek (1970)) form a monophyletic group. Neither their habits, nor their relationships with the other bethyloid families are known as yet.

The Embolemidae + Dryinidae form a monophyletic group. The Embolemidae are known from the Baltic amber (Embolemus and Ampulicimorpha). The females and some of the males are apterous. Some of the larvae are parasites on the nymphs of Homoptera and probably most live in ant nests. It is possible that the apterous females and males also have myrmecophilous habits, and feed in the nests on animal- or vegetable liquids. The dryinid larvae are ectoparasites of the nymphs of the Cicadina (Homoptera). The adults lick liquids of the host-nymphs. The oldest dryinid fossil dates from the Upper Cretaceous amber of Jatardach (Cretodryinus zherichini). Extant genera are known from the Baltic amber. Because the Embolemidae form the sister-group of the Dryinidae, they must have been also present in the Upper Cretaceous.

The Chrysididae + Cleptidae form a monophyletic group. The Cleptidae (including the Amiseginae) form a monophyletic group which is more plesiomorphous than the Chrysididae. The oldest Cleptidae-like fossils are known from the Upper Cretaceous amber of Taimyr, viz., species of the genera Hypocleptes and Protamisega, but they mainly have to be attributed to the stem-group of the Chrysididae + Cleptidae. From the Canadian amber of the same period Procleptes carpentieri is described, which probably can be attributed to the Amiseginae or their direct predecessors. This means that the Cleptidae or their direct predecessors were already separated from the Chrysididae or their direct predecessors before the end of the Cretaceous. The Amiseginae are egg parasites of the Phasmatodea. The females forage in the forest litter when in search for phasmatodean eggs. The larvae of Cleptes have a kind of cuckoolike or cleptoparasitic behaviour: they are parasites on the prepupae (mature larvae) of the Tenthredinoidea in their cocoons. About the feeding-habits of the adults no records were found, but the more or less saprophagous habits of the females of the Amiseginae indicate that the food may consist of liquids. The adult Chrysididae are often seen feeding on nectar and some species have an elongated proboscis to reach the deeper-lying nectar. These feeding-habits may have been derived from saprophagous liquid-feeding as it may occur in the Amiseginae (the larvae being egg parasites implies that the females cannot feed on the host-larvae) and this in its turn may be derived from liquid-feeding on host-larvae as it occurs e.g. in the Bethylidae and some of the Embolemidae and Dryinidae. The larvae have a more cleptoparasitic behaviour than those of the Amiseginae: they mainly occur in the nests of Eumenidae and Megachilidae. The oldest fossil that can be attributed to the Chrysididae is Prochrysis succinalis from the Baltic amber. But as has been mentioned above the 
Chrysididae or their direct predecessors probably were already present in the Upper Cretaceous.

The Scolebythidae + Plumariidae form a monophyletic group. The oldest fossil that can probably be attributed to the Scolebythidae is Cretabythus sibiricus from the Upper Cretaceous amber of Taimyr. The feeding-habits of the Recent Scolebythidae were not found; the insects are associated with burrows in wood (Richards \& Davies, 1977). The Plumariidae form the sister-group of the Scolebythidae and thus may be of Cretaceous origin. The setae on the mandibles of the adults may indicate liquid-feeding, possibly nectar- or pollenfeeding.

Within the Bethyloidea among the adults mainly liquid-feeding is found. Many females feed on body liquids of the host-larvae for their offspring. This is found in the Bethylidae, and also in the Sclerogibbidae, in which the females could become apterous because they live in the silken tunnels of the Embiidae where much food is available. Also the Dryinidae and the Embolemidae feed on animal liquids; the latter developed a type of myrmecophily that allowed most of the females to become apterous and within the ant nests they possibly also feed on the liquids of vegetable sources (here it has to be mentioned that food of vegetable sources for the larvae is a more apomorphous development in the Formicidae). The saprophagous feeding-habits of the females of the cleptid Amiseginae also may indicate feeding on liquids or half-liquids (decaying vegetable and animal material). The liquid-feeding on animals may be ancestral within the Bethyloidea. The only family in which nectarivory developed, is that of the Chrysididae. Within the Bethyloidea they are rather apomorphous and also their feeding-habits can be considered apomorphous. Thus, bethyloid anthophily led to some regularity in flower-visiting only in the Chrysididae and this behaviour may have originated in the Upper Cretaceous or lower Tertiary. If the Plumariidae also have anthophilous feeding-habits, their anthophily may date from the same time.

The Aculeata s.str. most probably form the sister-group of the Bethyloidea or, in the sense of Brothers (1975), of the Bethyloidea + Sclerogibbidae. The relationships within the Aculeata s.str. are not clear. It only can be said that the Apoidea + Sphecoidea have a sister-group relationship with the Sierolomorphidae + (Pompiloidea + Rhopalosomatidae $)+$ Bradynobaenidae + (Scoliidae + Vespoidea) + Formicoidea + Tiphiidae + Mutillidae + Sapygidae (see fig. 5-11).

Nothing was found about the feeding-habits in the small family Sierolomorphidae and no fossils are known.

The Pompiloidea + Rhopalosomatidae form a monophyletic group. The oldest pompiloid fossil may be Pompilopterus ciliatus from the Lower Cretaceous, but the features described do not include certain synapomorphies of the Pompiloidea. The first fossils that can be attributed with certainty to the Pom- 
piloidea are found in the Baltic amber (Epipompilus) and these forms have to be regarded as archaic within the Pompiloidea. In addition to the Baltic amber fossils in the Tertiary Psammochares and Priocnemis are known from the Oligocene of Rott. The Recent Pompiloidea are regular flower-visitors which feed on nectar. These feeding-habits probably were present in the middle Tertiary and their origin may be lower Tertiary or upper Cretaceous. The larvae of the most apomorphous Pompiloidea are ectoparasites on spiders, caught by the females and usually stored in simple subterranean nests or, less commonly, in mud cells constructed by the females. Within the Pompilidae the steps to more complicated maternal care are demonstrated: from laying the egg on the host of the future larva (spider) and then leave it (Notocyphus); through paralyzing the host, carrying it to a suitable place (e.g. a beetle burrow), depositing the egg and leave it (Gymnochares and Haploneuron); and paralysing the host, building a nest and ovipositing (Episyron, some species of Pompilus, Pepsis and Calicurgus); to building a nest, paralysing the host, transporting it into the nest and ovipositing (e.g. some apomorphous species of Pompilus, Priochilus, Paragenia, Macromeris, Auplopus, Dipogon, Priocnemis). The last five genera construct multicellular nests and a type of colonial behaviour is found in Paragenia and Macromeris. Some pompiloid species are cleptoparasitic on other Aculeata.

The Rhopalosomatidae most probably form the sister-group of the Pompiloidea. For the adults no feeding-habits were found. The larvae of the Nearctic species of Rhopalosoma are ectoparasites on crickets. Any higher development of the maternal care than the most plesiomorphous one in the Pompilidae (Notocyphus) is not found.

Ivo reeang-habits were found of the recently erected family Bradynobaenidae (Brothers, 1975). Their morphological features, however, may indicate some relationship with flowers. The Typhoctinae are a monophyletic group and they have pinnate setae on the integument as one of their synapomorphies. Within the Aculeata s.str. this type of setae is also found in the Apoidea and there it has the function to collect pollen grains; particularly the less sticky ones. Of the Typhoctini few species are known from America. The Eotillini (few species in America) form the sister-group of the Typhoctini and besides pinnate setae they also have pinnate scales on their integument. In the Typhoctinae strong indications are found for flower-visiting and possibly also pollen-collecting behaviour. The Apterogyninae (few species in Africa and India) are strongly setose, but the setae are smooth. The setae and sometimes dentate spores on the middle and hind tibiae of the Bradynobaeninae (few species in Chile and Argentina) and Chyphotinae (some species in America) may also indicate a relation with flowers. The parallel development of pinnate setae in comparison with the Apoidea, make the Bradynobaenidae very interesting and research regarding the habits of this family is much required. 
The Scoliidae + Vespoidea form a monophyletic group. The Scoliidae are setose insects, the adults of which feed on nectar. The larvae are ectoparasites of the larvae of Scarabaeidae or, more rarely, of Curculionidae. The females penetrate the soil to discover larvae on which they deposit their eggs. The maternal care of the Scoliidae does not exceed the level of laying the egg on the host of the future larva and then leave it. The adult Scoliidae play a role in the pollination of flowers. The only fossil known is Scolia from the Miocene (or lower/middle Oligocene) of Florissant. The Scoliidae form the sister-group of the Vespoidea and the first vespoid fossils are known from the Upper Cretaceous (see below). This means that the Scoliidae were present at that time and possibly their anthophilous habits may date from the same time. The Vespoidea consist of three families: Eumenidae, Vespidae and Masaridae. The relationships of these families and their subfamilies are illustrated in fig. 5-13. All families developed anthophily and the Masarinae can be considered entirely obligatory anthophilous.

The Eumenidae are solitary wasps which build nests of different types. The maternal care is higher developed than the highest level in the Pompilidae. After building the nest the egg is deposited and after that the food for the larva is collected: several larvae of Lepidoptera, or sometimes of Tenthredinidae or

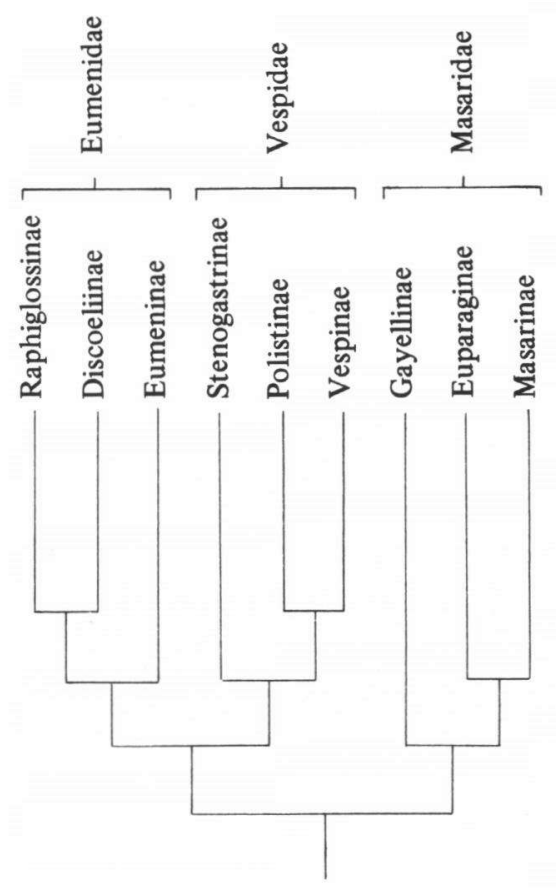

Fig. 5-13. Outline of the probable relationships within the Vespoidea, after Richards (1962), see Wilson (1971). 
Chrysomelidae, are deposited in the cell (e.g. Eumenes). In some species of Euodynerus and Synagris, new food is transported to the cells while the larvae are developing and in Synagris cornuta the prey is macerated and fed directly to the larvae.

The Vespidae are mainly social wasps and the more apomorphous types live in large communities. The Stenogastrinae are plesiomorphous Vespidae and they are solitary to showing stages of a plesiotypic social community. Maternal care consists of building a nest, depositing the eggs in the cells and the food for the larvae is carried into the cells progressively (most plesiomorphous Stenogastrinae). In Stenogaster micans the prey (other insect larvae) is macerated and fed directly to the larvae. In Stenogaster depressigaster the life of the females is prolonged, the young females remain in the nest, add cells, deposit eggs in the cells, macerate insect larvae brought as prey in by older females, and feed the larvae. The nectar-feeding by the adults serves to maintain their own life processes and the nectar is not used as food for the larvae. The Polistinae reach the highest levels of social behaviour. In Belonogaster some division of labour exists, but there are not yet true workers. In Polistes the original offspring consists of females, male eggs may be produced or not and the queen is dominant. In Protopolybia and Stelopolybia there is differential feeding of the larvae, the worker caste is present, but intermediates are common. In Polybia the worker caste is strongly differentiated and intermediates are rare. The larval food mainly consists of macerated insects and spiders, but in most cases also nectar is part of the larval diet. The Polistinae have a rather smooth integument and they only have a pollinating function on flowers with sticky pollen. The Vespinae show the same level of social life as that of Polybia. The larval food consists of macerated insects (more particularly Diptera and larvae of Lepidoptera), but the young larvae are fed for a short time with nectar, honey dew and fragments of ripe fruits. The adults of the Vespinae are somewhat more setose than those of the Polistinae and subsequently they have a somewhat more extended pollination function.

The Masaridae build their nests of mud or in burrows in the soil. Euparagia (Euparaginae) from Mexico and the Southern United States nests in the ground and stores larvae of Curculionidae as food for their larvae. The Masarinae store their cells with pollen and nectar, which the females transport in their crops. The adults often have very elongated, retractile mouth parts to reach deeper-situated nectar.

The earliest vespoid fossils are Curiosivespa curiosa and C. magna from the Upper Cretaceous of Kasachstan. They probably have to be attributed to the masarid Euparaginae. The genera Alastor, Vespa and Polistes are known from the Oligocene of Rott. The vespoid anthophily will date from the Upper Cretaceous, but then only the adults themselves fed on nectar while the larvae were fed with other insects or their larvae. In the course of the Tertiary nectar 
became a part of the diet of the larvae when social behaviour developed. The nectar- and pollen-collecting of the Masarinae may be of relatively early origin. If the Upper Cretaceous vespoid fossils indeed have to be considered masarid Euparaginae, this means that also the Masarinae must have been present at that time, since they probably form the sister-group of the Euparaginae. The presumed presence of the Euparaginae in the Upper Cretaceous also includes the presence of the Gayellinae (probable sister-group of the Euparaginae + Masarinae) and the stem-group of the Eumenidae + Vespidae (probable sister-group of the Masaridae). Vespid fossils are known from the Baltic amber (Vespa, Palaeovespa). The Formicoidea only consist of the Formicidae and form a monophyletic group. The probable relationships within the Formicoidea are outlined in fig. 5-14. The more plesiomorphous forms are

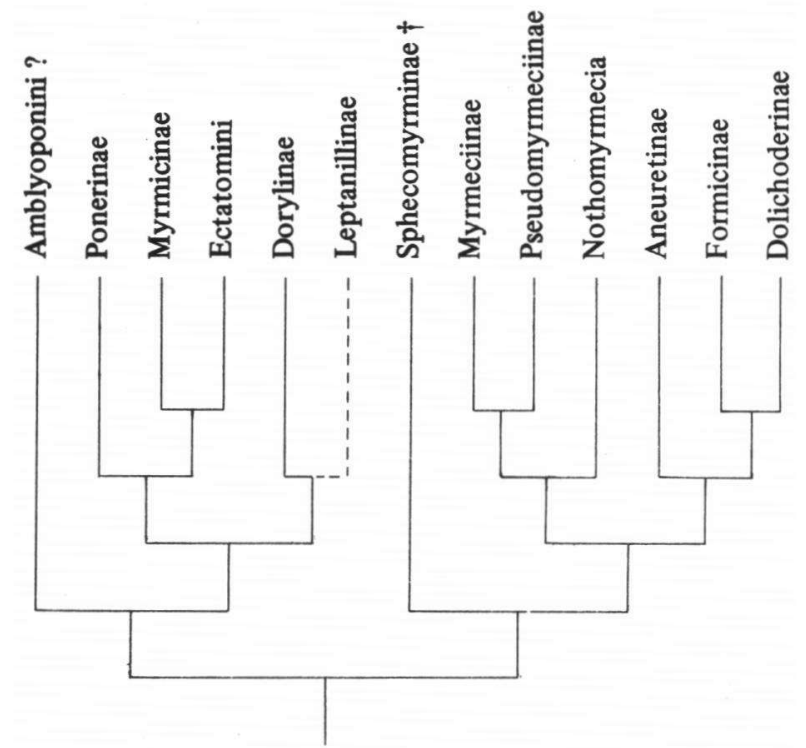

Fig. 5-14. Outline of the probable relationships within the Formicidae, modified after Wilson (1971).

found in the Amblyoponini, Ponerinae, Nothomyrmecia and Myrmeciinae. In these groups the workers are strongly nectarivorous, but only in order to maintain their own life-processes. As food for the larvae they collect insects. In fact, we here find the same difference between adult and larval feeding as in the Chrysididae, Pompiloidea, Scoliidae, Eumenidae and Vespidae. Although nearly all adult Formicidae are eager on sweet liquids, they never became effective cross-pollinators to any extent. This is due to the winglessness of the workers. The distance from the flower or inflorescence to the flower or inflorescence of another plant is in most instances very long for apterous 
insects, much longer than for flying insects. The only case of probably effective cross-pollination is that of the workers of the genus Formica which appear to be the primary pollinators of Orthocarpus pusillus, a moss-like North American member of the Scrophulariaceae (Kincaid, 1963) and indeed in this species the distance between the flowers of different plants may be very short. Dahl \& Hadac (1940) indicate primary ant-pollination in Glaux maritima. Because of the fact that the distance between the flowers of different plants in Glaux maritima is considerable for apterous insects the main pollination carried out by the ants will be self-pollination. Effective cross-pollination will be carried out by other, winged insects. According to Knuth (1899) they also visit the flowers of Glaux maritima and the records of Knuth do not include Formicidae. In some cases of extreme climatic conditions the formicid workers may have some function in pollination (probably mainly causing self-pollination of the plants and only to a certain extent effective cross-pollination), as e.g. in the observations of Hagerup (1943) concerning the possible role of ants as pollinators in the Sahara is indicated. Some other pollination activities (selfpollination) of ants are known. Hocking (1975) mentioned pollination activities of ants on Theobroma, Anacardium occidentale, Capsicum frutescens and Litchi chinensis (Free, 1970).

The greediness of ants for sugar-containing liquids can also be satisfied by consuming honey dew. Apomorphous Formicidae of different subfamilies developed a behaviour as in Myrmica rubra: the workers protect the honey-dewproducing Aphidae in the nests. Within the Myrmecinae members of the tribe Attini cultivate fungi in their nests. This means that the workers need to collect material for the substrate of their fungus gardens. The most plesiomorphous Attini collect insect faeces for this purpose (Cyphomyrmex) and the more apomorphous representatives collect fresh vegetable material, e.g. flowers or parts of flowers (Acromyrmex and Atta). The somewhat less apomorphous Trachymyrmex collects dead vegetable material and also flower parts. Here the anthophilous habits are injurious to the flowers (anthophagy). Other injurious Formicidae are the seed-collecting harvesting ants. The harvesting habits appear to have arisen sporadically, and often in distantly related genera, but all belong to the Myrmicinae. Some Formicidae (e.g. species of Pseudomyrmex, Allomerus, Strumigenis) live on plants. These myrmecophytes provide the ants shelter (myrmecodomy): hollow structures, as the hollow stipular thorns of some Acacia species and swollen and cavernous trunks of many other plants. These myrmecophilous plants derive protection against intruders from these, often very agressive ants (myrmecophylaxis). Because most of these ants live on one plant they only, in case of visiting the flowers, carry out self-pollination. In many cases, however, they are prevented to visit the flowers. It might be possible that this prevention was developed because of the small extent of crosspollination by the ants: they are lured away from the floral nectaries by 
extrafloral nectaries and specially developed food bodies (e.g. Schemske, 1980). To complete the survey it can be mentioned that the legionary ants (Dorylinae) have exclusively zoophagous habits.

The old Formicidae-like fossils are known from both Lower and Upper Cretaceous, and from the latter many fossils are known of the extinct Sphecomyrminae and the extant Ponerinae. The nectarivorous habits of the workers, being plesiomorphous, may be relatively old, but cannot be traced further back than the Upper Cretaceous (early Ponerinae).

The Tiphiidae + Mutillidae + Sapygidae (in Riek (1970) included in the Scolioidea) form a monophyletic group of which the external relationships are not certain. Within the group the Tiphiidae and the Mutillidae + Sapygidae are sister-groups (see fig. 5-11). Within the Tiphiidae the relationships of the subfamilies are not clear. The adult Tiphiidae often feed on nectar. In some cases nectar- or honey dew-feeding appear to be necessary for the development of the eggs. The apterous females of the Thynninae are carried by the males in a prolonged mating-flight, during which the female obtains food (nectar) from flowers. The maternal care of the Tiphiidae is plesiomorphous: the females deposit the eggs on the larvae of Scarabaeidae, or in some cases on those of Gryllotalpa. Very few fossils are known from the Tiphiidae: only doubtful Tiphia from the Baltic amber and two from the Miocene (or lower/middle Oligocene) of Florissant of which Königsmann (1978a) doubted whether they belong to the Tiphiidae or their direct predecessors. In the same publication Königsmann placed Cretavus sibiricus (extinct family Cretavidae) from the Upper Cretaceous of Siberia as a sister-group of the Mutillidae. This means that the Mutillidae or their direct predecessors originated in the Upper Cretaceous. Because the Tiphiidae form the sister-group of the Mutillidae + Sapygidae, they must have been present before the separation of the Mutillidae and Sapygidae. The anthophily (nectarivory) of the Tiphiidae then, may date from the Upper Cretaceous.

In the Mutillidae the adult males have nectarivorous feeding-habits. The larvae and possibly also the apterous females are parasitic on (mostly) aculeate Hymenoptera. The anthophilous feeding-habits of the males may have originated in the Upper Cretaceous. The feeding-habits of the adults (both sexes are winged) of the Sapygidae were not found. The Fedtschenkiinae may be interesting with regard to possible pollination functions, because their integument is shaggily setose. Because the Sapygidae form the sister-group of the Mutillidae they must have been present in the Upper Cretaceous.

Königsmann (1978a) proposed the name Sphecoidea s.lat. for the Sphecoidea and Apoidea. There are strong indications that the Sphecoidea s.lat. form a monophyletic group. Then, the sister-group is formed by the other Aculeata s.str. 
The Sphecoidea s.str. (Ampulicidae and Sphecidae) often have the plesiomorphous types of the apomorphies of the Apoidea, but a sister-group relationship between these superfamilies has not yet been proven. Probably the Apoidea are the sister-group of a part of the Sphecoidea s.str. The remaining Sphecoidea s.str. then, entirely or partly form the-sister-group of this complex, and probably are a paraphyletic group.

The maternal care of the Sphecoidea s.str. consists of carrying paralysed insects or larvae to the nests as food for the larvae. Many adults of the Sphecoidea s.str. visit flowers to feed on nectar. Here again there are strong indications that nectar-feeding developed from liquid-feeding on the hosts of the larvae as it occurs in the Bethyloidea and in the stem-group of the sistergroup of the Sphecoidea s.lat., viz. the Aculeata s.str. minus Sphecoidea s.lat. All Sphecoidea s.str. are solitary wasps, except for the South American Microstigmus which construct a nest of plant wool suspended on a long thread.

The oldest fossil that possibly could be attributed to the Sphecoidea is Archisphex crowsoni, one wing impression that was found in the Lower Cretaceous. We cannot be certain about this, since the synapomorphies do not include wing characters or character states. Archisphex is older than Cretavus (included in the sister-group of the Mutillidae). Cretosphex incertus from the Lower Cretaceous of Bajsa cannot be attributed with certainty to the Sphecoidea s.str. The same must be stated for the Upper Cretaceous amber fossils Taimyrisphex pristinus and Lisponema singularis. Certain Sphecoidea s.str. are known from the Tertiary. They are abundant e.g. in the Baltic amber, but relatively few species have been described. Larsson (1978) listed Ampulicidae, Crossocerus, Mellinus, Passaloecus, Psen, Mimeso, Germaraphis, Gorytes, Cerceris, Crabro and Pison. This means that the Sphecoidea s.str. were well-differentiated in the middle Tertiary. The time of origin of the sphecoid anthophily must be earlier than the middle Tertiary and even may be of (Upper) Cretaceous origin (supported by the probable origin of the Apoidea; see below).

The Apoidea form a monophyletic group. Many synapomorphies are known, e.g. the pinnate structure of the setae. The relationships within the Apoidea are not clearly known. A possible phylogeny (not based on demonstrated synapomorphies) is illustrated in fig. 5-15. The oldest fossils of the Apoidea or their direct predecessors are known from the Paleocene and these are already strongly specialized forms (Königsmann, 1978a). From the Baltic amber several species of Electrapis, Glyptapis, Meliponini, Andrenidae, Megachilidae and Anthophoridae are known. Fossil bees have also been described from the Oligocene of Oeningen and Florissant (the latter may be Miocene). For a meliponine bee from the Dominican amber (Miocene) Willemstein (1980) demonstrated that they collected pollen from Hymenaea. The presence of definite Meliponini in the middle Tertiary (Baltic amber) means that, if the phylogeny in fig. 5-15 is correct, all apoid families were pres- 


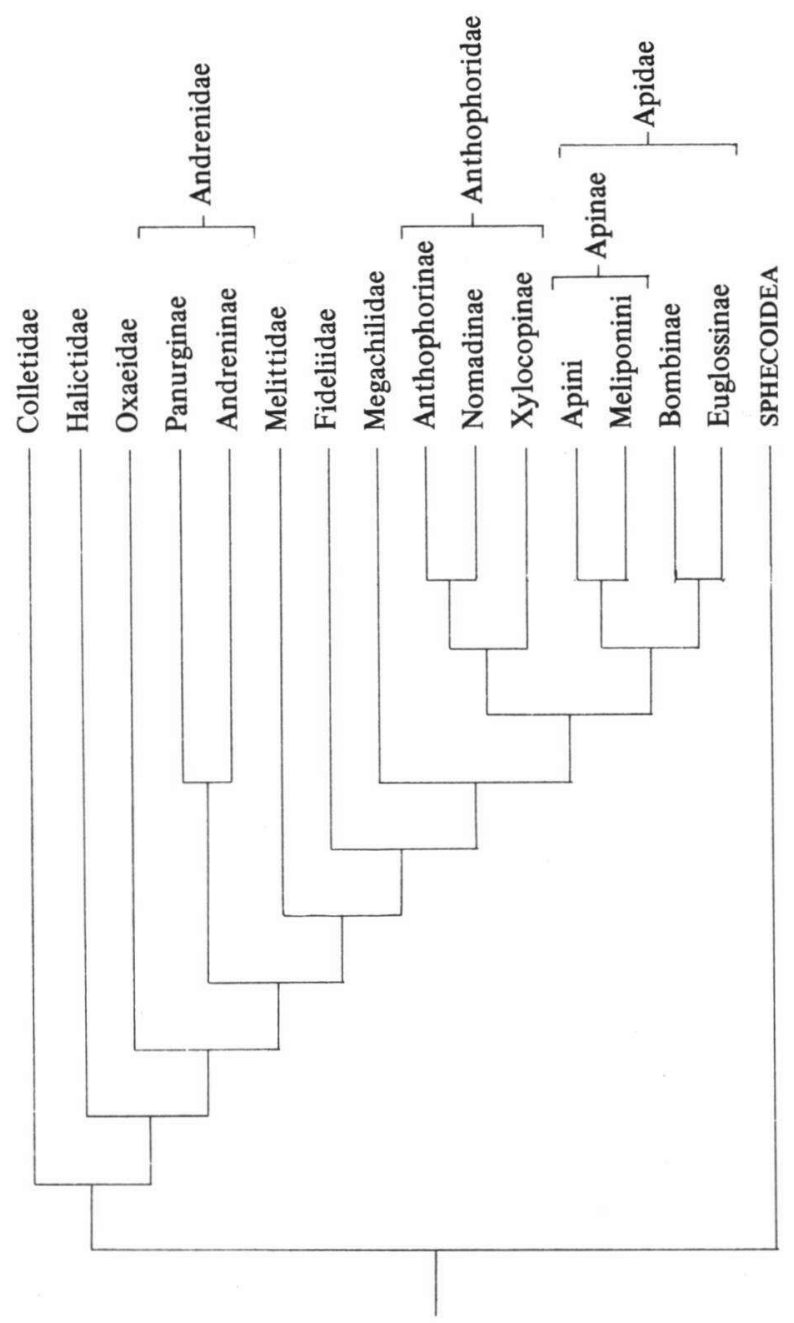

Fig. 5-15. Outline of the probable relationships within the Apoidea, after Michener (1964), see Wilson (1971).

ent at that time, and within the Apidae it means that the Apini and the stemgroup of the Bombinae + Euglossinae were present. If we combine this with the already strongly specialized forms in the Paleocene it can be suggested that the origin of the Apoidea must be in the (Upper) Cretaceous. The development of the long-tongued bees may have started about the middle Tertiary. Electrapis meliponoides from that time was interpreted by Cockerell (1909) to be intermediate between Bombus and Apis, but Wilson (1971) considered it a probable side branch of early apid evolution, rather than an ancestor of extant genera; at any rate it can be considered a representative of the development 
of bees with longer tongues. The first certain fossils of Apis belong to Synapis (subgenus of Apis) and are found in the lower Miocene of Rott and appear to be close to the ancestral line of the living species (Kelner-Pillault, 1969). Many groups of the Apoidea are still differentiating with the result that the bees as a whole are taxonomically difficult. The following general series from plesiomorphous to apomorphous exists: Colletidae, Halictidae, Andrenidae, Melittidae, Fideliidae, Megachilidae, Anthophoridae, Apidae.

Social life has developed in the Halictidae, Anthophoridae and Apidae. All Apoidea feed their larvae with nectar and pollen. In the solitary Andrenidae the nests are often found in large colonies and in some species (e.g. Andrena bucephala) several females use a common entrance gallery, but they are presumed to nest apart. As mentioned before the largest colonies are built by the apine Apis mellifera. In temparate regions the queen and the workers hibernate (in contrast to the Bombinae, in which only the fertilized queen hibernates). In many apoid families oligolectic species are known: Dufourea and Systropha in the Halictidae; many Andrenidae; all Melittidae, of which Macropis almost exclusively obtains pollen from Lysimachia; many Bombinae. Cuckoo bees (parasitic on the supplies of other bees: cleptobiosis) occur in most families.

A survey of the stratigraphical appearance of the (sub)families of the Hymenoptera in which anthophily developed is given in table 5-2.

\subsection{Lepidoptera}

The Mecopteroidea form the sister-group of the Hymenoptera. As mentioned in dating the first Hymenoptera or their direct predecessors, the stemgroup of the Hymenoptera + Mecopteroidea originates in the lower Permian, and the main groups of the Mecopteroidea were definitely present in the upper Permian (stem-group of the Trichoptera + Lepidoptera, Mecoptera and the Paratrichoptera indicating the ancestors of the Diptera). Within the Mecopteroidea the Trichoptera + Lepidoptera and the Mecoptera + Siphonaptera + Diptera from sister-groups (see fig. 5-1).

Within the group of the Mecopteroidea elongated mouth parts developed, mostly accompanied by reduction or transformation of the mandibles. In the Trichoptera the mouth parts are weak and specialized for the ingestion of liquid food, the mandibles are vestigial and in the Plectrotarsidae and some Psychomyiidae (Stenopsychodes) the mouth parts are produced to form a rostrum. In the Lepidoptera the galeae often are greatly enlarged, usually grooved internally and fastened together with interlocking hooks and spines to form a tubular haustellum; the most plesiomorphous lepidopteran mouth parts 


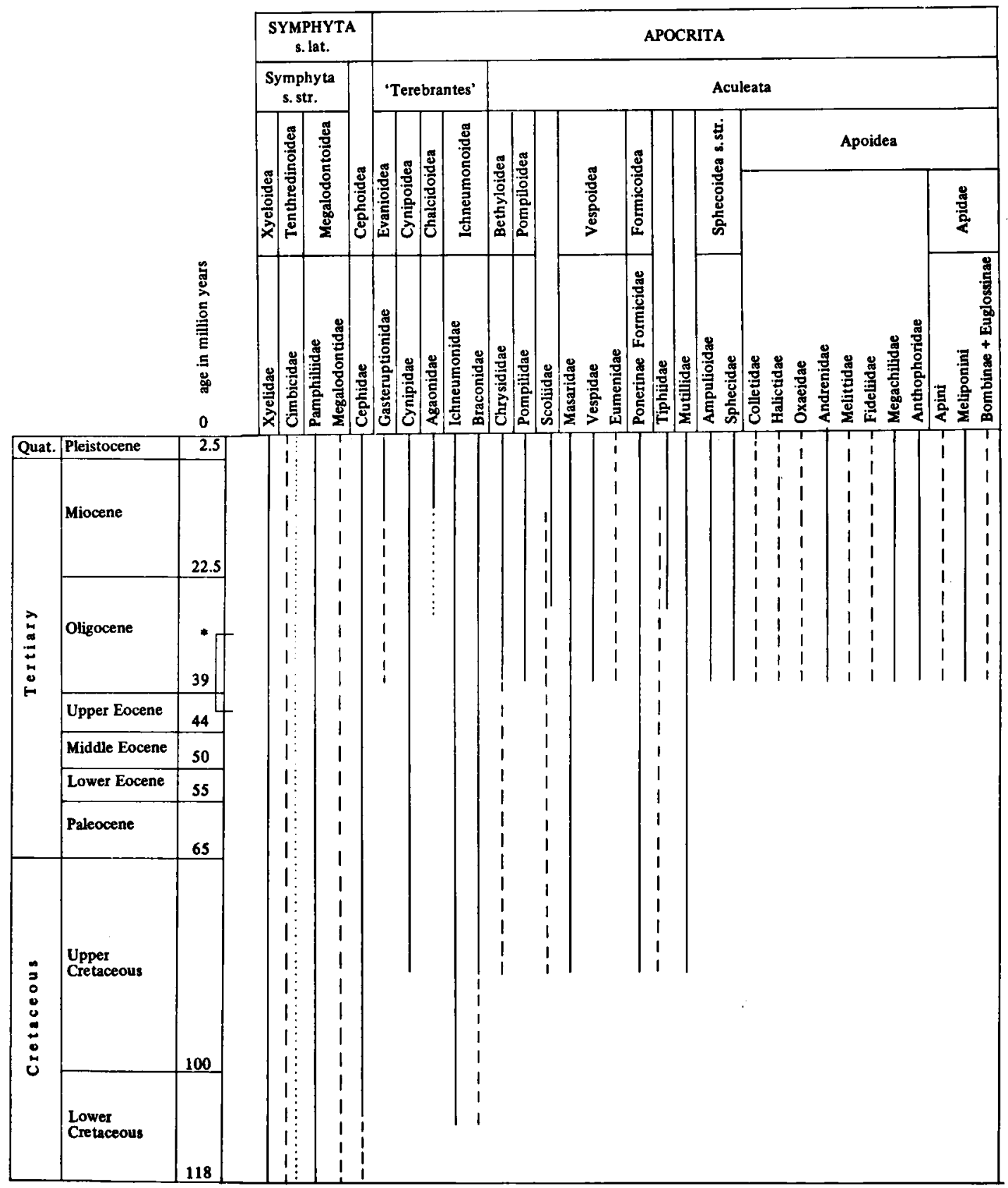

Table 5-2. Taxonomic arrangement of the appearance of the (sub)families (and some tribes) of the Hymenoptera in which anthophily developed.

Explanation: continuous lines mean presence proved by fossils; discontinuous lines mean presence based on sister-group relationships; dottes lined mean presence based on probable relationships. " indicates the period in which the Baltic amber was formed. 
are mandibulate. In the Mecoptera the mandibles are elongate, in the Nannochoristidae they are reduced. The Siphonaptera have mouth parts adapted for piercing and sucking, the mandibles are absent. In the Diptera the mouth parts are adapted for sucking and they form a rostrum, the mandibles, usually absent in the males and often also in the females, are found mainly in predatory species and are transformed into long stylets. The presence of functional mandibles and short other mouth parts has to be considered plesiomorphous within the Mecopteroidea. The most plesiomorphous Lepidoptera (Zeugloptera) have functional mandibles, as have the Mecoptera and within the Diptera the "biting" type of mouth parts ("stylets") is regarded as plesiomorphous by Downes (1958). This means that the reduction of the mandibles and the development of a rostrum in the Diptera and some Trichoptera, the piercing mouth parts of the Siphonaptera and the haustellum of the Lepidoptera have to be considered apomorphous conditions.

The Trichoptera + Lepidoptera or Amphiesmenoptera are a well-founded monophyletic group. The fossils from the upper Permian which are assigned to the Amphiesmenoptera cannot be attributed to the Trichoptera or the Lepidoptera. Both the Trichoptera and the Lepidoptera are well-founded monophyletic groups and within the Amphiesmenoptera they are sistergroups. The apomorphies on which the monophyly of the Trichoptera is based, are all present in organs or stages that are not, or only rarely, preserved in fossils. For this reason the only way to find the time of origin of the Trichoptera and thereby that of the Lepidoptera is provided by either fossils that can be attributed to the Lepidoptera or to one of the subgroups of the Trichoptera. The earliest of such fossils are known from the Mesozoic: the earliest certain Lepidoptera date from the Lower Cretaceous.

The larvae of the pre-trichopteran and pre-lepidopteran Amphiesmenoptera were terrestrial (in the ground plan of the group they have an open tracheal system). This means that the aquatic habits of the trichopteran larvae (tracheal system closed) have to be considered apomorphous. According to Hennig (1981) carnivory must have been the original feeding-habit of these larvae, because the presence of a gula is usually associated with prognathy and with carnivory. In my opinion the larval carnivory within the Trichoptera is derived, and plankton- and algae-feeding may be the most plesiomorphous feeding-habits of the aquatic larvae, derived from saprophagous feeding-habits of the terrestrial larvae of the stem-group of the Trichoptera + Lepidoptera. Kristensen (in Hennig, 1981) considered it unlikely that a true gula is ever present in the caddisfly larvae. The feeding-habits of the larvae, as in the stemgroup of the Mecopteroidea, then remained saprophagous in the stem-group of the Trichoptera + Lepidoptera and gave rise to probable carnivorous feeding-habits of the larvae of the stem-group of the Mecoptera (+ Siphonaptera)+Diptera. Within the Amphiesmenoptera the originally 
saprophagous feeding-habits of the larvae gave rise to plankton- and algaefeeding and later to carnivory (and in some cases phytophagy) in the Trichoptera and to saprophagy (micropterigid larvae feed on detritus) and later to phytophagy in the Lepidoptera. The adults of the Recent Trichoptera feed on exposed liquids. There are only few observations on adult feeding, which may be due to the fact that many species are crepuscular or nocturnal. Some species are attracted by moth collector's sugar (a fermenting mixture of sugar, treacle or molasses, and beer, rum or some other form of alcohol), and a few have been observed visiting flowers to feed on nectar. Despite this they never became pollinators of any importance, which may be due to their short life (and consequently they may need little food), and their poor powers of flight.

The time of origin of the separation between the Trichoptera and the Lepidoptera is not clear. The first fossils that can be attributed to the Lepidoptera are specimens of Parasabatinca aftimarca from the Lebanese amber of the Lower Cretaceous, which are assigned to the Micropterigidae, and another, not yet described type possibly belonging to the Incurvariina (see Kristensen in Hennig, 1981). Most fossils of Lepidoptera which can be attributed to extant taxa were described from ambers. A survey of fossil Lepidoptera in ambers has been compiled by Skalski (1976, 1976a and b). In most cases the fossils belong to the so-called Microlepidoptera; only very sporadically (parts of) specimens larger than micro's are found.

The relationships within the Lepidoptera are not quite clear. An approach has been made by Kristensen (in Hennig, 1981) and is illustrated in fig. 5-16. If from the Lower Cretaceous indeed fossils are known both from the Zeugloptera and the Incurvariina (amber of Lebanon), this means that in the phylogeny of fig. 5-16 that all larger groups of the Lepidoptera were present at that time. The presence of the Zeugloptera confirms the presence of the Glossata. Within the Glossata the presence of the Incurvariina (Heteroneura) confirms the presence of the Exoporia. The presence of the Neolepidoptera confirms the presence of the Neopseustina and the presence of the Myoglossata confirms the presence of the Dacnonypha. On the other hand, within the Heteroneura, the presence of the Incurvariina confirms the presence of the Ditrysia or their direct predecessors. This possibly well-differentiated Lepidoptera fauna in the Lower Cretaceous may indicate that the origin of the Lepidoptera is to be found (far) back in the Jurassic.

The adults of the Micropterigidae have dentate mandibles and feed on pollen, also on that of anemophilous flowers as Carex (see Proctor \& Yeo, 1973). The adults of the Agathiphagidae, which probably have to be classified in the Zeugloptera, also have mandibles, but feeding-habits were not found; the larvae, as the name indicates, live and feed on Agathis (GymnospermaeAraucariaceae), but on what parts of these plants they feed, is not found. 


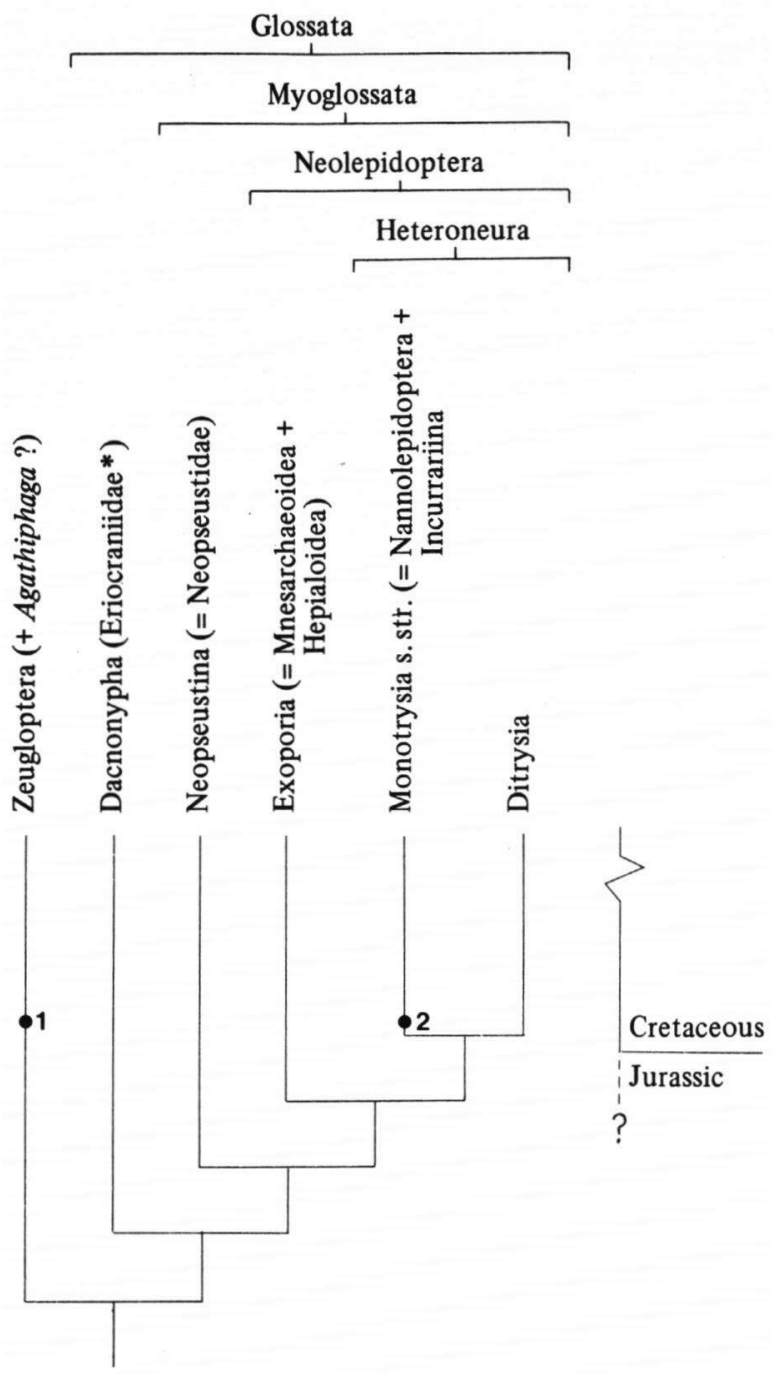

Fig. 5-16. Outline of the probable relationships within the Lepidoptera, after an approach of Kristensen (in Hennig, 1981). 1. Parasabatinca aftimarca; 2. Incurvariine type (both Lower Cretaceous). * The positions of the Lophocoronidae (see also Common, 1975) and Acanthopteroctetidae are still uncertain.

Besides from the Lower Cretaceous a micropterigid fossil is known from the middle Cretaceous amber Durtal in France.

The Dacnonypha include at least the Eriocraniidae. The adults have reduced, non-dentate mandibles, and the galeae are adapted to form a short haustellum. In the Neopseustina (only family Neopseustidae) the mandibles are wanting, the adults have a short haustellum, used as a sucking-organ. The 
Exoporia include the Mnesarchaeoidea (the galeae form a short haustellum) and the Hepialoidea (haustellum vestigial or absent). A fossil which can be attributed to the Mnesarchaeidae is known from the Upper Cretaceous amber of Taimyr in Siberia. The Monotrysia s.str. (the former Monotrysia also incuded the Hepialoidea) include the Nannolepidoptera (Nepticuloidea) and the Incurvariina; the adults have a short haustellum. The Incurvariina include e.g. the Prodoxidae. In this family there is an intimate relationship of the females of Tegeticula yuccasella with Yucca; with their specially modified mouth parts (special maxillary prehensile and spinous tentacle) they collect the pollen and apply it to the pistil in which they have deposited their eggs. In this way the development of the fruits, upon which the hatched larvae feed, is ensured. This case of monolectic behaviour must be a relatively late development, since the first pollen of Agavaceae is known from the upper Eocene and a possible Yucca type pollen is found in the middle Miocene (Muller, 1981).

The non-mandibulate Lepidoptera mentioned up to now have a short or vestigial haustellum. They all are small to minute moths and the haustellum serves to lick up exposed liquids (water, honey dew and later possibly nectar). The fact that the haustellum is often vestigial or absent may indicate that many adults hardly feed. In Recent times none of them, except the Yucca moth, has any pollination function. The plesiomorphous representatives which may have been present in the Lower Cretaceous will hardly have had any relation with flowers. Only the Micropterigidae may have visited the flowers of the early Angiospermae and may have had some contribution to their pollination.

The Ditrysia form a monophyletic group and they include more than $95 \%$ of the Recent Lepidoptera. An outline of the relationships within the Ditrysia is illustrated in fig. 5-17 (after Brock, 1971). The most plesiomorphous types are the Tineidae. The haustellum is vestigial in the Tineidae and Psychidae, present in the Lyonetiidae, Phyllocnistidae and Gracillariidae. If the Ditrysia or their direct predecessors were present in the Lower Cretaceous they must have been of a plesiomorphous tineid type and probably had nothing to do with flowers at that time.

The first certain ditrysian fossil is a representative of the Tineoidea from the Upper Cretaceous amber of Lac Cedar in Manitoba (Canada). This means that some (rare) flower-visiting may have been established at this time. The Tineidae are known from several ambers of the Tertiary (Baltic amber from the upper Eocene to lower/middle Oligocene and Mexican amber from the lower Oligocene to Miocene). The Psychidae are first known from the Baltic amber, as are the Lyonetiidae. Thus the Tineoidea probably differentiated from the Upper Cretaceous onwards. Some nectar-feeding may have existed from that time on, but it never led to a pollination function of any importance.

The Yponomeutoidea are first known from the Baltic amber: Epinomeuta (may belong to the Yponomeutidae); Plutellidae; Argyresthites (may belong to 


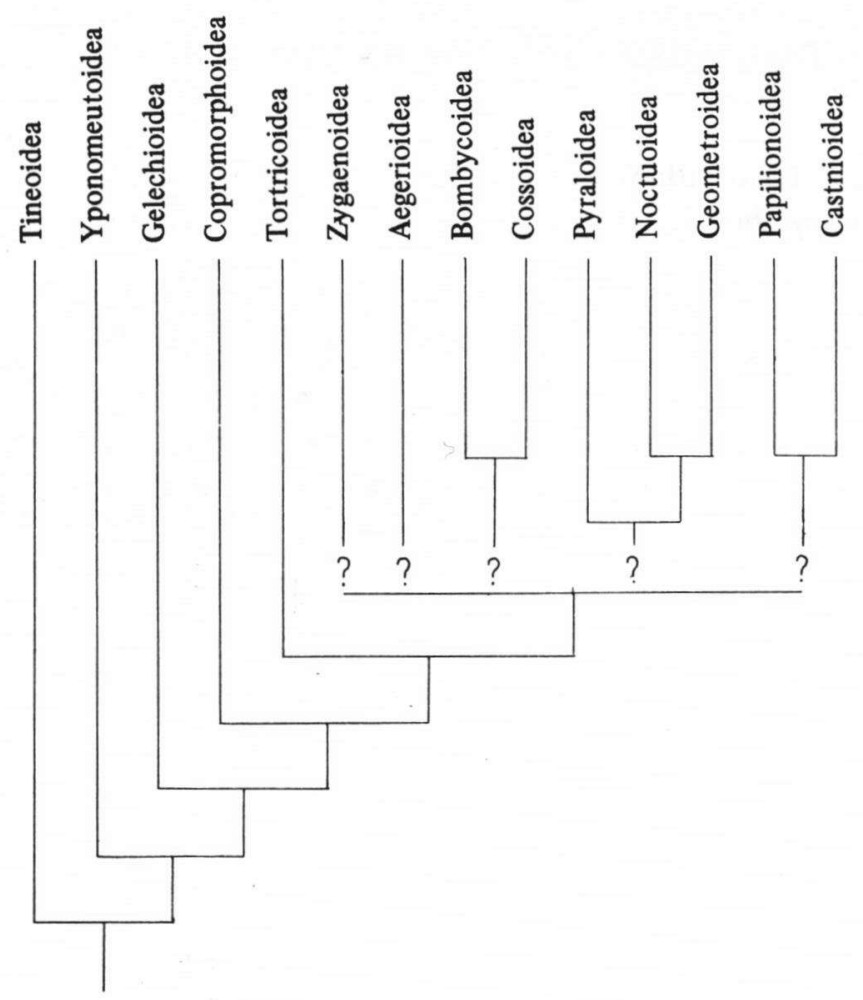

Fig. 5-17. Outline of the relationships within the Ditrysia, after Brock (1971).

the Argyresthiidae); Helodinidae. The differentiation of this superfamily in the middle Tertiary indicates the same development as in the Tineoidea. Although flower visits are not uncommon in these moths, they never became pollinators of any importance.

The Gelechioidea are first known from the Baltic amber: Scythropites may belong to the Scythrididae; Anybia may belong to the Elachistidae; Oecophoridae; Symmocidae; Gelechiidae. Gelechiidae and Cosmopterygidae are known from the Mexican amber (lower/middle Oligocene). The differentiation of this superfamily in the middle Tertiary indicates a similar development as in the Tineoidea and Yponomeutoidea. The few cases of real anthophily as known in the Recent Stathmopodidae may be of relatively late origin. Any certainty about the origin of this anthophily can only be obtained when the relationships of the families within the Gelechioidea are clear, since no fossils of the Stathmopodidae are known. The other gelechioid families did not develop anthophily of any importance.

The Copromorphoidea are not known as fossils, but since fossil Gelechioidea and Tortricoidea are known from the Baltic amber they must 
have been present in the middle Tertiary. No Recent flower-visiting of this family is found.

The Tortricoidea are known from the Baltic and Mexican amber (several species of the Tortricidae). There may be question of nectar-feeding in the middle Tertiary the Tortricoidea, however, never became pollinators of any importance.

Of the Zygaenoidea no fossils are known. Because the relationships within the group of Zygaenoidea + Aegerioidea + Bombycoidea + Cossoidea + Pyraloidea + Noctuoidea + Geometroidea + Papilionoidea + Castnioidea are not clear, the only statement that can be made is that the Zygaenoidea are of later origin than the Tortricoidea. This means that the origin of the zygaenoid nectarivorous anthophily cannot be dated properly in the Tertiary.

The Aegerioidea are also of later origin than the Tortricoidea. The wasp-like Aegeriidae represent the more apomorphous flower-visiting in moths, but, as in the Zygaenoidea, the origin of this anthophily cannot be dated properly, since no fossils are known.

Also there are no fossils found of the Bombycoidea and Cossoidea, so that anthophily is unknown. The Pyraloidea, Noctuoidea and possibly Geometroidea, are known from the Baltic amber. The presence in the middle Tertiary of the pyralid Glendotricha olgae confirms the presence of the sistergroup of the Pyraloidea, viz., the Noctuoidea + Geometroidea. The head capsule of a noctuoid type in the Baltic amber state the presence of the sister-group of the Noctuoidea in the middle Tertiary, viz., the Geometroidea (of which uncertain fossils are known from the same amber). In all superfamilies anthophily has developed and it may already have existed in the middle Tertiary. The Sphingoidea are related to the Noctuoidea via Notodontidae-like forms and form a relative apomorphous group.

The relationships within the Papilionoidea are illustrated in fig. 5-18 (after Kristensen, 1976). Durden Rose (1978) described three papilionoid butterflies from the Green River Shale of Colorado (middle Eocene), viz., Praepapilio colorado and $P$. gracilis (related to the Recent Baronia brevicollis and placed in the extinct subfamily Praepapilioninae), and Riodinella nympha, a plesiomorphous species of the Lycaenidae, related to the modern Ancyluris, Riodina and Rhetus in the tribe Riodini (Riodinae auct.). The presence of the Papilionidae (represented by the Praepapilioninae) and the Lycaenidae confirms the presence of the other families. The presence of the Papilionidae confirms the presence of their sister-group the Pieridae + Lycaenidae $+\mathrm{Nym}$ phalidae. The presence of the Lycaenidae confirms the presence of their sister-group the Nymphalidae, and both they confirm the presence of their sister-group the Pieridae. The presence of the Papilionidae (and Lycaenidae) confirms the presence of the sister-group of the Papilionidae + Pieridae + Lycaenidae + Nymphalidae and the Hesperiidae. In all families nectarivorous 


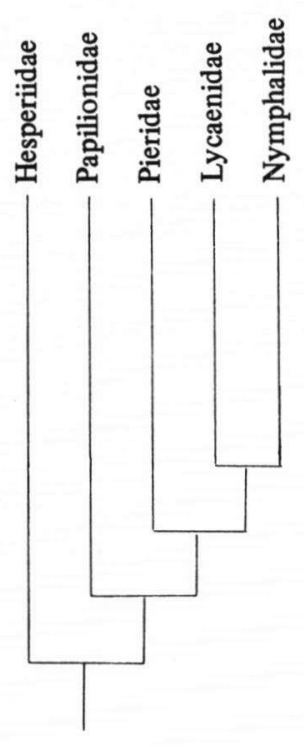

Fig. 5-18. Outline of the relationships within the Papilionoidea, after Kristensen (1976), based on demonstrated synapomorphies.

anthophily developed, although many species are also attracted to excrements, decaying material and mammal urine (particularly the Papilionidae). Rather advanced nectarivorous anthophily may have existed in the middle Tertiary.

The Castnioidea form the sister-group of the Papilionoidea and thus they must have been present in the middle Eocene. Recent anthophilous habits were not found; the haustellum is absent in some groups.

A survey of the stratigraphical appearance of the families of the Lepidoptera in which anthophily developed is given in table 5-3.

\subsection{Diptera}

The Mecoptera + Siphonaptera + Diptera form the sister-group of the Trichoptera + Lepidoptera. Within this group the Mecoptera + Siphonaptera and the Diptera form sister-groups. The Mecoptera are divided into two suborders, viz., the Protomecoptera (mainly fossil, only the extant Meropeidae and Nothiothaumidae) and the Eumecoptera in which flower-visiting occurs in the Panorpidae (Panorpa communis has often been observed on the flowers of Apiaceae, Asteraceae and Polemonium caeruleum; it can reach the nectar at the base of small tubular flowers by its lengthened snout) and the Bittacidae (Harpobittacus frequents blossoms, often those of Leptospermum to feed on nectar; the males are also carnivorous). Nectarivory may also occur in the Nan- 


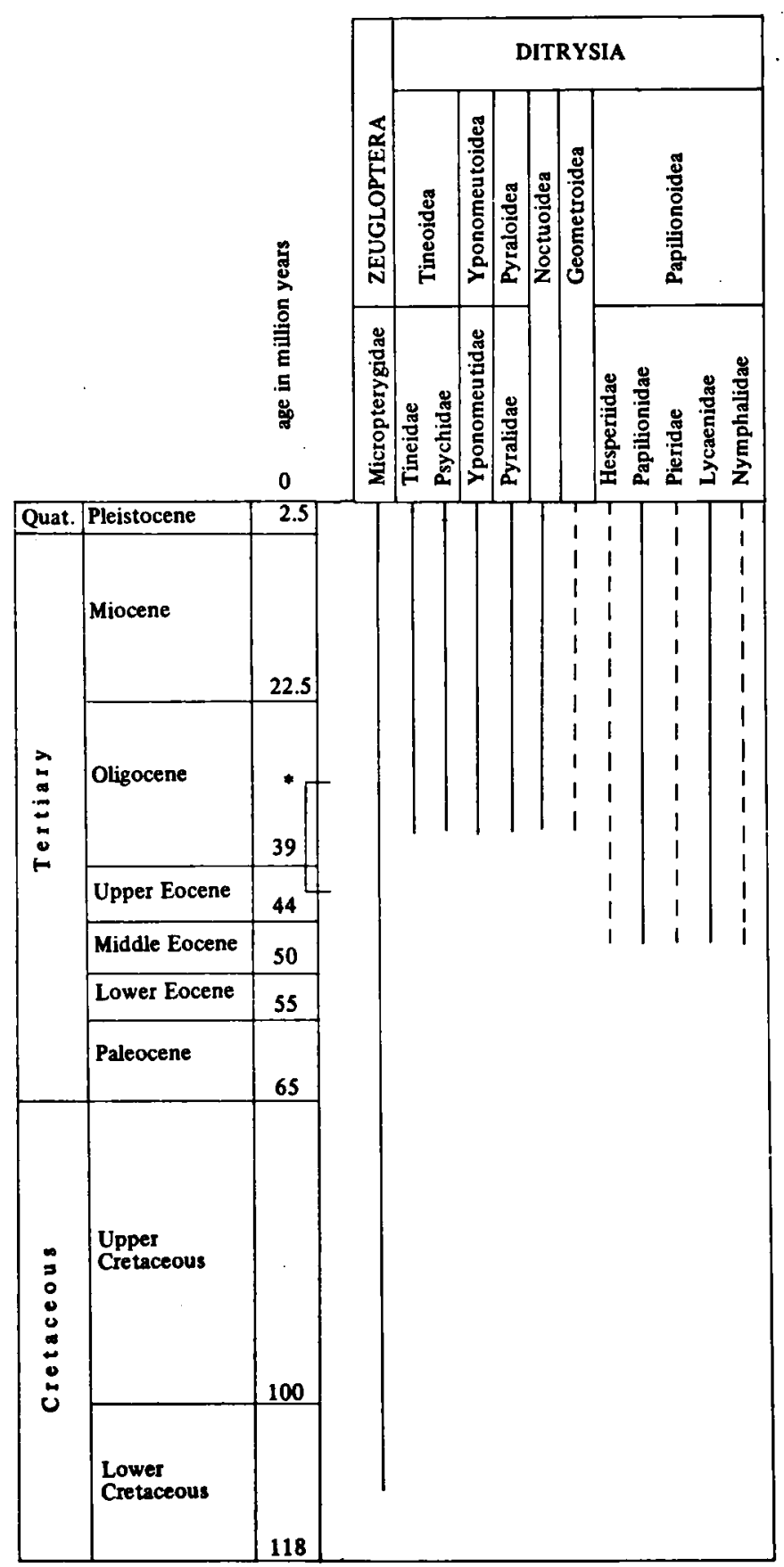

Table 5-3. Taxonomic arrangement of the appearance of the families of the Lepidoptera in which anthophily developed.

Explanation: continuous lines mean presence proved by fossils; discontinuous lines mean presence based on sister-group relationships. ${ }^{*}$ indicates the period in which the Baltic amber was formed. 
nochoristidae of which the snout is very narrow and needle-like. The nectarivorous habits of the Mecoptera did not lead to a pollination function of any importance. It is not likely that they had relationships with the earliest angiosperm flowers.

The sister-group of the Mecoptera are the Siphonaptera. As mentioned before, they could have been separated from the Mecoptera in the Triassic when the first warm-blooded animals appeared on which they suck blood.

It is not known whether carnivory in the adult Mecoptera is original. Hepburn $(1969,1969$ a) suggested detritivorous or phytophagous, rather than carnivorous habits to be original. Downes (1958) stated that the most plesiomorphous adult Diptera are predators upon other insects, like the Mecoptera. It is very well possible that the adults of the stem-group of the Mecoptera (+ Siphonaptera) + Diptera had carnivorous feeding-habits, derived from saprophagy in the stem-group of the Mecopteroidea.

The presence of the Mecoptera in the upper Permian of Australia forms the strongest proof for the presence of the Diptera or their direct predecessors in that time. The Paratrichoptera of the upper Permian probably, and those of the Triassic certainly, have to be considered survivors of the stem-group. Riek (1953) described three species of the Protodiptera from the upper Permian of Australia: Permotanyderus ableptus, Choristotanyderus nanus and Permotipula patricia, but they cannot be attributed to any of the subgroups of the Diptera or their direct predecessors.

The oldest fossils that can be attributed to the Diptera date from the Triassic Rhaetic. Architipula radiata confirms the presence of the Tipuloidea or their direct predecessors at that time. This means that also the Trichoceridae or their direct predecessors must have been present at that time, since they form the sister-group of the Tipuloidea (see the outline of the probable relationships within the Diptera, after Hennig (1981) in fig. 5-19). The presence of the Tipulomorpha includes the presence of the sister-group the Psychodomorpha + Culicomorpha + Bibionomorpha + Brachycera. This is confirmed by the presence of the Architendipedidae which have to be attributed to the stemgroup of the Thaumaleidae + Chironomoidea, and Rhaetomyia, Protorhyphus and Protolbiogaster which have to be attributed to the Bibionomorpha s.str. (nonperissommatid or -pachyneurid Bibionomorpha). The presence of the Culicomorpha and Bibionomorpha implies the presence of their sister-group the Psychodomorpha. The presence of the Bibionomorpha implies the presence of their sister-group the Brachycera or their direct predecessors. Thus both suborders (in the older classifications) Nematocera (inclusive all its divisions) and Brachycera were present in the upper Triassic Rhaetic.

The Tipulomorpha (Trichoceridae, Limnobiidae, Cylindrotomidae and Tipulidae) form a well-founded monophyletic group and are the sister-group of the rest of the Diptera. It is possible that Architipula radiata from the upper 


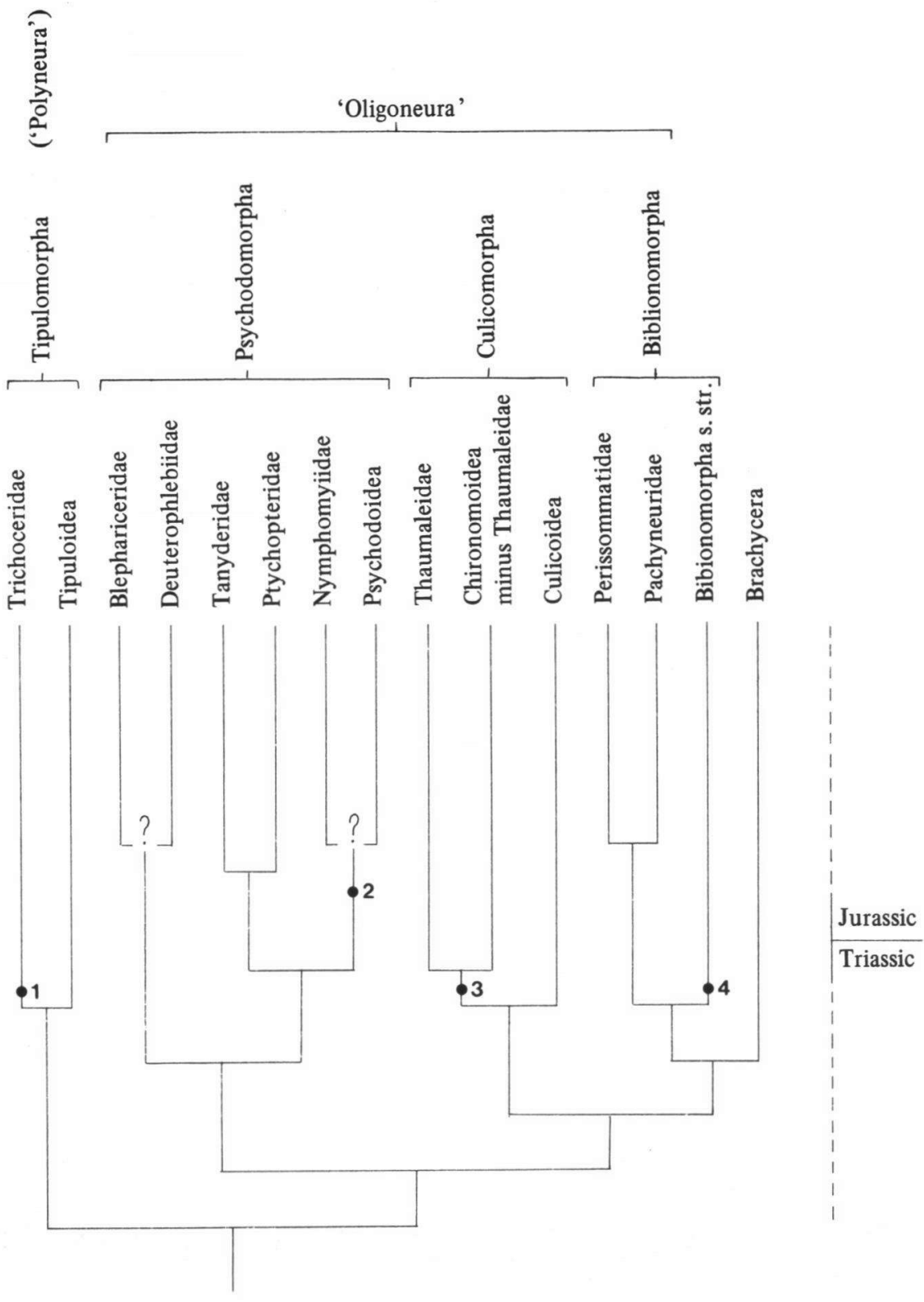

Fig. 5-19. Outline of the probable relationships within the Diptera, after Hennig (1981). 1. Architipula radiata (Triassic); 2. Tanyderophrine (Jurassic); 3. Architendipedidae (Triassic); 4. Rhaetomyia, Protorhyphus, Protolbiogaster (Triassic). 
Triassic Rhaetic (Keuper) actually belongs to one of the subgroups of the Tipuloidea, and that the sister-group relationship between the Trichoceridae and the Tipuloidea had already arisen (Hennig, 1981). The Recent adult Tipulomorpha feed on exposed liquids and some are to some extent nectarivorous; they are known from the Baltic amber. The adult Trichoceridae have strongly reduced mouth parts and observations on feeding are not found (no adult feeding?). The Limnobiidae and Cylindrotomidae lick up plant saps and the Tipulidae lick up exposed liquids, inclusive nectar. None of the recent Tipulomorpha play a role of importance in pollination. It is possible that the earliest angiosperm nectar attracted some Tipulomorpha.

The Psychodomorpha probably form the sister-group of the Culicomorpha + Bibionomorpha + Brachycera. The monophyly of the Psychodomorpha is not as well-founded as that of the Tipulomorpha. The Psychodomorpha include the Blephariceridae + Deuterophlebiidae ( = Blephariceroidea), Tanyderidae + Ptychopteridae ( = Ptychopteroidea) and Nymphomyiidae + Psychodoidea. The earliest psychodomorphan fossil is found in the middle Jurassic, Tanyderophryne multinervis which has psychodid features. If this species really can be assigned to the Psychodoidea or their direct predecessors, or the stem-group of the Nymphomyiidae + Psychodoidea, it means that also the Ptychopteroidea and Blephariceroidea or their direct predecessors were present at that time.

In the Recent adult Psychodomorpha occurs blood-sucking in addition to feeding on exposed liquids (inclusive nectar). In the psychodid Phlebotominae the females feed on blood of e.g. Lacertilia. This may be of early origin since the Lacertilia arose in about the middle Triassic and were definitely established in the upper Triassic (Romer, 1966). Psychoda is among the main visitors of the spadices of Arum species, but this is of comparatively late origin, since spadices of Araceae are known since the middle Eocene (Crepet, 1979). In the Deuterophlebiidae the mouth parts are almost absent (no adult feeding?). In the Blephariceridae many females are predacious on other small Diptera; the Recent males and some of the females probably feed on nectar). The Tanyderidae usually have elongated mouth parts and reduced mandibles. Although no observations on feeding were found, liquid-feeding may be suggested. The Ptychopteridae have elongated mouth parts and are nectarivorous. In the Nymphomyiidae the mouth parts are atrophied. The non-phlebotomine Psychodidae feed on plant sap and nectar. The nectar-feeding of some of the other families may have derived from licking-up exposed liquids and plant sap.

It is possible that the predacious feeding-habits are most plesiomorphous in the Psychodomorpha and also in the Psychodomorpha + Culicomorpha + Bibionomorpha + Brachycera and also in the Diptera or their direct predecessors as a whole (see above). The nectarivorous feeding-habits of the Psychodomorpha did not lead to a pollination function to some extent and it is not probable that they had one among the early angiosperm flowers, 
although they might have been attracted (as the Tipulomorpha) to the early angiosperm nectar.

The Culicomorpha $=$ Dixidae + Chaoboridae + Culicidae $(=$ Culicoidea $)$ + Thaumaleidae + Simuliidae + Ceratopogonidae + Chironomidae $(=$ Chironomoidea) (Schlee in Hennig, 1981) form a well-founded monophyletic group. The earliest fossils of the "Architendipedidae" from the upper Triassic (Architendipes tshernovskyi and Palaeotendipes alexii) probably can be assigned to the Chironomidae or their direct predecessors or to the stem-group of the Chironomoidea + Thaumaleidae. This means that their sister-group, the Culicoidea or their direct predecessors must have been present in the upper Triassic.

In the Recent Culicoidea blood-sucking is common. The females have long mouth parts adapted for piercing; the males also have elongated mouth parts, but the mandibles (forming the "stylets" in the females) are short, they feed on nectar and sometimes play a role in pollination. In the Dixidae the proboscis is somewhat projected and in the Chaoboridae it is very short. In both families the proboscis is not adapted for piercing. Although no observations on feeding were found, it may be suggested that, if adult feeding takes place, it will be restricted to licking-up liquids. The Thaumaleidae do not feed on blood. In the Simuliidae most females feed on the blood of warm-blooded animals and those of Gavia sometimes on the haemolymphe of other insects. As the females, the males also have elongated mouth parts adapted for piercing, but they mainly are nectarivorous. In the Ceratopogonidae the mouth parts are adapted for piercing. The females may suck blood from vertebrates (as in Culicoides) or the haemolymphe of large insects such as moths, caterpillars or dragon flies (e.g. Forcipomyia and Atrichopogon) or catch insects smaller than themselves (as in Palpomyia). The males and some of the females lick up plant fluids (e.g. nectar). In the Chironomidae the mouth parts are poorly developed and in many cases probably no food is taken in adult life. In some species of Chironomus the digestive canal is consequently reduced and empty. In the Culicomorpha we meet a possible plesiomorphous stage of sucking body fluids, i.e. sucking of the haemolymphe of other insects (adults and larvae). It is possible that the early angiosperm nectar attracted many of the culicomorph males and some of the females; a role of any importance in pollination does not seem probable.

The Bibionomorpha form a good monophyletic group. Within the Bibionomorpha there is a sister-group relationship between the Pachyneuridae (incl. Axymyiidae) + Perissommatidae and the Bibionomorpha s.str. Rhaetomyia necopinata from the upper Triassic is the only fossil from which possibly the Pachyneuridae (incl. Axymyiidae) + Perissommatidae could be derived (Hennig, 1981). For the Recent Pachyneuridae (incl. Axymyiidae) no feeding-habits were found, and for the Perissommatidae Colles \& McAlpine (1970) mentioned that Perissomma fusca breeds in decomposing fungi. 
Within the Bibionomorpha s.str. the Anisopodidae and Cramptonomyiidae have the most plesiomorphous wing venation. Two fossil species with this type of wing venation (Protorhyphus turanicus and Oligophryne fungivoroides) are known from the upper Triassic and another (Protorhyphus stigmaticus) has been described from the lower Jurassic Lias. These fossil species could belong to the stem-group from which the Recent Cramptonomyiidae have descended. A possible fossil of the Anisopodidae or their direct predecessors is Protolbiogaster rhaetica from the upper Triassic. The Recent Anisopodidae have somewhat elongated mouth parts and possibly feed on liquids. For the adult Cramptonomyiidae no feeding-habits were found.

All other families of the Bibionomorpha s.str. have more apomorphous wing venation. This type of wing venation is found in many fossils from the upper Triassic: Rhaetofungivora, Rhaetofungivorella, Rhaetofungivoroides, Archihesperinus, Protallactoneura, Archipleciomima and Palaeoplecia. The more apomorphous families in the Bibionomorpha s.str. are the Scatopsidae, Hyperoscelidae, Bibionidae, Cecidomyiidae, Sciaridae and Mycetophilidae. There are slight indications (based on the wing venation) that the Mycetophilidae or their direct predecessors were already established in the upper Triassic.

The Recent adult Scatopsidae often feed on nectar while also pollen may be taken. The Hyperoscelidae resemble the Scatopsidae, but whether they have the same feeding-habits was not found. The Bibionidae feed on nectar and honey dew and possibly also on pollen. Philia febrilis plays a role in the pollination of fruit trees (Jacobs \& Renner, 1974). The Cecidomyiidae feed on nectar, the Sciaridae on nectar and fungi, and the Mycetophilidae on nectar and pollen. In the Bibionomorpha or their direct predecessors probable liquidfeeding may have given rise to fungus- and pollen-feeding. Here we see again, as in many Coleoptera and Symphyta that the step from fungivory to pollenfeeding probably is only a small one. Whether pollen-feeding was already established in the Jurassic cannot be traced with certainty, but the probable separation of the Bibionomorpha s.str. and even of the Mycetophiliformia into a considerable number of subgroups in the upper Triassic suggests the presence of fungivory at that time. This feeding-habit easily could have given rise to pollen-feeding during the Jurassic. At any rate many Bibionomorpha must have been attracted by the early angiosperm nectar: Bibionidae, Mycetophilidae and Anisopodidae or their direct predecessors.

The Brachycera form a monophyletic group, the earliest fossils of which date from the lower Jurassic (Protobrachyceron liasinum from the upper Lias). Since they most probably form the sister-group of the Bibionomorpha, they must have been present in the upper Triassic. In most of the brachyceran fossils the wing venation includes the most clearly observable characters. But unfortunately very few changes took place in the wing venation when the Brachycera first separated into subgroups. The phylogenetic classification within the 
Brachycera is not clear. For the Homoeodactyla (Tabaniformia) monophyly is not certain. Jurassic fossils can fairly certainly be attributed to the various groups of the Homoeodactyla. Most of the adult Homoeodactyla in Recent times feed on exposed liquids, although many females of the Rhagionidae are predacious upon other insects and some females of the same family and those of the Tabanidae feed on blood. Of the Stratiomyidae it is known that they feed on nectar and pollen. Nectar-feeding is also known for the Rhagionidae (males and some females), Tabanidae (males, and in the absence of blood also the females), the plesiomorphous Pelecorhynchidae and the Xylomyidae. It is possible that blood-feeding and licking of exposed liquids were present during the Jurassic. Whether pollen-feeding (as in the Stratiomyidae) was present in that period is not known. It is possible that many Homoeodactyla were attracted by the early angiosperm nectar.

The Brachycera minus the Homoeodactyla form the Heterodactyla. It is not certain whether this group is monophyletic. The Heterodactyla consist of the Asiliformia and Eremoneura. The earliest fossils that can properly be attributed to the Asiliformia are known from the upper Jurassic: Protomphrale martynovi (may belong to the stem-group of the Scenopinidae) and some undoubted Nemestrinidae. The adults of the Recent Scenopinidae feed on exposed liquids and those of the Nemestrinidae feed on nectar, while hovering over the flowers. In the upper Jurassic probably both fed on exposed liquids. The adults of the Recent Asilidae are predacious upon other insects, as probably are the Therevidae. Anthophily occurs in the families Apioceridae, Mydaidae, Acroceridae, Nemestrinidae and Bombyliidae. The development of a long to very long proboscis is found in the Acroceridae, Nemestrinidae (Megistorhynchus longirostris and species of Prosoeca), and Bombyliidae. From the Baltic amber (upper Eocene to lower/middle Oligocene) Acroceridae (scarsely present: four species described), Bombyliidae ( 5 species), Therevidae (scanty) and Asilidae (as rare as Therevidae) are known. This means that the Asiliformia were well-differentiated in the middle Tertiary and probably they were already so in the Upper Cretaceous. The early angiosperm nectar may have attracted several groups of the Asiliformia (Nemestrinidae and may be some plesiomorphous representatives of the other families).

The Eremoneura consist of the Empediformia and the Cyclorrhapha. The Empediformia are known from the upper Jurassic (Protempis antennuata). This fossil, classified in the Protempedidae, could represent the Empediformia or their direct predecessors. An empediform fossil is also known from the Lower Cretaceous amber of the Lebanon. The adults of the Recent Empediformia (Empedidae or Empididae (in Colless \& McAlpine, 1970) and Dolichopodidae) are mainly predacious. Some species, particularly of the Empedinae, however, feed on nectar. In the upper Jurassic and Lower Cretaceous the Empediformia probably were predacious and in some groups nectarivorous habits developed, 
maybe already in the early Cretaceous. In the Baltic amber both the Empedidae and Dolichopodidae are very common.

The Cyclorrhapha form a monophyletic group and probably are the sistergroup of the Empediformia. The origin of the Cyclorrhapha cannot be traced with certainty. As is the case in all Brachycera, their ground plan characters are not found in the wing venation and this renders difficult proper interpretation of the fossils found in sediments. If there is a sister-group relationship between the Empediformia and the Cyclorrhapha, the presence of the Empediformia in the upper Jurassic and Lower Cretaceous includes the presence of the Cyclorrhapha in those times. The oldest cyclorrhaphan fossil is known from the Lower Cretaceous amber of South Lebanon, but it could not be assigned to any of the subgroups of the Cyclorrhapha. This means that it has to be considered as belonging to the direct predecessors of the Cyclorrhapha. Subsequent fossils are known from the Upper Cretaceous amber of Canada. These concern Sciadophora bostoni and Priophora canadambra. They were described by McAlpine \& Martin (1966) and placed in the Sciadoceridae, but Hennig (1981) considered them to be primitive Phoridae. From the same amber an ironomyiid fossil is known (McAlpine, 1973). This means that in the Upper Cretaceous the following cyclorrhaphan groups were present: Acroptera, Hypocera and the stem-group of the Platypezidea and Syrphidea + Schizophora. The classification followed here is in accordance with that presented by Griffiths (1972), after whom the relationships within the Cyclorrhapha are illustrated in fig. 5-20. Richards \& Davies (1977) follow the same classification. The Acroptera ( = Anatria, Anatriata) include only the Lonchopteridae. Because they form the sister-group of the Atriata, they must have been present in the Upper Cretaceous. The Recent adults of Lonchoptera are anthophilous and visit flowers with easily accessible nectar and pollen (Proctor \& Yeo, 1973); whether they also feed on pollen besides nectar was not found. The anthophily of the Lonchopteridae might have been present in the Upper Cretaceous. Because Acroptera can be regarded as the most plesiomorphous Cyclorrhapha, their probable anthophilous habits in the Upper Cretaceous may indicate that anthophily in the Cyclorrhapha is very old. It may have been present in pre-middle Cretaceous times, as probably were the nectarivorous feeding-habits of their probable sister-group the Empediformia.

The Atriata form the sister-group of the Acroptera and consist of four monophyletic groups (Griffiths (1972) calls them infraphalanxia of the subphalanx Atriata): Hypocera (= Phoroidea), Platypezidea, Syrphidea and Schizophora. The Hypocera include the Ironomyiidae, Sciadoceridae and Phoridae (incl. the termitophilous Termitoxeniidae). The presence of the Ironomyiidae and Phoridae (Hennig, 1981), the latter interpreted as Sciadoceridae (McAlpine \& Martin, 1966), in the Upper Cretaceous, whatever 


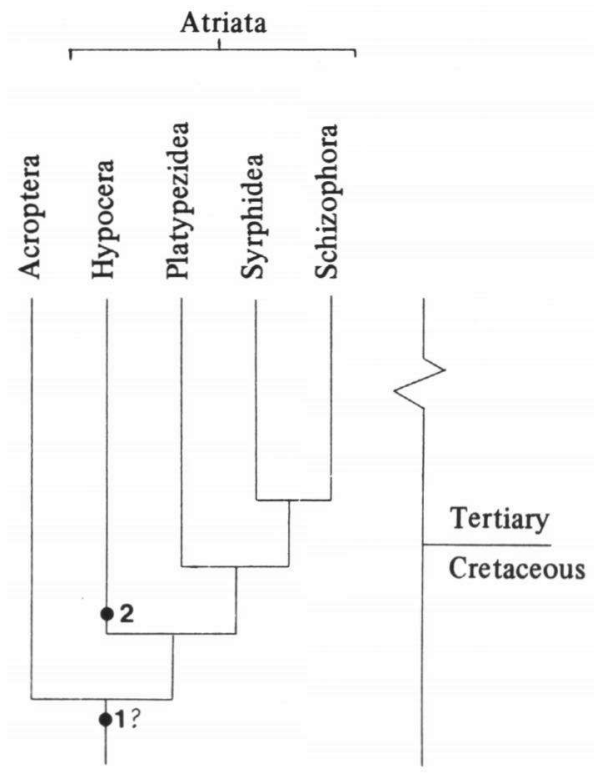

Fig. 5-20. Outline of the relationships within the Cyclorrhapha, after Griffiths (1972), based on demonstrated synapomorphies. 1. unassigned fossil from the Lower Cretaceous of South Lebanon; 2. Sciadoceridae (McAlpine \& Martin, 1966) or Phoridae (Hennig, 1981) and Ironomyiidae.

their relationships within the Hypocera are, means that also the Sciadoceridae or the Phoridae were present at that time. The Recent adult Phoridae (Phora) visit flowers with easily accessible nectar and pollen (Proctor \& Yeo, 1973), but whether they also feed on pollen besides nectar was not found. Many Phoridae also have saprophagous feeding-habits. It is possible that the Phoridae had already both anthophilous and saprophagous feeding-habits in the Upper Cretaceous and hypoceran anthophily might have existed even earlier (the differentiation of the families in the Upper Cretaceous may indicate an earlier origin).

The Platypezidea include only the Platypezidae. In fossil state they are known from the Baltic amber by a single species: Oppenheimiella baltica. The biology of the Recent representatives is poorly known. Many species form dancing swarms in shady and damp sites and may breed in the fruiting bodies of fungi. My suggestion is that these small flies, like many of the swarming midges, will hardly feed as adults and, if they do, only take up some liquids.

The Syrphidea + Schizophora form the sister-group of the Platypezidea. The Syrphidea include the Pipunculidae and Syrphidae. Both families are known from the Baltic amber. The Recent adults of both families are anthophilous, feeding on nectar and pollen. It is possible that this type of feeding was already present in the first half of the Tertiary. 
The Schizophora form the sister-group of the Syrphidea. The presence of the Syrphidea in the middle Tertiary means that also the Schizophora or their direct predecessors were present at that time. The relationships within the Schizophora are not clear. In this study we cannot treat them as a whole, because two types of relationships with flowers developed in the Schizophora: many species are attracted by sapromyiophilous flowers, where, as also other flies (e.g. Psychodidae, Ceratopogonidae, Simuliidae), they can play a role in the pollination; another group visits and pollinates myiophilous and entomophilous flowers. The latter group can be divided into moderately-sized to large flies visiting and pollinating myiophilous and less specialized entomophilous flowers and the many minute flies which possibly play a role in the pollination of the very small micro-entomophilous flowers. I will not follow Delpino (see Kugler, 1970) in distinguishing micromyiophilous flowers as a separate pollination class. We will treat the Schizophora following the classification of Griffiths (1972) and, checking their presence in the Baltic amber (Larsson, 1978), try to indicate the time of origin of the various subgroups.

The Schizophora consist of five superfamilies: Lonchaeoidea, Lauxanioidea, Drosophiloidea, Nothyboidea and Muscoidea.

The Lonchaeoidea include the Lonchaeidae and Cryptochetidae. Both families are known from the Baltic amber. They did not develop flower-visiting habits.

The Lauxanioidea include the prefamilies (subsuperfamilies) Lauxanioinea (Lauxaniidae, incl. Celyphidae) and Chamaemyioinea (Eurychoromyiidae and Chamaemyiidae). The Lauxaniidae and Chamaemyiidae are known from the Baltic amber. The adult Lauxaniidae developed anthophilous habits to some extent and the Recent representatives are reported from several, rather diverse flowers. The Recent adult Chamaemyiidae milk aphids for honey dew and possibly they are also attracted by nectar. Feeding on nectar, the minute Chamaemyiidae and the smallest Lauxaniidae may play a role in the pollination of micro-entomophilous flowers. For the Eurychoromyiidae no feedinghabits were found, but in view of the feeding-habits of the other two lauxanioid families, liquid-feeding may be suggested. The lauxaniid anthophily might have been present in the upper Eocene and the Chamaemyiidae may also have visited (small) flowers in that time.

The Drosophiloidea include the Drosophilidae, Camillidae (Camellidae in Colless \& McAlpine, 1970), Curtonotidae, Campichoetidae (= Diastatidae minus Diastata) and Ephydridae (incl. Diastata). The Drosophilidae, Camillidae and the former Diastatidae are known from the Baltic amber. The differentiation of the Drosophiloidea in the middle Tertiary indicates that their origin may be before the upper Eocene. The adult Drosophilidae developed some nectar-feeding and the Recent Ephydridae mainly feed on carrion and 
decaying plant material and in some cases on nectar; some species are predacious on other small insects. Some Ephydridae are attracted by sapromyiophilous flowers. The smallest Drosophilidae may play a role in the pollination of micro-entomophilous flowers. The nectarivorous habits of the Drosophilidae might have been present in the middle Tertiary, or even earlier.

The Nothyboidea (Nothybidae, Teratomyzidae, Periscelidae (Periscelididae in Colless \& McAlpine, 1970) incl. Somatiidae and Psilidae (= Loxoceridae)) did not develop anthophilous habits, except for some nectar-feeding in the Psilidae. The adults of the Recent Periscelidae feed on sap flows. Only the Psilidae are known from the Baltic amber and their nectarivorous habits may have been present in the middle Tertiary.

The Muscoidea form the largest superfamily of the Schizophora and include the prefamilies Tanypezoinea, Calyptratae, Micropezoinea, Australimyzoinea, Diopsioinea, Sciomyzoinea, Anthomyzoinea, Agromyzoinea and Tephritoinea.

The Tanypezoinea (Tanypezidae and Heteromyzidae) are not known from the Baltic amber and whether the Recent adults visit flowers was not found.

In the Calyptratae ( = Thecostomata) flower-visiting is found in almost all families, except for the haematophagous Glossinidae and the ectoparasitic Hippoboscidae. The Scatophagidae feed on liquids of decaying organisms and are often predacious. It is possible that they visit flowers to prey on small anthophilous insects; in some cases, however, they feed on nectar. The Anthomyiidae mainly feed on nectar and pollen, but decaying liquids, sweat, blood and plant fluids are also taken. Some species have fungivorous habits. The Fanniidae may have feeding-habits similar to those of the Anthomyiidae. In the Muscidae a wide variety of feeding-habits is found: haematophagous, coprophagous, saprophagous and the majority also feed on nectar and pollen. Except for the haematophagy, the Tachinidae (incl. Oestridae, Hypodermatidae, Cuterebidae, Gasterophilidae, Calliphoridae and Sarcophagidae) have the same variety of feeding-habits as the Muscidae. Anthophily is widespread and both nectar and pollen are eaten. Also anemophilous pollen is eaten: Elvers (1980) described pollen-feeding by Thricops on some grasses. The only calyptratan fossil in the Baltic amber is Fannia scalaris. The scarcity of fossils may indicate that the Calyptratae are of relatively late origin, and at any rate probably were not much differentiated in the middle Tertiary (in comparison with the other prefamilies (particularly the Anthomyzoinea and Sciomyzoinea) the calyptratan habits in many cases are similar or comparable, thus the chance that they were caught in the resin will not be much lower than for the other prefamilies).

The Micropezoinea include the Cypselosomatidae (incl. Pseudopomyzidae), Neriidae and Micropezidae (incl. Calobatidae and Taeniapteridae). The Cypselosomatidae are known from the Baltic amber. In the Micropezoinea no 
anthophily of any importance developed, they have mainly predacious habits.

No fossils are known of the saprophagous Australimyzoinea (only family Australimyzidae). The Diopsioinea include the Diopsidae and Syringogastridae. The Diopsidae are known from the Baltic amber and the Recent adult representatives feed on nectar and honey-dew. Their anthophilous habits might have existed in the middle Tertiary.

In the Sciomyzoinea various feeding-habits occur. At least a part of the Coelopidae has nectarivorous feeding-habits, the Phaeomyiidae are predacious, the Dryomyzidae are saprophagous and anthophilous, the Sciomyzidae have predacious habits, the Ropalomeridae feed on exuding saps and possibly also on nectar, and the Sepsidae share saprophagy with nectarivory. For the Helosciomyzidae, Megamerinidae and Cremifanniidae no feeding-habits were found. The smallest Coelopidae, Dryomyzidae and Sepsidae may play a role in the pollination of micro-entomophilous flowers. The Dryomyzidae, Sciomyzidae, Sepsidae and Megamerinidae are known from the Baltic amber and subsequent nectarivorous habits of some of them might have been present in the middle Tertiary.

In the Anthomyzoinea flower-visiting (mainly nectar-feeding) is relatively common. It occurs in the Heleomyzidae (besides coprophagy), Rhinotoridae, Anthomyzidae (associated with Araceae), Trixoscelidae, Asteiidae (probably also feeding on exuded saps), Sphaeroceridae (coprophagous and also attracted by sapromyiophilous flowers) and Chyromyidae. For the Borboropsidae and Opomyzidae no feeding-habits were found. The Aulacigastridae probably feed on exuded sap. The smallest representatives of the Rhinotoridae, Trixoscelidae and Asteiidae may play a role in the pollination of microentomophilous flowers. The Heleomyzidae, Anthomyzidae, Asteiidae and Aulacigastridae are known from the Baltic amber. This means that the Anthomyzoinea were already well-differentiated in the middle Tertiary. Anthomyzoine nectarivory (Heleomyzidae, Anthomyzidae, Asteiidae) may have been present in that time.

The Agromyzoinea include the Clusiidae (saprophagous and fungivorous) and Agromyzidae (feeding on plant fluids, honey-dew and possibly also on nectar). The Clusiidae are known from the Baltic amber and if the Agromyzidae are their sister-group, they also must have been present in the middle Tertiary. Whether agromyzoine nectarivory was present at that time is questionable.

The Tephritoinea include the families: Chiropteromyzidae; Mormotomyiidae (coprophagous on bat guano); Cnemospathidae; Odiniidae (feeding on exuded sap); Tethinidae (saprophagous); Acartophthalmidae (saprophagous, coprophagous); Carnidae (haematophagous, saprophagous, nectarivorous); Milichiidae (saprophagous, predacious and deceitedly attracted to flowers of e.g. Ceropegia); Chloropidae, incl. Mindidae (nec- 
tarivorous); Conopidae, incl. Stylogastridae (anthophilous); Eurygnathomyiidae, Richardiidae, Piophilidae, incl. Thyreophoridae and Neottiophilidae (anthophilous); Tephritidae ( $=$ Trypetidae), incl. Platystomatidae, Pyrgotidae, Tachiniscidae, Otitidae, Ulidiidae, Pterocallidae and Palloptera (nectarivorous, predacious). The Carnidae, Chloropidae and the smallest Piophilidae and Tephritidae may play a role in the pollination of micro-entomophilous flowers. The Odiniidae, Acartophthalmidae, Carnidae, Milichiidae, Chloropidae and Pallopteridae are known from the Baltic amber. This means that the Tephritoinea were well-differentiated in the middle Tertiary and that their anthophily (Carnidae, Chloropidae, Pallopteridae) probably was present at that time.

A survey of the stratigraphical appearance of the families and superfamilies of the Diptera in which anthophily developed is given in table 5-4.

\subsection{Notes on the stratigraphical appearance of the families in which anthophily developed}

The stratigraphic appearance of the (sub/super)families (and some tribes) of the Coleoptera (see table 5-1), Hymenoptera (see table 5-2), Lepidoptera (see table 5-3) and Diptera (see table 5-4) is illustrated in table 5-5.

The main representatives of the possibly anthophilous insects present at the time of appearance of the Angiospermae (Lower Cretaceous) are the Coleoptera, Symphyta and Nematocera ("Polyneura" and "Oligoneura"). Of the Lepidoptera only the pollen-feeding Micropterigidae were present, of the Brachycera only the Nemestrinidae and the "Terebrantes" were represented by the Ichneumonidae and Braconidae. In later Cretaceous times relatively few families appeared for the first time (mainly wasps belonging to the Aculeata).

Many of the families are found for the first time in the Tertiary period from the upper Eocene to the lower/middle Oligocene. This is due to the abundance of fossils in the Baltic amber and to the fact that these fossils in amber can be studied in detail (in contrast to most of those found in sediments). In many cases the fossils in the Baltic amber demonstrate quite a differentiation within the families, not only in those that were already present earlier, but also in the families which appear for the first time in this amber. Some striking examples are the Melyridae (Coleoptera) in which the separation between the Malachiinae, Dasytinae and Melyrinae appeared to be established already, and the Apidae within which (if the relationships as illustrated in fig. 5-15 are correct) the Apinae and Bombinae + Euglossinae were already separated and within the first subfam. also the Apini and Meliponini. This means that table 


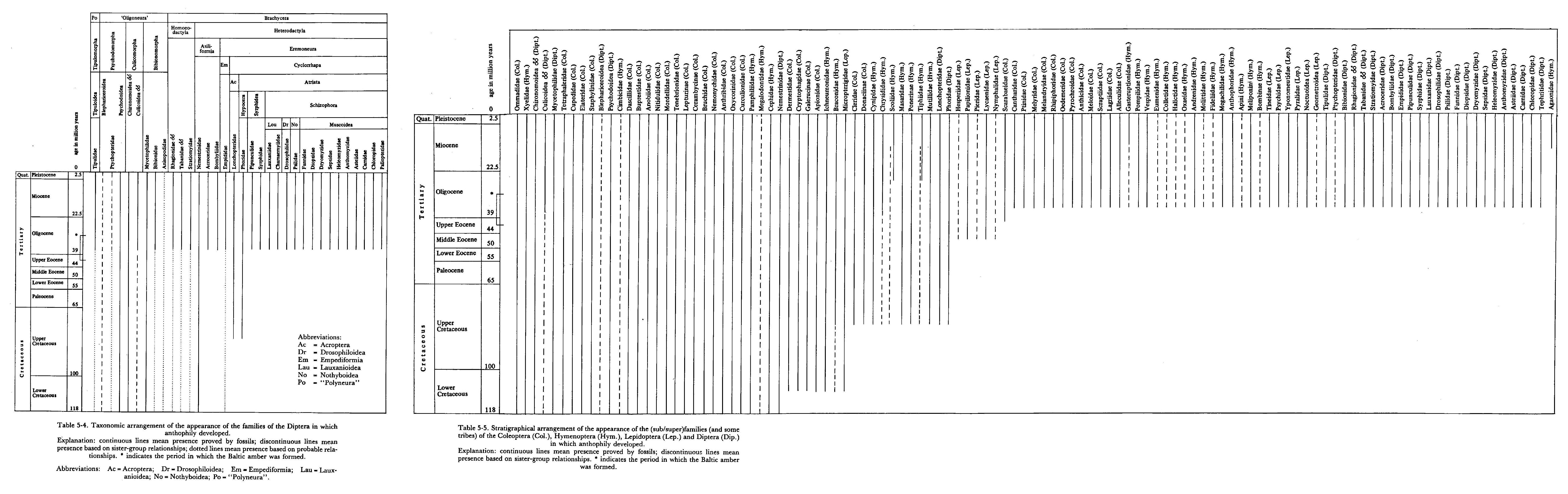


5-5 only gives an approach of the true appearance of many of the taxa included.

In conclusion it can be stated that most of the families mentioned here had a more or less strong adaptive radiation during the uppermost Cretaceous and the lower Tertiary. And as is illustrated by the well-differentiated Papilionoidea in the middle Eocene (fossils found in sediments) this may also be the case in the families of which the representatives are not easily trapped in resin and thus do not occur in the Baltic amber. In connection with this it is interesting to mention that Skalski (1976a) did not find more than $1 \%$ of the species of the Lepidoptera present in the area trapped in the resin of Recent Pinus. Although the trees from which the Baltic amber originates, might have produced considerably more resin than do the present Pinus species, only a relatively small part of the insect fauna was trapped in the resin. 


\section{STATISTICAL ANALYSIS OF THE FLORAL CHARACTERS IMPORTANT TO POLLINATION ECOLOGY}

In the following analyses, which are restricted to the central-European flora, the characters are defined after a short review of the sequence in which important groups of insects appear in the fossil record, and the samples are shortly described.

\subsection{Evaluation of the stratigraphical appearance of insect taxa in which anthophily developed}

Three phases in the stratigraphy may be recognized in an evaluation of the insect taxa in which anthophily developed.

In the early Cretaceous many insects with short mouth parts were present: Coleoptera, Symphyta, some wasps of the Aculeata, Micropterigidae, Nematocera and Brachycera-Asiliformia. Proctor \& Yeo (1973) listed the following Recent Nematocera visiting flowers (mainly to feed on nectar): Tipulidae, Culicidae, Bibionidae, Mycetophilidae, Cecidomyiidae, Simuliidae, Chironomidae, Ceratopogonidae, Scatopsidae, Anisopodidae and Psychodidae. All, except the Culicidae, have very short mouth parts, even the largest representatives of these families (as Bibio and Tipulidae) have a proboscis of only a millimeter or two in length. In the Culicidae the males have elongated mouth parts, which are not adapted to piercing as those in the females, but to sucking free-lying liquids as water, honey dew and nectar. Of the Brachycera-Asiliformia the Nemestrinidae were present. Fossil Nemestrinidae are easily recognizable by the venation of the wings. The tip of the wings is provided with more cross-veins than in other Diptera. Oldroyd (1964) suggested that the tip of the wing is reinforced with these veins, making a net-work. He did not believe that it is a primitive feature, but that it has evolved in conjunction with its exquisite powers of hovering flight. I do not share this opinion. The Recent Nemestrinidae often have fewer cross-veins, also many of those with a very long proboscis that have to hover above flowers when putting the proboscis into the flowers. Besides, why don't excellently hovering flies such as the Syrphidae have as many cross-veins. Richards \& Davies (1977) mentioned for the recent representatives that the proboscis is very variable and often long to very long, and then they restrict the description to the Nemestrinidae with a long to very long proboscis. This is also the case in the other more general books on entomology (here we also meet anecdotical information, giving an 
unbalanced picture of the reality in the Nemestrinidae). Paramonov (1953) revised the Australian Nemestrinidae and mentioned many representatives with a short to completely reduced or undeveloped proboscis. In Trichophthalma the proboscis varies from as long as the head (e.g. T.bivittata) to much longer than the head (e.g. T. calabyi and T. lutea). The proboscis in Hirmoneura is much shorter than the head to almost absent. In Nycterimorpha speiseri the proboscis is absent and in Exeretoneura tertia it is extremely short. Within the Nemestrinidae the long to very long probosces have to be considered apomorphous character states. Because the long to very long proboscis cannot be rolled up as the haustellum in the Lepidoptera, it would have been recognized in the fossils. Since this is not the case it seems reasonable to suppose that the Nemestrinidae in the early Cretaceous had a short or may be somewhat elongated proboscis.

In the late Cretaceous and early to middle Tertiary the adaptive radiation of many families led to longer probosces: within the Hymenoptera possibly already in the Chrysididae, Masaridae and the Apoidea; within the Diptera in families such as Bombyliidae, Pipunculidae, Syrphidae and Nemestrinidae; within the Lepidoptera in many moth families and also in some of the butterflies such as the Hesperiidae, Papilionidae, Pieridae, Lycaenidae and Nymphalidae.

From about the middle Tertiary (Eocene/Oligocene) onwards the very specialized insect-flower relationships could evolve: higher Apoidea and the higher Lepidoptera, the first with a long tongue and the second with a (very) long haustellum, started to appear.

In this first analysis as presented in this chapter the insect groups are the Coleoptera, Diptera, non-apoid Hymenoptera (wasps), Apoidea (bees and bumblebees) and Lepidoptera (except in section 6.8 where also taxa of lower rank are compared with regard to the floral colours). Within the Coleoptera included-i.e. represented in the records of Knuth (1898a, 1899)-the length of the mouth parts varies from short to very slightly elongated. The Diptera included have a short to long proboscis. Because most of the records concern the longer-tongued representatives (Asiloidea, Empidoidea, Syrphoidea and Muscoidea), the total can be considered having elongated to long mouth parts. In the non-apoid Hymenoptera included the mouth parts are short to somewhat elongated. The included Apoidea have somewhat elongated to long tongues. Because the majority of the records concern longer-tongued representatives, the total sample has to be considered as having intermediate to long mouth parts. In the Lepidoptera included, the length of the haustellum varies from short (absent) to very long. Of the Lepidoptera with a short or absent haustellum only very few records are included. This means that the total sample has to be considered long to very long haustellate. 
In the stratigraphical dating of the functions of the flower-ecologically important characters in the next sections the samples of the Coleoptera and non-apoid Hymenoptera will give a reasonable representation (as far as the morphology of the mouth parts is concerned) of the anthophilous insects from the early Cretaceous onwards. The sample of the Diptera represents the developments in anthophily from the middle to late Cretaceous onwards. The samples of the Apoidea and Lepidoptera represent (different) developments in anthophily starting in the late Cretaceous and early Tertiary.

\subsection{Pollination types}

In this section the pollination types are considered in two ways: the complex of facultative and obligatory combined, indicated as beetle-, fly-, bee- and butterfly-/moth-pollinated flowers, and the obligatory pollination types separately. The first mentioned can best be described as pollinatable by the various insect groups and thus pollinated in case of visiting; the last mentioned correspond with the pollination syndromes.

\subsubsection{The complex of facultative and obligatory pollination types}

For the central European Angiospermae the facultative and obligatory pollination types were defined after the literature. The records in Knuth $(1898 \mathrm{a}, 1899)$ were taken as a basis and for each insect visit recorded, the probability of successful pollination of the flower was estimated. Plant species of which no records of insect visits to the flowers were found, were compared with related species of which insect visits to the flowers were known. The best way to describe the process of estimation is: to trace the probability of successful pollination by the various insect groups. Because the facultative and obligatory pollination types are compared with the obligatory pollination types (see section 6.2.2) based on the pollination syndromes, in this section only beetle-, fly-, bee- and butterfly-pollinated flowers are taken into consideration. Because no proper syndrome of wasp flowers has been described, the wasp-pollinated flowers are not taken into account. It will be clear that many flowers can be pollinated by beetles, flies, bees and short-tongued butterflies and moths, and. thus the same (non-specialized entomogamous) plant species may occur in more than one column in table 6-1.

In this section the anemophilous flowers also are part of the analysis. Because there are only very few species with anemophilous flowers that are also pollinated by insects, the anemophily is only treated in the sense of a combination of the facultative and obligatory types. The syndrome of anemophily includes the following characters: flowers unisexual (see in this respect also section 6.15); flowering before the leaves unfold, or flowers exposed outside the 
leaf mass; perianth insignificant, small or absent; attractants absent; anthers and stigmas exposed; pollen grains small (Wodehouse (1935) mentioned the range of 17-50 micron), dry (not sticky) and produced in large quantities; pollen-arresting mechanisms frequent; reduction in numbers of ovules. Whitehead (1969) mentioned some necessary environmental factors: specimens not too widely separated in the vegetation; vegetation open in structure or deciduous; flowering coordinated by relatively unambiguous environmental stimuli; pollen release should coincide with the most favourable time of the year for transport (low pobability of precipitation, adequate winds and turbulence, deciduous season).

Distribution of the facultative and obligatory pollination types among the species of which the flowers are visited by the various insect groups, Qualitative analysis

\section{Anemogamy}

Species of which the flowers are visited by the various insect groups only rarely are anemogamous (table 6-1A). Species of which the flowers are visited by the Coleoptera and Diptera have the highest frequencies of anemogamy, the latter more so than the species of which the flowers are visited by the Apoidea and Lepidoptera (table 6-1A-4). The only attractant of anemophilous flowers for anthophilous insects is the pollen, and indeed pollen-feeding on anemophilous pollen is rather widespread among the Coleoptera (see e.g. Willemstein, 1978): Cetoniinae and some subfamilies of the Cerambycidae; and Knuth (1898-1905) for the other beetle taxa) and Diptera (particularly Syrphoidea, see e.g. Porsch, 1956; Van der Goot \& Grabandt, 1970; Holloway, 1976; Stelleman \&eeuse, 1976; Leereveld et al., 1976; Stelleman, 1978, 1981 and 1982). Species of which the flowers are visited by the Apoidea only in some cases are anemogamous. Although almost all Apoidea (except the cuckoo bees) collect pollen as food for their offspring, they only in some cases obtain it from anemophilous flowers. Berner (1942) observed Apis mellifera visiting the flowers of woody anemogamous plants in the early spring, when other flowers did not yet blossom. Species of which the flowers are visited by the Lepidoptera have even a lower frequency of anemogamy. Only Micropterix consistently feed on pollen. Knuth (1899) recorded Micropterix spec. feeding on the pollen of Plantago media. The species of which the flowers are visited by the non-apoid Hymenoptera have the lowest frequency of anemogamy (table 61A), lower than the species of which the flowers are visited by the Coleoptera and Diptera (tables 6-1A-3 to 5). This may mean that the non-apoid Hymenoptera are more exclusively nectarivorous than the Coleoptera and Diptera. 
Table 6-1. Frequencies of the facultative and obligatory pollination types among the species of which the flowers are visited by the various insect groups, Qualitative analysis (A); ibid Quantitative analysis (B) of the central European flora.

Abbreviations: $\mathrm{An}=\mathrm{ANE}=$ Anemogamous; $\mathrm{Be}=\mathrm{BeF}=$ Bee-pollinated flowers; $\mathrm{BM}=$ $\mathrm{BMF}=$ Butterfly- or moth-pollinated flowers; $\mathrm{Bt}=\mathrm{BtF}=$ Beetle-pollinated flowers; $\mathrm{CEF}=$ Central European flora; COL = Coleoptera; DIP = Diptera; ENT = Entomogamous; Fl = FlF $=$ Fly-pollinated flowers; LEP $=$ Lepidoptera; NAH $=$ Non-apoid Hymenoptera.

A-1 to 6 and B-1 to 4 give the significances of the differences in tables $A$ and $B$ by chi-square testing. Explanation: $1=0.01<p \leq 0.05 ; 2=0.001<p \leq 0.01 ; 3=0.0001<p \leq 0.001 ; 4=$ $\mathrm{p} \leq 0.0001$.

\begin{tabular}{|c|c|c|c|c|c|c|c|c|c|c|c|c|}
\hline A & Total & ANE & BtF & FlF & $\mathrm{BeF}$ & BMF & A-1 & An & $\mathrm{Bt}$ & Fl & $\mathrm{Be}$ & BM \\
\hline COL & 444 & 3.15 & 53.15 & 75.90 & 76.58 & 25.67 & $C E F$ & & & & & \\
\hline DIP & 845 & 3.90 & 50.92 & 74.96 & 78.22 & 23.19 & COL & 4 & 4 & 4 & & 2 \\
\hline $\mathrm{NAH}$ & 445 & 0.90 & 53.92 & 68.76 & 72.81 & 16.44 & DIP & 4 & 4 & 4 & 2 & 2 \\
\hline APO & 945 & 2.12 & 38.84 & 56.30 & 86.58 & 20.95 & NAH & 4 & 4 & 4 & & \\
\hline LEP & 518 & 1.35 & 37.45 & 55.79 & 81.47 & 35.91 & APO & 4 & & & 4 & \\
\hline CEF & 3249 & 20.25 & 36.44 & 53.68 & 66.30 & 17.94 & LEP & 4 & & & 2 & 4 \\
\hline ENT & 2610 & 0.73 & 45.36 & 66.82 & 82.53 & 22.34 & ENT & 4 & 4 & 4 & 4 & 3 \\
\hline
\end{tabular}

\begin{tabular}{|c|c|c|c|c|c|c|c|c|c|c|c|c|c|}
\hline $\begin{array}{l}\text { A-2 } \\
\text { ENT }\end{array}$ & Bt & Fl & $\mathrm{BM}$ & $\begin{array}{l}\text { A-3 } \\
C O L\end{array}$ & An & $\mathrm{Bt}$ & $\mathrm{Fl}$ & BM & $\begin{array}{l}\text { A-4 } \\
D I P\end{array}$ & An & Bt & $\mathrm{Fl}$ & BM \\
\hline $\mathbf{A B}$ & 1 & & 1. & NAH & 1 & & & 2 & NAH & 2 & & & \\
\hline & 1 & 2 & & APO & & 2 & & & APO & 1 & & 3 & \\
\hline EI & 1 & 1 & 4 & LEP & & 2 & 2 & 1 & LEP & 2 & 2 & 2 & \\
\hline
\end{tabular}

$\begin{array}{lcccccccccccc} & & \begin{array}{l}\text { A-5 } \\ \text { NAH }\end{array} & \text { Bt } & \text { Fl } & \text { Be } & \text { BM } & \text { A-6 } & \text { BM } & & & \\ & & & & & & \text { APO } & & & & \\ & & \text { LEP } & 2 & 2 & 1 & & \text { LEP } & 4 & & & \\ & & & 2 & & 4 & & & & & \\ \text { B } & \text { Total } & \text { ANE } & \text { BtF } & \text { FlF } & \text { BeF } & \text { BMF } & \text { B-1 } & \text { An } & \text { Bt } & \text { Fl } & \text { BeBM } \\ \text { COL } & 1598 & 3.50 & 58.14 & 88.86 & 64.58 & 22.65 & \text { COL } & & & \\ \text { DIP } & 6628 & 1.69 & 58.98 & 89.38 & 74.74 & 28.46 & \text { DIP } & 4 & & 33 \\ \text { NAH } & 2148 & 0.47 & 41.81 & 91.76 & 50.89 & 20.11 & \text { NAH } & 4 & 4 & 4 \\ \text { APO } & 7918 & 1.16 & 42.51 & 58.73 & 93.80 & 30.50 & \text { APO } & 4 & 4 & 4 & 44 \\ \text { LEP } & 2867 & 0.73 & 40.98 & 58.81 & 81.83 & 58.98 & \text { LEP } & 4 & 4 & 4 & 44\end{array}$

\begin{tabular}{|c|c|c|c|c|c|c|c|c|c|c|c|c|c|}
\hline $\begin{array}{l}\text { B-2 } \\
D I P\end{array}$ & An & $\mathrm{Bt}$ & $\mathrm{Fl}$ & $\mathrm{Be}$ & $\mathrm{BM}$ & $\begin{array}{l}\mathrm{B}-3 \\
N A H\end{array}$ & An & $\mathrm{Fl}$ & $\mathrm{Be}$ & BM & $\begin{array}{l}\mathrm{B}-4 \\
A P O\end{array}$ & $\mathrm{AI}_{\mathrm{I}}$ & $\mathrm{Be}$ \\
\hline NAH & 4 & & & 3 & 3 & APO & 2 & 4 & 4 & 4 & LEP & 1 & 4 \\
\hline APO & 2 & 4 & 4 & 4 & 1 & LEP & & 4 & 4 & 4 & & & \\
\hline LEP & 3 & 4 & 4 & 2 & 4 & & & & & & & & \\
\hline
\end{tabular}

\section{Beetle-pollinated flowers}

The species of which the flowers are visited by the Coleoptera, Diptera and non-apoid Hymenoptera, generally have higher frequencies of beetlepollinated flowers than the species of which the flowers are visited by the Apoidea and Lepidoptera (tables 6-1A and 6-1A-3 to 5). It is striking that the frequency of beetle-pollinated flowers among the species of which the flowers are visited by the Coleoptera is low in comparison with the frequencies of fly- 
and bee-pollinated flowers among the species of which the flowers are visited by the Diptera and Apoidea, respectively. This means that, with regard to pollination the Coleoptera are the least specialized flower visitors.

\section{Fly-pollinated flowers}

In the fly-pollinated flowers the same tendencies are found as in the beetlepollinated flowers: the species of which the flowers are visited by the Coleoptera, Diptera and non-apoid Hymenoptera have higher frequencies of flypollinated flowers than the species of which the flowers are visited by the Apoidea and Lepidoptera (tables 6-1A and 6-1A-3 to 5). The comparatively high frequency of fly-pollinated flowers among the species of which the flowers are visited by the Diptera indicates that Diptera are more efficient flower visitors with regard to pollination, than are the Coleoptera.

\section{Bee-pollinated flowers}

In the bee-pollinated flowers the reverse is found as in the beetle- and flypollinated flowers, but the differences are less pronounced. There are no significant differences between the species of which the flowers are visited by Coleoptera, Diptera, Apoidea and Lepidoptera, respectively. Only the species of which the flowers are visited by the non-apoid Hymenoptera have a lower frequency of bee-pollinated flowers, than the species of which the flowers are visited by the Apoidea (tables 6-1A and 6-1A-5). These results are not surprising, because more than $80 \%$ of the entomogamous species of the central European flora is pollinatable by Apoidea. The comparatively high frequency of bee-pollinated flowers among the species of which the flowers are visited by the Apoidea indicate that the Apoidea are the most effective flower visitors with regard to pollination of the insect groups included.

\section{Butterfly- or moth-pollinated flowers}

The species of which the flowers are visited by the Coleoptera, Diptera, nonapoid Hymenoptera and Apoidea, respectively, have lower frequencies of butterfly- or moth-pollinated flowers than the species of which the flowers are visited by the Lepidoptera. The comparatively low frequency of butterfly/moth-pollinated flowers among the species of which the flowers are visited by the Lepidoptera (table 6-1A and 6-1A-1-6) indicate that the Lepidoptera overall are inefficient insect visitors with regard to pollination. Here it becomes clear that the plant species which are butterfly- or moth-pollinated form a small part of the central European flora, highly adapted to the long haustellum of the Lepidoptera. 
Dispositicn of flower visits of the various insect groups with reference to the facultative and obligatory pollination types, Quantitative analysis

\section{Anemogamy}

The Coleoptera appear to visit more anemogamous species than the other insect groups (tables 6-1B and 6-1B-1). We may state here that the Coleoptera are more attracted solely by pollen than are the other insect groups. It is interesting to see that the frequency of the visits of the Diptera to anemogamous species is lower than that of the Coleoptera, although the plant species of which the flowers are visited by the Diptera in the qualitative analysis have a comparatively high frequency of anemogamy. This means that the Diptera as a whole are less attracted solely by pollen, than are the Coleoptera (tables 6-1B and 6-1B-1), but more so than are the non-apoid Hymenoptera, Apoidea and Lepidoptera (table 6-1B-2). The non-apoid Hymenoptera and Lepidoptera visit least anemogamous species.

\section{Beetle-pollinated flowers}

In visiting beetle-pollinated flowers two different groups can be distinguished: the Coleoptera and Diptera, and the non-apoid Hymenoptera, Apoidea and Lepidoptera (tables 6-1B and 6-1B-1 and 2). The main difference between these groups may be based on the more extensive pollen-feeding of the Coleoptera and Diptera (as indicated in visiting anemogamous species) in comparison with the more exclusively nectarivorous non-apoid Hymenoptera, Apoidea and Lepidoptera.

\section{Fly-pollinated flowers}

Like in visiting beetle-pollinated flowers two different groups can be distinguished in visiting fly-pollinated flowers (tables 6-1B and 6-1B-1 to 3). But this time the non-apoid Hymenoptera share the company of the Coleoptera and Diptera. The Apoidea and Lepidoptera visit less fly-pollinated flowers than the other insect groups. Here the difference between the two groups may be based on the difference in lengths of the mouth parts.

\section{Bee-pollinated flowers}

All insect groups appear to differ in visiting bee-pollinated flowers, in the sequence from high to low frequencies: Apoidea, Lepidoptera, Diptera, Coleoptera and non-apoid Hymenoptera (tables 6-1B and 6-1B-1 to 4). The comparatively high frequency of bee-pollinated flowers among the flowers visited by the Lepidoptera will be due to the fact that they easily can reach concealed nectar (here in the sense of nectar thieves). 


\section{Butterfly- or moth-pollinated flowers}

It appears that both the Coleoptera and non-apoid Hymenoptera comparatively rarely visit butterfly- or moth-pollinated flowers. The Diptera do more so. The Apoidea visit butterfly- or moth-pollinated flowers somewhat more than do the Diptera; and the Lepidoptera do indeed most frequently visit this type of flower (tables $6-1 \mathrm{~B}$ and $6-1 \mathrm{~B}-1$ to 4 ).

\section{Discussion}

Comparing the visits of the insect groups to their corresponding facultative and obligatory pollination types in the quantitative analysis the same tendencies in effectiveness in visiting with regard to pollination are found as in the qualitative analysis; in the sequence of, overall, low to high: Lepidoptera (highly specialized on a small part of the central European flora), Coleoptera, Diptera and Apoidea. If we compare in the quantitative analysis (table 6-1B) the frequencies of the insect groups visiting their corresponding facultative and obligatory pollination types with the next higher frequencies within the pollination types, it is striking that in the butterfly- or moth-pollinated flowers the frequency of the Lepidoptera is almost double of that of the Apoidea. This difference is much higher than the differences between the Apoidea and Lepidoptera in the bee-pollinated flowers, Diptera and non-apoid Hymenoptera in the fly-pollinated flowers, and Coleoptera and Diptera in the beetle-pollinated flowers. This means, as is already indicate in the qualitative analysis, that the relations of the Lepidoptera with the butterfly- or mothpollinated flowers are more restrictive (more specialized) than those of the Apoidea with bee-pollinated, the Diptera with fly-pollinated, and the Coleoptera with beetle-pollinated flowers. The same can be stated, although less decidedly, for the Apoidea and bee-pollinated flowers in comparison with the Diptera and Coleoptera and their corresponding pollination types.

If we compare these findings with the phylogeny and fossil record of the insects involved, it can be stated that the more specialized insect-flower relationships developed during the late Cretaceous and became established around the middle Tertiary (Eocene/Oligocene). This would not contradict the hypothesis that the earliest entomogamous Angiospermae had a nonspecialized pollination type. This means that the flowers then, were pollinatable by Coleoptera, Diptera and non-apoid Hymenoptera (probably mainly Symphyta). Wagenitz (1975) concluded that there is no evidence that anemogamy is plesiomorphous in any of the Recent Angiospermae, thus original anemogamy seems unlikely. Daumann (1975) found evidence for secondary anemogamy in some Ulmus species. Ulmus glabra has a minor nectarium at the filament excreting very few nectar at anthesis (which starts 
already in the bud phase when the receptive stigma protrudes) and in $U$. minor some filamental sugar-containing tissue occurs. Ulmus laevis has neither nectaries nor sugar-containing tissue. These character states are paralleled by quantities of "Pollenkitt": Ulmus glabra and U. minor have about the same quantities and $U$. laevis has less. The species are mainly anemogamous, although pollen-collecting Apis mellifera may cause pollination in the female phase. The flowers first have a female phase, then a homogamous phase and finally a second homogamous phase. This extension of the female phase may be an adaptation to increase the chance of cross-pollination in the single-ovuled flowers. The comparatively long time of anthesis (Ulmus glabra 4-17 days; $U$. minor 4-18 days and $U$. laevis 3-11 days) may stress this. The second female phase may indicate that there may be some selection between pollen from the plant itself and from other plants. Then delay of fertilization may be the case (see Willson \& Burley, 1983). It strongly suggests a delay as in Populus (up to three days: Winton, 1968; Fechner, 1972 and 1976) and Juglans (two to five days: Funk, 1970), which is longer than in most Angiospermae (Krugman et al., 1974). Similar developments were found in Mercurialis (see Daumann, 1972).

\subsubsection{Obligatory entomophilous pollination types}

The obligatory entomophilous pollination types are determined after the syndromes by Faegri \& Van der Pijl (1980), with additions of Baker \& Hurd (1968). The terminology of the obligatory pollination types (syndromes) is in accordance with Delpino (see Knuth, 1898). It differs from that of Faegri \& Van der Pijl (1980) in myiophilous in stead of myophilous (Gr. myia = a fly, see Webster, 1971). Delpino (see Knuth, 1898) divided the Lepidopterapollinated flowers into psychophilous (Gr. Psyche $=a$ butterfly) and sphingophilous (the greek sphinx, sphinxes or sphinges, literally meaning "the strangler") including all specialized moth-pollinated flowers. Later (see Kugler, 1970) phalaenophilous ( $\mathrm{Gr}$. Phalaina $=\mathrm{a}$ moth) was distinguished within the syndrome of sphingophily. In the moth-pollinated flowers I will not follow Delpino. Because phalaenophily is derived from the greek word moth, I will follow Faegri \& Van der Pijl (1980) in dividing Lepidoptera-pollinated flowers into psychophilous and phalaenophilous. The meaning of the Greek sphinges is more connected with "hawk" than with "moth" in hawkmoth, and therefore sphingophily is considered a subsyndrome within phalaenophily. The syndromes can be described as follows.

Myiophilous (syndrome of fly blossoms): blossom regular, simple, no depth effect; colours generally light, dull; nectar guides frequently present; odour imperceptible; nectar open and easily obtainable; sexual organs well exposed; anthesis day and night. 
Melittophilous (syndrome of bee and bumblebee blossoms): zygomorphic with great depth effect; mechanically strong, with adequate facilities for landing and a surface that gives good hold, frequently intricate, semiclosed; colours lively, generally yellow or blue; nectar guides present; odour fresh, generally not very strong; nectar hidden, but not very deeply, in moderate quantities; sexual organs concealed, stamens few; many ovules per ovary; anthesis day and night or diurnal.

Psychophilous (syndrome of buttertly blossoms): diurnal anthesis, no closing at night; odour weak, generally fresh, agreeable; vividly coloured, inclusive of pure red (pink being very common); blossom rim not very much dissected; blossom erect, radial, rim generally flat, but often narrow; anthers fixed; nectar well-hidden in tubes or spurs, tubes narrow; nectar ample; simple nectar guides or mechanical tongue guide (groove).

Phalaenophilous (syndrome of moth blossoms, inclusive of sphingophilous): nocturnal anthesis, often closing during day-time, or crepuscular; strong, heavysweet perfume at night; mostly white or faintly coloured, sometimes red or drab, insignificant; deeply dissected lobes or fringed petals; blossom horizontal or pendent, rim absent or bent back; zygomorphy if present, caused by lower rim bending back; anthers versatile; nectar deeply hidden in long tubes or spurs; much nectar; nectar guides generally absent, guidance by contour of the blossom.

The numbers of obligatory sapromyiophilous and obligatory cantharophilous flowers in the central European flora are too low for proper statistical treatment. They are not taken into acccount in this section, but in order to compare them with the visiting activities of the Diptera and Coleoptera in the next sections, they are described below.

Sapromyiophilous (syndrome of carrion fly blossoms): anthesis day and night; predominant colours purple-brown to greenish; odour strong, unpleasant, often of decaying proteins; shape usually actinomorphic; no depth effect or deep in case of trap type; no nectar guides; nectar open or none, sometimes pseudonectaries; often no food provided; transparant windows or other features contribute to temporary traps; mobile filiform appendages to flowers or "tails" to petals often present.

Cantharophilous (syndrome of beetle blossoms): anthesis day and night; colours, variable, usually dull, often whitish, greenish, yellowish; odour strong, fruity or aminoid; shape actinomorphic (in the sense of Leppik (1957) haplomorphic and actinomorphic); flat to bowl-shaped flowers with easily accessible pollen, rarely closed; no nectar guides; pollen, nectar or food bodies; flower parts in large numbers.

It will be clear that ornithophily and chiropterophily and pollination by nonflying mammals (see Sussman \& Raven (1978) for the latter) cannot be studied in the central European area. These pollination systems are treated shortly in sections 6.16 and 7.3 . 
In table 6-2 the frequencies of the obligatory entomophilous pollination types within the facultative and obligatory are given. It appears that within the bee-pollinated flowers most species developed the obligatory pollination type, followed by the butterfly- or moth-pollinated species and least among the flypollinated species (tables 6-2-1 and 2).

Table 6-2. Frequencies of the obligatory pollination types among the species with flowers of the corresponding facultative and obligatory pollination types of the central European flora.

Abbreviations: $\mathrm{BeF}=$ Bee-pollinated flowers; $\mathrm{BMF}=$ Butterfly- or moth-pollinated flowers; $\mathrm{FlF}=$ Fly-pollinated flowers; $\mathrm{O}=\mathrm{OBL}=$ Obligatory pollination type.

1 and 2 give the significances of the differences by chi-square testing.

Explanation $4=\mathrm{p} \leq 0.0001$.

\begin{tabular}{|c|c|c|c|c|}
\hline & Total & OBL & $1 F l F$ & $\mathrm{O} 2 \mathrm{BeF}$ \\
\hline FlF & 1744 & 8.66 & BeF & BMF 4 \\
\hline $\mathrm{BeF}$ & 2154 & 29.66 & BMF & 4 \\
\hline $\mathrm{BMF}$ & 589 & 16.30 & & \\
\hline
\end{tabular}

The comparatively low frequency of obligatory myiogamy among the flypollinated species may be caused by the fact that myiophilous flowers as they are described above, certainly also are beetle- and bee-pollinated and may be pollinated by the non-apoid Hymenoptera (see below). Because of the odour being imperceptible, the insects must be visually attracted by the flowers (lively colour) and indeed many of the higher Diptera generally have larger eyes than the other insects mentioned, and probably can see the nectar guides better. The higher Diptera will be quantitatively the most effective pollinators of these flowers, but the relationship with these flowers did not become so specialized that clear evolutionary lines developed within the myiogamy (apart from the specialized sapromyiogamy).

Also the Diptera with longer tongues did not establish more exclusive pollinator relationships in central Europe. E.g. the Bombyliidae can pollinate psychophilous flowers (odour weak) in which the nectar is not too deeply hidden (the central European Bombylius have probosces of up to $12 \mathrm{~mm}$ ). In the present analysis these flowers are included in the psychophilous/phalaenophilous pollination type. Outside central Europe the Diptera developed more specialized relationships with flowers in correspondence with the length of the proboscis. The most striking example is the pollination of the South African Lapeyrousia fabricii (Iridaceae) by Megistorhynchus longirostris (Nemestrinidae with a proboscis of $60-70 \mathrm{~mm}$ ), but also here, as in the case of flowers pollinated by Tabanidae like Pangonia (proboscis up to $40 \mathrm{~mm}$ ) and Corizoneura (proboscis up to $25 \mathrm{~mm}$ ), the flowers mainly are psychophilous (Vogel, 1954).

Comparing the differences and overlap (mainly outside central Europe) of flowers pollinated by longer-tongued Diptera and the psychophilous flowers 
with the phylogeny and fossil record of the insect taxa in which anthophily developed, it may be suggested that, e.g. by the early presence of the Nemestrinidae, myiophilous flowers (in the obligatory sense) may have existed in the middle to late Cretaceous. These flowers might have had a depth effect and may have been pollinatable only by the longer-tongued Diptera, and not by Coleoptera and non-apoid Hymenoptera with their short mouth parts. They may have formed a stepping-stone in the development towards psychophilous flowers.

The highest frequency of the obligatory pollination types is reached within the bee-pollinated species. This may be due to the fact that both morphology and behaviour in the Apoidea vary considerably. Within the melittogamy various evolutionary lines could develop in correspondence with the various tongue lengths and visiting habits of the Apoidea. The habits here concern the type of pollen-collecting by the Apoidea in view of the transportation: in the crop (e.g. Prosopis, Xylocopa); at the ventral side of the abdomen (e.g. Osmia, Eriades, Anthidium, Megachile); on the hind legs (most of the Apoidea).

Although the higher Lepidoptera also are exclusive pollinators, their habits are not so much varied as those of the Apoidea. Within the psychogamy and phalaenogamy there is less room for differentiation, which may explain the lower frequency of the obligatory pollination type in the butterfly- or mothpollinated flowers in comparison with the bee-pollinated flowers.

The obligatory myiogamy as it may have existed in the middle to late Cretaceous also may have been a stepping-stone towards melittogamy, ending with the stronger zygomorphy of the flowers that caused the often semi-closed flowers and the entire concealment of the nectar and the sexual organs.

Distribution of the obligatory entomophilous pollination types among the species of which the flowers are visited by the various insect groups, Qualitative analysis

\section{Myiogamy}

It is striking (table 6-3A) that the species of which the flowers are visited by the non-apoid Hymenoptera have the highest frequency of obligatory myiogamy (tables 6-3A-3 to 5). The species of which the flowers are visited by the Diptera have a much lower frequency, about equal to that of the species of which the flowers are visited by the Coleoptera. In the species of which the flowers are visited by the Apoidea and Lepidoptera the frequencies are lower (tables 6-3A-3 to 5).

The difference between the frequencies of the species of which the flowers are visited by the non-apoid Hymenoptera and those visited by the Diptera is very large. One wonders why the flowers are not pollinatable by the non-apoid Hymenoptera, because the open position of the nectar must be very attractive 


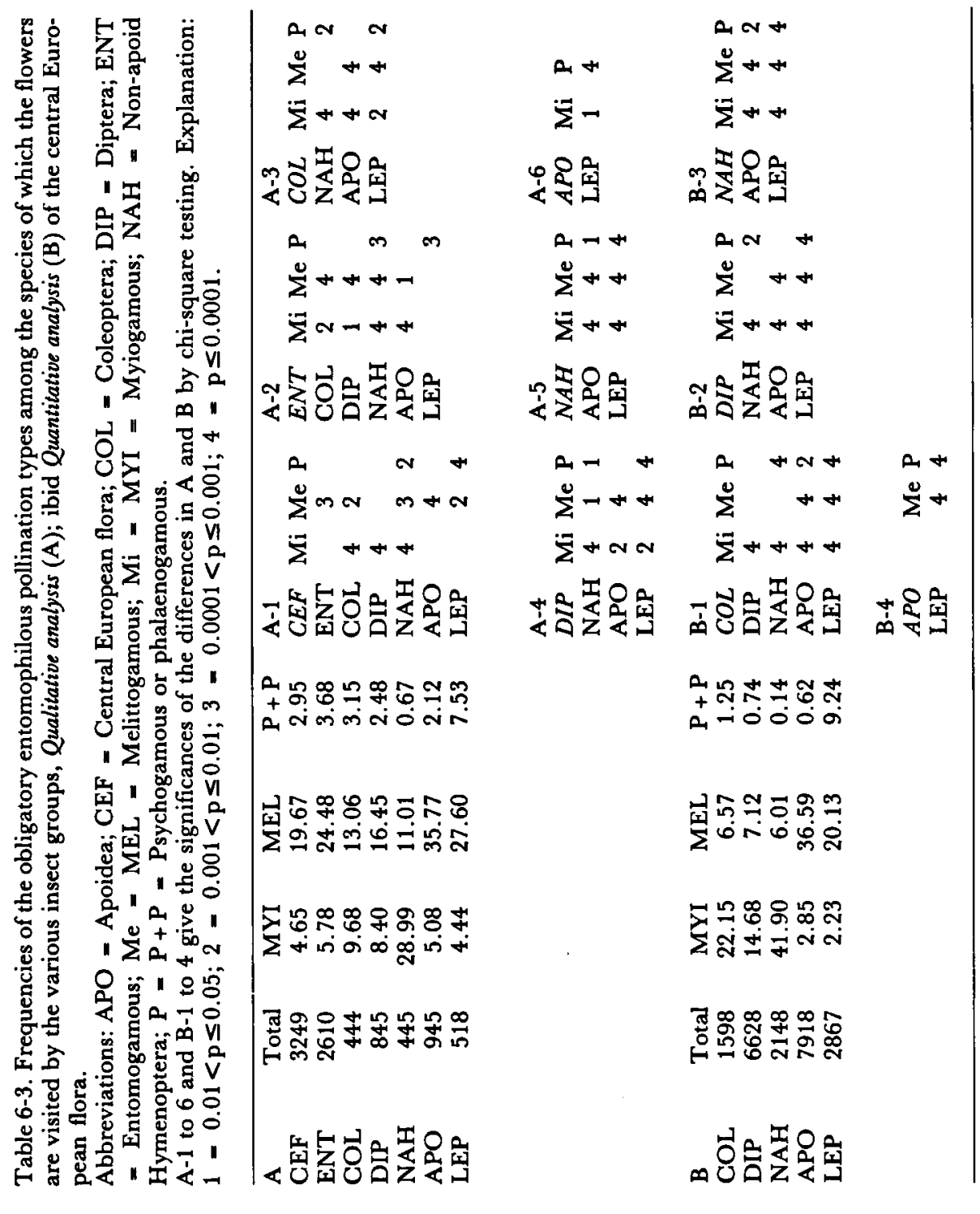


to the mainly nectarivorous wasps (see section 4.2 ). One also wonders whether the flowers are pollinatable by the Coleoptera (no difference between the frequencies of the species of which the flowers are visited by the Diptera and those visited by the Coleoptera is found). Both the open position of the nectar and the exposed position of the anthers (pollen-feeding) must be very attractive to the anthophilous Coleoptera. The effectiveness of the possible pollination of these flowers by the non-apoid Hymenoptera and Coleoptera in comparison with that by the Diptera should be studied in the field.

\section{Melittogamy}

In the melittogamy the expected picture appears. The species of which the flowers are visited by the Apoidea have the highest frequency of obligatory melittogamy (tables 6-3A and 6-3A-3 to 5). Also the species visited by the Lepidoptera have a high frequency of melittogamy. It is known that Lepidoptera often visit melittophilous flowers, but they do not effect pollination. Among the species of which the flowers are visited by the other insect groups no interesting differences appear.

\section{Psychogamy or phalaenogamy}

The species of which the flowers are visited by the Lepidoptera have the highest frequency of obligatory psychogamy or phalaenogamy (tables 6-3A and $6-3 \mathrm{~A}-3$ to 5 ). The species of which the flowers are visited by the non-apoid Hymenoptera have the lowest frequency, lower than the species of which the flowers are visited by Coleoptera, Diptera and Apoidea. Apparently the psychophilous or phalaenophilous flowers are least attractive to the non-apoid Hymenoptera.

Disposition of flower visits of the various insect groups with reference to the obligatory pollination types, Quantitative analysis

\section{Myiogamy}

Here it appears (tables 6-3B and 6-3B-1 to 4) that not only the non-apoid Hymenoptera, but also the Coleoptera visit more myiophilous flowers than do the Diptera. Although the Diptera may be the most effective pollinators, it may be difficult to consider this genuine obligatory myiogamy. It may appear that the myiogamy in Recent times finds its most obligatory form in the sapromyiophilous flowers. Kugler (1955) stated that among the Diptera or fly flowers only the carrion flowers have a more or less direct relationship with some of the Diptera. The main attractant is the odour, attracting carrion flies and beetles. Diptera, however, visit much more flowers and those producing amine odours can be considered transitions towards carrion flowers. They 
favour the visits of e.g. Muscidae and Tachinidae and restrict the visits of Apoidea. Generally there are no such restricted fly-flower relationships that there is question of special adaptations. When, in many forms, in which nonamine odours are produced, the flies are the main flower visitors, this is less due to the form and development of the flowers, than to the habitat in which the Diptera are most common. Such habitat is found in soils with a high humidity, that is not a suitable habitat for the Apoidea. The description of myiophily by Vogel (1954), then, appears to be more adequate than that of the restricted sense of Faegri \& Van der Pijl (1980) and Baker \& Hurd (1968): colours brown-red, brown, flesh-coloured, dirty yellow, greenish white, with spotted pattern and striation all over the leaf; form dish- to bowl-shaped and trap flowers (proboscis and leg pollination); flowers in the vicinity of the soil, flowers more or less flat, with often concealed entrances, window-forming, curling, caudiform, bearded, "Flimmerkörper" (glittering bodies); nectar open, easily reachable; odour unpleasant; diurnal opening, without periodicity in movement and odour; glittering or dull wart-like surface, fringes. Thus, this is about the same as the description of sapromyiophily of Faegri \& Van der Pijl (1980) and Baker \& Hurd (1968). Because in the central European flora these myiophilous flowers are very rare, they have to be studied in other regions.

\section{Melittogamy}

Here the same tendencies are found as in the qualitative analysis: the Apoidea visit most obligatory melittophilous flowers. In some cases nectar robbery will be included, particularly short-tongued Apoidea sometimes steal nectar by biting holes near the basis of the corolla in the vicinity of the nectar (see e.g. Kugler, 1933). Examples are Xylocopa valga and Megachile circumcincta on Galeopsis speciosa, other Megachile species on Salvia glutinosa and Apis mellifera on Vicia villosa. It appears that the Lepidoptera often visit melittophilous flowers, even more than the obligatory psychophilous or phalaenophilous flowers. The Lepidoptera do not effect pollination, the proboscis is thin and can reach the nectar without coming into contact with anthers and stigma and at the same time it is so long that the body of the insect remains outside the flower (Schremmer, 1953). They have to be regarded as nectar thieves.

\section{Psychogamy or phalaenogamy}

It appears that the Lepidoptera are the main visitors of the obligatory psychophilous and phalaenophilous flowers. Comparing the differences of the various insect groups within the corresponding pollination types, they are the most exclusive visitors of these flowers. The Coleoptera visit more psychophilous or phalaenophilous flowers than do the non-apoid Hymenoptera and Apoidea. An example of their activities on these flowers is given by Kugler (1977): Cetonia aurata lands on the flower of Lonicera caprifolium, feeds on the 
pollen, by which pollination can take place, ascends to the basis of the corolla tube, bites a hole in it and steals the nectar. Also Apoidea may act as nectar robbers on psychophilous or phalenophilous flowers, e.g. Bombus terrestris, $B$. mastrucatus, B. agrorum and Xylocopa violacea do so on Saponaria villosa.

\section{Discussion}

Summarizing this section, it can be stated that the obligatory melittophily and psychophily and phalaenophily form proper syndromes. The myiophily as described by Faegri \& Van der Pijl (1980) and Baker \& Hurd (1968), should be restudied in the field and probably the syndrome of myophily mainly includes sapromyiophilous elements.

As mentioned earlier, it is possible that myiophilous flowers with some depth effect may have arisen in the second half of the Cretaceous. True melittophilous and psychophilous flowers probably developed in the early Tertiary. The first might have been already somewhat differentiated in the early Oligocene, but bumblebee flowers developed later; the second could already have had considerably long corolla tubes in the middle Eocene. Phalaenophilous flowers developed later in the Tertiary.

\subsection{Blossom-pollinator relationships}

In this study principally the flower is considered. Thus, only the blossomrelationships (Faegri \& Van der Pijl 1980: 48, left part of table 2) are analyzed. They can be defined as follows:

Allophilic: no morphological adaptations for guiding visitors; can be utilized by unadapted, short-tongued, allotropic insects;

Hemiphilic: imperfectly adapted to being utilized by insects of an intermediate degree of specialization (hemilectic, or hemitropic insects);

Euphilic: strongly adapted to being utilized by specialized, eulectic or eutropic insect visitors.

Especially the euphilic blossom relationship can be differentiated into subtypes dealing principally with the character of the visitors received: polyphilic (pollinated by many different taxa of visitors); oligophilic (pollinated by some related taxa of visitors); monophilic (pollinated by one single or some closely related species only). The analysis of these subtypes has not been undertaken, because in fact too little of the characteristics of the insect visits and pollination is known in the central European flora. Only the types described above are taken into account, they deal principally with the adaptation of the blossom.

Classification of the central European flora into these types of blossompollinator relationships was not always easy. The allophilic type did not give difficulties, but separation between the hemiphilic and euphilic type did, and, 
indeed in a number of cases is arbitrary. E.g. melittophilous flowers, pollinated by many taxa of bees can either be classified in the euphilic (possibly euphilic-polyphilic) or in the hemiphilic type. If the pollinators included more morphologically differentiated families of bees, I classified them in the hemiphilic type. Only the melittophilous flowers pollinated by higher longtongued bees (culminating in the bumblebee flowers) were classified as euphilic. In the myiophilous flowers only those requiring flies with a long proboscis (e.g. Bombyliidae and many Syrphidae) were classified as euphilic. Also in the psychophilous or phalaenophilous flowers the separation between hemiphilic and euphilic was (arbitrarily) based on the required length of the haustellum.

If more is known about the characteristics of the insect visits and about pollination, it might well appear that the hemiphilic type I used should be replaced by euphilic-polyphilic. In this study, however, this discrepancy will not cause problems, because we are searching for tendencies, and the classification into allophilic, hemiphilic and euphilic types gives an idea whether the various insect groups visit more or less specialized blossoms and whether the pollination types (both belonging to the complex of facultative and obligatory and to the obligatory types) as a whole are more or less advanced in adaptation. The totals of the frequencies do not reach $100 \%$ in the facultative and obligatory pollination types and in the various insect groups in the qualitative and quantitative analyses (tables 6-4A, C and D). This is due to the fact that anemophilous flowers are not taken into account; by definition anemophilous flowers cannot be classified in the blossom-pollinator relationships.

Distribution of the various types of blossom-pollinator relationships among the facultative and obligatory, entomophilous pollination types

It appears that two groups can be distinguished with regard to the blossompollinator relationships (table 6-4A). The beetle- and fly-pollinated flowers are more often allophilic and less often hemiphilic and euphilic than the bee- and butterfly- or moth-pollinated flowers (tables 6-4A-3 and 4). The fly-pollinated flowers are more often hemiphilic and euphilic than the beetle-pollinated flowers (table 6-4A-3) and the bee-pollinated flowers less often are euphilic than butterfly- or moth-pollinated flowers (table 6-4A-5).

Distribution of the various types of blossom-pollinator relationships among the obligatory, entomophilous bollination types

It appears (table 6-4B) that myiophilous flowers, as defined after the syndrome of Faegri \& Van der Pijl (1980) and Baker \& Hurd (1968) cannot be considered obligatory myiophilous. The morphology of these flowers caused me to include them into the allophilic type. The melittophilous and psychophilous 


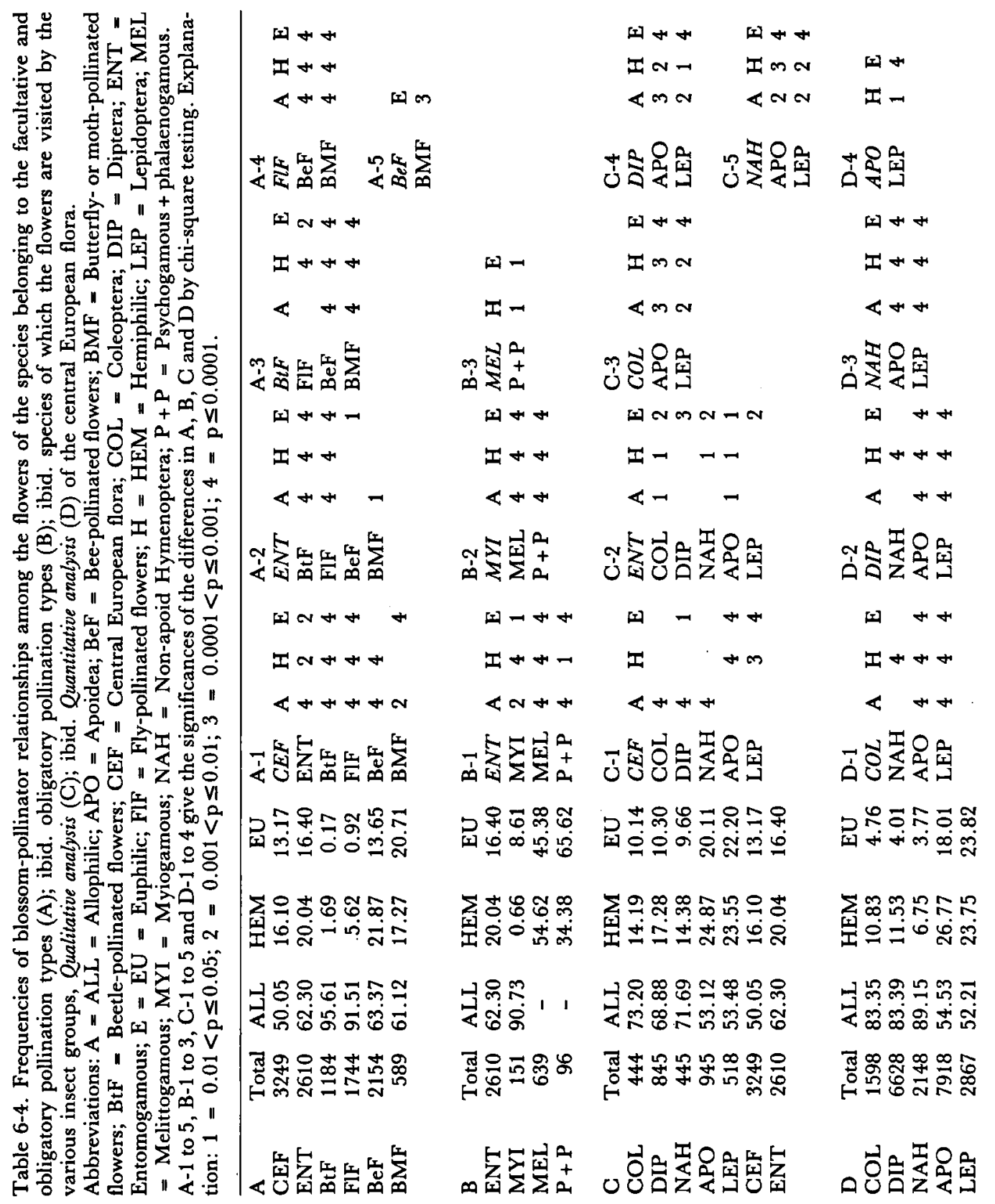


or phalaenophilous flowers are never allophilic and more often hemi- and euphilic than myiophilous flowers (table 6-4B-2). The melittophilous flowers are more often hemiphilic and less often euphilic than the psychophilous or phalaenophilous flowers (table 6-4B-3).

Distribution of the various blossom-pollinator relationships among the species of which the flowers are visited by the various insect groups, Qualitative analysis

It appears that two groups can be distinguished with regard to the blossompollinator relationships (table 6-4C). The species of which the flowers are visited by Coleoptera, Diptera and non-apoid Hymenoptera have more often allophilic and less often hemi- and euphilic flowers than the species of which the flowers are visited by the Apoidea and Lepidoptera (tables 6-4C-3 to 5). Within the two groups no differences exist.

Disposition of flower visits of the various insect groups with reference to the various types of blossom-pollinator relationships, Quantitative analysis

Here (table 6-4D) the same two groups are found as in the qualitative analysis (tables 6-4D-1 to 3). Within the group of the Coleoptera, Diptera and non-apoid Hymenoptera, the first two visit more hemiphilic flowers than do the last (tables 6-4D-1 and 2). Within the group of the Apoidea and Lepidoptera the first visit more hemiphilic and less euphilic flowers than do the second (table 6-4D-4).

\section{Discussion}

It appears that beetle-pollinated flowers form the least specialized facultative and obligatory pollination type, closely followed by the fly-pollinated flowers. Both the bee- and butterfly- or moth-pollinated flowers are distinctly more specialized, the latter more so than the first. The latter tendency is more strongly demonstrated in the obligatory pollination types. Obligatory myiophilous flowers, as already mentioned in section 6.2 , only rarely occur. These tendencies are also found in the qualitative and quantitative analyses. After the stage of morphological adaptation of the flowers they visit, the various insect groups have to be arranged as follows (in the sequence from lowly to highly advanced): non-apoid Hymenoptera, Coleoptera/Diptera, Apoidea and Lepidoptera.

Compared with the phylogeny and fossil record of the insect taxa in which anthophily developed, it can be stated that allophilic flowers occured in the early Cretaceous or late Jurassic. Hemiphilic flowers may have originated from the late Cretaceous. Some of them might have been euphilic in that time, only pollinatable by longer-tongued Diptera (see section 6.2: Cretaceous, obligatory myiophily), in the absence of other longer-tongued, anthophilous 
insects. Hemiphilic melittophilous and psychophilous or phalaenophilous flowers became functional during the early Tertiary and were then euphilic. The Recent euphilic melittophilous and psychophilous or phalaenophilous flowers developed during the later Tertiary and the Quaternary.

\subsection{Flower types}

The flower types are defined after Leppik (1957). The amorphic or paleomorphic type (flowers without symmetry; usually with an indefinite number of stamens and carpels, and usually subtended by bracts or discoloured upper leaves; mostly fossil forms) and the haplomorphic type (flowers with parts spirally arranged at a simple level in a semispheric or hemispheric form; petals or tepals coloured; parts numerous; e.g. Nymphaea and Magnolia) are not taken into account, because there are too few representatives of the haplomorphic type in the central European flora for proper comparison with the other types. The actinomorphic and pleomorphic types are taken together because of their vague separation (actinomorphic flowers have radial symmetry and the parts are arranged at one level, with a definite number of parts; pleomorphic flowers are actinomorphic with the number of parts reduced), The stereomorphic type (flowers three-dimensional with basically radial symmetry, parts many or reduced, and usually regular; e.g. Narcissus, Aquilegia) and the zygomorphic type (flowers with bilateral symmetry, parts usually reduced in number and irregular; e.g. Cypripedium and Salvia) are considered separately. As regards flower types, the heads of many Asteraceae with an actinomorphic arrangement of actino- and stereomorphic, and zygomorphic flowers are considered to belong to the highest (reached) level: zygomorphic. In the blossom classes (see section 6.5) these inflorescences are considered dish- to bowl-shaped, as they functionally are.

\section{Distribution of the flower types among the anemophilous and entomophilous pollination types}

The frequencies of the flower types among the anemophilous and entomophilous pollination types are presented in table 6-5A. It appears that anemophilous flowers are mainly actinomorphic (or of actinomorphic origin). Stereomorphic and zygomorphic anemophilous flowers are very rare, but the fact that some of these flower types are pollinated by wind (and insects), indicate that their anemophily is secondary. In all types the anemophilous flowers differ highly from the entomophilous flowers (table 6-5A-2).

Distribution of the flower types among the facultative and obligatory, entomophilous pollination types

It appears (table 6-5A) that two groups can be distinguished. The beetle- 


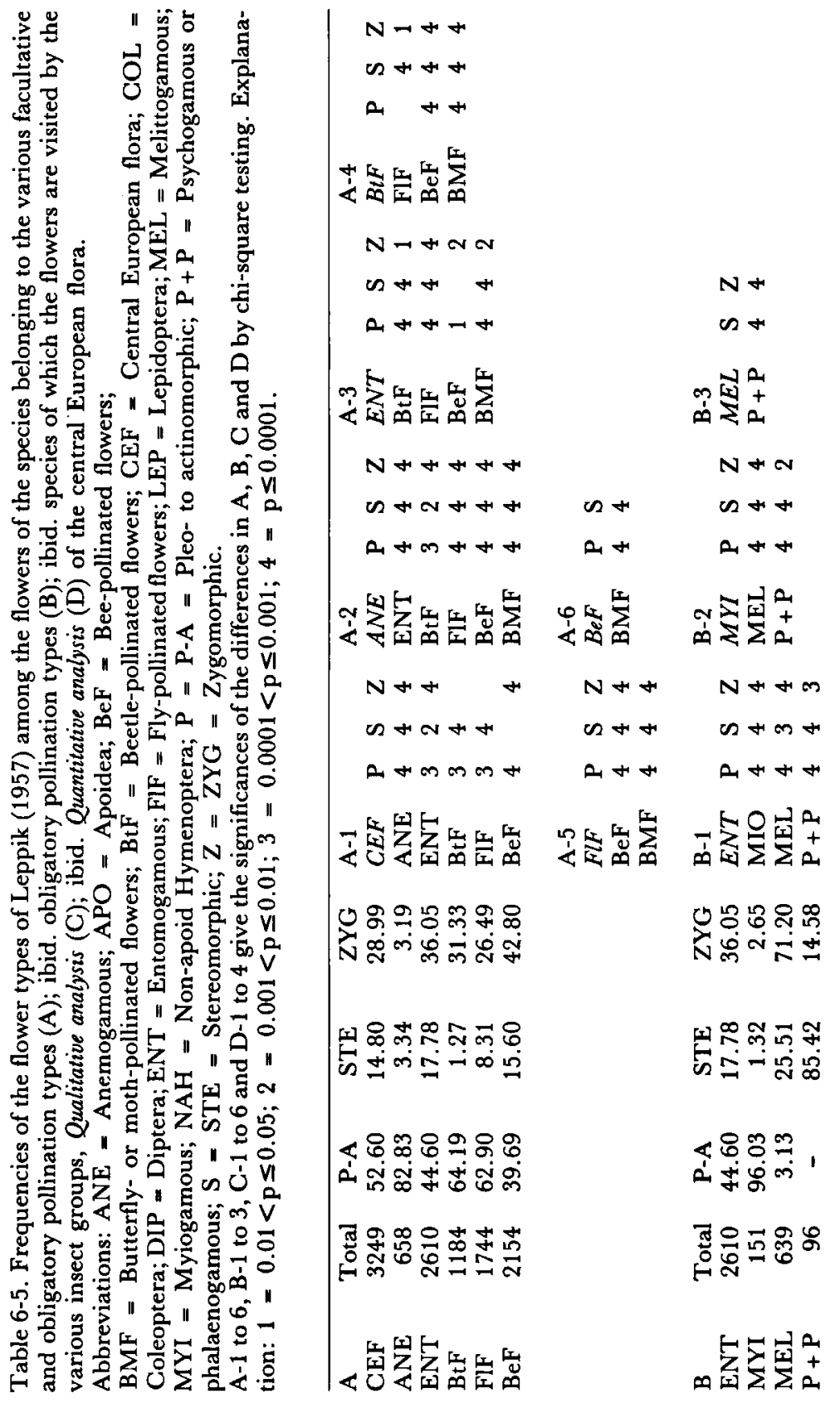




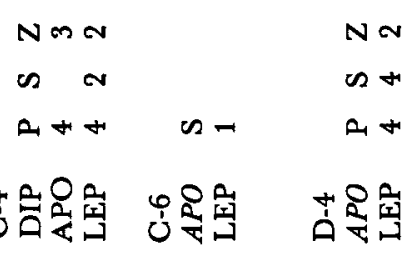

\begin{tabular}{|c|c|c|}
\hline$N m \propto$ & $N m \mathbb{N}$ & $N++$ \\
\hline$n$ & $n=m$ & $\Omega \sim$ \\
\hline 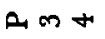 & ค サ + & \\
\hline
\end{tabular}

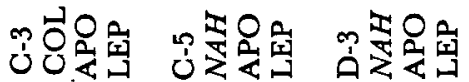

$$
\begin{aligned}
& \mathbf{N} \boldsymbol{N} \boldsymbol{N}-1 \\
& \text { थ } \rightarrow \\
& N+4+ \\
& \text { D. } \rightarrow \mathrm{N}-\mathrm{O}
\end{aligned}
$$

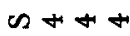

$$
\begin{aligned}
& \text { 布 }
\end{aligned}
$$

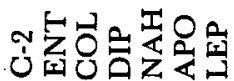

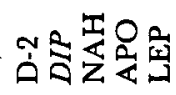

$$
\begin{aligned}
& N+\% \\
& n \leftarrow+ \\
& \operatorname{H}
\end{aligned}
$$

它空员品 $N \propto 2 \pi$ n N Dar + a

눈

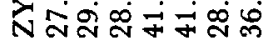

뙤요

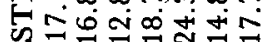
되 藏

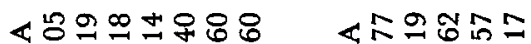

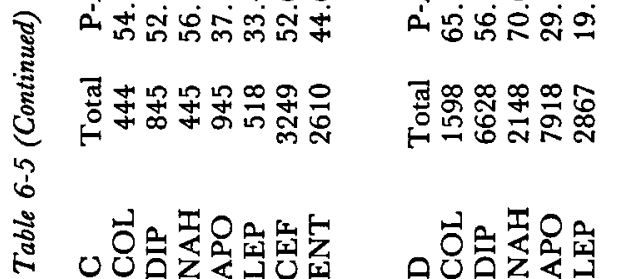


and fly-pollinated flowers more often are pleo- to actinomorphic and less often stereo- and zygomorphic than are the bee- and butterfly- or moth-pollinated flowers (tables 6-5A-4 and 5). In the group of the beetle- and fly-pollinated flowers the latter are more often stereo- or zygomorphic than the first (table 6-5A-4). In the group of the bee- and butterfly- or moth-pollinated flowers the latter are less often pleo- to actinomorphic and more often stereomorphic than the first (table 6-5A-6).

\section{Distribution of the flower types among the obligatory entomophilous pollination types}

The myiophilous flowers are mainly pleo- to actinomorphic (table 6-5B) and only rarely stereo- or zygomorphic. The zygomorphic flowers (e.g. Veronica species) are mainly pollinated by the Syrphidae (Knuth, 1898). The melittophilous flowers mainly are zygomorphic and more often stereomorphic than are the myiophilous flowers (table 6-5B-2). Only in some cases they are pleoto actinomorphic. The psychophilous or phalaenophilous flowers mainly are stereomorphic, more often than the melittophilous flowers, but less often zygomorphic (table 6-5B-3).

Distribution of the flower types among the species of which the flowers are visited by the various insect groups, Qualitative analysis

The species of which the flowers are visited by the Coleoptera, Diptera and non-apoid Hymenoptera have higher frequencies of pleo- to actinomorphic types than the species of which the flowers are visited by Apoidea and Lepidoptera (tables 6-5C and 6-5C-3 to 5). The species of which the flowers are visited byvColeoptera, Diptera, non-apoid Hymenoptera and Apoidea have less often a stereomorphic structure than those visited by the Lepidoptera (tables 6-5C-3 to 6). The species of which the flowers are visited by Apoidea and Lepidoptera more often have a zygomorphic structure than those visited by the other insect groups (tables 6-5C-3 to 5).

Disposition of flower visits of the various insect groups with reference to the flower types, Quantitative analysis

With regard to the flower types the visiting insects are divided into two groups (tables 6-5D). The Coleoptera, Diptera and non-apoid Hymenoptera visit more plesio- to actinomorphic and less stereo- and zygomorphic flowers than do the Apoidea and Lepidoptera (tables 6-5D-1 to 3). Within the first group the Coleoptera and non-apoid Hymenoptera visit more pleo- to actinomorphic flowers and less zygomorphic flowers than do the Diptera, and the Coleoptera and Diptera visit more stereomorphic flowers than do the nonapoid Hymenoptera, the Diptera more so than the Coleoptera (tables 6-5D-1 and 2). Within the group of the Apoidea and Lepidoptera the first visit more pleo- to actinomorphic and less stereo- and zygomorphic flowers than do the latter (table 6-5D-4). 


\section{Discussion}

The non-apoid Hymenoptera are the most plesiomorphous with regard to the flower types they visit, directly followed by the Coleoptera. The Diptera visit some more flowers with depth effect than do the Coleoptera and nonapoid Hymenoptera. The Apoidea and Lepidoptera visit most flowers with depth effect. The stereomorphic type appears to be more correlated with the Lepidoptera, and although the Lepidoptera visit more zygomorphic flowers than do the Apoidea (tables 6-5C and D), the very high frequency of zygomorphy of the melittophilous flowers (table 6-5B) suggest a correlation with the Apoidea.

Comparing these results with the phylogeny and fossil record of the insect taxa in which anthophily developed, it can be supposed that the actino- (to pleo-)morphic flowers could have been present in the early Cretaceous. The fact that the Diptera visit more flowers with depth effect than do the Coleoptera and non-apoid Hymenoptera, may indicate the presence of late Cretaceous obligatory myiophilous flowers. Slight stereomorphy and also zygomorphy might already have developed in these flowers. Stronger stereo- and zygomorphy became functional during the early and middle Tertiary and the extreme forms in the late Tertiary.

\subsection{Blossom classes}

The blossom classes are defined after Faegri \& Van der Pijl (1980).

\section{CONSPICUOUS BLOSSOM CLASSES}

Dish- to bowl-shaped blossoms: diffuse visual attraction (if any); diffuse alighting of visiting insects (because in the central European flora no ornithogamous and chiropterogamous species occur, the only visitors taken into account are insects); no guiding; diffuse, open display of attractant; diffuse pollen deposition and reception (inside); primarily adapted to plesiomorphous, anthophilous insects (as examples of these insects Faegri \& Van der Pijl (1980) mentioned only beetles). To this class belong the actinomorphic flowers, i.e. pleo- to actinomorphic flowers (non stereomorphic, radially symmetric in the sense of Leppik (1957), see section 6.4), which have the parts arranged at one level, and also inflorescences, like the heads of many Asteraceae.

Bell-to funnel-shaped blossoms: diffuse visual attraction; diffuse alighting of insect visitors; attractant displayed half-hidden, approximately in the centre of the blossom (inside); primarily adapted to insects that crawl into the flower, e.g. bees. To this class belong campanulate, many cruciform, infundibular and some coronate perianth types. The globose and urceolate perianth types are also included here. 
Brush-shaped blossoms: diffuse visual attraction; diffuse alighting of visiting insects; no guiding of the visitors; display of attractant diffuse, open; pollen deposition and reception diffuse (outside); primarily adapted to alighting insects with longer mouth parts (bees, butterflies). Examples of this class are some species of Thalictrum (e.g. T. aquilegifolium), Salix and species of Rubus (e.g. R. idaeus).

Flag-shaped blossoms: visual attractant by standard; alighting of visiting insects on carina; insects guided by marks on standard; attractant well-hidden, entrance to be forced; primarily adapted to alighting insects which can force their way in (higher bees). To this class the carinate, papilionaceous and personate perianth types belong.

Gullet-shaped blossoms: visual attraction by both lips; alighting of visiting insects on lower lip, guiding of the insects by symmetry of lower lip; attractant wellhidden; pollen deposition and reception nototribous, in upper lip; primarily adapted to alighting insects which can force their way in (higher bees). To this class the bilabiate perianth type belongs, and also the calceolate or saccate perianth type is supposed to belong here.

Trumpet-shaped blossoms: visual attraction by margin; alighting of visiting insects on this margin; guiding towards a central opening; attractant hidden; pollen deposition and reception central (inside); primarily adapted to alighting insects with long mouth parts (butterflies). The salverform and some unguiculate perianth types and others belong to this class.

Tube-shaped blossoms: visual attraction usually supplemented by other parts of the flower; no alighting of the visiting insects; guiding by perianth structure; attractant deeply hidden; pollen deposition and reception variable; primarily adapted to hovering insects or alighting insects perching on adjacent structures (moths).

INCONSPICUOUS BLOSSOM CLASS: no optical attraction; with reduced flowers; mainly anemophilous, but also entomophilous taxa as Reseda odorata and Vitis; generally with greenish-brown flowers, which do not strongly contrast with the green leaves in the background.

Classifying the species of the central European flora into these classes did not cause many difficulties, except for the brush-shaped blossoms. Faegri \& Van der Pijl (1980) also included the head-shaped inflorescences without ligulate flowers in the brush-shaped class, which is said to differ only from the dishto bowl-shaped blossoms in the pollen deposition and reception (outside and inside, respectively) and in the adaptation to the insect visitors (bees and beetles, respectively). The latter may be questioned, because where easily available pollen is one of its attractants, insects with short mouthparts can also be effective pollinators. Since, functionally spoken, there exist intermediate 
types between the dish- to bowl-shaped blossoms and the, probably more apomorphous, brush-shaped blossoms, the two are here taken together. In the present study difficulties like these will not cause problems, since we are searching for tendencies and do not attempt a rigid classification of all types.

Distribution of the blossom classes among the anemophilous and entomophilous pollination types

As is clearly demonstrated in tables 6-6A and 6-6A-2, most anemophilous blossoms are inconspicuous, while only some are dish- to bowl- or brushshaped (e.g. Polygonum), bell- to funnel-shaped or tube-shaped. The entomophilous blossoms are mainly conspicuous; those that are inconspicuous may attract insects by odour.

Distribution of the blossom classes among the facultative and obligatory, entomophilous pollination types

\section{Inconspicuous blossoms}

The inconspicuous blossoms are mainly found among the beetle-, fly- and butterfy- or moth-pollinated flowers (compare the tables 6-6A and 6-6A-4 to 6). The bee-pollinated flowers are least inconspicuous (table 6-6A-4 to 6).

Dish- to bowl- and brush-shaped blossoms

The dish- to bowl- and brush-shaped blossoms are mainly found among the beetle- and fly-pollinated flowers. The bee-pollinated flowers rather often are of this blossom class and the butterfly- or moth-pollinated flowers rarely belong to this type (tables $6-6 \mathrm{~A}$ and $6-6 \mathrm{~A}-4$ to 6 ).

\section{Bell- to funnel-shaped blossoms}

The bell- to funnel-shaped flowers are mainly found among the flowers pollinated by longer-tongued insects. There are two groups: the beetlepollinated flowers and the fly-, bee- and butterfly- or moth-pollinated flowers (table 6-6A-4). Within the last group the fly-pollinated flowers are less often bell- to funnel-shaped than the bee-pollinated ones are (table 6-6A-5).

\section{Trumpet-shaped blossoms}

Trumpet-shaped flowers are almost exclusively found among those pollinated by butterflies or moths (tables $6-6 \mathrm{~A}$ and $6-6 \mathrm{~A}-4$ to 6 ).

\section{Tube-shaped blossoms}

Tube-shaped flowers are mainly found among those pollinated by butterflies or moths (tables 6-6A and 6-6A-4 to 6), although the frequencies among the other facultative and obligatory pollination types are comparatively high. The 


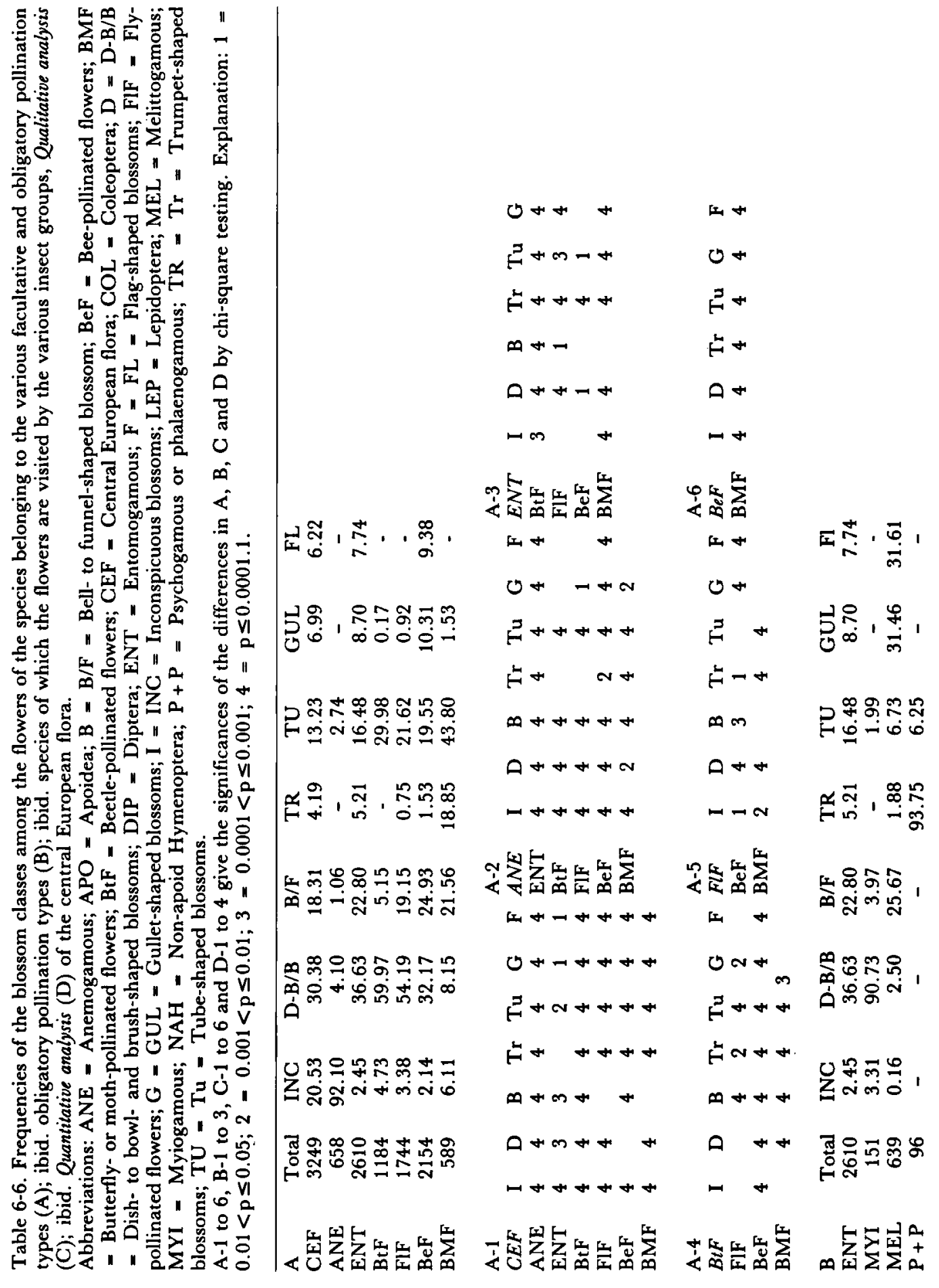




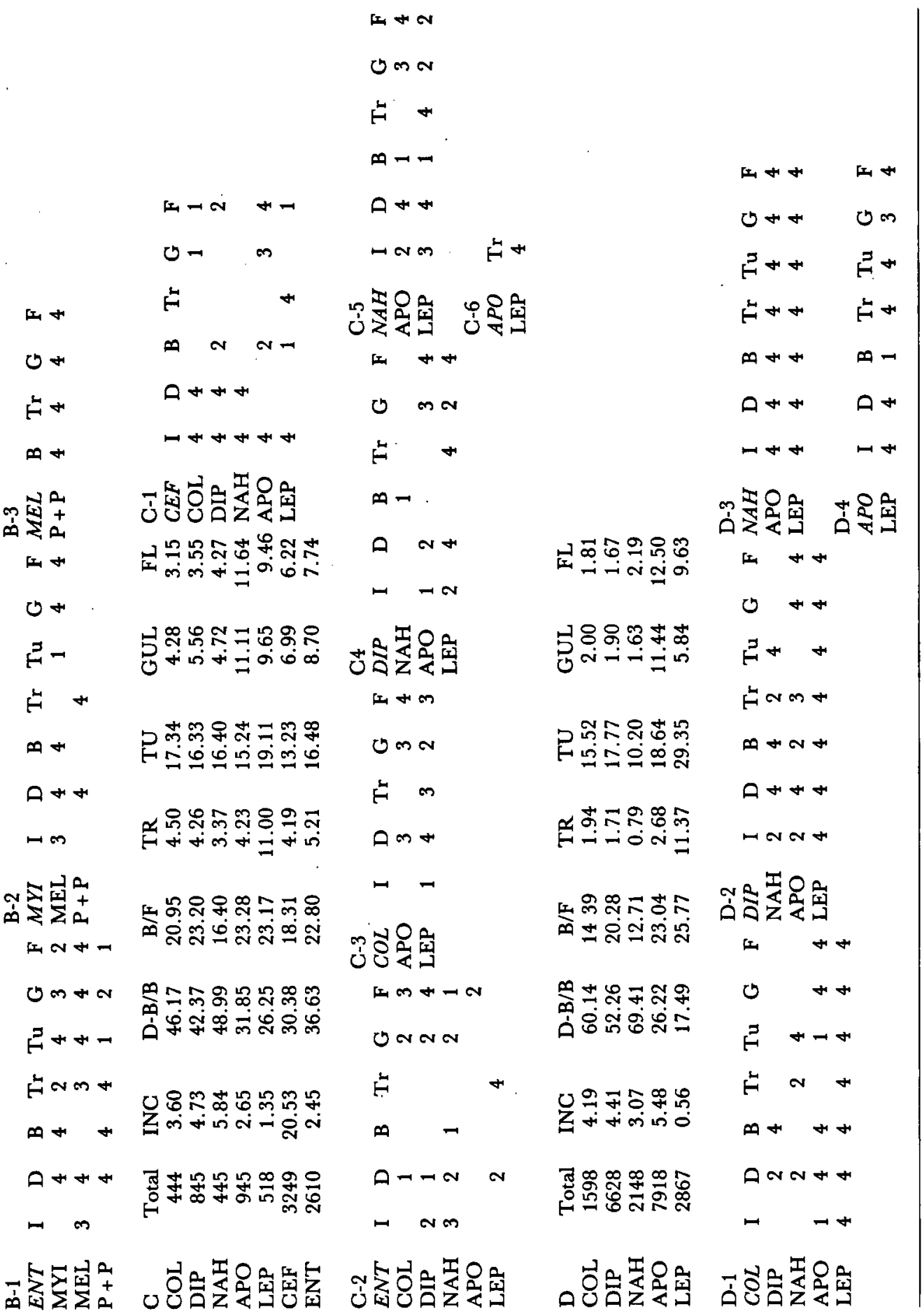


high frequencies among the beetle- and fly-pollinated flowers are due to the fact that many phanerantherous flowers that have the stigmas protruding from the corolla, can easily be pollinated by the pollen-eating Coleoptera and Diptera. This is e.g. the case in many Asteraceae with the more loose inflorescences.

\section{Gullet- and flag-shaped blossoms}

Gullet- and flag-shaped flowers are almost exclusively found among the beepollinated flowers (tables 6-6A and 6-6A-4 to 6).

Distribution of the blossom classes among the obligatory entomophilous pollination types

It appears that some myiophilous flowers or inflorescences are inconspicuous (table 6-6B). Dish- to bowl- and brush-shaped blossoms are characteristic for myiophily (table 6-6B and 6-6B-2). The melittogamous species have most bellto funnel-shaped flowers (tables 6-6B and 6-6B-2 and 3) and exclusively gulletand flag-shaped flowers (table 6-6B). The psychophilous or phalaenophilous flowers are mainly trumpet-shaped and in some cases tube-shaped (tables 6-6B and 6-6B-2 and 3). There are no differences between the psychophilous or phalaenophilous flowers and the myiophilous and the melittophilous flowers concerning the tube-shaped class (tables 6-6B-2 and 3). This is due to the fact that the samples within the central European flora are too small for a finer separation, but it does not mean that the psychophilous or phalaenophilous flowers and myiophilous and melittophilous flowers cannot be separated in this respect. The corolla tubes of the first are generally considerably longer than those of the second.

Distribution of the blossom classes among the species of which the flowers are visited by the various insect groups, Qualitative analysis

\section{Inconspicuous blossoms}

It appears that the species of which the flowers are visited by the non-apoid Hymenoptera and Diptera more often have inconspicuous flowers than the species of which the flowers are visited by the Apoidea and Lepidoptera (tables 6-6C and 6-6C-4 to 6). The species of which the flowers are visited by the Coleoptera differ in this respect only from those visited by the Lepidoptera (table 6-6C-3).

\section{Dish- to bowl- and brush-shaped blossoms}

With regard to the dish- to bowl- and brush-shaped blossoms two groups are recognized: the species of which the flowers are visited by the non-apoid Hymenoptera, Coleoptera and Diptera more often have these blossoms than have those visited by Apoidea and Lepidoptera (tables 6-6C-3 to 6). 


\section{Bell- to funnel-shaped blossoms}

The species of which the flowers are visited by the various insect groups do not differ in having bell- to funnel-shaped blossoms; only the species of which the flowers are visited by non-apoid Hymenoptera appear to have fewer blossoms of this type than have those visited by the Apoidea and Lepidoptera (table 6-6C-5).

\section{Trumpet-shaped blossoms}

The trumpet-shaped blossoms are characteristic for the species of which the flowers are visited by Lepidoptera (tables 6-6C-3 to 6).

\section{Gullet- and flag-shaped blossoms}

Gullet- and flag-shaped blossoms occur mainly among the species of which the flowers are visited by the Apoidea and Lepidoptera. No differences exist between these two (table 6-6C-6), which reflect the rather extensive nectarthieving habits of the Lepidoptera on these exclusively melittophilous flowers.

Disposition of flower visits of the various insect groups with reference to the blossom classes, Quantitative analysis

\section{Inconspicuous blossoms}

The Apoidea appear to visit most inconspicuous blossoms (table 6-6D and 6-6D-1 to 4), more than the other insect groups involved. Comparing this with the quantitative analysis of the facultative and obligatory pollination types for anemophily in section 6.2 , they visit mainly entomophilous flowers belonging to this class. The Coleoptera, Diptera and non-apoid Hymenoptera visit fewer inconspicuous blossoms than do the Apoidea (tables 6-6D-1 to 3). Within this group the non-apoid Hymenoptera visit less blossoms of this class than do the Diptera (table 6-6D-2). The Lepidoptera appear to be least attracted by the inconspicuous blossoms (tables 6-6D-1 to 4).

\section{Dish- to bowl- and brush-shaped blossoms}

In visiting the dish- to bowl-shaped blossoms two groups can be distinguished: the Coleoptera, Diptera and non-apoid Hymenoptera, and the Apoidea and Lepidoptera (tables 6-6D-1 to 3). The first visits more flowers or inflorescences belonging to this class than does the second. Within the first group the non-apoid Hymenoptera visit more of these blossoms than do the Coleoptera and the latter do more so than the Diptera (tables 6-6D-1 and 2). In the second group the Apoidea do more so than the Lepidoptera (table 6-6D-4). 
In visiting the bell- to funnel-shaped blossoms the following series of groups can be arranged from fewer to more visits: non-apoid Hymenoptera and Coleoptera; Diptera; Apoidea; and Lepidoptera.

\section{Trumpet-shaped blossoms}

The trumpet-shaped blossoms, also as regards visiting activities, are highly interdependent with the Lepidoptera (tables 6-6D-1 to 4). The non-apoid Hymenoptera visit the least trumpet-shaped blossoms, followed by the group of the Coleoptera, Diptera and Apoidea, within which the Diptera do less so than the Apoidea (tables 6-6D-1 to 3).

\section{Tube-shaped blossoms}

Within the tube-shaped flowers the Lepidoptera are the main visitors (tables 6-6D-1 to 4). The non-apoid Hymenoptera do so least. Within the intermediate group the Coleoptera visit less tube-shaped flowers than do the Apoidea (table 6-6D-1).

\section{Gullet- and flag-shaped blossoms}

Both within the gullet- and flag-shaped blossoms two groups can be recognized: the Coleoptera, Diptera and non-apoid Hymenoptera, and the Apoidea and Lepidoptera (in which the first visit more flowers of this class than do the second) (tables 6-6D-1 to 4). As in the qualitative analysis it appears that the nectar-thieving activities of the Lepidoptera on melittophilous flowers must be of considerable importance.

\section{Discussion}

Summarizing the results it appears that the non-apoid Hymenoptera mostly visit the more simple blossom classes (dish- to bowl- and brush-shaped), directly followed by the Coleoptera which can feed on pollen, while staying on the surface of inflorescences of tube shaped, phanerantherous flowers or on the rim of similar trumpet-shaped flowers. The Diptera visit more blossom classes with depth effect (also found in the analysis of the flower types, see section 6.4): bell- to funnel-, trumpet- and tube shaped blossoms, but the differences are small. The Apoidea visit more blossoms with depth effect: bell- to funnel-, trumpet- and tube-shaped blossoms, and are the main visitors of the gulletand flag-shaped blossoms. Finally the Lepidoptera are the main visitors of the trumpet- and tube-shaped blossoms. The analyses among the facultative and obligatory, and obligatory pollination types demonstrate interdependence between the gullet- and flag- shaped flowers and the Apoidea, and between the trumpet- and tube-shaped flowers (the latter of another type than those visited 
by the Apoidea, i.e. with a much longer corolla tube) and the Lepidoptera.

Comparison of these results with the phylogeny and fossil record of the insect taxa in which anthophily developed, leads to the following possible evolution of the blossom classes. Among the early Cretaceous, entomogamous Angiospermae the following blossom classes may have been present: the inconspicuous class; the dish- to bowl- shaped class, and possibly some type of the brush-shaped class, as far as not primarily adapted to bee visitors. From about the middle Cretaceous blossom classes with some depth effect probably could become functional. Part of the Diptera (e.g. the Nemestrinidae) from that time on may have allowed the development towards bell- to funnel-shaped flowers. These types, particularly the latter, may have been myiophilous in that time. They could have given rise to the more obligatory myiophilous class of trumpet-shaped flowers (compare also the sections 6.2 to 6.4) and if the $\mathrm{Ne}$ mestrinidae already had developed a longer proboscis and hovering flight, the Cretaceous obligatory myiophily may already have given rise to tube-shaped flowers. The latter, then, may have remained myiophilous during a long period and, may be, by way of an intermediate psychophilous/phalaenophilous phase, may have given rise to the sphingophilous flowers in the second half of the Tertiary. As the Recent Nemestrinidae, also the Sphingidae can feed on nectar hovering above the flowers. The trumpet-shaped flowers became more and more psychophilous during the latest Cretaceous and the early Tertiary and reached the obligatory state in the middle Eocene. From this time on, somewhat earlier developments from psychophilous flowers to phalaenophilous flowers became possible, possibly completed already in the lower Oligocene.

The funnel- and trumpet-shaped types may also have given rise to the gulletshaped class, by extending zygomorphy, starting in the late Cretaceous and becoming definitely functional in about the middle Tertiary. The flag-shaped flowers possibly are directly derived from the dish- to bowl-shaped flowers (particularly of the latter), by increasing zygomorphy. This process may have started later in the Cretaceous, and, may be by way of early Tertiary stages of Syrphidae-pollinated forms and later more melittophilous types, they became definite in the Paleocene-Eocene (Crepet \& Taylor, 1985), in connection with the development of the higher bees.

The discrepancy between the single flowers and the inflorescences as pollination units, in the blossom classes taken together, in this possible evolution will be discussed in the next section.

\subsection{Single flower as pollination unit}

Defining the single flower as pollination unit in connection with the pollinating insects for the central European flora did not give many difficulties, except for the species with small-flowered inflorescences. Here the minimum 
size of the pollinating insects was fixed on intermediate, i.e. insects with a length of about $7 \mathrm{~mm}$. Anemophilous flowers are not included, since they are by definition not referable to pollinating insects.

Distribution of the single flower as pollination unit with reference to the pollinating insects among the facultative and obligatory, entomophilous pollination types

The bee-pollinated flowers appear to have the highest frequency of single flowers as pollination units (tables 6-7A and 6-7A-3 to 5). The beetle-

Table 6-7. Frequencies of the single flower as pollination unit among the species belonging to the facultative and obligatory pollination types (A); ibid. obligatory pollination types (B); ibid. species of which the flowers are visited by the various insect groups, Qualitative analysis (C); ibid. Quantitative analysis (D) of the central European flora.

Abbreviations: $\mathrm{APO}=$ Apoidea; $\mathrm{BeF}=$ Bee-pollinated flowers; $\mathrm{BMF}=$ Butterflyor moth-pollinated flowers; $\mathrm{BtF}=$ Beetle-pollinated flowers; CEF = Central European flora; COL = Coleoptera; DIP = Diptera; ENT = Entomogamous; FIF = Fly-pollinated flowers; LEP = Lepidoptera; MEL = Melittogamous; MYI = Myiogamous; $\mathrm{NAH}=$ Non-apoid Hymenoptera; $\mathrm{P}+\mathrm{P}=$ Psychogamous or phalaenogamous; $\mathrm{SF}=$ Single flower as pollination unit.

A-1 to 5, B-1 and 2, C-1 to 4 and D-1 to 4 give the significances of the differences in $\mathrm{A}, \mathrm{B}, \mathrm{C}$ and $\mathrm{D}$ by chi-square testing. Explanation: $1=0.01<\mathrm{p} \leq 0.05 ; 2=$ $0.001<p \leq 0.01 ; 3=0.0001<p \leq 0.001 ; 4=p \leq 0.0001$.

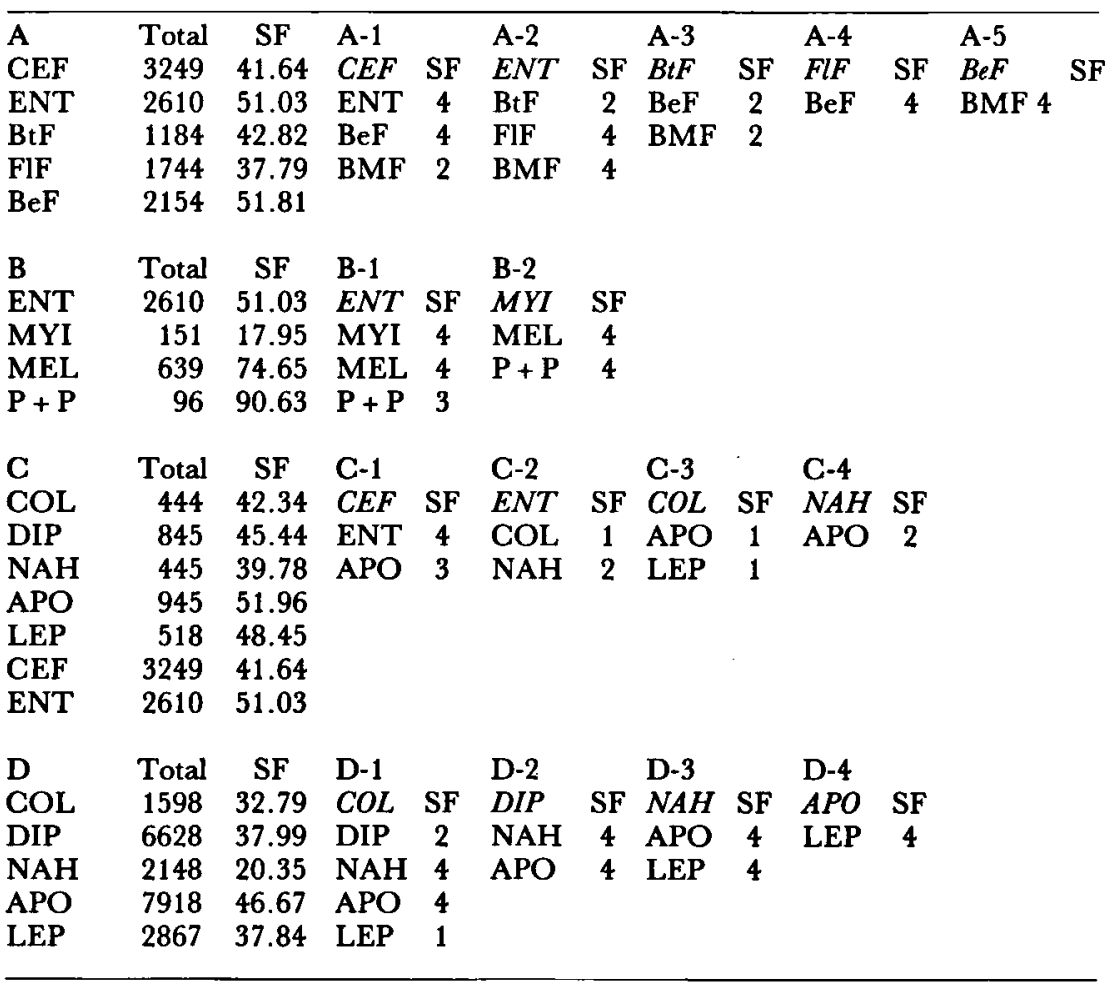


pollinated flowers have a lower frequency than the bee-pollinated flowers, but higher than the butterfly- or moth-pollinated flowers (table 6-7A-3). The flypollinated flowers are intermediate, (table 6-7A-4).

Distribution of the single flower as pollination unit with reference to the pollinating insects among the obligatory, entomophilous pollination types

It appears (table 6-7B) that the more specialized obligatory pollination types mainly have single flowers as pollination units. Only the myiophilous flowers have significantly much less single flowers as pollination units (table 6-7B-2).

Distribution of the single flower as pollination unit with reference to the pollinating insects among the species of which the flowers are visited by the various insect groups, Qualitative analysis

There are no pronounced differences between the species of which the flowers are visited by the various insect groups (tables 6-7C and 6-7C-3 and 4). In comparison with the species of which the flowers are visited by the Apoidea and Lepidoptera, only those visited by the non-apoid Hymenoptera (and to some degree by the Coleoptera) have less often single flowers as pollination units (tables 6-7C-3 and 4).

Disposition of flower visits of the various insect groups with reference to the single flower as pollination unit in reference with the pollinating insects, Quantitative analysis

The differences between the insect groups are much more pronounced than in the qualitative analysis. After the tables 6-7D and 6-7D-1 to 4 the following series can be made, arranged from low to high frequency of the single flower as pollination unit: non-apoid Hymenoptera; Coleoptera; Diptera and Lepidoptera; and Apoidea.

\section{Discussion}

The more specialized obligatory, entomophilous pollination types mainly are single flowers as pollination units. Only for the bee-pollinated flowers (table 6-7A) and the visiting-activities of the Apoidea (table 6-7D) the melittophilous tendency (table 6-7B) is pronounced. For the other insect groups in comparison with their corresponding pollination types this is much less clear. In Recent times many insects of all groups visit inflorescences with small flowers on which the insect can pollinate also the flowers adjacent to those they are feeding on.

In comparison with the phylogeny and fossil history of the insect taxa in which anthophily developed, this does not mean that the inflorescences were the main pollination units in the early Cretaceous, because in Recent times they are more interdependent with the Coleoptera and non-apoid Hymenoptera, than with the other insect groups involved. Inflorescences are 
more restricted in their developmental possibilities than are single flowers and mainly have developed the dish- or brush-shaped type, which is indeed more interdependent with the Coleoptera and non-apoid Hymenoptera. In finding the early Cretaceous pollination units, we have to consider the inflorescences and single flowers separately as pollination units. The question is then, which was first, the inflorescence or single flower as pollination unit. This problem cannot be solved by this statistical analysis, because two entirely different structures developed about the same functional pollination units, viz. the dish(to bowl-) and brush-shaped flowers and the dish- and brush-shaped inflorescences. The question can only be answered by interpretation of the evolutionary lines within the angiosperm pollination units, based on the Recent morphology, since fossils of inflorescences and flowers are rare.

Because almost all more obligatory pollination types concern single flowers as pollination units, it seems logical to suppose single flowers as pollination units of the dish- to bowl- and brush-shaped type to be the ultimate ancestors, somewhere in the early or middle Cretaceous. As mentioned in the preceeding sections single myiophilous flowers with some depth effect in the Upper Cretaceous may have given rise to the melittophilous and psychophilous flowers. To estimate the time (early or middle Cretaceous) in which the direct ancestors of these myiophilous flowers were present, we have to question what structure is the most probable original pollination unit within the entomogamous Angiospermae. There are two developments possible: from inflorescences to single flowers as pollination units and the reverse. In the first development we have to consider inflorescences with unisexual and hermaphroditic flowers separately. It seems difficult to start with unisexual flowers. There is no pressure demonstrated that favours the development of concentrations of the male and female organs into bisexual pollination units. Such a concentration would happen only accidentally, and although it cannot be excluded, the chance that such a development really occurs, is extremely small. In pre-angiosperm times it, as far as known yet, happened only very rarely, viz. in the Bennettitales and the Czekanowskiales. In the latter, however, it is a specialization of monoecy (male and female reproductive structures adjacent; male possibly loosely subtending the female).

Starting with inflorescences with hermaphroditic flowers, however may be possible. A selective pressure that favours continuing reduction of the numbers of flowers can be specialization of the pollination in less, larger flowers. Such pressure, however, seems weak and this process will mainly take place in connection with increase of the numbers of ovules per carpel.

There are also arguments for the development from single flowers to inflorescences. Starting with the single, non-specialized entomophilous, dishto bowl- or brush-shaped flower as pollination unit, the often injurious visits of mandibulate, anthophilous insects with more or less developed 
anthophagous feeding-habits, may have formed the pressure to favour the development of more, smaller flowers on the plant to spread the ovaries and by that to avoid too extensive loss of the gynoecia. With the reduction of the size of the flowers the food supply per flower may have become too low to be of interest for the injurious insects. Then, the flowers became dependent on small insects for pollination, and as we can derive from the chapters 4 and 5, the smallest, possibly anthophilous insects present in the early Cretaceous were the smallest Chironomoidea, the somewhat larger males of Culicoidea, Mycetophilidae, males of Blephariceroidea, Psychodidae and Nitidulidae. As far as known, none of these taxa became pollinators of any importance, but as I stated before the pollination of the many, very small flowers, acting as individual pollination units, still have to be studied in detail. It may be a very early development within the Angiospermae. For larger, stronger- and fartherflying, anthophilous insects the diffusely presented flowers probably were not very attractive and as in the case of the injurious insects they had a food supply too small to be interesting for these insects. Particularly in the case of larger plants or trees of which the specimens were growing more distantly from each other, the small anthophilous insects may have been imperfect crosspollinators. In these plants a selection to more concentrated arrangements of flowers to attract larger pollinators is possible. The concentrations of flowers attracted the larger pollinators and had the advantage of a certain spreading of the ovaries. As mentioned above the inflorescences are restricted in their developments and formed mainly dish- and brush-shaped types (with the exceptions such as in Ficus and Arum inflorescences). The certain spreading of the ovaries in the inflorescences allowed to a certain extent the visits of more injurious (pollinating) insect visitors. Once compact and small-flowered, the infloresences might have had advantages over single flowers as pollination units. The inflorescences composed of small flowers, each with one or very few ovules, may flower over a comparatively long time. As Burtt (1961) suggested for Asteraceae this would lead to many different pollinations, which means that possible recombination is explored extensively. This is in contrast to the single, larger flowers with mostly many ovules, which receive much pollen from one specimen (exploring possible recombination intensively).

From this reasoning it can be derived that inflorescences are more interdependent with the more injurious than with the harmless pollinators. This indeed is demonstrated indirectly in the quantitative analysis (table 6-7D) and to some extent in the qualitative analysis (table 6-7C). It appears that the Coleoptera (possibly more injurious when visiting flowers than the mainly nectarivorous non-apoid Hymenoptera) are less interdependent with the single flower as a pollination unit and, thus, more interdependent with the inflorescences as pollination units, than are the Diptera, Apoidea and Lepidoptera. 
In conclusion it can be stated that there are also arguments for the development from the small single flower to the small-flowered, more compact inflorescence as pollination unit. This means that in the early Angiospermae extensive presence of small single flowers as pollination unit may have existed, pollinated by small insects., and these may have given rise of more compact small-flowered inflorescences pollinated by larger insects.

Because the Coleoptera have to be considered the main injurious flower visitors the developments from the single flowers to inflorescences as pollination units could have started very early in the phylogeny of the Angiospermae and the appearance of dish- or brush-shaped inflorescences in the (early) Cretaceous is probable.

\subsection{Perianth developed or rudimentary}

In order to assess the importance of the perianth in attracting anthophilous insects, with regard to possible transformation series from entomogamous to anemogamous pollination units in the Angiospermae, the visits of the insects to flowers with rudimentary perianth are analysed.

Distribution of flowers with rudimentary perianth among the species of which the flowers are visited by the various insect groups, Qualitative analysis

It appears that only the species of which the flowers are visited by the Lepidoptera differ from the species of which the flowers are visited by the other insect groups (table 6-8A). They have the smallest number of flowers with rudimentary perianth (tables 6-8A-1 to 4). Within the species of which the flowers are visited by the other insect groups only those visited by the Diptera have more often flowers with rudimentary perianth than those visited by the Apoidea (table 6-8A-2).

Disposition of insect visits of the various insect groups with reference to the flowers with rudimentary perianth, Quantitative analysis

As already demonstrated in the qualitative analysis the Lepidoptera least visit flowers with rudimentary perianth (tables 6-8B and 6-8B-1 to 4) in comparison with the other insect groups involved. Among the latter two groups can be recognized: the Coleoptera and non-apoid Hymenoptera visit fewer flowers with rudimentary perianth than do the Apoidea and Diptera (tables 6-8B-1 to 4).

\section{Discussion}

It has to be mentioned that this analysis is somewhat unbalanced by the very many observations of insect visits to Salix species (Knuth, 1899). It appears 
Table 6-8. Frequencies of perianth absent among the species of which the flowers are visited by the various insect groups, Qualitative analysis (A); ibid. Quantitative analysis (B) of the central European flora.

Abbreviations: $\mathrm{APO}=$ Apoidea; $\mathrm{COL}=$ Coleoptera; $\mathrm{DIP}=$ Diptera; LEP = Lepidoptera; NAH $=$ Non-apoid Hymenoptera; $P R=$ Perianth rudimentary.

A-1 to 4 and B-1 to 4 give the significances of the differences in $A$ and $B$ by chi-square testing. Explanation: $1=0.01<p \leq 0.05 ; 2=$ $0.001<p \leq 0.01 ; 3=0.0001<p \leq 0.001 ; 4=p \leq 0.0001$.

\begin{tabular}{lccllllllll}
\hline A & Total & PR & A-1 & & A-2 & & A-3 & & A-4 & \\
COL & 444 & 4.73 & COL & PR & DIP & PR & NAH & PR & $A P O$ & PR \\
DIP & 845 & 6.98 & LEP & 1 & APO & 1 & LEP & 1 & LEP & 1 \\
NAH & 445 & 4.94 & & & LEP & 4 & & & & \\
APO & 945 & 4.34 & & & & & & & & \\
LEP & 518 & 1.93 & & & & & & & & \\
& & & & & & & & & & \\
B & Total & PR & B-1 & & B-2 & & B-3 & & B-4 & \\
COL & 1598 & 3.44 & COL & PR & DIP & PR & NAH & PR & APO & PR \\
DIP & 6628 & 6.34 & DIP & 4 & NAH & 3 & APO & 2 & LEP & 4 \\
NAH & 2148 & 4.19 & APO & 3 & LEP & 4 & LEP & 4 & & \\
APO & 7918 & 5.82 & LEP & 4 & & & & & & \\
LEP & 2867 & 1.19 & & & & & & & & \\
\hline
\end{tabular}

that the more harmless insect visitors such as Diptera and Apoidea, are the main visitors of flowers with rudimentary perianth among the insect groups included. Both can be attracted to nectar and pollen.

It appears that the most injurious anthophilous insects, viz. the Coleoptera (together with the non-apoid Hymenoptera, and in addition to the Lepidoptera) least visit flowers with rudimentary perianth. This means that the loss of perianth, causing inconspicuousness, could be considered to give some protection against visits of injurious anthophilous insects. However, owing to the fact that rudimentary perianth is correlated with developments towards unisexual pollination units (both entomophilous and anemophilous types), which have the same effect (separation in space of the gynoecia and the pollen), but which are possibly mainly developed under the selective pressure of imperfect self-pollination avoiding dichogamy (see section 6.14), it is not known whether reduction of the perianth is effected under the selective pressure of the visits of injurious insects. May be within hermaphroditic, entomophilous, flowers with rudimentary perianth it may be the case, but it is subject to doubt since it is known that the Coleoptera visit more anemophilous flowers or inflorescences to feed on pollen than do the other insect groups included (see section 6.2). In conclusion, it can be said that reduction of perianth can be considered mainly a development towards anemophily, or in the case of the presence of nectar, towards a rather specialized type of entomophily (e.g. Salix species that are mainly melittogamous and in aroids which developed sapromyiophily). 
Because no clear evolutionary lines are demonstrated, it is not possible to correlate the state of development of the perianth with the phylogeny and fossil record of the insect taxa in which anthophily developed. Wagenitz (1975) considered reduction of flowers to be an apomorphous feature.

\subsection{Colours}

\section{co-authored by M. ZANDEE}

The colours occurring among the flowers of the central European flowers are registered after Hegi (1906-1931, 1936, etc. and 1966, etc.). In this analysis all colours mentioned are taken into account, viz., the variation within the species, as well as the various colours within the flower.

The colours taken into account are listed as follows, mainly according to Lanjouw et al. (1968):

White (albus), inclusive pure white, snow white (candidus, niveus), milky white (lacteus), creamish white (eburnus), silvery white (argenteus) and whitish (albidus);

Yellow (flavus), inclusive vivid yellow (luteus, lutescens), lemon yellow (citrinus), sulphuric yellow (sulphureus), ochre (ochraceus), straw (stramineus), pale yellow (luridus) and yellowish (flavescens);

Orange (aurantiacus);

Red (ruber), inclusive blush (rubeus, rubicundus, rubellus), brick red (lateritius), carmine (puniceus), blood red (cruentus, sanguineus), fiery red (flammeus, igneus), vermillion, cinnabar (cinnabarinus), scarlet (coccineus), ruddy (rufus), reddish (rubescens) and redding (sanguinalis);

Pink (roseus);

Brown (brunneus), inclusive auburn (badius, spadiceus), dusky brown, grey brown (fuscus, fuscescens, phaeus) and rust-coloured (ferrugineus, rubiginosus);

Purple (purpureus, purpurascens);

Lilac (lilacinus);

Bluelviolet (caeruleus and violaceus), inclusive azure (azureus), Prussian blue (cyaneus), lavender, grey blue (caesius) and blueish (caerulescens);

Green (viridis), inclusive olive green (olivaceus), dark green (atrovirens), sea green (glaucus), blueish green (glaucescens) and greenish (virescens).

Grey and black, as mentioned in Hegi (loc. cit.), appear to occur in too low frequencies to be taken into account. They exclusively occur within entomophilous flowers and together with other colours they may play a role in guiding the insects towards the nectaries. Most instances of grey and black, however, are found in Ophrys species which imitate female Bombinae to attract the male Bombinae for pollination purposes. 
The analysis in this section only concerns the colours visible to the human eye, not "translated" to insect colours, as mentioned in Kevan (1978). Ultraviolet is not taken into account, because there are not enough observations made in the central European flora at species level to carry out proper comparative statistical analysis. This means that the analysis misses one of the wavebands attractive to insects, as Kevan (1978) noted: "despite the wellfounded observations that ultra-violet is highly visible to insects, it appears no more important in attraction than other wavebands of the light reflected from flowers".

Mixtures of colours visible to the human eye with ultra-violet (bee colours) (Daumer, 1956 and 1958; Kevan, 1978) are not taken into account. This means that some colours are incorrectly correlated with the insect groups, e.g. Primula veris lacking ultra-violet is yellow, but Helianthus annuus with ultra-violet reflection is bee purple; Papaver rhoeas reflecting red and ultra-violet is ultraviolet for the red-blind Apoidea.

One of the aims of this analysis is to trace whether pigments taking part in the metabolism of the plants (chlorophylls, carotenoids and xanthophylls; see e.g. Seward, 1964) can be considered more plesiomorphous in attracting insects, than are other pigments (flavones and anthocyanins).

\subsubsection{Analysis by $2 \times 2$ chi-square testing}

Distribution of the floral colours among the anemophilous and entomophilous pollination types

It appears that the entomogamous species have more often white and real colours and less green in their flowers than have the anemogamous species (tables 6-9A and 6-9A-2). All facultative and obligatory, entomophilous pollination types show these differences (table 6-9A-2), except the species with beetle-pollinated flowers for brown and lilac, and those with fly-pollinated flowers for brown.

Distribution of the floral colours among the species belonging to the facultative and obligatory, entomophilous pollination types

Within the analysis among the entomogamous species white and green are taken apart. Green does not effect any conspicuity in the foliage. White does, but cannot be considered a selective colour, because it is due to multiple reflections of all wave-lengths in the intercellular spaces between uncoloured cells, while all real colours are due to pigments.

Beetle-pollinated flowers (table 6-9A-4) appear to have comparatively low frequencies of white and real colours, except for yellow and green. Comparison with the other facultative and obligatory pollination types shows that beetlepollinated flowers need less real colours to attract their pollinators. In com- 


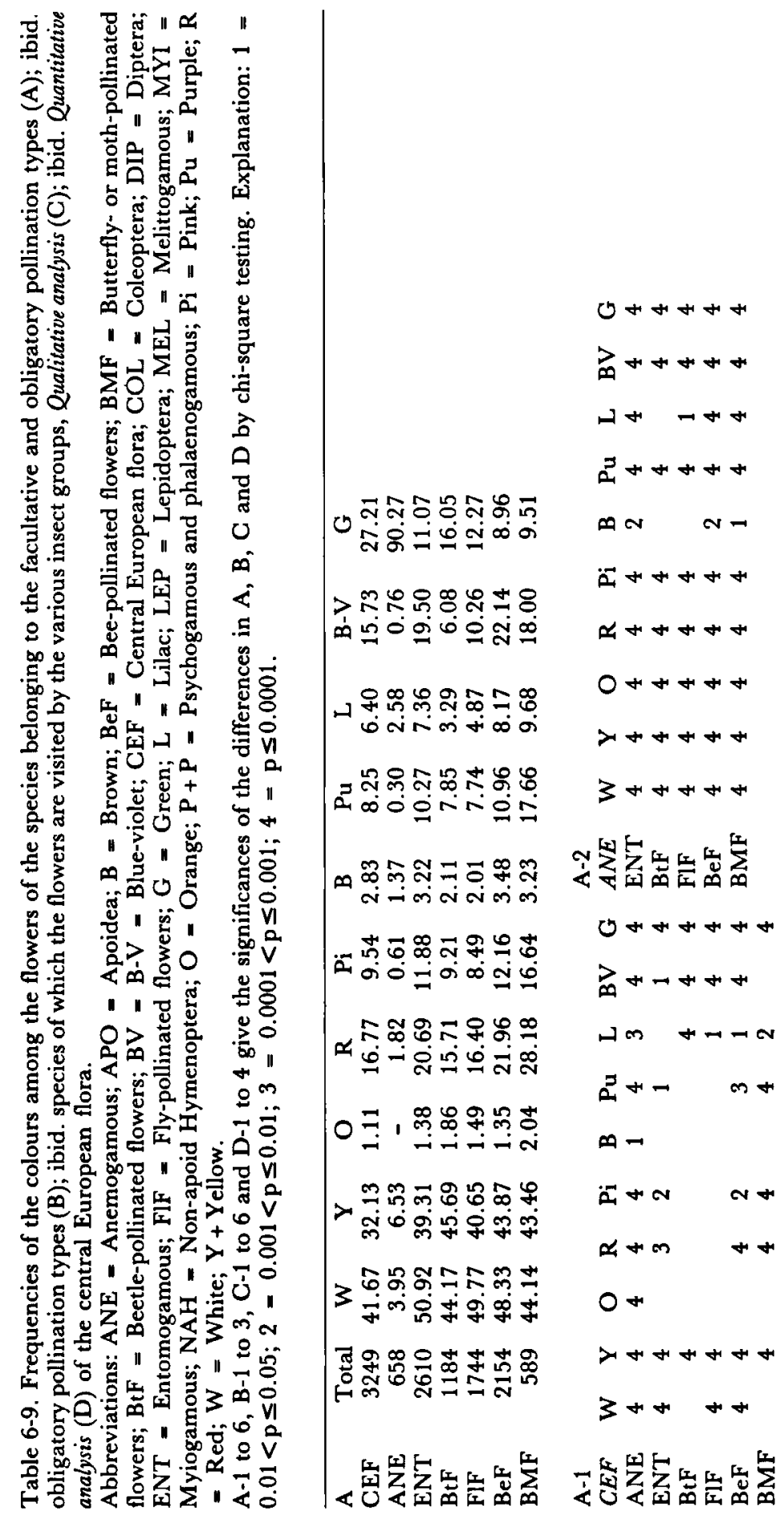


$0 N+m$

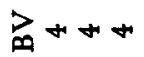

$\mapsto+$

E $N+$

$\infty \quad-$

a $N+$

$\propto+\infty$

$>N$

$3 \times-$

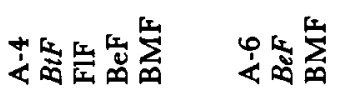

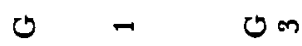

$\nabla_{m}+\infty$

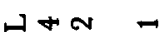

न 1 क म

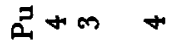

$m \infty$

inn$$
>
$$

$\operatorname{mos}$

An $m$

$n m m+$

$\alpha++$

$r m N$

$3 m$

N

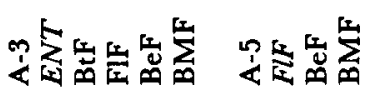

$>-$

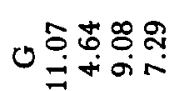

$>$ 유ํํํ

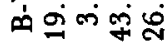

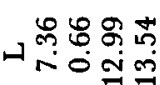

วิักิ

든

๓ พิ

लं 0 व

உ

E $=$ -

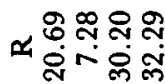

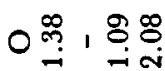

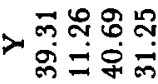

ว ริธิธัธ

踠

종읍 응

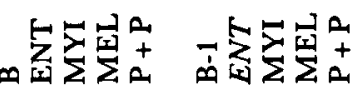

$\sum_{\infty}+$

$\sqrt[A]{ }$

$\ddot{2}+$

$\pi+$

$3+4$

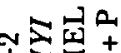
m $\Sigma$

$0 \mathrm{~N}$

$\geqslant++$

$\mu \propto+$

$2+4$

$m$ m

$\ddot{A}+N$

$\alpha++N$

$>+$

$3+$ $\sum_{\infty}$

$\rightarrow$ 包

$\therefore$ คे

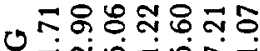

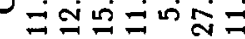

ต

,

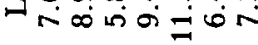

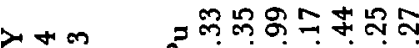

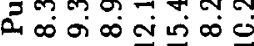

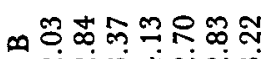
त लं

車

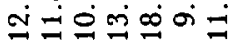

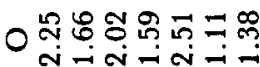

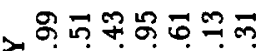

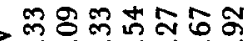
路

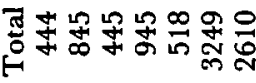

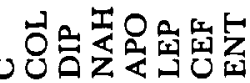




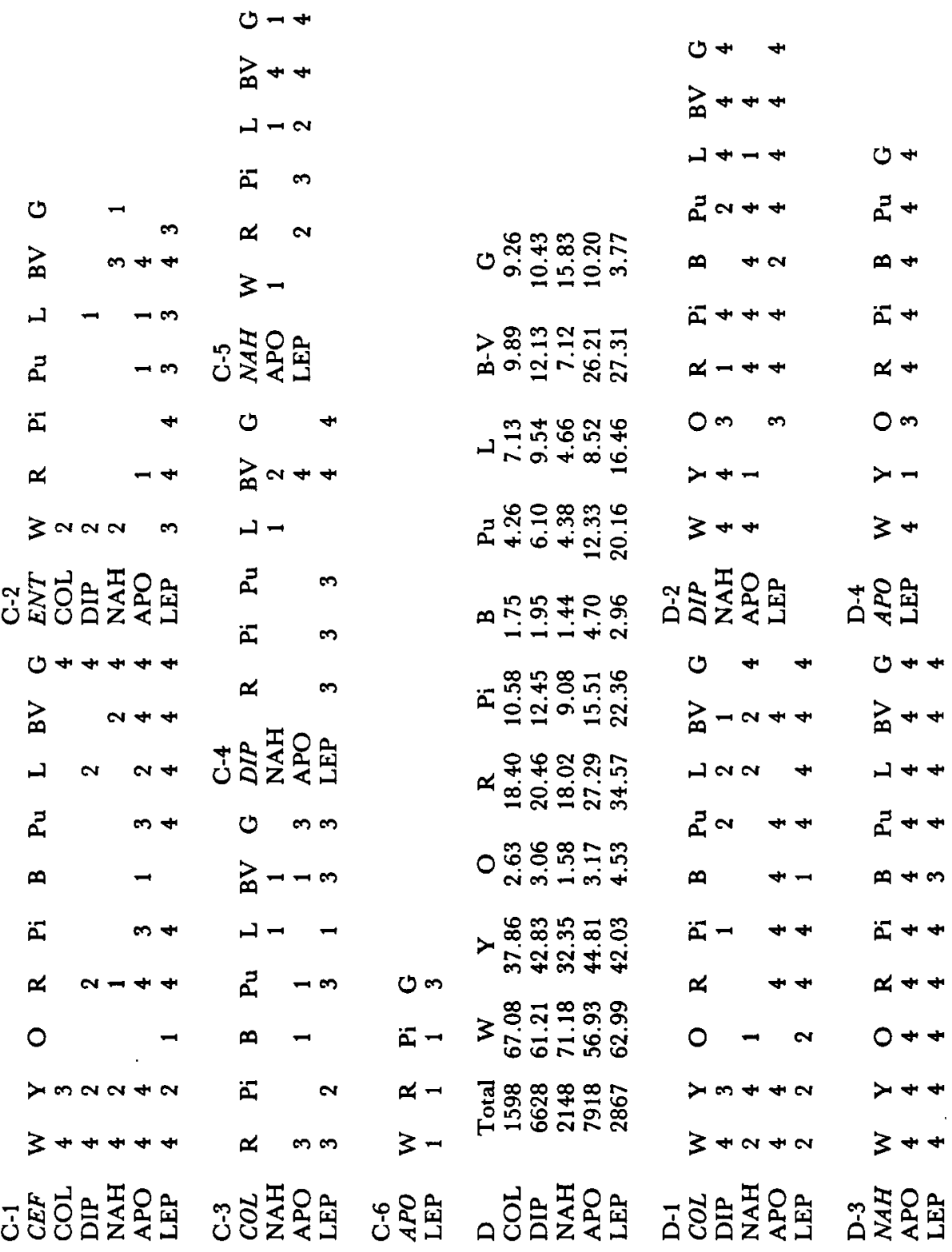


parison with the fly-pollinated flowers the beetle-pollinated flowers more often have yellow colours. Green is more common in the beetle-pollinated flowers than in the flowers pollinated by other insect groups.

Fly-pollinated flowers (tables 6-9A-4 and 5) are much like the beetlepollinated flowers in comparison with the bee- and butterfy- or mothpollinated flowers. They have more often white, lilac and blue-violet and less often yellow and green floral colours than have the beetle-pollinated flowers. This means that the fly-pollinated flowers utilize more shorter wave-lengths in attracting their pollinators than do the beetle-pollinated flowers.

Bee- and butterfly- or moth-pollinated flowers utilize more extreme wavelengths in attracting their pollinators than do beetle- and fly-pollinated flowers (tables 6-9A-4 to 6). The bee-pollinated flowers show a shift towards the shorter wave-lengths (purple (in comparison with the beetle- and fly-pollinated flowers), lilac and blue-violet) and somewhat less to the longer wave-lengths (red, pink, purple (in comparison with the butterfly- or moth-pollinated flowers) and lilac). In the butterfly- or moth-pollinated flowers the reverse is demonstrated (tables 6-9A-5 and 6).

\section{Distribution of the floral colours among the obligatory entomophilous pollination types}

Here the tendencies found in the facultative and obligatory, entomophilous pollination types are demonstrated again. In the myiophilous flowers fewer real colours are present than in the melittophilous and psychophilous and phalaenophilous flowers (tables 6-9B and 6-9B-2 and 3). The melittophilous flowers show a strong shift towards colours of shorter wave-lengths (table 6-9B3 ) and the psychophilous and phalaenophilous flowers do less so. The red and red-mixed colours do not discriminate between the psychophilous + phalaenophilous and melittophilous flowers. This may be due to the fact that the mostly whitish, phalaenophilous flowers are included, which decreases the overall frequency of red and red-mixed colours.

Distribution of the floral colours among the species of which the flowers are visited by the various insect groups, Qualitative analysis

Let us now see to what extent the flowering plant species behave in correspondence with the utilization of the colours in the entomophilous pollination types, with regard to their insect visits. The frequencies of this qualitative analysis are presented in table 6-9C. As is demonstrated in the tables 6-9C-3 to 5 the species of which the flowers are visited by the non-apoid Hymenoptera have more white and green, and fewer real colours (particularly lower frequencies of lilac and blue-violet) in the flowers than have the species of which the flowers are visited by the other insect groups. The species of which the flowers are visited by the Coleoptera and Diptera have less white and green, and more real colours in their flowers (yellow, orange, lilac and blue-violet) than have 
those visited by non-apoid Hymenoptera, but fewer real colours and more white than those visited by Apoidea and Lepidoptera. Besides some differences between particular groups this is expressed in blue-violet. The species of which the flowers are visited by the Apoidea and Lepidoptera have more real colours of short wave-lengths in their flowers than have those visited by the other insect groups. The red and red-mixed colours are more interdependent with the species of which the flowers are visited by the Lepidoptera than with those visited by the Apoidea (red and pink).

Disposition of flower visits of the various insect groups with reference to the floral colours, Quantitative analysis

Here the same tendencies are found as in the qualitative analysis. The differences, however, are more pronounced. In tables 6-9D and 6-9D-1 to 4 two groups can be distinguished. The Coleoptera, Diptera and non-apoid Hymenoptera visit less real colours (red, pink, brown, purple and blue-violet) than do the Apoidea and Lepidoptera. Within the first group the non-apoid Hymenoptera least visit real colours (particularly those of the shorter wavelengths: lilac and blue-violet). The Coleoptera do so somewhat more than the non-apoid Hymenoptera (orange, lilac and blue-violet), but less than do the Diptera (pink, purple, lilac and blue-violet). Within the second group the Apoidea visit more yellow and brown, and less orange, red, pink and purple, than do the Lepidoptera.

\subsubsection{The interdependence among floral colours and visiting insect groups. An analysis by reciprocal averaging}

\section{Introduction}

Reciprocal averaging or correspondence analysis is a technique for displaying the rows and columns of a two-way contingency table as points in (lowdimensional) space. We can either choose to make separate displays for rows and for columns, or we can make a joint display for both of them. The latter option is chosen here. By interpreting the geometrical relations within and among the joint representation of row and column profiles, we hope to arrive at a more comprehensive overview of associations among insect taxa and the colours of the flowers visited by them, than can be attained by breaking up the data matrix into numerous $2 \times 2$ chi-square tests.

In the present context both types of analysis (correspondence analysis and chi-square tests) are used for descriptive purposes only. A strict probabilistic interpretation is made impossible by the violation of assumptions relating to 
sampling-procedures and statistical interdependence. In correspondence analysis the displays are simply representations of the data in a form which is more convenient for interpretation. For a detailed account on the mathematics and computations involved in correspondence analysis we refer to Greenacre (1984), and Lebart et al. (1984). Here we will only give an informal account on interpretative guidelines.

The analysis starts with a table of frequencies (data matrix). The insect taxa are represented by the rows and the colours by the columns. In case of ordinary characters, instead of visit frequencies for flowers of given colours, we could measure the similarity among insect taxa by e.g. their euclidean distances. Now we have to apply a weighted euclidean distance, i.e. the normal euclidean distance based on frequency disparity is weighted by the expected frequency. The statistic result is called a chi-square distance. The correspondence analysis is aimed at providing a parsimonious representation $(=$ in as few dimensions as possible) of these chi-square distances both among taxa and among colours. Because of the weighting of the euclidean distances the analysis is independent of differences in absolute frequencies and solely results from the disparities in relative frequencies (proportions).

Each dimension (axis) resulting from the analysis summarizes a part of the total variance (or inertia) present in the distances among rows and among columns. The first dimension takes the largest share of the total inertia, the others take lesser and gradually decreasing parts. The dimensions are mutually orthogonal (perpendicular) and therefore the summaries are mutually independent. We can judge the importance of each dimension by the proportion of the total inertia that it carries. We can judge the importance of the insect groups and flower colours (row and column points respectively) with respect to the separate dimensions by their absolute contributions to the respective inertia of the dimensions. For interpretative purposes we can also compute the extent by which the separate dimensions explain the variance in relative frequencies in each insect and colour profile. Based on these absolute and relative contributions we can assign some descriptive name to each axis to guide us in our interpretation. Also we must realize that geometrically a particular insect profile tends to occupy a position which corresponds to the colour categories which are prominent in that insect profile. However, we must be aware of the emphasis on profiles. It is legitimate to interpret the relative position of one insect profile with respect to all colour profiles (or vice versa), but we should avoid interpreting distances between single points of different origin, i.e. a separate insect group (row) and colour (column), since such distances are not explicitly defined; only the distances either between rows or between columns are. 


\section{Results}

The results are presented in figs. 6-1 and 2. These are scattergrams displaying the rows and columns of table $6-9 \mathrm{C}$ as points in a 2-dimensional space. Fig. 6-1 summarizes 72 percent of the total variation in frequencies; 58 percent in the first dimension and 14 percent in the second.

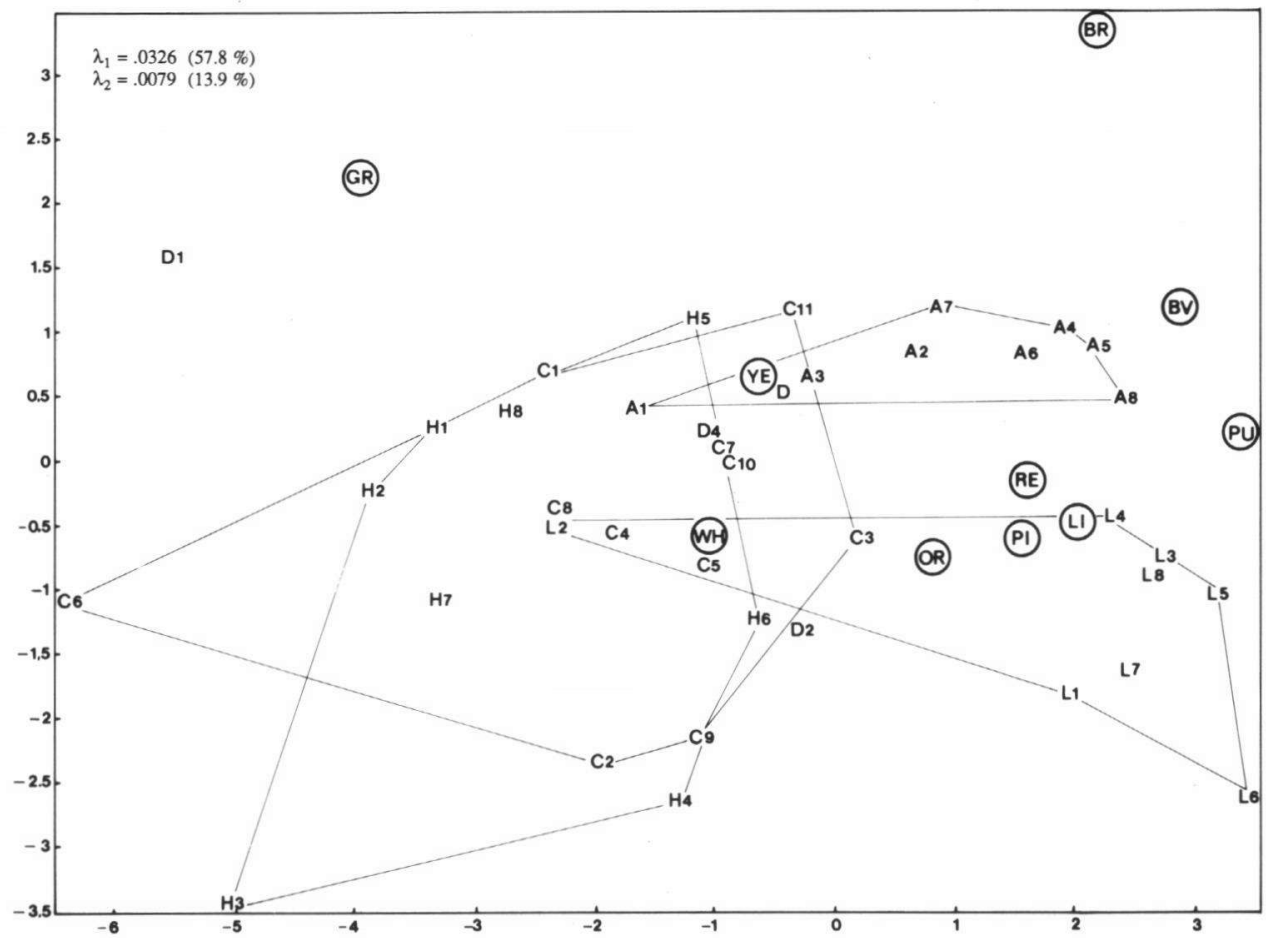

Fig 6-1. Scatter diagram showing the ordination of rows (insect taxa) and columns (colours), as for the insect groups in table 6-9C, on the first pair of principal axes (dim 1, dim 2), resulting from reciprocal averaging. Scale measurement for both abcissa and ordinate is in weighted proportional deviations from the average frequency $(x 10)$. Explanation: $\lambda 1=$ first eigen value; $\lambda 2$ $=$ second eigen value. The figures in parenthesis indicate the percentages of total inertia. COLEOPTERA: C1 = Staphyliniformia; C2 = Scarabaeiformia; C3 = Buprestoidea; C4 = Elateriformia; C5 - Cantharoidea; C6 = Dermestoidea; C7 = Nitidulidae; C8 - Coccinellidae; C9 = Cerambycidae; C10 = Chrysomelidae; C11 = Curculionidae. DIPTERA: D1 = "Nematocera"; D2 = Orthorrhapha; D3 = Aschiza; D4 = Schizophora. NON-APOID HYMENOPTERA: H1 = Symphyta; H2 = Ichneumonoidea; $\mathrm{H3}=$ Evanioidea; H4 - Scolioidea; H5 = Vespoidea; H6 = Sphecoidea; H7 = Chrysoidea; H8 - Formicoidea. APOIDEA: A1 = Colletidae; A2 = Halictidae; A3 = Andrenidae; A4 = Melittidae; A5 = Megachilidae; A6 = Anthophoridae; A7 = Apinae; A8 = Bombinae. LEPIDOPTERA: L1 = Tortricoidea; L2 = "Tineoidea" (in the sense of Knuth (1898a, 1899), compare section 4.3); L3 = Pyraloidea; L4 = 'Rhopalocera"' (in the sense of Knuth (1898a, 1899), compare section 4.3); L5 = Geometroidea; L6 = Bombycoidea; L7 = Sphingoidea; L8 = Noctuoidea.

COLOURS; BR = brown; BV = blue-violet; $\mathrm{GR}=$ green; $\mathrm{LI}=$ lilac; $\mathrm{OR}=$ orange; PI = pink; $\mathrm{PU}=$ purple; $\mathrm{RE}=$ red; $\mathrm{WH}=$ white; $\mathrm{YE}=$ yellow. 
Interpreting the first dimension in terms of colours we see a gradual shift from green and white at the left, through yellow in the center, to the red and finally blue colours at the right. This shift in colours is accompanied by a shift in insect groups from Coleoptera and non-apoid Hymenoptera at the left to Apoidea and Lepidoptera at the right. We also notice that both left hand groups and the Diptera occupy a larger space, i.e. are more variable with respect to visit frequencies, than the right hand ones (Apoidea and Lepidoptera). The position of the Tinoidea (L2) is very distinct when compared with the other Lepidoptera, and can be explained by the relatively larger contribution of yellow and white $(+$ green) in its colour profile (much more "coleopteran" or "non-apoid hymenopteran").

The second dimension shows a distinct disparity between the Lepidoptera on the one hand and the Apoidea on the other. Again the Coleoptera and nonapoid Hymenoptera are inseparable and both very variable, spanning about the same space as the difference between Apoidea and Lepidoptera. This is accompanied by a shift in colour profile from white + red colours to blue colours + brown + green.

The third dimension (fig. 6-2) adds another 12 percent of summarized variation in frequencies. It features the outstanding contribution of orange in some insect profiles. With respect to insect groups it is accompanied by a slight shift from non-apoid Hymenoptera to Lepidoptera + some Coleoptera groups (C3, C10). All Apoidea are situated indifferently in the center of this axis, i.e. in this respect their profiles correspond more to the average insect profile.

\section{Colour vision in anthophilous insects}

The results of the $2 \times 2$ chi-square testing and the reciprocal averaging for the taxa of higher rank are compared with a survey of the literature on the colour vision of the anthophilous insects.

In 1793 Sprengel realized that floral colours attracted bees and other insects, where pollination was accomplished in the process of collecting food in the form of nectar and pollen. Ilse \& Vaidya (1956) stated that unspecialized anthophilous insects mainly visit yellow flowers. Valentine (1975) mentioned that yellow as a floral colour is adaptively neutral. Although these two statements seem to imply a contradiction, it will appear that both are correct.

\section{Colour vision in the Coleoptera}

Faegri \& Van der Pijl (1980) mentioned that the main colours of the beetlepollinated (cantharophilous) flowers are brown, drab and white. Müller (1881) mentioned that the Coleoptera prefer yellow and Harde (1979) recorded that the anthophilous Buprestidae prefer yellow flowers.

Schlegtendal (1934) found for Chrysomela fastuosa that it can distinguish 


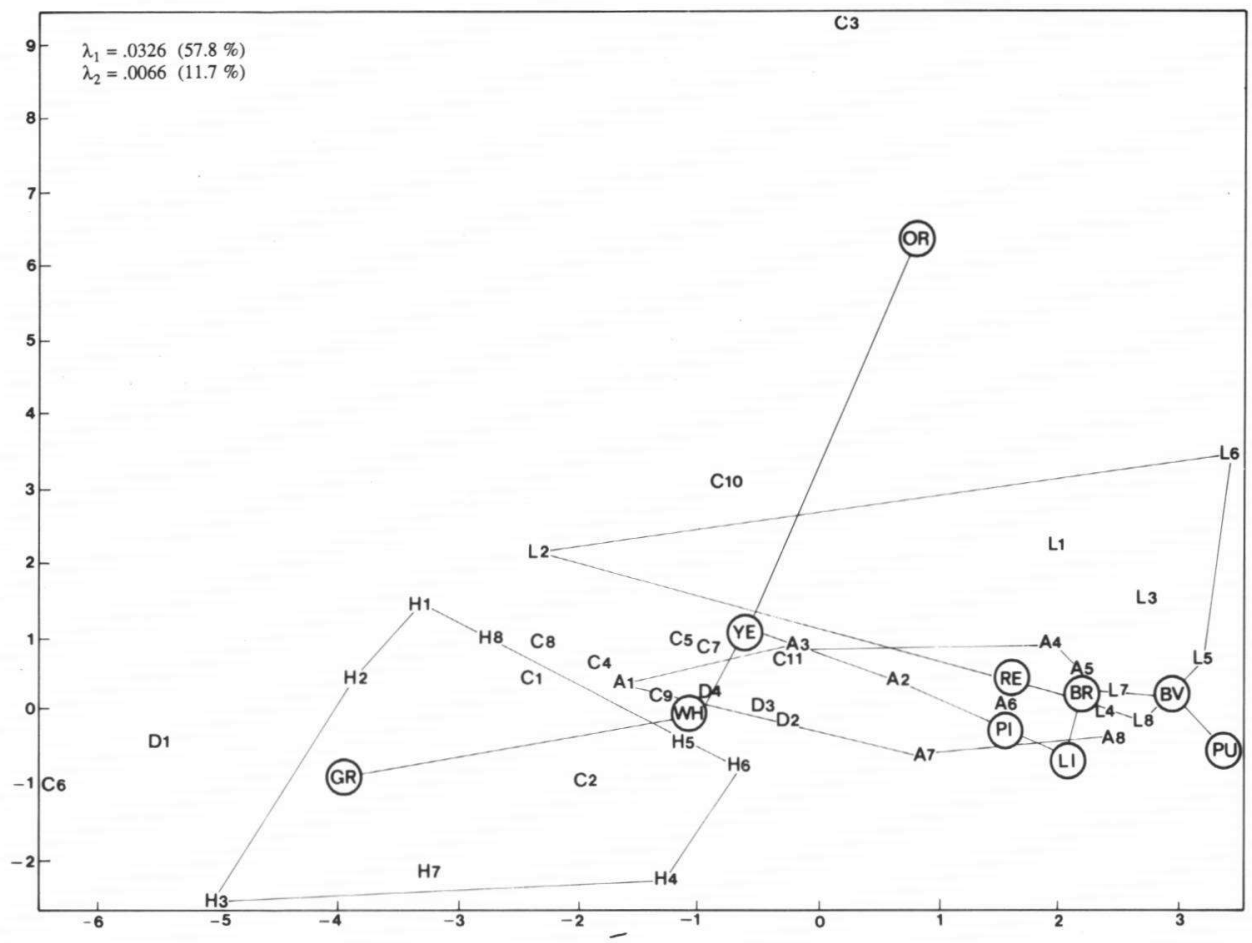

Fig. 6-2. Scatter diagram showing the ordination of rows (insect taxa) and columns (colours), as for the insect groups in table 6-9C, on the second pair of principal axes (dim 1, dim 3) resulting from reciprocal averaging. Scale measurement for both abcissa and ordinate is in weighted proportional deviations from the average frequency $(x 10)$. The figures in parentheses indicate the percentages of total inertia. Explanation: $\lambda 1=$ first eigen value; $\lambda 2=$ second eigen value. The figures in parentheses indicate the percentages of total inertia. COLEOPTERA: C1 - Staphyliniformia; C2 $=$ Scarabaeiformia; C3 = Buprestoidea; C4 = Elateriformia; C5 = Cantharoidea; C6 = Dermestoidea; C7 = Nitidulidae; C8 = Coccinellidae; C9 = Cerambycidae; $\mathrm{C} 10$ = Chrysomelidae; C11 = Curculionidae. DIPTERA: D1 = "Nematocera"; D2 = Orthorrhapha; D3 = Aschiza; D4 = Schizophora. NON-APOID HYMENOPTERA: H1 = Symphyta; H2 = Ichneumonoidea; H3 = Evanioidea; H4 - Scolioidea; H5 = Vespoidea; $\mathrm{H} 6=$ Sphecoidea; $\mathrm{H} 7=$ Chrysoidea; $\mathrm{H} 8=$ Formicoidea. APOIDEA: $\mathrm{A} 1$ = Colletidae; $\mathrm{A} 2$ = Halictidae; $\mathrm{A} 3$ = Andrenidae; $\mathrm{A} 4=$ Melittidae; $\mathrm{A} 5$ = Megachilidae; A6 - Anthophoridae; $\mathbf{A} 7$ = Apinae; A8 = Bombinae. LEPIDOPTERA: L1 = Tortricoidea; L2 = "Tineoidea" (in the sense of Knuth (1898a, 1899), compare section 4.3); L3 = Pyraloidea; L4 = "Rhopalocera" (in the sense of Knuth (1898a, 1899), compare section 4.3); L5 = Geometroidea; L6 - Bombycoidea; L7 - Sphingoidea; L8 = Noctuoidea. COLOURS: BR = brown; BV = blue-violet; GR - green; LI = lilac; OR = orange; PI = pink; $\mathrm{PU}=$ purple; $\mathrm{RE}=$ red; $\mathrm{WH}=$ white; $\mathrm{YE}=$ yellow.

yellow from blue, yellow from green, orange from blue, orange from green, and green from violet. It does not distinguish between blue and violet. This means that Chrysomela fastuosa distinguishes better in the longer wave-lengths (shorter than red) than in the shorter wavelengths. Geotrupes silvaticus can distinguish yellow from blue, yellow from green, orange from green, violet 
from blue, and violet from orange. It does not distinguish between green and violet. This means that Geotrupes silvaticus can distinguish the same colours as Chrysomela fastuosa, but has a somewhat better sensitivity in the wave-lengths a little shorter than blue.

Goldsmith \& Bernard (1974) registered that the sensitivity maxima of the adult Dineutes are at ca. $380 \mathrm{~nm}$ (longer wave-length of ultraviolet) and $520 \mathrm{~nm}$ (green), and of Carabus at $348 \mathrm{~nm}$ (ultraviolet), $430 \mathrm{~nm}$ (violet), $500 \mathrm{~nm}$ (longer wave-length of blue) and (possibly) $620 \mathrm{~nm}$ (orange). Savidge (1976) considered the Coleoptera being red-blind (except for the glow-worms) and towards the short wave-lengths they can not see further than blue. This is in accordance with the results of Schlegtendal (1934), may be except to some degree for Geotrupes silvaticus which may have its vision extended into violet. This beetle, however, is not anthophilous (see section 4.1). Goldsmith \& Bernard (1974) found at any rate some Coleoptera having sensitivity maxima in the ultraviolet. Their examples, however, do not concern anthophilous beetles. There is no evidence from the literature that the Coleoptera can see red.

From the analysis it appears that the Coleoptera visit less yellow, red and red-mixed and blue and blue-mixed colours than do the Apoidea and Lepidoptera (tables 6-9D and 6-9D-1). This is also expressed in figs. 6-1 and 2. In addition it appears that the Coleoptera visit more white than do the Apoidea and Lepidoptera (table 6-9D-1) and this is partly expressed in fig. 6-1, and somewhat weakened in fig. 6-2. Evans (1975) mentioned that beetles have not yet been shown to see ultra-violet.

Drab and brown colours (Faegri \& Van der Pijl, 1980) appear not to be interdependent with the Coleoptera. This may be due to the fact that in central Europe the number of the more obligatory beetle-pollinated flowers is too low to get a complete survey. Faegri \& Van der Pijl (1980) mention in this respect that typical beetle-pollination (cantharophily) is rare in the European, extratropical flora, and prevailing concepts in pollination ecology still depend largely on the European tradition. Beetle-pollination is as characteristic of the tropical zone as bee-pollination is of the (semi-arid) temperate regions.

\section{Colour vision in the Diptera}

Faegri \& Van der Pijl (1980) noted that the main colours of the fly-pollinated flowers are brown and drab. Thus, they restrict the fly-pollinated flowers (myiophily) to the syndrome of sapromyiophily. Müller (1881), see also Kugler (1951), stated that the Diptera with poor flower constancy prefer colours of the white-yellow-green group above those from the blue-violet-purple group, and that the Diptera with more developed flower constancy do so less (see also Parmenter, 1957). Knoll (1921 and 1926a) and Kugler (1951) mentioned that Bombylius fuliginosus is associated with blue-violet flowers. In the experiments 
of Knoll (1921) it appeared that Bombylius fuliginosus ignored scarlet flowers. This may mean that it is red-blind.

Eristalis tenax prefers yellow (Ilse, 1949; Kugler,1951) above blue and white and mainly visits yellow and white flowers (Kugler, 1951, 1952). It can distinguish blue and probably also purple and violet (Kugler, 1950a) and to some degree can be trained on visiting blue; it is red-blind (Kugler, 1951). Kay (1978) reported that Eristalis spp. show a very strong preference for yellow in colour-polymorphic (white and yellow) populations of Raphanus raphanistrum. Calliphora, hatched in captivity, prefered yellow above brown-purple if sweet scents were simultaneously present, and brown-purple above yellow in case of carrion-scents. The same was found for Sarcophaga (Kugler, 1950a, 1956). The electrophysiological research of Autrum \& Stumpf (1953) demonstrated that the vision in Calliphora erythrocephala ranges from $400 \mathrm{~nm}$ (short wave-length in violet) to $690 \mathrm{~nm}$ (intermediate wave-length in red) with sensitivity maxima at $540 \mathrm{~nm}$ (green) and $630 \mathrm{~nm}$ (orange/red). It has to be mentioned that the discrimination in the range of red (630-690 $\mathrm{nm}$ ) is very faint. Goldsmith \& Bernard (1974) found for the adult Calliphora sensitivity maxima at $470 \mathrm{~nm}$ (violet), $490 \mathrm{~nm}$ (blue), 510 and $520 \mathrm{~nm}$ (green), and for Musca at $360 \mathrm{~nm}$ (ultraviolet), 464 and $480 \mathrm{~nm}$ (blue). Schlegtendal (1934) found that Fannia canicularis can distinguish yellow from blue, yellow from green, orange from blue, orange from green, violet from green, and violet from orange. It does not distinguish violet from blue. Wasmann (1918) found that it was red-blind. Kugler $(1951,1952)$ pointed out that Lucilia prefers yellow above blue and white and mainly visits yellow and white flowers. It can, however, to some degree be trained on blue. Sick (1967) found that Delia brassicae prefers yellow above white and blue.

Savidge (1976) considered the Diptera to be red-blind. Red-blindness was indeed found in a number of species, but some can distinguish red colours, albeit very faintly. Towards the shorter wave-lengths some Diptera can see ultraviolet (Musca), but many will not.

In the quantitative analysis (tables 6-9D and 6-9D-1 and 2) it appears that Diptera visit white less and yellow, pink, purple, lilac and blue-violet more than do the Coleoptera; white and lilac more (possibly mainly due to the white component) and yellow, red, pink, brown, purple and blue-violet less than do the Apoidea; and orange, red, pink, brown, purple, lilac and blue-violet less than, and white and yelow about equally as much as do the Lepidoptera. These results are to some degree (based on the qualitative analysis) also exposed in figs. 6-1 and 2, and generally agree with the survey of colour-vision in the Diptera, compared with that in the other insect groups.

\section{Colour vision in the non-apoid Hymenoptera}

Faegri \& Van der Pijl (1980) indicated only brown as a typical colour of 
wasp-pollinated flowers. Müller (1881), see also Kugler (1951), mentioned that the non-apoid Hymenoptera mainly visit flowers of the white-yellowgreen group with a preference for yellow. Kevan $(1972,1973)$ concluded that the non-apoid Hymenoptera (Parasitica) visit white flowers (with open nectar). Goldsmith Bernard (1974) found in adult Paravespula sensitivity maxima at $374 \mathrm{~nm}$ (relatively long wave-length of ultraviolet), $455 \mathrm{~nm}$ (short wave-length in blue) and $530 \mathrm{~nm}$ (green). In contrast to Molitor (1936), Schremmer (1941) found that Vespa rufa is red-blind. Molitor (1937a) found red-blindness in the Sphecidae. Menzel (1971) concluded in his research on colour vision of Paravespula germanica that wasps can see ultra violet and more colours up to 630 $\mathrm{nm}$. Red with longer wave-lengths than $630 \mathrm{~nm}$ is not seen.

In the quantitative analysis (table 6-9D) it appears that the non-apoid Hymenoptera visit white flowers most of all insect groups included in this study and yellow and blue and blue-mixed colours less than do the Coleoptera and Diptera (tables 6-9D-1 and 2). In comparison with the Apoidea and Lepidoptera they visit less real colours (table 6-9D-3). These tendencies are also exposed in figs. 6-1 and 2.

In the central European flora it is unlikely that brown (Faegri \& Van der Pijl, 1980) can be considered as typical for wasp-pollinated flowers: it is based on too few observations. It can be concluded that the "typical" wasp-pollinated flowers, at any rate in the central European area, belong to the non-specialized entomophilous pollination type, with white as the main attractive colour. Further research on wasps and types as Scrophularia nodosa (cf. Schremmer, 1959; Shaw, 1962) should be done.

\section{Colour vision in the Apoidea}

Faegri \& Van der Pijl (1980) recorded white, yellow and blue as typical colours of bee-pollinated (melittophilous) flowers. Müller (1881), see also Kugler (1951), noted that the short-tongued Apoidea prefer colours of the whiteyellow-green group, and longer-tongued Apoidea those of the blue-violetpurple group.

Most of the research on the colour vision of the Apoidea has been carried out on the honey-bee Apis mellifera. Von Frisch (1914) found that Apis mellifera can be trained on blue and also distinguishes yellow, blue-green and ultraviolet (Kühn \& Pohl, 1924; Kühn, 1927; Kugler, 1951). After the records of Knuth (1899) Kugler (1951) found that the flowers visited by Apis mellifera for $61 \%$ belong to the white-yellow-green group and for $39 \%$ to the blue-violet-purple group. This means that the statement of Müller (1881) that long-tongued Apoidea prefer colours of the blue-violet-purple group is not valid for Apis mellifera. The honey-bee, indeed, forms an exception within the higher Apoidea. As pointed out earlier (chapter 5) the hibernating colonies need many flower visits to build sufficient supplies. It is very well possible that these 
necessary supplies could not built up satisfactorily when the honey-bee should be too much restricted in colour preference to the shorter wave-lengths (blueviolet-purple group). Kühn \& Pohl (1924) found that Apis mellifera is red-blind (see also Kugler, 1951 and 1971a), as Molitor (1937, 1937a) did for some solitary bees: Prosopis, species of Colletes, Halictus and Osmia (while Panurgus and Tetralonia are not). Kühn (1927) pointed out that the colour vision of honeybees ranges from 313 to $650 \mathrm{~nm}$, with the following ranges distinguished: 313$400 \mathrm{~nm}$ (ultraviolet), 480-500 $\mathrm{nm}$ (blue-green) and 500-650 nm (green, yellow). Daumer $(1956,1958)$ found that Apis mellifera can see in the yellow range orange $(616 \mathrm{~nm})$, yellow $(588 \mathrm{~nm})$ and green $(530 \mathrm{~nm})$; in the blue-green range green $(530 \mathrm{~nm})$ and blue $(474 \mathrm{~nm})$; in the blue range blue $(474 \mathrm{~nm})$ and blue-violet $(440 \mathrm{~nm})$; and in the ultraviolet range 375 and $360 \mathrm{~nm}$. Discrimination in the blue range is better than in the yellow range. Pedersen \& Todd (1949) and Kauffeld \& Sorensen (1971) found that Apis mellifera prefers purple flowered cultivars in colour-polymorphic populations of Medicago sativa. Leleji (1973) found that Apis mellifera, searching for pollen, visited white flowers more often than purple flowers in colour-polymorphic populations of Vigna sinensis. Also Kugler (1929) found that the white-yellow-green group is attractive for honey-bees in Bryonia dioica. Goldsmith \& Bernard (1974) found sensitivity maxima for adult female Apis mellifera at $340(345) \mathrm{nm}$ (ultraviolet), $430 \mathrm{~nm}$ (violet), $460 \mathrm{~nm}$ (blue) and $530 \mathrm{~nm}$ (green).

The colour vision of the Bombinae is much like that of Apis mellifera (Kugler, 1943a). They can distinguish yellow, green and blue-violet (Kugler, 1930, $1943 \mathrm{a}, 1950,1951)$ and within the latter they perform best. They prefer purple, and to a lesser extent yellow (Kugler, 1931, 1932, 1935, 1943). Also Werth (1949) and Kevan (1972) mentioned that flowers reflecting blue, receive proportionally greater attention from bumblebees than from other insects. Leleji (1973) reported that bumblebees, apparently sucking nectar, in colourpolymorphic populations of Vigna sinensis visit purple flowers more often than white ones. In colour-polymorphic populations of Raphanus raphanistrum Kay (1978) found that Bombus spp. show a preference for white over yellow. Kugler (1951) mentioned that Bombus as well as Apis mellifera are red-blind (see also Molitor, 1937). Vuyk (1922) mentioned that purple seems to be very attractive to Bombus. Knoll (1935) found the same for Prosopis. For the Megachilidae Goplen \& Brandt (1975) found that Megachile pacifica prefers purple flowers in colour-polymorphic populations of Medicago sativa. Kugler (1929) mentioned that Andrena florea is attracted by colours of the white-yellow-green group in Bryonia dioica.

In the quantitative analysis (table 6-9D) it appears that the Apoidea visit less white and more yellow, red and blue and blue-mixed colours than do the Coleoptera, Diptera and non-apoid Hymenoptera (tables 6-9D-1 to 3). These tendencies are also illustrated in figs. 6-1 and 2. In this respect it has to be men- 
tioned that the relatively high frequency of visits to red flowers (table 6-9D) is not caused by attraction of the wave-lengths of red, but, more probably by the reflection of ultraviolet, since the Apoidea can be considered red-blind. The Apoidea visit red and pink less than do the Lepidoptera (table 6-9D-4 and figs 6-1 and 2).

\section{Colour vision in the Lepidoptera}

Faegri \& Van der Pijl (1980) indicated yellow, blue and red as typical colours of butterfly-pollinated flowers, and drab and white as typical for mothpollinated flowers. Müller (1881), see also Kugler (1951), found a slight preference of Lepidoptera for flowers belonging to the blue-violet-purple group over those belonging to the white-yellow-green group. Ilse \& Vaidya (1956) concluded that some apomorphous butterflies are associated with blue flowers and Ilse (1928) and Tinbergen et al. (1942) stated that the less advanced Lepidoptera mainly are attracted by yellow flowers. Ilse (1928) found that many higher Lepidoptera can see red and orange, yellow and yellow-green, and blue-violet-purple. Proctor \& Yeo (1973) noted that in the Mediterranean region the scarlet flowered Lychnis chalcedonica is visited by butterflies, as are many scarlet flowers in subtropical and tropical regions. Goldsmith \& Bernard (1974) also reported that some apomorphous Lepdioptera have red-sensitive vision. Kugler (1951) found that some butterflies react spontaneously to red. Vogel (1972) reported that Levin (1969) found that butterflies prefer violet over white in Phlox flowers. The Noctuidae Amphipyra pyramidea, Orthosia lota, $O$. circellaris, Orrhodia vaccinii and Scopellosoma satellitia can distinguish yellow from blue, and orange from blue. They do not distinguish between yellow and green, orange and green, and violet and blue. The sensitivity maxima lie in yellow and blue (Schlegtendal, 1934). Dufay (1961) found that Noctuidae prefer short wave-lengths and Knoll (1920-1926) reported that they are not interested in ultraviolet.

For the Sphingidae Deilephia livornica and Macroglossum stellatarum Knoll (1925) found that they can distinguish blue-violet and purple from yellow and also white. The latter was also found by Porsch (1904). Kugler (1971) trained Sphingidae on the white-flowered Datura (reflecting white and ultraviolet, but because the flowers open at sunset the latter colour will play only a minor role in attraction) and found that between the visits to the flowers they also visit other white objects (e.g. Kugler's shirt). Knoll (1927) also found that the Sphingidae are highly sensitive for the optical signal "white'. Kugler (1951) found that Macroglossum is red-blind. Goldsmith \& Bernard (1974) demonstrated the following sensitivity maxima: for Manduca at ca. $360 \mathrm{~nm}$ (ultraviolet), ca. $450 \mathrm{~nm}$ (violet-blue), ca. $500 \mathrm{~nm}$ (blue-green) and ca. $550 \mathrm{~nm}$ (green); for Deilephia at $350 \mathrm{~nm}$ (ultraviolet), ca $450 \mathrm{~nm}$ (violet-blue) and 545 $\mathrm{nm}$ (green); for Macroglossum at $348 \mathrm{~nm}$ (ultraviolet), $430 \mathrm{~nm}$ (violet), $500 \mathrm{~nm}$ 
(blue-green) and (?) $620 \mathrm{~nm}$ (orange). Baker (1961) found for sphingophilous flowers not only white to creamy colours, but also pale yellow (Oenothera hooker) and pink (Amaryllis belladonna).

For the Geometridae Schlegtendal (1934) found that Operophtera (Cheimatobia) brumata distinguishes the same colours as the Noctuidae. Besides the colours that are not distinguished by the Noctuidae, Operophtera (Cheimatobia) brumata also does not distinguish between red-pink and blue and red-pink and blueviolet.

Ilse (1928) found within the Papilionoidea two groups concerning colour preferences. Aglais urticae, Nymphalis polychlorus and $N$. io are strongly attracted by yellow and blue; Pieris brassicae, Gonepteryx rhamni and Papilio machaon show a strong preference for blue, violet and purple. Gonepteryx rhamni and Papilio machaon also made visits to red, orange and yellow. Green and blue-green were ignored by all species. Ilse (1941) demonstrated that Pieris brassicae can distinguish at least three groups of colours: red to yellow, green to blue-green, and blue to violet. It was stated that these results apply to the Pieridae and Papilionidae in general. Bennet (1883) found that species of Pieris visited many purple, violet and white flowers, but no yellow ones; Aglais urticae did show some preference for yellow (however, there is question of only one set of observations); and Vanessa cardui invariably visited only violet and purple flowers. Maniola jurtina visited yellow, pink and purple flowers. Kay (1978) mentioned that Pieris spp. show a very strong preference for yellow in colour-polymorphic populations of Raphanus raphanistrum (white and yellow). Dronamraju (1960) observed that in pink to oranged flowered populations of Lantana camara, Precis almana (Nymphalidae) prefer orange and Papilio demoleus (Papilionidae), Catopsila pyranthe (Pieridae) and Baoris mathias (Hesperiidae) prefer pink. Kugler (1971a) reported that Pieridae and Papilionidae can see red. In Nymphalidae (Heliconiinae) Struwe (1972) found in three species (Heliconius erato, $H$. numata and $H$. sara), measuring the range from 310 to $650 \mathrm{~nm}$, sensitivity maxima at $370 \mathrm{~nm}, 470 \mathrm{~nm}$ and $550-570 \mathrm{~nm}$. In Heliconius numata the sensitivity of single photoreceptor cells is maximal at $390-410 \mathrm{~nm}, 450-470 \mathrm{~nm}$ and $530-550 \mathrm{~nm}$ (Struwe, 1972a). Swihart (1971) mentioned that Heliconius charitonius spontaneously prefers orange, and can discriminate finely in the yellow portion of the spectrum. It can be conditioned to visit colours in the blue, green, orange and red range. In multi-coloured conditioning magenta, reflecting both blue and red components appears very attractive.

In the quantitative analysis (table 6-9D) it appears that the Lepidoptera visit white, orange, red, pink, purple and lilac more than the Apoidea and yellow and green less, and blue-violet about equally as much (table 6-9D-4). In the reciprocal averaging these tendencies are also illustrated (figs. 6-1 and 2). Particularly the high frequencies of visits to red and red-mixed colours are partly caused by direct attraction by the red wave-lengths. 
Ultraviolet is visible for many insects (see above) and it has to be considered a distinct colour in attracting anthophilous insects to flowers (Kevan, 1978). Kugler $(1963,1966,1971$ a) found that ultraviolet reflection is more common in specialized flower-pollinator relationships. In dish- to bowl- and bell- to funnel-shaped blossoms he found $50 \%$ of the species reflecting ultraviolet, in gullet- and flag-shaped blossoms (almost exclusively pollinated by Apoidea) $70 \%$ and in butterfly-pollinated flowers $88 \%$.

Also the number of ultraviolet reflecting patches on the petals increases with the specialization of the pollination system, as does the number of nectar guides in the spectrum visible to the human eye (Sprengel, 1793). Jones \& Buchmann (1974) also found that ultraviolet patterns serve as definitive orientation-cues for visiting bees (Clements \& Long, 1923; Knoll, 1926a; Troll, 1930; Manning, 1956). Ultraviolet-markers also may serve (as those of other colours) to break up an otherwise uniform colour pattern, making it more conspicuous for bees. Hertz $(1929,1930,1931,1935)$ found that the degree of dissection of the flower (-pattern) is very important in the flowerrecognition of bees.

Kugler (1972) noted, basing himself on observations of Cammerloher (1931) and of Van der Pijl (1954) that Xylocopa-pollinated flowers often have pale, dull colours; and here ultraviolet will be the main attractive colour.

\section{Retrospect on the insect groups and floral colours}

The records of colour-vision in the various insect groups are summarized in fig. 6-3. After the results of both statistical analyses for the insect groups of higher taxonomical rank, it can be concluded that with the increase of specialization of the pollination, more colours of the blue-violet-purple group occur in the flowers (the same can be stated for ultraviolet (see above) and in some cases of butterfly-pollinated flowers also more red and red-mixed colours). In the non-specialized entomophilous flowers yellow and white prevail.

\subsubsection{The interdependences among floral colours and visiting taxa of lower rank within the insect groups}

For the taxa of lower rank within the various insect groups separate reciprocal averaging analyses were carried out.

\section{Coleoptera}

The results of the analysis are illustrated in fig. 6-4, displaying 61 percent of the variation among frequencies. Knowing that there is no evidence from 


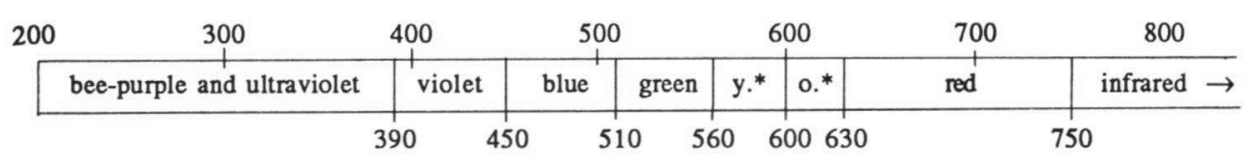

y.* $=$ yellow

$0 .{ }^{*}=$ orange

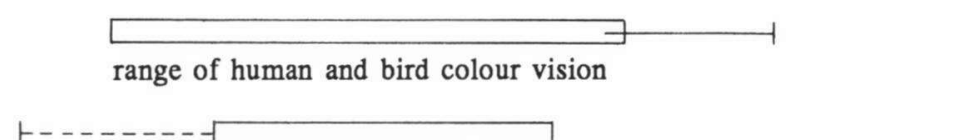

range of colour vision in Coleoptera

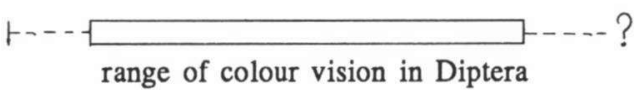

range of colour vision in Apoidea

range of colour vision in non-Apoid Hymenoptera

range of colour vision in some Lepidoptera

Fig. 6-3. Ranges of colour vision in human, birds and of the various insect groups, after Savidge (1976), extended with data from literature treated in the text.

literature that the Coleoptera can see red, and most probably are red-blind (Savidge, 1976), it can be stated that green, orange, brown and blue-violet are the most abberant and thereby the most discriminating colours in attracting the various taxa of the Coleoptera. The other colours hardly discriminate. Among the Coleoptera the Buprestoidea, Scarabaeiformia, Dermestoidea and to some degree the Chrysomelidae, are abberant. Two main tendencies in profile shift are displayed in fig. 6-4. A shift in colours from orange + purple + blue-violet to the others, associated with a shift in Coleoptera from Staphyliniformia + Nitidulidae +Chrysomelidae + Curculionidae + Buprestoidea to Dermestoidea + Scarabaeiformia. Another trend is visible in the shift from the colours blue-violet, through brown to red, as in green to red, accompanied by a shift from Staphyliniformia + Dermestoidea, through all other Coleoptera minus Buprestoidea, to Buprestoidea.

In spite of the ability of the non-anthophilous scarabaeid Geotrupes silvaticus to distinguish blue from violet (Schlegtendal, 1934), preference for blue-violet is not expressed in the anthophilous Scarabaeiformia. It is possible that the anthophilous Scarabaeiformia, more than other Coleoptera, are guided by odours; their basic lamellicorn antennae are suggestive of special olfactorial powers (Crowson, 1954): indeed Warnke (1934) found up to tens of thousands olfactorial sense organs on the lamellae. The possible association between the 


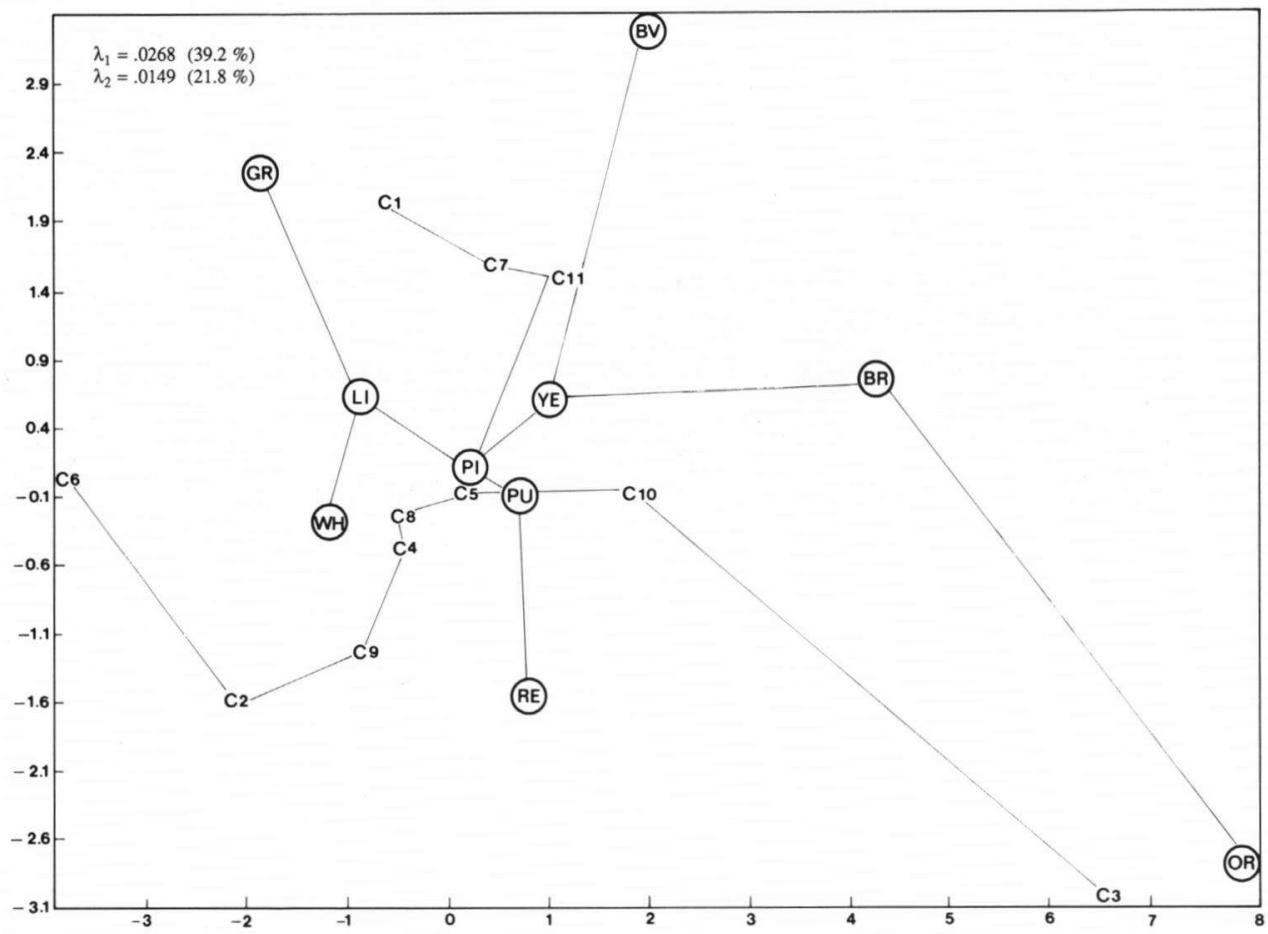

Fig. 6-4. Scatter diagram showing the ordination of rows (taxa of Coleoptera) and columns (colours), as for the insect groups in table 6-9C, on the first pair of principal axes (dim 1, dim 2) resulting from reciprocal averaging. Scale of measurement for both abcissa and ordinate is in weighted proportional deviations from the average frequency $(x 10)$. Explanation: $\lambda 1=$ first eigen value; $\lambda 2=$ second eigen value. The figures in parentheses indicate the percentages of total inertia. COLEOPTERA: C1 = Staphyliniformia; C2 = Scarabaeiformia; C3 = Buprestoidea; C4 = Elateriformia; C5 = Cantharoidea; C6 = Dermestoidea; C7 = Nitidulidae; C8 - Coccinellidae; C9 = Cerambycidae; C10 = Chrysomelidae; C11 = Curculionidae. COLOURS: BR = brown; BV = blue-violet; GR = green; LI = lilac; OR = orange; $\mathrm{PI}=$ pink; $\mathrm{PU}=$ purple; $\mathrm{RE}=$ red; $\mathrm{WH}=$ white; $\mathrm{YE}=$ yellow.

Chrysomelidae and blue-violet is supported by the results of Schlegtendal (1934) on the colour vision in Chrysomela fastuosa.

Comparing these results with the phylogenetic relationships within the Coleoptera-Polyphaga (fig. 5-6) it appears that the Scarabaeiformia showing some association with green and white are faintly plesiomorphous, while the Chrysomelidae belonging to the more apomorphous Cucujiformia show somewhat more association with short wave-lengths. The rather apomorphous elateriform Buprestoidea show some association with orange in their colour profile. The comparatively plesiomorphous Dermestoidea do so with green. There is some evidence that within the Coleoptera the more plesiomorphous taxa are more attracted by the colours of intermediate wave-lengths, while the 
more apomorphous taxa are more attracted by short wave-lengths. Coleoptera in general are attracted by yellow floral colours and to some degree also by white.

\section{Diptera}

The results of the analysis are illustrated in fig. 6-5, displaying 97 percent of the variation among frequencies, thus in geometrical terms give an almost complete picture. As in the Coleoptera we have to keep in mind that the Diptera can be considered red-blind (may be only Schizophora-Muscidae have sensitivities for the shorter wave-lengths in red, see Autrum \& Stumpf (1953) for Calliphora erythrocephala). It appears that white, yellow and orange attract Diptera in general, but do not discriminate in attracting taxa of lower rank.

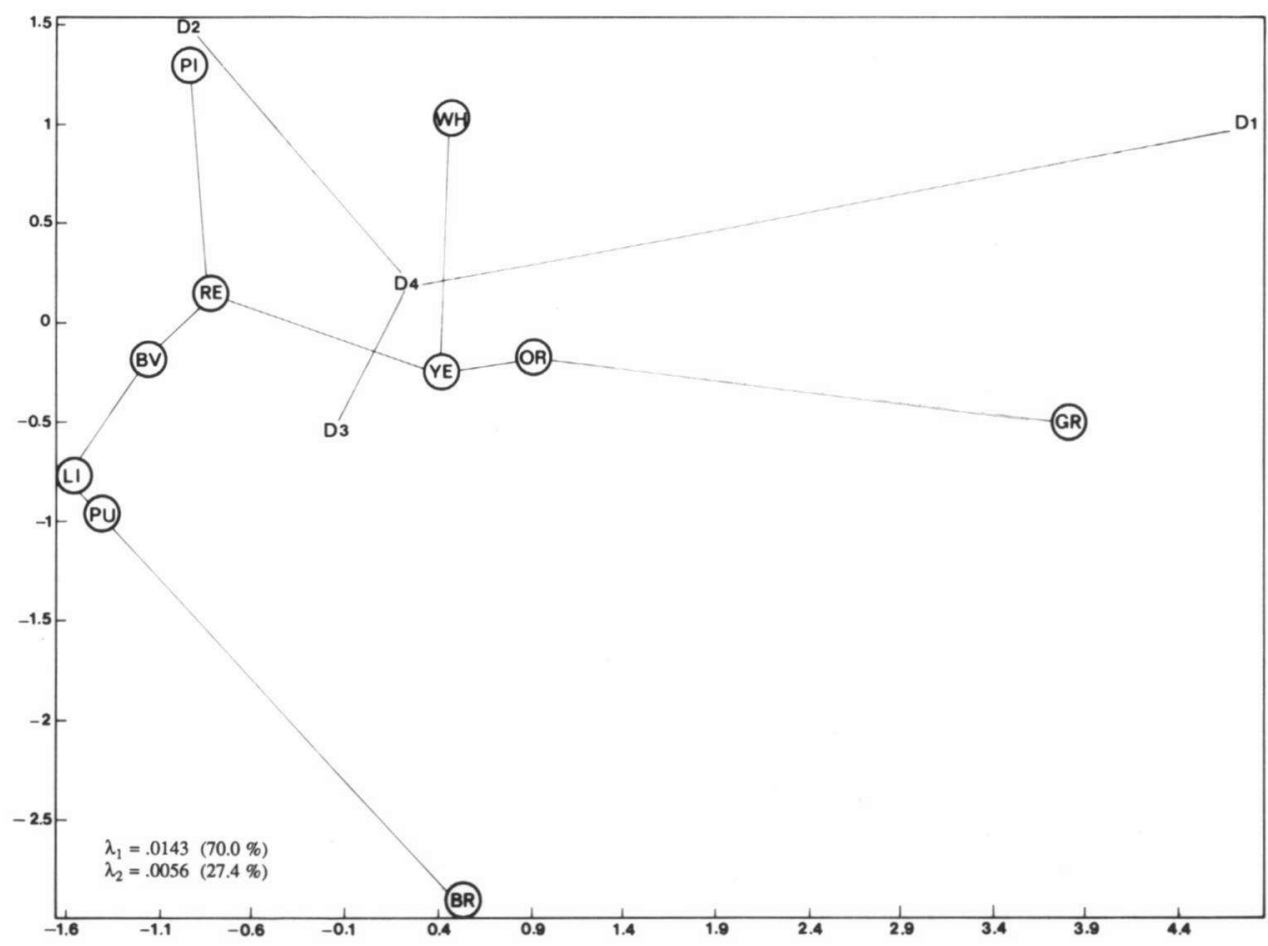

Fig. 6-5. Scatter diagram showing the ordination of rows (taxa of Diptera) and columns (colours), as for the insect groups in table 6-9C, on the first pair of principal axes (dim1, dim2) resulting from reciprocal averaging. Scale of measurement for both abcissa and ordinate is in weighted proportional deviations from the average frequency $(x 10)$. Explanation: $\lambda 1=$ first eigen value; $\lambda_{2}$ - second eigen value. The figures in parentheses indicate the percentages of total inertia. DIPTERA: D1 = "Nematocera"; D2 = Orthorrhapha; D3 = Aschiza; D4 = Schizophora. COLOURS: BR = brown; BV = blue-violet; GR = green; LI = lilac; OR orange; $\mathrm{PI}=$ pink; $\mathrm{PU}=$ purple; $\mathrm{RE}=$ red; $\mathrm{WH}=$ white; $\mathrm{YE}=$ yellow. 
Geometrically we can focus on several shifts in insect profiles, each associated with a shift in colour profiles. First the largest space is spanned by the "Nematocera" versus Orthorrhapha. This shift is accompanied by a shift from green, through white, yellow, orange towards the red and blue colours (caused by the fact that many of the observations included concern flower visits of the Bombyliidae). Perpendicular to this largest space is the small space spanned by "Nematocera" + Orthorrhapha, through Aschiza to Schizophora, associated with parallel shifts in white, through yellow/orange to brown and pink, through red to blue colours. hese results are in accordance with the records in the colour vision of the Diptera.

Comparing these results with the phylogenetic relatioships within the Diptera (fig. 5-19) it appears that the "Nematocera" (in the analysis "Polyneura" + "Oligoneura") are highly associated with green and because of their plesiomorphy within the Diptera, this may be considered a plesiomorphous condition. For the Brachycera (Orthorrhapha + Cyclorrhapha) it can be stated that they are more sensitive to the other colours (inclusive white) than the other Diptera, and this can be considered an apomorphous condition within the Diptera. Within the Brachycera, Aschiza and Schizophora the taxa chosen are too highly ranked for statements on the state of advancement of colour preferences.

\section{Non-apoid Hymenoptera}

The results of the analysis are illustrated in fig. 6-6, displaying 77 percent of the variation among frequencies. Before interpreting the distribution of the taxa and the colours in the graph, it has to be kept in mind that the non-apoid Hymenoptera are also red blind. There are two most prominent aspects of the insect and colour profile spaces spanned in fig. 6-6. First, the shift from orange, through green and yellow ( + brown) to the other colours, associated with a shift from Symphyta + Formicoidea + Ichneumonoidea to Evanioidea + Scolioidea, through the others (Vespoidea + Sphecoidea + Chrysoidea). Second, a shift from brown, through the red colours to white, accompanied by a shift from Vespoidea, through Symphyta + Formicoidea + Sphecoidea and Ichneumonoidea + Chrysoidea + Scolioidea to Evanioidea. The latter is in contradiction to Kevan (1972 and 1973) that white is the least discriminating colour among non-apoid Hymenoptera.

Comparing these results with the phylogenetic relationships in the nonapoid Hymenoptera (fig. 5-8) it appears that the Symphyta, the most plesiomorphous non-apoid Hymenoptera, are mainly associated with green and yellow. So are the Ichneumonoidea, within the Apocrita, belonging to the plesiomorphous sister-group of the Aculeata s. lat. (fig. 5-9). The Formicoidea 


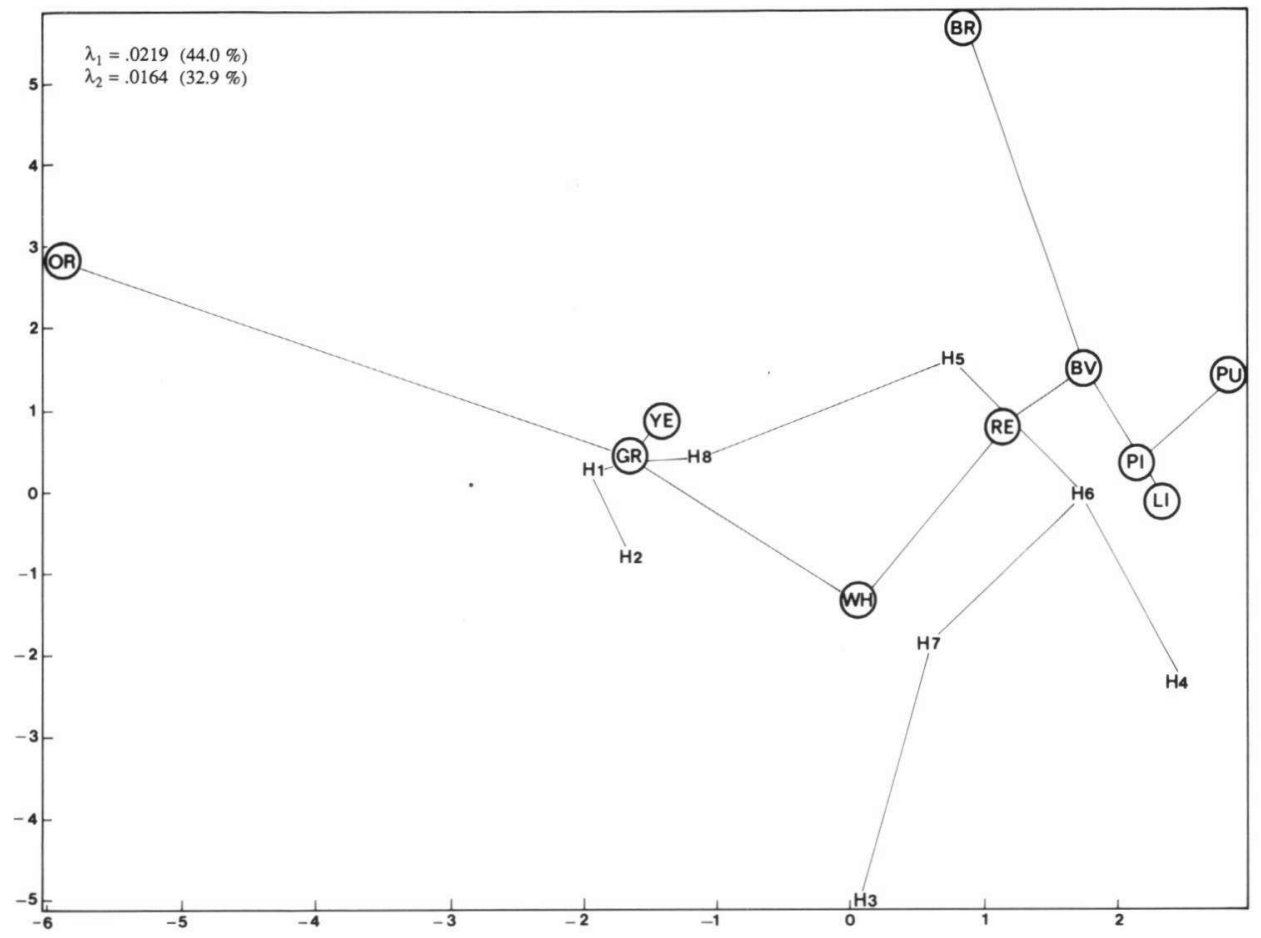

Fig. 6-6. Scatter diagram showing the ordination of rows (taxa of non-apoid Hymenoptera) and columns (colours), as for the insect groups in table 6-9C, on the first pair of principal axes (dim1, dim2) resulting from reciprocal averaging. Scale of measurement for both abcissa and ordinate is in weighted proportional deviations from the average frequency (x10). Explanation: $\lambda 1$ - first eigen value; $\lambda 2$ = second eigen value. The figures in parentheses indicate the percentages of total inertia. NON-APOID HYMENOPTERA: H1 $=$ Symphyta; $\mathrm{H} 2=$ Ichneumonoidea; H3 = Evanioidea; H4 = Scolioidea; H5 = Vespoidea; H6 - Sphecoidea; H7 = Chrysoidea; H8 = Formicoidea. COLOURS: BR = brown; BV = blue-violet; GR = green; $\mathrm{LI}=$ lilac; $\mathrm{OR}=$ orange; $\mathrm{PI}=$ pink; $\mathrm{PU}=$ purple; $\mathrm{RE}=$ red; $\mathrm{WH}=$ white; $\mathrm{YE}$ = yellow.

are rather apomorphous within the Aculeata s. lat. (see fig. 5-11), but they occupy a special position, because they hardly developed obligatory anthophily. It can be stated that in the non-apoid Hymenoptera the more obligatory preference for orange, green and yellow is a plesiomorphous condition. The Scolioidea, Sphecoidea and to some degree, perhaps the Vespoidea, all are apomorphous non-apoid Hymenoptera which all, particularly the Specoidea, have developed preferences for colours of the shorter wave-lengths (blue-violet and blue-mixed colours), which can be considered an apomorphous condition. 


\section{Apoidea}

The results of the analysis are illustrated in fig. 6-7, displaying 87 percent of the variation among frequencies. As in the preceeding insect groups, it has to be kept in mind that the Apoidea probably are red-blind. Within the Apoidea two trends are visible. The first, a shift from Colletidae to Megachilidae + Bombinae + Melittidae, through Andrenidae and Halictidae + Apinae. The second, and more or less independent (= perpendicular) from the first, the shifts between Apinae from Colletidae, Andrenidae, Halictidae, Anthophoridae and Bombinae versus Melittidae. These shifts are associated with shifts in colour profiles. The first from green, through white and yellow, red and blue-violet to purple. The second, white versus orange and

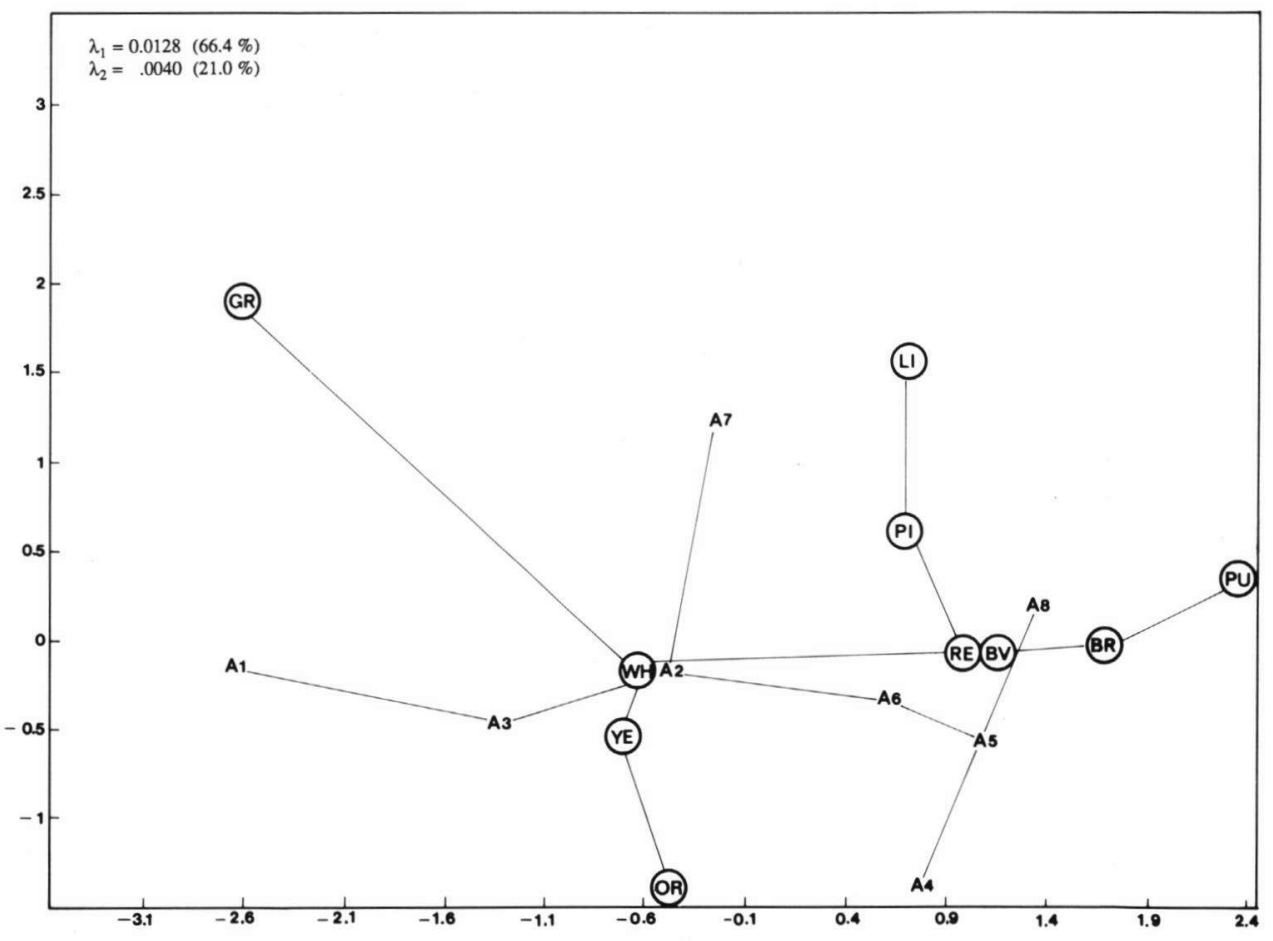

Fig. 6-7. Scatter diagram showing the ordination of rows (taxa of Apoidea) and columns (colours), as for the insect groups in table 6-9C, on the first pair of principal axes (dim1, dim2) resulting from reciprocal averaging. Scale of measurement for both abcissa and ordinate is in weighted proportional deviations from the average frequency $(x 10)$. Explanation: $\lambda 1=$ first eigen value; $\lambda 2=$ second eigen value. The figures in parentheses indicate the percentages of total inertia. APOIDEA: A1 = Colletidae; $\mathrm{A} 2=$ Halictidae; $\mathrm{A} 3$ = Andrenidae; $\mathrm{A} 4=$ Melittidae; A5 = Megachilidae; A6 = Anthophoridae; A7 = Apinae; A8 = Bombinae. COLOURS: $\mathrm{BR}=$ brown; $\mathrm{BV}=$ blue-violet; $\mathrm{GR}$ = green; $\mathrm{LI}=$ lilac; $\mathrm{OR}$ = orange; $\mathrm{PI}$ = pink; $\mathrm{PU}=$ purple; $\mathrm{RE}$ = red; $\mathrm{WH}=$ white; $\mathrm{YE}=$ yellow. 
lilac, through pink versus red and blue-violet. The observation by Kugler (1929) that Andrena florea is attracted to the colours of the white-yellow-green group in Bryonia dioica is in agreement with this picture, as is the observation of Goplen \& Brandt (1975) that Megachile pacifica prefers purple flowers in colour-polymorphic monocultures of Medicago sativa. The Apinae are situated somewhat in between.

Comparing these results with the phylogenetic relationships within the Apoidea (fig. 5-15), we see that the most plesiomorphous Colletidae show green as relatively prominent in their profile. The fairly plesiomorphous Halictidae and Andrenidae show a shift towards yellow and white. The more apomorphous Melittidae, Megachilidae, Anthophoridae and Bombinae show an increasing association with blue-violet and blue-mixed colours. This means that a preference for yellow and white, within the Apoidea can be considered a plesiomorphous condition and the preference for blue-violet and blue-mixed colours an apomorphous one. The phylogenetically apomorphous Apinae behave aberrantly, and remain somewhat in between. This possibly is due to the enormous amounts of food they have to collect (see above).

\section{Lepidoptera}

The results of the analysis are illustrated in fig. 6-8, displaying 72 percent of the variation among frequencies. There are two very distinct trends in colour shift. The first from orange towards brown, the second from green, through yellow to white and to the other colours. The first trend is associated with shift from Bombycoidea + Tortricoidea versus the other Lepidoptera. The second is associated with a shift from Tineoidea versus the other Lepidoptera. There is found evidence for the statement of Ilse (1928), Tinbergen et al. (1942) (see also Kevan, 1978) that the more plesiomorphous Lepidoptera mainly visit yellow flowers (Tineoidea and Tortricoidea). It is known that at least the Pieridae and Papilionidae can see red (Kugler, 1970) and the Papilionoidea generally are attracted by blue and yellow (Ilse, 1928). The Pieridae also visit blue and white (Bennet, 1883), but in other cases they prefer yellow above white (Kay, 1978), also pink is visited. This means that the Rhopalocera are attracted by many colours, and thereby are situated centrally in the graph. The same can be stated for the other superfamilies: Pyraloidea; Geometroidea, for which Schlegtendal (1934) found that sensitivity maxima of Operophtera (Cheimatobia) brumata are found in yellow and blue, and the graph suggests a higher sensitivity for the latter than for the first; Sphingoidea; and Noctuoidea.

Comparing these results with the phylogenetic relationships within the Ditrysia (fig. 5-17), it appears that the most plesiomorphous Ditrysia, the Tineoidea, show a more exclusive preference for (green and) yellow than do 


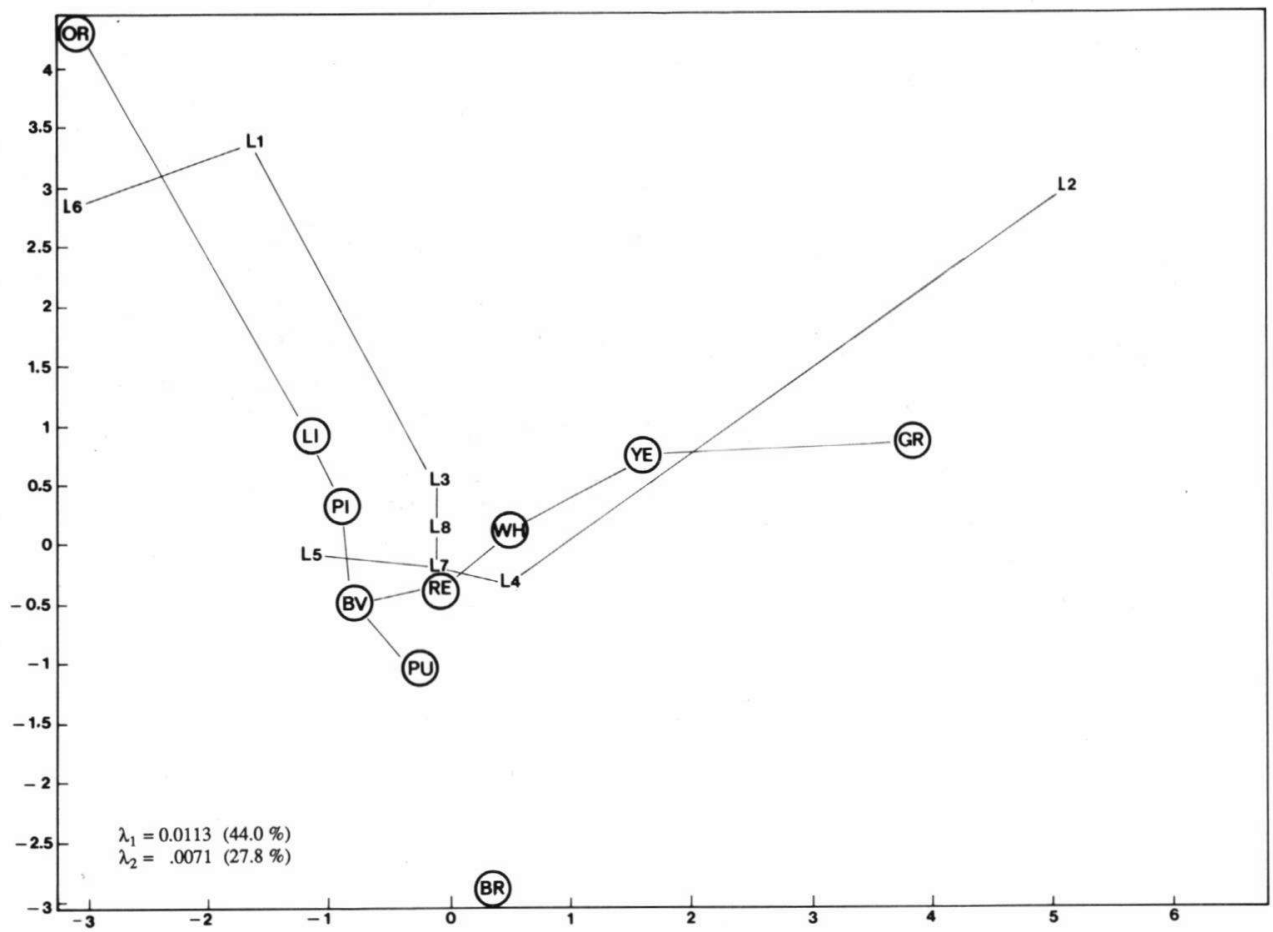

Fig. 6-8. Scatter diagram showing the ordination of rows (taxa of Lepidoptera) and columns (colours), as for the insect groups in fig. 6-9C, on the first pair of principal axes (dim1, dim2) resulting from reciprocal averaging. Scale of measurement for both abcissa and ordinate is in weighted proportional deviations from the average frequency $(x 10)$. Explanation: $\lambda 1=$ first eigen value; $\lambda 2=$ second eigen value. The figures in parentheses indicate the percentages of total inertia. LEPIDOPTERA: L1 = Totricoidea; L2 = "Tineoidea" (in the sense of Knuth (1898a, 1899), compare section 4.3); L3 = Pyraloidea; L4 = "Rhopalocera" (in the sense of Knuth (1898a, 1899), compare section 4.3); L5 = Geometroidea; L6 = Bombycoidea; L7 = Sphingoidea; L8 = Noctuoidea. COLOURS: BR = brown; BV = blue-violet; GR = green; $\mathrm{LI}$ - lilac; $\mathrm{OR}$ = orange; $\mathrm{PI}=$ pink; $\mathrm{PU}=$ purple; $\mathrm{RE}=$ red; $\mathrm{WH}=$ white; $\mathrm{YE}$ = yellow.

the other Ditrysia. The more apomorphous groups are also attracted by colours of longer and shorter wave-lengths.

Retrospect on the interdependences among colours and taxa of lower rank within the insect groups

In the paragraph on colour vision in anthophilous insects it was stated that the unspecialized anthophilous insects mainly visit yellow flowers (Ilse \& Vaidya, 1956) and that yellow as a floral colour is adaptively neutral (Valentine, 1975). It appears in the quantitative analysis (table 6-9D) that all insect groups have the highest frequencies of visits to white, directly followed by visits 
to yellow. This means that white, nor yellow can be considered adaptively selective colours. Only the non-apoid Hymenoptera and Coleoptera visit more white and less yellow than do the other insect groups (table 6-9B-1 and 3). For the insect groups it can only be said that the Coleoptera, non-apoid Hymenoptera, and to a somewhat lesser degree, also the Diptera visit less blueviolet and blue-mixed colours and red and red-mixed colours than do the Apoidea and Lepidoptera, thus, that they visit white and yellow flowers more exclusively. The reciprocal averaging demonstrated about the same tendencies. It has to be stressed here again that reciprocal averaging is based on the numbers of the qualitative analysis (table 6-9C). But despite the less pronounced results of the qualitative analysis, it is clearly demonstrated in figs. 6-1 and 2 that the non-apoid Hymenoptera, Coleoptera and Diptera are more exclusively associated with white and yellow than are the Apoidea and Lepidoptera.

The reciprocal averaging of the taxa of the insect groups separately show that unspecialized anthophilous insects more exclusively visit yellow flowers. Many Coleoptera show interdependence with yellow and within the order mainly the more plesiomorphous taxa show more close and more exclusive associations with yellow. In the taxa of the Diptera some faint, more exclusive associations with (white and) yellow for the more plesiomorphous taxa are indicated. In the non-apoid Hymenoptera it appears that the most plesiomorphous taxon (the Symphyta) is highly associated with yellow (and green) and also in the Apocrita the relatively plesiomorphous Ichneumonoidea are highly interdependent with yellow. In the Apoidea the more plesiomorphous families (Colletidae, Halictidae and Andrenidae) are more exclusively associated with (white and) yellow. Also in the Lepidoptera, although faintly, particularly the plesiomorphous Tineoidea, show a more exclusive association with yellow than do the more apomorphous taxa.

It can be concluded that the least specialized insect-flower (pollination) relationships mainly are characterized by yellow floral colours, directly followed by white. With the increase of the specialization of the pollination blue-violet and blue-mixed colours, and red and red-mixed colours become more important. As mentioned before this also applies for ultraviolet.

\section{Correlation of the insect-colour relationships with the fossil record of the insect taxa in which anthophily developed}

Compared with the fossil record of the insect taxa in which anthophily developed the following developments in floral colour can be traced.

In the early Cretaceous the following Coleoptera were present (table 5-1): Cupedoidea, Staphyliniformia (Staphylinidae), Scarabaeiformia (Dascillidae), Buprestoidea (Buprestidae), Elateroidea (Elateridae), Bostrychoidea 
(Anobiidae), Nitidulidae (and the cucujoid Mordellidae and Tenebrionidae), Cerambycidae (and the chrysomeloid Bruchidae), and Curculionidae (and the curculionoid Nemonychidae, Anthribidae and Oxycorynidae). The Cupedoidea, Bostrychoidea, Mordellidae, Tenebrionidae, Bruchidae and the non-curculionid curculionoid familes are not included in the analyses. The same applies to the Scarabaeiformia which are represented by the Dascillidae, while in the analyses only the scarabaeid subfamilies Cetoniinae, Trichiinae, Hopliinae, Rutelinae and Melolonthinae (see section 4.1) are included. The most plesiomorphous of these subfamilies, the Melolonthinae, first appear in the upper Eocene. Most of the taxa present in the early Cretaceous in Recent times appear to be rather closely associated with yellow and white (figs. 6-1 and 2). In the reciprocal averaging for the taxa within the Coleoptera the same can be illustrated. The colours with shorter wave-lengths that do not discriminate extensively are lilac, purple and pink. Lilac and pink have a white component and can form a bright spot on a green background. Purple does not and it is questionable what role it plays in attracting Coleoptera. To answer this question it is necessary to check whether the purple concerns unicoloured flowers or takes part in multicoloured flowers, which, as said before, is beyond the scope of this first study, tracing only general tendencies.

The Diptera present in the early Cretaceous (table 5-4) were the "Nematocera" (= Polyneura + "Oligoneura") and the Orthorrhapha (= Homoeodactyla + Asiliformia + Empediformia; only represented by the Nemestrinidae). The Nemestrinidae are not included in the Orthorrhapha in the analyses (Rhagionidae, Tabanidae, Stratiomyidae, Therevidae, Bombyliidae and Empedidae do, see section 4.4). As is illustrated in table 5-4 the Rhagionidae, Tabanidae, Stratiomyidae, Bombilyiidae and Empedidae are definitely present in the upper Eocene to lower/middle Oligicene (Baltic amber). Speculating on probable relationships, these families could have been present in the early Cretaceous. The "Nematocera" in Recent times are associated with green and only very faintly with white and orange. The Orthorrhapha show more association with other colours. Starting from the incertainty of the presence of the orthorrhaphan taxa, taking part in this analysis, in the early Cretaceous, it is concluded that the Diptera present in that time had poorly developed sensitivity for floral colours, with only a faint preference for yellow colours.

In the early Cretaceous the only non-apoid Hymenoptera present were the Symphyta s. lat. (table 5-2). In Recent times they are closely associated with yellow (and green). In the course of the Lower Cretaceous also the Ichneumonoidea appear. As has been demonstrated these relatively plesiomorphous Apocrita are also highly associated with yellow (and green). It can be concluded that the non-apoid Hymenoptera present in the early Cretaceous preferred yellow flowers. 
As described in section 5.2 (see table 5-2) the Apoidea were not present in the early Cretaceous and of the Lepidoptera (section 5.3) only the Micropterigidae might have been present (see table 5-3). The Micropterigidae are not included in the analysis. In Knuth (1899) visits of Micropterix calthella are mentioned to the flowers of Ranunculus acer, $R$. bulbosus, $R$. auricomus, $R$. repens (all yellow-flowered). Proctor \& Yeo (1973) mentioned that the same species is one of the characteristic visitors of Ranunculus acris an that it also frequents Narthecium ossifragum (yellow flowers), Rubus fruticosus (white to pink flowers), Potentilla erecta (yellow flowers) and Galium verum (lemon-yellow flowers). This survey indicates that sensitivity for yellow very probably is present.

\section{Discussion}

It can be suggested that the Angiospermae in the early Cretaceous had yellow flowers. That yellow is a plesiomorphous colour in the angiosperm flowers may find its evidence in the fact that the change from green to yellow in leaves only requires the removement of the chlorophyll. As we can see in autumn leaves: when the chlorophyll disappears the remaining carotenoids (and possible xanthophylls, see below) (being part of the metabolism of the plant) colour the leaves yellow to orange. A probably comparable, comparatively simple, step is that to white flowers: the loss of the carotenoids (white colour being the result of multiple reflections of all wave-lengths in the intercellular spaces between uncoloured cells). Concerning the colours of the earliest angiosperm flowers Savidge (1976) mentioned that in the earliest flowering plants there were only few, if any, anthocyanines and flavones. Instead the floral parts, mainly the sepals, appear to have been pigmented with certain carotenoids and xanthophylls. This plesiomorphous type of sepal, which still can be found in surviving "primitive" species (which he did not mention) contains small amounts of chlorophyll $a$ and $b$, but rather extensive quantities of the other two photosynthetic pigments, the yellow to orange-red carotenoids and the yellow to brown xanthophylls. Concerning the simultaneous presence of chlorophyll and carotenoids in petaloid sepals or petals, Goodwin (1976) mentioned Caltha palustris and Forsythia intermedia (of which the latter cannot be considered a "surviving plesiomorphous species").

Rothschild (1975) mentioned that carotenoids occur in the pollen of all entomophilous flowers (Goodwin, 1952; Barbier, 1970). In this respect the nutritional value is described by e.g. Lepage Bloch (1968), Morere (1971), Dadd (1973). This means that within the entomophilous flowers no evolutionary lines are present in the colouring of pollen. In comparison with the anemophilous flowers it appears that the carotenoids are absent in Populus, Betula and Alnus (and also in Pinus). 
In many Angiospermae carotenoids occur in the petals. A survey after Goodwin (1958, 1965, 1966, 1976), Karrer \& Junker (1950) and Zechmeister (1932) shows that carotenoids up to now are found in the floral parts (nonpollen) of representatives of the following angiosperm orders: Magnoliales, Nymphaeales, Ranunculales, Papaverales, Plumbaginales, Malvales, Violales, Capparales, Primulales, Rosales, Fabales, Myrtales, Proteales, Sapindales,- Geraniales, Umbellales, Gentianales, Polemoniales, Lamiales, Scrophulariales, Campanulales, Rubiales, Asterales, Poales, Bromeliales, Zingiberales, Liliales, and Orchidales. This means that only a very extensive research on the occurrence of pigments can decide whether the biochemical evolution of the floral pigments occurred parallel to the development of the colour-vision in the anthophilous insects. We will leave these complex problems here and content ourselves with the following global evolutionary lines. After Faegri \& Van der Pijl (1980), who mentioned that pink, red, violet are caused by anthocyanins, and yellow, red and purple by carotenoids and xanthophylls or flavones, it can be concluded that there is evidence that the carotenoids and xanthophylls are the most plesiomorphous floral pigments. We then suggest that the anthocyanins must be the most apomorphous floral pigments (we will return to this below) and the flavones may occupy an intermediate position.

About the development of the shorter wave-lengths in floral colours the following can be said. Within the Coleoptera no more exclusive associations with blue-violet and blue-mixed colours occur (fig. 6-4) and also according to the colour vision in the Coleoptera it can be stated, that blue-violet and bluemixed colours hardly play a role in attracting Coleoptera. In the non-apoid Hymenoptera blue-violet and blue-mixed colours are to some degree functional in attracting the Sphecoidea, Scolioidea and Vespoidea (fig. 6-6). The Vespoidea (Masaridae) and thereby the Scolioidea (Scoliidae) (fig. 5-11) appeared in the Upper Cretaceous and the Sphecoidea are definitely present in the upper Eocene to lower/middle Oligocene (Baltic amber). The observations on the Masaridae and Scoliidae form only a minority of the records of Knuth for the Scolioidea and Vespoidea (see section 4.2), but it can be suggested that blue-violet and blue-mixed colours might have some function in attracting these Vespoidea in the late Cretaceous. This function will have increased during the early Tertiary and became definite in the Oligocene.

In the Diptera mainly the Brachycera-Orthorrhapha, Aschiza and Schizophora are associated with blue-violet and blue-mixed colours (fig. 6-5). The Bombyliidae (Asiliformia) are definitely present in the Baltic amber, but the Nemestrinidae were present throughout the Cretaceous. Here the same may be suggested as for the Masaridae: blue-violet and blue-mixed colours may have had some function in attracting the Nemestrinidae in the late Cretaceous. The Homoeodactyla-Aschiza (= Acroptera + Hypocera + Syr- 
phidea) and Schizophora were definitely present with many families in the Baltic amber (table 5-4). This means that their origins may be much older. It can be suggested that blue-violet and blue-mixed colours became functional to some degree in attracting Aschiza and Schizophora in the course of the Tertiary and established their function in the second half of the Tertiary.

The apoid families are definitely present in the Baltic amber (table 5-2). From the Paleocene already strongly specialized types are known. Mainly the higher Apoidea (Megachilidae, Anthophoridae and Bombinae) are closely associated with blue-violet and blue-mixed colours (fig. 6-7). It may be suggested that in the late Cretaceous and earliest Tertiary the more plesiomorphous Apoidea were present, only faintly attracted by blue-violet and bluemixed colours. In the upper Eocene to lower/middle Oligocene blue-violet and blue-mixed floral colours were definitely functional in attracting Apoidea and this culminated at the time of origin of the higher Bombinae, probably somewhere in the late Tertiary.

In the Lepidoptera the taxa that are more or less associated with blue-violet and blue-mixed colours are the Pyraloidea, Rhopalocera, Geometroidea, Sphingoidea and Noctuoidea (fig. 6-8). All, except the Sphingoidea, were definitely present in the Baltic amber and the Papilionoidea were so in the middle Eocene (table 5-3). This means that blue-violet and blue-mixed colours could have been definitely functional in attracting Lepidoptera in the middle Eocene. In earlier Tertiary times, may be starting in the late Cretaceous, blueviolet and blue-mixed colours might have had some function in attracting Lepidoptera.

Since red-blindness in the non-lepidopteran groups is very extensive, the longer wave-lengths in floral colours, red and red-mixed colours, became functional at the appearance of the higher Lepidoptera (fig. 6-8) and the function in attracting Lepidoptera could have been well-established in the middle Eocene (Papilionoidea) (table 5-3).

Within the floral colours in the Angiospermae theoretically four general transformation series can be distinguished:

1. from (green) yellow to white: this development could have taken place in the very early evolution of the angiosperm flowers;

2. from yellow or white to blue-violet and blue-mixed colours: this development possibly started in the late Cretaceous;

3. from yellow or white to red and red-mixed colours: this development possibly also started in the late Cretaceous;

4. from blue to red or vice versa: within butterfly-pollinated flowers, knowing that both red and violet can be caused by anthocyanins and that both red and purple can be caused by carotenoids and flavones (Faegri \& Van der Pijl, 1980), 
these developments might have been functional from the late Cretaceous onwards.

It has been mentioned that these four transformation series are theoretically possible. Regarding the floral colours in general the following three transformation series seem more probable (Kalkman. pers. comm.: the impression exists that species which have yellow and blue flowers within the variation must be extremely rare; white and blue, and white and red more generally occur together within the same variation):

1. yellow to white and vice versa;

2. white to blue and vice versa;

3. blue to red and vice versa.

Returning to the floral pigments, as mentioned by Faegri \& Van der Pijl (1980), it can be said that the red and violet causing anthocyanins were present in the late Cretaceous. But if these anthocyanins were present in basically white and yellow flowers in such small quantities that the flower still formed a relatively "bright" (light-blue, pink, lilac, orange) subject against the green background, they may have originated earlier, not functionally attracting the anthophilous insects present at that time, but just present as far as the "patio ludens" (Van Steenis, 1976) of this evolutionary development allowed. The same can be said for the red and purple-causing flavones. The flavones in general, however, may be of earlier origin than the anthocyanins, since also yellow causing flavones exist. As mentioned before, carotenoids and xanthophylls probably are the earliest angiosperm floral pigments, and for their development towards orange, red and purple the same can be said as for the anthocyanins and flavones. Gottsberger \& Gottlieb $(1980,1981)$ mentioned that blue flowers mainly occur in the apomorphous angiosperms, viz. in those taxa which are characterized by an evolutionary trend towards herbaceous habit. They are comparatively rare in more plesiomorphous taxa. They correlate these facts by considering the changes in flavonoid chemistry known to accompany the evolution from woody to herbaceous forms with respect to the chemical composition of the blue pigment complexes. Muller (1981) mentioned that families which are predominantly herbaceous appeared later in the fossil record than dominantly woody ones. The earliest herbaceous angiosperms may date from about the middle Cretaceous, and their development accelerated towards the Maestrichtian and early Tertiary.

\subsection{Position of the anthers}

In order to assess the position of the anthers in relation to the visiting (partly pollinating) insects and to analyse whether the concealment of the anthers can be considered an adaptation against the pollen-feeding and otherwise destruc- 
tive habits by the Coleoptera, the visits of these insects to phanerantherous and cryptantherous flowers are analysed. Because generally speaking, flowers are either phanerantherous or cryptantherous, it suffices to analyse the visits of the insect groups to one of the categories; we will take the cryptantherous flowers. For phanerantherous flowers, then, the reverse counts with the same $p$-values of the differences.

Comparison of the anemophilous and the entomophilous pollination types is not necessary, because the first by definition concern only phanerantherous flowers. Cryptanthery only occurs in entomophilous flowers.

Distribution of the position of the anthers among the facultative and obligatory entomophilous pollination types

It appears (table 6-10A) that cryptanthery mainly occurs among the beeand butterfly- or moth-pollinated flowers, more so than in beetle- and flypollinated flowers (tables 6-10A-3 and 4). The beetle-pollinated flowers are less often cryptantherous than the fly-pollinated flowers (table 6-10A-3). This means that crypteranthery increases from beetle-, through fly- to bee- and butterfly- or moth-pollinated flowers.

Distribution of the position of the anthers among the obligatory entomophilous pollination types

Here (table 6-10B) the same tendency is found as in the facultative and obligatory pollination types. It appears that the majority of the myiophilous flowers is phanerantherous and both melittophilous and psychophilous and phalaenophilous flowers are mainly cryptantherous (table 6-10B-2).

Distribution of the position of the anthers among the species of which the flowers are visited by the various insect groups, Qualitative analysis

It appears that two groups can be distinguished (tables 6-10C and 6-10C-3 to 5). The species of which the flowers are visited by the Coleoptera, Diptera and non-apoid Hymenoptera less often show cryptanthery (thus more often phaneranthery) than those visited by the Apoidea and Lepidoptera.

Disposition of flower visits of the insect groups with reference to the position of the anthers, Quantitative analysis

It appears (table 6-10D) that the non-apoid Hymenoptera visit least cryptantherous flowers of the insect groups included (tables 6-10D-1 to 3). The Coleoptera and Diptera do not differ and both visit cryptantherous flowers less than do the Apoidea and Lepidoptera (tables 6-10D-1 and 2). It appears that the Apoidea visit cryptantherous flowers more than do the Lepidoptera (table 6-10D-4). This may be due to the facts that many bee-pollinated flowers compel bees to crawl in, and that the bees developed the corresponding behaviour, in contrast to the butterfly- or moth-pollinated flowers and the Lepidoptera. 
Table 6-10. Frequencies of cryptanthery among the flowers of the species belonging to the facultative and obligatory pollination types (A); ibid. obligatory pollination types (B); ibid. species of which the flowers are visited by the various insect groups, Qualitative analysis (C); ibid. Quantitative analysis (D) of the central European flora.

Abbreviations: APO = Apoidea; BeF $=$ Bee-pollinated flowers; BMF $=$ Butterfly- or mothpollinated flowers; BtF = Beetle-pollinated flowers; CEF - Central European flora; COL - Coleoptera; Cr = Cryptantherous; DIP = Diptera; ENT = Entomogamous; FlF = Flypollinated flowers; LEP - Lepidoptera; MEL = Melittogamous; MYI = Myiogamous; $\mathrm{NAH}=$ Non-apoid Hymenoptera; $\mathrm{P}+\mathrm{P}=$ Psychogamous + phalaenogamous.

A-1 to 4, B-1 and 2, C-1 to 5 and D-1 to 4 give the significances of the differences in A, B, $\mathrm{C}$ and $\mathrm{D}$ by chi-square testing. Explanation: $1=0.01<\mathrm{p} \leq 0.05 ; 2=0.001<\mathrm{p} \leq 0.01 ; 3=$ $0.0001<\mathrm{p} \leq 0.001 ; 4=\mathrm{p} \leq 0.0001$.

\begin{tabular}{|c|c|c|c|c|c|c|c|c|c|c|c|c|}
\hline $\begin{array}{l}\text { A } \\
\text { CEF } \\
\text { ENT } \\
\text { BtF } \\
\text { FlF } \\
\text { BeF } \\
\text { BMF }\end{array}$ & $\begin{array}{r}\text { Total } \\
3249 \\
2610 \\
1184 \\
1744 \\
2154 \\
589\end{array}$ & \begin{tabular}{r}
\multicolumn{1}{c}{$\mathrm{r}$} \\
19.84 \\
24.60 \\
0.67 \\
3.84 \\
23.91 \\
23.60
\end{tabular} & $\begin{array}{c}\mathrm{A}-1 \\
C E F \\
\mathrm{ENT} \\
\mathrm{BtF} \\
\mathrm{FlF} \\
\mathrm{BeF}\end{array}$ & $\begin{array}{c}\mathrm{Cr} \\
3 \\
4 \\
4 \\
2\end{array}$ & $\begin{array}{l}\text { A-2 } \\
E N T \\
\text { BtF } \\
\text { FIF } \\
\text { BMF }\end{array}$ & $\begin{array}{c}\mathrm{Cr} \\
4 \\
4 \\
4\end{array}$ & $\begin{array}{l}\text { A-3 } \\
B t F \\
\text { FlF } \\
\text { BeF }\end{array}$ & $\begin{array}{c}\mathrm{Cr} \\
4 \\
4\end{array}$ & $\begin{array}{l}\text { A-4 } \\
F l F \\
\text { BeF } \\
\text { BMF }\end{array}$ & $\begin{array}{c}\mathrm{Cr} \\
4 \\
4\end{array}$ & & \\
\hline $\begin{array}{l}\text { B } \\
\text { ENT } \\
\text { MYI } \\
\text { MEL } \\
\text { P + P }\end{array}$ & $\begin{array}{r}\text { Total } \\
2610 \\
151 \\
639 \\
96\end{array}$ & \begin{tabular}{r}
\multicolumn{1}{c}{$\mathbf{C r}$} \\
24.60 \\
5.96 \\
69.01 \\
67.71
\end{tabular} & $\begin{array}{l}\text { B-1 } \\
E N T \\
\text { MYI } \\
\text { MEL } \\
\mathrm{P}+\mathrm{P}\end{array}$ & $\begin{array}{c}\text { Cr } \\
4 \\
4 \\
4\end{array}$ & $\begin{array}{l}\mathrm{B}-2 \\
M Y I \\
\mathrm{MEL} \\
\mathrm{P}+\mathrm{P}\end{array}$ & $\begin{array}{c}\mathrm{Cr} \\
4 \\
4\end{array}$ & & & & & & \\
\hline $\begin{array}{l}\text { C } \\
\text { COL } \\
\text { DIP } \\
\text { NAH } \\
\text { APO } \\
\text { LEP } \\
\text { CEF } \\
\text { ENT }\end{array}$ & $\begin{array}{r}\text { Total } \\
444 \\
845 \\
445 \\
945 \\
518 \\
3249 \\
2610\end{array}$ & $\begin{array}{c}\mathrm{Cr} \\
15.77 \\
17.87 \\
14.38 \\
31.32 \\
31.27 \\
19.82 \\
24.60\end{array}$ & $\begin{array}{l}\text { C-1 } \\
C E F \\
\text { COL } \\
\text { DIP } \\
\text { NAH } \\
\text { APO } \\
\text { LEP }\end{array}$ & $\begin{array}{c}\mathrm{Cr} \\
2 \\
3 \\
2 \\
1 \\
3\end{array}$ & $\begin{array}{l}\text { C-2 } \\
E N T \\
\text { NAH } \\
\text { APO } \\
\text { LEP }\end{array}$ & $\begin{array}{c}\text { Cr } \\
1 \\
4 \\
4\end{array}$ & $\begin{array}{l}\text { C-3 } \\
\text { COL } \\
\text { APO } \\
\text { LEP }\end{array}$ & $\begin{array}{c}\mathrm{Cr} \\
4 \\
4\end{array}$ & $\begin{array}{l}\text { C-4 } \\
D I P \\
\text { APO } \\
\text { LEP }\end{array}$ & $\begin{array}{c}C r \\
4 \\
4\end{array}$ & $\begin{array}{l}\mathrm{C}-5 \\
N A H \\
\text { APO } \\
\text { LEP }\end{array}$ & $\begin{array}{c}\mathrm{Cr} \\
4 \\
4\end{array}$ \\
\hline $\begin{array}{l}\text { D } \\
\text { COL } \\
\text { DIP } \\
\text { NAH } \\
\text { APO } \\
\text { LEP }\end{array}$ & $\begin{array}{l}\text { Total } \\
1598 \\
6628 \\
2148 \\
7918 \\
2867\end{array}$ & $\begin{array}{r}\mathrm{Cr} \\
8.32 \\
8.66 \\
5.40 \\
31.71 \\
26.09\end{array}$ & $\begin{array}{l}\text { D-1 } \\
C O L \\
\text { NAH } \\
\text { APO } \\
\text { LEP }\end{array}$ & $\begin{array}{c}\mathrm{Cr} \\
3 \\
4 \\
4\end{array}$ & $\begin{array}{l}\text { D-2 } \\
D I P \\
\text { NAH } \\
\text { APO } \\
\text { LEP }\end{array}$ & $\begin{array}{c}\mathrm{Cr} \\
4 \\
4 \\
4\end{array}$ & $\begin{array}{l}\mathrm{D}-3 \\
N A H \\
\text { APO } \\
\text { LEP }\end{array}$ & $\begin{array}{c}\mathrm{Cr} \\
4 \\
4\end{array}$ & $\begin{array}{l}\mathrm{D}-4 \\
A P O \\
\text { LEP }\end{array}$ & $\begin{array}{c}\mathrm{Cr} \\
4\end{array}$ & & \\
\hline
\end{tabular}

\section{Discussion}

It appears that cryptantherous flowers are highly associated with the longtongued insects (Apoidea and Lepidoptera). In comparison with the beetlepollinated flowers, the fly-pollinated flowers are more often cryptantherous. This means that, correlated with the phylogeny and fossil record of the insect taxa in which anthophily developed, cryptantherous flowers for the first time may have been present in the late Cretaceous in co-development with the 
lengthening of the mouth parts in the Diptera (Nemestrinidae) and became well-established and functional in the early Tertiary in co-development with the lengthening haustella of the Lepidoptera and tongues of the Apoidea, and later in the Tertiary also in co-development with the penetrating behaviour of the higher Apoidea. In later Tertiary development towards sphingophilous, ornithophilous and chiropterophilous flowers, lengtening of the stamens could have taken place, i.e. possible developments from cryptanthery to phaneranthery.

It is clear that concealment of the anthers can be considered an adaptation against pollen-feeding and otherwise destructive insects, i.e. mainly the Coleoptera. In some cases, however, reverse developments may be possible. In e.g. some psychophilous and ornithophilous flowers (e.g. Hibiscus and Fuchsia respectively) phaneranthery can be considered apomorphous.

\subsection{Number of stamens per flower}

In this section an analysis is performed to check whether the number of stamens per flower is related to the pollination type. It may be expected that non-specialized entomophilous flowers pollinated by insects with short mouth parts, will need many stamens to spread the pollen diffusely over the integument of the pollinating insect, in order to increase the chance of pollendeposition on the stigma of the next-visited flower. Specialized flowers, pollinated by long-tongued insects, will need fewer stamens, because the pollen is deposited on a restricted part of the integument of the pollinating insect. This restricted part corresponds with the position of the stigma of the next flower visited. Here the minimum numbers of stamens, i.e. corresponding with the maximum developments in the evolutionary line supposed above, are analysed.

\section{Distribution of the numbers of stamens per flower in the anemophilous and entomophilous pollination types}

It appears (table 6-11A) that the anemophilous flowers generally have fewer stamens than the entomophilous flowers. Anemophilous flowers have more often one and three stamens, and less often four, five, eight, ten and many (more than 10) stamens than have the entomophilous flowers (table 6-11A-2).

This seems in contradiction with the supposed evolutionary line from many to few stamens within the entomophily (anemophily being an "unspecialized" pollination system). Here it has, however, to be mentioned that most $(98 \%)$ of the anemogamous species have many- and small-flowered inflorescences. Compared with the single flower as a pollination unit (table 6-7A: 51.03\%), the many small-flowered inflorescences among the entomogamous species will not exceed $50 \%$. Both anemophilous and entomophilous many- and small- 


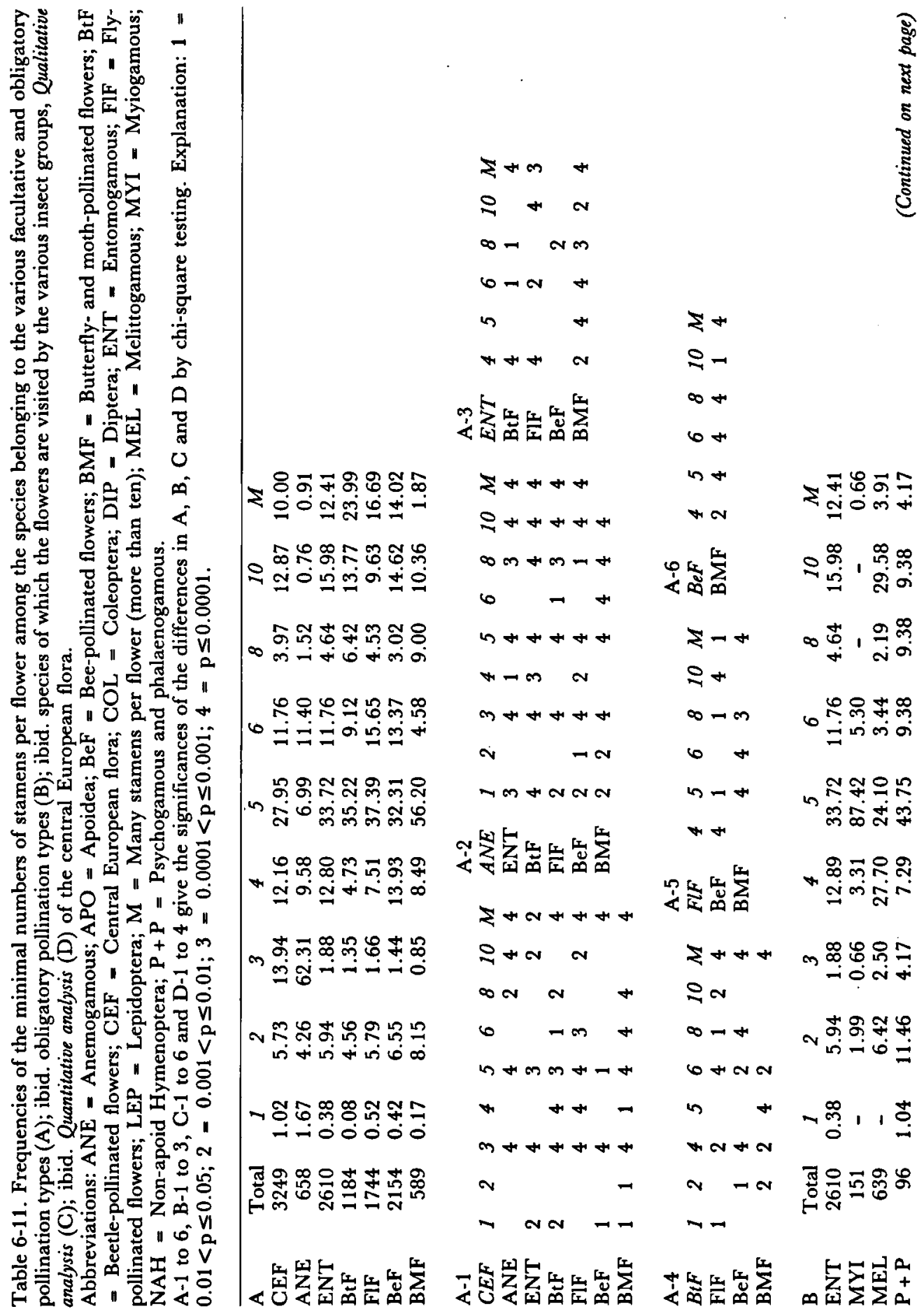


요

$\infty n$

$6-$

in ov

$+\infty$

$\because \sqrt{2}+$

คे

$\Sigma-$

아

$\infty$ v

$n+N$

$+$

$r-v$

논

我这

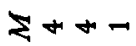

아

$\infty-N$

$6-4$

$\omega+m$

HO

$N=$

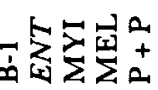

$-1$

号焉

$\sum+4$

$0-N$

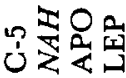

$\&+N$

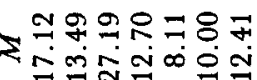

ㅇำ

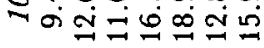

$\infty$ ๓ लें + +

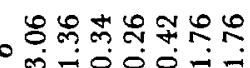

ต

o $-\mathrm{N}$

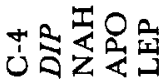

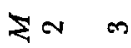

$\rightarrow \quad \mathrm{m}$

in 7

$*-$

ஸல்要吕

ஸ去유.

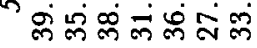

ฟ

*ำำ

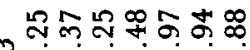

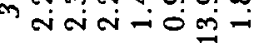

ح

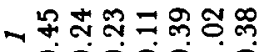

०0000

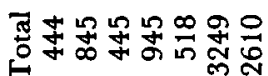

$\Sigma-+$

$0 \times-$

$+$

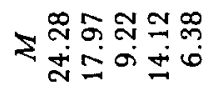

ำ คำ ต

- 0 \%

$\infty \sigma \infty \varpi \tilde{\omega}$ तो लं

எ on को in

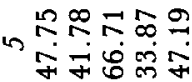

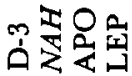

$\Upsilon *$

$-7$

$\Sigma+t$ $0++$

$\infty m m$

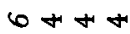

$n+t a$

$\operatorname{MA\rightarrow ~}$

$m+\infty$

v

$r-1$

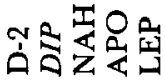

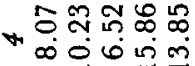

$\sum \nleftarrow+4$

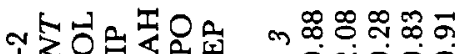

요

$\infty \propto$

$\sum+\rightarrow+-$

요 $\quad-\infty$

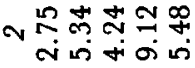

$6+-$

$\ln \alpha$

आm N N

$\sim$

*नー+

$M N-$

in +

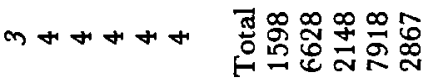

$-\quad-N$

ขaน+น

$*-$

$v+$

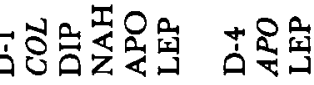


flowered inflorescences may have developed to increase the chance of pollen deposition on the stigmas. Knowing that the development of such inflorescences (see section 6.6) in entomophily is probably secondary, there may be evidence that the anemophilous many- and small-flowered inflorescences are derived from similar entomophilous structures and, thus, that this type of anemophilous "pollination units" is secondary.

Distribution of the numbers of stamens per flower among the species belonging to the facultative and obligatory entomophilous pollination types

Beetle-pollinated flowers (table 6-11A-4) have most often many and least often four stamens per flower of all facultative and obligatory pollination types. Besides, they have: less often one and six, and more often eight and ten stamens than have the fly-pollinated flowers; less often two and six, and more often eight stamens than have the bee-pollinated flowers; less often two and five, and more often six stamens than have the butterfly- or moth-pollinated flowers.

Fly-pollinated flowers (table 6-11A-5) more often have many stamens than beeand butterfly- or moth-pollinated flowers. In five and eight stamens per flower they are aberrant, being intermediate between the bee-pollinated flowers (having less often five and eight) and the butterfly- or moth-pollinated flowers (having more often five and eight). The fly-pollinated flowers have less often four and ten stamens than have the bee-pollinated flowers, and more often six than have the butterfly- or moth-pollinated flowers.

Bee- and butterfly-or moth-pollinated flowers (table 6-11A-6) differ considerably concerning the numbers of stamens per flower. The bee-pollinated flowers have more often four, six, ten and many, and less often five and eight stamens than have the butterfly- or moth-pollinated flowers.

It is demonstrated that the least specialized flowers (beetle-pollinated flowers) generally have more stamens per flower than have the facultative and obligatory pollination types which include longer-tongued insects. The highly specialized butterfly- or moth-pollinated flowers least often have many stamens. The fly- and bee-pollinated flowers are somewhat in between. The fly-pollinated flowers partly resemble the butterfly- or moth-pollinated flowers (four, five, eight, and ten stamens per flower) and partly more the beepollinated flowers (six and many stamens per flower).

Distribution of the numbers of stamens per flower among the obligatory entomophilous pollination types

It appears that the obligatory entomophilous pollination types (table 6-11B) only rarely encompass flowers with many stamens, compared with the entomogamous species (table 6-11B-1). 
Myiophilous flowers (table 6-11B-2) have least two and ten, and most five, stamens of all obligatory pollination types. Besides, they less often have four, and many stamens than the melittophilous flowers and less often eight than the psychophilous ot phalaenophilous flowers.

Melittophilous flowers (table 6-11B-3) less often have six and eight, and more often four and ten stamens than have the psychophilous or phalaenophilous flowers.

It appears that with the increase of the specialization of the pollination the number of stamens per flower decreases, here demonstrated by the very low frequencies of many stamens per flower in the obligatory entomophilous pollination types.

Distribution of the numbers of stamens per flower among the species of which the flowers are visited by the various insect groups, Qualitative analysis

The differences in the qualitative analysis (table 6-11C) are mainly found in ten and many stamens per flower. In many stamens per flower we see the following series (from more to less often having many stamens per flower); species of which the flowers are visited by the non-apoid Hymenoptera, Coleoptera + Diptera + Apoidea, Lepidoptera (tables 6-11C-3 to 6). In ten stamens per flower it appears that there are two groups: species of which the flowers are visited by the Coleoptera, Diptera and non-apoid Hymenoptera, and those visited by the Apoidea and Lepidoptera. The first have less often ten stamens than have the latter (tables 6-11C-3 to 5). Besides these main differences there are some minor ones: the species of which the flowers are visited by the Coleoptera less often have four stamens than have those visited by the Apoidea and Lepidoptera, and more often five stamens than have those visited by the Apoidea (table 6-11C-3).

As in the preceeding analyses it appears that the species of which the flowers are visited by the least specialized anthophilous insects (non-apoid Hymenoptera and to some degree different from Diptera and Apoidea, also the Coleoptera) have most often many stamens per flower. The species of which the flowers are visited by the very long-tongued insect (Lepidoptera) have least often many stamens per flower.

Disposition of flower visits of the various insect groups with reference to the numbers of stamens per flower, Quantitative analysis

The quantitative analysis (table 6-11D) demonstrates the same tendencies as found in the qualitative analysis, except for the non-apoid Hymenoptera. It appears that they mainly visit flowers with five stamens and much less flowers with many stamens. In visiting the latter the following series is demonstrated (from more to less often): Coleoptera, Diptera, Apoidea, non-apoid Hymenoptera, Lepidoptera (tables 6-11D-1 to 4). Both the Coleoptera and 
Diptera feed on pollen and the Apoidea collect pollen as food for their offspring. The non-apoid Hymenoptera and Lepidoptera mainly feed on nectar.

In ten stamens per flower two groups are found: the Coleoptera, Diptera and non-apoid Hymenoptera visit less often flowers with ten stamens than do the Apoidea and Lepidoptera. Within the first group the Diptera do more so than the Coleoptera and non-apoid Hymenoptera (tables 6-11D-1 to 4). In eight, three and one stamens per flower there are some differences, but they are comparatively small and it can be questioned whether they have any importance (compare tables 6-11D-1 to 4, and 6-11D).

Coleoptera visit more often flowers with six stamens than do the non-apoid Hymenoptera and Lepidoptera (table 6-11D-1), the Diptera do more so than the non-apoid Hymenoptera, Apoidea and Lepidoptera (table 6-11D-2) and the Apoidea and Lepidoptera do more so than the non-apoid Hymenoptera (table 6-11D-3).

It appears that all insect groups mainly visit flowers with five stamens. In this number the following series is demonstrated (from more to less often): non-Apoid Hymenoptera, Coleoptera + Lepidoptera, Diptera and Apoidea (table 6-11D-1 to 4).

In visiting flowers with four stamens the following series (from more to less often) is demonstrated: Apoidea, Lepidoptera, Diptera and Coleoptera + nonapoid Hymenoptera; and in visits to flowers with two stamens (in the same sequence): Apoidea, Diptera + non-apoid Hymenoptera + Lepidoptera and Coleoptera (tables 6-11D-1 to 4).

\section{Discussion}

It appears that with the specialization of the pollination the number of stamens per flower decreases. This is mainly expressed in many (more than 10) stamens per flower (versus ten or less). The variation in the lower numbers of stamens will be mainly determined taxonomically. The high frequencies of visits to flowers with five stamens is due to the fact that most of the smallflowered inflorescences have flowers with five stamens (e.g. Apiaceae, Asteraceae). As mentioned before the development of small-flowered inflorescences can be considered an adaptation against extensive entomophagous ovule damage and if we consider these inflorescences as pollination units, than they can be considered having many stamens, but spread over a larger surface. If the majority of flowers with five stamens are small and arranged in more compact inflorescences, then we see about the same as flowers with many stamens. The least specialized visitors (Coleoptera and non-apoid Hymenoptera) more often visit these flowers than do the more specialized Diptera and Apoidea (table 6-11D). The Lepidoptera comparatively often visit flowers with five stamens (e.g. the longer-tubed 
Asteraceae). In the lower numbers of stamens per flower (two and four) the non-specialized anthophilous insects visit least (see table 6-11D). In ten stamens per flower the same is found, although this number of stamens can be considered as rather high. In the Fabaceae (melittogamous) and Caryophyllaceae (often psychogamous or phalaenogamous), both often having ten stamens per flower, the frequencies of visits by Apoidea and Lepidoptera are comparatively high.

Correlated with the phylogeny and fossil record of the insect taxa in which anthophily developed, it can be hypothesized that the early Angiospermae had flowers with many stamens. The development towards five stamens per flower, in co-development with the small-flowered inflorescences (see section 6.6) might have taken place early in the development of the Angiospermae. Because it appears that anemophilous flowers have only very few (mainly three) stamens, it can be hypothesized that this is an apomorphous condition, co-developed with the development of small-flowered inflorescences. With the appearance of the myiophilous flowers in the second half of the Cretaceous, in the single flower as pollination unit, the number of stamens decreased to ten and less, giving rise to the restricted numbers of stamens in melittophilous and psychophilous or phalaenophilous flowers during the uppermost Cretaceous and the Tertiary.

\subsection{Position of the ovaries}

In this analysis the position of the ovaries is studied, questioning whether half- and entirely inferior ovaries can be considered floral adaptations to protect the ovules against potentially destructive visitors (pollinators) as Grant (1950) pointed out for beetles. In this study, limited to the central European area, the protective function is studied for insect-visitors with biting mouth parts (Coleoptera and non-apoid Hymenoptera). Here half- and entirely inferior ovaries are taken together, because the first as a separate category has too low frequencies to be properly comparable $(0.8 \%$ of the whole central European flora; there are no particular taxa having comparatively often halfinferior ovaries). It has to be mentioned that the approach is functional, e.g. Prunus is considered to have inferior ovaries.

Distribution of the various positions of the ovaries among anemophilous and entomophilous pollination types

It is easily seen that the half- and entirely inferior position of the ovaries are features of the entomophilous flowers (tables 6-12A and 6-12A-2). It appears that if the frequency of entomogamous species increases, the ovaries more often are half- or entirely inferior (table 6-13). 
Table 6-12. Frequencies of half- and entirely inferior ovaries among the flowers of the species belonging to the various facultative and obligatory pollination types (A); ibid. obligatory pollination types (B); ibid. species of which the flowers are visited by the various insect groups, Qualitative analysis (C); ibid. Quantitative analysis (D) of the central European flora.

Abbreviations: ANE = Anemogamous; APO = Apoidea; BeF = Bee-pollinated flowers; BMF - Butterfly- and moth-pollinated flowers; BtF = Beetle-pollinated flowers; CEF = Central European flora; COL = Coleoptera; DIP = Diptera; ENT = Entomogamous; FlF = Flypollinated flowers; I = Half- to entirely inferior ovaries; LEP = Lepidoptera; MEL = Melittogamous; MYI = Myiogamous; NAH = Non-apoid Hymenoptera; $\mathrm{P}+\mathrm{P}=$ Psychogamous and phalaenogamous.

A-1 to $6, \mathrm{~B}-1$ to $3, \mathrm{C}-1$ to 5 and D-1 to 4 give the significances of the differences in $\mathrm{A}, \mathrm{B}, \mathrm{C}$ and $D$ by chi-square testing. Explanation: $1=0.01<p \leq 0.05 ; 2=0.001<p \leq 0.01 ; 3=$ $0.0001<\mathrm{p} \leq 0.001 ; 4=\mathrm{p} \leq 0.0001$.

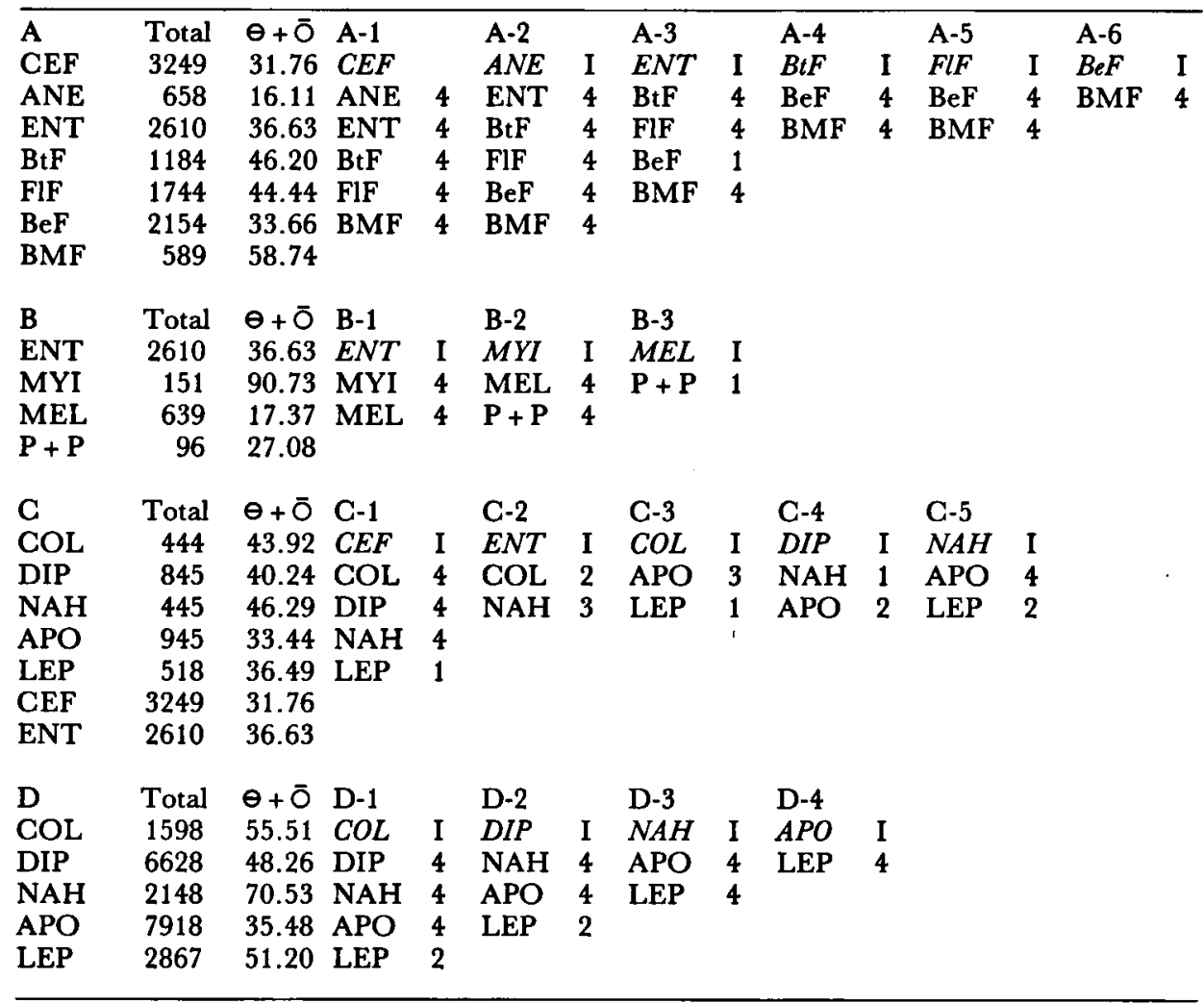

However, a fair amount of anemogamous (mainly facultative, but also obligatory) species have flowers with half- or entirely inferior ovaries (table 612A). This may be caused by the fact that many insects with biting mouth parts (particularly beetles and plesiomorphous wasps) visit anemophilous flowers feeding on pollen. Kugler (1970), after Porsch listed the following families of the Coleoptera: Staphylinidae, Scarabaeidae, Crypterophagidae, 
Table 6-13. Frequencies of entomogamy compared with those of half- and entirely inferior position of the ovaries within the central European flora. The classification is those used by Hegi (1906-1931). "Choripetalae" and "Sympetalae" here mean choripetalous and sympetalous respectively.

\begin{tabular}{lcc}
\hline & Entomogamous & $\ominus+\overline{0}$ \\
whole central European flora & 79.75 & 31.76 \\
Monocotyledonae & 31.09 & 14.50 \\
"Choripetalae" & 89.69 & 23.92 \\
"Sympetalae" & 96.22 & 53.97 \\
\hline
\end{tabular}

Phalacridae, Dermestidae, Elateridae, Cantharidae, Derodontidae, Anobiidae, Ptinidae, Tenebrionidae, Alleculidae, Oedemeridae, Cerambycidae, Chrysomelidae and Curculionidae. Redtenbacher \& Fricken (in Knuth, 1899) observed e.g. Alleculidae, Melyridae (in Knuth mentioned under Telephoridae), Anobiidae and Curculionidae on Pinus sylvestris and Picea excelsa). Rhagium $(R$.) bifasciatum was observed visiting the male cones of Pinus cembra (Teppner, pers. comm.) and Willemstein (1978) found many pollen grains of Pinus mugo in the digestive tracts of specimens of Cetonia aurata. The anemogamous Angiospermae visited by beetles are e.g. species of Alnus, Corylus, Populus, Urtica, Ulmus, Humulus, Thalictrum, Sanguisorba, Plantago (Berner, 1942 and Porsch, 1956). The plesiomorphous Xyelidae (Symphyta) also feed on anemophilous pollen (see section 4.2). Because the only attractant to insect visitors in anemophilous flowers is pollen, only in hermaphroditic flowers these visitors can exert selective pressure favouring the ovaries to become half- or entirely inferior (as in some facultatively anemogamous Chenopodiaceae). In many cases, however, the half- or entirely inferior position will have been developed in a previous entomophilous phase. This will also be the case in the female flowers with half- or entirely inferior ovaries (as in Fagaceae and some small-flowered Loranthaceae). The half- or entirely inferior ovaries in the female anemophilous flowers can be considered an ancestor's character state (see discussion).

Distribution of the various positions of the ovaries among the species belonging to the facultative and obligatory entomophilous pollination types

Beetle- and fly-pollinated flowers have about equal frequencies of half- to entirely inferior ovaries (table 6-12A). These frequencies are intermediate between those of the bee-pollinated flowers (lower) and butterfly- and mothpollinated flowers (higher) (tables 6-12A and 6-12A-4 and 5). The beetlepollinated flowers are of course often visited by Coleoptera but also very often by the non-apoid Hymenoptera (see table 6-1B). The fly-pollinated flowers are of about the same structure as the beetle-pollinated flowers, mostly, however, 
with somewhat deeper laying nectar. This means that also these flowers are often visited by Coleoptera and non-apoid Hymenoptera (table 6-1B). Compared with the bee-pollinated flowers (bees, operating with their tongues in most cases harmless to flowers), there is evidence that the biting mouth parts of the Coleoptera and non-apoid Hymenoptera formed the pressure favouring development of half- and entirely inferior ovaries (table 6-12A-4 and 5).

It appears that the butterfly- and moth-pollinated flowers have the highest frequency of half- to entirely inferior ovaries (tables 6-12A-4 to 6). The Lepidoptera operating with their long haustellae are harmless to flowers, thus there is no evidence that they form a pressure favouring the development of half- and entirely inferior ovaries. The explanation here may be that the inferior position of the ovaries can be considered a favourable condition for the development of (very) narrow corolla tubes. Perhaps the position of the ovaries is to some degree correlated with sympetaly. In fig. 6-13 it is demonstrated that among the entomogamous species those with sympetalous flowers have a strikingly higher frequency of half- to entirely inferior ovaries, than have those with choripetalous flowers. However, it is only one of the developments towards butterfly- or moth-pollinated flowers; in the obligatory psychophilous and phalaenophilous flowers a much lower frequency of half- to entirely inferior ovaries is found (table 6-12B).

Distribution of the various positions of the ovaries among obligatory entomophilous pollination types

Here the same tendencies are found as in the facultative and obligatory pollination types (tables 6-12B and 6-12B-2 and 3). The very high frequency in the myiophilous flowers is due to the definition of myiophily (see section 6.2.2); they are mostly visited by non-apoid Hymenoptera and Coleoptera (see table 6-3B).

Distribution of the various positions of the ovaries among the species of which the flowers are visited by the various insect groups, Qualitative analysis

The results of the qualitative analysis are presented in table 6-12C. Here it appears that the species of which the flowers are visited by insects with short, biting mouth parts (Coleoptera and non-apoid Hymenoptera) have higher frequencies of half- to entirely inferior ovaries, than have those visited by Apoidea and Lepidoptera (tables 6-12C-3 and 5).

Disposition of flower visits of the various insect groups with reference to the position of the ovaries, Quantitative analysis

Comparing the Coleoptera and non-apoid Hymenoptera with the Apoidea (tables 6-12D and 6-12D-1 and 3), the same tendencies are found as in the qualitative analysis. The Lepidoptera often visit flowers with half- to entirely 
inferior ovaries, but less than do the Coleoptera and non-apoid Hymenoptera (tables 6-12D-1 and 3).

\section{Discussion}

In part of the female anemophilous flowers and also in some cleistogamous flowers the ovaries remained half- to entirely inferior. It is suggested that the ovaries got these positions in an earlier entomophilous phase. These positions of the ovaries, then, must be considered an ancestor's character state (as the cenchri in the Symphyta, see section 5.2). Here it means: present, but without function, remnant of an older functional state. Apparently there are no pressures on the ovaries to become superior again. Because of this the half- or entirely inferior position of the ovaries has to be considered an apomorphous character state in the phylogeny of the Angiospermae. The following transformation series is established: superior- half-inferior- inferior position of the ovaries.

In relation to the phylogeny and fossil record of the insect taxa in which anthophily developed, it is clear that the pressure under which the ovaries became half- or entirely inferior was present from the very origin of the Angiospermae, since in the late Jurassic and early Cretaceous the Coleoptera and Symphyta were the main flower visitors. Thus, the lower positions of the ovaries may be of very early origin. From the middle Senonian (upper Cretaceous) Friis (1983) described some flowers of the genus Manningia with definite inferior ovaries.

The inferior position of the ovaries in some cases can be considered a favourable condition for the development of very narrow corolla tubes (petals implanted closer together) and may have played a role in some cases of the development of narrow, long-tubed flowers.

In table 6-14 a world survey is given, from which it can be suggested that the inferior (and perhaps also the half-inferior) position of the ovaries provided such a good protection of the ovules, that the taxa having these features could speciate more successfully than those with superior ovaries. Because of the fact that an inferior position of the ovaries occurs in some large families having small-flowered inflorescences with one ovule per flower (e.g. Asteraceae, according to Willis (1966) more than 13,000 species, and Apiaceae, about 3,000 species), the successful speciation for a large part also will be due to the extensive exploration of possible recombination (Burtt, 1961). In Orchidaceae (ca 20,000 species), however, the reverse will be the case. Starting from the presupposition that the development of taxa of higer rank takes more time than that of taxa of lower rank, particularly table 6-14B (genera per family) indicates that the development of half- and entirely inferior ovaries started 
Table 6-14. Numbers and frequencies of ovary position within the world's flora (A) and the numbers of genera per family, species per family and species per genus (B) for the superior and half- and entirely inferior positions of the ovaries. The numbers form an approach compiled after Willis (1966), inclusive the key to the families of flowering plants based on Engler's classification as given in the "Die natürlichen Pflanzenfamilien" incorporated in this dictionary. Families in which both superior and half- to entirely inferior ovary postion occur, are counted twice.

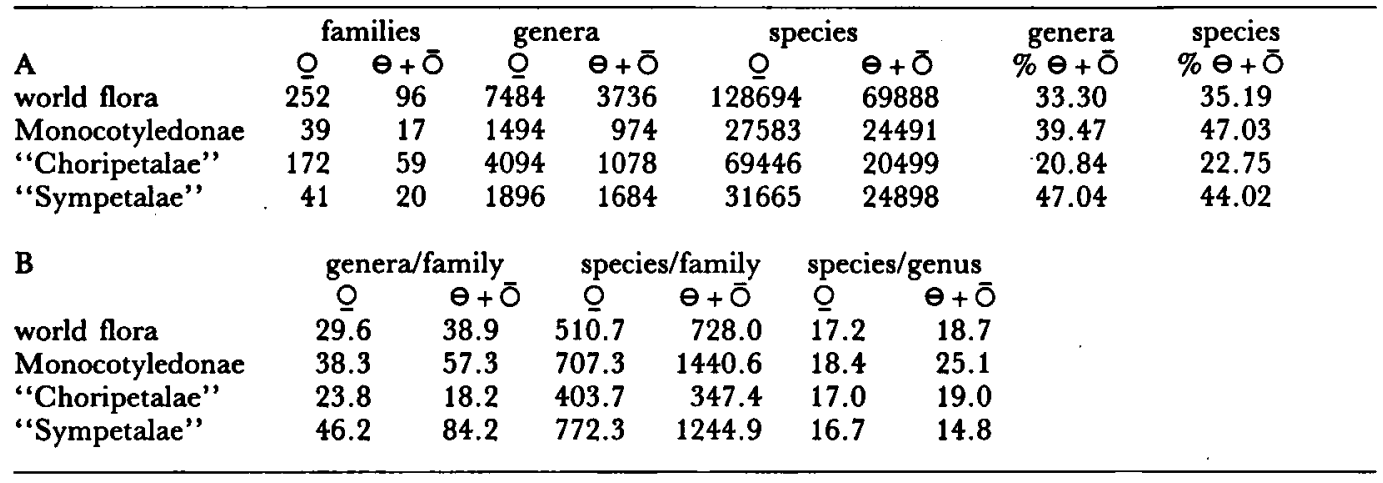

early in angiosperm phylogeny. An alternative explanation may be that the inferior position of the ovaries accellerated the speciation rate.

It appears that superior ovaries, both in the central European flora (table 612) and among the angiosperms world-wide (table 6-14), more often occur than half- and entirely inferior ovaries. This means that possible pollinator- or visitor-favoured developments of the latter only took place in certain groups of angiosperms (e.g. predecessors of Orchidaceae, Asteraceae, etc.). Increasing frequencies of entomogamy are accompanied by increasing frequencies of half- and entirely inferior ovaries (table 6-13), and there are slight indications that more specialized pollination types less often have these ovary positions (table 6-12).

\subsection{Numbers of ovules per stigma}

Every potential seed (ovule) needs a separate pollen grain for fertilization. It is therefore expected that increasing specialization (increasing directedness of the pollen vector) goes hand in hand with an increase of the number of ovules per stigma. This process is also reflected in increasing stickyness of the pollen and in the development of dyads, tetrads and polyads, culminating in the pollinia of some Orchidaceae and Asclepiadaceae. Cruden \& Jensen (1979) pointed out that e.g. viscin threads in pollen of Onagraceae and exinal connections in Caesalpiniaceae increase efficiency of pollination (clumps of pollen grains and subsequent low pollen-ovule ratio), i.e. many ovules per (large) stigma. Here the minimum numbers of ovules per stigma (carpel) are analysed. 


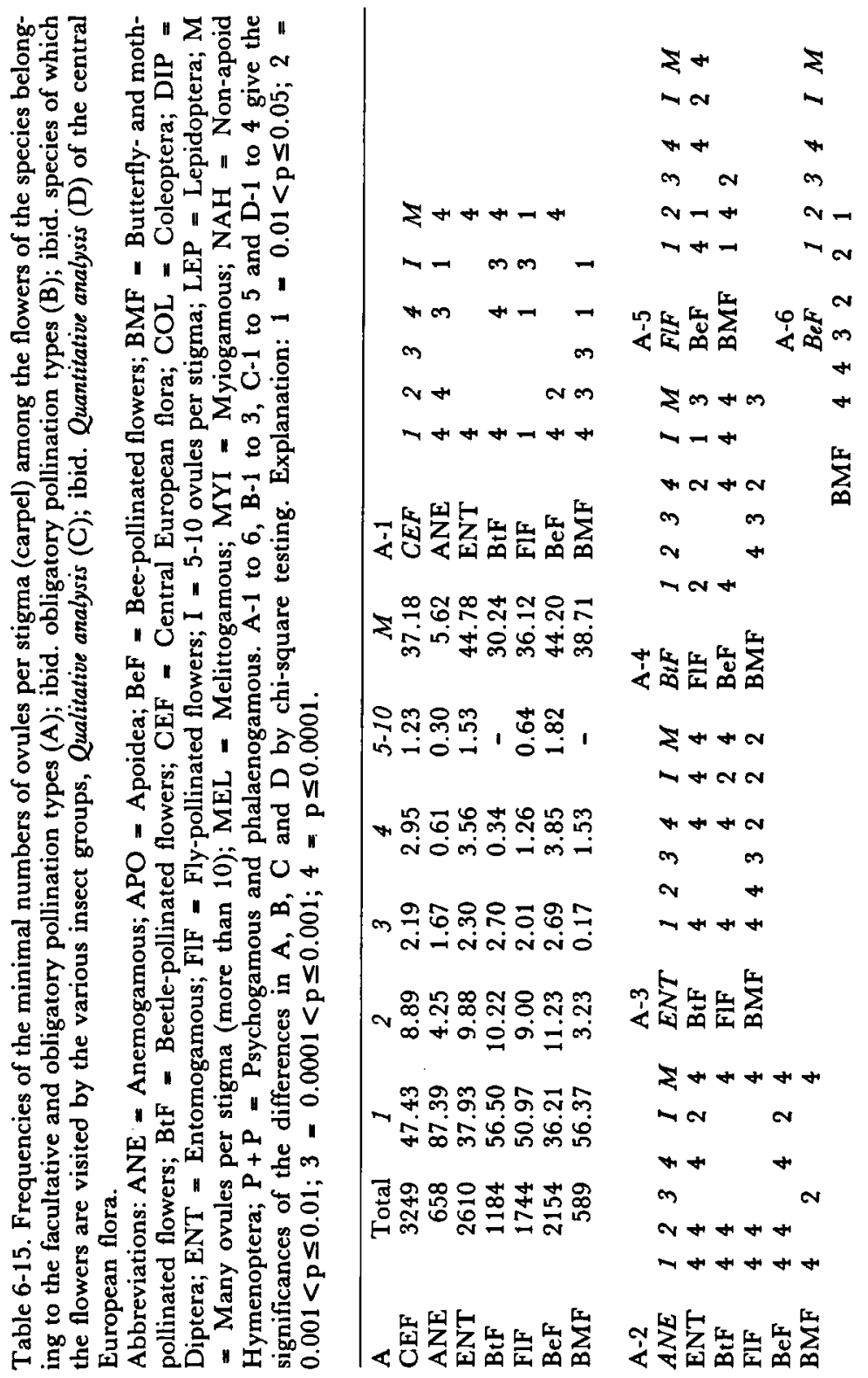




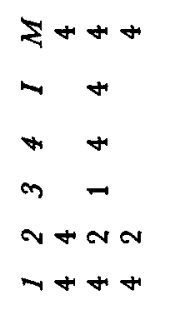

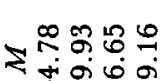

ษ人。்

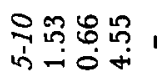

พ

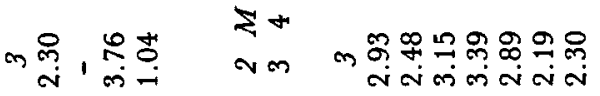

恶

ํㅐㅇำ

किष्च

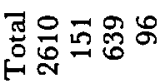

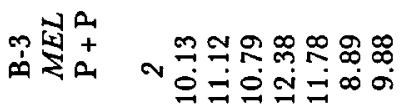

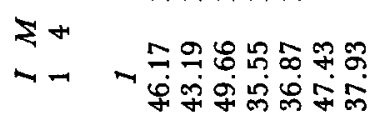

in

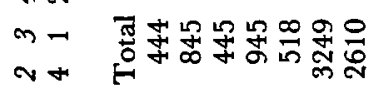

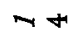

$$
\begin{aligned}
& \text { \& } \\
& \text { * } \rightarrow+m \\
& \text { m }-1 \\
& \text { N } \mathrm{N}- \\
& \text { ᄀー }
\end{aligned}
$$

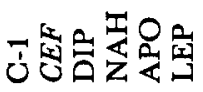

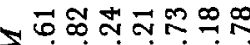

的品安安命

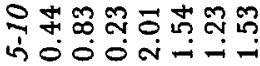

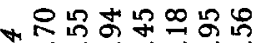
N

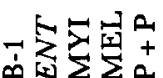

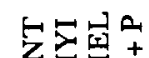

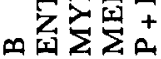

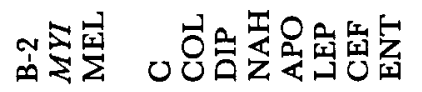

$\geq-$

$-1$

* NO

$r \quad m$

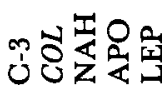

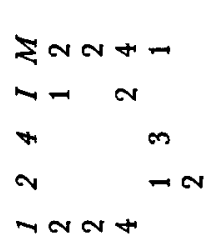

SNOW

$\sim-N$

$\sum m \pi+$

$\rightarrow+$

$\forall m \sim F$

$m n$

N $N+$

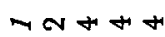

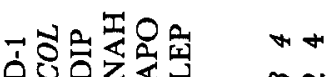
mor $v+$

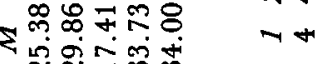
용 ले

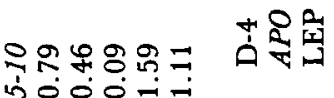
$\checkmark+$ *

けナ miñ

$\pi A+$

र

m กำ

ح

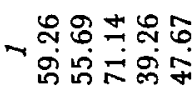

$\sum \pi+4$

$r+m$

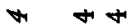
종 तै स 低A

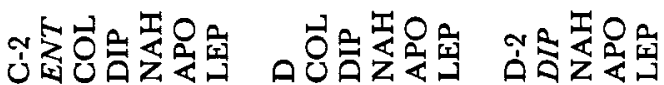


Distribution of the numbers of ovules per stigma among the anemophilous and entomophilous pollination types

It appears that anemophilous flowers have the lowest number of ovules per stigma (tables 6-15A and 6-15A-2). The higher number of ovules per stigma is correlated with entomophily.

Distribution of the numbers of ovules per stigma among the species belonging to the facultative and obligatory entomophilous pollination types

There appears to be a significant decrease of flowers with one ovule per stigma in the series: beetle-pollinated, fly-pollinated, bee-pollinated flowers (tables 6-15A and 6-15A-4 and 5). The butterfly- and moth-pollinated flowers have a higher frequency of one ovule per stigma than have the bee-pollinated flowers (table 6-15A-6).

Two ovules per stigma hardly discriminate between the facultative and obligatory pollination types; the butterfly- and moth-pollinated flowers have least often (tables 6-15A-4 to 6) and bee-pollinated flowers more often have two ovules per stigma than have fly-pollinated flowers (table 6-15A-5).

Three ovules per stigma do not discriminate between the facultative and obligatory pollination types, except for the lowest frequency of the butterflyand moth-pollinated flowers (tables 6-15A-4 to 6).

In four ovules per stigma an increase is found in the series: beetle-pollinated, fly-pollinated, bee-pollinated flowers (tables 6-15A-4 and 5), and the butterflyand moth-pollinated flowers have about as often four ovules per stigma as have the fly-pollinated flowers.

Five to ten ovules per stigma is only found in the fly- and bee-pollinated flowers and in the latter they occur more often than in the first (table 6-15A-5).

In the expectation mentioned above many ovules per stigma should be an apomorphous character state within the entomogamous groups and indeed the increased adaptation of the flowers to their pollinators (compare in this respect the flower types in table 6-5 and the blossom classes in table 6-6) in the series beetle-pollinated, fly-pollinated, bee-pollinated flowers, demonstrates an increase of the number of species with many ovules per stigma (tables 6-15A-4 and 5). Although the frequency of many ovules per stigma of the butterfly- and moth-pollinated flowers is higher than that of the beetle-pollinated flowers (table 6-15A-4), it is lower than that of the bee-pollinated flowers (table 6-15A-6).

The comparatively high frequency of one ovule per stigma of the butterflyand moth-pollinated flowers and the lower frequencies of all higher numbers of ovules per stigma than those of the bee-pollinated flowers, indicate that in the wide range of flowers "pollinatable" by the bees and those "pollinatable" by butterflies and moths, the bees may be considered more successful pollinators than the butterflies and moths. 
Distribution of the numbers of ovules per stigma among the obligatory entomophilous pollination types

It appears that the myiophilous flowers are least specialized to their pollinators concerning the numbers of ovules per stigma (tables 6-15B and 6-15B-2 and 3 ). Comparing the melittophilous with psychophilous and phalaenophilous flowers, the reverse is found as in the bee-pollinated and butterfly- and mothpollinated flowers (table 6-15B-3). Here, in the small ranges of more specialized obligatory melittophilous and psychophilous and phalaenophilous flowers the Lepidoptera appear be more effective pollinators than the (higher) Apoidea.

Distribution of the numbers of ovules per stigma among the species of which the flowers are visited by the various insect groups, Qualitative analysis

From this analysis it appears that the species of which the flowers are visited by the non-apoid Hymenoptera are least successfully pollinated by these insects (table 6-15C) if the numbers of ovules per stigma are taken as a criterium, directly followed by those visited by the Coleoptera and Diptera (tables 6-15-3 and 4). Mutual comparison of the species of which the flowers are visited by the Apoidea and Lepidoptera demonstrates no differences. Both species of which the flowers are visited by Apoidea and Lepidoptera respectively (tables 6-15C-3 to 5), differ from the species of which the flowers are visited by the other insect groups in one (less) and four (more) ovules per stigma (although only different from the species of which the flowers are visited by the non-apoid Hymenoptera).

Disposition of flower visits of the various insect groups with reference to the numbers of ovules per stigma, Quantitative analysis

In this quantitative analysis (table 6-15D) the same tendencies are found as in the qualitative analysis. The non-apoid Hymenoptera very often visit flowers with one ovule per stigma, followed by the Coleoptera and Diptera (tables 6-15D-1 and 2), and the Apoidea and Lepidoptera do so less (tables 615D-1 to 3). The Lepidoptera more often visit flowers with one ovule per stigma than do the Apoidea (table 6-15D-4). This is in accordance with the results of the analysis of the bee- and butterfly- and moth-pollinated flowers (table 6-15A-6). The Apoidea most often visit flowers with two, three, four and five to ten ovules per stigma than do the other insect groups included (tables 6-15D-1 to 4). In visiting flowers with many ovules per stigma there is an increase from the non-apoid Hymenoptera, via the Coleoptera and Diptera to the Apoidea and Lepidoptera (tables 6-15D-1 to 4). 


\section{Discussion}

The expectation mentioned at the beginning of this section is confirmed by this analysis. Increasing specialization of the pollination includes a tendency to develop more ovules per stigma.

Comparing these results with the phylogeny and fossil history of the insect taxa in which anthophily developed, it can be suggested that the earliest Angiospermae had only few ovules per stigma. In the upper Jurassic and Lower Cretaceous the Coleoptera and Symphyta were the main flower visitors and they probably transported the pollen diffusely spread over their integuments. To enlarge the chance of successful pollination the early Angiospermae may have had flowers with many stigmas, each corresponding to few ovules. In the probably early development of small-flowered, more compact inflorescences (see section 6.6) the same effect was reached. In the late Cretaceous the development of more ovules per stigma became functional with the appearance of the longer-tongued Diptera (more concentrated deposition of the pollen on the insect integument), and in the uppermost Cretaceous and early Tertiary the numbers of ovules could increase because of the development of more specialized flower-pollinator relationships at the differentiation of the long-tongued Apoidea and (very) long-haustellate Lepidoptera. As we have seen (section 6.10) this development was accompanied by a reduction of the numbers of stamens (in the single flower as a pollination unit) and certainly will also have been accompanied by a reduction of stigmas per flower (the latter not analyzed in this study). As has been mentioned in section 6.6 either manyovuled flowers and compact inflorescences with small, one-ovuled flowers can be considered apomorphous. The latter extensively explore possible recombination (Burtt, 1961). The more intensive exploration of possible recombination of larger flowers with many ovules per stigma will make them evolutionary more conservative than small-flowered inflorescences. However, this conservatism may be decreased by extensively delayed fertilization, as e.g. in the many-ovuled orchids Calanthe veitchii (5 weeks after pollination), Cypripedium insigne and Dendrobium nobile (10 to 12 weeks) (Poddubmayer-Arnoldi, 1960), providing a selection possibility between pollen of more specimens (see Willson \& Burley, 1983) and thus increasing extensive exploration of possible recombination.

It has to be mentioned that in this respect the ultimate number of seeds per stigma (carpel) can be different from the number of ovules. Only when the flower is sufficiently pollinated the number of seeds corresponds to the number of ovules, provided that there is no question of resource limitation (see Willson \& Burley, 1983). The latter seems to be mostly the limiting factor. Pollen limitation of seed production has been demonstrated in relatively few species. It often seems to occur in species flowering in (very) early spring: Arisaema 
triphyllum (Bierzychudek, 1981; Knuth, 1904 and 1905); Asimina trilobata (Willson Schemske, 1980; Knuth, 1904 and 1905); Phlox divaricata (Willson et al., 1979; according to Knuth (1905) earliest flowering Phlox species in the vicinity of Carlinville, Illinois); Podophyllum peltatum (Swanson \& Sohmer, 1976; Knuth, 1904 and 1905); and possibly in addition Trientalis europea (Hiirsalmi, 1969 ) at the high latitudes of Finland. It also occurs in some species in which self-pollination in practice is difficult or impossible, e.g.: Liriodendron tulipifera (Wilcox \& Taft, 1969; Knuth, 1904) and Vanilla species as V. fragans (Purseglove, 1972; Knuth, 1904 and 1905; McGregor, 1976).

\subsection{Nectar presence and position}

Here pollen-flowers and flowers containing nectar are distinguished. In this study pollen-flowers are the obligatory anemophilous flowers (see definition in section 6.2.1) and the entomophilous flowers which only offer pollen as food for their insect visitors (e.g. Anemone, Papaver, Hypericum, Helianthemum, Rosa, Solanum, Sambucus nigra), including the flowers of which the pollen can only be reached after special handling of the corolla (e.g. Sarothamnus, Genista). For a report on reward and deception in pollination ecologically apomorphous pollen flowers, see Vogel (1978b).

The flowers containing nectar are divided into groups according to the position of the nectar: free, half concealed, and entirely concealed. In flowers with free nectar it is always visible and can directly be reached by the visiting insects (e.g. most Apiaceae, Parnassia, Ilex, Lloydia, Saxifraga, Sambucus ebulus, Acer, Rhamnus, Euonymus). In flowers with the nectar half-concealed it is only visible in suitable circumstances (e.g. bright sunshine), otherwise it is covered in the "corners" of the flower basis (e.g. Brassicaceae, Caryophyllaceae-Alsinoideae, Ranunculus, Crataegus, Berberis, Fragaria, Potentilla, Sanguisorba). In flowers with entirely concealed nectar it is not visible whatever the circumstances are. The nectar is stored in the corolla tube, in spurs (e.g. Corydalis, Fumaria, Viola, Linaria, Gymnadenia), or is covered in other ways, e.g. by hairs (Swertia, Lamium, Verbena, Valeriana, etc.).

Distribution of nectar presence and position among the anemophilous and entomophilous pollination types

It is clear (tables 6-16A and 6-16A-2) that the presence of nectar is a floral adaptation to insect pollination. Few flowers are facultatively anemophilous and some of therr may produce some nectar (some Chenopodiaceae).

Distribution of nectar presence and position among the species belonging to the facultative and obligatory entomophilous pollination types

It is demonstrated that the frequencies of pollen flowers decrease in the series: beetle-pollinated, fly- and bee-pollinated, butterfly- and moth- 
Table 6-16. Frequencies of nectar presence and position among the flowers of the species belonging to the facultative and obligatory pollination types (A); ibid. obligatory pollination types (B); ibid. species of which the flowers are visited by the various insect groups, Qualitative analysis (C); ibid. Quantitative analysis (D) of the central European flora.

Abbreviations: ANE = Anemogamous; $\mathrm{APO}=$ Apoidea; $\mathrm{BeF}=$ Bee-pollinated flowers;

$\mathrm{BMF}=$ Butterfly- and moth-pollinated flowers; $\mathrm{BtF}=$ Beetle-pollinated flowers; $\mathrm{C}=$ Nectar concealed; $\mathrm{CEF}=$ Central European flora; COL $=$ Coleoptera; DIP = Diptera; ENT = Entomogamous; F = Nectar free; FlF = Fly-pollinated flowers; HC = Nectar half-concealed; LEP = Lepidoptera; MEL = Melittogamous; MYI = Myiogamous; NAH = Non-apoid Hymenoptera; $P=$ Pollen-flower; $P+P=$ Psychogamous and phalaenogamous. A-1 to $6, B-1$ and 2, C-1 to 6 and D-1 to 4 give the significances of the differences in $A, B, C$ and $D$ by chi-square testing. Explanation: $1=0.01<\mathrm{p} \leq 0.05 ; 2=0.001<\mathrm{p} \leq 0.01 ; 3=0.0001<\mathrm{p} \leq 0.001 ; 4 \mathrm{p} \leq 0.0001$.

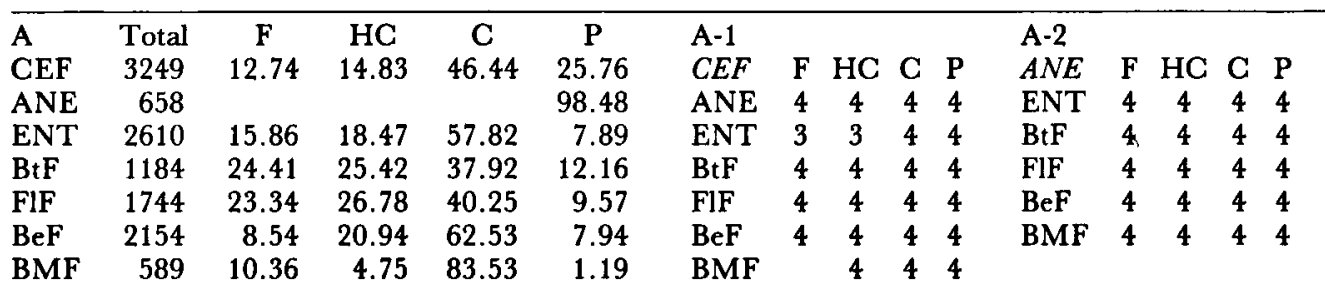

A-3

ENT

$\begin{array}{lllll}\mathrm{BtF} & 4 & 4 & 4 & 4 \\ \mathrm{FIF} & 4 & 4 & 4 & \end{array}$

$\mathrm{BeF} 44 \quad 4$
A-4

BtF

FIF

BeF

B

ENT 2610

MYI 151

MEL 639

$\mathrm{P}+\mathrm{P} \quad 96$

$\begin{array}{lccc}\text { C } & \text { Total } & \text { F } & \text { HC } \\ \text { COL } & 444 & 20.04 & 20.04\end{array}$

$\begin{array}{llll}\text { COL } & 444 & 20.04 & 20.04 \\ \text { DIP } & 845 & 18.34 & 19.88\end{array}$

$\begin{array}{llll}\text { NAH } & 445 & 25.62 & 18.65\end{array}$

APO $\quad 945 \quad 12.59$

LEP $\quad 518 \quad 11.20$

CEF $\quad 3249 \quad 12.74$

ENT $\quad 2610 \quad 15.86$

14.81

12.74

14.83

18.47

F $\quad \mathrm{HC} \quad \mathrm{C} \quad \mathrm{P}$

A-5

FlF $\quad$ F HC $\quad$ C $\quad$ P $\begin{array}{lcccc}\text { BeF } & 4 & 4 & 4 & \\ \text { BMF } & 4 & 4 & 4 & 4\end{array}$

\section{A-6}

BeF F HC C $\begin{array}{llll}\text { BMF } & 4 & 4 & 4\end{array}$

$\begin{array}{llllllllllllllllll}\text { C-3 } & & & & & \text { C-4 } & & & & \text { C-5 } & & & & \\ \text { COL } & \text { F } & \text { HC } & \text { C } & \text { P } & \begin{array}{l}\text { DIP } \\ \text { NAH }\end{array} & \text { F } & \text { HC } & \text { C } & \text { P } & \text { NAH } & \text { F } & \text { HC } & \text { C } & \text { P } & A P O & \text { C } & \text { P } \\ \text { APO } & 3 & 1 & 4 & 1 & \text { APH } & 2 & & 1 & & \text { APO } & 4 & & 4 & 1 & \text { LEP } & 1 & 1 \\ \text { LEP } & 3 & 2 & 4 & 4 & \text { LEP } & 3 & 2 & 4 & 1 & \text { LEP } & 4 & 1 & 4 & 3 & & & \\ \end{array}$

\begin{tabular}{|c|c|c|c|c|c|c|c|c|c|c|c|c|c|c|}
\hline D & Total & $F$ & HC & C & $\mathbf{P}$ & D-1 & & & & & D-2 & & & \\
\hline $\begin{array}{l}\text { COL } \\
\text { DIP }\end{array}$ & $\begin{array}{l}1598 \\
6628\end{array}$ & $\begin{array}{l}37.61 \\
32.66\end{array}$ & $\begin{array}{l}16.52 \\
17.98\end{array}$ & $\begin{array}{l}35.61 \\
43.32\end{array}$ & $\begin{array}{r}10.01 \\
5.96\end{array}$ & $\begin{array}{l}\text { COL } \\
\text { DIP }\end{array}$ & $\begin{array}{l}F \\
3\end{array}$ & $\mathrm{HC}$ & $\begin{array}{l}C \\
4\end{array}$ & $\begin{array}{l}P \\
4\end{array}$ & $\begin{array}{l}D I P \\
\text { NAH }\end{array}$ & $\begin{array}{l}F \\
4\end{array}$ & $\begin{array}{c}\mathrm{HC} \\
4\end{array}$ & $\begin{array}{l}C \\
4\end{array}$ \\
\hline NAH & 2148 & 59.54 & 10.33 & 27.56 & 2.56 & $\mathrm{NAH}$ & 4 & 4 & 4 & 4 & APO & 4 & 4 & 4 \\
\hline APO & 7918 & 13.17 & 13.00 & 69.56 & 4.23 & APO & 4 & 2 & 4 & 4 & LEP & 4 & 4 & 4 \\
\hline LEP & 2867 & 6.35 & 7.57 & 83.68 & 2.41 & LEP & 4 & $\vec{A}$ & 4 & 4 & & & & \\
\hline
\end{tabular}


Table 6-16 (Continued)

$\begin{array}{lccccccccc}\text { D-3 } & & & & & \text { D-4 } & & & & \\ \text { NAH } & \text { F } & \text { HC } & \text { C } & \text { P } & \text { APO } & \text { F } & \text { HC } & \text { C } & \text { P } \\ \text { APO } & 4 & 4 & 4 & 3 & \text { LEP } & 4 & 4 & 4 & 4 \\ \text { LEP } & 4 & 3 & 4 & & & & & & \end{array}$

pollinated flowers (tables 6-16A and 6-16A-4 to 6). In nectar presence the beetle- and fly-pollinated flowers do not differ (table 6-16A-4). Both more often have free nectar and half-concealed nectar than have bee- and butterfly- and moth-pollinated flowers (tables 6-16A-4 and 5). The reverse is found in flowers with concealed nectar (tables 6-16A-4 to 6).

The rather high frequencies of concealed nectar for beetle- and fly-pollinated flowers are probably mainly derived from phanerantherous flowers. In the central European area only some flies (mainly Bombyliidae and some Syrphidae) can reach deeper concealed nectar, the others and the Coleoptera will visit these flowers to feed on pollen (e.g. as is the case in many Asteraceae; see discussion).

Distribution of nectar presence and position among the species belonging to the obligatory entomophilous pollination types

It appears that the myiophilous flowers most often have free nectar (tables 6-16B and 6-16B-2) (see in this respect the definition of myiophily in section 6.2.2). Comparison of the obligatory pollination types demonstrates the same tendencies as in the facultative and obligatory pollination types (table 6-16B-2).

Distribution of nectar presence and position among the species of which the flowers are visited by the various insect groups, Qualitative analysis

The frequencies of the qualitative analysis are presented in table 6-16C. Species of which the flowers visited by the Coleoptera, Diptera and non-apoid Hymenoptera most often appear to be pollen flowers. In this respect they differ from the species of which the flowers are visited by the Apoidea and Lepidoptera (tables 6-16C-3 to 5). Species of which the flowers are visited by the non-apoid Hymenoptera have most often free nectar (tables 6-16C-3 to 5), those visited by the Diptera and Coleoptera have somewhat less, and those visited by the Apoidea and Lepidoptera have least free nectar. In flowers with half-concealed nectar about the same tendency is found: species of which the flowers are visited by the Coleoptera, Diptera and non-apoid Hymenoptera have more often half-concealed nectar than those visited by the Apoidea and Lepidoptera (although the flowers visited by the non-apoid Hymenoptera do not differ from those visited by the Apoidea) (tables 6-16C-3 to 5). Species of which the flowers are visited by the Apoidea and Lepidoptera have more often concealed nectar than those visited by the other insect groups (tables 6-16C-3 to 6). 
Disposition of flower visits of the various insect groups with reference to nectar presence and postion, Quantitative analysis

In the quantitative analysis in general the same tendencies are found as in the qualitative analysis (tables 6-16D and 6-16D-1 to 4). In visiting pollen flowers there appears to be a significant decrease in the series: Coleoptera, Diptera, Apoidea, non-apoid Hymenoptera and Lepidoptera. In visiting flowers with free nectar a similar decrease is found in the series: non-apoid Hymenoptera, Coleoptera, Diptera, Apoidea, and Lepidoptera. It appears that the Diptera more often visit flowers with half-concealed nectar than do the Apoidea, non-apoid Hymenoptera and Lepidoptera. In visiting flowers with concealed nectar there appears to be an increase in the series: non-apoid Hymenoptera, Coleoptera, Diptera, Apoidea, Lepidoptera.

\section{Discussion}

It appears that the flower-visiting of anthophilous insects corresponds with the presence and position of nectar in the flowers. In the series: Coleoptera, Diptera, Apoidea, non-apoid Hymenoptera and Lepidoptera (table 6-16D) the attraction by pollen only, decreases. All insect groups appear to visit mainly nectar-containing flowers. This means that it is not possible to derive directly stochastic propositions on the plesio- or apomorphy of pollen or nectar as an attractant for anthophilous insects. Here a proper stochastic proposition requires extensive knowledge of the feeding-habits on the flowers of the insect groups. For this reason comparison with the phylogeny and fossil record of the insect taxa in which anthophily developed, will also not answer this question. Thus, it cannot be suggested whether the earliest Angiospermae had nectar or not. Willemstein (1978) carried out extensive pollen analyses on the contents of the digestive tracts and integuments of central European Cetoniinae, Cerambycinae and Lepturinae. The results of these analyses are given in the appendix in four tables arranged after nectar position and presence. From the totals in these tables it appears that the Coleoptera in $27.8 \%$ fed on pollen flowers. This frequency is much higher than those found in the analyses of table 6-16. In table 6-17 it is demonstrated that on nectar-containing flowers often also pollen was eaten (in $77.4 \%$ of the visits). The only indication that only nectar is eaten can be found in the cases in which the pollen was found on the integument and not in the digestive tract (possibly these frequencies are somewhat too high because of some contamination of pollen from the integuments of other beetles during the pollen-sampling, although the utmost care was taken to avoid this, and by collecting the beetles from the flowers before they started to feed). We then see in table 6-17 that Coleoptera very often feed on pollen while visiting nectar-containing flowers. In the cases of free- and half-concealed nectar it is possible that they also fed on nectar (the 
presence of nectar in the digestive tracts has not been checked) (see table 617B). However, it can be concluded that it is possible that for the Coleoptera during the upper Jurassic and early Cretaceous feeding on pollen could have sufficed and that they were fairly effective pollinators. It would be interesting to carry out also pollen analyses on the contents of the integuments and digestive tracts of the other anthophilous insects which were already present in the upper Jurassic and early Cretaceous. Incidentally one should mention that Coleoptera function least as pollinators on flowers with entirely concealed nec$\operatorname{tar}$ (in this sample mainly represented by the Asteraceae) (see table 3 in the appendix, and table 6-17B).

Table 6-17. Frequencies of the occurrence of pollen in or on Coleoptera (Cetoniinae, Cerambycinae, Lepturinae) which visited nectar-containing flowers. Abbreviations : $\mathrm{d}=$ digestive tract; $\mathrm{i}=$ integument.

\begin{tabular}{lccccccc}
\hline A & Total & $\mathrm{d}+\mathrm{i}$ & $|\mathrm{i}|$ & $|\mathrm{d}|$ & $\mathrm{B}$ & $\boldsymbol{\Sigma} \mathrm{d}$ & $\boldsymbol{\Sigma} \mathbf{i}$ \\
nectar free & 587 & 54.00 & 23.34 & 22.66 & 76.66 & 77.34 \\
nectar half-concealed & 200 & 60.00 & 28.00 & 12.00 & 72.00 & 88.00 \\
nectar concealed & 318 & 30.82 & 17.93 & 51.26 & $\mathbf{8 2 . 0 8}$ & 48.75 \\
\hline
\end{tabular}

It is clear that once nectar is present the development from a free position, through half-concealed to entirely concealed could start. Half-concealed nectar, and perhaps to some degree also entirely (but not very deeply) concealed nectar could have become functional in the Upper Cretaceous, and the deeper hiding of the nectar probably developed in the latest Cretaceous and early Tertiary, to become functional at the appearance of the Lepidoptera with long haustella. Entire concealment of the nectar as an adaptation to long-tongued Apoidea may have started at about the same time, but deeper hiding became functional in the later Teriary at the appearance of the higher Apoidea.

It can be concluded that if the nectar becomes more concealed, highly specialized insects will visit the flowers. Within the Apiaceae Bell (1971) found that Zizia aurea (in which the strongly induplicate petals do not spread, but rather remain erect forming an effective "corolla tube" of one mm length or more, through which only the very centre of the stylopodium is exposed to the pollinators, whereas the nectar is almost entirely concealed) and Eryngium yuccifolium (in which a septum between the basal and apical portions of the infolded petals prevents the petal from straightening, the septa together forming a kind of "corolla tube") are more often visited by longer-tongued Apoidea and the latter also by Lepidoptera, than are Cicuta maculata, Heracleum lanatum, Pastinaca sativa, Sium suave and Sanicula marilandica, having entirely exposed nectar. Bell (1971) concluded that once developed, specialization for 
pollinator-plant specifity will be difficult to reverse. Knuth (1898) also mentioned already that the central European species of Eryngium are more visited by Lepidoptera with long haustella than are the other Apiaceae of this area. Although the most probable development is from pollen to nectar-containing flowers Daumann (1972 and 1975) found the reverse in some species of Mercurialis and Ulmus.

\subsection{Varation in time between receptivity and dehiscence}

\subsubsection{Protandry and protogyny}

In this section the variation in time between receptivity and dehiscence is analysed. The various possibilities can be defined as follows:

Homogamy: anthers and stigma(s) of the same flower or on different flowers in monoecious plants ripening at the same time (no difference in time between receptivity and dehiscence);

Dichogamy: anthers and stigma(s) of the same flower or on different flowers in monoecious plants ripening at different times (difference in time between receptivity and dehiscence).

Dichogamy is expressed in two ways:

Protandry: anthers ripening before the stigma(s) of the same flower or, (second order protandry) on different flowers in monoecious plants is (are) receptive (dehiscence preceeds receptivity);

Protogyny: stigma(s) réceptive before the anthers of the same flower or, (second order protogyny) on other flowers in monoecious plants discharge their pollen (receptivity preceeds dehiscence).

The differences in time between receptivity and dehiscence are rarely absolute. There often is overlap with homogamy. This is why the sum of the frequencies in table 6-18 exceeds 100 percent. The totals of the numbers of species are lower than in the analyses of the other character states. This is due to the fact that dioecious plants are excluded, and that of many species of the central European flora the receptivity-dehiscence ratio is not known.

Here we will try to establish whether differences in time between receptivity and dehiscence can be considered floral adaptations to avoid damage to the ovules by anthophilous insects with anthophagous habits.

Distribution of the variation in time between receptivity and dehiscence among the anemophilous and entomophilous pollination types

It appears that homogamy less often occurs in anemogamous species than in entomogamous species (tables 6-18 A and 6-18A-2). Most anemophilous flowers are protogynous, more often than are fly-, bee-, and butterfly- and moth-pollinated flowers, and about to the same extent as the beetle-pollinated 
Table 6-18. Frequencies variation in time between receptivity and dehiscence among the flowers of the species belonging to the various facultative and obligatory pollination types (A); ibid. obligatory pollination types (B); ibid. species of which the flowers are visited by the various insect groups, Qualitative analysis (C); ibid Quantitative analysis (D) of the central European flora.

Abbreviations: $\mathrm{ANE}=$ Anemogamous; $\mathrm{APO}=$ Apoidea; $\mathrm{BeF}=$ Bee-pollinated flowers; BMF Butterfly- and moth-pollinated flowers; $\mathrm{BtF}=$ Beetle-pollinated flowers; CEF = Central European flora; COL = Coleoptera; DIP = Diptera; ENT = Entomogamous; FlF = Fly-pollinated flowers; $\mathrm{H}=\mathrm{HOM}$ = Homogamous; LEP = Lepidoptera; MEL = Melittogamous; MYI = Myiogamous; $\mathrm{NAH}=$ Non-apoid Hymenoptera; $\mathbf{P}+\mathbf{P}=$ Psychogamous and phalaenogamous; $\mathrm{PA}=\mathrm{Pa}=$ Protandrous; $\mathbf{P G}=\mathbf{P g}=$ Protogynous.

A-1 to $6, \mathrm{~B}-1$ and 2, C-1 to 4 and D-1 to 4 give the significances of the differences in A, B, C and $\mathrm{D}$ by chi-square testing. Explanation: $1=0.01<\mathrm{p} \leq 0.05 ; 2=0.001<\mathrm{p} \leq 0.01 ; 3=$ $0.0001<\mathrm{p} \leq 0.001 ; 4=\mathrm{p} \leq 0.0001$.

\begin{tabular}{|c|c|c|c|c|c|c|c|c|c|c|c|}
\hline $\begin{array}{l}\text { A } \\
\text { CEF }\end{array}$ & $\begin{array}{l}\text { Total } \\
2830\end{array}$ & $\begin{array}{c}\text { HOM } \\
64.21\end{array}$ & $\begin{array}{c}\text { PA } \\
31.20\end{array}$ & $\begin{array}{c}\text { PG } \\
41.66\end{array}$ & $\begin{array}{l}\text { A-1 } \\
C E F\end{array}$ & $\mathrm{H} \mathrm{Pa} \mathrm{Pg}$ & $\begin{array}{l}\mathrm{A}-2 \\
A N E\end{array}$ & $\mathrm{H} \mathrm{Pa} \mathrm{Pg}$ & $\begin{array}{l}\text { A-3 } \\
E N T\end{array}$ & & $\mathrm{Pg}$ \\
\hline ANE & 481 & 51.35 & 3.53 & 70.89 & ANE & 244 & ENT & 244 & $\mathrm{BtF}$ & 4 & 4 \\
\hline ENT & 2368 & 66.60 & 36.61 & 36.40 & ENT & 2 & $\mathrm{BtF}$ & 4 & FlF & & 4 \\
\hline $\mathrm{BtF}$ & 1009 & 51.54 & 33.99 & 60.95 & $\mathrm{BtF}$ & 4 & FlF & 1 & $\mathrm{BeF}$ & 2 & \\
\hline FIF & 1553 & 61.75 & 35.16 & 49.78 & FlF & 2 & $\mathrm{BeF}$ & 2 & BMF & 4 & 4 \\
\hline $\mathrm{BeF}$ & 1970 & 66.65 & 30.71 & 41.07 & BMF & 1 & BMF & 4 & & & \\
\hline
\end{tabular}

$\begin{array}{lllll}\text { BMF } & 537 & 29.61 & 38.55 & 52.89\end{array}$

\begin{tabular}{|c|c|c|c|c|c|}
\hline $\begin{array}{l}\text { A-4 } \\
B t F\end{array}$ & H Pg & $\begin{array}{l}\text { A-5 } \\
F l F\end{array}$ & $\mathrm{H} \mathrm{Pa} \mathrm{Pg}$ & $\begin{array}{l}\text { A-6 } \\
B e F\end{array}$ & $\mathrm{H} \mathrm{Pa} \mathrm{Pg}$ \\
\hline FlF & 22 & $\mathrm{BeF}$ & 12 & BMF & 412 \\
\hline $\begin{array}{l}\text { BeF } \\
\text { BMF }\end{array}$ & $\begin{array}{ll}4 & 4 \\
4 & \end{array}$ & BMF & 4 & & \\
\hline
\end{tabular}

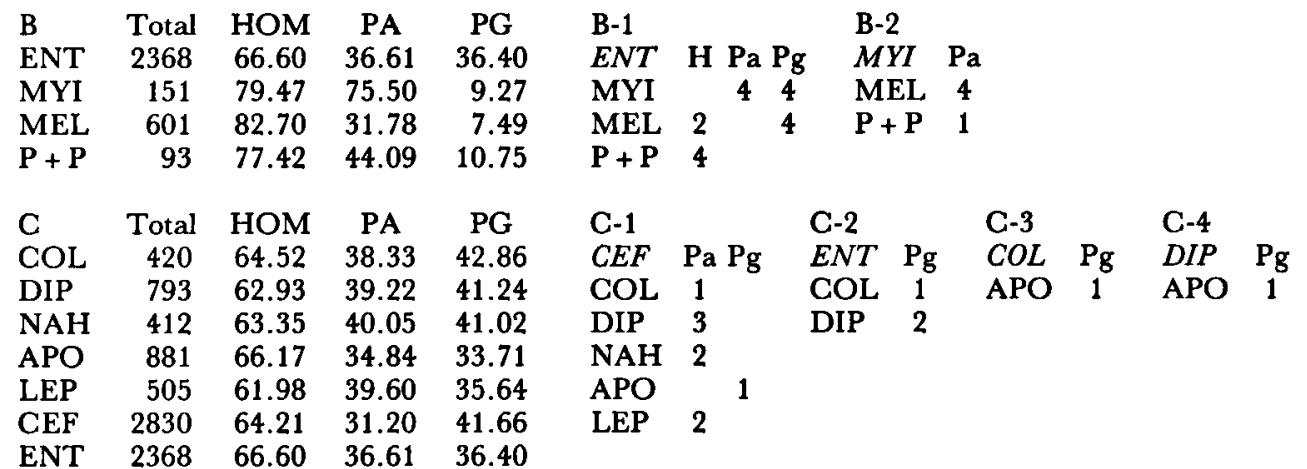

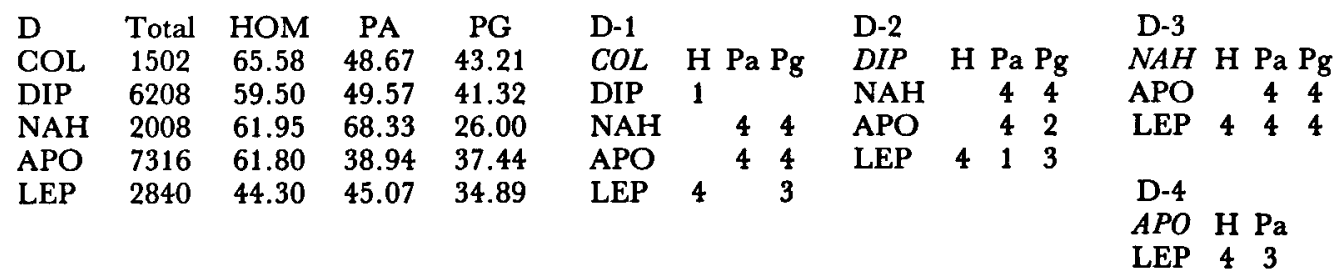


flowers. Protandry is very rare among the anemophilous flowers and it can be concluded that this state of dichogamy is typical for entomophilous flowers.

The totals of dichogamy (sums of the frequencies of protandry and protogyny) do not differ between anemophilous and entomophilous flowers (74.42\% and $73.01 \%$, respectively). Within the anemophilous flowers, and also in comparison with the zoophilous flowers, the differences between protandry and protogyny are striking. Protogyny is a more effective adaptation to avoid self-fertilization than is protandry (see Faegri \& Van der Pijl, 1980). After pollen has germinated on the stigma, there is competition for the ovules. Under these circumstances, it is obvious that receptivity of the stigma even a few hours before the anthers open, will mean that any allogamous pollen received during these hours will have the greatest chance to carry out fertilization (by contrast, in order to be effective, protandry must be total: all pollen of the individual in question being swept out of the flower or out of the male flowers in case of monoecious plants, before the stigma(s) become(s) receptive).

Here it can be concluded that in the least specialized pollen-depositing on the stigma(s), that by wind, protogyny has an advantage over protandry in achieving cross-pollination (fertilization). In protandry the insect behaviour, guided by the flower or inflorescence may provide sufficient defence against self-pollination (see below). Homogamy will cause self-pollination unless it is combined with protogyny. It is therefore not surprising that anemophilous flowers are less often homogamous than are the entomophilous flowers.

Distribution of the variation in time between receptivity and dehiscence among the flowers of the species belonging to the facultative and obligatory entomophilous pollination types

It appears that the most specialized flowers (butterfly- and moth-pollinated) flowers have the lowest frequency of homogamy (tables 6-18A and 6-18A-4 to 6). This may be due to the fact that in the non-obligatory psychophilous and phalaenophilous flowers the spatial separation of the anthers and the stigma(s) is such that under homegamous conditions self-pollination would happen too easily (in the obligatory psychophilous and phalaenophilous flowers the frequency of homogamy is not as low as in the facultative and obligatory pollination types; compare table 6-18B). Particularly the difference with the beepollinated flowers (table 6-18A) in this respect may be compared with table 62 , which demonstrates that fewer of the butterfly- and moth-pollinated flowers are obligatory psychophilous or phalaenophilous, than bee-pollinated flowers are obligatory melittophilous. Entire clarification of this phenomenon, however, requires further research.

The beetle-pollinated flowers are less often homogamous than are the flyand bee-pollinated flowers. This may be due to the fact that in the least specialized entomophilous flowers (beetle-pollinated flowers) in pollen deposi- 
tion on the stigma(s) the spatial separation of anthers and stigma(s), prevents self-pollination to a lesser extent than it does in the more specialized fly- and bee-pollinated flowers. In protandry there are no striking differences between the facultative and obligatory pollination-types. As has been mentioned before, protandry seems to be characteristic for entomophilous flowers. Protandry, particularly in case of inflorescences, requires guidance of the visiting insects. It is not improbable that without guidance the visiting insects show different behaviour on the flowers or inflorescences. Because protandry in inflorescences causes second order herkogamy, sufficient cross-pollination can be achieved by attraction of the pollinators to certain parts of the inflorescence by colours and/or odour, once the insects have alighted by guidance by the presence of nectar. Striking examples of such guidances are found in many Asteraceae. The insects alight on or in the vicinity of the ray-flowers, guided by their colours, and after alighting, guided by the nectar, they first visit the flowers with receptive stigmas, then the flowers with ripe pollen and finally because of the absence of further nectar they will leave the inflorescence. Second order herkogamy is also caused in protogynous inflorescences and here the nectar will be the guidance for correct orientation of the insect movements over the inflorescence. Here it probably will be the topmost or central flowers of the inflorescence which guide the alighting of the insects. In protogyny it is demonstrated that the frequencies decrease with the increase of the specialization of the facultative and obligatory pollination types, except for the butterflyand moth-pollinated flowers. The frequencies of protogyny decrease in the series: beetle-pollinated, fly-pollinated, bee-pollinated flowers (tables 6-18A and 6-18A-4 and 5). The comparatively high frequency of protogyny among the butterfly- and moth-pollinated flowers, about as high as in the flypollinated flowers, may indicate that there may be taxonomical relationships between the species having these flowers.

Distribution of the variation in time between receptivity and dehiscence among the obligatory entomophilous pollination types

There is slight evidence that the obligatory pollination types more often are homogamous than are the entomophilous flowers in general. The melittophilous flowers do not differ from the myiophilous and psychophilous or phalaenophilous flowers, but they do from the entomophilous flowers in general (tables 6-18B and 6-18B-1 and 2). The myiophilous flowers are most often protandrous, due to the definition of myiophily in section 6.2 in which e.g. many Apiaceae fit (they will have a considerable share in the myiophilous flowers). It appears that the obligatory pollination types have much less protogyny than the entomophilous flowers in general (and the separate facultative and obligatory pollination types. Compare in this respect tables 6-18A and B) demonstrating that in more specialized insect-flower relationships protandry 
can be as effective in avoiding self-pollination as is protogyny and that the spatial separation of the anthers and stigma(s) in specialized flowers makes protogyny redundant and allows more homogamy.

Distribution of the variation in time between receptivity and dehiscence among the species of which the flowers are visited by the various insect groups, Qualitative analysis

It appears that, comparing the species of which the flowers are visited by the various insect groups, there are only minor differences (tables 6-18C and 6$18 \mathrm{C}-3$ and 4). Thus the qualitative analysis gives no evidence that dichogamy can be considered an adaptation preventing the ovules being damaged by anthophilous insects with anthophagous habits.

Disposition of flower visits of the various insect groups with reference to the variation in time between receptivity and dehiscence, Quantitative analysis

Here it also appears that (as in the facultative and obligatory pollination types) that the Lepidoptera least often visit homogamous flowers (tables 6-18D and 6-18D-1 to 4). The Apoidea least often visit protandrous flowers and the non-apoid Hymenoptera do so mostly. This may be due to the fact that the first more often visit single flowers as a pollination unit than do the latter (compare table 6-7D), taking into account that protandry possibly mainly occurs in (small-flowered) inflorescences. Except for the non-apoid Hymenoptera it appears that the least specialized insects (here the Coleoptera and Diptera) visit protogynous flowers more than do the more specialized insects (Apoidea and Lepidoptera).

The totals of the visits of the various insect groups to dichogamous flowers illustrate a slight difference between the Coleoptera, Diptera and non-apoid Hymenoptera on the one hand, and the Apoidea and Lepidoptera on the other. It is, however, questionable, because of irregular differences in protandry, only a distinct tendency in protogyny, whether this corresponds with ovule-protection against injurious visits of anthophilous insects with anthophagous habits. Dichogamy will have as main function reduction of selfpollination (Darwin, 1876; Cruden and Hermann-Parker, 1977; Faegri \& Van der Pijl, 1980; Thomson \& Barret, 1981).

\section{Discussion}

Because the flower represents the end of a stem, the "natural" development of the appendages is centripetal. This means that the most "logical" sequence of ripening within the flowers is: calyx, corolla, androecium, gynoecium. Protandry, thus, is the most "logical" phenomenon. Homogamy (simultaneous ripening of the pollen and the stigma(s)) is a consistent telescoping of the development of appendages in the floral region, protogyny is the reversal of 
the regular order of events. Following this reasoning it would appear that protandry has to be considered the most plesiomorphous variation in time between receptivity and dehiscence, at any rate accompanied by a homogamous phase.

It is, however, questionable whether protandry, being the most "logical" phenomenon, is the plesiomorphous state of dichogamy within the Angiospermae. In the Gymnospermae, within part of which the sister-group of the Angiospermae most probably has to be sought (e.g. Hill \& Crane (1982) mentioned in this respect the "Coniferophytes", except for Ginkgo, and Crane $(1985,1985$ a) mentioned Gnetum + Welwitschia + Ephedra), both protandry and second order protogyny developed. The first has been found in the hermaphroditic reproductive structures of Cycadeoidea (Crepet, 1972 and Gothan \& Weyland, 1973) and the second has been observed in the diclinous, monoecious Pinus sylvestris (Kirchner in Knuth 1899: 566). Protogyny in monoecious Gymnospermae is an effective adaptation to favour crosspollination (see above). It would be the same for the hermaphroditic reproductive structures, but here protogyny was not found. These structures, however, are very rare in the fossil record, and it can be questioned whether the few observations definitely indicate the absence of protogyny. In the continuation of this discussion it will be argued that the occurrence of protogyny in these reproductive structures is very improbable.

The positioning of the microsporangiate and ovulate reproductive organs in close proximity in the Gymnospermae, forming hermaphroditic reproductive structures, resulted in the microsporangiate structures subtending the ovulate ones (pre-angiosperm evolutionary development, mentioned by Dilcher (1979)). In Cycadeoidea and Williamsoniella the microsporophylls will form the optical attractant to insects. Although many anemogamous Angiospermae have hermaphroditic flowers (see section 6.15), the hermaphroditic reproductive structures in the Gymnospermae probably were not anemophilous (Irania hermaphroditica possibly excepted). An indication for this is that these structures were not inconspicuous. Most of them can be classified in the conspicuous (yellow pollen or -"leaf"' colour) dish- to bowl-shaped bossom class (see section 6.5). In Sturiella (Sturianthus) langeri the microsporangia are concentrated at the base of the microsporophylls and the sterile tips of these increase the conspicuousness.

In this type of entomophilous reproductive structures protogyny would favour cross-pollination. In the case of rostrate Diptera as potential pollinators, it would function very well. In the late Mesozoic Tipulomorpha and some male Blephariceridae and Psychodoidea might have visited these reproductive structures, optically attracted by the microsporophylls or sterile appendages and feeding on liquids secreted by these structures. Whether in this case one might think of nectar is not known (extra-micro- or macrosporophyllous secretive 
tissue has not been demonstrated in the fossils); at any rate the pollination droplets must have been present. Here remains, however, a question as to whether feeding by Diptera on these saps can be considered injurious or not; at any rate it would have decreased the chance of proper pollination. When we take into account the other potential insect visitors and pollinators in that time, viz. the mandibulate Coleoptera and Hymenoptera Symphyta, protogyny in these Gymnospermae has the disadvantage of the simultaneous presence of considerable amounts of endosperm (the proliferation of this "primary" endosperm starts already before the fertilization) and of pollen in a certain phase of the development. Probably this is the condition which prevented the development of protogyny in these hermaphroditic reproductive structures. Knowing that, besides Diptera, also Coleoptera and Symphyta are fond of nectar, it seems unlikely that the this kind of secretion has ever been present in the hermaphroditic reproductive structures, because it certainly would have enlarged the chance of the establishment of protogyny in these structures. As said before, protogyny has not been found in the fossil remains, and if it had developed, a much larger differentiation would have been established, and competition with the hermaphroditic Angiospermae would have been much stronger than in case of only protandrous reproductive structures (compare e.g. the extinction of the Bennettitales, after the appearance of the Angiospermae).

Instead, protandry could develop in these structures, avoiding to some degree self-pollination (much less than protogyny would have done) and avoiding the simultaneous presence of too large amounts of endosperm and pollen. There is the disadvantage, however, that insects (alighting on the microsporophylls or in the vicinity of the sterile appendages) first visit the microsporangiate and only afterwards the ovulate reproductive organs (in contrast to the protandrous inflorescences of e.g. the Asteraceae as mentioned above), causing a too large amount of self-pollination, weakening the genetical strength (restricting the variability) of the populations of the species. Crepet (1972) found obligatory protandry in Cycadeoidea having poor pollination possibilities.

It is possible that these unfavourable conditions formed a constant selective pressure favouring the development of protogyny, but this could only develop successfully in combination with, or after, a completed development of protection of the ovules. The "double fertilization", in which the proliferation of the (secondary) endosperm starts only after fertilization, could have been such a development. The angiosperm angio-ovuly at the same time could be considered an adaptation to avoid pollination-decreasing pollen droplet-feeding. Following this reasoning, protogyny could be the plesiomorphous state of dichogamy within the Angiospermae, forming, however, the apomorphous pendant of the protandry in the sister-group. Thus, among first 
entomogamous Angiospermae protogyny may be original. Because of the arrangement of the microsporangiate and megasporangiate reproductive structures and possible sterile appendages, the combination of protandry, "double fertilization" and angio-ovuly would not have the advantage of protogyny combined with these synapomorphies and adapations respectively, of the Angiospermae, and therefore would be less probable as the plesiomorphous state of dichogamy in the Angiospermae. The chance, however, that all these developments were established simultaneously seems to be very small. The chance that the earliest entomogamous Angiospermae were protandrous cannot be excuded, because the sole development of the "double fertilization" already provides the considerable advantage of the separation in time of the presence of endosperm and pollen in the flower. This condition causes a more extensive seed-production, and although a large amount of self-pollination took place, they could disperse more successfully than the Gymnospermae. The "double fertilization" then opened the way to the development of protogyny in the hermaphroditic flowers. Thus it depends on which selective pressure favouring the "double fertilization" was the strongest, the pressure favouring the development of protogyny, or the pressure of injury to the endosperm by visiting mandibulate insects. It can be suggested that developments avoiding too much self-pollination will have their effect on the longer term and those avoiding injury have their effect on the short term. It, then, can be suggested that the latter was the selective pressure leading to the "double fertilization" which in its turn opened the way to the development of protogyny.

In this respect it has to be mentioned that anemogamous diclinous monoecious first Angiospermae more probably would have been protogynous (symplesiomorphous with their gymnosperm sister-group) rather than protandrous. But then the selective pressure of endosperm-feeding insects (or other animals) would not have resulted in the development of "double fertilization", which can be derived from the fact that many anemogamous Gymnospermae have survived. The selective pressure mentioned would not have been stronger than that caused by the Recent seed-feeding insects (and other animals). In hermaphroditic gymnosperm conditions the selective pressure (avoiding the presence of "advertized" endosperm) seems to be much stronger and therefore much more probable. Whitehead (1969) concluded that it is possible that the evolution of wind pollination in the Angiospermae parallelled the evolution of the deciduous habit. Axelrod (1966) suggested that the deciduous habit evolved in response to seasonal drought as the Angiospermae migrated into lower middle latitudes during the early Cretaceous. Both the deciduous habit and the physical conditions existing just peripheral to the tropics would have favoured the evolution of wind pollination. As has been mentioned by Wagenitz (1975) wind pollination has to be considered secondary in the 
Angiospermae. This type of pollination in hermaphroditic flowers is abundantly accompanied by protogyny (table 6-18).

There are theoretical indications that protogyny is a very early development in the Angiospermae (probably not the original state of dichogamy). In the unspecialized flower-insect relationships protogyny remained unchanged. Protandry required adjacent developments to avoid too much self-pollination, and this might have been the case in the development of nectar in inflorescences, directing the insect movements over the inflorescence. It can be suggested that protandry may have been the original form of dichogamy in the Angiospermae and that protogyny could develop from the very origin, which may indicate that both forms of dichogamy are of very early origin and may have been present at the time of appearance of the Angiospermae in the Lower Cretaceous.

As has been mentioned in the beginning of this section dichogamy in the Recent flora is only rarely absolute (no overlap of the male and female phase); mostly it is combined with homogamy. Various authors (Wallace, 1958; Bateson, 1978; Lloyd, 1979; Pice \& Waser, 1979; Thiesen \& Gregg, 1980; see also Willson \& Burley, 1983) have suggested that organisms may benefit from optimalizing, rather than maximalizing outbreeding, in the case of plants cross-pollination (and -fertilization). This also might have been the case in the hermaphroditic reproductive structures of the gymnospermous sister-group of the Angiospermae to assure pollination. Pollen as attractant and most "harmless" food source for the (mandibulate) pollinators, must have been present during receptivity of the female parts.

In the Recent flora protandry is widespread in Asteraceae, Campanulaceae, Lamiaceae, Caryophyllaceae, Fabaceae, Apiaceae etc. (Faegri \& Van der Pijl, 1980; Bell, 1971; Hess, 1983). Extreme cases, in which the anthers are shed before the female phase is established, occur e.g. in Saxifraga, Impatiens (Faegri \& Van der Pijl, 1980) and in some species of the Apiaceae (Knuth, 1898a) (see table 6-19). Proctor (in press) mentioned that protandry is particularly effective in favouring cross-pollination in species which have flowers in erect spikes or racemes, because bees (and many other insects) tend to land near the bottom of an inflorescence and work upwards. Absolute protandry is a sufficient defence against self-pollination as long as it concerns single flowers. In cases of inflorescences, however, additional developments have to optimalize this defence. As we have seen, the presence of nectar is one of such developments, but others are also present as we will see in discussing the families mentioned as examples.

In Asteraceae protandry is often accompanied by the development of separate female flowers. This gynomonoecy is found in the TubulifloraeCorymbiferae Homogyne, Aster, Bellidiastrum, Bellis, Stenactis, Erigeron, Solidago, Dahlia, Inula, Pulicaria, Filago, Gnaphalium, Helichrysum, Artemisia, Cotula, Achillea, Doronicum, Aronicum, Arnica, Senecio and Calendula. Monoecy is found 
in Tussilago (female marginal and male central flowers) and Petasites is dioecious to polygamous. Xanthium is monoecious (second degree protogyny) and in Antennaria dioecy occurs. In Tubuliferae-Cynarae and Linguliflorae no gynomonoecy occurs. In the first dioecy occurs in Cirsium and Serratula (Knuth, 1898a). The development of gynomonoecy in the Corymbiferae assures a minimum amount of cross-pollination, also in the very early stages of the flowering of the inflorescences. In the Cynarae and Linguliflorae the alighting of the visiting insects will be guided towards the margins of the inflorescences by floral colours.

In the Campanulaceae and Fabaceae no gynomonoecy and -dioecy or other forms of dicliny occur. In the case of inflorescences the alighting of the visitng insects will be guided by colours. Many Fabaceae are self-incompatible (Knuth, 1898).

In the mainly protandrous Fabaceae dichogamy may vary. Couderc \& Gorenflot (1978) gave evidence for a homogamous phase in Anthyllis in which autogamy may occur. Couderc (1980) reported autogamy in Anthyllis cytisoides.

In the Lamiaceae in many cases both gynomonoecy and -dioecy developed: Mentha, Lycopus, Origanum, Thymus, Satureja, Calamintha, Clinopodium, Horminium, Nepeta, Glechoma, Dracocephalum, Galeopsis, Ballota, Scutellaria, Brunella. Gynodioecy is found in Lavandula, Salvia, Melissa (also andromonoecy in combination with protogyny), and gynomonoecy in Betonica, Ajuga and Teucrium. In the large-flowered Lamiaceae, as Lamium, Galeobdolon, etc., the alighting of the visiting insects will be guided by floral colours.

In the Caryophyllaceae separation of female flowers also often occurs. Gynomonoecy and -dioecy occur in Gypsophila, Tunica, Dianthus, Saponaria, Vaccaria, Cucubalus, Silene, Viscaria, Coronaria, Agrostemma, Sagina, Spergula, Spergularia, Minuartia, Moehringia, Arenaria, Holosteum, Stellaria, Malachium, Cerastium. Andromonoecy and -dioecy is found in Viscaria and Coronaria, and andromonoecy, trioecy, dioecy and gynomonoecy were observed in Melandrium. In this respect it is interesting to mention that in Viscaria and Melandrium protogynous flowers occur. In Honckenya dioecy, monoecy and polygamy occur.

In the Apiaceae the matter is more complicated because of the compound umbels, in which in the various umbels forming the compound umbels, different developments occur. Knuth (1898a) used the terms umbels of the first, second, third and higher order. In contrast to the "Parakladien" of various orders mentioned in Strassburger (1967), here the "Haupt"- and "Cofloreszenzen" are meant, these are separate umbels of compound umbels as described and illustrated in e.g. Porter (1959), Radford et al. (1974), Raven et al. (1976), Heywood (1978) (compare also Froebe, 1971), in which the central umbel is of the first order and towards the margins of the compound umbel the umbels are those of a higher order (in contrast to the flowering sequence, 


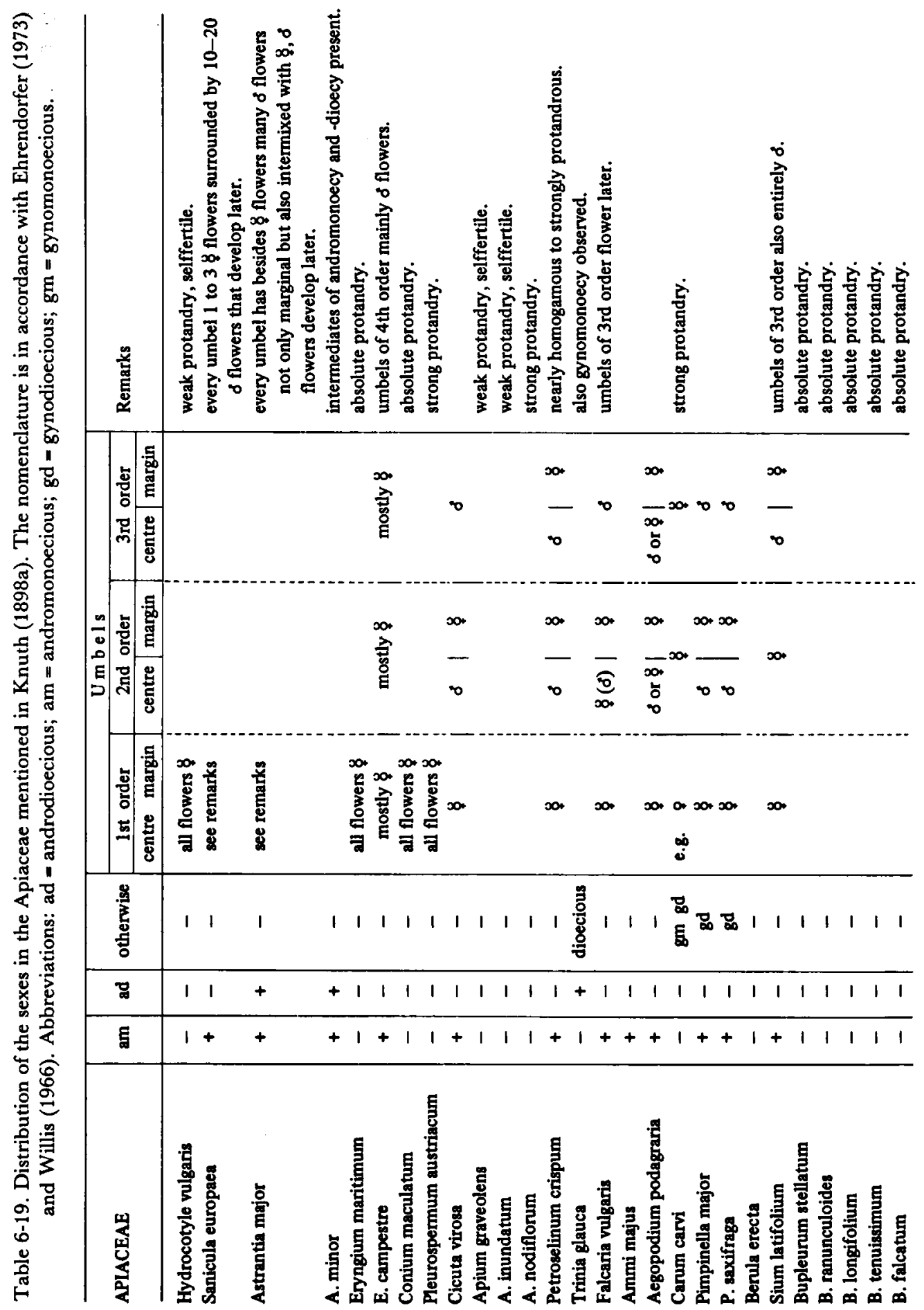




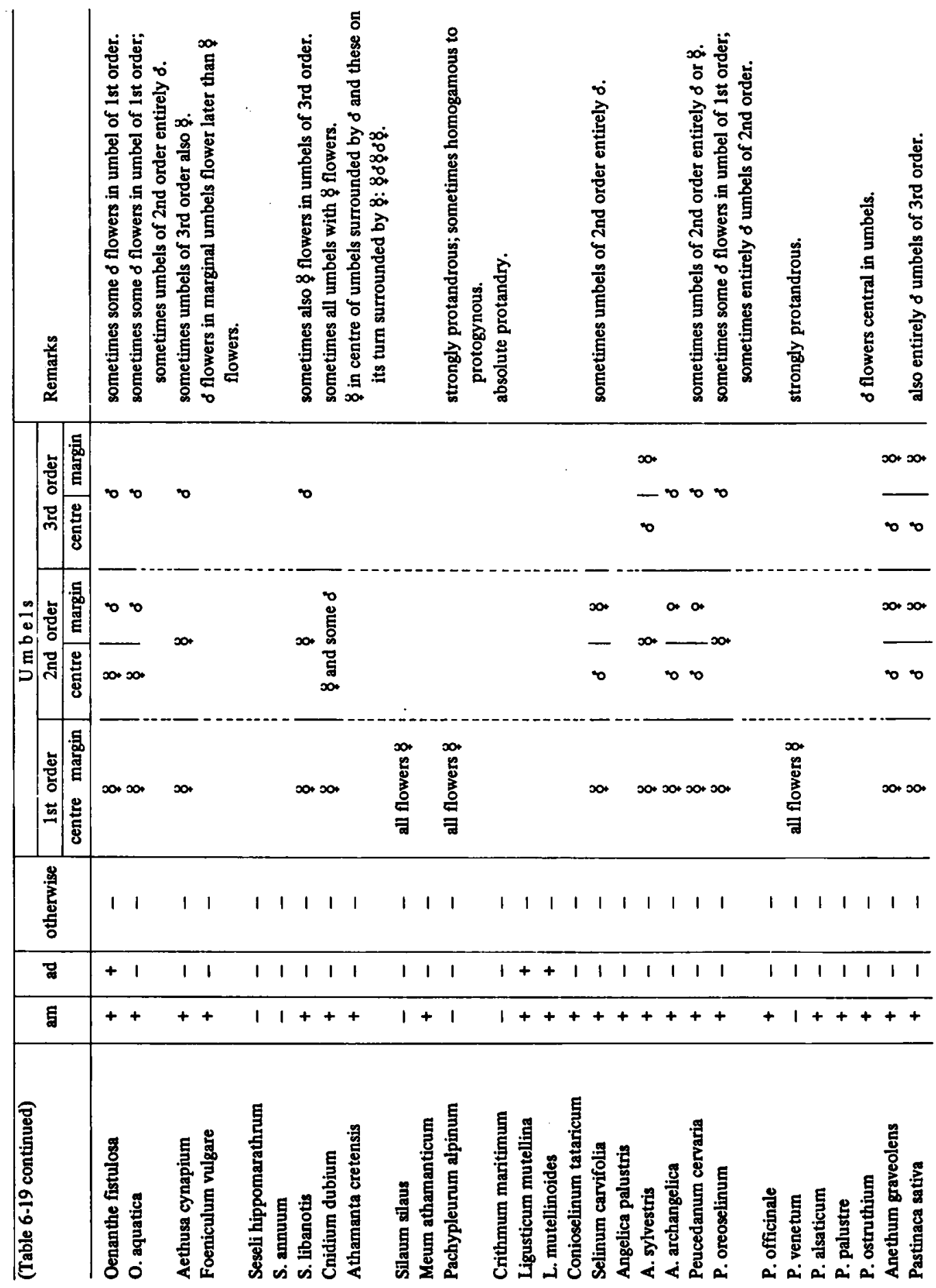




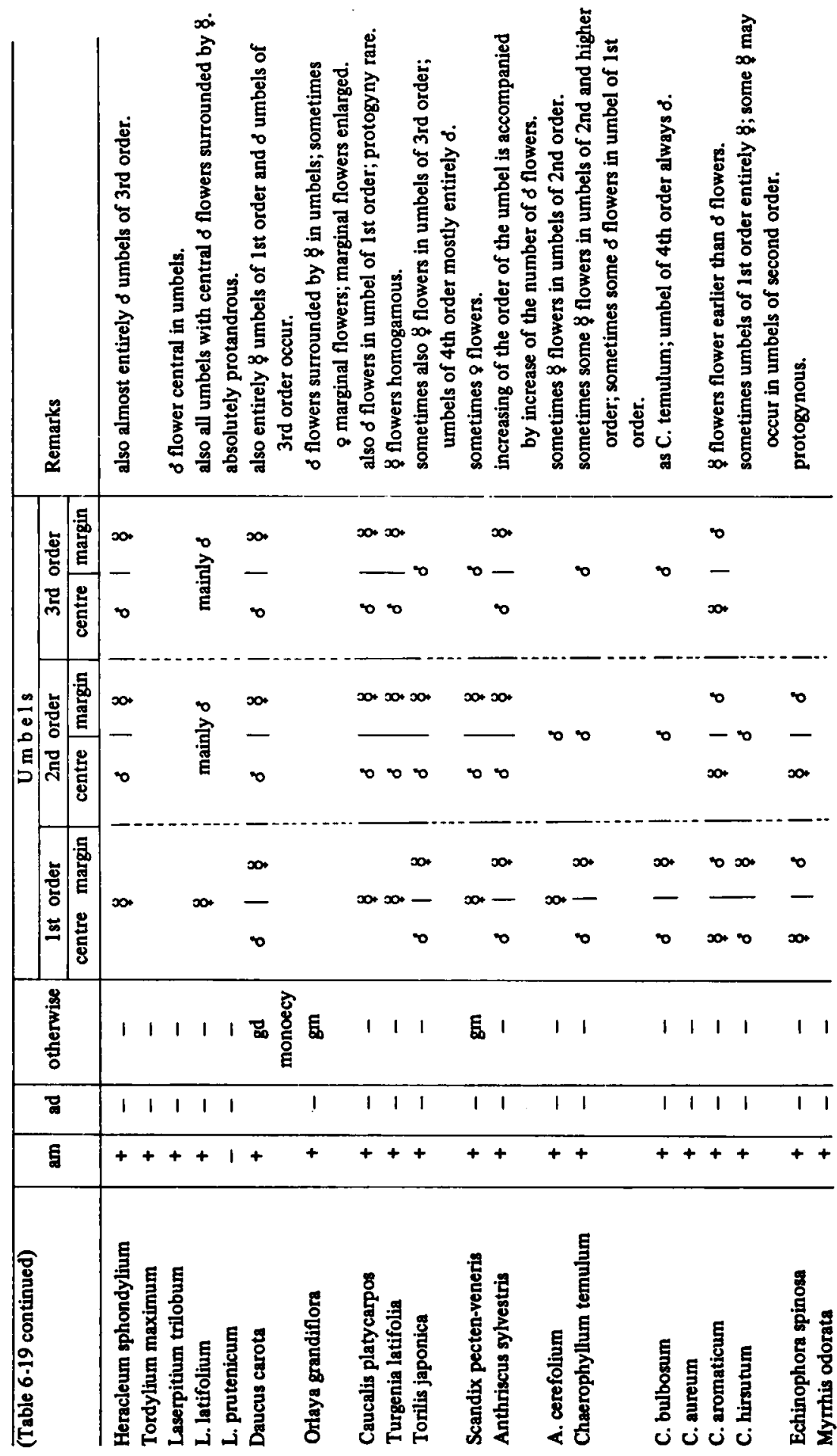


see e.g. Cronquist (1968) and (evolutionary indicated by) Froebe (1971)). The distribution of the sexes in the Apiaceae mentioned in Knuth (1898a), is surveyed in table 6-19. The same author mentioned protogynous Apiaceae from North America (see also Bell, 1971). It is easily seen that protandry in the Apiaceae is often accompanied by andromonoecy, sometimes by androdioecy and in rare cases by gynomonoecy and -dioecy, monoecy and dioecy. The development of andromonoecy adjacent to protandry is characteristic for the Apiaceae; the other protandrous families mainly developed gynomonoecy. In most cases the male flowers are centrally placed in the umbels and surrounded by hermaphroditic ones and they often develop later. If the visiting insects alight on the margins of the umbel (often guided by laterally enlarged, zygomorphic margin-flowers), they first meet the hermaphroditic flowers. If these are in the second (female) phase this may result in cross-pollination, and after that the insects, guided by nectar, reach the male flowers which deposit their pollen on the insects before they leave. However, because of the compound umbels (many umbels) and considering that these developments did not take place in all Apiaceae, it can be concluded that the Apiaceae generally are less protected against self-pollination than the preceeding families. Only in the absolutely protandrous Apiaceae (e.g.Bupleurum) and in the self-incompatible species (very rare) self-pollination is completely avoided.

Protogyny is widespread in Brassicaceae, Rosaceae, Berberidaceae, Thymelaeaceae, Caprifoliaceae, Juncaceae, monoecious Cyperaceae (second degree protogyny), etc. (Faegri \& Van der Pijl, 1980; Knuth, 1899). Extreme cases, in which the style is shed before the male phase is established, occur e.g. in Parietaria, Magnolia grandiflora and Annonaceae. In the latter two herkogamy is more or less present (dependent on the seize of the visiting insects), to avoid damage to the sedondary endosperm. Parietaria is mainly wind-pollinated. As mentioned above, protogyny has an advantage over protandry in avoiding selffertilization, and we will see in discussing the families mentioned as examples, whether protogyny needs less additional developments to avoid selfpollination, than does protandry.

In the Brassicaceae most species have only hermaphroditic flowers. Gynomonoecy occurs in protogynous Arabis pumila. In some homogamous Brassicaceae gynomonoecy occurs. Cardamine amara sometimes has female flowers, Arabidopsis thaliana is gynomonoecious, and in homogamous Capsella bursa-pastoris Warnstorf, Breitenbach and Willis (see Knuth, 1898a) observed gynomonoecy and -dioecy.

In the Rosaceae there is also some dicliny. In the homogamous to weakly protogynous Rubus chamaemorus andromonoecy and -dioecy occur, as is the case in sometimes mainly homogamous species of Geum. In the mostly homogamous Potentilla gynomonoecy and -dioecy occur. In homogamous 
Sanguisorba gyno- and andromonoecy occur. Aruncus dioicus is dioecious. The rare cases of a development towards dicliny in real protogynous Rosaceae are found in Fragaria, in which andromonoecy and -dioecy and (rarely) gynomonoecy and -dioecy occur, and in Geum reptans (androdioecy).

In the Berberidaceae and Caprifoliaceae all flowers are hermaphroditic. In the homogamous Daphne mezereum (Thymelaeaceae) both gynomonoecy and -dioecy occur.

Juncaceae are anemogamous (in the South-American genera Distichia, Oxychloe, Patosia (partial) dicliny (see section 6.15 ) or dioecy occur) with only some homogamous or cleistogamous species. The Cyperaceae are protogynous-monoecious.

On inflorescences with protogynous flowers second order herkogamy is present. The visiting insects have to alight on the higher or central flowers to meet first those in the female phase and later, guided by nectar, those in the male phase, before leaving. One imperfectly described case is known: wasps visiting the inflorescences of Scrophularia nodosa from higher to lower situated flowers (Faegri \& Van der Pijl, 1980, and Hess, 1983), but it requires more observation. In contrast to many inflorescences with protandrous flowers, those with protogynous flowers only rarely have enlarged margin flowers (Viburnum opulus with large sterile margin-flowers is homogamous). The guiding of the alighting of the visiting insects will mainly be caused by floral colours. It would be interesting to study whether floral colours change (particularly ultraviolet) during the development of the flowers (both in cases of protandry and protogyny); this is known to occur in Echium plantagineum (Bos \& Ratering, pers. comm.).

It would be interesting to correlate homogamy and dichogamy with selfincompatibility and -compatibility. Relevant data may be obtained by analysing the central European observations in the lists, compiled by Knuth (1898: 42-50), see table 6-20. It is indicated that protandry more often occurs in selfincompatible plants than does protogyny. The reverse is not found in selfcompatible plants. In plants in which self-incompatibility occurs, the frequency of protandry is higher than in those in which self-compatibility occurs. In protogyny the reverse is found. Thus, there are indications that, besides in homogamy, also in protandry more self-incompatibility developed than in protogyny. This supports the statement that exclusive protandry is less effective in avoiding self-pollination than is protogyny.

As we see that in entomophilous flowers protogyny is correlated with the degree of specialization of the insect-flower relationship (viz., the lower the degree of specialization, the higher the frequency of protogyny), and moreover that, within the protogynous flowers and inflorescences, only rarely developments to gynomonoecy or -dioecy occur, it can be concluded that the 
Table 6-20. Frequencies of protandry, homogamy and protogyny among the self-incompatible and self-compatible plants. After the compilation of Knuth (1898: 42-50) as far as it concern the central European observations.

\begin{tabular}{lcccc}
\hline & total & protandrous & homogamous & protogynous \\
self-incompatiblity & 127 & 38.6 & 74.8 & 10.0 \\
self-compatibility & 131 & 26.7 & 75.6 & 28.3 \\
\hline
\end{tabular}

visiting of unspecialized, mandibulate insects does not form a selective pressure favouring developments to avoid ovule damage by gynomonoecy or -dioecy. Dicliny in this cases has to be considered an adaptation to avoid selfpollination and is mainly induced by protandry.

Gyno- and andro-dioecy can be considered derived states from gyno- and andromonoecy respectively, and if both developments occur in the same plant, it would lead to monoecy; if both developments occur in different specimens of the same species it would lead to dioecy. Carlquist (1966) found $15.5 \%$ dioecism in New Zealand and 27.5\% in Hawaii. Baker (1967) and Raven (1973) concluded that evolution of dioecious taxa may have occured in response to selective pressures favouring outcrossing after the islands were colonized.

Returning to the hermaphroditic Gymnospermae, it will be clear that part of their protandry, not accompanied by developments towards angio-ovuly and "double fertilization", would easily lead to monoecy and dioecy. It will also be clear that in homogamous species in the Angiospermae, there will be a selective pressure favouring dicliny avoiding self-pollination in the absence of selfincompatibility or sufficient herkogamy.

\subsubsection{Homogamy}

In section 6.14.1 the facultative and obligatory homogamy has been discussed shortly. It appeared not to discriminate significantly between the insect groups compared, possibly by the very extensive overlap with dichogamy. In this section the species are included for which Knuth (1898a and 1899) and Hegi (1906-1931; 1936 etc.; 1966 etc.) only recorded homogamous flowers. This may mean that these species really only have homogamous flowers, or that dichogamy has not yet been found. Because of the extensive studies made of the central European flora, the latter may be defined as "homogamous, very rarely dichogamous". At any rate the homogamy in this section is much more absolute than that in the preceeding section. The comparisons made in this section will indicate whether the more or less obligatory homogamy is related to certain groups of species. 
Table 6-21. Frequencies of obligatory homogamy among the flowers of the species belonging to the various facultative and obligatory pollination types (A); ibid obligatory pollination types (B); ibid species of which the flowers are visited by the various insect groups, Qualitative analysis (C); ibid. Quantitative analysis (D) of the central European flora.

Abbreviations: $\mathrm{ANE}=$ Anemogamous; $\mathrm{APO}=$ Apoidea; $\mathrm{BeF}=$ Bee-pollinated flowers; $\mathrm{BMF}=$ Butterfly- and moth-pollinated flowers; $\mathrm{BtF}=$ Beetle-pollinated flowers;

CEF = Central European flora; COL = Coleoptera; DIP = Diptera; ENT = Entomogamous; FlF = Fly-pollinated flowers; $\mathrm{H}=\mathrm{HOM}=$ obligatory homogamous; $\mathrm{LEP}=$ Lepidoptera; $\mathrm{MEL}$ $=$ Melittogamous; MYI $=$ Myiogamous; NAH $=$ Non-apoid Hymenoptera; $\mathbf{P}+\mathbf{P}=$ Psychogamous and phalaenogamous.

A-1 to $6, \mathrm{~B}-1$ and 2, C-1 to 3 and D-1 to 4 give the significances of the differences in A, B, C and $\mathrm{D}$ by chi-square testing. Explanation: $1=0.01<\mathrm{p} \leq 0.05 ; 2=0.001<\mathrm{p} \leq 0.01 ; 3=$ $0.0001<\mathrm{p} \leq 0.001 ; 4=\mathrm{p} \leq 0.0001$.

\begin{tabular}{|c|c|c|c|c|c|c|c|c|c|c|c|c|c|c|}
\hline $\begin{array}{l}\text { A } \\
\text { CEF }\end{array}$ & $\begin{array}{l}\text { Total } \\
2830\end{array}$ & $\begin{array}{c}\text { HOM } \\
32.97\end{array}$ & $\begin{array}{l}\text { A-1 } \\
C E F\end{array}$ & $\mathrm{H}$ & $\begin{array}{l}\mathrm{A}-2 \\
A N E\end{array}$ & $\mathrm{H}$ & $\begin{array}{l}\text { A-3 } \\
E N T\end{array}$ & $\mathrm{H}$ & $\begin{array}{l}\text { A-4 } \\
B t F\end{array}$ & $\mathrm{H}$ & $\begin{array}{l}\text { A-5 } \\
F l F\end{array}$ & $\mathrm{H}$ & $\begin{array}{l}\text { A-6 } \\
B e F\end{array}$ & $\mathbf{H}$ \\
\hline ANE & 481 & 26.61 & ANE & 1 & ENT & 1 & $\mathrm{BtF}$ & 4 & FlF & 2 & $\mathrm{BeF}$ & 4 & BMF & 4 \\
\hline ENT & 2368 & 33.95 & $\mathrm{BtF}$ & 4 & $\mathrm{BtF}$ & 2 & FlF & 4 & $\mathrm{BeF}$ & 4 & BMF & 4 & & \\
\hline $\mathrm{BtF}$ & 1009 & 17.84 & FIF & 4 & $\mathrm{BeF}$ & 2 & BMF & 4 & & & & & & \\
\hline FlF & 1553 & 23.82 & BMF & 4 & BMF & 4 & & & & & & & & \\
\hline $\mathrm{BeF}$ & 1970 & 35.94 & & & & & & & & & & & & \\
\hline BMF & 537 & 13.96 & & & & & & & & & & & & \\
\hline B & Total & HOM & B-1 & & B-2 & & & & & & & & & \\
\hline ENT & 2368 & 33.95 & $E N T$ & H & $M Y I$ & $\mathbf{H}$ & & & & & & & & \\
\hline MYI & 151 & 15.89 & MYI & 3 & MEL & 4 & & & & & & & & \\
\hline MEL & 601 & 61.23 & MEL & 4 & $\mathbf{P}+\mathbf{P}$ & 4 & & & & & & & & \\
\hline $\mathbf{P}+\mathbf{P}$ & 93 & 48.38 & & & & & & & & & & & & \\
\hline C & Total & HOM & C-1 & & C-2 & & C-3 & & & & & & & \\
\hline COL & 420 & 25.95 & $C E F$ & $\mathbf{H}$ & $E N T$ & $\mathbf{H}$ & $A P O$ & $\mathrm{H}$ & & & & & & \\
\hline DIP & 793 & 26.36 & COL & 1 & DIP & 1 & COL & 2 & & & & & & \\
\hline NAH & 412 & 27.67 & DIP & 2 & DIP & 2 & & & & & & & & \\
\hline APO & 881 & 36.44 & NAH & 1 & & & & & & & & & & \\
\hline LEP & 505 & 30.50 & & & & & & & & & & & & \\
\hline CEF & 2830 & 32.97 & & & & & & & & & & & & \\
\hline D & Total & HOM & D-1 & & D-2 & & D-3 & & D-4 & & & & & \\
\hline COL & 1502 & 31.68 & $C O L$ & $\mathrm{H}$ & $D I P$ & $\mathrm{H}$ & $N A H$ & $\mathrm{H}$ & $A P O$ & $\mathrm{H}$ & & & & \\
\hline DIP & 6208 & 29.56 & DIP & 1 & NAH & 4 & APO & 4 & LEP & 4 & & & & \\
\hline NAH & 2008 & 17.04 & NAH & 4 & APO & 4 & LEP & 4 & & & & & & \\
\hline APO & 7316 & 49.52 & APO & 4 & LEP & 4 & & & & & & & & \\
\hline LEP & 2840 & 54.93 & LEP & 1 & & & & & & & & & & \\
\hline
\end{tabular}

Distribution of homogamy among the anemophilous and entomophilous pollination types It appears that anemogamous species less often have homogamous flowers than have entomogamous species (tables 6-21A and 6-21A-2). Here it has to be mentioned that in the anemogamous species also the monoecious species are included (second degree homogamy). Comparing only the hermaphroditic species will give more striking differences between the frequencies because monoecy in entomogamy is rare (see section 6.15 ). Thus, there are indications 
that hermaphroditic anemophilous flowers or inflorescences need more dichogamy (as we have seen in section 6.14.1 mainly protogyny) to favour cross-fertilization than hermaphroditic entomophilous flowers do.

\section{Distribution of homogamy among the facultative and obligatory entomophilous pollination types}

Beetle- and butterfly- and moth-pollinated species have less homogamous flowers than have fly- and bee-pollinated species (tables 6-21A and 6-21A-4 to 6 ). In the case of beetle-pollinated flowers this is due to their unspecialized structure, correlated with the diffuse pollen transport by the Coleoptera. In the case of butterfly- and moth-pollinated flowers it may be due to the comparative narrowness of the corolla tubes, limiting developments towards herkogamy of any extent.

In the series: beetle-pollinated, fly-pollinated, bee-pollinated flowers, an increase of homogamy is demonstrated (tables 6-21A and 6-21A-4 and 5), from which it can be derived that increase of specialization of pollination is accompanied by increase of the frequency of homogamy. Important additional developments to achieve this will be herkogamy, as it occurs in many melittophilous flowers, and self-incompatibility (see table 6-19).

\section{Distribution of homogamy among the obligatory entomophilous pollination types}

Here the same tendencies are indicated as among the facultative and obligatory pollination types. Among the myiophilous flowers less homogamy occurs than in the melittophilous and psychophilous and phalaenophilous flowers (tables 6-21B and 6-21B-2). This is due to the fact that the definition of myiophily includes many Apiaceae (see earlier remarks).

Distribution of homogamy among the species of which the flowers are visited by the various insect groups, Qualitative analysis

This analysis hardly demonstrates differences. Only the species of which the flowers are visited by the Apoidea more often are homogamous than are those visited by the Coleoptera, Diptera and non-apoid Hymenoptera (tables 6-21C and $6-21 \mathrm{C}-3$ ).

Disposition of flower visits of the insect groups with reference to homogamy, Quantitative analysis

It appears that the least specialized insects visit less homogamous flowers than the more specialized insects do. The non-apoid Hymenoptera visit leastvhomogamous flowers (tables 6-21D and 6-21D-1 to 3). In the series: Diptera, Coleoptera, Lepidoptera an increase of visits to homogamous flowers is demonstrated (tables 6-21D-1 to 4). This corresponds largely with the derivation made in the facultative and obligatory pollination types. The 
Lepidoptera, however, behave otherwise than expected (see butterfly- and moth-pollinated flowers in table 6-21A). This may be due to the fact that, although butterfly- and moth-pollinated flowers are abundantly visited (see table 6-1B), only a very small minority of the Lepidoptera visit psychophilous and phalaenophilous flowers (see table 6-3D).

\section{Discussion}

It appears that more absolute homogamy more often occurs in specialized insect-flower relationships than in unspecialized ones. As mentioned in section 6.14.1, original absolute homogamy is not probable in the Angiospermae. Absolute homogamy can be considered an apomorphous, mainly entomophilous development, often accompanied by effective herkogamy or self-incompatibility (see table 6-19), mainly occurring in the specialized pollination types, particularly in developments towards melittogamy. It therefore may be of comparatively late origin in the phylogeny of the Angiospermae: it may have become functional in the latest Cretaceous and lower Tertiary.

In the central European flora absolute homogamy is only rarely accompanied by developments towards dicliny. Some examples are found in Caltha palustris (androdioecious), Capsella bursa-pastoris (gynomonoecious and dioecious specimens occur), Vitis vinifera (androdioecious), Geum (andromonoecious and -dioecious), Sanguisorba (gyno- and andromonoecious), Ribes (gynodioecious and sometimes entirely dioecious), Turgenia latifolia (andromonoecious) and Daphne mezereum (gynomonoecious and -dioecious). See also some examples in table 6-22. These developments mainly occur in unspecialized flowers and can be considered adaptations to avoid selfpollination.

Heterostyly also can be considered an adaptation to avoid self-pollination and it mainly occurs in homogamous flowers, e.g.: Hottonia palustris, Primula, Linum, Pulmonaria officinalis, Lythrum salicaria. The heterostylous Fagopyrum esculentum is mostly homogamous and only rarely protandrous, and also gynoand andromonoecy and -dioecy occur. The weakly protogynous Menyanthes trifoliata is homo- or heterostylous and sometimes cleistogamy occurs.

On the other hand, many homogamous species are self-compatible (as indicated in table 6-20) and apparently self-pollination in many cases is part of the strategy of the species. Solbrig \& Rollins (1977) mentioned that the "general consensus" is that self-incompatibility is the plesiomorphous condition in the Angiospermae and that self-compatibility is therefore apomorphous (see also Stebbins, 1974). If the sister-group of the Angiospermae has to be found in the "Gymnospermae" (Hill \& Crane, 1983; Crane 1985 and 1985a), self-incompatibility has to be considered a synapomorphy of the Angiosper- 
mae. In "Gymnospermae" only interspecific incompatibility has been found, see Hess, 1983). If it is correct that dichogamy can be considered an adaptation favouring cross-pollination and that insufficiently self-pollination avoiding protandry is one of the main selective pressures favouring the development of dicliny to assure cross-pollination, then there may be evidence that already very early in the development of the Angiospermae self-compatibility was present. Assuming a monophyletic origin of the Angiospermae, the possible presence of unisexual flowers in the Lower Cretaceous (see section 7.4) indicates that the whole process from protandrous hermaphroditic flowers to (partial) dicliny must have been traversed. It can be questioned whether in many cases reverse developments occur. In table 6-20 it appears that protandry comparatively often occurs among self-incompatible plants. If plants are obligatory self-incompatible, dichogamy would not be necessary otherwise than according to the economy principle of no useless loss of own pollen on the stigma. The opposite explanation, however, seems more reasonable to me. In non-absolute protandrous conditions the development of self-incompatibility is functional in avoiding self-pollination and -fertilization.

It can be stated that cross-pollination is necessary for evolutionary developments, i.e. in long-term processes. In the short term, however, autogamy may be advantageous under certain conditions (see below), e.g. in colonizing species, because it reduces the problem of "mate-finding" and permits offspring which is similar to their parents to occupy the space like that occupied by the parents, and because it provides larger numbers of offspring in all cases where competition is small, autogamy will be favourable (see Willson \& Burley, 1983). In my opinion self-compatible plants, with sufficient adaptations to favour cross-pollination will be in practice the fittest (in case of self-pollination only delayed greater chance of recombination is established). Optimalizing recombination may have an advantage over obligately maximalizing recombination (see section 6.14.1). Autogamy may be advantageous in e.g. colonizing species (e.g. Baker, 1955; Bannister, 1965; Willson, 1981), small population size, expense of dispersal, ecologically and geographically marginal conditions (e.g. Antonovics, 1968, 1976; Williams, 1975; Vasek \& Harding, 1976; Bengtsson, 1978), unpredictable fluctuations in pollen availability (Stebbins, 1950; Baker, 1959; Lloyd, 1980), kin-selected adaptations (Willson Burley, 1983). Besides by the many cases of autogamy and geitonogamy in inflorescences, autogamy is obligatory in cleistogamous flowers. In order to establish whether homogamous and/or dichogamous flowers tend to practice cleistogamy, the central European representatives of the lists of species with cleistogamous flowers compiled by Knuth (1898) are correlated with homogamy and dichogamy of their chasmogamic flowers in table 6-22. It concerns cases not only of almost entire cleistogamy, but also of hydro- (submersion), psychro- (too low temperatures), thermo- (too high 
Table 6-22. Central European species in which cleistigamy occurs, correlated with dichogamy in their chasmogamous conditions. This list is based on Knuth $(1898,1898 \mathrm{a}, 1899)$; the nomenclature is in accordance with Ehrendorfer (1973) and for some introduced and cultivated species with Heukels \& Van Ooststroom (1973). Abbreviations: HOM = homogamous; PA = protandrous; $\mathrm{PG}=$ protogynous.

\begin{tabular}{|c|c|c|c|c|}
\hline & & & & \\
\hline $\begin{array}{l}\text { AUSMATACEAE } \\
\text { Luronium natans }\end{array}$ & & + & & \\
\hline ASTERACEAE & & $T$ & & \\
\hline Taraxacum officinale & + & & & \\
\hline Filago minima & + & & & gynomonoecy \\
\hline BALSAMINACEAE & & & & \\
\hline Impatiens noli-tangere & + & & & \\
\hline BRASSICACEAE & & & & \\
\hline Subularia aquatica & & + & & \\
\hline Arabis caenulea & & + & + & weak protandry \\
\hline Nasturtium officinale & & + & + & weak protandry \\
\hline Sinapis arvense & & + & + & weak protandry \\
\hline Thlaspi arvense & & + & + & weak protandry \\
\hline CARYOPHYLLACEAE & & & & \\
\hline Stellaria media & + & + & ' & $\begin{array}{l}\text { weak protandry; gynomonoecy and } \\
\text {-dioecy }\end{array}$ \\
\hline Spergularia nubra & + & + & & gynomonoecy and -dioecy \\
\hline Spergula arvensis & & + & + & $\begin{array}{l}\text { weak protandry; gynomonoecy and } \\
\text {-dioecy }\end{array}$ \\
\hline S. morisonii & & + & & gynomonoecy and -dioecy \\
\hline S.pentandra & & + & & gynomonoecy and -dioecy \\
\hline Myosoton aquaticum & + & & & gynomonoecy and -dioecy \\
\hline Holosteum umbellatum & & + & + & gynomonoecy and -dioecy \\
\hline Cerastium arvense & + & & & gynomonoecy and -dioecy \\
\hline C. semidecandrum & + & + & & $\begin{array}{l}\text { weak protandry; gynomonoecy and } \\
\text {-dioecy }\end{array}$ \\
\hline C. diffusum & & + & & \\
\hline C. glomeratum & & + & & gynodioecy \\
\hline C. cerastoides & + & + & + & $\begin{array}{l}\text { weak protandry and protogyny; } \\
\text { gynomonoecy and -dioecy }\end{array}$ \\
\hline Moenchia erecta & & & + & \\
\hline Sagina saginoides & & + & + & $\begin{array}{l}\text { weak protogyny; gynomonoecy and } \\
\text {-dioecy }\end{array}$ \\
\hline S. apetala & + & + & & weak protandry \\
\hline S. nodosa & + & & & gynomonoecy and -dioecy \\
\hline S. procumbens & + & + & + & $\begin{array}{l}\text { weak protandry and protogyny; } \\
\text { gynomonoecy }\end{array}$ \\
\hline Illecebrum verticillatum & & + & & \\
\hline Corrigiola litoralis & & + & & \\
\hline Polycarpon tetraphyllum & & $\begin{array}{l}+ \\
+\end{array}$ & & \\
\hline Scleranthus annuus & + & + & & $\begin{array}{l}\text { weak protandry; gynomonoecy and } \\
\text {-dioecy }\end{array}$ \\
\hline
\end{tabular}


(Table 6-22 continued)

\section{CISTACEAE}

Tuberaria guttata

CONVOLVULACEAE

Cuscuta epithymum

C. europaea

DROSERACEAE

Drosera rotundifolia

D. intermedia

D. anglica

Aldovandra vesiculosa

\section{FABACEAE}

Vicia sativa

Lathyrus setifolius

GENTIANACEAE

Menyanthes trifoliata

Gentiana prostrata

Gentianella tenella

G. campestris

HYDROPHYLACEAE

Nemophila maculata

HYPERICACEAE

Hypericum humifusum

JUNCACEAE

Juncus bufonius

J. effusus

J. copitatus

J.pygmaeus

LAMIACEAE

Lamium amplexicaule

LIIACEAE

Gagea lutea

LYTHRACEAE

Lythrum thesoides

MALVACEAE

Malva neglectis

OLEACEAE

Forsythia viridissima

\section{OXALIDACEAE}

Oxalis acetosella

O. comiculata

O. deppei

PAPAVEraceae

Hypecoum pendulum

POACEAE

Stipa pennata

Hordeum vulgare

$H$. distichon

Avena sativa

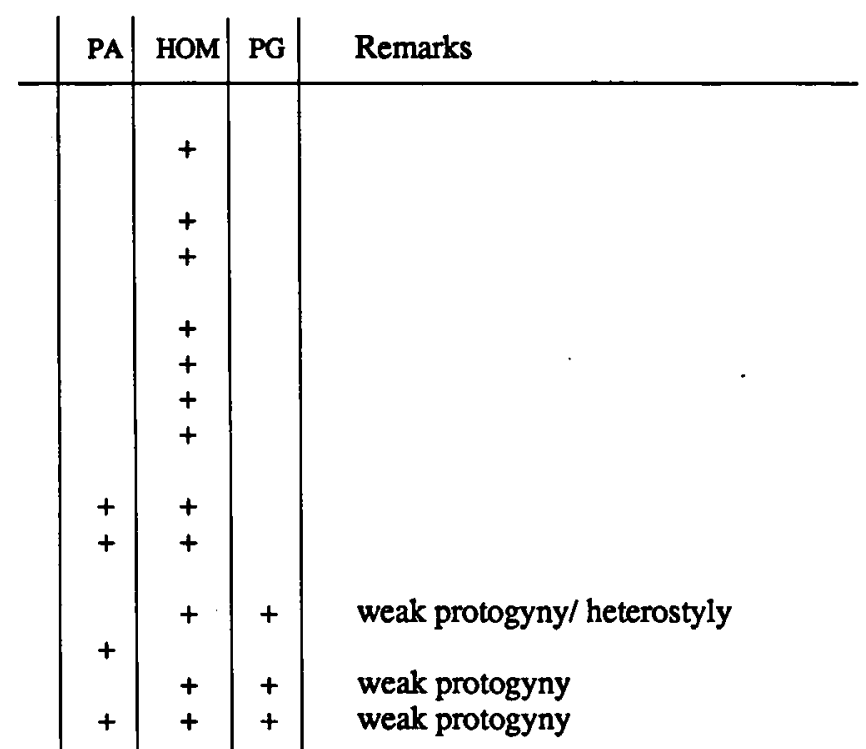

weak protogyny

heterostyly

andromonoecy 
(Table 6-22 continued)

(Poaceae continued)

Bromus secalinus

Secale cereale

POLYGalaceaE

Polygala spec.

POLYGONACEAE

Polygonum persicaria

$P$. hydropiper

$P$.mite

$P$. minus

$P$. aviculare

PoRTUlacaceaE

Montia fontana

Portulaca oleracea

$P$. grandiflora

PRIMULACEAE

Hottonia palustris

Centrunculus minimus

Androsace vitaliana

Cyclamen purpurascens

RUBIACEAE

Galium uliginosum

SCROPHULARIACEAE

Veronica hedenfolia

$V$. serpyllifolia

V. agrestis

V. triphyllos

$V$. peregrina

$V$. arvensis

V.persicaria

$V$. polita

Limosella aquatica

Linaria spec.

Scrophularia spec.

\section{VIOLACEAE}

Viola mirabilis

V.persicifolia

V. canina

V. hirta

V. suavis

$V$. elatior

$V$. biflora

$V$. reichenbachiana

$V$. rupestris

V. cucullata

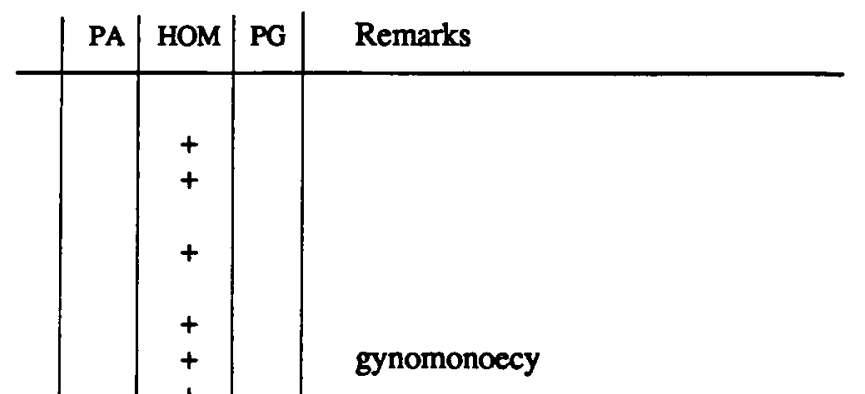

heterostyly

heterostyly

rarely protandrous or protogynous 
temperatures), xero- (drought) and mainly scio- (shading) cleistogamy, and perhaps some cases of oligotropic cleistogamy (low soil nutritients).

It appears that cleistogamy mainly occurs in homogamous flowers, but some species appear to be very flexible: also dichogamous species (whether or not with developments towards dicliny) can develop cleistogamy under unfavourable conditions.

To conclude, it can be stated that homogamy in some cases favours developments towards dicliny (but much less than does protandry) and is the main condition favouring developments towards heterostyly (heteromorphy). Both developments can be considered adaptations to avoid self-pollination. Because the more absolute homogamy probably is of comparatively late origin, heterostyly may also be so in the phylogeny of the Angiospermae. This can also be said for homogamy-favoured dicliny, but not for dicliny in general (see section 6.14.1). The latter also applies to cleistogamy: homogamy-favoured it will be of comparatively late origin, but because it also occurs in otherwise dichogamous species, it may have originated much earlier.

\subsection{Dicliny}

Knowing that particular insect groups do not, or hardly, exert a selective pressure towards developments to partial, and (thereby to full) dicliny (see section 6.14.1), in this section only the high-leveled comparison is made between anemogamous and entomogamous species, considering the following states of dicliny:

\section{Partial dicliny}

-andromonoecy: hermaphroditic and male flowers on the same plant;

- gynomonoecy: hermaphroditic and female flowers on the same plant;

- polygamy: hermaphroditic, male and female flowers on the same plant;

-androdioecy: hermaphroditic and male flowers on different plants;

-gynodioecy: hermaphroditic and female flowers on different plants;

- trioecy: hermaphroditic, male and female flowers on different plants;

Full dicliny

- monoecy: male and female flowers on the same plant;

- dioecy: male and female flowers on different plants.

The results are illustrated in table 6-23.

\section{Hermaphroditism}

It appears that, although most are protogynous (see table 6-18), anemogamous species more often have unisexual flowers than entomogamous species (tables 6-23A and B). It is, however, questionable whether the frequencies can be compared properly, i.e. representing different grades of the same development, as we will see in discussing the separate states of partial and full 
Table 6-23. Frequencies of partial and full dicliny among the anemogamous and entomogamous species of the central European flora.

Abbreviations: $\mathrm{AD}$ = Androdioecious; $\mathrm{AM}$ = Andromonoecious; ANE = Anemogamous; $\mathrm{D}=\mathrm{DIO}=$ Dioecious; $\mathrm{ENT}=$ Entomogamous; $\mathrm{GD}=$ Gynodioecious; $\mathrm{GM}=$ Gynomonoecious; $\mathrm{H}=$ HER $=$ Hermaphroditic; $\mathrm{M}=\mathrm{MON}=$ Monoecious; $\mathrm{P}=$ POL $=$ Polygamous; $\mathrm{T}=\mathrm{TRI}=$ Trioecious .

$\mathrm{B}$ gives the significances of the differences in $\mathrm{A}$ by chi-square testing. Explanation: $3=$ $0.0001<\mathrm{p} \leq 0.001 ; 4=\mathrm{p} \leq 0.0001$.

\begin{tabular}{|c|c|c|c|c|c|c|c|c|c|c|c|c|c|}
\hline $\begin{array}{l}\text { A } \\
\text { ANE } \\
\text { ENT }\end{array}$ & $\begin{array}{c}\text { Total } \\
658 \\
2610\end{array}$ & $\begin{array}{l}\text { HER } \\
62.31 \\
88.54\end{array}$ & $\begin{array}{l}2 \\
1 \\
4\end{array}$ & $\begin{array}{l}\text { AM } \\
6.77 \\
4.54\end{array}$ & & $\begin{array}{l}.49 \\
.49 \\
.28\end{array}$ & $\begin{array}{l}\text { PC } \\
8.6 \\
0.6\end{array}$ & & $\begin{array}{c}\text { MON } \\
24.16 \\
1.53\end{array}$ & $\begin{array}{l}\text { TRI } \\
0.15 \\
0.99\end{array}$ & $\begin{array}{c}\text { AD } \\
4.41 \\
0.61\end{array}$ & $\begin{array}{c}\text { GD } \\
0.15 \\
0.19\end{array}$ & $\begin{array}{l}\text { DIO } \\
2.58 \\
3.25\end{array}$ \\
\hline B & $\begin{array}{l}A N E \\
\text { ENT }\end{array}$ & $\begin{array}{cc}\mathrm{H} & \mathrm{A} \\
4 & \end{array}$ & $\begin{array}{c}\text { AM } \\
3\end{array}$ & $\begin{array}{c}\text { GM } \\
4\end{array}$ & $\begin{array}{l}P \\
4\end{array}$ & $\begin{array}{c}M \\
4\end{array}$ & $\begin{array}{l}\mathrm{T} \\
-\end{array}$ & $\begin{array}{c}\mathrm{AD} \\
4\end{array}$ & GD & D & & & \\
\hline
\end{tabular}

dicliny. The main difference between anemogamous and entomogamous species, that has to be taken into account, is that in anemogamous species the pollen transport is nearly totally at random and in entomogamous species, whatever diffuse pollen deposition on the integument of the insect, it is much more directed (insects searching for the flowers).

\section{Andromonoecy and -dioecy}

Although andromonoecy and -dioecy in anemogamous species may have some function in avoiding self-pollination, they mainly have to be interpreted as developments to increase the production of pollen and thereby to increase the chance of pollination. In entomogamous species, however, andromonoecy has to be considered an imperfectly functioning adaptation to avoid selfpollination, mainly in combination with protandry (see e.g. the Apiaceae) and to some extent with homogamy. This may also be the case in entomophilous androdioecy. Both andromonoecy and -dioecy more often occur in anemogamous than in entomogamous species. Particularly the difference between the frequencies of the latter indicate evidence for the functional difference mentioned (see tables 6-23A and B).

\section{Gynomonoecy and -dioecy}

Gynodioecy appears to be very rare in the central European flora. In both anemogamous and entomogamous species it can be considered a derivation of gynomonoecy (see section 6.14.1). In anemogamous species the development of gynomonoecy mainly has to be considered an adaptation to enlarge the total stigmatic surface of the plants and thereby to increase the chance of pollination, although some function in avoiding self-pollination may not be neglected. In entomogamous species gynomonoecy appeared to be a successful development to avoid self-pollination in protandrous inflorescences by creating second 
order herkogamy from the beginning of the development of the inflorescence onwards (many Asteraceae), rather than an adaptation to enlarge the total stigmatic surface of the plant. In entomogamous species more often gynomonoecy occurs than in anemogamous species (tables 6-23A and B). Because in gynodioecy there is no difference, it is difficult to establish whether the difference in gynomonoecy indicates the correctness of the functional difference mentioned. The next state of partial dicliny will give more evidence.

\section{Polygamy}

Polygamy can be considered the result of simultaneous developments of andro- and gynomonoecy on the same specimen. It appears that anemogamous species more often are polygamous than are entomogamous species (tables 6-23A and B). In entomogamous species andro- and gynomonoecy only rarely occur simultaneously, indicating that the separate developments, in combination with protandry and to some degree with homogamy, in many cases function sufficiently in avoiding self-pollination. In anemogamous species both developments are aimed to increase the chance on pollination and therefore can easily occur simultaneously on the same specimen, however, limiting each other. Only combined with dichogamy (mainly second degree protogyny) sufficient defence against self-pollination is obtained.

\section{Trioecy}

Trioecy is the simultaneous presence of andro- and gynodioecy within the same species. As has been mentioned in section 6.14.1 andro- and gynodioecy can be considered continuous developments of andro- and gynomonoecy respectively. There is no difference between anemogamous and entomogamous species. In both the frequency is very low. For the entomogamous species this can be explained by the final function of androand gynomonoecy. For the anemogamous species it is rather surprising, at least because of the high frequency of androdioecy. Here it is stressed again that androdioecy has to be considered an adaptation to enlarge the pollen production.

\section{Monoecy}

Continuous simultaneous developments of andro- and gynomonoecy on the same specimen, causing polygamy from the very beginning, will lead to monoecy. This process has been completed in many anemogamous species, and combined with dichogamy (mainly second degree protogyny) it provides defence against self-pollination. In entomogamous species this process was completed in some cases only, for the same reasons as mentioned in explaining the rarity of polygamy among them. It is therefore not suprising that 
anemogamous species are monoecious far more often, than are entomogamous species (tables 6-23A and B).

\section{Dioecy}

Continuing development towards andro- and gynodioecy within the same species can result in dioecy. In both anemogamous and entomogamous species these developments can be completed. The chance of completing this development in entomogamous species may be higher than in anemogamous species, because of the final result: entomophilous dioecy may easily become anemophilous, while the reverse developments seem to be more improbable. The frequencies, however, do not differ (tables 6-23A and B).

\section{Discussion}

It appears that two developments to full dicliny can be distinguished.

In anemogamous species, because of the totally inselective pollen vector (wind), both developments of andro- and gynomonoecy on the same specimen are mainly favoured by the selective pressure to increase the chance of successful pollination, resulting in polygamy. On the hermaphroditic flowers of the polygamous specimens the same selective pressure will favour continuous development of andro- and gynomonoecy, and the final result will be monoecy. Dioecy evolving from monoecy seems unlikely (Lewis, 1942). Among entomogamous species these developments may also occur, but the selective pressure to increase the chance of successful pollination is much weaker because of the directed pollen vectors, i.e. anthophilous insects.

Although in entomogamous species gynomonoecy may increase autogamy (that this is a positive adaptation under unfavourable conditions, may not be neglected), combined with other features (guiding the pollinator over the inflorescence, such as colour(s), nectar, odours), it can be stated that in those species development towards andro- and gynomonoecy is mainly favoured by imperfect autogamy-preventing mechanisms, i.e. mainly protandry and to some degree also homogamy, more or less to avoid self-pollination. Both developments can take place on different specimens within a species and form the final result of andro- and gynodioecy, because of the constant selective pressure of imperfect defence against self-pollination on the hermaphroditic flowers. The simultaneous presence of andro- and gynodioecy in a species results from the very beginning in trioecy and the selective pressure will continue to favour the above-mentioned developments in the hermaphroditic specimens. The final result will be dioecy. Among anemogamous species these developments may also take place, but because of the widespread (second degree) protogyny among these species (see table 6-18), the selective pressure to avoid self-pollination will be much weaker. Once a plant is perfectly 
diclinous (monoecious or dioecious), the chance of development from entomogamy to anemogamy is larger than of the reverse developments. Kaplan \& Mulcahy (1971) concluded in their study on Thalictrum that most probably dicliny favours anemogamy and that dicliny evolved in response to selective pressures favouring cross-pollination. The discrepancy between forms of dicliny in response to anemogamy (mainly monoecy) and entomogamy (mainly dioecy) finds evidence in the research of Bawa \& Opler (1975). They concluded that the remarks of Grant (1951) and Stebbins (1951) that dioecism (and monoecism) in temperate forests evolved in response to selective pressures favouring anemogamy (anemogamy in temperate regions being more common than in tropical regions, see Whitehead, 1969) had to be reviewed. They found that the proportion of dioecious species and individuals in northern temperate regions generally is lower than in tropical forests. The large number of tropical dioecious (and to a lesser degree monoecious) trees they studied appeared to be entomogamous, mainly pollinated by small bees. This indicates that indeed dioecy mainly evolved in response to selective pressures, favouring optimal cross-pollination in entomogamous conditions. The comparative abundance of monoecy in northern temperate forests (Bawa \& Opler, 1975) and anemogamy (Whitehead, 1969) indicate that monoecy mainly evolved in response to selective pressures favouring (cross-)pollination in anemogamous conditions. Bawa \& Opler (1975) concluded that it is conceivable that a change from hermaphroditism to unisexuality preceeded the change from zoogamy to anemogamy. They believe that dioecy has evolved from a breeding-system characterized by floral hermaphroditsm and selfcompatibility. As has been argued, the main selective pressure favouring this development is protandry. Cruden \& Hermann-Parker (1977) concluded that if "temporal dioecism" (a flowering sequence which is synchronized so that there is little or no overlap between staminate and pistillate phases of an individal plant) in entomogamous Apiaceae is plesiomorphous, then dioecy is an apomophous condition and, in particularly selective regimes, dioecious plants must enjoy a selective advantage to "temporally dioecious" plants. In my opinion if "temporary dioecism" is not absolute, development towards dioecy may take place through andro- and gynomonoecy. Webb (1979) described the sex distribution and the evolution of New Zealand ApiacaeApioideae and concluded that gynodioecy cannot be interpreted as only a transitional stage to dioecy, but also representing a long-persistent breeding-system in some species. However, if androdioecy also occurs in the same species and the female plants provide offspring which is fitter than that of the hermaphroditic flowers, development towards dioecy will take place.

It can be concluded that dioecy mainly developed under entomophilous conditions and that monoecy mainly developed under anemophilous conditions. 
This means that dicliny has to be approached more broadly than Meeuse does (1978). It means that entomophilous dioecy will be mainly of entomophilous origin and even many cases of anemophilous dioecy may be so. Anemophilous monoecy will be of anemophilous origin. Whether entomophilous monoecy can be of anemophilous origin remains questionable. It will mainly be the result of development from entomophilous polygamy (simultaneous presence of andro- and gynomonoecy in the same specimen). Although in some cases of anemogamy original entomogamy seems resonable, the question of absolute original entomogamy in the Angiospermae is not solved in this analysis. In my opinion original entomogamy is more probable (see section 6.14.1, particularly with regard to the "double fertilization") and the origin of angiosperm anemogamy have to be placed somewhere in the development towards spreading of the ovaries (as adaptation to avoid ovule damage by large mandibulate, anthophilous insects, see section 6.6 ) by small-flowered plants, and later towards small-flowered inflorescences, particularly among the species which did not develop an inferior position of the ovaries and nectar production.

In this respect we have to consider that the dioecy in Salix originated finally from andro- and gynomonoecious conditions (by way of andro- and gynodioecy). This means that the occasional and irregular occurrence of hermaphroditic flowers in Salix and Populus (see Erlanson \& Hermann, 1928) cannot to be considered an anomaly (Meeuse, 1978), but the last remains of andro- and gynodioecy or polygamy, compare Eichler (1878), Velenovsky (1904), Takhtajan (1969). It will be clear that anemogamous Populus is considered apomorphous in comparison with the mainly entomogamous Salix. Within Salix, e.g. the entomo- and anemogamous $S$. discolor, S. petiolaris and $S$. bebbiana are more apomorphous than the obligatory entomogamous $S$. lucida (see Argus, 1974).

Because it is argued that unisexual flowers not only can develop in anemogamous species, but also (favoured by other selective pressures) in entomogamous species, it cannot be said that unisexual flowers are characteristic for the syndrome of anemogamy. The definition (see section 6.2) of anemogamy has to be altered in this respect. Although unisexual flowers more often occur in anemogamous than entomogamous species, a better definition will include: "unisexual flowers, in case of monoecy second degree protogynous, or protogynous hermaphroditic flowers".

\subsection{Concluding remarks: the transformation series within angiosperm flowers, derived from the insect-flower relationships}

From the analyses of the relationships of anthophilous insects and character states of flowers in the preceeding sections $(6.2$ to 6.15$)$ the following general, 
functionally and stratigraphically/phylogenetically directed transformation series can be hypothesized. These are very general transformation series which means that the direction indicated is more probable than that of the opposite. Reverse directions, however, are possible in taxa of lower rank.

Within the complex of facultative and obligatory pollination types:

1. from beetle- (and wasp-) pollinated flowers and flowers pollinated by shortly rostrate flies (in the next transformation series indicated as flowers pollinated by short-tongued insects) to flowers pollinated by longer-rostrate flies (insects unspecialized, whether or not anthophilous);

2. from flowers pollinated by short-tongued insects to mainly beetle-pollinated flowers (anthophilous beetles) (derived transformation series, continued in 3); 3. from mainly beetle-pollinated flowers to cantharophilous flowers (beetles specialized anthophilous, e.g. in the sense of Fuchs, 1974) (derived transformation series);

4. from flowers pollinated by short-tongued insects to (mainly) wasp-pollinated flowers (wasps anthophilous) (derived transformation series, in only some cases reaching more or less obligatory wasp-pollination);

5. from flowers pollinated by flies with longer proboscis (apomorphous state of 1) to bee-pollinated flowers (bees anthophilous);

6. from flowers pollinated by flies with longer proboscis (apomorphous state of 1) to butterfly-pollinated flowers (butterflies not necessarily anthophilous), in its turn giving rise to moth-pollinated flowers (moths not necessarily anthophilous);

7. undirected, derived transformation series: from bee-pollinated flowers to butterfly-pollinated flowers, and vice versa (both bees and butterflies anthophilous.

Generally these transformation series are accompanied by an increase of the general effectiveness of the pollination (mainly those towards bee-pollinated flowers) and for a part of the specialization of the pollination (highly efficient for a restricted number of species), becoming obligatory in e.g. 3 (see also the next transformation series).

Between the obligatory entomophilous pollination types, based on the description of each other excluding syndromes, no transformation series can be described, without taking into account the facultative pollination types. Including the latter the following transformation series can be constructed:

8. from flowers pollinated by short-tongued insects (in the sense of 1) by way of flowers pollinated by flies with longer proboscis (apomorphous state of 1) to myiophilous flowers (obligatory anthophilous and specialized flies) as they may have existed in the Upper Cretaceous, obligatory in absence of higher, longtongued Apoidea and Lepidoptera; in Recent times these flowers would be des- 
cribed as pollinated by longer-tongued insects than Coleoptera and non-apoid Hymenoptera and the plesiomorphous Apoidea and Lepidoptera);

9. from myiophilous flowers (apomorphous state of 8) to (fly- and) beepollinated flowers (anthophilous, but not necessarily specialized bees);

10. from (fly-and) bee-pollinated flowers to melittophilous flowers (specialized anthophilous bees);

11. from myiophilous flowers (apomorphous state of 8) to (fly- and) butterfly(and later moth-) pollinated flowers (anthophilous, but not necessarily specialized butterflies and moths);

12. from (fly- and) butterfly- (and later moth-) pollinated flowers to psychophilous and phalaenophilous flowers (both butterflies and moths specialized);

13. possible, undirected transformation series derived from 7: from melittophilous flowers through bee- and butterfly- (or moth-) pollinated flowers to psychophilous and phalaenophilous flowers, and vice versa (bees, butterflies and moths fairly specialized);

14. derived transformation series: from flowers pollinated by short-tongued insects (in the sense of 1) to sapro-entomophilous flowers (mainly sapromyiophilous flowers or inflorescences) (not necessarily anthophilous carrion insects);

Some derived transformation series are possible:

15. from melittophilous flowers through bee- and bird-pollinated flowers to ornithophilous flowers (birds in first instance not necessarily anthophilous); 16. from psychophilous and certain sphingophilous flowers flowers through butterfly-, diurnally Sphingidae- and bird-pollinated flowers to ornithophilous flowers (birds in first instance not necessarily anthophilous);

17. from phalaenophilous and certain sphingophilous flowers through moth-, nocturnally Sphingidae- and bat-pollinated flowers to chiropterophilous flowers (bats in first instance not necessarily anthophilous).

Note. It is also possible that certain chiropterophily originated from pollination by non-flying mammals.

Within the complex of blossom-pollinator relationships the following transformation series are directed:

18. from allophilic to hemiphilic flowers or inflorescences (more or less corresponding with the transformation series in the complex of facultative and more obligatory pollination types);

19. from hemiphilic to euphilic flowers or inflorescences (more or less corresponding with the transformation series to the obligatory pollination types); 20. derived transformation series from 19: within the euphilic blossompollinator relationships, from polyphilic, through oligophilic to monophilic flowers or inflorescences (Faegri \& Van der Pijl, 1980). 
In the complex of flower types the following transformation series are constructed:

21. from actino- or pleomorphic to stereomorphic flowers;

22. from actino- or pleomorphic to zygomorphic flowers (without depth-effect, mainly in conjunction with flowers arranged in more small-flowered inflorescences);

23. from stereomorphic to zygomorphic flowers (with depth-effect);

24. derived transformation series: from choripetalous to sympetalous flowers. Following Leppik (1957) the following transformation series can be added:

25. from amorphic or paleomorphic to haplomorphic flowers;

26. from haplomorphic to actinomorphic flowers;

27. from actinomorphic to pleomorphic flowers.

Within the complex of conspicuous blossom classes the following transformation series are constructed:

28. from dish- to bowl-shaped to bell- and funnel-shaped blossoms (whether or not accompanied by the development of sympetaly);

29. from bell- and funnel-shaped (particularly the latter) to tube-shaped blossoms;

30. from bell- and funnel-shaped to tube-shaped blossoms;

31. possible transformation series: from bell- and funnel-shaped to gulletshaped blossoms;

32. possible transformation series: from trumpet-shaped to gullet-shaped blossoms;

33. possible transformation series: from dish- to bowl-shaped (particularly the latter) to flag-shaped blossoms, possibly with bell- to funnel-shaped choripetalous intermediates.

Following Faegri \& Van der Pijl (1980) the following transformation series can be added:

34. from dish- to bowl-shaped to brush-shaped blossoms, more or less as 35. from conspicuously entomophilous to inconspicuously entomophilous blossoms.

In the question of plesiomorphy of the single flowers or the inflorescence as pollination unit the following transformatione series are suggested:

36. from intermediate to large flowers as pollination unit (see section 7.1); 37. from small flowers to small-flowered inflorescences as pollination unit. Note. Both transformation series in taxa of lower rank often occur in the reverse direction. Size of flowers is in many cases connected with inflorescences. The inflorescence may also become reduced to a single flower. Because forms of inflorescences are not part of the analyses, the transformation series mentioned cover only part of the possibilities. 
In the floral colours the following transformation series are highly probable: 38. from (green and) yellow to white;

39. from white to blue and blue-mixed colours;

40. from yellow or white to red and red-mixed colours;

41. undirected, derived transformation series: from blue- and blue-mixed colours to red and red-mixed colours, and vice versa.

In the bosition of the stamens one clear transformation series has appeared: 42. from phanaerantherous to cryptantherous flowers.

Note. In some sphingophilous, ornithophilous and chiropterophilous flowers phanaeranthery can be considered apomorphous (e.g. Hibiscus and Fuchsia).

In the number of stamens per flower also one clear transformation series appeared:

43. from many to few stamens per flowers (corresponding either with the transformation series towards small flowers and small-flowered inflorescences as pollination unit, or with an increase of specialization of the pollination).

In the position of the ovaries one transformation series is constructed: 44. from superior, via half-inferior to entirely inferior ovaries; According to Grant (1950) also the following occurs: 45. from superior to stiped ovaries (Capparidaceae).

In the number of ovules per stigma (carpel) one main general transtormation series was constructed:

46. from few to many ovules per stigma (corresponding with an increase of the specialization of the zoophilous pollination).

Note. Within entomogamy reduction of the numbers of ovules occurs in the development towards small-flowered inflorescences (see 67 for anemogamous conditions).

In the nectar presence and position, only in the case of nectar presence transformation series concerning the position could be constructed:

47. from free to half-concealed nectar;

48. from half-concealed to entirely concealed nectar.

In the variation in time between receptivity and dehiscence the most probable transformation series is:

49. from protandry through homogamy to protogyny (in case of monoecy there is question of second degree dichogamy);

Note: the states of dichogamy here are not meant obligatory; there is always an overlap with homogamy. Towards the obligatory states of dichogamy the next two transformation series can be established: 
50. from protandrous with a homogamous phase to obligatory protandrous; 51. from protogynous with a homogamous phase to obligatory protogynous. In case of second order herkogamy caused by dichogamy in both large- and smallflowered inflorescences nectar has a guiding function. It is possible that this is one of the original functions of nectar in taxa of lower rank. This would mean that the following transformation series may be possible:

52. from pollen flowers to nectar-containing flowers.

Note. Pollen flowers may be apomorphous as e.g. in Narthecium (Liliaceae) (see Vogel, 1978) and Solanum dulcamara ("Tauschblume") (Knuth, 1899). Whether nectar has to be considered a prerequisite for the development of second order herkogamy (dichogamy) and dicliny in inflorescences (Vogel, pers. comm.) remains questionable. It may be possible, but also in inflorescences consisting of pollen flowers dichogamy and/or dicliny has been observed, e.g. (Knuth, 1898a, 1899): Sambucus australis is gynodioecious; Artemisia has female margin flowers; Plantago is protogynous and occasionally andromonoecy, androdioecy, gynomonoecy and gynodioecy are observed; Filipendula sometimes is andromonoecious. To decide whether these pollen flowers are derived from nectar-containing flowers, the phylogenetic positions of the genera and species within their families have to be studied.

Under homogamous conditions the following derived transformation series can be suggested:

53. from phanaerogamy to cleistogamy.

In partial and full dicliny the following transformation series are argumented: 54. from plants with hermaphroditic flowers to andromonoecy;

55. from plants with hermaphroditic flowers to gynomonoecy;

56. as a result of simultaneous development of 54 and 55 on the same specimen: from plants with hermaphroditic flowers to polygamy;

57. from polygamy to monoecy;

58. from andromonoecy to androdioecy;

59. from gynomonoecy to gynodioecy;

60. as a result of simultaneous development of 58 and 59 within the same species: from andro- and gynomonoecy to trioecy;

61. from trioecy to dioecy.

As derived transformation series can be suggested:

62. from entomogamy to anemogamy;

Note. Anemogamy derived from entomogamy occurs in e.g. Euphorbiaceae (Vogel, pers. comm.).

This means that the following transformation series are possible:

63. from conspicuous to inconspicuous blossoms, whether or not with entomophilous intermediates; 
Note. The reverse development is possible in taxa of lower rank (see note on 62).

64. from flowers with perianth to flowers with reduced perianth;

65. in connection with 64: from coloured to green flowers;

66. from many to few stamens per flower (as in 43 , but not corresponding with increase of specialization of entomophilous pollination);

67. from more than one to one (see section 7.1) ovules per stigma (carpel) (the reverse of 46). 


\section{RECONSTRUCTION OF THE EVOLUTIONARY DEVELOPMENTS IN POLLINATION}

\subsection{A theoretical model of the earliest angiosperm flowers}

The general transformation series as mentioned in section 6.16 , traced in the reverse direction (from apomorphous to plesiomorphous), indicate a complex of characters or character states of part of the morphology of the plesiomorphous (earliest) angiosperm flowers. The indefinite terms "a complex" and "part of the morphology" are caused by the restricted geographical area covered by the statistical analyses (central European flora). Besides the functionally derived transformation series (chapter 6), there are also comparativemorphologically derived transformation series, based or partly based on taxa which do not occur in the central European flora, or on taxa which are too insufficiently represented in that area to be properly covered by the statistical analyses. In this section a survey is given of the characters or character states of the earliest angiosperm flowers, based both on the functionally and comparative-morphologically derived transformation series.

To understand the developments towards or in the earliest angiosperm flowers, first the angiosperm synapomorphies have to be considered. Hill \& Crane (1982) gave a survey of the synapomorphies of the Angiospermae:

“1) presence of axially aligned companion cells, derived in development from the same mother cells as the sieve elements;

2) megaspore (embryo sac) wall lacking sporopollenin;

3) 4-16 nuclei in megaprothallus;

4) "double fertilization";

5) pollen wall endexine not laminated as seen in TEM sections, except under germination apertures;

6) pollen-receptive stigmatic surface present, and borne on an enclosing or partly enclosing structure which is external to the integument;

7) pollen development has formed three nuclei by the time of fertilization, i.e. prothallials are lacking"'.

Meanwhile the number has been reduced to 1, 3, 4 and 5, by Crane (1985, 1985a) and he added three homoplasies with regard to his cladogram of the relationships of the major groups of seed plants.

All synapomorphies are distinctly functional in aspect and six of those of Hill \& Crane (1982) are connected with reproduction. Two of them are directly cor- 
related with insect visitors: the "double fertilization" avoiding the simultaneous presence of endosperm and pollen (see section 6.14) and the entirely or partially closed carpels with a pollen-receptive stigmatic structure avoiding pollination droplet-feeding and protecting the ovules. Because in the recent Angiospermae not all carpels are closed and the partly open condition is considered plesiomorphous, it can be argued that the earliest angiosperm flowers had at least a partly open carpel (Hemiangiospermae). This means that angiospermy, or better angio-ovuly, was at least not completed in the earliest Angiospermae and the crucial developments (synapomorphies) were the "double fertilization" and the stigmatic surface. Because we do not know which characters or character states are connected with these synapomorphies, nor when they developed, it is difficult to define the earliest angiosperm flowers any further. In fact for many characters or character states we do not even know whether we are dealing with the earliest (plesiomorphous) angiosperm flowers, or with their direct (in their taxon apomorphous) predecessors. It only can be concluded that complete angio-ovuly was a later development than that of the "double fertilization" and the stigmatic surfaces. The "double fertilization" and the developments towards the other synapomorphies seem to have a complicated genetical basis and it would be difficult to believe that they are polyphyletically derived. I do not directly agree with Stebbins (1974): "The condition of double fertilization, coupled with the deferment of endosperm production until after fertilization, is of prime importance because it is the most clear-cut evidence in favour of the monophyletic origin of the angiosperms", and "The independent origin two or more times of the complex readjustment of metabolic regulators that must have been required for this shift is hard to imagine". There seems to be karyological evidence for the monophyly of the Angiospermae (Ehrendorfer, 1976). This in contrast to the polyphyly as accepted by Just (1948), older publications of Melville (1962, 1963), Meeuse (1965, 1972, 1974, 1975, 1977, 1979, 1979a, etc.), Hughes (1976), Krassilov (1977), and Nair (1979).

Angiosperm "double fertilization" most probably originated in hermaphroditic reproductive structures, because there a functional selective pressure favouring this condition is strongest. The presence of such a pressure may favour polyphyly, but restricted to the very rare hermaphroditism of the direct ancestors.

\subsubsection{General floral characters or character states}

\section{Pollination type}

As has been argued in section 6.14.1 the most probable pollination type of the earliest Angiospermae and their direct predecessors is entomogamy. This pollination type provided a much stronger selective pressure favouring the 
development of the double fertilization, than anemogamy would have done. The possible range of pollinators of the earliest angiosperm flowers or their direct predecessors depends on the time of origin of the Angiospermae. It is generally accepted that the Angiospermae were definitely present in the Lower Cretaceous (Aptian/Albian). It is, however, possible that the Angiospermae are of (much) earlier origin (see in this respect the discussion of the possible sister-groups of the Angiospermae in section 7.2 and the remarks on the interpretation of both macro- and microfossils of the Angiospermae in section 7.4), and therefore the stratigraphical appearance of the possible pollinators of the earliest Angiospermae or their direct predecessors is illustrated from the Permian to the Lower Cretaceous in table 7-1. It will be clear from this table that the Coleoptera, Hymenoptera (Symphyta s.lat.) and Diptera, in which anthophily developed, show already a considerable radiation during the Jurassic, and thus, that the earliest Angiospermae, if their origin is somewhere between the upper Triassic and the Lower Cretaceous, may have been pollinated by beetles, wasps and flies with short rostrum. This may mean that the earliest Angiospermae or their direct predecessors more probably were non-specialized entomophilous, rather than cantharophilous. In this case a comparison with the earliest known hermaphroditic reproductive structure may support this. The reproductive structures of Sturiella (Sturianthus) langeri from the upper Triassic (Keuper) of Australia were small structures arranged in cone-shaped inflorescences, and these structures do not represent a typical beetle-pollinated structure, but rather a non-specialized entomophilous pollination type.

Many authors have indicated beetles as pollinators of the earliest Angiospermae and even consider beetle pollination a plesiomorphous feature in the Angiospermae. Whether they are right, depends on the origin of the double fertilization. It is beyond doubt that flower visitors like beetles, and to some extent also symphytan wasps, formed the main selective pressure favouring double fertilization, but this does not mean that the earliest Angiospermae were more exclusively pollinated by beetles. The development of protection of the offspring against injurious visitors, in this case avoiding injury to the endosperm, can be compared with the later development of inferior ovaries within the Angiospermae (see section 6.11). It appeared that many nonspecialized entomophilous flowers and inflorescences developed inferior ovaries, not because they were more exclusively pollinated by beetles, but because beetles were the most injurious (pollinating) insect visitors among the often extensive range of pollinators. Another argument for original angiosperm non-specialized entomophily may be the fact that the other synapomorphy that is directly connected with the pollinators, the development of stigmatic surfaces, probably was not only favoured by the selective pressure of the beetles and symphytan wasps, but also of the flies with their mouth parts adapted for licking or sucking liquids (pollination droplets). 
Table 7-1. Possible pollinators of the earliest Angiospermae and other entomogamous plants in Lower Cretaceous and pre-Cretaceous times. The occurence of the taxa of higher rank is illustrated until their taxa of lower rank appeared.

\begin{tabular}{|c|c|c|c|c|c|c|c|c|c|}
\hline \multicolumn{2}{|c|}{ PERMIAN } & \multicolumn{2}{|c|}{ Triassic } & \multicolumn{3}{|c|}{ JURASSIC } & \multicolumn{2}{|c|}{ CRETACEOUS } & \\
\hline lower & upper & lower & upper & lower & middle & upper & lower & upper & \\
\hline & 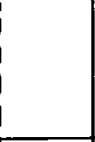 & & $\begin{array}{l}1 \\
1 \\
1 \\
1 \\
1\end{array}$ & & $\begin{array}{l}1 \\
1 \\
1 \\
1 \\
1\end{array}$ & $\begin{array}{l}\vdots \\
\vdots \\
\vdots\end{array}$ & . & $\begin{array}{l}1 \\
\text { I } \\
\text { I }\end{array}$ & $\begin{array}{l}\text { COLBOPIERA-ARCHOSTEMATA } \\
\text { Cupedoidea } \\
\text { Ommadidae }\end{array}$ \\
\hline & $\Gamma$ & & I & & 1 & + & & 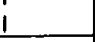 & Tetraphaleridae \\
\hline & 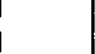 & & । & & T & 1. & & 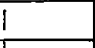 & Cupedidae \\
\hline & 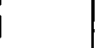 & & ! & & 1 & 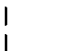 & & 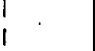 & COLEOPIERA-POLYPHAGA \\
\hline & 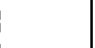 & & ! & & 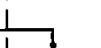 & i & & i & STAPHYLINIFORMIA \\
\hline & 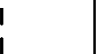 & & 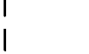 & & + & 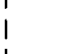 & & 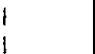 & Staphylinoidea \\
\hline & 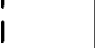 & & ! & & 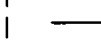 & 1 & & & Staphylinidae \\
\hline & i & & $\frac{1}{1}$ & & i & 1 & & 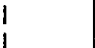 & SCARABAEIFORMIA \\
\hline & I & & 1 & & $\frac{1}{1}$ & & & i & Dascilloidea \\
\hline & I & & 1 & & i & $1-$ & & $T$ & Dascillidae \\
\hline & 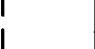 & & 1 & & $i$ & $\frac{1}{1}$ & & I & ELATERIFORMIA \\
\hline & i & & ! & & 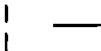 & 1 & & 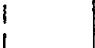 & Buprestoidea \\
\hline & I & & 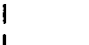 & & i & i & & T & Buprestidae \\
\hline & ! & & 1 & & i & $!$ & & i & Elateroidea \\
\hline & i & & 1 & & $\frac{1}{1}$ & 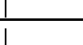 & & $\frac{1}{1}$ & Elateridae \\
\hline & | & & i & & $\frac{1}{1}$ & $\frac{1}{1}$ & & 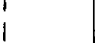 & BOSTRYCHIFORMIA \\
\hline & 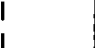 & & ! & & $T$ & & t & i & Dermestoidea \\
\hline & 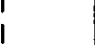 & & I & & i & 1 & & 1 & Dermestidae \\
\hline & 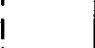 & & 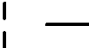 & & + & $\frac{1}{1}$ & & $!$ & Bostrychoidea \\
\hline & 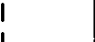 & & i & & 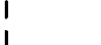 & 1 & & $\frac{1}{1}$ & Anobiidae \\
\hline & ( & & i & & $T$ & 1 & & 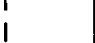 & CUCUIIFORMIA \\
\hline & 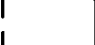 & & 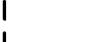 & & i & 17 & & i & Cucujoidea \\
\hline & i & & 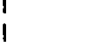 & & $!$ & 1 & & $\perp$ & Nitidulidae \\
\hline & 1 & & $i$ & & $!$ & i & & $\frac{1}{1}$ & Crypterophagidae \\
\hline & | & & 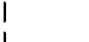 & & 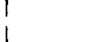 & I & & 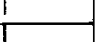 & Mordellidae \\
\hline & 1 & & 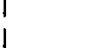 & & $\begin{array}{l}1 \\
1 \\
1\end{array}$ & ! & & + & Tenebrionidae \\
\hline & $!$ & & i & & 1 & 1 & & 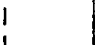 & Chrysomeloidea \\
\hline & 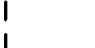 & & i & & 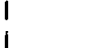 & 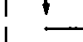 & & 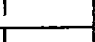 & Cerambycidae-Lepturinae \\
\hline & 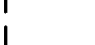 & & $!$ & & i & 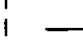 & & $\perp$ & Cerambycidae-Cerambycinae \\
\hline & I & & 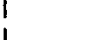 & & i & I & & 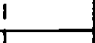 & Chrysomelidae-Galerucinae \\
\hline & ! & & i & & 1 & ! & & 1 & Bruchidae \\
\hline & 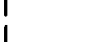 & & 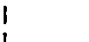 & & i & + & & 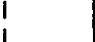 & Curculionoidea \\
\hline & i & & 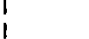 & & i & ! & & $\perp$ & Nemonychidae \\
\hline & I & & i & & I & 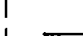 & & i & Anthribidae \\
\hline & I & & ! & & I & 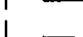 & & $T$ & \\
\hline & 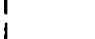 & & 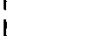 & & I & i & & 1 & Axycuidulat \\
\hline & i & & i & & i & 1 & & i & Aproniabe \\
\hline & I & & 1 & & 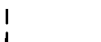 & in & & 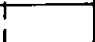 & Curculionidae \\
\hline
\end{tabular}


(Table 7-1 continued)

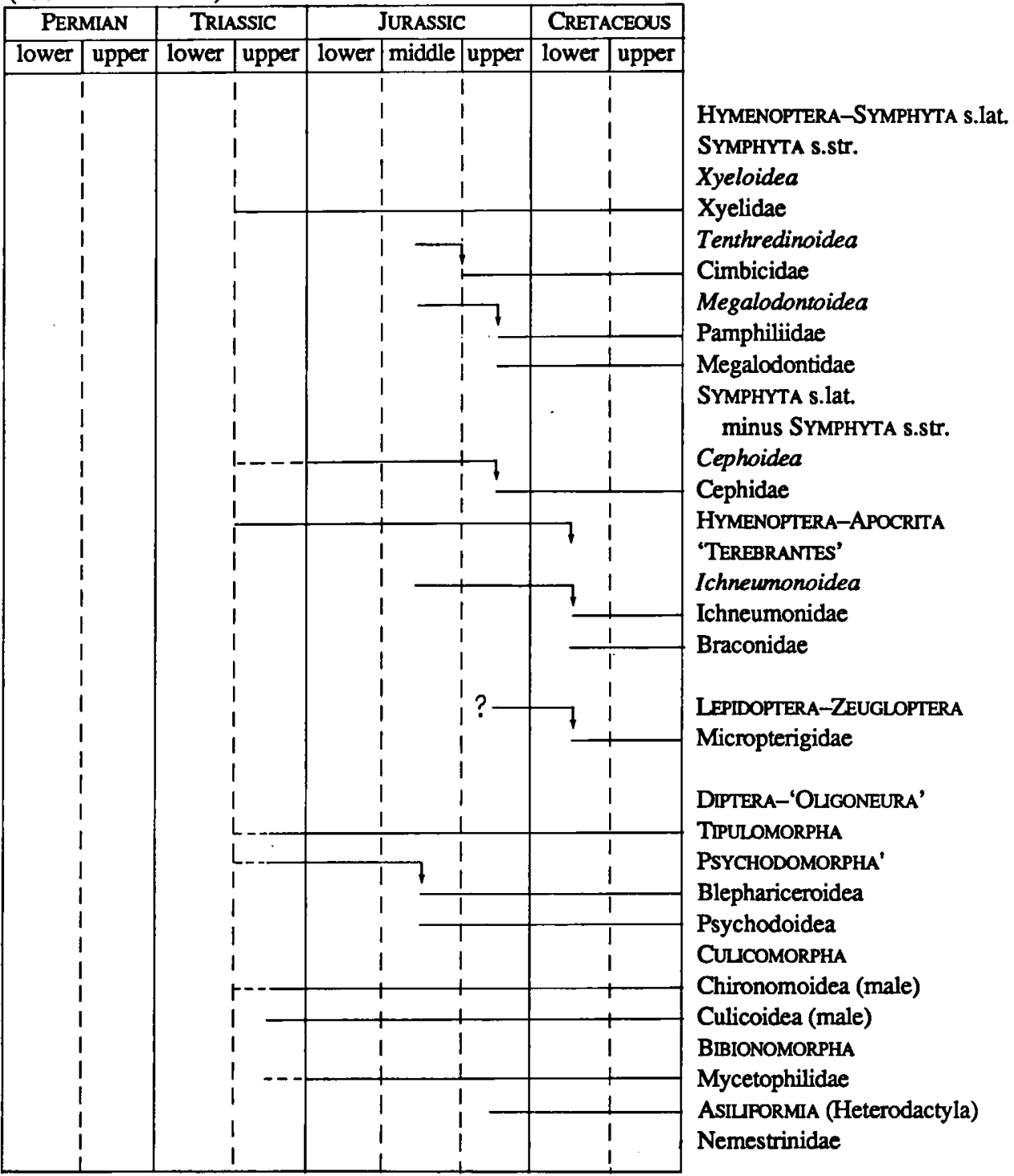

The more obligatory beetle pollination in many of the so-called primitive (plesiomorphous) Angiospermae (e.g. Magnoliaceae, some Winteraceae etc.) may be a(n) (early) specialization within the earliest Angiospermae, or be indeed the pollination type of the earliest Angiospermae, as specialization among their direct predecessors. In the latter case the development of the stigmatic surfaces preceeded the development of double fertilization. Within 
the Spermatophyta the earliest transformation series of the pollination types might have been from non-specialized entomophilous reproductive structures or flowers or inflorescences (see also the discussion of: the solitary flower or the inflorescence as earliest angiosperm reproductive structure) to beetlepollinated flowers.

\section{Blossom-pollinator relationship}

If we conclude to a less specialized entomophilous pollination type of the earliest Angiospermae or their direct predecessors, then the least specialized blossom-pollinator relationship is to be expected. They were allophilic in the sense of the present day definition: no morphological adaptation for guiding visitors; can be utilized by unadapted short-tongued visitors (Faegri \& Van der Pijl, 1980). The possible pollinators mentioned in table 7-1 all, except possibly the males of the Culicoidea, have short mouth parts. Because there are arguments that all possibly anthophilous insects present at the time of origin of the Angiospermae formed a selective pressure favouring the development of both "double fertilization" (mainly beetles and wasps) and pollen-receptive stigmatic surfaces (see the preceeding "pollination type") (mainly wasps and flies), it can be concluded that the earliest angiosperm flowers or their direct predecessors most probably were allophilic. If the development of the stigmatic surfaces was completed before the development of the double fertilization, a more euphilic (more or less cantharophilous) pollination type might have been original among the earliest angiosperm flowers (see, however, the discussion of the solitary flower and inflorescence as original angiosperm reproductive structure).

\section{Flower type}

The extremes of the functionally derived transformation series of the flower types in section 6.16 are actino- or pleomorphic and zygomorphic. This is due to the restricted geographical area covered by the statistical analysis (section 6.4). Leppik (1957) derived from the comparative-morphologically directed transformation series two more types, viz., haplomorphic and paleomorphic or amorphic. I will not use the term amorphic and agree with a possible paleomorphic type as original in the earliest angiosperm flowers or their direct predecessors. In the paleomorphic type, the flowers or hermaphroditic reproductive structures are "without symmetry" (Vogel (pers. comm.) does not consider them asymmetrical); usually subtended by bracts or discoloured upper leaves, although the "discoloured upper leaves" cannot directly be derived from the transformation series (see below). If the paleomorphic type did already develop in the predecessors of the Angiospermae, there might be the possibility that the haplomorphic type was original in the Angiospermae (see below). 


\section{Blossom classes}

Among the possible pollinators mentioned in table 7-1 there are hardly insects that are strongly guided by odours. These are mainly diurnal species, which may find their way to flowers guided by visual attractants. Only in the Staphylinidae, Dermestidae and Mordellidae some species developed which are attracted to sapro-entomophilous flowers (compare section 4.1). This is the reason to consider inconspicuous pollination units very improbable among the earliest Angiospermae or their direct predecessors. They most probably had conspicuous pollination units of the dish- to bowl-shaped type (diffuse open display of attractant; diffuse open deposition).

\section{Inflorescence versus solitary flowers in the earliest Angiospermae or their direct predecessors}

For reasons of convenience I will not use the classification and terminology of Troll $(1964,1969$; see also Weberling, 1981) in this study.

From the three dominant theories on the form of the blossom of the earliest Angiospermae or their direct predecessors (Parkin (1914): solitary terminal flower; Rickett (1944): simple dichasium with a terminal flower and two lateral flowers; Takhtajan (1969): leafy, i.e. not bracteate cyme), Stebbins (1974) found arguments for the leafy cyme as original in the Angiospermae by comparing taxa within some families on floral features and habitat-ecological aspects.

MAGNOLIACEAE have solitary flowers and they appear to be specialized with regard to their vascular anatomy and carpel dehiscence. Eames (1961) argued that the presence of occasional accessory flowers in several genera and axillary clusters of flowers in Michelia provide evidence that the usually solitary flowers represent a reduction from an inflorescence. Also the peduncular bracts between the upper leaves and the flower may indicate inflorescence ancestry (Stebbins, 1974). Also in view of the pollination ecology the Magnoliaceae are specialized. They often produce a strong odour and are mainly beetle-pollinated. The Recent pollinators are mainly Cetoniinae and related taxa, although also halictid bees and tiphiid wasps have been reported visiting the flowers. In some cases the flowers are adapted to visits by beetles. Examples are the stigmatic warts in some Magnolia species from which the beetles (or other mandibulate insects) can obtain sugar-containing liquids after biting and in Michelia a kind of herkogamy is achieved by the apical position of the ovaries on the receptaculum, which can be considered a development to avoid ovule damage by mandibulate pollen- and flower parts-feeding insects (comparable to the stiped ovaries in the Capparidaceae, compare Grant (1950)). In Liriodendron tulipifera food bodies occur at the base of some tepals from which mandibulate insects can obtain sugar-containing liquids. In many cases the flowers can act as traps for beetles: the inner tepals can keep the beetle 
captive in closed position. This will happen mainly voluntarily: the beetles staying overnight in the flowers (as do many individuals of Oxythyrea funesta between the flowers in the heads of e.g. Leontodon hispidus, as the author repeatedly observed in Austria). Most Magnoliaceae are protogynous (in Liriodendron homogamous conditions have been observed) and when beetles are caught in the female phase, they will leave the flower the next day in the male phase (after pollen-shedding) and the conditions for successful crosspollination are assured. These features of the Recent Magnoliaceae indicate a rather specialized pollination type and the flowers can be considered euphilic (compare section 6.3). Particularly the stigmatic warts in some species of Magnolia and the food bodies in Liriodendron can be considered morphological adaptations to guide the pollinators over the flower after alighting to avoid injury and optimalize successful cross-pollination. These structures do fit the syndrome of cantharophily (see section 6.2). Thien (1974) regarded the flowers of Magnolia as highly specialized beetle flowers. The pollinators, Cetoniinae and possibly Halictidae and Tiphiidae, are of comparably late origin. To study the pollination in the earliest Magnoliaceae we have to compare their fossil record with those of their possible pollinators.

The oldest fossils comparable to the Magnoliaceae are known from the Upper Cretaceous of North America and Europe (Magnolia lacoeana and $M$. amplifolia) and by a fructescence from the same period of Greenland (Magnoliaestrobus gilmouri). Chesters et al. (1967) mentioned Magnolia spp. from the Cenomanian of Dakota, U.S.A. Leaves comparable to Liriodendron are described from the Upper Cretaceous of North America. Many magnoleacean seeds are known from the Oligocene of Great Britain. The earliest Magnolia type pollen has been found in the middle Eocene of central Europe (Magnolipollis graciliexinus and $M$. megafiguratus) and other records are known from the Oligocene (Muller, 1981). He also accepted Liriodendron tulipifera pollen from the Oligocene of the Sahara, described as Liriodendron tulipiferoides ( = Liriodendroipollis) which was also found in lower and middle Miocene and Pleistocene deposits. According to the fructescence of Magnoliaestrobus gilmouri there can hardly be doubt that the Magnoliaceae have been mainly pollinated by beetles since their appearance in the fossil record. The Recent pollinators, the Cetoniinae and related taxa, are of about late Eocene to Oligocene origin. Perhaps their ancestors in pollination were Melolonthinae (Macrodactylus subspinosus has in Recent times been observed on the flowers of Magnolia glauca) and possibly in late Cretaceous times the Glaphyrinae played a role in pollination (Glaphyra has in Recent times been recorded visiting the flowers of Magnolia macrophylla). If the origin of the Magnoliaceae is somewhere in the Upper Cretaceous, it can be stated that they were rather specialized in pollination from their origin onwards.

It can be concluded that all Magnoliaceae (of Michelia no pollination records 
were found) are specialized in pollination. Stebbins (1974) considered them specialized in other aspects. It is therefore possible that they are derived from inflorescence-bearing ancestors. Whether the solitary flowers in all cases can be derived from inflorescences with respect to flower-ecological and other features will be studied in the next families, particularly in those taxa in which both solitary flowers and inflorescences occur. We will first follow the families selected by Stebbins (1974) and thereafter consider a number of families in the western Palaearctic region following Knuth (1898a and 1899).

WINTERACEAE. Most of the genera of this family have flowers arranged in axillary cymes or dichasia. Solitary flowers, such as in Zygogynum are probably derived by reduction (Bailey \& Nast, 1945). The types of inflorescences are probably not the most plesiomorphous in the Angiospermae; they are always axillary and terminal inflorescences on the main axis probably are more plesiomorphous (see Stebbins, 1974). The small flowers show a certain reduction, particularly the crowding of the stamens and the small number of carpels. It is questionable whether these can be considered advanced (derived) features. It is possible that the more separate positioning of the stamens in the Magnoliaceae is an adaptation to beetle pollination and the large number of carpels almost certainly will be (see below). With regard to their pollination the Winteraceae show some specialization. In e.g. Pseudowintera anemogamy occurs. The occurrence of functionally unisexual flowers with rudiments of the opposite sex, indicate development towards polygamy (e.g. Drimys lanceolata is almost dioecious), which can be considered derived (see below). No extensive details are known about the entomogamy of the Winteraceae. Gottsberger (1974) found that Drimys brasiliensis flowers produce a sweet odour and are pollinated by pollen-feeding beetles. It may be clear that, presupposed that the early Winteraceae were protandrous (about their Recent dichogamy no extensive records were found), a development towards polygamy easily could take place (avoiding too much self-pollination as e.g. in the Apiaceae, compare section 6.14.1) with final developments towards dioecy. These developments, in the absence of extra-androecial or -gynoecial food supply for the insect visitors like food bodies or nectaries, easily gave rise to anemophilous conditions. Having no adaptations for food supply to beetles, the entomogamous Winteraceae can hardly be considered beetle flowers and do tend to a less specialized entomophilous pollination type attracting pollen-feeding insects. This type of pollination, however, must have been rather successful, because it allowed the development of pollen in permanent tetrads (see in this cornection the discussion of the numbers of ovules per stigma, below), parallelled in the Ericaceae and Juncaceae (in the latter of which probable successful entomogamy did not prevent the development of anemogamy, possibly also favoured by development towards unisexual flowers by protandry in inflorescences without nectar or food bodies). The crowding of the many 
stamens may be an adaptation to cover the unspecialized visiting insects as densely as possible with pollen tetrads and the fact that the tetrads increase the chance of successful pollination may have allowed a reduction of the number of carpels (accompanied by an increase of the number of ovules per carpel). It may be clear that the pollination type of the Winteraceae, although in most species less specialized than that of the Magnoliaceae, cannot be considered the most plesiomorphous within the Angiospermae, because of the apomorphous character states of the flowers. The earliest pollen of the Winteraceae was recorded from the Maestrichtian of South Australia and the uppermost Cretaceous of New Zealand. It concerns Pseudowinterapollis ( = Gephyrapollenites) and is adopted by Muller (1981) as a Drimys type being closest to Drimys sect. Tasmannia. It is interesting that the earliest Winteraceae pollen, Pseudowinterapollis wahooensis was compared to Pseudowintera by Mildenhall \& Crosbie (1979). As will be discussed in section 7.4 and 7.5 anemophilous pollen quantitatively more often occurs in stratigraphical pollen analysis than does entomophilous pollen. Also the fact that the pollen of Pseudowinterapollis couperi from the late Eocene of Australia and the Oligocene of New Zealand is both comparable to Drimys and Pseudowintera, may indicate that Pseudowintera or its ancestors comparable to Drimys sect. Tasmannia, were already anemogamous in an early stage, perhaps already in the Upper Cretaceous.

In comparison with the solitary flowers of the Magnoliaceae, it can be stated that the inflorescences in the Winteraceae, as far as they were entomophilous in Cretaceous times, were less specialized in pollination type, also with regard to their small flowers, pollinatable by many pollen-feeding insects ocurring in that time and earlier (compare tables 7-1 and 5-5).

ANNONACEAE. The inflorescences ressemble those of the Winteraceae (bracteate cymes or variously modified dichasia), but they are basically terminal. The solitary flowers of Rollinia, Oxymitra and Hornschuchia are considered apomorphous. For Rollinia and Oxymitra Knuth (1904) suggested cleistogamy after Engler's illustrations (Nat. Pflanzenf. III, 2. Abt.), as it also occurs in e.g. Unona, Artabotrys (modified inflorescences), Goniothalamus and Cyathocalyx. Most Annonaceae are beetle-pollinated and the visitors are mainly trapped voluntarily in the flowers for feeding. Most flowers have fruity odours, although carrion odours also occur. The often nodding flowers are fragrant and mainly large or of indeterminate size, also when they are arranged in (mostly few-flowered) inflorescences (e.g. in Cananga odorata, Polyalthia laterifolia, Uvaria). The specialization of the pollination in solitary flowers does not differ much from that in the flowers arranged in inflorescences. Because there is often question of cleistopetaly, cleistogamy may have developed in many species. This strategy of reproduction can be considered derived from rather specialized entomogamy. Some species are specialized in fly-pollination. In e.g. Asimina trilobata (solitary flowers with nectar) flies (mainly carrion flies, 
Muscidae and sometimes Syrphidae) intrude into the strongly protogynous flowers with their compressed petals in the female stage and can only leave the flowers in the male phase after spreading of the petals. This pollination type, accompanied by carrion scent, can be considered as derived as the cantharophily in most of the Annonaceae. It means that the basis from which both cantharophily and myiophily developed, must have been a stage of beetle- and fly-pollination, perhaps also trap flowers, but with somewhat less strongly compressed petals (beetles being stronger insects than flies), by developing carrion scent and the production of nectar in the direction of myiophily. Another argument for specialization of the original pollination in the Annonaceae is the presence of the dioecious Stelechocarpus. The flowers are arranged in inflorescences and on the female plants they are cauliflorous. The dull yellowish colours of the cauliflorous flowers in Stelechocarpus burakol (Knuth, 1904) indicate entomophily. Then, it is probable that the dioecious condition has been derived from protandrous inflorescences with hermaphroditic flowers (as in the case of Salix, see section 6.15). It can be concluded that, within the Annonaceae, the original blossom must have been a rather compact inflorescence, leading to the development of dioecy and cantharophily and myiophily, the last two accompanied by reduction of the numbers of flowers in the inflorescences, until solitary flowers, in some cases leading to cleistogamy.

Annona- and Asimina-like leaves and seeds are known from the Upper Cretaceous onwards. A fruit (Xylopiaecarpum) from the lower Eocene of Hungary was compared to Xylocopia. The earliest possible Annonaceae pollen is Foveomorphomonocolpites humbertoides from the Maestrichtian and Paleocene of Columbia and it can be considered as the Malmaea type. The Annona type is known from the Eocene and Oligocene of southeast U.S.A. Van der Hammen (1963) has shown that pollen of Annona cf glabra, a common South American swamp species, is preserved in Quaternary deposits. It appears that the Annonaceae were already fairly differentiated at the end of the Cretaceous. At that time cantharophily may already have been present, and myiophily may have existed in the same time (in the latter case Phoridae and Empididae may have been the main pollinators, see table 5-4; the Muscidae and Syrphidae are of later origin). The earliest Asimina pollen, however, is first known from the Miocene (Van der Hammen et al., 1971). It will be clear that the earliest (hypothetical) Annonaceae or their direct predecessors with non-specialized entomophilous inflorescences may be of much earlier origin than the Upper Cretaceous.

Within the Annonaceae there may be indications that early inflorescences had a non-specialized entomophilous pollination type than the later few- and large-flowered inflorescences and solitary flowers. Takhtajan (1969) mentioned that, e.g. in Polyalthia and Fissistigma the anthers have completely 
sunken in the staminal tissue. This can be considered an adaptation to avoid self-pollination in protandrous conditions (pollen not entirely free) and the laminar stamens (not differentiated into filament and connective) produced above the anthers in Polyalthia can be considered a food supply for the trapped beetles.

DILLENIACEAE. Dichasia occur in the subfamily Tetraceroideae. This subfamily is regarded as more specialized than the Dillenioideae in which solitary flowers occur. To this subfamily belongs the genus Hibbertia of which the sections found in New Caledonia, Trisema, Polystiche and Spicatae, either have a simple or a compound spike (as in the Australian section Hemistemma). Solitary flowers occur in the Australian section Cyclandra. They are sessile at the end of leafy branches with the upper leaves passing gradually into sepals (see Stebbins, 1974). According to Knuth (1904) the Brazilian Tetracera sp. and Davilla rugosa are entomogamous, frequently visited by bees, Melipona bipunctata and Halictus respectively. If these bees are the main pollinators, the pollination type has to be considered non-specialized entomophilous rather than melittophilous. The illustrations of Hibbertia tetrandra, Dillenia indica, D. suffruticosa and Tetracera masuiana in Heywood (1978) do not indicate a very specialized pollination type. These belong to the dish- to bowl-shaped blossom class. The only specialization can be considered the large size of the flowers. In species of Dillenia the flowers are like gigantic buttercups up to $20 \mathrm{~cm}$ across in $D$. indica. These large flowers are short-flowering (lasting one day) and this requires rapid and adequate pollination by insects, but in some cases also by birds plucking petals (Feagri \& Van der Pijl, 1980). Although the latter is not a case of specialized ornithophily, it can be considered (very) derived. The non-specialized entomophilous solitary flowers will not differ very much in pollination type from the flowers arranged in inflorescences, but in case of short-flowering and enlargement of the flowers (allowing birds to act as pollinators) these can be considered specializated. Then, the idea of Stebbins (1974) that the solitary flowers, sessile on the apices of leafy branches may be the most generalized floral condition in the Dilleniaceae, differing only from the leafy cyme in the absence of branches from the axils of upper leaves, may not be true. It is possible that the earliest Dilleniaceae had (leafy) cymes developing on the one hand more specialized solitary flowers and on the other hand bracteate dichasia.

The earliest fossil remains of the Dilleniaceae are comparatively young. There are few macrofossils, possibly comparable to Dillenia, from the Eocene of Europe (Dillenites) and Dillenia type pollen has been reported from the upper Miocene of northwest Borneo. Curatella pollen is known from the middle Miocene and Pliocene of Guyana. The presence of Dillenia pollen in stratigraphical pollen analysis may indicate an already considerable size of 
their flowers with a non-specialized entomophilous pollination type with a consequent large pollen production in the Eocene.

PAEONIACEAE. In the only genus Paeonia both solitary flowers and inflorescences occur. The latter is the case in e.g. Paeonia albiflora, $P$. delavayi, $P$. brownii and $P$. californica (leafy cymes). The species Paeonia suffrutescens and $P$. ovata and the $P$. daurica-corallina complex have solitary flowers and in the last one the distinction between vegetative and floral parts is clear-cut. Stebbins (1974) concluded that in Paeonia the leafy cyme almost certainly is original and the solitary terminal flowers a derived condition.

The flowers of Paeonia are showy and large to very large, up to $14 \mathrm{~cm}$ across in $P$. officinalis. Knuth (1898a) mentioned Bombus terrestris visiting Paeonia officinalis and Cetoniinae as pollinators of the Chinese $P$. arborea. The presence of a nectar-containing disk at the base of the receptaculum indicates a more specialized pollination type. Differences in specialization of the pollination between solitary flowers and the large-flowered inflorescences are not found. The entomophily of the flowers of Paeonia may be absolute, because Paeonia pollen has not been found in stratigraphical pollen analysis (neither are, however, macrofossils).

RANUNCULACEAE. The most common inflorescence is the leafy cyme. It is found in the least specialized genera in the tribe Helleboreae, Helleborus, Trollius, Caltha and Isopyrum. In Ranunculus developments towards bracteate cymes and solitary flowers can be traced. Most species have a leafy cyme, but in Ranunculus flammula and $R$. alsimaefolius the cyme is bracteate. In Myosurus the flowers are solitary at the end of leafy scapes. It is possible that the bracteate cyme in Thalictrum is derived from an Isopyrum-like leafy cyme. Solitary flowers are associated with vegetative specialization in Eranthis, Coptis, Hepatica, Anemone and the subalpine species of Caltha. In many species in the determinate cymes the buds in the axils below the terminal flower develop in descending order and this may be considered an adaptation in the unspecialized entomophilous flowers to optimalize successful cross-pollination in protogynous circumstances. Although protogyny alone already may be effective in this regard this second order herkogamy may strengthen this effect. In protandrous Nigella spp. and others, after the terminal flower is formed, the buds develop in ascending order, so that a raceme with an end flower is formed. Here the end flower may function as "leaving-point" for the visiting insects, making sure that after first visiting the lower flowers in the female phase also the higher flowers in the male phase are visited. In Aconitu' $\iota$ and other genera the same occurs as in Nigella, but the end flower rarely develops. In the case of Aconitum the large nectar production may have taken over the guidance of the insects over the inflorescence.

Isopyrum (often with solitary flowers) is fly- and bee-pollinated and the same is the case in the loose inflorescences of Caltha. Both Helleborus and Trollius are 
bee-pollinated; the first ofter has solitary flowers in $H$. niger and in the second the flowers mostly are solitary. Ranunculus is pollinated by flies and bees and to some degree also by beetles; there are no differences found in specialization of the pollination between inflorescences and solitary flowers, but perhaps this requires a fine statistical analysis (e.g. correlated to the different types of nectar scales). The solitary flowers of Myosurus are mainly fly-pollinated. In Thalictrum mainly anemogamy occurs, although also sometimes pollination is effected by pollen-feeding or -collecting insects. The solitary flowers of Eranthis are fly- and bee-pollinated, those of Coptis probably bee-pollinated and in the arctic regions, as in $C$. trifoliata, fly-pollinated. In Hepatica pollination by pollenfeeding flies and -collecting bees is known to occur and also Caltha (often with loose inflorescences) these insects are the main pollinators. It appears that in the taxa mentioned by Stebbins (1974), there is a slight shift to bee-pollination in the development from inflorescences to solitary flowers or in flowers which developed nectar. The specialization of pollination accompanied by the developments towards solitary flowers is also illustrated in the following examples. In the central European species of Clematis, $C$. vitalba and $C$. recta (according to Knuth (1898a) both have pollen lowers. Vogel (pers. comm.) mentioned nectaries for Clematis vitalba) have small flowers arranged in inflorescences. These are pollinated by flies and bees and to some degree also by beetles. The solitary flowers of Clematis viticella (large, blue to violet or purple flowers), $C$. cirrhosa, $C$. integrifolia (in both species nectaries at the base of the stamens) and $C$. alpina (some of the stamens entirely reduced to nectaries) are mainly pollinated by bees. The pollen flowers of Anemone narcissiflora are arranged in inflorescences (these are protandrous, and Schulz in Knuth (1898a) in some cases observed stigmas without function) and are pollinated by pollen-feeding flies. The solitary flowers of other species of Anemone are more often visited by bees and those of $A$. nemorosa (in the tissue of the receptaculum sweet liquids are available for e.g. Apis mellifera) by bees and bumblebees. The flower-ecologically highest specialized Ranunculaceae are Aconitum, Delphinium, Consolida, Aquilegia. The majority of the species of these genera is pollinated by bumblebees. Vogel (1954) mentioned, psychogamy, sphingogamy and ornithogamy for South African Aquilegia and the same, except sphingogamy, for Delphinium. All have inflorescences, although there is a tendency towards few-flowered inflorescences can be traced.

It can be concluded that within the Raunculaceae reduction of the numbers of flowers in inflorescences is generally accompanied by a somewhat increasing specialization of pollination and that species with solitary flowers in most cases have a somewhat more specialized pollination type than related species with the flowers arranged in inflorescences. The most apomorphous pollination types, however, are found in flowers arranged in inflorescences. There may be some support from flower ecology for the opinion of Stebbins (1974) that in 
the Ranunculaceae the original condition of (leafy) cymes has in various lines given rise to more specialized conditions of both bracteate cymes and solitary flowers. The fossil history of the Ranunculaceae is comparatively young. The oldest fossil is a fruit of Clematis panos from the upper Oligocene. Chesters et al. (1967) recorded Clematis vectensis and Ranunculus ovaliformis from the Oligocene of Great Britain. From the Miocene of Europe and the Pliocene of Japan leaves and fruits are described comparable to Batrachium, Ranunculus, Clematis and Helleborus (Helleborites). The earliest pollen belongs to the Thalictrum type: Punctioratipollis ludwigi from the lower Miocene and Pliocene is very similar to the pollen of Thalictrum. Ranunculus type pollen was described from the upper Miocene of France. The fossil record does not give indications of inflorescences preceding solitary flowers, but, whatever limited it is, it indicates that ranunculacean anemogamy is a derived development (Thalictrum pollen found in much younger deposits than macrofossils of probable entomogamous Ranunculaceae).

PAPAVERACEAE. Leafy cymes occur in species of Papaver, e.g. P. somniferum and the genera Argemone, Dendromecon, Eschscholzia, Glaucium, Hypecoum, Hunnemania, Meconella, Platystemon and Romneya. Some species of Papaver (e.g. P. alpinum), Eschscholzia (e.g. E. lobbii), Meconella and Canbeya have solitary flowers on long scapes and are rather specialized. The bracteate cyme in the genus Chelidonium and the related family Fumariaceae is definitely associated with floral specializations (Stebbins, 1974).

In the central European area Papaver rhaeticum and P. sendineri (according to Ehrendorfer (1973) belonging to the $P$. alpinum complex) have solitary flowers. The same is the case in the northern European arctic species Papaver radicatum and the related Asian $P$. nudicaule. Knuth (1898a) mentioned that the large white or yellow flowers of Papaver alpinum are mainly pollinated by flies (Müller, 1881). The flowers have a musky odour. Papaver nudicaule has sulphuric-yellow flowers and is mainly pollinated by flies, although Alfken in Knuth (1898a) observed in cultivated garden flowers pollen-collecting bees of the genera Andrena and Osmia. Papaver radicatum probably is only pollinated by flies (Knuth, 1905), the flowers having an unpleasant smell. In the central European area and adjacent areas the following Papaver species have leafy cymes: $P$. somniferum, $P$. rhoeas, $P$. dubium, $P$. pinnatifidum, $P$. lecogii, $P$. orientale, $P$. argemone and $P$. hybridum. Although all species can be pollinated by pollenfeeding and -collecting insects (beetles, flies and bees), this mainly happens by bees (ultra-violet reflection) and also flies play a substantive role in pollination. Even highly advanced bees such as Apis mellifera and some Bombus species, have been observed collecting pollen on Papaver rhoeas and $P$. somniferum. Within Papaver the pollination type of the alpine and arctic species is more specialized than in the species living in a milder climate. The specialization for more obligatory fly pollination by the production of unpleasant organic odours is 
accompanied by developments towards solitary flowers and less selfincompatibility (more self-pollination). The observations of insect visits to the flowers of Argemone fit the developments in Papaver. Knuth (1904) described the observation of Merrit that Bombus californicus collected pollen in flowers of Argemone hispida by rolling itself in the pollen. Also cases of seeking shelter (probably staying overnight) are known. Cockerell (see Knuth, 1904) found in the closed flowers of Argemone platyceras five bee species (Andrena argemonis, Epeolus auriginea, E. enavata, E. menuacha and Podalirius occidentalis) and two beetles (the curculionid Peritaxia hispida and the nitidulid Carpophilus pallipennis). Although besides these bees and beetles no pollen-feeding flies have been recorded, they almost certainly play a role in pollination. Bees have also been reported visiting the flowers of species of Eschscholzia. Cockerell in Knuth (1904) observed two short-tongued bees (Augochlora and Halictus on the flowers of Eschscholzia mexicana and Knuth himself observed Apis visiting the flowers of $E$. californica. Although not mentioned in the American observations, pollenfeeding Syrphidae may also play a role in pollination, as they do in Europe on imported specimens of the last species (Knuth, 1898a). Glaucium is also pollinated by flies and bees. Although Knuth (1898a) did not mention insects visiting the flowers of Hypecoum the description of the floral features indicate fly and bee pollination. Platystemon and Romneya may have the same flower ecology as the preceeding genera. In Romneya coulteri bees become fuddled and only very slowly recover (see Knuth, 1904). Unfortunately no flower ecological observations are found for the solitary flowered species, except $P$. somniferum, mentioned by Stebbins (1974).

The fossil record of the Papaveraceae is very limited. A fruit (Papaverites) from the Eocene of Germany may be associated with the Papaveraceae. Chesters et al.(1967) mentioned Papaver pictum from the Oligocene of England. Fossil pollen is not known, which may indicate that the entomogamy of the Papaveraceae is very effective.

It can be concluded that there is some evidence that developments in the Papaveraceae from inflorescences to solitary flowers was accompanied by increasing specialization of the pollination, at any rate in Papaver in the northwest Palaearctic region. Then, it can be concluded that the leafy cyme is the most plesiomorphous blossom in the Papaveraceae. The developments towards bracteate inflorescences, as it appears in Chelidonium and the related Fumariaceae indeed is accompanied by specialization of the pollination. In Chelidonium majus, besides beetles and flies (mainly Syrphidae) Knuth (1898a) recorded many apomorphous bees visiting the flowers: Anthophora pilipes, Apis mellifera, Bombus agrorum, $B$. hortorum, $B$. lapidarius, $B$. pratorum, B. rajellus and $B$. terrestris, noting that the more plesiomorphous bees such as Halictus only rarely can cause pollination. Knuth (1904) observed in California Bombus 
californicus as a visitor. The related Fumariaceae are exclusively bee-pollinated, i.e. obligatory melittogamous.

ROSACEAE. In the subfamily Spiraeoideae (we follow here the classification of Focke, see Willis (1966)) in the tribe Spiraeeae, bracteate, highly compound cymiform inflorescences occur in Spiraea, Physocarpus, Aruncus and Sorbaria. The same is the case in the tribe Holodisceae (only genus Holodiscus). In the Quillajeae e.g. Quillaja has leafy cymes or forms which approach this condition, and Lindleya has solitary flowers at the ends of leafy branches. Stebbins (1974) associated the bracteate inflorescences with deciduous shrubs or trees and leafy cymes with plants with persistent foliage, and concluded that the leafy cyme may well have been the original kind of inflorescence in the Spiraeoideae, i.e. Quillajeae having the most plesiomorphous inflorescences in the Rosaceae. The development from leafy cymes to bracteate dichasia and compound cymes can also be traced in the Potentilleae Potentillinae and Dryadinae. Leafy cymes occur in Fallugia, Cowania, Purshia, Geum and Potentilla fruticosa. In the prostrate arctic genus Dryas and in the creeping Potentilla anserina, the inflorescence is reduced to a single scapose flower. In other species of Potentilla, such as $P$. tridentata, the inflorescence is a bracteate cyme (also occurs in Fragaria).

Unfortunately only one record of insect visits to the flowers of Quillajeae is known. Johow (in Knuth, 1904) described that the flowers of Quillaja saponaria in central Chile are frequently visited by the introduced Apis mellifera and in bee-keeping in that area this plant plays the same role as Calluna vulgaris in Germany. This may mean that the Quillaja flowers are specialized in the Spiraeoideae and within the Quillajeae easily could give rise to solitary flowers, as in Lindleya. The highly compound bracteate inflorescences in the Spiraeeae and Holodisceae can be considered an early specialization to small flowered inflorescences, functioning as pollination units.

In Potentilla leafy and bracteate inflorescences occur, as well as solitary flowers. In Potentilla fruticosa (leafy cyme), besides some pollen-feeding beetles, mainly flies have been recorded from the flowers (Knuth, 1898a) and of the Hymenoptera Apis mellifera, Halictus zonulus and two sphegid species Oxybelus bellus and $O$. uniglumis. The insect visits to Potentilla anserina (solitary flowers) do not differ much from those of $P$. fruticosa, but besides the more plesiomorphous bees some more apomorphous bees are among the visitors: Bombus terrestris, Apis mellifera and some Osmia and Nomada species (Knuth, 1898a). Potentilla tridentata (bracteate cymes) is an arctic species, often withtself-pollination. The development towards solitary flowers in the alpine Dryas octopetala may parallel that in the Papaveraceae towards Papaver alpinum.

There are slight indications that the developments from leafy cymes to bracteate inflorescences and solitary flowers in the Rosaceae are accompanied by an increase of the specialization of pollination. 
The oldest fossil remains of the Rosaceae date from the Upper Cretaceous (Rosa hilliae) and Chesters et al. (1967) indicate Pyrus spp. as occurring in the Cenomanian of Dakota U.S.A. In the Tertiary Spiraeoideae, Prunoideae, Rosoideae, Pomoideae and Chrysobalanoideae were present. Whether there was question of inflorescences or solitary flowers cannot be derived from the fossil record. Very interesting fossils are the flowers of Mengea, comparable to the Recent flowers of Quillaja in the Baltic amber. The earliest pollen is Psilatricolporites undulatus from the Oligocene and lower Miocene and this has been considered by Muller (1981) as the Parastemon type. Filipendula type pollen is known from the Pliocene of the Netherlands and Sanguisorba officinalis from the same period of Germany.

It can be concluded that generally inflorescences have a less specialized pollination type than have solitary flowers. This means that solitary flowers can be considered derived and the transformation series is directed from inflorescences to solitary flowers by suppression of the branches and nodes, usually accompanied by elongation of the scape. This is in accordance with Stebbins (1974) and Takhtajan (1970) as far as it concerns leafy cymes. On the basis of the comparative-morphology there is also support for a transformation series from leafy cymes to bracteate inflorescences by reduction of branch length and the modification of leaves into bracts.

In the next part we will study whether solitary flowers can also be derived from bracteate inflorescences. It appears that in the evolution of the Angiospermae small-flowered inflorescences have been very successful in pollination. Particularly the compound inflorescences in which the flowers produce nectar, have radiated extensively: Brassicaceae, Resedaceae, Rubiaceae, Valerianaceae, Dipsacaceae, Asteraceae, Apiaceae, etc. Generally it can be concluded that in the inflorescences the reduction of the number of flowers is accompanied by an increase of specialization of pollination. In e.g. the Caprifoliaceae this process can be shown in the following series: fly- and bee-pollinated Viburnum, mainly bee-pollinated Symphoricarpus, some Lonicera species such as $L$. alpigena and $L$. xylosteum (both with paired bee-pollinated flowers) and the obligatory melittophilous $L$. caerulea and $L$. nigra (also with paired flowers) and the butterfly-/moth-pollinated $L$. periclymenum and $L$. caprifolium (flowers in terminal pedunculate heads). A similar development can be traced in parts of the Asteraceae, e.g. within the Cynareae in the series: Echinops, Cirsium, Carduus, Carlina, some species of Centaurea accompanied by a shift towards more exclusive pollination by more apomorphous bees (Bombus species) and sometimes butterflies (compare Knuth, 1898a), or in other words, by a decrease of pollination by plesiomorphous, short-tongued bees such as Halictidae. 
In several families both bracteate inflorescences and solitary flowers occur. We here follow Knuth (1898a and 1899).

CISTACEAE have flowers solitary or in loose inflorescences. In Cistus most species have inflorescences (in $C$. ladanifer the flowers are mostly solitary). The species mentioned in Knuth (1898a), Cistus incanus, C. hirsutus, C. monspeliensis and $C$. salviifolius are mainly pollinated by plesiomorphous bees (Andrenidae and Halictidae) and also honeybees may play an important role in pollination. Although no insect visits are known to Cistus ladanifer, it may have a somewhat more specialized pollination type because of the brownish-purple spot at the base of the white petals in many species, possibly attracting the insects visitors (apomorphous bees?) and guiding them more effectively. In Helianthemum the flowers are arranged in inflorescences. The pollen flowers are mainly pollinated by pollen-feeding and -collecting insects (beetles, flies and bees). In Fumana the outer stamens are sterile with the filaments forming a string of bulbs, which may be an adaptation to visits by beetles (providing sterile food in addition to pollen). Fumana thymifolia has loose inflorescences, but $F$. procumbens and $F$. ericoides have solitary flowers. Within the Cistaceae there are slight indications that solitary flowers are flower ecologically more specialized than inflorescences.

CARYOPHYLLACEAE. The fowers are mostly arranged in inflorescences. In Arenaria serpyllifolia (loose inflorescences), short-tongued bees and Syrphidae may be the main pollinators. In the alpine species Arenaria biflora the flowers are solitary or two by two. Müller (1881) exclusively observed flies (Muscidae, Syrphidae and Empididae). Here we may find a parallel with Papaver alpinum and Dryas octopetala: numbers of flowers reduced and specialized in unfavourable (here mountain) conditions. The same may be the case in Arenaria ciliata and $A$. balearica. Ekstam (see Knuth, 1905) observed a fly visiting the flowers of Arenaria ciliata at Spitsbergen. In Cerastium, C. uniflorum has solitary flowers, while most other species have more or less loose inflorescences. Cerastium alpinum has very loose inflorescences and in $C$. glomeratum they are compact. In most Cerastium species flies and short-tongued bees are the main pollinators (e.g. in C. arvense). In Cerastium alpinum with widely flutted inflorescences flies are the main pollinators. Of Cerastium uniflorum no pollinators are known, but because its floral ecology resembles that of $C$. latifolium flies will be the most important pollinators. Sagina has small, solitary, terminal and axillary flowers. In Sagina procumbens the flowers are visited by small flies and bees. These small insects will be the main pollinators. In Sagina procumbens and $S$. apetala ants have also been observed visiting the flowers. It may be possible that these wingless insects play a role in pollination. Sagina procumbens forms small erect plants of $3-10 \mathrm{~cm}$ in height and $S$. apetala has creeping stems. In Sagina nodosa the comparatively large flowers (up to 1 $\mathrm{cm}$ across) are visited by the bombyliid Anthrax. In Silene, S. acaulis has solitary 
flowers and is mainly pollinated by butterflies, but apomorphous bees may also play a role in pollination. Particularly in northern regions bumblebees visit the flowers. Schneider (see Knuth, 1898a) observed Bombus agrorum and B. lapponicus on the flowers. The other Silene species (with inflorescences) in Knuth (1898a) vary from exclusively psychophilous/phalaenophilous (e.g. S. vulgaris, $S$. nutans, S. armeria, S. longiflora, $S$. saxifraga) and fly- and butterfly-/mothpollinated (e.g. S. rupestris) to entomophilous/anemophilous flowers (S. otites). In the central European Dianthus both species with solitary flowers (or few flowers together) and inflorescences occur. Dianthus barbatus, $D$. armeria and $D$. carthusianorum have more compact inflorescences and are psychogamous. Dianthus barbatus is visited by long-haustellate Lepidoptera, e.g. (the length of the haustellum of the visiting Lepidoptera is mentioned between brackets after Knuth (1898)): Macroglossum stellatarum $(22-28 \mathrm{~mm})$, Pieris brassicae $(16 \mathrm{~mm})$ and Vanessa urticae (14-15 $\mathrm{mm}), D$. armeria by Vanessa urticae $(14-15 \mathrm{~mm})$ and D. carthusianorum by e.g. Macroglossum stellatarum $(22-28 \mathrm{~mm})$, Rhodocera rhamni (16-17 mm), Plusia gamma $(15-16 \mathrm{~mm})$ and the short-tongued Zygaena species $Z$. carniolica, $Z$. lonicerae and $Z$. trifolii $(7-11 \mathrm{~mm})$. According to Müller (1881) and Knuth (1898a) the visting Lepidoptera with the shortest haustellum were also sucking nectar and thus can play a role in the pollination. Dianthus deltoides has solitary flowers or branched inflorescences. It is psychogamous and the flowers are visited by the bombycid Gnophria quadra (short-tongued), Hesperis lineola (most common visitor with a haustellum length of ca. $15 \mathrm{~mm}$ ), Lycaena icarus (less than $10 \mathrm{~mm})$, Pieris napi $(10-12 \mathrm{~mm})$, P. brassicae $(16 \mathrm{~mm})$, P. rapae (13-18 $\mathrm{mm})$, Argynis pandora $($ ca. $10 \mathrm{~mm})$, Rhodocera rhamni $(16-17 \mathrm{~mm})$, Epinephele janira $(10 \mathrm{~mm})$, and also by the syrphid Volucella bombylans (trying to reach the nectar with its ca. $8 \mathrm{~mm}$ long tongue). The syrphid visitor of this psychogamous/phalaenogamous species may be an indication that the origin of the psychophilous/phalaenophilous flowers may have been myiophilous (compare sections 6.2.2 and 6.16). Solitary flowers or some flowers together, occur in Dianthus superbus and D. monspessulanus. Dianthus superbus has sphingophilous flowers and is mainly visited by the very long-haustellate Macroglossum species. The only visitor reported from the flowers of Dianthus monspessulanus is Macroglossum stellatarum. Dianthus plumarius has solitary flowers and they have been seen visited by Bombus hortorum (Müller, 1881; Knuth, 1898a). This bumblebee has a tongue length of $18-19 \mathrm{~mm}$ (Proctor \& Yeo, 1973). Dianthus sylvestris also has solitary flowers and seems to be very specialized: the nectar is hidden at a depth of 18 to $25 \mathrm{~mm}$.

In the Caryophyllaceae there are indications that the reduction of the numbers of flowers in the inflorescences and the developments towards solitary flowers are accompanied by increasing specialization of the pollination. In Armeria a shift from short-tongued insects to more exclusively flies as pollinators can be traced, in Cerastium they are also accompanied by some 
specialization, in Sagina (almost exclusively solitary flowers) specialization to various insects is indicated (flies and bees, possibly ants and bombyliid flies), in Silene the reduction of the number of flowers may be accompanied by a shift from less specialized entomophilous to psychophilous/phalaenophilous (via flyand bee- pollinated flowers) and bumblebee-pollinated flowers, and in Dianthus they are accompanied by specialization to very long-tongued Sphingidae (deeper hiding of the nectar) and possibly also to long-tongued bumblebees. MALVACEAE. Hibiscus has solitary flowers and is specialized in pollination. The southeastern European species Hibiscus trionum is mainly pollinated by higher bees (Apis mellifera) and although sometimes pollen-feeding flies may play a role in pollination, the flowers can be considered melittophilous. In Alcea the flowers are arranged in inflorescences and the main pollinators are apomorphous bees (e.g. Apis mellifera, Bombus hortorum and B. agrorum on $A$. rosea). Besides apomorphous bees Syrphidae may also play a role in pollination on the inflorescences of Althaea cannabina, such as e.g. Eristalis nemorum and $E$. tenax. In the central European Malva both solitary flowers and inflorescences occur. Inflorescences are found in Malva sylvestris (mainly pollinated by longtongued bees, but also by short-tongued Halictus species) and $M$. rotundifolia (pollinated by both short- and long-tongued bees). Malva alcea and $M$. moschata have solitary flowers and are somewhat more frequently pollinated by longtongued bees and Bombyliidae, and more Lepidoptera are reported from the flowers. Within the central European Malvaceae there are slight indications that solitary flowers are more specialized in pollination than are inflorescences. Including also other species it appears that the solitary flowers can reach a high degree of specialization. The solitary flowers of Hibiscus lasiocarpus are mainly pollinated by higher bees, such as Podalirius and Xenoglossa, sometimes by anthophilous beetles (Euphoria sepulchralis) and humming-birds (Trochilus colubris) and those of $H$. schizopetalus, $H$. liliiflorus and $H$. rosa-sinensis are pollinated by nectar-feeding birds and butterflies. The solitary flowers of Gossypium herbaceum are pollinated by birds and higher bees (Knuth, 1904). GERANIACEAE. Solitary flowers occur in e.g. Geranium sanguineum, which is mainly pollinated by long-tongued insects (bees, Syrphidae, Bombyliidae and occasional Sphingidae), but also by Tenthredinidae and Sphecidae. In e.g. Geranium dissectum, G. columbinum, G. rotundifolium, G. molle, G. lucidum and $G$. robertianum the flowers are small are arranged two by two. The pollination of these species is mainly effected by flies (Syrphidae and Muscidae) and shorttongued bees (species of Andrena and Halictus). This type of pollination also occurs in Erodium malacoidea (3-8 flowers together) and E. cicutarium (2-9 flowers together). Loose inflorescences occur in e.g. Geranium pyrenaicum, G. pratense and $G$. sylvaticum. They are visited by long-tongued bees, but also by comparatively many short-tongued bees and flies from the families Empedidae, Muscidae and Syrphidae. Within the central European Geraniaceae it seems 
that the inflorescences are somewhat less specialized entomophilous than are the solitary flowers (expressed by less short-tongued bees participating in pollination). Small flowered species with two or some flowers together tend to become specialized as syrphid-flowers. Outside Europe Pelargonium is phalaenophilous and ornithophilous.

OXALIDACEAE. In the central Eropean area the Oxalidaceae are often cleistogamous. Oxalis acetosella has solitary flowers and is mainly pollinated by flies (Müller, 1881) and possibly also by Meligethes species (Nitidulidae). Oxalis pes-caprae and $O$. corniculata have inflorescences and are also mainly pollinated by flies. The only difference with Oxalis acetosella is a greater probability of selfpollination, because of the position of the anthers (as in the introduced species $O$. dillenii and $O$. fontana).

RUTACEAE. The small-flowered, dense inflorescences of Ruta are nonspecialized entomophilous and the loose, large-flowered inflorescences of Dictamnus are melittophilous.

FABACEAE-PAPILIONOIDEAE. In comparison with the small-flowered inflorescences of the Mimosoideae (pollinated by a wide range of insects, including higher bees and butterflies), the Papilionoideae with generally more large-flowered inflorescences are more exclusively melittogamous.

PYROLACEAE. The flowers of the central European Pyrolaceae are only rarely visited by insects. The inflorescences of Pyrola minor are more or less nonspecialized entomophilous and the loose inflorescences of $P$. rotundifolia, $P$. media and the related Orthilia secunda are probably pollinated by flies and selfpollination can occur during the entire time of flowering. Moneses uniflora has solitary flowers and self-pollination is only possible at the end of flowering. The apomorphous saprophytic Monotropa hypopitys has inflorescences with more or less melittophilous flowers. In comparison with Pyrola and Orthilia, Moneses uniflora has somewhat more specialized flowers because of the restricted period of possible self-pollination.

APOCYNACEAE. Solitary flowers occur in Vinca and they are pollinated by bees and Bombyliidae. Nerium has inflorescences and these are specialized psychophilous/phalaenophilous (sphingophilous).

SCROPHULARIACEAE. Verbascum (inflorescences to solitary flowers) and Veronica (more or less dense inflorescences and solitary flowers) are pollinated by flies and bees. Scrophularia (loose inflorescences) is mainly visited and pollinated by wasps of the genus Vespa. Digitalis, Antirrhinum and Linaria (all more compact to loose inflorescences) are pollinated by bees (the more compact inflorescences) and bumblebees (often the more loose inflorescences). Tozzia (loose inflorescences) is almost exclusively pollinated by flies (Muscidae and Syrphidae). The species of Euphrasia, Rhinanthus, Melampyrum and Pedicularis (all inflorescences) are pollinated by flies and bees, bees and bumblebees, butterflies, dependent on the length of the corolla tube. In Linaria, L. alpina has 
few-flowered inflorescences and is almost exclusively pollinated by longtongued bumblebees. In other species with inflorescences with more flowers more often short-tongued bees play a role in pollination (e.g. Linaria vulgaris, L. striata, L. organifolia). Solitary flowers occur in Kickxia spuria (often cleistogamous), Cymbalaria muralis (non-specialized entomogamous), Gratiola officinalis (melittogamous). Comparing these genera and species there may be only in Linaria indications of specialization of the pollination in case of reduction of the number of flowers in inflorescences. In Veronica these trends can also be traced. The many-flowered inflorescences of Veronica spuria, $V$. beccabunga, $V$. anagallis, $V$. officinalis, $V$. montana and $V$. chamaedrys are pollinated by flies and mainly short-tongued bees; the few-flowered inflorescences of $V$. serpyllifolia and $V$. alpina are more exclusively pollinated by flies and those of $V$. arvensis and $V$. triphyllos by Halictidae. The solitary flowers in Veronica hederifolia are mainly pollinated by Halictidae and those of $V$. persica by generally longertongued insects (flies, bees and occasionally butterflies).

PRIMULACEAE. In the genus Primula the species with many-flowered inflorescences are mainly bee- and butterfy-pollinated (occasionally also by long-tongued flies). The reduction of the numbers of flowers in the inflorescences (e.g. in Primula integrifolia) and the development towards solitary flowers (e.g. in P. minima) are accompanied by specialization to psychogamy. In Soldanella species with inflorescences (e.g. S. montana) are more often pollinated by flies and bees, while species with solitary flowers are more exclusively pollinated by bees (e.g. S. alpina and S. pusilla).

AMARYLLIDACEAE. Leucojum vernum (solitary flowers or two together), $L$. aestivum (2-8 flowers together) and Galanthus nivalis are pollinated by bees. In Narcissus (solitary flowers or some together) $N$. odorus and $N$. pseudo-narcissus are pollinated by bumblebees, $N$. triandrus, $N$. tazetta, $N$. polyanthus and $N$. primulus by both bumblebees and butterflies, and $N$. poeticus, $N$. triflorus and $N$. jonquilla by butterflies.

IRIDACEAE. Sisyrinchium (few flowers together) is possibly pollinated by small bees, Iris (few flowers together) by bumblebees or occasionally by Syrphidae, Crocus (solitary flowers or few together) by butterflies, and Gladiolus (some to many flowered inflorescences) by bumblebees.

The Amaryllidaceae and Iridaceae are rather to very specialized with regard to their pollination and they mainly have only few flowers together.

LILIACEAE. More or less dense and many-flowered inflorescences occur in Tofieldia, Narthecium (both hardly specialized entomogamous and mainly pollinated by flies and bees), Veratrum (non-specialized entomogamous), Asphodelus (loose inflorescences pollinated by flies and butterflies), Anthericum (non-specialized entomogamous), Gagea (more or less loose inflorescences, hardly specialized entomophilous, mainly pollinated by flies and bees), Allium (flies and bees as pollinators), Scilla hyacinthoides, S. peruviana (non-specialized 
entomogamous), $S$. verna (2-12 flowers together pollinated by flies and bees), $S$. italica (flies and bees), Ornithogalum (non-specialized entomogamous), Hyacinthus (many to few flowers pollinated by bees), Majanthemum (small flies), Convallaria (bees). Solitary flowers or few together occur in Aphyllanthes (flies and bees), Colchicum, Bulbocodium (butterflies and bumblebees), Paradisea (phalaenogamous), Hemerocallis (psychogamous), Lilium (butterflies), Fritillaria (higher bees, sometimes flies), Tulipa (bees and pollen-feeding flies), Erythronium (bees and butterflies), Scilla bifolia (2-8 flowers together; pollinated by flies), Asparagus (bees), Streptopus (bumblebees), Polygonatum (bees and/or bumblebees), Paris (specialized in pollination by carrion flies). In the Liliaceae clear trends can be traced of increasing specialization of the pollination in connection with decreasing numbers of flowers in inflorescences and developments towards soïtary flowers.

Reduction of the number of flowers in inflorescences and final reduction to single flowers seems to be accompanied by specialization of pollination, at least in larger flowers. More observations should be made in the field to obtain sufficient records for proper statistical analysis in the various families. According to the trends in many taxa of the Angiospermae, some of which described above, it can be concluded that the earliest Angiospermae had inflorescences rather than that they had solitary flowers, the latter almost always being specialized. Comparative-morphologically it is very well possible that the earliest Angiospermae had leafy cymes. This type of inflorescence gave rise to solitary flowers (of the type as occurs in e.g. the Magnoliaceae) and to bracteate inflorescences. The latter could already have taken place in early development of the Angiospermae. Connected with nectarless (see below) and protandrous conditions (see sections 6.14.1 and 6.15), this could easily lead to monoecious and dioecious anemogamous types, and this would explain the early appearance of the anemogamous "Amentiferae" in the fossil record.

The development from inflorescences to solitary flowers, may be paralleled in the hermaphroditic reproductive structures in the Bennettitales. Sturiella (Sturianthus) langeri (Williamsoniaceae) had cone-shaped inflorescences in the late Triassic (Keuper) and the much younger Williamsoniella (Wielandiellaceae) from the middle Jurassic and Cycadaeoidea (Cycadeoideaceae) from the upper Jurassic to Upper Cretaceous had solitary reproductive structures.

\section{Size of the flowers}

The size of the flowers of the earliest Angiospermae or their direct predecessors depended on the size of the potential pollinators. The approximate size of the possible pollinators as mentioned in table 7-1 are surveyed in table 7-2. 
Table 7-2. Approximate sizes of the possible pollinators of the earliest Angiospermae and other entomogamous plants in the Lower Cretaceous and preCretaceous times (compare fig. 7-1).

\begin{tabular}{|c|c|c|c|c|}
\hline & $\begin{array}{l}\text { minute } \\
<3 \mathrm{~mm}\end{array}$ & $\begin{array}{c}\text { small } \\
3-7 \mathrm{~mm}\end{array}$ & $\begin{array}{l}\text { intermediate } \\
8-15 \mathrm{~mm}\end{array}$ & $\begin{aligned} & \text { large } \\
> & 15 \mathrm{~mm}\end{aligned}$ \\
\hline 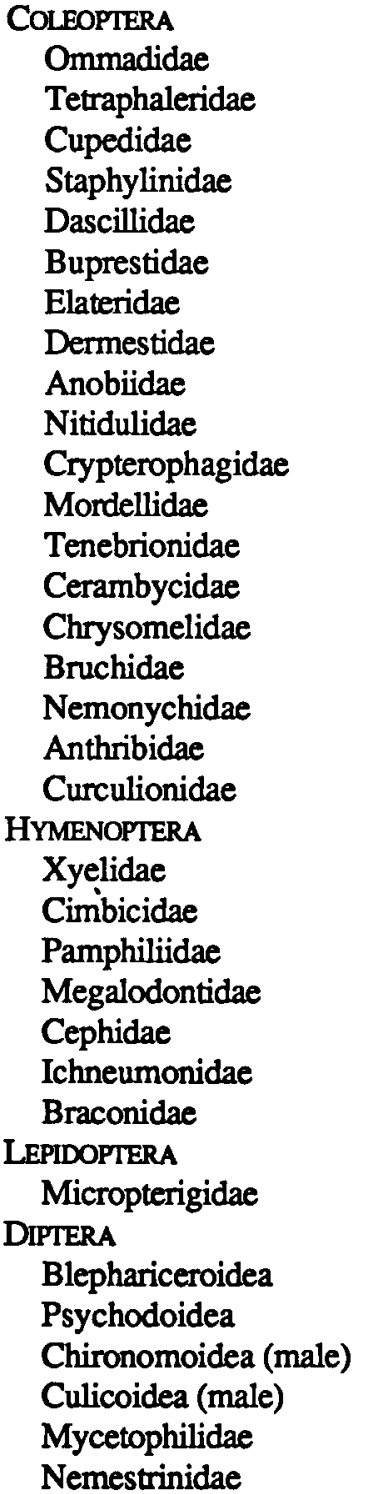 & + & $\begin{array}{l}+ \\
+ \\
+ \\
+ \\
+ \\
+ \\
+ \\
+ \\
+ \\
+ \\
+ \\
+ \\
+ \\
+\end{array}$ & $\begin{array}{l}+ \\
+ \\
+ \\
+ \\
+ \\
+ \\
+ \\
+ \\
+ \\
+ \\
+ \\
+ \\
+ \\
+ \\
+ \\
+ \\
+ \\
+ \\
+ \\
+ \\
+ \\
+ \\
+\end{array}$ & $\begin{array}{l}+ \\
+ \\
+\end{array}$ \\
\hline
\end{tabular}


In the Angiospermae both woody plants (generally a plesiomorphous condition) and herbs (apomorphous condition) occur. In the Gymnospermae, in which the sister-group of the Angiospermae has to be sought, only woody plants occur (may be except the stumpy turnip-like Gnetales (Welwitschia), which are, however, not real herbs). This means that the earliest Angiospermae and their direct predecessors most probably were woody plants. These shrubs or trees are generally larger than herbs and this means that the average distance between the individual specimens is larger than in herbs. This average large, distance required strong fliers as pollinators to cause optimum crosspollination. The larger the distance between the separate specimens, the fewer specimens on a square unit, the stronger fliers as pollinators are required. This may indicate that particularly the stronger, larger flying insects pollinated the earliest Angiospermae and their direct predecessors. With this probable emphasis on the larger insects (in table 7-2 intermediate to large insects) as pollinators (Coleoptera, Hymenoptera and Diptera), it is easily argued that the flowers or reproductive structures, if they formed separate pollination units in the leafy cymes (distance between the flowers considerable), must have been of intermediate size, about as large as or somewhat larger than the visiting insects to provide them a good alighting platform. If the inflorescences as a whole functioned as a pollination unit, i.e. if the leafy cymes were more compact, the flowers or reproductive structures could have been (much) smaller.

It can be concluded that before, or at any rate soon after, the origin of the Angiospermae the development towards small-flowered (bracteate) inflorescences took place forming the basis of e.g. the development of the "Amentiferae". On the other hand, the development towards enlargement of the flowers, accompanied by reduction of the numbers of flowers in the inflorescences and culminating in solitary flowers, probably started in an early stage of the phylogeny of the Angiospermae.

\section{Floral colours}

If the flowers of the earliest Angiospermae or their direct predecessors possessed sterile optical attractants (perianth parts or partly or entirely discoloured bracts or upper leaves in the sense of Leppik (1957)) both yellow (partly discoloured: remaining carotenoid-caused colour after loss of the chlorophyll) and/or white (entirely discoloured: remaining after the loss of chlorophyll and carotenoids, being the result of reflections of light in the intercellular spaces between colourless cells) may have attracted the insects. If the optical attractant was formed by the microsporophylls or stamens there are two possibilities. If the pollen served as optical attractant the colour most probably was yellow and, if the sterile parts of the microsporophylls or stamens did so, the same possibilities occur as for the partly or entirely discoloured leaves. 


\section{Pollen flowers or nectar-containing flowers}

From the statistical analysis in section 6.13 it was not possible to decide whether pollen flowers are more plesiomorphous than nectar-containing flowers. To solve this problem a comparative study has to be made of the floral food supply for the pollinators within the Angiospermae.

In the Magnoliaceae both fertile food (pollen) and sterile food (staminodes and other food bodies and nectar) occur. Staminodes occur in the Austrobaileyaceae (staminodes with wart-like glands), Degeneriaceae, Himantandraceae, Illiciaceae (the inner petals gradually merging into stamens, i.e. presence of staminodes; I prefer to formulate this as outer stamens gradually merging into petals, see below, and the discussion of the perianth), Eupomatiaceae (staminodes bearing small food bodies in the form of glandular hairs), Gomortegaceae, Calycanthaceae (staminodes and food bodies on the apices of the connectives), Lauraceae (often staminodes; stamens in the third whorl and sometimes also in the others with two glands at the base of the filament), Hernandiaceae (staminodes in the female flowers), Gyrocarpaceae (staminodes in the female flowers), Nymphaeaceae (staminodes, and nectariferous petals in Nuphar), Barclayaceae (although rarely emerse flowers, staminodes present), Kingdoniaceae, Sargentodoxaceae (staminodes in the female flowers), Menispermaceae (staminodes in the female flowers), Corynocarpaceae, Sabiaceae (in the sense of Willis, 1966). Here the staminodes are considered food bodies for mandibulate visitors. It is interesting to note that the staminodes mainly occur in flowers which have numerous stamens (except in the Hernandiaceae and Gyrocarpaceae which have 3-5, Corynocarpaceae and Sabiaceae with five stamens and some families in which the number of stamens varies from few to numerous, as e.g. in the Illiciaceae). The staminodes are developed by the stamens becoming sterile, most probably favoured by the selective pressure of (mandibulate) pollen-feeding insect visitors. This means that the presence of staminodes is an apomorphous character in the Angiospermae (see below).

In some entomogamous families only the female flowers have staminodes (sterilization of all stamens in hermaphroditic flowers) as in e.g. the Hernandiaceae, Gyrocarpaceae, Sargentodoxaceae and Menispermaceae. The dicliny in these families probably has arisen, favoured by the selective pressure of protandry (compare sections 6.14.1 and 6.15). The pollinating insects will feed on pollen on the male flowers.

Developments towards nectaries are found in the glandular food bodies in the flowers, as is the case in the Magnoliaceae (e.g. glandular warts on the stigma, and in Liriodendron tulipifera food bodies at the base of some tepals), Monimiaceae (stamens often with two glandular appendices at the basis). Together with the cases in the Austrobaileyaceae (wart-like glands on the staminodes), Eupomatiaceae (gland hairs on the staminodes), Calycanthaceae 
(food bodies at the apices of the connectives), Lauraceae (glands at the base of the filaments), Nymphaeaceae (nectariferous petals), it appears that most of the glandular bodies are developed on the stamens or staminodes (the first being the parts exposed to injury). The same can be concluded for the stigmatal warts in the Magnoliaceae. Here we can conclude that in the first place the fertile parts of the flowers produced an additional food supply for insect visitors in the following transformation series:

1) from plain stigma to stigma with glandular warts;

2) from stamens to staminodes;

3) from plain stamens to stamens with glandular bodies at the bases of the filaments;

4) from plain stamens to stamens with glandular bodies at the apex of the connective;

5) from plain staminodes to staminodes with glandular bodies, or more probably;

6) from stamens with glandular bodies to staminodes with glandular bodies.

In the transformation series stamens-staminodes-tepals or petals (see below) glandu'ar bodies could become situated on the tepals or petals (as in the case of Liriodendron tulipifera).

The glandular bodies probably were forerunners of some types of real nectaries. This could happen at the basis of the filaments (as in the Fumariaceae), at the carpels (Caltha), on the tepals or petals (Berberidaceae and Lardizabalaceae with petaloid "nectar leaves"), or on the sepals (majority of the Ranunculaceae). The many different types of nectaries demonstrate that they, however, will have developed in several ways.

In the Magnoliidae possibly also other flower parts may function as a food supply for the (mandibulate) insect visitors, as the thick sepals in the Canellaceae, the scale-like bracts in the apetalous flowers of the Piperaceae and the fleshy bracts in the related, also apetalous Peperomiaceae, and the fleshy petals in the Coriariaceae.

Magnoliidae without sterile food supply are the Lactoridaceae, Winteraceae, Annonaceae, Myristicaceae, Schisandraceae, Amborellaceae, Trimeniaceae, Chloranthaceae, Meliosmaceae (in the sense of Willis (1966)), and Papaveraceae. These families in this respect can be considered plesiomorphous within the Magnoliidae.

In the protogynous Magnoliidae with a sterile food supply, as in the Magnoliaceae and Nymphaeaceae, exclusively hermaphroditic flowers could persist. In some families probable protandry caused unisexual flowers, although they have a sterile food supply: those mentioned under the survey of staminodes and Monimiaceae (commonly unisexual flowers), Lauraceae (sometimes unisexual and bisexual flowers on the same plant), Piperaceae (bisexual and unisexual flowers, the latter in monoecious or dioecious distribu- 
tion), Lardizabalaceae (monoecious, rarely bisexual flowers). These families retained an entomogamous system and the developments towards dicliny parallel those in the Apiaceae and Salix. Of the Magnoliidae without sterile food supply all, except the Papaveraceae (which developed entomophilous pollen flowers), developed dicliny. Anemogamy is known in Winteraceae in Pseudowintera.

In the Ranunculaceae the development of nectaries is accompanied by increasing specialization of the pollination, and often with development of fewflowered inflorescences and solitary flowers. In e.g. the central European Clematis, $C$. recta has pollen flowers in many-flowered inflorescences, and $C$. flammula with a similar inflorescence produces nectar. Clematis vitalba with many-flowered inflorescences, has nectar. The large solitary flowers (specialized for pollination by bees and bumblebees) of Clematis cirrhosa, $C$. alpina (also staminodes, possibly indicating earlier pollination by mandibulate insects) and $C$. integrifolia all produce nectar. The solitary pollen flowers of e.g. Adonis are pollinated by pollen-feeding beetles and flies and pollen-collecting bees. The nectar-producing solitary flowers (or few flowers in inflorescences) are more specialized: Helleborus (pollinated by bees), Eranthis (flies and bees), Nigella (bees), Trollius (bees), Isopyrum (flies and bees), Caltha (flies and bees) and the bumblebee flowers Aconitum, Delphinium, Consolida and Aquilegia. The solitary pollen flowers of Pulsatilla vernalis and $P$. patens are mainly pollinated by flies and pollen-collecting bees and the solitary nectar-producing flowers of $P$. vulgaris and $P$. pratensis are more exclusively pollinated by bees.

Similar tendencies are found in many families such as Rosaceae (except Rosa), Caprifoliaceae (Sambucus and the other central European genera), Pyrolaceae (Pyrola and Orthilla, Moneses), etc.

The guidance of visiting insects over inflorescences by e.g. nectar can be traced in the Caryophyllaceae, Malvaceae, Aceraceae, Hippocastaneaceae, Vitaceae, Linaceae, Geraniaceae, Oxalidaceae, Rutaceae, Celastraceae, Rhamnaceae, Anacardiaceae, Fabaceae, Rosaceae, Rubiaceae, Valerianaceae, Dipsacaceae, Asteraceae, Apiaceae, Liliaceae, etc.

Summarizing it can be stated that the production of nectar is apomorphous within the various angiosperm taxa (possibly with rare exeptions in nectariferous entomophilous flowers becoming anemophilous, see e.g. Daumann (1972 and 1975) for Mercurialis and Ulmus, section 6.2.1), with the functions: attracting insects, luring away potentially injurious insects from the fertile flower parts, guiding the visiting insects over the flower or the inflorescence. This means that the earliest angiosperm flowers and their direct predecessors had pollen flowers or reproductive structures. The development of nectar production in the Gnetales has to be considered a parallelism (as within the Angiospermae it developed parallel in many taxa). 


\section{Dichogamy}

The most probably dichogamy in the predecessors of the Angiospermae was protandry (see section 6.14.1). The development of more exclusive homogamy and protogyny could only happen after the establishment of double fertilization. This means that the last two may be of very early origin in the Angiospermae, but the very first had protandrous flowers.

\section{Dicliny}

In section 6.15 it has been argued that the earliest Angiospermae and their direct predecessors had hermaphroditic flowers (forming the most probable opportunity, together with entomophily, for the development of the double fertilization). The protandrous conditions in the earliest Angiospermae gave rise to dicliny in a very early stage of the phylogeny of the Angiospermae, leading to the origin and diversification of the "Amentiferae".

\section{Perianth}

As we have concluded in section 6.7 apetalous flowers almost certainly have to be considered derived in the Angiospermae. In the Angiospermae or their predecessors the earliest perianth parts, the tepals, may have evolved in two different ways (Eames, 1961). In several recent genera, particularly Calycanthus, Paeonia and few species of Hibbertia there is a gradual transition from leaves through bract-like structures to typical sepals or petals. In these forms there is developmental evidence that the sepals and petals are derived from the tepals (Hiepko, 1965). In other families, however, such as the Ranunculaceae and Berberidaceae, the petals are anatomically similar to stamens and staminodal nectaries (Hiepko, 1965a) and in the Caryophyllaceae and Loasaceae the petals resemble sterile stamens (see Stebbins, 1974). The fact that these different developments both occur in the Angiospermae means that they are favoured by the same selective pressure within the Angiospermae. Both could have taken place together in the same species.

The existence of laminar stamens in recent archaic Angiospermae such as Austrobaileyaceae, part of the Magnoliaceae, Winteraceae, Degeneriaceae (fleshy stamens), Himantandraceae, some Annonaceae, Illiciaceae, some Nymphaeaceae and some Papaveraceae, indicate that there might have been question of developments from laminar stamens via laminar staminodes to petals or tepals (stamens becoming sterile being a not uncommon feature, see e.g. the staminodes as food bodies). The examples in which the perianth parts are derived from leaves through bract-like structures, have stamens differentiated into filament and anther: Calycanthaceae (short filament), Paeoniaceae and Dilleniaceae. This may mean that the original stamen in the Angiospermae was differentiated into filament and anther. Then, from this type of stamen (see also the discussion of the androecium) the laminar stamen derived, 
flower-ecologically to form an optical attractant for insect visitors. In the other cases the stamens remained differentiated in filament and anthers and their staminodes developed nectaries as in Helleborus and Eranthis. The latter got a leafy apex, as in Nigella, and finally the petals derived, as they occur in Ranunculus. On the other hand, the "normal" stamens gradually were surrounded by petals and sepals derived from leaves.

We can conclude that most probably the earliest Angiospermae and/or their direct predecessors had many (see discussion of the androecium) stamens or slender microsporophylls as primary optical attractants, possibly subtended by partly or entirely discoloured upper leaves (corresponding with the paleomorphic flower type). Probably already before the origin of the Angiospermae, developments as mentioned above could take place (in the probale sister-group of the Angiospermae, the Gnetales, rudimentary perianths are present). It is also possible that both developments took place in the same species.

\section{Androecium}

According to Stebbins (1974) (without further reading) there is developmental and anatomical evidence that the earliest angiosperm stamens were placed in bundles that represented compound microsporophylls, each bundle being arranged in a phyllotactic spiral continuing that of the floral envelopes. The homology between groups of stamens and carpels and tepals is derived from a number of flowers with many stamens, e.g. Degeneria, Hibbertia, Paeonia, Cercidiphyllum, Hypericum, Butomaceae, Annonaceae (Cananga odorata, Guatteria olivaeformis, Goniothalmus), Schisandraceae (Kadsura) and many more plesiomorphous flowers. The stamen filaments were short. This type of stamen could have given rise to either introrse or extrorse laminar stamens. This would contradict the hypothesis of Takhtajan (1969) that the ancestral form of these types was a laminar stamen with marginal anthers. It would be interesting to find out whether the development of the adaxial position of the anthers was accompanied by protogyny, and the abaxial position with homogamy or protandry. E.g. the introrse Magnoliaceae are protogynous and in the extrorse Liriodendron tulipifera at least homogamous conditions have been demonstrated, and the in adult state extrorse Polygonaceae are mainly protandrous.

Ozenda (1952), Canright (1952), Moseley (1958) and Eames (1961) consider immersion of the microsporangia in the tissue of the stamen a plesiomorphous feature. In Degeneria and Himantandra the microsporangia are deeply sunken in the tissue of the stamen, as they are in the Magnoliaceae (except Liriodendron) and Victoria amazonica. This condition in my opinion is not plesiomorphous, because it is either an adaptation to avoid too much self-pollination in protandrous, introrse conditions, or it is an adaptation to avoid too much pollenfeeding by the insect visitors. The condition in e.g. Degeneria (fleshy stamens) 
is paralleled in the Bennettitales in Williamsoniella coronata (fleshy microsporophylls) in clearly cantharophilous circumstances.

\section{Number of stamens}

As is definitely concluded in section 6.10, the earliest Angiospermae and their direct predecessors must have had many stamens. Soon after the origin of the Angiospermae the number could decrease in combination with the development towards small-flowered inflorescences.

\section{Position of the stamens}

From section 6.9 can be concluded that the earliest stamens in the Angiospermae and their direct predecessors were phanerantherous, cryptantherous stamens first appearing late in the phylogeny of the Angiospermae.

\section{Gynoecium}

From comparative-morphologically derived transformation series it can be concluded that plesiomorphous carpels in the Angiospermae were comparatively large (which would mean intermediate sized, rather than smaller earliest angiosperm flowers) and contained a fair number of ovules (Prantl, 1887; Hallier, 1901, 1912; Arber and Parkin, 1907; Eames, 1961). These conduplicate carpels occur in the Recent Drimys sect. Tasmannia and Degeneria (Bailey \& Swamy, 1951) and in a lesser degree in the Magnoliaceae. In the latter, however, the compact positioning of the carpels is considered apomorphous. The petiole-like stiped carpels, as they occur in Drimys, Bubbia, Austrobaileya, Calycanthus, etc. are more plesiomorphous than the sessile ones (Bailey \& Swamy, 1951 and Eames, 1961). As has been mentioned at the beginning of this section the most plesiomorphous carpels were not entirely closed at anthesis. This is still the case in Drimys sect. Tasmannia (Bailey \& Swamy, 1951), Coptis (Eames, 1961), Platanus (Boothroyd, 1930) and Reseda (see Hill \& Crane, 1982), i.e. hemiangiospermous. The stigma was sessile.

\section{Position of the ovaries}

The earliest Angiospermae and their direct predecessors had superior ovaries (see section 6.11).

\section{Number of ovules per stigma (carpel)}

In unspecialized entomogamous conditions the number of ovules per stigma (considering the earliest angiosperm flowers this is equivalent to the number of ovules per carpel) is one to few. Although there may be some difference in small-flowered inflorescences (often only one ovule per carpel) and larger flowers, whether or not in inflorescences (probably some more ovules per carpel), it can be suggested that the "fair number" based on the comparative- 
morphologically directed transformation series, mentioned above in the earliest angiosperm carpels, was lower than it is in the examples given. Drimys sect. Tasmannia has a generally entomophilous pollination type which apparently is, or has been, very successful. It allowed the development of pollen in permanent tetrads, indicating a rather specialized condition. The number of carpels varies from several to only one, each with few to many ovules. Degeneria has specialized beetle-pollinated flowers and has only a single carpel with many ovules. These specialized conditions allowed increase of the numbers of ovules per carpel. In the earliest angiosperm flowers probably more carpels were present, each with few ovules.

\subsubsection{Survey of the characters or character states of the earliest angiosperm flower}

The pollen flowers were arranged in inflorescences, most probably in leafy cymes, and were of intermediate size. They were hermaphroditic, protandrous and allophilic, entomophilous but not specialized, pollinated by beetles, wasps of the Symphyta and oligoneuran (possibly mainly bibionomorphan) and possibly asiliformian flies. Their general appearance was dish- to slightly bowlshaped, paleomorphic.

The optical attractant was formed by the stamens and discoloured upper leaves (already to some degree perianth-like). The floral colours most probably were yellow. The many stamens were arranged in bundles that represented compound sporangiophores, bundles being formed in a phyllotactic spiral continuing that of the floral envelopes. The stamen filaments were short.

The gynoecium consisted of probably many superior, petiole-like stiped, at anthesis not entirely closed, carpels which were infolded cupules with sessile stigmas. Each carpel contained a few ovules in a laminar or submarginal position. Double fertilization was practiced.

\subsection{Remarks on the origin of the Angiospermae}

Because of the inadequacy and ambiguity of the fossil record the hypotheses on the relationships within the Spermatophyta are based only on characters or character states of the Recent Angiospermae and of Recent and fossil "Gymnospermae". Hill \& Crane (1982) have based some cladograms of (among others) the Spermatophyta entirely on characters or character states of the Recent representatives of the taxa, neglecting the extinct taxa (fig. 7-1). Parenti (1980) also included extinct taxa (fig. 7-2). Crane (1985 and 1985a) based a cladogram both on characters or character states of Recent representatives and of the best known fossil representatives of the extinct taxa (fig. 7-3). Ehrendorfer (1976) presented a phylogenetic tree (fig. 7-4) representing the 
more common "precladistic" (in the sense of Hennig, 1966) view on the phylogeny of the Spermatophyta,

The cladograms of Hill \& Crane (1982), Parenti (1980) and Crane (1985 and 1985a) show marked similarities. The Gnetales (here the classification used by Sporne (1965) is followed), Gnetum, Welwitschia and Ephedra (figs 7-1 and 3) or Gnetidae (fig. 7-2) appear closely related to the Angiospermae. In figs 7-1A,

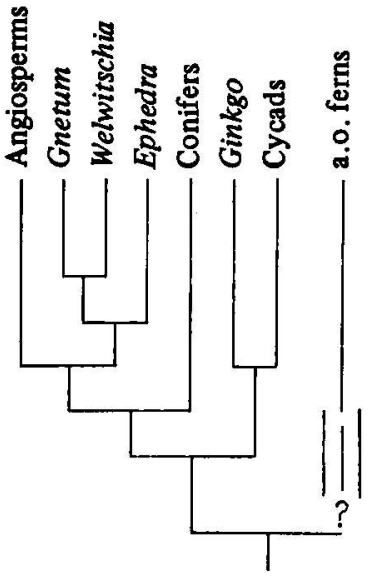

A
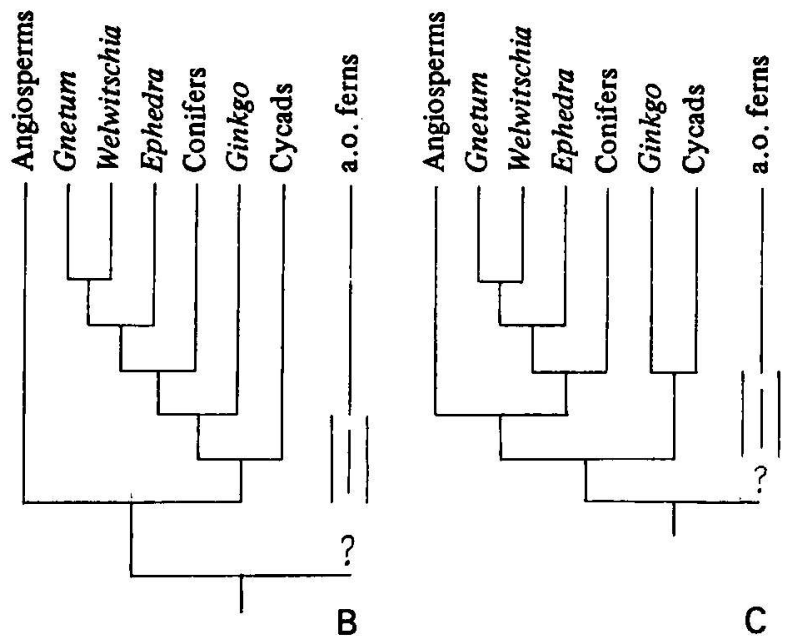

C

Fig. 7-1. Three cladograms of the relationships within the Spermatophyta, which are more or less equally parsimonious. The cladograms are based on the character states of the Recent representatives. After Hill \& Crane (1982).

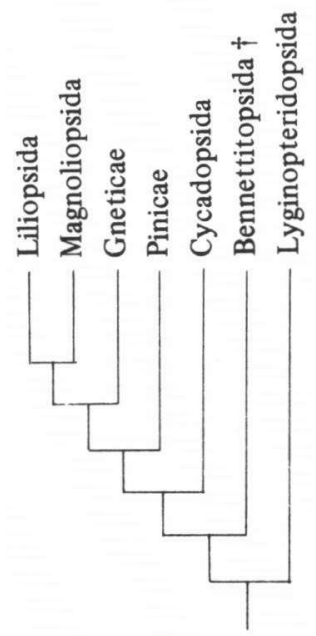

Fig. 7-2. Cladogram of the relationships within the Spermatophyta, based on Recent and fossil character states, after Parenti (1980). 


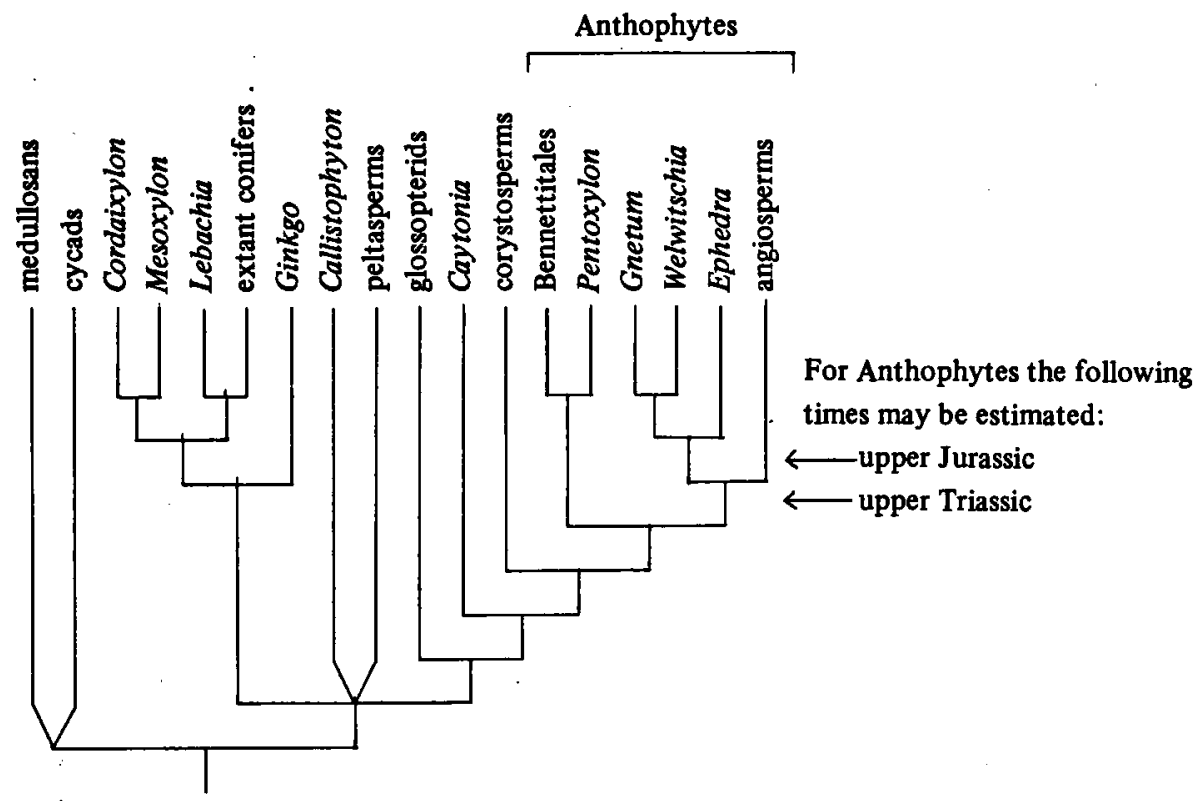

Fig. 7-3. Relationships between some Pteridospermales and Gymnospermae, closest related to the Angiospermae, after the cladogram of Crane (1985a).

2 and 3 they form the sister-group of the Angiospermae, in fig. 7-1B they do so together with the conifers, Ginkgo and cycads, and in fig. 7-1C together with the conifers. Ehrendorfer (1976) considered them more closely related to the Bennettitales than to the Angiospermae (fig. 7-4).

In some cladograms the Coniferales (conifers in fig. 7-1 and Pinicae in fig. 7-2) appear more or less closely related to the Angiospermae. In figs 7-1A and 2 they form the sister-group of the Angiospermae + Gnetales, and in figs 7-1B and $\mathrm{C}$ they form the sister-group of the Gnetales; in the first they appear less closely related to the Angiospermae than in the latter. In fig. 7-3 (extant conifers) and in fig. 7-4 they are very distantly related to the Angiospermae.

A sister-group relationship between the Angiospermae and Gnetales provides problems. Cronquist (1968) mentioned that the Gnetales and Coniferales are closely related in their vessel perforations, probably uniting them in a taxon of higher rank, as is the case in figs $7-1 \mathrm{~B}$ and C. Close relationships between the Coniferales and Angiospermae also give problems. The first certain fossils of the Coniferales, or as in fig. 7-3 of the stem-group of Lebachia + extant conifers, are already known from the Stephanian (Upper Carboniferous) and later fossils of the Lebachiaceae became numerous in the lower Permian (Gothan \& Weyland, 1973; Sporne, 1965). According to fig. 7-3 


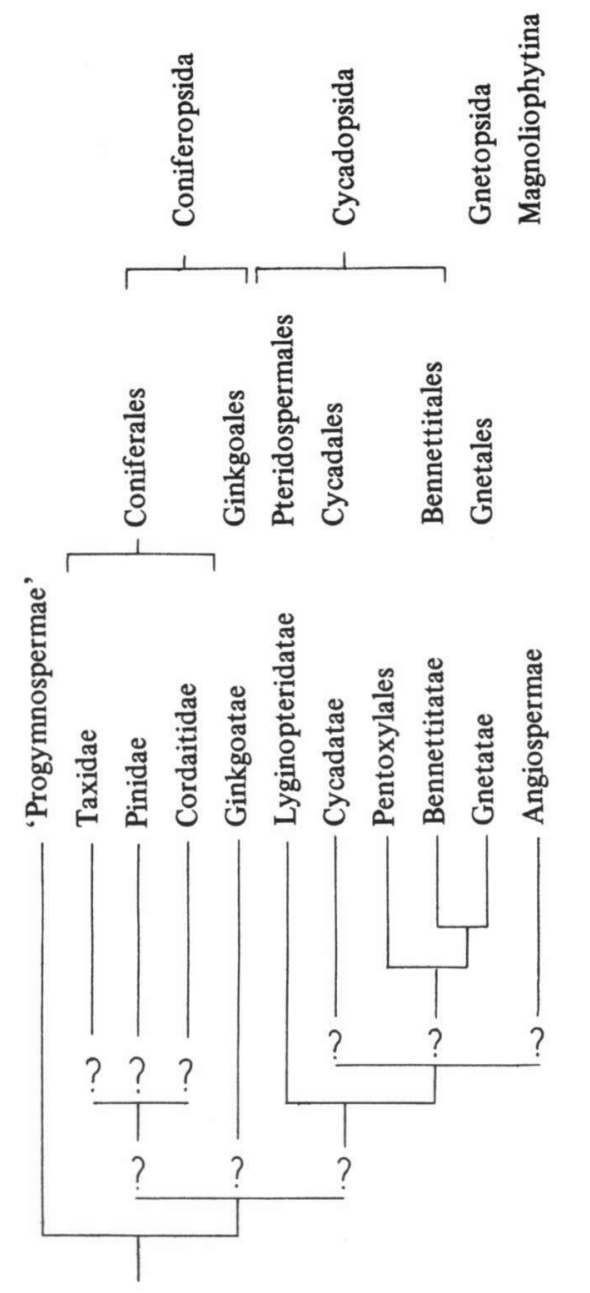

Fig. 7-4. Illustration of the probable relationships within the Spermatophyta, after Ehrendorfer (1976).

the presence of Lebachiaceae (Lebachia) includes the presence of representatives of the extant taxa of conifers in the lower Permian. This early presence of Coniferales would mean in the cladogram of fig. 7-1C that the Angiospermae must have been present in the Upper Carboniferous. In the cladograms of figs 7-1A and 2 it would mean that the stem-group of the Angiospermae + Gnetales was present at that time. An even earlier presence may be derived from the cladogram of fig. 7-1B. This early presence of the Angiospermae or of the stem-group of the Angiospermae + Gnetales does not seem very probable. Although the common type of vessel perforations in the Gnetales and Coniferales (Cronquist, 1968) (which, however, may be biphyletic) are not taken 
into account, the cladogram of Crane (1985 and 1985a) and the phylogenetic tree of Ehrendorfer (1976) are more in accordance with the fossil record.

The main difference of figs. 7-3 and 4 with figs. 7-1 and 2 is the origin of the Coniferales (Taxidae, Pinicae and Cordaitidae). In the cladogram of fig. 7-3 they form a comparatively apomorphous part of the large sister-group of the Anthophytes. In the phylogenetic tree of fig. 7-4 they are derived from the "Progymnosperms" (as are the Ginkgoales). There appear to be many question marks in fig. 7-4 and the proper possible sister-group of the Angiospermae is not indicated. Considering only the right part of the tree, the three question marks in the presumed sister-group of the Lyginopteridatae (Pteridospermae) represent an equal number of hypotheses on the origin of the Angiospermae: the Cycadales theory, Gnetalean theory and Bennettitalean theory. Besides these theories there are some that derive the Angiospermae directly from Mesozoic Pteridospermales-like ancestors, see Melville (1983) who derived Angiospermae from theoretically hermaphroditic Glossopteridae-like ancestors (this hypothesis will not be discussed in this study). The cladograms seem more decisive in indicating the relationships within (parts of) the Spermatophyta. In all cases these are provisional cladograms, because in none of them all fossil information of the taxa has been taken into account. Besides they are based on the parsimony principle. If the general transformation series described in section 6.16 are compared with the phylogeny of the Angiospermae as expressed in the current classifications, it will appear that many parallel developments occur, thus that there may be question (depending of the rank of the taxon studied) of many homoplasies. Some examples we have met already, e.g. classifying plants corresponding with the pollination syndromes, results in artificial groupings; development from inflorescences to single flowers by reduction took place in many different taxa as did sympetaly, cryptanthery and anemogamy, etc. Within the genus Saxifraga the inferior position of the ovaries can be considered an apomorphy, as it can indeed be in entire families or taxa of even higher rank. Nearly all transformation series will occur in many taxa of lower rank within te Angiospermae (inclusive scattered developments in the reverse direction). This means that the parsimony principle will not always be valid in taxa of the Angiospermae (particularly in those of higher rank). In many cases it will not be possible to neglect (many) parallel developments and these may have to be expressed in the cladogram for proper understanding of the relationships. A classifiation with more biologically explainable parallelisms will be more "natural" than one with fewer parallelisms which cannot be correlated with selection pressures. It means that phylogenetic systematics in the sense of Hennig (1966) of the Angiopermae has to be approached with due care.

Knowing that within the Angiospermae many parallel developments took place, it is questionable whether and to what extent also in the Spermatophyta 
parallelisms have to be taken into account. The cladogram of Crane (1985 and $1985 \mathrm{a}$ ) in fig. 7-3 is one out of ten. It would be interesting to compare these cladograms with regard to the biological interpretation of the parallelisms, and also considering transformation series derived from functional morphology existing in the separate taxa, indicating characters or character states of the original representatives.

Here we can conclude that much more research is needed before proper relationships within the Spermatophyta can be described. Many or perhaps most homologies are not yet known and because of this the following speculations on hermaphroditism and relationships with the "Gymnospermae" have to be considered provisional.

A flower-ecological approach does not provide decisive evidence for one of the theories on the origin of the Angiospermae, nor does it for one of the cladograms illustrated in fig. 7-1 to 3 , but it may clarify some circumstances under which the development towards the Angiospermae took place. Thus, it will be possible to select the flower-ecologically most probable classification of the ones considered in figs 7-1 to 4. It has been argued in sections 6.14.1 and 6.15 that the earliest Angiospermae most probably had hermaphroditic flowers. This means that at the time of origin this was a common character state of the Angiospermae. Whether this was a synapomorphy of the Angiospermae or a common character state with their possible sister-group (in consequence of the theories mentioned above: Cycadales, Gnetales, Bennettitales (or parts of them), is not known from the fossil record, except possibly for the Bennettitales, but in all cases except probably for the Cycadales, following the developments towards dicliny, as mentioned in sections 6.14.1 and 6.15 (as completed in e.g. Salix), there may be evidence for the last-mentioned. To arrive at this conclusion, we have to discus the orders forming the "sistergroup" of the Pteridospermales in fig. 7-4.

CYCADALES. The Cycadales are obligatory dioecious. The extant Cycadales are facultatively pollinated by wind and at least in Macrozamia reidlei, Baird (1938) found Coleoptera and Hemiptera on both male and female cones, and possibly pollination by beetles takes place in species of Cycas (Willis, 1966). Although no insect pollination has been studied in detail, there are indications that it indeed can take place. Knuth (1904) mentioned that the temperature in the ripe male cones of Cycas circinalis is considerably higher than the ambient air temperature and at the same time a disgusting odour is produced. The odours may be attractants to saprophagous insects (compare e.g. the Araceae). The same is found in the male cones of Dioon edule (here a temperature has been measured of 10 degrees above the ambient air temperature). In the ripe male cones of Macrozamia mackenzi the temperature is 9-11 degrees higher than the ambient air temperature and a strong, fine odour is produced that attracts 
small bees which collect pollen on the cones. Schmiedeknecht (in Knuth, 1904) observed in the botanical garden of Bogor two bee species, Trigona iridipennis and Allodaphe cupulifera, on the male cones. However, whether they carry out effective pollination, still has to be studied. In the ripe male cones of Ceratozamia longifolia only a raised temperature (11.7 degrees above the ambient air temperature) was present; there was no production of odours and insects have not been observed on the cones. The simultaneous absence of odours and insects may indicate that the production of heat is a "normal" physiological process of ripening male cones and cannot be regarded as an attractant (also doubted by Faegri \& Van der Pijl, 1980). In the South African Encephalartos and other Cycadales the female reproductive structeres are visited by female beetles of Phlaeophagus which deposit their eggs in the carpels (Rattray, 1913). These pollen-feeding beetles can carry out pollination in this way (Corner, 1928; Gottsberger, 1970).

In some Cycadales attractants are present in the ripe male cones (odour). Whether the female cones also have similar attractants is not found, which would mean that insects attracted to the male reproductive structures have to be considered injurious. Allocorynus (Attelabida) breed in the male cones of Cycas. The presence of Coleoptera and Hemiptera on both male and female cones in Macrozamia reidlei and in Encephalartos may indicate some form of insect pollination. There certainly will be some relationship of the reproductive structures with insects, but whether real entomophily occurs or not, is not known and requires more field work.

The combination of dioecy and attractants to insects (odour) recalls the dioecious entomogamous Salix, evidently of hermaphroditic origin, however, only in some male cones an attractant has been found. Early hermaphroditic reproductive structures may be possible in Cycadales. Whether there is then question of a close relationship with the Angiospermae or the Anthophytes is not sure. Their sister-group relationship with the medullosans, given the number of synapomorphies of the medullosans + cycads and their predecessors mentioned in Crane (1985), seems to justify a very distant relationship with the Anthophytes.

PENTOXYLALES. Of the extinct Jurassic Pentoxylales only fossil fragments are found: stems (Pentoxylon, Nipanioxylon), seed-bearing organs (Carconites) and pollen-bearing organs (Sahnia) (Sporne, 1965). The only conclusion to be drawn is that the reproductive structures were possibly unisexual. Whether the species were monoecious or dioecious cannot be derived from the fossil material. Neither Gothan Weyland (1973) nor Sporne (1965) mentioned the presence of Pentoxylales pollen from stratigraphical pollen analysis, which may be an indication of insect pollination, as does to some extent the granular pollen wall stratification (pollen from macrofossils) (Crane, 1985).

BENNETTITALES. The Bennettitales appeared in the middle Keuper 
(late Triassic) and were considerably diverse from the late Keuper to the Lower Cretaceous. Already in the Keuper the hermaphroditic reproductive structure of Sturiella (Sturianthus) langeri (Williamsoniaceae) has been found. From the same time the unisexual reproductive structures of another genus of the Williamsoniaceae, Williamsonia are also known. In Williamsonia both hermaphroditic and unisexual reproductive structures occur (see Crane, 1985). In the Wielandiellaceae, Wielandiella probably had unisexual reproductive structures, e.g. W. angustifolia. It is first recorded from the upper Keuper. The other genus of the Wielandiellaceae, Williamsoniella (earliest records from the middle Jurassic of Yorkshire) had hermaphroditic reproductive structures. Crane (1985) mentioned Williamsoniella coronata and W. lignieri. The Cycadeoidaceae (probably only genus Cycadeoidea) range in age from the upper Jurassic to the Upper Cretaceous. The vast majority of the species (more than thirty) had hermaphroditic reproductive structures (Sporne, 1965). Gothan \& Weyland (1973) mentioned that the pollen-rich forms appeared later in the fossil record than the relatively pollen-poor forms. They based this statement on the number of pollen sacs, which could be studied in fossils and they conclude that a possible development from entomophilous hermaphroditic reproductive structures to (facultative) anemophilous hermaphroditic or unisexual reproductive structures would be the reverse of the expected development. In my opinion the hermaphroditic structures of Cycadeoidea form the last remains of original hermaphroditic reproductive structures in the Cycadeoideaceae, Wielandiellaceae and Williamsoniaceae, and the developments towards (anemophilous?) unisexual reproductive structures seem logical in comparison with the developments in the Salicaceae and other Angiospermae (in all cases induced by protandry). The closed cones of Cycadeoidea described by Crepet $(19,2)$ were obligatory protandrous and thus functioned as unisexual flowers, possibly pollinated by tunneling, and/or ovipositing insects (beetles). Pollination by these kinds of insects, lacking pollen transport provisions as e.g. in the Agaonidae, will be very poor. Examples of the presence of insects in which endosperm-feeding developed are known from the Jurassic and Cretaceous: Lygaeidae (Hemiptera: Heteroptera: Lygaeoidea) liquify seed components preparatory to their digestion (present in the Jurassic); Bruchidae (Coleoptera) (present in the Jurassic); Cryptorrhynchinae (Coleoptera: Curculionidae) (possibly present in the Jurassic); Scolytidae (Coleoptera) (present in the Jurassic); larvae of Gelichiidae (Lepidoptera) (possibly present in the earlier Cretaceous); and larvae of Eriocraniidae belonging to the Dacnonypha or Eriocranioidea (Lepidoptera) being the sister-group of the Zeugloptera (= Micropterigidae), thus present in the Lower Cretaceous (of the Recent adults no feeding-habits were found, but these may be micropterigid-like because of the presence of mandibles; the Recent larvae live in the seeds of Gymnospermae). Cleistogamy may also have occurrea. As Crepet (1972) mentioned out- 
breeding at any rate must have been minimal. It can be concluded that original hermaphroditic reproductive structures were probable in the Bennettitales. This is not in accordance with the cladogram of the Bennettitales in Crane (1985). In my opinion Vardekloeftia has to be considered apomorphous, derived in the same way as Salix from hermaphroditic ancestors. In the same way the unisexual cones of Williamsonia sewardiana, $W$. harrisiana and $W$. gigas have to be considered more apomorphous than the hermaphroditic cones of $W$. hildae.

GNETALES. In most species of the Gnetales the male reproductive structures bear ovaries which are normally sterile, but occasionally may be fertile, as e.g. in Gnetum gnemon. The Gnetaceae are normally dioecious (or androgynoecious as in Gnetum gnemon), in some cases, however, they are monoecious (Sporne, 1965). Knuth (1904) mentioned that Gnetum gnemon probably is wind-pollinated, but that the "cauliflorous" reproductive structures of some species on Borneo probably are pollinated by small insects (Diptera, Hymenoptera and Coleoptera, i.e. non-specialized entomophilous). De Wit (1963) mentioned that the female reproductive structures produce a sweet droplet that may be eaten by insects and the production of a strong odour also suggests insect pollination. Meeuse (1982) mentioned that the sterile ovaries of the male plants are not reduced and anything but non-functional, because they produce the sugary exudate necessary to lure insects. In my opinion these are the remains of an earlier hermaphroditic stage, the ovaries being transformed into "nectaries", in view of the fact that probably in the first place the endangered parts of the flowers or reproductive structures developed a food-supply for insect visitors. The sterilization of the ovaries must have been favoured by protandry.

In Gnetum africanum Waterkeyn (1954) found that there is a correlation between the degree of development of the pollen tube (length) and that of the development of the endosperm in pollinated female flowers (although in nonpollinated flowers endosperm is also formed). If this development took place after the origin of unisexual flowers, it may be considered a development according to the economy principle, as Doyle \& Hickey (1976) mentioned for the double fertilization of the Angiospermae (see below). If, however, this development took place in hermaphroditic reproductive structures in the Gnetales, it might have been favoured by the same selective pressure that favoured double fertilization in the Angiospermae. It certainly would be an advantage in hermaphroditic reproductive structures (avoiding the simultaneous presence of too much endosperm and pollen) against injury by mandibulate insect visitors. Then, solely the failure to develop protogyny would have resulted in the development of dicliny.

In the Welwitschiaceae the only extant species, Welwitschia bainesii is dioecious, but the male reproductive structures have a sterile ovary. Pollination is most probably entomophilous. Willis (1966) mentioned Heteroptera as 
pollinators, Knuth (1904) suggested that pollination is transmitted by Cetoniinae (Scarabaeidae) and De Wit (1963) mentioned that, as in the Gnetaceae, the female reproductive structures produce a sweet sugar-containing liquid on the stigma-like structures and that the beetle Odontopus sexpunctatus, bees and flies can carry out pollination, i.e. the reproductive structures are nonspecialized entomophilous. The development from original hermaphroditic reproductive structures to the functional unisexual ones, may have taken place in the same way as mentioned for the Gnetaceae.

In the Ephedraceae the only genus Ephedra is typically dioecious, but there are occasional reports of hermaphroditic reproductive structures, which Eames (1952) regarded as monstrosities. In my opinion these cannot be considered monstrosities, but the remains of original hermaphroditic reproductive structures in the Ephedraceae (as are e.g. the occasional hermaphroditic flowers in the Salicaceae). De Wit (1963) mentioned that in the female reproductive structure a sweet liquid is produced and that pollination can be transmitted both by wind and insects. Bino \& Meeuse (1983) found the same in Ephedra aphylla.

It may be suggested that within the Gnetales all families developed dioecy in a way comparable to that in Salix. The rare cases of monoecy in the Gnetaceae may have developed in the same way (favoured by protandry), but in the absence of a food supply in addition to pollen and pollination droplets. The original Gnetales most probably had hermaphroditic entomophilous reproductive structures (probably with some kind of perianth), which may be an indication of close relationship with the Angiospermae. The earliest fossils of the Gnetales are pollen grains from the Oligocene of Germany, and later in the late glacial sediments of Denmark, southern Alps and Mediterranean area, and from the late Tertiary of the U.S.S.R. This pollen is compared with Ephedra, but the identifications are not entirely certain. The fact that these pollen types are found in stratigraphical pollen analysis may indicate that the transition from entomophilous to (facultative) anemophilous pollination in part of the species was completed at about the middle Tertiary. If, however, Ephedrites pollen may be attributed to the Ephedraceae (Crane, 1985), this must have happened much earlier (Muller, 1984). Here it has to be mentioned that, if they form the sister-group of the Angiospermae they have remained unknown for millions of years. This may be due to very effective insect pollination.

We now see that there is a possibility that in two important orders within the "sister-group" of the Pteridospermales as illustrated in fig. 7-4, original hermaphroditism may have been possible, and this would mean that this also might have been the case in the stem group of the whole group (Pentoxylales + Bennettitales + Gnetales + Angiospermae, or Anthophytes). This 
means that differences in the distribution of the sexes in Recent taxa of higher rank within this group not necessarily have an impact on the relationships of these taxa. It would also mean that out-group comparison, at any rate in taxa of higher rank is not always indicative for plesio- or apomorphous characters or character states.

The stem-group of the Gnetales + Angiospermae then must be of late Triassic origin. When they separated cannot be derived from the fossil record. An "upland" theory to bridge the gap of very many million years does not seem to be necessary. There may have been, and there probably was, an as yet undetected evolution of entomogamous early Angiospermae and Gnetales or their stem-group, but then due to the fact that entomophilous pollen is comparatively rarely found in stratigraphical pollen analysis. To detect this evolution, the most promising way is carrying out pollen analyses on fossil anthophilous insects (see Willemstein, 1978a and 1980).

As Hughes (1976) and Hughes \&mart (1967) mentioned that, given the Triassic flora, the appearance of the hermaphroditic reproductive structure of Sturiella (Sturianthus) langeri was rather unexpected and contrary to the tendency of hiding the ovules against injury by herbivorous animals (insects as well as possibly omnivorous or herbivorous small reptiles). Besides, the development of hermaphroditic reproductive structures appeared to be rather complex. In the Angiospermae experimental biochemistry could not induce normal hermaphroditic flowers and it might be concluded that the sex expression is under control of a complex of genes and modification of one gene is incapable of stimulating the induction of bisexuality (Melville, 1983). It is therefore not to be expected that development towards hermaphroditic reproductive structures took place in many parallel lines. In Sturiella (Sturianthus) langeri the microsporophylls subtended the ovuliferous part and the sterile apices of the first provided an extra visual attractant. The entire structure strongly suggests entomophilous pollination, rather than zoophilous pollination including small reptiles. An argument for entomophily is also the low pollen production (see before). The insect pollination must have been successful to some extent, because the hermaphroditic reproductive structures persisted throughout the Jurassic and gave rise to the specialized Williamsoniella and Cycadeoidea pollinated by mandibulate insects (probably mainly beetles). At any rate the hermaphroditic reproductive structures gave rise to the stem-group of the Gnetales + Angiospermae, and later to the Angiospermae. It has to be mentioned that some of the hermaphroditic reproductive structures of Bennettitales and Gnetales might have become (facultatively) anemophilous. However, because of the fact that they became extinct, it can be concluded that anemophily in the hermaphroditic reproductive structures never became obligatory. The structures most probably continued attracting insects, because of the simultaneous presence of pollen and endosperm as a food supply, pro- 
hibiting the development of protogyny, as appeared to be very successful in the Angiospermae in which many anemophilous, hermaphroditic flowers could develop, by the possibility of the development of this type of dichogamy (only possible after the development of the double fertilization).

In fig. 5-1 it is illustrated that in the earliest times of the presence of hermaphroditic reproductive structures not only Coleoptera (or the stem-group of the Coleoptera + Strepsiptera) were potential pollen-feeding visitors, and thereby pollinators, but also possibly representatives of the Neuropteroidea, Hymenoptera, Mecoptera, and Diptera or their direct predecessors (Paratrichoptera). Because pollen-feeding must have been present in the upper Triassic, the Coleoptera probably were the main pollinators of entomophilous reproductive structures. They had already differentiated considerably at the end of the Triassic (compare figs. 5-4 and 5: Archostemata and most polyphagan series). Among the probably less important pollinators the pollenfeeding Hymenoptera, showing some adaptive radiation at the end of the Triassic (compare fig. 5-8: possibly mainly xyeloid types), may have been the most effective pollinators of these structures. Perhaps possible Mycetophilidae or their direct predecessors (Bibionomorpha, see fig. 5-19) could also have played some role in the pollination of the hermaphroditic reproductive structures.

The remark of Hughes (1976a) that it is not clear why visual rather than olfactorial attraction should have been provided for many crawling animals (including Coleoptera), olfactorial attraction alone could have been provided without a perianth-like structure (sterile appendages of the microsporophylls or the microsporophylls themselves), is probably easily understood. Besides the non-coleopteran potential pollinators mentioned above, also the majority of the Coleoptera in the upper Triassic were perfect flyers (as we have seen, the pollination by crawling or flightless insects, such as ants, never became of any importance, not even in the Angiospermae). A transfer, or extension of the function of animal visits from initial seed dispersal to cross-pollination (Hughes, 1976a; Corner, 1964) in the insects probably never took place (compare the examples of the transfer from fungi-feeding to pollen-feeding insects in many taxa, see chapter 5); in addition to, insects probably never played a role of any importance in seed dispersal.

It may be possible that the development of hermaphroditic reproductive structures, in which the microsporangiate organs subtended the ovulate organs happened only once in the Pteridospermales, i.e. in the stem-group of the Anthophytes. In the Czekanowskiales, probably related to the Ginkgoales (Sporne, 1965), the microsporangiate organs of Irania hermaphroditica (Schweitzer, 1977) do subtend the ovulate organs, but are separate "inflorescences" and can be considered a specialized, possibly entomophilous, case of monoecy. The tendency of the positioning of microsporangiate and 
ovulate organs in close proximity, with the microsporangiate subtending the ovulate ones (Dilcher, 1979), then, was already very early completed. From that time on entomophily may have fostered continued presence of the structures. However, as already mentioned in section 6.14.1, the gymnospermous hermaphroditic reproductive structures could not become protogynous to provide optimal cross-pollination (because of the unfavourable simultaneous presence of primary endosperm in connection with mandibulate insect visitors). The only development to avoid this simultaneous presence of insect food sources was protandry, but this only allowed to a very limited ("at random") degree cross-pollination. It has been argued that the protandrous hermaphroditic reproductive structures easily could give rise to monoecious anemogamous plants, which could become protogynous, particularly if no sterile attractants or food sources were developed to guide the insects over the reproductive structures after alighting. If non-fertile food sources were developed this could finally easily lead to successful entomophilous dioecy (as in Salix); however, in Bennettitales no evidence for specialized sterile food supply for visiting insects has been found and thus, the only food could have been parts of the reproductive structures. Then, mainly anthophagous insects, whether or not pollinating, visited the flowers. Whether hermaphroditic Gnetales may have had a sterile food supply for visiting pollinating insects is not known, but there may be some evidence with regard to the nectar secreted in the female reproductive structures of Recent representatives. It may be possible that Gnetales had already some gynoecial nectar poduction in hermaphroditic reproductive structures. Obviously this did not lead to more specialized relationships with pollinating insects, increasing the chance of cross-pollintion. They must have continued attracting mandibulate insects which fed also on pollen and endosperm. If nectaries were present in the original Gnetales they have to be considered a synapomorphy of the taxon. In several cases the hermaphroditic reproductive structures in Bennettitales + Pentoxylon and Gnetales must have given rise to unisexual ones.

Only if other protective structures developed, the continuation of hermaphroditic reproductive structures could be ensured. The covering of the seeds and fruit-like developments in the hermaphroditic Gymnospermae obviously did not provide these conditions. This development towards angioovuly (avoiding pollination-decreasing pollination droplet-feeding by insects) appeared only successful in ensuring the continuation of hermaphroditic reproductive structures in combination with the development of double fertilization, in which the proliferation of the endosperm only starts after fertilization. The double fertilization therefore has to be considered more an adaptation against endosperm-feeding by anthophilous (anthophagous), also pollen-feeding insects, rather than an expression of the economy principle, in which it ensures that the embryo-nourishing tissue (endosperm) is not 
elaborated until after fertilization has occurred (avoiding unnecessary growth), as mentioned by Doyle \& Hickey (1976). These may have been the conditions that gave rise to the Angiospermae.

Because double fertilization also allowed protogynous conditions in already entomophilous conditions (with directed pollen transmission), optimalizing successful cross-pollination, a condition of population potency was reached that never had existed before in the plant kingdom. These conditions, with sufficient seed dispersal developments, causing distribution in altitude and latitude (invading niches), combined with continental drift (see Schuster, 1976), gave rise to an unprecedented rapid adaptive radiation.

\subsection{Approximate dating of the flower-ecologically important apomorphies} on basis of the fossil record and phylogeny of the insect taxa in which anthophily developed.

The apomorphous character states of section 6.16 are dated approximately, based on the fossil record and phylogeny of the insect taxa in which anthophily developed. The numbers correspond with those of the transformation series in section 6.16.

1. Non-specialized entomophilous flowers (pollinated by insects with short mouth parts) probably were functional from the very origin of the Angiospermae onwards (see section 7.1). Pollination by flies with longer rostrum may have become functional during the Cretaceous and established in the late Cretaceous (developments within the Nemestrinidae troughout the Cretaceous and possible stem-groups of flies with longer rostrum in the Atriata in the Upper Cretaceous, compare table 5-4).

2. The shift to more specialized beetle pollination could have started very early in the evolutionary development of the Angiospermae (compare the presence of many beetle families in table 5-1).

3. Developments towards cantharophily may have followed directly after the more obligatory beetle pollination and may have been established in the lower to middle Cretaceous.

4. A shift to mainly wasp pollinated flowers could have started very early in the evolutionary development of the Angiospermae which developed nectar production, possibly already in the Lower Cretaceous (Ichneumonidae and Braconidae) and became established in the Upper Cretaceous (Chrysididae, possible Scoliidae and particularly the appearance of the Masaridae, Tiphiidae and Mutillidae, see table 5-2).

5. Bee pollination might have originated in the uppermost Cretaceous or at any rate in the lower Tertiary (derived from the considerable differentiation 
of the bee families in the upper Eocene to lower/middle Oligocene, see table 5-2).

6. Butterfly/moth pollination (except pollination by the mandibulate Micropterigidae), i.e. pollination by longer-tongued butterflies and moths may have become functional in the uppermost Cretaceous or lower Tertiary (derived from the already considerable diversity of the Papilionoidea in the middle Eocene).

7. Developments from bee-pollinated to butterfly-/moth-pollinated flowers might have happened from the Eocene onwards.

8. Myiophilous flowers (in the absence of other longer-tongued insects) might have occurred in the late Cretaceous and early Tertiary.

9. These temporarily myiophilous flowers in the late Cretaceous and early Tertiary could easily develop towards fly- and bee-pollinated flowers.

10. Being already longer-tongued the bees participating in this pollination easily could permit the development of melittophilous flowers in the course of the Tertiary, obligatory melittophilous flowers could have arisen in the late Eocene or early Oligocene.

11 and 12. The temporarily myiophilous flowers of the late Cretaceous and early Tertiary on the other hand, could have been the basis for butterflypollinated flowers and finally for psychophilous flowers in about the middle Eocene (and later for phalaenophilous flowers).

13. In the course of the development of flies with very long rostrum (forms like some Tabanidae and Nemestrinidae, compare Vogel, 1954) the transition of psychophilous to myiophilous flowers (and vice versa), or intermediate forms may have occurred, but these probably are of comparatively recent origin (uppermost Tertiary, or even Quaternary).

14. Sapro-entomophily may have an early origin because dung-feeding beetles (e.g. species of Staphylinidae and Dermestidae) were present throughout the development of the Angiospermae. The higher carrion- and dung-feeding beetles and flies are of later, mainly post-Cretaceous, origin.

15. and 16. Ornithophilous flowers attract birds and thereby provide a basis for the development of bird specialization to flowers. The main Recent flowervisiting families of birds are Trochilidae, Coerebidae, Nectariniidae, Zosteropidae, Meliphagidae, Dicaeidae, Drepanididae and PsittacidaeLoriinae (Proctor \&eo, 1973). Kugler (1970) also mentioned the Pardalotidae and the following families in which anthophily sporadically occurs: Muscicapidae, Turdidae, Sylviidae, Ploceidae, Oriolidae and Dicruridae. Romer (1966) mentioned the following oldest fossil records: Trochilidae (Pleistocene of South America), Coerebidae (Pleistocene of the West Indies), Meliphagidae (Pleistocene of New Zealand), Psittacidae (some extinct forms from the Miocene of Europe and North America, but no fossils of the Loriinae which occur in Recent times in Australia, New Guinea, Malaya and 
Polynesia), Muscicapidae (Pleistocene of New Zealand and Asia), Turdidae (Pleistocene of Europe, Asia, North America and the West Indies), Sylviidae (Pleistocene of Europe), Ploceidae (Pleistocene of Europe, Asia and North America), Oriolidae (Pleistocene of Europe and Asia) and Dicruridae (Pleistocene of Asia). Sussman \& Raven (1978) also mentioned Philepittidae from Madagascar which should be older than the Miocene; however, Romer (1966) did not mention fossil remains. It can be concluded that developments towards ornithophily could have taken place in about the middle Tertiary and could have been established (in relation with genuine flower birds) very late in the evolutionary development of the Angiospermae in the Pleistocene or in the latest Miocene, which may be derived from the fact that the suborder Passeres of the order Passeriformes (to which all above families, except the Psittacidae and Trochilidae, belong), was already clearly differentiated in the Pleistocene. Ornithophilous flowers may have been derived from melittophilous and psychophilous or phalaenophilous flowers, particularly sphingophilous flowers. The latter probably first arose in the late Tertiary, derived from the fact that Sphingoidea are closely related to the Noctuoidea and that the latter are known from the Baltic amber; sphingoid fossils, however, are not known. Derivation from melittophilous and/or psychophilous flowers may have started early, possibly from the late Eocene onwards.

17. Chiropterophilous flowers could become functional attracting unspecialized bats and thereby providing a basis for the development of bat specialization to flowers. The plant-feeding Megachiroptera of the old world are mainly phytophagous and fructivorous, and some species developed nectarivory. Of the genera mentioned in Romer (1966) only Rousettus of the Miocene of Europe might have been anthophilous. Of the New World's Microchiroptera the following fossil, probably nectarivorous, genera are known (Kugler, 1970; Romer, 1966): Glossophaga (Pleistocene of South America), Leptonycteris (Pleistocene of Central America), Lonchoglossa and Phyllostomus (both from the Pleistocene of South America). It can be concluded that chiropterophilous flowers could have become functional from about the middle Tertiary and established in relation with genuine flower bats in the (late) Miocene to Pleistocene, both in the old and new world. In the latter the possible Miocene origin is derived from the fact that the Phyllostomatidae, to which the genera mentioned belong, are known from the Miocene (possibly already from the Oligocene) and are much differentiated in the Pleistocene. The main predecessors of chiropterophilous flowers will be phalaenophilous flowers, which could become functional in the upper Eocene to lower/middle Oligocene (Pyralidae, Noctuoidea and possible Geometroidea are known from the Baltic amber). It is possible that chiropterophilous flowers are partly derived from flowers pollinated by non-flying mammals (see Sussman \& Raven, 1978). This might have happened in the late Cretaceous or early Ter- 
tiary or later dystropic (pre-)chiropterophilous flowers drifting with the continents. This would explain chiropterophily in circumtropical plant species (Vogel, pers. comm.).

18. Hemiphilic flowers (derived from allophilic flowers) may have come into existence in the early evolutionary development of the entomogamous Angiospermae in the developments towards beetle and fly pollination. In later times this development has taken place in many different angiosperm taxa correlated with other insect taxa.

19. The development of euphilic flowers from hemiphilic flowers will have taken place in different times connected with the insect taxa involved. The developments towards cantharophily might have been completed in the late Lower or middle Cretaceous, those towards myiophily in the Upper Cretaceous, those towards melittophilous and psychophilous/phalaenophilous flowers in the lower/middle Tertiary.

20. The increasing specialization within the euphilic flowers took place after the establishment of the obligatory pollination types.

21. Stereomorphic flowers, derived from actino- or pleomorphic flowers may have become functional in the Upper Cretaceous (appearance of longertongued insects).

22. Zygomorphic flowers in entomophilous inflorescences (in margin flowers to increase the optical attractance to insects) may be of Cretaceous origin; in solitary flowers it may have developed from the Upper Cretaceous onwards (here zygomorphy derived from actino- or pleomorphic flowers).

23. Zygomorphic flowers derived from stereomorphic flowers may have developed from the Upper Cretaceous onwards.

24. Sympetaly has developed many times. In may have been completed very early (about middle Cretaceous), but mainly became functional in the late Cretaceous and early Tertiary, in conjunction with the developments of longer-tongued insects.

25. The development of haplomorphic flowers from paleomorphic flowers may have started from the very origin of the Angiospermae.

26. Actinomorphic flowers (derived from haplomorphic flowers) also might have occurred already in the Lower Cretaceous.

27. Reduction of flower parts in the transformation series from actino- to pleomorphic flowers may have been completed early, particularly in the developments towards more compound small-flowered inflorescences (in prehamamelid times: Cenomanian).

28. Bell- en funnel-shaped blossoms possibly may have become functional in the Upper Cretaceous.

29. Tube-shaped blossoms with long corolla tubes may have become functional comparatively late (correlated with the development of hovering pollinators such as Sphingidae in about the Miocene). 
30. Trumpet-shaped blossoms may have become functional in post-Eocene times (correlated with the development of long-tongued Lepidoptera and Diptera).

31 and 32. Gullet-shaped blossoms may be of Oligocene or Miocene origin, correlated with the appearance of higher bees, late enough to allow either bellto funnel-shaped of trumpet-shaped origin.

33. Flag-shaped blossoms may be of Upper Cretaceous to early Paleocene origin (see section 7.4).

34 and 35. The development of brush-shaped blossoms must have been completed very early within the Angiospermae, particularly in connection with developments towards inconspicuous entomophilous blossoms giving rise to anemophilous blossoms (e.g. Hamamelidae) completed in the Cenomanian. Later it has developed in several other taxa.

36. The development of large solitary flowers possibly was completed in the middle Tertiary (mainly in connection of cantharophily).

37. Small-flowered inflorescences may have been present already in the Lower Cretaceous (e.g. as forerunners of the Hamamelidae).

38. Yellow and white floral colours probably have existed since the time of origin of the Angiospermae.

39. Blue and blue-mixed colours may have become functional in the uppermost Cretaceous and early Tertiary, particularly in correlation with the development of apomorphous flies, bees, butterflies and diurnal moths. 40. Red and red-mixed colours may be of comparatively late origin and they may have become functional with the development of some Lepidoptera (early Tertiary), and later that of anthophilous birds (Miocene-Quaternary).

41. Mutual developments of blue and red colours may be of about late Tertiary origin.

42. Cryptantherous flowers are mainly connected with longer-tongued pollinators. The development might have started in the early Tertiary.

43. Reduction of the numbers of stamens per flower might have been completed towards the middle Cretaceous, particularly in connection with the development of small-flowered inflorescences. In later times it was correlated with increasing specialization of the pollination in many taxa.

44. The development of half- and entirely inferior ovaries may have started from the very origin of the Angiospermae and may have been completed early. 45. Stiped ovaries as a development to protect the ovaries (as in the Capparidaceae) may be of comparatively early origin: Chesters et al. (1967) mentioned Capparites cynphylloides from the Cenomanian of Alabama U.S.A.

46. The increase of the number of ovules per stigma probably developed very early in connection with specialization of the pollination by beetles and may have been completed at about the middle Cretaceous. Later it took place in developments towards more specialized pollination in many different taxa. 
46a. Reduction of the number of ovules per stigma (carpel) may have taken place very early in connection with the development of small-flowered entomophilous inflorescences.

47. Nectar production may have taken place very early in the evolutionary development of the Angiospermae and partly concealed nectar may have become functional in the late Cretaceous.

48. Complete concealment of the nectar may have started in the uppermost Cretaceous and have been completed in the early Tertiary.

49. The development of protogyny (via homogamy) may have started very early in the evolutionary development of the Angiospermae (the double fertilization allowing this development) and old groups may have had this type of dichogamy before the middle Cretaceous.

50 and 51. When obligatory protandry or protogyny occurred, cannot be derived from the fossil record and phylogeny of the insect taxa in which anthophily developed.

52. Transition from pollen flowers to nectar-containing flowers, see 47 .

53. Cleistogamy may have developed any time in self-compatible specimens under unfavourable pollination conditions.

54-57. The first developments from hermaphroditic flowers to andro- and gynomonoecy and polygamy may have been completed early in the evolutionary developments of the Angiospermae, before the middle Cretaceous.

58-61. The first developments of andro- and gynodioecy, trioecy and dioecy may have been completed before the middle Cretaceous.

62-67. The establishment of anemophily, accompanied by inconspicuous reduced perianth, green flowers with few stamens and one or few ovules per stigma (carpel) was completed before the middle Cretaceous. Whitehead (1969) mentioned that it must have been evolved rapidly in reponse to seasonal drought as the Angiospermae migrated into lower middle latitudes during the early Gretaceous.

The age of the pollen-ecologically important characters or character states is based on the fossil record and phylogeny of both pollinators and plants. Derivations from continental drift have not been taken into account in this study (cf. Vogel, 1980).

7.4.Comparison of the fossil record of the Angiospermae (extant taxa) and the fossil record and phylogeny of the insect taxa in which anthophily developed

For the fossil record of the insect taxa in which anthophily developed we refer to chapter 5 , inclusive the restrictions of this record, particularly with regard to the fossils in amber representing mainly insects living on or in the 
vicinity of the stems of resin-producing trees. The fossil record of some extant taxa of the Angiospermae was compiled after the survey of the stratigraphical appearance of pollen grains by Muller (1970, 1981 and 1984) and with regard to the macrofossils after Gothan \& Weyland (1973) and to some extent after Mägdefrau (1968), and for both some of the records of Chesters et al. (1967) were taken into account.

Like the fossil record of the insects that of the Angiospermae also has its restrictions. Although pollen grains of zoogamous species are comparatively often found in peats or sediments (see tables 7-3 to 7), they are always infrequent and their occurrence is rather irregular (Faegri \& Iversen, 1964; Straka, 1975). Qualitative stratigraphical pollen analysis will only give a restricted view of the Angiospermae present in the period studied. A more successful substratum to find fossil, obligatory zoophilous pollen (in the majority of cases it will be entomophilous pollen) in larger quantities, is formed by fossil anthophilous animals (insects). On or in meliponine bees from the amber of the Dominican Republic (Miocene) Willemstein (1980) found Hymenaea pollen, a type that represents entomophilous (melittophilous and in Recent times also chiropterophilous) flowers which had not been found in stratigraphical pollen analysis of the Miocene of Central America (extensive study of the stratigraphical pollen analytical literature and Germeraad, pers. comm.). This first result of paleo-entomopalynology indicates that fossil anthophilous insects may contain concentrations of fossil entomophilous pollen. The majority of the pollen grains found in abundance in stratigraphical pollen analysis represents anemophilous flowers.

The incomplete survey of the Angiospermae in periods studied by stratigraphical pollen analysis, can be completed to some degree by studying the macrofossils. "To some degree", because the majority of the macrofossils of Angiospermae are trees and shrubs. Macrofossils of herbs appear to be very rare (Gothan \& Weyland, 1973) and mainly represent peat-inhabiting species (abundant fossil pollen representing herbs is known from the Tertiary, see Muller, 1981). Comparison of the presence of macrofossils and fossil pollen can give a first idea about the pollination type. There are three possibilities: 1) if in a period macrofossils are present and fossil pollen of the same taxon is not found in stratigraphical pollen analysis, or does not occur in some abundance (pollen not originating from the macrofossils), there is a major chance that the fossils represent entomophilous (or otherwise zoophilous) flowers;

2) if in a period both macrofossils and stratigraphical pollen of the same taxon in considerable quantities are found (pollen not originating from the macrofossils), there is a major chance that the fossils represent anemophilous flowers;

3 ) if only stratigraphical pollen is found in considerable quantities, it most probably represents anemophilous flowers. 
The pollen morphology may also indicate the pollination system. Muller (1984) mentioned that there are at least three functions of the columellate exine: to hold pollenkitt and lipid material in connection with entomophily and for sealing purposes; to store recognition substances for stigmatic germination; and to give structural support in connection with harmomegathy. With regard to the first Willemse (1985) surveyed the possible functions of pollenkitt: protection against UV radiation; prevention of desiccation; keeping pollen stuck together (whether this function developed in connection with the increase of ovules per stigma, which accompanies increase of specialization of the pollination system, see section 6.12 , may be possible and it would be interesting to study this); attractant for some insects, particularly for bees and also for some flies and beetles for which these are part of their pollen diet; and storing recognition substances. The pollenkitt originates from the tapetal cells and inside the locules it is smeared over the exine, but it can also participate in wall formation (Willemse \& Reznickova, 1980), which may be connected with the fact that the columellae may also contain recognition substances. The stickiness of the pollen diminishes gradually from the moment of anther opening (Hesse, 1979). If at the time of dehiscence the pollenkitt is deposited on the tectum surface, the pollen becomes sticky, if it is deposited in the tectum cavities, the pollen becomes powdery (Hesse, 1980). In some cases the latter may represent a very early anemophilous stage derived from an entomophilous one. The reduction of the amount of pollenkitt indicates that in anemophilous circumstances the protection function against desiccation of the pollenkitt is less important than in entomophilous conditions. It can be suggested that the longer the transport from the locule to the stigma takes, the more need there will be for a protective layer against desiccation. This may be the basic difference between anemophilous (mostly dry) and entomophilous (mostly sticky) pollen.

In wind pollination the comparatively few pollen grains that are deposited on a stigma are generally transported in a straight line. Knowing that a reasonable chance of successful pollination diminishes very rapidly with the increase of the distance from the plant producing the pollen, the average time between dehiscence and reception will be very short. The mean dispersal distance of anemophilous pollen in which the gene flow provides sufficient selection pressure is somewhat more than three meters (average about 10 feet, based on Lolium perenne, Pinus, Lycopodium (spores) and accepted for Anthoxanthum odoratum' (Antonovics \& Bradshaw, 1970). The height of the flowers above the ground will also play a role. The exposition of the pollen grain to the open air thus is very short, apparently so short that the presence of an extra protective layer is not necessary in most cases. Not needing such a layer pollen sculpture is also not necessary, see the first function of the columellate exine mentioned by Muller (1984): "to hold the pollenkitt" and I will add: equally distributed over the entire exine. 
In a zoophilous pollination system the pollen grains are exposed for much longer from the locule to the stigma and thus are longer open to desiccation. Dried pollen can germinate, but will hardly be able to compete with fresh pollen. Besides that, in many cases (insects) the pollen is transported by coldblooded animals, of which many of the diurnal species only become active in dry, sunny weather. The adaptation of the pollen to these circumstances is the production of an oily layer, equally distributed over the exine by sculpturing (columellae). At the same time this layer is sticky and functions as adhering agent to the animal body (insect body, insect setae, bird feathers, hairs of bats or other small mammals). In adhering to the animal body the combination of columellate sculpture and pollenkitt may have a function in itself. The sculpture enlarges the surface of the exine and the pollen adheres to the body of the pollen vector only at the outer parts of the tectum. This means that the adhering surface of the pollenkitt to the pollen is much larger than that to the pollen vector. In case of the removal of the pollen from the body by a stigma, then, most of the pollenkitt will remain on the exine and only some will be left on the body of the pollen vector, and the part of the pollen on the stigma exposed to the open air is sufficiently protected against desiccation and UV radiation.

On the stigma the pollen adheres by mechanical spreading and possibly by electrostatic forces (Corbet et al., 1982). On wet stigmas the lipophilous pollenkitt is decomposed by the hydrophilous exudate. On dry stigmas it adheres to the pellicula, surface tension being the most important force in sticking (Woittiez \& Willemse, 1979). Also here the comparatively small adhering surface of the pollen to the animal body will be an advantage: the force of the stigma to remove the pollen, whether by stickiness, electrostatic forces or surface tension, will have to be comparatively limited.

It can be suggested that for the pollenkitt the function of adhering to the body of the biotic pollen vector is the original one. The combination with a columellate sculptured exine to distribute the pollenkitt equally over the exine surface at the same time, can be considered an adaptation against desiccation and UV radiation. It then can be suggested that a sculptured columellate exine is an indication of zoophily, or indicates a comparatively recent state of anemophily, see the remark of Hesse (1980) concerning the deposition of the pollenkitt on the exine.

\subsubsection{Origin and early development}

It is interesting that Cornet $(1980,1981)$ has discovered pollen grains with a columellate structure in the Triassic; whether they are produced by representatives of predecessors of the Angiospermae or not, they may indicate a very 
early zoophilous pollination system. Muller (1984) also mentioned in this respect that Klaus (1979) has found evidence for relicts of columellate structure in Pinus; the columellate structure of Classopollis also suggests that the difference may not be fundamental between Angiospermae and Gymnospermae. Entomophily, being the most probable original pollination system in the Angiospermae, then, may mean that the earliest Angiospermae or their direct predecessors had columellate, sculptured pollen, which would mean that atectate, psilate pollen (as e.g. in the Degeneriaceae) has to be regarded as apomorphous.

\subsubsection{Lower Cretaceous}

\section{Barremian-Albian}

These periods are characterized by a very restricted number of the earliest recognizable angiosperm pollen, at first only indicating the presence of Magnoliidae (sensu Takhtajan, 1969) and possibly of early Laurales. Later in the same period pollen grains indicate the presence of some other taxa of the Magnoliopsida and pollen grains occur which indicate the presence of early Liliopsida. Gothan \& Weyland (1973) mentioned the Aptian as the period of origin of the Angiospermae and they concluded that macrofossils do not indicate a difference in time in the appearance of the dicotyls and monocotyls, although macrofossils of the first occur more often than those of the latter.

Besides the forerunners of the Magnoliopsida and Liliopsida (probably representing extinct taxa) Muller (1981) accepted pollen that can be attributed to the Chloranthaceae or their predecessors, starting in the Barremian (Muller, 1984). Within the Clavatipollenites-Ascarina complex the Clavatipollenites type can be connected with the Ascarina type and in Australia, Ninetyeast Ridge (Indian Ocean) and New Zealand a virtually continuous record is available from the Albian onwards. In Central Africa, South, Central and North America and Europe this type is known from the Aptian. Within the complex some types can be distinguished. Doyle (1969) compared the finely clavate-retipilate fossil forms of the Lower Cretaceous with Ascarina, the coarser clavate, irregularly aperturate ones with Hedyosmum, and the reticulate, nearly inaperturate types with Sarcandra. Van der Hammen \& Gonzales (1960) have shown that Hedyosmum has anemophilous flowers and a high pollen production; it fossilizes well in the Quaternary sediments of Columbia, and according to Muller (1981), Doyle (1969) might be correct in comparing the irregularly aperturate forms from the Lower Cretaceous with this genus. In this respect it is also interesting to mention that Mildenhal (1978) has reported up to $12 \%$ Ascarina lucida pollen in coastal Plio-Pleistocene sediments in New Zealand, which according to Muller (1981) "throws an interesting light on the 
Lower Cretaceous abundance of Clavatipollenites", as do the records of Kemp \& Harris (1977) (up to 18 percent in one site of Tertiary sediments) and Habib (1970) (up to 8,5 percent Clavatipollenites hughsii pollen in samples from the Cenomanian).

Because the fossil pollen occurs in considerable quantities and no macrofossils of the Chloranthaceae or their predecessors are known, it may be concluded that all types within the Clavatipollentites-Ascarina complex represent anemophilous flcwers. Muller (1984), however, also mentioned the possibility of pollination by indiscriminate insect visitors, which may be indicated by the remark of Norvick \& Burger (1976) that it occurs rarely to occasionally in the Albian of Australia. Then, anemophily did develop shortly before from entomophily in the Lower Cretaceous. Apart from Hedyosmum, however, no Recent pollination types are known, but the reduced inconspicuous flowers (unisexual in Ascarina, Ascarinopsis and Hedyosmum, hermaphroditic in Chloranthus and Sarcandra, the former with three stamens and the latter with one stamen) strongly indicate anemophily. The Chloranthaceae form a rather advanced family within the Magnoliidae (sensu Takhtajan, 1980) and also in comparison with the theoretical model of the earliest angiosperm flowers or their direct predecessors, they are apomorphous in many respects. This may mean that in the Aptian already comparatively apomorphous forms were present and this means that the origin of the (Hemi)Angiospermae may be earlier. The presence of fossils indicating other Magnoliopsida and Liliopsida or their predecessors in the Aptian, given the probably very restricted range of the direct predecessors (see section 7.1), may support this.

Recently Walker et al. (1983) discovered undoubted Winteraceae pollen tetrads in the late Aptian/early Albian of Israel. The subsequent record is fossil pollen of the Drimys type: Pseudowinterapollis (= Glephyrapollenites) wahooensis from the Maestrichtian of South Australia and the uppermost Cretaceous of New Zealand. This type is closest to Drimys sect. Tasmannia. Later records are known from the lower and upper Eocene of Australia and the late Oligocene of New Zealand: Pseudowinterapollis couperi, which is comparable to the pollen of Pseudowintera and Drimys. The earliest macrofossils are known from the Tertiary of North and South America (Gothan \& Weyland, 1973).

Thomson in Knuth (1904) mentioned that recent Drimys axillaris in New Zealand has greenish, inconspicuous, separated solitary, hermaphroditic flowers without odour and nectar, but with an extensive pollen production. This flower type indicates either pollination by pollen-feeding insects or by wind, at any rate anemophily is possible. This may be in accordance with the remarks of Cronquist (1981) that some species of Drimys are pollinated by Coleoptera and that Tasmannia (in this study considered a section of Drimys) is pollinated by Diptera and wind. Pervukhina (1967) (see Gottsberger et al., 1980) already mentioned this discussing the anemogamous and/or 
entomophilous pollination systems of the old world Winteraceae and the presumed entomophilous ones of the American species. Recent species of Pseudowintera and Drimys sect. Tasmannia are at least partly entomogamous (Sampson, 1963; Tucker \& Gifford, 1966; Pervukhina, 1967; Gottsberger, 1977; Gottsberger et al., 1980). Thien (1976) mentioned that four species of the section Tasmannia are pollinated by a variety of Diptera, which are attracted to the unisexual flowers by exudates of the stigmatic area and on stamen connectives. In this respect the fairly regular appearance (in time) of Pseudowinterapollis may be interesting. All fossil pollen is known from the Australian region and Israel, and the absence of macrofossils in these areas may indicate that facultative anemogamy is very old; it may have existed already in the Maestrichtian. The macrofossils of Drimys in the Tertiary of North and South America and the absence of pollen in the sediments of that area may indicate that Drimys in the new world did not develop anemogamy to any extent. This may be confirmed by the observations of Gottsberger et al. (1980) on the polination system of Drimys brasiliensis. The protogynous flowers (probably withholding the development of unisexual flowers) are visited and pollinated by a wide range of small insects. The most regular visitors are Coleoptera (mainly Curculionidae, but also Nitidulidae, Mordellidae, Anobiidae, Tenebrionidae, Chrysomelidae and Dermestidae); also a variety of Diptera can be considered regular visitors (Bibionidae, Scatopsidae, Sciaridae, Syrphidae and Chloropidae). Thysanoptera, probably breeding in the flowers, are abundant visitors. In rare cases Hymenoptera (Bombinae, Meliponinae, Vespidae, Formicidae and other, small Hymenoptera), Hemiptera, Collembola and small Lepidoptera are visiting the flowers. It will be easily seen that this non-specialized entomogamous pollination system might have been present since the early Tertiary. All beetle families mentioned were already represented in the Upper Cretaceous (see table 5-1). Of the Diptera (table 5-4) Bibionidae may have been present in the early Cretaceous and Syrphidae and Chloropidae may have been present in the early Tertiary. The Thysanoptera are of Permian origin (see fig. 5-2). The Recent rare visitors may have been present in the early Tertiary. In this respect the conclusion of Gottsberger et al. (1980), that within the Magnoliidae the less specialized entomophilous (or at least a less specialized cantharophilous) pollination system can be considered more plesiomorphous than obligatory cantharophily, is in accordance with the transformation series of the pollination systems.

The Recent Winteraceae have the following plesiomorphous character states: mainly entomophilous, mostly hermaphroditic flowers with many stamens (and many petals); mostly several carpels with usually many ovules (the latter may be considered somewhat apomorphous in case they are numerous). The apomorphous character states are: (rare) protogyny (as in 
Drimys brasiliensis); (occasional) anemogamy (probably derived within the family because the most related taxa according to Takhtajan (1980), as Degeneriaceae and Illiciales, are obligatory entomogamous); few petals and carpels (minimal numbers of four, a type that may have been developed in combination with the development towards more obligatory myiophily and probably anemophily); exudate to attract and feed insects on the stamen connective in Tasmannia (the exudate on the stigmas can be considered a normal stigmatic exudate to catch the pollen), indicating that the development of unisexual flowers took place under entomogamous circumstances, probably under the selective pressure of protandry; reduction of the number of ovules per carpel (minimum number of one, probably evolved in connection with the development of anemogamy).

It is suggested that anemophily in the Winteraceae is very old (at least of Maestrichtian origin). This means that the pollination systems in the late Cretaceous were about the same as they are now, which means that the flower morphology in the late Cretaceous also had about the same varieties as the Recent ones. The development of exudates on the stamen connectives in the section Tasmannia may be of later origin, since it can be considered an adaptation to the visits of apomorphous flies, which radiated mainly in the early Tertiary. Possible Daphnandra or Nemuaron type pollen (Stellatopollis barghoornii) (Monimiaceae) is known from the middle Albian (Doyle, et al., 1975). It is represented by more than a few grains per slide. This may indicate entomogamy in those times.

The second main angiospermous pollen type to appear is the tricolpate reticulate type in the Albian. This pollen generally is small and this would mean that it represents small flowers (Muller, 1970; Dilcher, 1979) or anemophily (Crepet, 1981). The first seems more probable than the last in this case (see below). Muller (1984) indicated that this pollen type more probably indicates the presence of Ranunculidae and Hamamelidae or their predecessors than Dillenidae or Rosidae or their predecessors. The pollen type is widespread among the Recent Angiospermae. The retention of this basic pollen type in many Recent genera is considered by Muller (1984) a striking example of "stasis" in pollen evolution and presumably also in pollination biology. There are, indeed, indications for the type of pollen transport. In the majority of the families in which this pollen type occurs, mentioned by Muller (1984), entomogamy occurs (varying from non- to more specialized): Menispermaceae; Berberidaceae; Papaveraceae; Fumariaceae; Hamamelidaceae; Trochodendraceae and Tetracentraceae (suggested to have the entomophilous brush-shaped blossom type); Dilleniaceae; Salicaceae (type only occurs in a number of species of Salix); Brassicaceae; Oxalidaceae; Verbenaceae; and Lamiaceae. Only in the Platanaceae anemogamy occurs, 
although the presence of staminodia in both the male and female flowers indicates facultative entomogamy or at least recent entomogamy, in which mandibulate insects (beetles) are involved. The correlation between entomophily and this pollen type will be based on the reticulate exine, rather than on the tricolpate structure.

The same will be the case in the related pollen type that occurred in the Albian: tricolporate reticulate pollen. This type probably was derived independently in several lineages from the tricolpate reticulate type and the development of endo-apertures will be an adaptation to increase pollen/stigma interaction. In Menispermaceae, Flacourtiaceae and Dilleniaceae transitional stages have been retained and in Rosidae the types have become dominant today. Muller (1984) concluded that identification of this pollen type is possible only in a very generalized way and probably indicates the presence of (entomogamous) Dillenidae and especially Rosidae in the Albian.

The third main early angiosperm pollen type is the monocotylous one from the Albian. The monosulcate Liliacidites, which is characterized by a differentiation in coarseness of the reticulate exine sculpture, described by Doyle (1973), is the earliest recognizable pollen type of the Liliopsida or their predecessors. However, it cannot be identified to taxa of lower rank, because it survived in a number of families. Doyle et al. (1977) have recorded it as early as the Aptian of Gabon. The reticulate exine sculpture may indicate entomogamy. Several other types are known, as types with a crotonoid pattern (Stellatopollis) and with a dipterocarpoid pattern (both patterns indicating entomophily).

A fourth main group is the periporate group from the Albian which shows some similarity to Alisma and Trimenia, but of which no connections have been made with younger groups. Muller (1981) mentioned the pending case of Cretacaeiporites scabratus from the Albian-Cenomanian of Brazil (and the Turonian of west Africa) which may be compared to Trimenia pollen. Recent Alismataceae are entomogamous and Trimeniaceae are anemogamous, thus, whether the pollen represents anemophilous or entomophilous flowers cannot be established. Herngreen (1973) mentioned frequent occurrence of Cretaceiporites scabratus according to Jardine (1967), which may an indication for anemophily of the pollen.

Some macrofossils from this period mentioned by Chesters et al. (1967) as: Celastrophyllum (Hauterivian-Barremian), Ficophyllum (Aptian) and Myrtophyllum (Albian), are not taken into account, because Gothan \& Weyland (1973) indicate that these form genera are not properly identifiable in the Lower Cretaceous. 
According to Muller (1984) the simultaneous presence of taxonomically not closely related Magnoliidae (Chloranthaceae and Winteraceae) in the Aptian, may suggest a much earlier, possibly Jurassic, origin and differentiation of this subclass of the Angiospermae. This early origin may be supported by the presence of comparatively advanced pollination systems in the Aptian Magnoliidae (probable anemogamy in the Chloranthaceae and Winteraceae, which fossilized in deposits now forming sediments in the Old World). Whether the origin(s) of the Magnoliidae (with the most archaic Recent members of the Angiospermae, possibly containing the most plesiomorphous taxon or taxa of lower rank) coincides with the origin(s) of the Angiospermae is not known. The presence of traces of other angiosperm subclasses indicates a wider differentiation in the Aptian than those within the Magnoliidae and may consequently suggest (an) earlier origin(s).

To the remarks of Muller (1984) about the detection of traces of early Angiospermae by stratigraphical palynology (positive correlation between the differentiations of pollen types and leaf forms in these periods) one can be added: paleo-entomopalynology (see the beginning of this section), particularly important in the earliest times of angiosperm origin(s), because of the high probability of obligatory entomogamy of these earliest Angiospermae. In this respect the large numbers of fossil insects found in the upper Jurassic Kara Tau deposits are fascinating.

In the earliest detected angiosperm differentiation, established in the Barremian-Albian, the following apomorphous states of the transformation series mentioned in section 7.3 may have been established:

- anemophilous flowers including inconspicuous, green flowers with reduced perianth, few stamens and a reduced number of ovules per stigma (carpel) (62-67);

- some more obligatory beetle pollination (2);

- possible sapro-entomogamy (14);

- somewhat hemiphilic flowers are possible (in connection with more obligatory beetle pollination) (18);

- possible haplomorphic flowers (25);

-actino- and pleomorphic flowers $(26,27)$;

- probable (partial) sympetaly (24);

-brush-shaped blossoms $(34,35)$;

- small-flowered inflorescences (37);

-yellow and white floral colours (38);

-reduction of the numbers of stamens per flower in connection with entomogamy (43);

- reduction of the numbers of ovules per stigma (carpel) in entomophilous small-flowered inflorescences (46a); 
- possible protogyny (49);

-unisexual flowers (54-61).

\subsubsection{Upper Cretaceous}

The fossil history of the insect taxa in which anthophily developed has not been dated as finely as the fossil record of the angiosperm pollen (neither is the record of angiosperm macrofossils). Therefore the survey of the differentiation of the insect taxa in which anthophily developed is given for the whole Upper Cretaceous, keeping in mind that the period from the beginning of the Cenomanian to the end of the Maestrichtian covers 35 million years, in which a considerable diversification of insect morphology and habits must have occurred.

The differentiation of the anthophilous Coleoptera was already considerable in the Upper Cretaceous (see table 5-1). The only new development traced in the fossil record in this period is the appearance of the Donaciinae (Chrysomelidae). This subfamily cannot be connected to particular developments in floral morphology; neither does the possible presence of early differentiation of the Cucujoidea (Phalacridae, Byturidae, Melandryidae, Scraptiidae, Lagriidae and Alleculidae). The detected and possible Upper Cretaceous developments in the Coleoptera are only connectable with nonspecialized entomogamy. Within the existing differentiation of the Coleoptera already further developments towards more obligatory cantharogamy are possible.

The differentiation of the Hymenoptera in the Upper Cretaceous gives more indications of new differentiation in anthophily and possibly, consequently more new floral developments than does that of the Coleoptera. There appears to be a considerable differentiation of the non-Apoid Apocrita (see table 5-2), of which particularly the Chrysididae, Scoliidae, Masaridae, Tiphiidae and Mutillidae indicate the presence of nectar-producing flowers. The early differentiation of the Apoidea and Sphecoidea or their stem-group, forming the sister-group of the Tiphiidae (see fig. 5-11), may have started already in the Upper Cretaceous, indicating that obligatory anthophily (with feeding also the offspring with nectar and pollen, as in e.g. Recent Masarinae) may have been present and could guide floral evolution. Towards the Maestrichtian the chances of the presence of this anthophily increase.

Anthophilous higher Lepidoptera probably started to differentiate in the Upper Cretaceous. The presence in that period of Papilionoidea with long haustella or their predecessors may be indicated by the complete differentiation into the Recent families of this superfamily in the middle Eocene (see table 53 ). Incidentally it should be mentioned that the chances of the presence of Lepidoptera with long haustella increases towards the Maestrichtian. 
The differentiation within the Diptera was considerable in the Upper Cretaceous (see table 5-4). With the presence of the Mycetophilidae and possible presence of Bibionidae and Anisopodidae more obligatory, mainly nectarbased, anthophily was probably present. The same can be stated in connection with the possible presence of the Empedidae (Empedinae?) and with the appearance of the Lonchopteridae and Phoridae. None of these families, however, although containing effective pollinators, will have played an important role in the development of specializations in floral morphology, only, together with the smaller Coleoptera, apomorphous wasps, the earliest possible Apoidea and Sphecoidea or their predecessors, they firmly established non-specialized entomophilous pollination systems of flowers with easily reachable (open) nectar. The presence of the Nemestrinidae, if they had already developed longer rostra, may have had its impact on the floral morphology, as may have had the possible presence of the stem group of the Syrphoidea and Schizophora (see fig. 5-20 for the relationships within the Cyclorrhapha and table 5-4 for the extensive differentiation of these taxa in the upper Eocene to lower/middle Oligocene). Towards the Maestrichtian the chances that these taxa were present increase. Developments towards more obligatory myiophilous pollination systems (in the relative sense, regarding the absence of higher Apoidea and probably relative scarcity higher Lepidoptera or their predecessors in the earliest periods of the Upper Cretaceous) may have been established in a number of taxa during the upper Cretaceous.

Many angiosperm fossils are described from the Upper Cretaceous, but many of the leaves cannot be identified with certainty. Most of the taxa mentioned by Chesters et al. (1967) are based on fossil leaves, many of which need reconsideration. In the following surveys of the occurrence of the Angiospermae in the various periods of the Upper Cretaceous only those records are taken into account for which also Gothan \& Weyland (1973) mentioned the occurrence in these periods. In the surveys the families of the Angiospermae are arranged according to Takhtajan (1980).

\section{Cenomanian-Turonian}

The increase in abundance of angiosperm macrofossils is accompanied by a further differentiation of the pollen types, with as main event the appearance of triporate types. By the end of the Turonian the ecological breakthrough of the Angiospermae appears to have been largely completed. The taxa in these periods, in most cases, were different from the Recent ones (Muller, 1984). As Tiffney (1981) (see Muller, 1984) has suggested, the increasing efficiency of the Angiospermae established their differentiation after a slow and gradual additive phase in the Lower Cretaceous. This differentiation may have been 
accompanied by a differentiation of the pollination systems and developments towards successful cross pollination.

The following Angiospermae have been described from the CenomanianTuronian.

MAGNOLIACEAE. If the record of Magnolia spp. by Chesters et al. (1967) is correct (it may be supported by the presence of the as yet pending pollen type Magnolipollis sp. in the Cenomanian (Muller, 1981); other macrofossils in the later Upper Cretaceous more certainly indicate the presence of Magnolia), the floral morphology may have differed little from the Recent Magnolia. The flowers may have been somewhat smaller than the Recent ones and the cantharophilous pollination system will have been of the type in which the number of visiting beetle species is large, as mentioned in the Recent observations by Heiser (1962), Thien (1974), Leppik (1975) and Gottsberger et al. (1980). This is more probable than the more specialized type as in e.g. Talauma ovata in which only one Dynastine species is responsible for pollination (Gottsberger, 1977, 1977a; Gibbs et al., 1977), because the Dynastinae form a comparatively late development in the Scarabaeidae (probably of about middle Tertiary origin). Recent developments to attract and feed beetles may have been present in the Cenomanian-Turonian: in addition to pollen, glucose-containing warts on the stigma, or some stigmatal nectar secretion (Dauman, 1930), presence of glucose-rich tissue at the bases of the tepals, whether or not accompanied by attracting odours.

TRIMENIACEAE. The presence of Trimenia-like pollen and their occurrence in considerable quantities in the Cenomanian and Turonian may indicate an anemophilous pollination system in the Cenomanian Trimeniaceae or their predecessors. Although no Recent pollination system is known, the deciduous floral appendages at or before anthesis, the feathery stigmas and the single ovule per carpel indicate anemogamy.

LAURACEAE. Leaves of Sassafras are known from the Cenomanian. The Recent Sassafras officinale is mainly visited by shortly rostrate flies (Robertson in Knuth, 1904). Some form of myiogamy (more absolute than it is now) may have existed in Cenomanian Lauraceae, indicating that easily reachable nectar may have been present in the flowers.

PIPERACEAE. If Piperites tuscalooensis indeed represents Piper-like flowers, then a kind of non-specialized entomogamy may have been present in the Cenomanian Piperaceae or their predecessors. Presentation of open nectar may have been possible.

NYMPHAEACEAE. If Nelumbites spp. can be included in the Nymphaeaceae, then cantharogamy may have been present in Cenomanian representatives of this family or its predecessors. The Recent pollination systems include mainly beetles, but in more rare cases bees and flies are involved in pollination. The beetles may have been the more exclusive 
pollinators in the Cenomanian, however, possibly less euphilic than in Recent Nymphaea.

NELUMBONACEAE. Nelumbo may have been present in the Cenomanian (pending Nelumbo type pollen). Leaves are known from the Upper Cretaceous. It seems that a pollination system more or less restricted to beetles can be suggested for the Cenomanian Nelumbonaceae or their predecessors.

CERCIDIPHYLLACEAE. Cercidiphyllum may represent this family in the Cenomanian; Cercidiphyllous pollen is known from the Campanian. The appearance of macrofossils before the fossil pollen may indicate entomogamy in the Cenomanian Cercidiphyllaceae or their predecessors. Recent Cercidiphyllum japonicum seems to be anemogamous (female flowers with long, slender stigmas and flowering before the leaves appear). The presence of still many ovules per carpel, however, indicates at least a recent entomogamous phase or some Recent entomogamy. It is possible that from an original entomogamous state in the Cenomanian and Turonian, facultative anemogamy was developed in the later Upper Cretaceous (also pollen known from the Maestrichtian).

HAMAMELIDACEAE. Liquidambar is represented in the Cenomanian by leaves (certain Liquidambar pollen is known from the Paleocene. It may be suggested that the flowers of the Cenomanian Hamamelidaceae were mainly pollinated by beetles (in the Recent dioecious plants the female flowers often have staminodes) and perhaps in later times anemogamy developed (rare Recent female flowers without staminodes and a minimum of only one ovule per carpel).

PLATANACEAE. Platanus spp. may have been present in the Cenomanian, although fossil pollen of the Platanus type is first known from the upper Eocene. Recent Platanus is anemogamous. However, staminodes are present in hermaphroditic, male and female flowers, which indicate a phase of dominant beetle pollination. The absence of pollen in the Upper Cretaceous may indicate entomogamy with beetles as main pollinators in the Cenomanian Platanaceae or their predecessors.

MYROTHAMNACEAE. There is a pending Myrothamnus type pollen known from the Cenomanian. Recent Myrothamnus is anemogamous. The pollen tetrads and the fair number of ovules per locule in the Recent representatives, however, indicate comparatively recent entomogamy (no later records of fossil pollen are known). It is possible that the Myrothamnaceae or their predecessors in the Cenomanian were entomogamous of a non-specialized type.

ULMACEAE. The continuous occurrence of Celtis type pollen from the Turonian onwards indicates early Ulmaceous anemogamy, as the Recent genera still are.

MORACEAE. Leaves (Ficophyllum) and pieces of wood (Ficoxylon) are 
known from the Upper Cretaceous. The absence of fossil pollen indicates entomogamy. In the Cenomanian this must have been of a less specialized type, because the monolectic Agaonidae and monophilic Ficus are known from the middle to late Tertiary.

BETULACEAE. The occurrence of Alnites grandiflora in the Cenomanian and the absence of pollen in that period, may indicate entomogamy. In the later Upper Cretaceous several Betulaceous macrofossils and fossil pollen occur, the latter (Alnus) in abundance from the Campanian onwards, indicating the establishment of anemogamy.

JUGLANDACEAE. Juglans-like fossils are known from the Cenomanian onwards. The earliest Juglandaceous pollen (Momipites fragilis type) is known from the Campanian. The difference in time between the appearance of macrofossils and fossil pollen may indicate entomogamy in the CenomanianTuronian. Recent Juglandaceae are anemogamous, but the inferior position of the ovaries indicate pre-anemogamous entomogamy in which beetles may have been the main pollinators. The latter pollination system may have existed in the Juglandaceae or their predecessors in these periods.

SALICACEAE. Salix- and Populus-like fossils from the Cenomanian may indeed represent this family. The earliest (pending) Salix type pollen is known from the Maestrichtian and more certain pollen of this type dates from the Oligocene. Certain Populus pollen is first recorded from the Miocene. There are strong indications that the Cretaceous Salicaceae were entomogamous and probably in the pre-Maestrichtian with a smaller pollen production than in Tertiary and Recent Salix.

ERICACEAE/ERICALES. Andromeda sp. from the Cenomanian may belong to the Ericales. The earliest pollen of this genus is known from the Maestrichtian. There will be no doubt that the earliest Ericales were entomogamous of a hardly specialized type, probably producing already nectar in the Cenomanian. Some inferior ovaries in the Recent Ericales (Grubbiaceae, many Vaccinioideae) may indicate a considerable influence of visiting beetles.

SAPOTACEAE. Sapotacites is known from the Cenomanian and the earliest fossil pollen dates from the Santonian. The pollination system of the Cenomanian Sapotaceae or their predecessors may have been non-specialized entomogamous.

BOMBACACEAE. Bombax virginensis occurs in the Cenomanian and the earliest Bombax type pollen is known from the Maestrichtian. Recent Bombacaceae have large showy flowers (bat and bird pollination occur). In the Cenomanian the flowers probably were entomophilous, whether already more or less specialized to longer-tongued insects remains questionable, but some specialization to flies with a somewhat longer rostrum may be possible (myiophily). Whether some relationships with ant colonies (see Heywood, 1978 ) in the form of myrmecodomy, mymecophylaxis and/or myrmecogamy 
was already present is not known, but according to the fossil record and phylogeny of the ants (table 5-2 and fig. 5-14) the possibility does exist. It can be suggested that nectar production in the Cenomanian Bombacaceae did exist.

GUNNERACEAE. Pollen of Gunnera is known from the Turonian onwards. Recent Gunnera is anemogamous (Hamilton and Thomson in Knuth, 1904). The abundance of the fossil pollen and the absence of macrofossils may indicate that this pollination system existed already in the Upper Cretaceous. However, the inferior ovaries of the Recent Gunneraceae indicate an entomogamous phase with extensive beetle visits in the family or its predecessors (possibly in the stem-group of the Haloragaceae + Gunneraceae).

ROSACEAE. Because of the extensive differentiation of the Rosaceae in the lower Tertiary, the Pyrus spp. macrofossils from the Cenomanian are accepted as representatives of the Rosaceae or their predecessors in the Cenomanian. The flowers represented by these fossils most probably were entomophilous and if there was already question of Pyroideae or their direct predecessors, the Recent inferior ovaries may indicate mainly beetle pollination, or nonspecialized entomogamy with beetle influence in the Upper Cretaceous.

FABACEAE. There are indications that all three subfamilies were already present in the Upper Cretaceous.

MIMOSOIDEAE. A pending Mimosa type pollen (eight-celled polyad) is known from the Cenomanian. This pollen may represent small-flowered inflorescences, may be already specialized for pollination by longer-tongued insects, possibly flies (although the Recent sporadic occurrence of perigyny may indicate some influence of beetles as flower visitors). The early presence of polyads strongly indicates a more specialized pollination system and can be correlated with many ovules per carpel in the Cenomanian Mimosoideae or their predecessors.

CAESALPINIOIDEAE. Caesalpinia may have been present in the Cenomanian, and then the Caesalpinioideae or their predecessors most probably were entomogamous (as are all Recent representatives). It most probably represents Gleditschia-like flowers, rather than the Recent Caesalpinea.

FABOIDEAE (PAPILIONOIDEAE). Possibly not yet in the CenomanianTuronian, but in later Upper Cretaceous probably Faboideae or their predecessors are represented by Colutea- and Dalbergia-like fossils. The slight to rarely strong perigyny of the Recent Faboideae may indicate some influence of beetles as flower visitors in a very early phase, if the variation in ovary positions was not inherited from the stem-group of the Faboideae and their sistergroup. Some irregularity (zygomorphy) may have been present in the Upper Cretaceous, and if this already existed in the Cenomanian-Turonian it was probably correlated with more exclusive fly pollination.

RUTACEAE. The fossil leaf Citrophyllum is accepted for the Cenomanian, 
because in the Upper Gretaceous also Rutaceous woods occur. The rare occurrence of staminodes in the Recent Rutaceae and the rare perigyny (as in Adenandra) may indicate influence of beetles as flower visitors in the Rutaceae or their predecessors. Somewhat longer corolla tubes may have been present in the Upper Cretaceous.

ANACARDIACEAE. It is possible that Rhus powelliana in the Cenomanian represents Anacardiaceae or their predecessors. The occurrence of rare perigyny or epigyny and sterile stamens in the Recent Anacardiaceae may indicate influence of beetle visitors in a period of their development, or of that of their predecessors. In the Upper Cretaceous myiophilous flowers may have been present, as is the case in e.g. the Recent Rhus glabra and $R$. canadensis (Meehan, Riley and Robertson in Knuth, 1904), while in later Cretaceous periods possible, early, short-tongued Apoidea or their predecessors also may have visited the flowers.

SAPINDACEAE. Because of the possible, fair diversity of the Sapindaceae (leaves) in the Upper Cretaceous and the definite presence of pollen in the Coniacian, Sapindopsis brevifolia is accepted as a representative of this family or its direct predecessors in the Cenomanian. The Recent pollination systems in Serjania sp., Paullinia pinnata and Pseudima frutescens (Duke in Knuth, 1904) may be interesting in this respect, because, besides some, mainly plesiomorphous, bees, also many wasps are involved in pollination (Sphecoidea and Vespoidea, the first possibly and the latter certainly present in the Upper Cretaceous, see fig. 5-11). It may be possible that the combination of these wasps and possible, early Apoidea or their predecessors, or at any rate representatives of the stemgroup of the Sphecoidea and Apoidea as flower visitors existed already in the Upper Cretaceous. It is, however, possible that in the Cenomanian wasps were the main pollinators. Nectar production in the Cenomanian Sapindaceae or their direct predecessors is then probable.

ACERACEAE. Acer amboynense is considered to represent this family in the Cenomanian (many Acer-like fossils in the Upper Cretaceous and a pending case of $A$. campestre type pollen in the Maestrichtian). Recent Acer is mainly pollinated by Apoidea and Diptera (Wittrock and Warnstorf in Knuth, 1898). This may mean that the Cenomanian Aceraceae or their predecessors were myiogamous, with the possibility that in later periods of the Upper Cretaceous also Apoidea or their predecessors became involved in pollination. It is probable that nectar production was present throughout the Upper Cretaceous.

ARALIACEAE. Araliaephyllum crassinerve from the Cenomanian is accepted to represent this family, because many leaves comparable to Aralia and Hedera occur in the Upper Cretaceous and pending Plerandra pickeringii type pollen is described from the Turonian. The mostly inferior ovaries in the Recent Araliaceae indicate a phase of beetle visiting and/or pollination. In this case it most probably has been part of a hardly specialized entomophilous pollina- 
tion system, because in the Recent Araliaceae the main pollinators are flies in Schefflera digittata (Thomson in Knuth,1904) and both flies and wasps in Hedera helix (Delpino in Knuth, 1898). The latter may also have been the case in the Upper Cretaceous, beetles then being among the visitors of hardly specialized entomogamous, nectar-producing Araliaceae or their direct predecessors.

ICACINACEAE. The fruit remains Phytocreme microcarpa are likely to represent this family in the Cenomanian. The Recent Icacinaceae are entomogamous (only record Pennantia corymbosa, see Thomson in Knuth, 1904). Because of the absence of fossil pollen in the Upper Cretaceous (first pollen types known from the Paleocene) the Icacinaceae or their predecessors most probably were entomogamous in the Cenomanian.

AQUIFOLIACEAE. Ilex was definitely present in the Cenomanian (I. scudderi), the earliest Ilex pollen dates from the Turonian, and there is a pending case of this "highly characteristic" pollen type (Muller, 1981) known from the Cenomanian. Recent Ilex is mainly pollinated by flies and in some cases also by Hymenoptera and diurnal Lepidoptera (Trelease in Knuth, 1904), although also facultative anemogamy occurs as in $I$. opaca (Meehan in Knuth, 1904). Some form of a mainly myiophilous pollination system may have existed in the Cenomanian Aquifoliaceae.

APOCYNACEAE. Possible earliest Apocynaceae or their predecessors were present in the Cenomanian. These will have been of the most plesiomorphous type, like the Recent Plumerioideae with wholly fertile anthers that are distinct from each other and free from the style. They probably were non-specialized entomogamous (more apomorphous flower remains are known from the Eocene). Pollination systems in Recent Plumerioideae are e.g. (Knuth, 1899, 1905): Allamanda pollinated by bees and birds; Vinca pollinated by longtongued bees and long-haustellate Lepidoptera; and Cerbera which is mainly psychogamous. Psychogamy also developed in e.g. Nerium. In a later phase ornithogamy developed from melittogamy in e.g. Allamanda and from psychogamy in e.g. Dipladenia and Nerium oleander. The Apocynaceae or their predecessors in the Cenomanian may have had comparatively small flowers in which the nectar was not too deeply hidden. Pollination will mainly have taken place by somewhat longer-tongued insects (flies?), compare the morphology of e.g. Alyxia reinwardtii in Van Steenis (1972) (see for the Alyxia pollen type also the Paleocene), and possibly in the later Upper Cretaceous also the earliest Apoidea or their predecessors and early higher Lepidoptera played a role in pollination.

CAPRIFOLIACEAE. Viburnum grewiopsidum is accepted as a representative of the Caprifoliaceae or their predecessors in the Cenomanian (many Viburnum-like leaves known from the Upper Cretaceous). Pollination most probably was entomophilous; it was carried out by flies and wasps and possibly beetle visitors favoured the development of epigyny and rare perigyny. 
ALISMATACEAE. Possible Alismataceae or their predecessors were present in the Cenomanian-Turonian. Recent Alismataceae are mainly pollinated by flies (see Graenicher and Lovell in Knuth, 1904 and Müller and MacLeod in Knuth, 1899), only some short-tongued Apoidea have been observed visiting the flowers. The Alismataceae or their predecessors in the Cenomanian most probably were mainly myiogamous.

SMILACACEAE. Smilax kansana from the Cenomanian may represent this family. Recent Smilax is mainly myiogamous (although some melittogamous species occur). The staminodes in the Recent female flowers may indicate a phase of intensive beetle visits to the flowers, which may be still going on (see Graenicher in Knuth, 1904): Malachiidae, Cerambycidae, Chrysomelidae, Elateridae, Mordellidae and Scraptiidae have been observed visiting the flowers (most of these families were already present in the Upper Cretaceous, see table 5-1). It is suggested that the Smilacaceae or their predecessors in the Cenomanian were hardly specialized entomogamous, possibly with some tendency to myiogamy.

ARECACEAE. Fruits of $N y p a$ are known from the Cenomanian and later Upper Cretaceous. Besides some earlier, pending cases of fossil pollen, definite Arecaceae pollen is known from the Maestrichtian. It is probable that the earliest Arecaceae were entomogamous, as are e.g. the Recent Bactris and Johannesteijsmannia, which are mainly pollinated by beetles. In some cases (e.g. Phytelephas) numerous stamens or other flower parts can be considered modifications to permit insect-feeding (in my opinion this is a plesiomorphous character state). It is probable that also anemogamy was already present in the Cenomanian.

PANDANACEAE. Pandanus tectoria type pollen is known from the Cenomanian. Recent Pandanaceae are either anemogamous (open field species) or entomogamous (bush dwellers). In the Cenomanian both pollination systems may have existed. Because of the relative abundance of the fossil pollen and the absence of macrofossils in the Upper Cretaceous (earliest macrofossils known from the Oligocene), the pollen most probably represents anemogamous species. The Recent numerous stamens and the occurrence of staminodes in the female flowers of some species may indicate beetle pollination, which may also have existed in the Upper Cretaceous.

In the angiosperm differentiation detected in the Cenomanian-Turonian, the following new apomorphous states of the transformation series mentioned in section 7.3 may have been established:

- early more obligatory myiophily $(1,8)$;

-more obligatory cantharophily (3);

-early more obligatory wasp pollination (4); 
-earliest somewhat stereomorphic and possibly zygomorphic (margin flowers of small-flowered inflorescences) $(21,22)$;

-earliest possible bell- to faintly funnel-shaped flowers (28);

- larger solitary flowers (36);

-possibly some blue-mixed colours in connection with early more obligatory myiophily (39);

-peri- and epigyny (44) (Friss (1983) described flowers of Manningia and Friis \& Skarby (1982) of the Saxifragalean Scandianthus with inferior ovaries from the middle Senonian fluviatile clays and sands of Scania, southern Sweden);

-nectar-containing flowers with exposed nectar $(47,52)$.

\section{Coniacian-Santonian-Campanian}

The period covering the Coniacian, Santonian and Campanian is largely a continuation of the Cenomanian-Turonian, expressed in further differentiation of many insect taxa. This will also have been the case in the taxa of anthophilous insects. The presence of the differentiation in the Upper Cretaceous may have been definitely established in these periods and towards the end of the Campanian also more probably than in the CenomanianTuronian, early Apoidea or their predecessors may have been present and also the early higher Lepidoptera or their direct predecessors.

Strong diversification appeared among the angiosperm taxa. Many of the taxa mentioned from the Cenomanian-Turonian with the uncertainty that it is not known whether there was question of the taxa themselves or of their (direct) predecessors (stem-groups of the taxa and sister-groups), became more certain in the Coniacian-Santonian-Campanian. Establishment was observed for e.g. the Dillenidae (Malvanae), Fagales, Betulales, Juglandales and Myrtales (Muller, 1981).

The following taxa occurred in the Coniacian-Santonian-Campanian.

BUXACEAE. Pachysandra type pollen occurred in the Campanian. Knuth (1905) considered the Recent Buxaceae anemogamous, a pollination system that may have existed already in the Campanian, because the earliest macrofossils first occurred in the upper Miocene. The position of the male and female flowers in monoecious plants (dioecious and polygamous ones also occur) in the same inflorescence (females below males) and the morphology of the stamens may indicate entomogamy. Dicliny, then, was probably favoured by protandry.

FAGACEAE. Nothofagus pollen is known from the Santonian and macrofossils are also known from the Upper Cretaceous. Castanea type pollen is described from the Campanian. The simultaneous occurrence of (widespread) fossil pollen and macrofossils of Nothofagus indicates anemogamy of this 
genus in the Upper Cretaceous. Recent Castanea is entomogamous. According to Cronquist (1981) this would be secondary, derived from wind pollination. The positioning of the flowers in Castanea may suggest this: the female flowers at the base of otherwise male inflorescences, may indicate dicliny favoured by protandry. Also the inferior ovaries of all Recent Fagaceae and the occurrence of staminodes in some of the female flowers (correlated with the rare occurrence of hermaphroditic flowers) indicate an entomogamous phase in the Fagaceae or in the Fagales, with beetles as extensive visitors. The comparatively late appearance of macrofossils of Castanea (Teriary) and the relative abundance of the fossil pollen may indicate that in the Upper Cretaceous the genus may have had an anemogamous pollination system, although entomogamy may have been present as well.

BETULACEAE. Besides the occurrence of Alnus (possibly already in the Cenomanian-Turonian), Betula pollen is also abundantly known from the Santonian. Because the earliest macrofossils of Betula date from the Eocene, anemogamy is suggested for this genus in the Upper Cretaceous.

MYRICACEAE. Myrica type pollen is, probably abundantly, known from the Santonian and macrofossils, based on the characteristic epidermis structure of leaves, are known from the Upper Cretaceous. Some other myricaceous pollen types indicate some differentiation of this family or its direct predecessors in the Campanian (see Muller, 1981). It seems that the Myricaceae or their direct predecessors were already anemogamous in the Santonian, as they are in Recent times (Myrica gale, MacLeod in Knuth, 1899).

RHOIPTELEACEAE. A pending Rhoiptelea type pollen is known from the Campanian. This pollen may represent anemophilous flowers, although the tetrads indicate an entomophilous pollination system in the Rhoipteleaceae or their predecessors in the Campanian.

NYGTAGINACEAE. Pisonia-like leaves are known from the Campanian and Maestrichtian. The earliest Nyctaginaceous pollen is known from the lower Miocene. Recent Nyctaginaceae are often autogamous, but many species are entomogamous, pollinated by Lepidoptera (e.g. Mirabilis longiflora), wasps (Allionia sp. pollinated by Scolia thoracica), and oligolectic bees (Allionia incarnata, Pisonia cauliflora) (see Knuth, 1904). This may mean that in the Campanian a non-specialized entomophilous pollination system was present in the Nyctaginaceae or their predecessors, possibly with some myiogamous tendencies as a phase intermediate between non-specialized entomogamy (including wasp visitors) and Tertiary psychogamy and melittogamy.

THEACEAE. Ternstroemites harwoodensis from the Coniacian-Campanian and Ternstroemioxylon dachelense from the Upper Cretaceous may indicate the presence of the Theaceae or their predecessors in the Coniacian. The earliest theaceous pollen is known from the lower Eocene. If the fossils already represent the Ternstroemieae or their direct predecessors, then a non-specialized 
entomophilous pollination system may have existed in the Upper Cretaceous Theaceae. In this pollination system beetles may have played a role, which may be derived from the semi- and wholly inferior ovaries in the Recent Annesleya and Symplococarpon (Ternstroemieae) respectively.

MYRTACEAE. The earliest myrtaceous pollen is known from the Santonian and many leaf remains are known from the Upper Cretaceous. Eucalyptus would be present in the Upper Cretaceous. The Santonian Myrtaceae were probably entomogamous, possibly already to a slight degree adapted to longertongued insects. The inferior position of the ovaries may indicate beetles as visitors and pollinators in the Myrtaceae or their predecessors. The possible upper Cretaceous Eucalyptus may have been pollinated by longer-rostrate flies or the earliest other longer-tongued insects.

SAPINDACEAE. The Cupaniopsis type pollen is definitely present in the Coniacian (see under Cenomanian-Turonian).

OLEACEAE. Ligustrum subtile may represent this family or its predecessors in the Coniacian. The winged fruits of Fraxinus are known from the Upper Cretaceous. The earliest pollen of the family is known from the Oligocene. The earliest Oleaceae or their predecessors may have been more or less myiogamous, with the nectar somewhat concealed. This pollination system, already in the Upper Cretaceous, may have given rise to more pollination by Apoidea or their predecessors and to a more psychophilous pollination system. The obligatory anemogamy of the Recent Fraxinus (Knuth, 1899) may be of comparatively late origin, because certain Fraxinus type pollen is first known from the upper Miocene.

LAMIACEAE. There is a pending case of Salvia-like pollen from the Coniacian. According to Muller (1981) this type may also occur in other genera of the Lamiaceae. Possible Lamiaceae or their predecessors in the Coniacian may have already been more or less myiogamous, whether or not also pollinated by the earliest Apoidea or their predecessors and the earliest higher Lepidoptera or their direct predecessors. Thus, this was similar to the pollination system of e.g. the Recent Mentha or Lycopus and not of the Recent Salvia.

CYPERACEAE. Carex clarkii may represent this family or its predecessors in the Coniacian. Gothan \& Weyland (1973) mentioned that several genera are described from the Upper Cretaceous, but they are not comparable with Recent genera. It is interesting that the earliest pollen of the Carex type is first known from the middle Eocene. It can be suggested that the earliest Cyperaceae or their predecessors had entomophilous flowers, possibly mainly pollinated by flies in the Upper Cretaceous.

POACEAE. Uncertain Phragmites is known from the Coniacian. This genus also appears in the Maestrichtian, as do Arundo-like fossils. There is a pending case of Poaceae-like pollen from the Campanian/Maestrichtian. There are indications that the Poaceae or their predecessors were anemogamous in the 
Campanian. The possible Coniacian representatives may have been pollinated by flies, just like the Cyperaceae or their predecessors.

In the angiosperm differentiation detected in the Coniacian-SantonianCampanian, the following new apomorphous states of the transformation series mentioned in section 7.3 may have been established in the Campanian: - possible very early pollination by Apoidea or their predecessors (bee pollination) and early pollination by butterflies or their direct predecessors $(5,6)$; - possible presence of fly- and bee-pollinated flowers (9);

- possible presence of fly- and butterfly-pollinated flowers (11).

\section{Maestrichtian}

In the Maestrichtian most of the developments mentioned under the Cenomanian-Turonian and Coniacian-Santonian-Campanian may have been completed to a level from which new development could start. Floral developments towards myiophily may have been continued. The probable presence of the earliest Apoidea or their direct predecessors may have allowed the development of more obligatory bee pollination, derived from already established myiogamy. From the same or other myiogamy more obligatory butterfly pollination (may be already some form of psychogamy) could have developed because of the probable presence of the earliest Papilionoidea or their direct predecessors. Besides these specializations, the diversification of other nectar-feeding insects may have been considerable, assuring the full success of nectar-based entomogamy. Cross pollination favouring developments must have been established (protogyny, diverse distributions of the sexes, and floral morphology). These flower-ecological developments may have accelerated the diversification of the Angiospermae, exploring newly developed pollination systems.

The following taxa appear in the Maestrichtian.

EUPOMATIACEAE. Although Muller (1981) considered it a pending case because of the Recent geographical distribution, the unique pollen grain of Eupomatia from the Maestrichtian can be regarded as a representative of the Eupomatiaceae in that period. The Recent Eupomatia laurina is cantharogamous (Delpino in Knuth, 1905) and in addition to pollen also the gland-bearing inner staminodes function as food for the visiting beetles (Browns in Knuth, 1905). The exclusive visiting species is Elleschodes hamiltoni (Curculionidae) and in Eupomatia bennettii another species of the same genus is the exclusive visitor (Hamilton, 1897; Hotchkiss, 1958; Gottsberger et al., 1980). This highly specialized cantharophilous pollination system may have already existed at the end of the Cretaceous, because the Curculionidae were considerably differentiated at that time (almost all subfamilies were established in the early Tertiary). 
ANNONACEAE. Malmea type pollen (Foveomorphomonocolpites humbertoides, according to Sole de Porta (1971) occurring in some abundance), Annona- and Asimina-like leaves and Annonaspermum gilbediensis represent this family in the Maestrichtian. The earliest Annona type pollen is known from the lower Eocene. The Recent Annonaceae are mainly entomogamous (in many cases obligatory autogamous), mostly cantharogamous. The pollination of the Annonaceae is mainly carried out by small beetles, mainly Nitidulidae and Curculionidae, and the flowers often function as breeding-place for these beetles. The latter is also the case for Thysanoptera which may also play a role in pollination. Gottsberger (1970) mentioned beetle visits to the flowers of e.g. Annona spp., Asimina, Canangium, Drepananthus, Xylopia, Goniothalamus and Anaxagorea. Flies also may act as pollinators: Drosophila sp. has been observed in the bore holes of small beetles in the fleshy petals of a flower of Annona crassiflora, and flies of the families Anthomyzidae, Cordyluridae, Muscidae, Sarcophagidae, Syrphidae and Tachinidae visited the flowers of Asimina trilobata (more or less sapro-entomophily). Uphof (1933) mentioned flies visiting the flowers of Asimina speciosa and $A$ pygmaea. In the Maestrichtian Annonaceae mainly beetle pollination will have occurred. The fly families mentioned visiting Recent Asimina trilobata are of comparatively late origin. Only the Anthomyzidae and Syrphidae are known from the Baltic amber (upper Eocene to lower/middle Oligocene). Although predecessors of the families may have had their impact in pollination of the Annonaceae in the Maestrichtian, it seems that a more exlusive myiophilous pollination system in the Annonaceae is of Tertiary, rather than of Upper Cretaceous, origin.

ILLICIACEAE. Illicium type pollen, may be intermediate between Illiciaceae and Schisandraceae, is known from the Maestrichtian. The Recent Illicium is cantharogamous (Delpino in Knuth, 1898). There seems to be no reason to suppose that the Illiciaceae or their stem-group would have had another pollination system in the Maestrichtian.

SCHISANDRACEAE. Schisandra type pollen, corresponding to the Recent pollen of the most plesiomorphous section Pleiostigma of Schisandra occurs in the Maestrichtian. Recent Schisandraceae are successfully entomogamous and most probably cantharogamous. Although no records of insect visits to the flowers are known, this can be derived from the floral morphology: flowers small, solitary, rarely paired or arrranged in few-flowered inflorescences, unisexual, actinomorphic, hypogynous; perianth parts 5-24; androecium of 480 stamens with short filaments, from only basically to wholly connate in a globular, fleshy mass (next to pollen, probably food for visiting beetles); gynoecium 12-300 separate carpels, unsealed with wet, papillose, decurrent stigmas (possible attractant for insects to the female flowers; the hermaphroditic flowers of the Illiciaceae have dry stigmas); each carpel with 2-5(11) ovules. It is probable that the Schisandraceae in the Maestrichtian had an 
entomophilous pollination system, possibly of a more cantharophilous type. MONIMIACEAE. Pieces of wood are known from the Upper Cretaceous (e.g. Protoatherospermoxylon and Hedycaryoxylon). The earliest pollen is known from the Oligocene. Recent Monimiaceae may be anemogamous (SolmsLaubach in Knuth, 1904), but entomogamy also occurs: Mollinedia and Siparuna (Perkins in Knuth, 1904). The entomogamy may be of a more cantharogamous type, which may be derived from the Recently often occurring perigyny; numerous stamens of which the filaments sometimes bear nectariferous appendages which are considered to be staminodial in origin, presence of more ordinary staminodes between the fertile stamens and the separate carpels (varying from one to many in number), with in each one ovule. The Maestrichtian Monimiaceae may have had a non-specialized cantharophilous pollination system.

LAURACEAE. Laurus, Laurophyllum and Cinnamomum can be considered present in the Upper Cretaceous. The earliest Cinnamomum type pollen is known from the Paleocene. Of the Recent Lauraceae, besides Sassafras (see Cenomanian-Turonian), only for Laurus nobilis observations of insect visits are known. According to Müller (in Knuth, 1904) the perianth parts contain glucose; Schletterer and Alfken (in Knuth, 1899) mentioned higher bees and wasps as flower visitors. The pollination system may be somewhat more specialized than that of Sassafras, but still can be included in the non-specialized entomophilous type. The Maestrichtian Lauraceae can be considered nonspecialized entomogamous.

HAMAMELIDACEAE. Macrofossils of Hamamelis and Fothergilla are known from the Upper Cretaceous. Of both the earliest pollen types occur in the Pliocene. Recent Hamamelis virginiana may have a facultative entomophilous/anemophilous pollination system (Meehan in Knuth, 1904). Graenicher (in Knuth, 1904) observed nine species of Syrphidae visiting the flowers. The facultative anemogamy of Hamamelis may have developed late (see first appearance of the pollen). Maestrichtian specializations to Syrphidae as pollinators do not seem very probable (first Syrphidae known from the upper Eocene to lower/middle Oligocene). Myiogamy, however, may have been present in the Maestrichtian Hamamelidaceae, possibly including representatives of the stem group of the Platypezidea + Syrphidea + Schizophora (see fig. 5-20), at any rate including the possible longerrostrate flies mentioned under the Upper Cretaceous.

ULMACEAE. Abundant Ulmus type pollen and the absence of macrofossils indicates further differentiation of anemogamy in the Maestrichtian Ulmaceae, already present in the Cenomanian-Turonian.

BETULACEAE. The appearance of Corylus pollen in the Maestrichtian indicates further differentiation of betulacean anemogamy.

AMARANTHACEAE/CHENOPODIACEAE. Polyporina cribraria may 
represent the Amaranthaceae as well as the Chenopodiaceae in the Maestrichtian. This pollen, then, may represent a complex of bee, fly, wind and possibly beetle pollination. Because no macrofossils are known from these families and pollen is continuously known from the Maestrichtian to the upper Miocene, wind may have played a considerable role in the pollination from the Maestrichtian onwards. The Recent insect pollination found in Amaranthus spinosus, Cladothrix cryptantha (both visited by oligolectic bees, see Knuth, 1904), Salsola and Chenopodium (sometimes nectar-producing) (Knuth, 1899) may also indicate Maestrichtian entomogamy in which mainly flies and possible early Apoidea or their direct predecessors were involved (some nectar production in the Recent Amaranthaceae and Chenopodiaceae and up to many ovules per carpel in the Celosieae). Some impact of beetle-visiting may be derived from the perigyny in the Recent Beta.

ERICACEAE/ERICALES. The Ericipites type pollen from the Maestrichtian may represent Ericaceae, Empetraceae, Epacridaceae and some Clethraceae. The Recent representatives of these families are mainly pollinated by bees and to some degree also by flies. For the Maestrichtian this may mean (in contrast to the Cenomanian-Turonian) that possibly an early type of more obligatory bee pollination has been derived from a more myiophilous one (in its turn derived from a non-specialized entomophilous one).

CLETHRACEAE. Clethra type pollen in the Maestrichtian may represent possible, early, more obligatory, bee pollination. Recent Clethra is almost exclusively visited by Apis mellifera (Barnes in Knuth, 1905).

SYMPLOCACEAE. Symplocos type pollen represents the family in the Maestrichtian; the earliest macrofossils (fruits) are kown from the lower Eocene. Recent Symplocaceae are entomogamous of a non-specialized type with easily available nectar (if present) and the Recent epi- and perigyny indicate the influence of beetle visitors in the Symplocaceae or their predecessors. This generally entomophilous pollination system may have existed already in the Maestrichtian.

MALVACEAE. Possible malvaceous wood remains Hibiscoxylon niloticum are known from the Upper Cretaceous, other macrofossils and Hibiscus type pollen are known from the Eocene. Recent Malvaceae are often ornithogamous. In the Maestrichtian they or their predecessors may have been more specialized to longer-tongued insects, although a non-specialized entomophilous pollination system may have existed as well, including flowervisiting by beetles as the Recent sometimes staminodial outer stamens may indicate. The longer-tongued insects pollinating the Maestrichtian Malvaceae or their predecessors may have been early Apoidea or their predecessors and, more probably, early apomorphous Lepidoptera, rather than longer-rostrate 
Diptera. Obligatory melittogamy and psychogamy may have developed in the Tertiary.

FABACEAE/CAESALPINIOIDEAE. The presence of Sindora type pollen in the Maestrichtian definitely confirms the presence of the Caesalpinioideae. For the flower-ecological implications see the Cenomanian-Turonian.

ONAGRACEAE. The Epilobium type pollen confirms the presence of the Onagraceae in the Maestrichtian. This type of pollen is found in the Recent Boisduvallia, Chamaenerium, Circaea, Clarkia, Epilobium p.p., Fuchsia p.p., Hauya, Ludwigia (incl. Jussieua), Oenothera p.p. and Zauscheria. Recent Boisduvallia cleistogama is first cleistogamous and later small, pink to purple flowers appear, possibly pollinated by bees or flies. Circaea lutetiana is mainly visited and pollinated by longer-rostrate flies (Robertson in Knuth, 1904; Knuth, 1898). Epilobium can be considered to some degree non-specialized entomogamous, but, because of the entirely concealed nectar, specialized to longer-tongued insects (mostly Apoidea and Lepidoptera and only some Diptera) (the flowerecology of many species is described in Knuth, 1898). Fuchsia is mainly ornithogamous (hummingbirds) but pollination by bumblebees also occurs, as in $F$. macrostemma (Johow in Knuth, 1904) and $F$. sp. (Schneider in Knuth, 1898). Ludwigia is mainly pollinated by long-tongued Apoidea as in L. alternifolia (Robertson in Knuth, 1904). Oenothera is sphingogamous (many species described in Knuth, 1898 and 1904). Of Clarkia, Hauya and Zauscheria no pollination systems are known. The flowers represented by the Epilobium type pollen in the Maestrichtian may have been pollinated by longer-tongued insects. A pollination system as occurs in the Recent Boiduvallia, Circea and Epilobium is most probable for that period. Pollination systems as in Fuchsia, Ludwigia and Oenothera may have existed in a prephase in the early Tertiary. This possibly was a kind of myiogamy, because of the later development of sphingophilous flowers.

CORIARIACEAE. Pending Coriaria-like pollen may indicate the presence of this family or its predecessors in the Maestrichtian. Recent Coriaria is anemogamous (Thomson in Knuth, 1904). Maestrichtian Coriariaceae or their predecessors may have had the same pollination system.

BATACEAE. A pending possible Bataceae type pollen may indicate the presence of this family in the Maestrichtian. Of the Recent Bataceae no flowerecological records are known. The floral morphology is as follows: monoecious or dioecious with very reduced flowers in strobiloid spikes (in the monoecious Batis argillocola male and female flowers intermingle in the same spike); staminate flowers initially enclosed in a membranous saccate organ which opens near the top, four very small tepals and four stamens with distinct filaments; pistillate flowers without perianth, composed essentially of a naked, bicarpellate but four-loculed ovary with two sessile stigmas, each locule with a solitary ovule. This morphology indicates anemogamy (except for the form 
of the stigmas). The occurrence of pollen only (only known from the Maestrichtian) may indicate anemogamy in that period. The densely granular infratectal structure of the pollen may indicate a smooth exine surface, which may support anemophily, but then probably derived from entomophilous granular pollen. Also the mixture of male and female flowers in the same spike may indicate a protandrous entomophilous phase.

LINACEAE (incl. Ctenolophonaceae). Ctenolophon engleri type pollen is known from the Maestrichtian and $C$. parvifolius type pollen occurs in the Paleocene. Of the Recent Ctenolophon no observations of pollination are known. The floral morphology indicates entomophily in which longer-tongued insects are involved: distinct convolute petals and an extrastaminal well-developed nectary disk, filaments of stamens connate over much of their length and forming a tube. In the Maestrichtian the possible pollinators were Diptera, early Apoidea and Lepidoptera or their direct predecessors.

NYSSACEAE. Pending Nyssa type pollen is known from the Maestrichtian and it is definitely present in the Paleocene. Of Recent Nyssaceae no pollination systems are known. The floral morphology indicates entomophily: small flowers arranged in various inflorescences, to solitary flowers, staminate, hermaphroditic or functionally pistillate; a well-developed nectary disk present in all flowers; functionally inferior ovary with one locule containing one ovule. Non-specialized entomogamy, possibly including many short-tongued insects may have existed in the Maestrichtian. Whether there may be question of some anemogamy cannot be said. It may be possible that some pollen is dispersed by wind (Cohen (1975) has found 7-15\% Nyssa pollen in Recent Nyssa peat), but it may also be possible that the flowers produce great quantities of pollen and grow in habitats favourable for fossilization.

APIACEAE. Uncertain Apiaceae-like fruits are described from the Upper Cretaceous, more certain Peucedanites nordenskioldi is known from the Paleocene and the earliest Hydrocotyle type pollen is described from the lower Eocene. It is possible that the Apiaceae or their predecessors were non-specialized entomogamous (flowers with exposed nectar). The epigyny will have been caused by intensive beetle visits in the development of the family itself or in its predecessors.

CELASTRACEAE. A possible celastraceous wood Celastroxylon celastroides is known from the upper Cretaceous. Of Recent Celastraceae the flowers of Euonymus have open to half-concealed nectar and Diptera are the main pollinators (Knuth, 1898, and Robertson in Knuth, 1904). In some species also many species of wasps (mainly Chrysididae) visit the flowers (Euonymus japonicus and $E$. variegatus, see Kohl in Knuth, 1898). Both Diptera and wasps may have played a role in the pollination of possible Celastraceae or their predecessors in the Maestrichtian.

OLEACEAE. Anacolosa type pollen indicate that the Oleaceae were 
definitely present in the Maestrichtian. It is possible that in comparison with the possible Oleaceae or their predecessors in the Campanian the developments towards more obligatory bee-pollinated and possible, early psychophilous flowers had made progress (further diversification can be followed in the Paleocene).

PROTEACEAE. Guevina and Helicia type pollen indicate the definite presence of the Proteaceae in the Upper Cretaceous. The flowers of the Recent Proteaceae are pollinated by birds (e.g. Protea and Leucospermum), insects, mice or small marsupials. The non-insects as pollinators are obviously late developments. As Johnson \& Briggs (in Cronquist, 1981) mentioned, the plesiomorphous Proteaceae were entomogamous of a relatively unspecialized form. However, between this supposed original pollination system and the Recent ornithogamy, myiogamous, psychogamous or even melittogamous phases may have existed, some of which might have had some development in the Maestrichtian.

BUTOMACEAE. Possible butomaceous leaves and cross-sections of rhizomes are known from the Upper Cretaceous. Recent Butomus umbellatus has half-concealed nectar and is pollinated by generally longer-tongued insects (mainly flies and bees and in some cases also Sphecidae). Probably the possible Butomaceae or their predecessors in the Maestrichtian had a non-specialized entomophilous pollination system, somewhat adapted to longer-tongued pollinators.

POSIDONIACEAE, GYMODOCEACEAE, ZOSTERACEAE. Remains of Posidonia, Cymodocea and Zostera are known from the Upper Cretaceous. The Recent representatives of these families are hydrogamous and they most probably were already so in the Maestrichtian.

LILIACEAE. A pending case of Tofieldia type pollen (considered pending for reasons of geographical distribution) is known from the Maestrichtian. Recent Tofieldia has flowers with half-concealed nectar and can be considered non-specialized entomogamous, perhaps with a slight specialization to somewhat longer-tongued insects. This pollination system could already have existed in the Maestrichtian.

AGAVACEAE. Possible Agave-like pollen is known from the Maestrichtian. Pollination at that time may have been carried out by flies, early Apoidea and Lepidoptera or their predecessors.

IRIDACEAE. An Iris type pollen, which may represent several, not closely related, genera of the Iridaceae, is known from the Maestrichtian. Because of the large variability in the floral morphology of the Recent Iridaceae only the basic shape will be considered in reconstructing the earliest possibilities of pollination: hermaphroditic, probably actinomorphic flowers with free petals; three stamens; inferior ovary (very rarely superior), with usually numerous ovules per carpel; possibly a three-lobed style; and nectar production. Bird 
pollination (as in Rigidella) certainly and wind pollination (as in Dierama) almost certainly did not exist in the Maestrichtian. The most probable pollination system in this period is somewhat specialized entmophilous, possibly already to some degree specialized to longer-tongued insects, but the widespread inferior position of the ovaries indicates a non-specialized entomogamous phase in the Maestrichtian Iridaceae or their predecessors in which also insects with short mouth parts (beetles) regularly visited and possibly pollinated the flowers.

RESTIONACEAE. The Restio subverticillatus type pollen indicate the presence of the Restionaceae in the Maestrichtian. Hieronymus in Knuth (1905) concluded that all Recent Restionaceae are anemogamous. Because, however, the Recent female flowers may have a variable number of staminodes, an entomogamous phase in the Restionaceae or their predecessors cannot be excluded. Whether this phase was present in the Maestrichtian cannot be decided, but the absence of macrofossils in the whole fossil record may indicate that the Restionaceae were mainly anemogamous, and it is possible that the entomogamous phase existed already in the pre-Maestrichtian.

ARECACEAE. The appearance in the Maestrichtian of Areca ipot and Acrocomya type pollen indicates further diversification of the Arecaceae and both may include further differentiation of anemogamy and entomogamy. Recent Areca varies from entomogamous to anemogamous. Recent Acrocomya seems entomogamous, because of the fact that the temperature in ripe inflorescences is considerably higher than the ambient air temperature, which may be an attractant to insects.

TYPHACEAE. The possible presence of Typhaceous fossils in the Upper Cretaceous, suggested by some differentiation of the family in the Paleocene, indicate anemogamy in the Maestrichtian.

In the angiosperm differentiation shown in the Maestrichtian, the following new apomorphous states of the transformation series mentioned in section 7.3 may have been established:

- possible earliest psychogamy (13);

-because of the possible early psychogamy, some early function of red-mixed colours in attracting butterflies (40);

- euphily (in cantharogamy) (19).

Note. It is possible that in the late Cretaceous or early Tertiary non-flying mammals were more extensively involved in pollination of some taxa (e.g. Myrtaceae) (see Sussman \& Raven, 1978) than in Recent times, forming one of the bases for the development of some types of later Tertiary chiropterophily. 


\subsubsection{Tertiary}

\section{Paleocene}

In the Angiospermae, differentiation at a higher level decreased in rate but family diversity remained at a fairly high level. The stratigraphical appearance of the genera and some presumed pollen types of species are listed in table 7-3.

Table 7-3. Stratigraphical appearance of angiosperm fossils comparable to extant genera or species in the Paleocene. The families are arranged according to Takhtajan (1980).

Abbreviations: $\mathrm{fp}=$ fossil pollen; $\mathrm{mf}=$ macrofossils; between brackets means that there is question of a pending case.

\section{MONIMIACEAE}

Monimiopsis

DIDYMELACEAE

Didymeles type EUCOMMIACEAE

Eucommia type BETULACEAE

Carpinus type JUGLANDACEAE

Carya type

Platycarya type POLYGONACEAE

Polygonum persicaria type TILIACEAE

Brownlowia type

Tilia type

STERCULIACEAE

Reveesia

CUNONIACEAE

Weinmannia

FABACEAE/CAESALPINIOIDEAE

Crudia type

Maniltoa grandiflora type

FABOIDEAE (PAPILIONOIDEAF)

HALORAGACEAE

Myriophyllum type

MELIACEAE

Carapa type

ANACARDIACEAE

Rhus type $\mathrm{mf}$ fossil flag-shaped flower;

mf entomogamous

fp anemogamous

fp anemogamous

fp anemogamous

$\mathrm{fp}, \mathrm{mf}$ anemogamous

$\mathrm{fp}, \mathrm{mf}$ anemogamous

fp anemogamous/entomogamous

fp cf. entomogamous

fp entomogamous

fp entomogamous with possible tendency to melittogamy

mf entomogamous with possible tendency to melittogamy

fp entomogamous with possible tendency to melittogamy

fp as Crudia type melittophilous

fp anemogamous

mf entomogamous with possible tendency to melittogamy

fp non-specialized entomogamous 


\section{POLYGALACEAE}

Monnina type
NYSSACEAE
Nyssa
ALANGIACEAE
Alangium type
APIACEAE
Peucedanum type
ICACINACEAE
Iodes type
Platea type
OLACACEAE
Olax type
Erythopalum type
APOCYNACEAE
Alyxia type

POTAMOGETONACEAE

Potamogeton type RUPPIACEAE

Ruppia type

RESTIONACEAE/CENTROLEPIDACEAE

Hypolaena laterifolia type

POACEAE

ARECACEAE

Mauritia type

Calamus longisteus type

TYPHACEAE

Typha latifolia type

Sparganium type

LEMNACEAE

Lemna type fp entomogamous with possible

tendency to melittogamy

fp,mf non-specialized entomogamous

(fp) non-specialized entomogamous

$\mathrm{mf}$ non-specialized entomogamous

fp cf. non-specialized entomogamous

fp non-specialized entomogamous

mf entomogamous with possible

tendency to melittogamy

mf ditto

fp entomogamous with possible tendencies to melittogamy and psychogamy

(fp,mf) hydrogamous/cleistogamous

(fp) hydrogamous

$\begin{array}{cl}\mathrm{fp} & \text { anemogamous } \\ \mathrm{fp} & \text { anemogamous } \\ \mathrm{fp} & \text { cf. anemogamous } \\ \mathrm{fp} & \text { entomogamous/anemogamous } \\ \mathrm{fp}, \mathrm{mf} & \text { anemogamous } \\ \mathrm{fp}, \mathrm{mf} & \text { anemogamous } \\ \mathrm{mf} & \text { possible wind, water and animal } \\ & \text { pollination (see Knuth, 1899) }\end{array}$

The possibly main new development in the Angiospermae in the Paleocene is the tendency towards more melittophilous flowers (specialized for pollination by Apoidea or their direct predecessors). This may be the case in the Sterculiaceae represented by the pollen of Reveesia. Although no pollination system of Recent Reveesia is known, the floral morphology and the observations mentioned in Knuth (1904) for the Sterculiaceae indicate Recent melittogamy (in some cases, as e.g. in Lasiopetalum bracteatum flies are also attracted to the flowers). The occasional presence of staminodes (as in e.g. Theobroma cacao) may indicate a phase in which beetles took part in pollination in the development of the Sterculiaceae or their predecessors. In the Paleocene Sterculiaceae some specialization for pollination by Apoidea or their direct predecessors is possible. 
Recent Weinmannia of the entirely zoogamous Cunoniaceae is mainly pollinated by Apoidea; the corolla tube is not very long (ca. $3 \mathrm{~mm}$ ) and this means that many short-tongued Apoidea visit and pollinate the flowers. This pollination system may also have existed in the Paleocene (early, not very longtongued Apoidea or their direct predecessors).

The Caesalpinioideae represented by the Crudia type pollen may have been melittogamous to some degree in the Paleocene. The same can be suggested for the Meliaceae, represented by Carapa type. In the case of Carapa shorttongued Apoidea can also pollinate the flowers (derived from floral morphology summarized for some species in Willemstein, 1975).

Recent Monnina sp. are visited by Apoidea. Most Polygalaceae are pollinated by long-tongued bees. The Paleocene Polygalaceae most probably already had a form of melittogamy, while zygomorphic flowers may have occurred.

The olacaceous Olax and Erythopalum fruits from the Paleocene may represent melittophilous flowers, although also some tendency towards psychogamy may have existed. These suggestions are based on Recent floral morphology, because no pollination systems of the Olacaceae have been described.

Crepet \& Taylor (1985) described a definite flag-shaped flower of Faboideae (Papilionoideae) from Paleocene-Eocene deposits. This type of flower indicates the presence of obligatory melittophily, and of definite zygomorphy in the single flower as pollination unit.

In the angiosperm differentiation exhibited in the Paleocene, the following new apomorphous character states of the transformation series mentioned in section 7.3 may have been established:

-obligatory melittogamy (10);

- more obligatory psychogamy (already mentioned in the Maestrichtian);

-definite earliest zygomorphic solitary flowers (23);

- earliest small tube-shaped flowers (29);

- definite earliest flag-shaped flower (33);

- earliest cryptanthery (42);

-complete concealment of the nectar (48).

\section{Eocene}

Much of the differentiation, already visible in the Paleocene is accelerated in the Eocene. The stratigraphical appearance of genera and presumed pollen types of species are listed in table 7-4. 
Table 7-4. Stratigraphical appearance of angiosperm fossils comparable to extant families, genera or species with their possible pollination system in the Eocene including records of Crepet Dilcher (1977, Crepet \& Daghlian (1980), Jan du Chene et al. (1978) with regard to quantities of pollen grains. The families are arranged according to Takhtajan (1980).

Abbreviations: $\mathrm{fp}=$ fossil pollen; $\mathrm{mf}=$ macrofossil(s); between brackets means that there is question of a pending case.

ANNONACEAE

cf. Xylopia

MYRISTICACEAE

Pycnanthus type

Myristica type

SCHISANDRACEAE

Kadsura

CERATOPHYLLACEAE

cf. Ceratophyllum

NELUMBONACEAE

cf. Nelumbo

MENISPERMACEAE

Menispermum

PAPAVERACEAE

\section{cf. Papaver}

EUPTELEACEAE

BUXACEAE

cf. Stylocetas

ULMACEAE

Zelkowa

MORACEAE

Ficus type

\section{ERICACEAE}

Rhododendron

URTICACEAE

BETULACEAE

Ostrya type

NYCTAGINACEAE

Phaeoptilum type

DILLENIACEAE

cf. Dillenia

cf. Sarauia

OCHNACEAE

Schuurmansia type

THEACEAE

Gordonia axillaris type

CARYOCARACEAE Caryocar

PELLICIERACEAE

Pelliciera

CLUSIACEAE

mf entomogamous, cantharogamous

fp cf. entomogamous

(fp), mf entomogamous, myrmecogamy possible

mf entomogamous, probably cantharogamous

mf hydrogamous

fp entomogamous, possibly cantharogamous

mf non-specialized entomogamous and possibly development of anemogamy

mf non-specialized entomogamous

fp anemogamous

mf anemogamous

mf anemogamous

fp possibly already pollinated by fig wasps or their predecessors (middle Eocene)

mf possibly early melittogamous

$\mathrm{mf}$ cf. anemogamous

fp anemogamous

fp entomogamous, possibly psychogamous

mf non-specialized entomogamous

mf ditto

(fp) cf. non-specialized entomogamous

fp entomogamous with possible specialization for longer-tongued insects

fp entomogamous, possibly psychogamous (in Recent times also chiropterogamous)

fp generally entomogamous with possible specialization for longer-tongued insects 


\section{Kielmeyera type \\ Symphonia globulifera type Clusiaphyllum \\ Guttiferoxylon FLACOURTIACEAE \\ Oncoba type PASSIFLORACEAE \\ Passiflora type CUCURBITACEAE}

CAPPARIDACEAE ACTINIDIACEAE

Actinidia type EPACRIDACEAE

Leucopogon

Epacridicarpum

CYRILLACEAE

Cyrilla

ELAEOCARPACEAE

Echinocarpus

Elaeocarpus

TILIACEAE

Grewia type

Trichospermum type

Triumfetta-Grewia type STERCULIACEAE Sterculia

Buettneria type

Mansonia type

BOMBACACEAE

Catostemma type

MALVACEAE

Hibiscus type

Abutilon

EUPHORBIACEAE

THYMELAEACEAE ESCALLONIACEAE Quintinia type

CRASSULACEAE

cf. Sedum fp non-specialized entomogamous with possible specialization for longertongued insects

fp ditto.

$\mathrm{mf}$ ditto (in Recent times also ornithogamous)

mf ditto

mf melittogamous

mf melittogamous

$\mathrm{mf}$ entomogamous with possible (slight) specialization for longer-tongued insects

mf entomogamous to possibly melittogamous

mf entomogamous

$\mathrm{mf}$ entomogamous, psychogamous

$\mathrm{mf}$ entomogamous

mf entomogamous

mf cf. entomogamous

(mf) entomogamous to slightly specialized for longer-tongued insects

fp cf. entomogamous

fp cf. entomogamous

fp entomogamous

$\mathrm{mf}$ differentiated entomogamy with possible tendencies to myiogamy and melittogamy

$\mathrm{mf}$ ditto

(fp) ditto

fp cf. entomogamous with possible specialization for longer-tongued insects

fp differentiated entomogamy of a possible psychogamous type

mf ditto

mf many representatives in early Tertiary indicate differentiated entomogamy of various types

$\mathrm{mf}$ entomogamous, possibly psychogamous

fp cf. non-specialized entomogamous/ anemogamous

(mf) entomogamous with possibly some specialization for longer-tongued insects 


\section{DROSERACEAE}

\author{
Aldrovanda \\ ROSACEAE \\ Chrysobalanus type
}

\section{fp,mf entomogamous \\ mf non-specialized entomogamous (in Recent times also chiropterogamous and ornithogamous species occur)}

FABACEAE/MIMOSOIDEAE

Pentaclethra macrophylla type

Parkia type

Pseudoprosopis sericeus type

Eomimosoidea type

Calpocalyx type

Adenanthera type

Acacia type

FABACEAE/CAESALPINIOIDEAE

Caesalpinia type

Brachystegia type

Gleditschia type

Ceratonia type

Cassia type

FABACEAE/PAPILIONOIDEAE

LYTHRACEAE

Crena type

MYRTACEAE

Eucalyptus type

COMBRETACEAE

Terminalia type

HALORAGACEAE

Haloragis type

RHIZOPHORACEAE

Rhizophora type

\section{LECYTHIDACEAE}

Barringtonia racemosa type

RUTACEAE

Ptelea type

\section{Phellodendron type \\ Zanthoxylum type \\ Erythrochiton type \\ Fagara type \\ Pilocarpus type \\ SIMARUBACEAE \\ Ailanthus type}

fp ditto

fp ditto

fp ditto

fp ditto

fp ditto

fp ditto

\section{fp differentiated melittogamy/psychogamy}

$\begin{array}{cc}\mathbf{f p} & \text { ditto } \\ \mathbf{f p} & \text { ditto } \\ \mathbf{m f} & \text { ditto } \\ \mathrm{mf} & \text { ditto } \\ \mathrm{mf} & \text { ditto }\end{array}$

fp melittogamous

fp entomogamous with possible tendency to melittogamy

(fp) entomogamous with possible specialization for longer-tongued insects

fp,mf entomogamous with possible specialization for longer-tongued insects

fp,mf anemogamous

fp entomogamous with possible specialization for longer-tongued insects

fp psychogamous and possibly early phalaenogamous (in Recent times also

(fp), mf differentiated entomogamy with possible, slight specialization for longertongued insects

$\mathrm{mf}$ ditto

$\mathrm{mf}$ ditto

$\mathrm{mf}$ ditto

$\mathrm{mf}$ ditto

$\mathrm{mf}$ ditto

fp entomogamous chiropterogamous) 


\section{Suriana type MELIACEAE}

Toona type BURSERACEAE

Bursera type SAPINDACEAE

Cardiospermum type

Diplopeltis type

Thoninia type

SABIACEAE

Meliosma

LINACEAE

Linum type

HOUMIRIACEAE

Vantanea type

Sacoglossis

MALPIGHIACEAE

Banisteria

Brachypteris type

POLYGALACEAE

Securidaca bombacopsis type

ALANGIACEAE

Alangium

\section{CORNAGEAE}

Mastixia type

APIACEAE

Hydrocotyle type

Bupleurum type

Pleurospermum type

Echinophora type

Hohenhackeria type

ICACINACEAE

Sachyanthus type

CELASTRACEAE

Euonymus

Celastrus type

Elaeodendron type

Maytenus type

LORANTHACEAE

Loranthus elegans type

Arceuthobium type

Amylotheca type

VISCACEAE

Viscum type mf cf. entomogamous

mf entomogamous

fp,mf non-specialized entomogamous

(fp) entomogamous

fp ditto

(fp) ditto

$\mathrm{mf}$ non-specialized entomogamous, possibly cantharogamous

(fp) non-specialized entomogamous with possible tendency to specialization for longer-tongued insects

mf non-specialized entomogamous

$\mathrm{mf}$ ditto

mf entomogamous, cf. melittogamous

fp cf. entomogamous

fp entomogamous, possibly with some tendency to melittogamy

$\mathrm{fp}, \mathrm{mf}$ entomogamous, possibly with some specialization for longer-tongued insects

$\mathrm{mf}$ entomogamous, probably of a general type

fp differentiated unspecialized entomogamy

fp ditto

fp ditto

fp ditto

fp ditto

fp entomogamous/anemogamous

$\mathrm{mf}$ non-specialized entomogamous with possible tendency to myiogamy

mf ditto

mf cf. entornogamous

$\mathrm{mf}$ ditto

fp psychogamous/cf. phalaenogamous (in Recent times also ornithogamous)

fp cf. myiogamous/psychogamous

fp ditto

mf myiogamous 


\section{VITACEAE}

\section{Vitis}

\author{
Ampelopsis \\ Tetrastigma \\ Cissus \\ Parthenocissus \\ ELAEAGNACEAE \\ Elaeagnus type \\ LOGANIACEAE \\ cf. Strychnos \\ RUBIACEAE \\ Gardenia type \\ Randia type \\ Chomelia type \\ cf. Cephalanthus
}

APOCYNACEAE

Rauwolfia type

CONVOLVULACEAE

Merremia macrocalyx type

Porana

BORAGINACEAE

VERBENACEAE

cf. Vitex

cf. Petraea

Avicennia type

SOLANACEAE

BIGNONIACEAE

Dolichandrone type

HIPPURIDACEAE HYDROCHARITACEAE

Stratiotes type

NAJADACEAE

LILIACEAE

Astelia

PHORMIACEAE

Phormium type

PONTEDERIACEAE

Eichhorria type

CYPERACEAE

Carex type

Scirpus type

ARECACEAE

Iriartea type

CYCLANTHACEAE

cf Cyclanthus or Carludovica mf differentiated entomogamous, possibly with some specialization for somewhat longer-tongued insects

mf ditto

$\mathrm{mf}$ ditto

mf ditto

mf ditto

fp melittogamous

mf cf. myiogamous/psychogamous

fp differentiated psychogamy/cf.

phalaenogamy

(fp) ditto

fp ditto

mf ditto

many other leaf genera from ditto, including non-specialized ento-

the Eocene onwards mogamy

fp entomogamous, possibly specialized for longer-tongued insects

fp entomogamous, possibly specialized for longer-tongued insects

$\mathrm{mf}$ ditto

mf cf. psychogamous/melittogamous

$\mathrm{mf}$ psychogamous/melittogamous

$\mathrm{mf}$ ibid.

(fp) entomogamous

$\mathrm{mf}$ entomogamous

fp entomogamous, possibly already specialized for longer-tongued insects

$\mathrm{mf}$ entomogamous/anemogamous

mf entomogamous, possibly already specialized for longer-tongued insects

mf hydrogamous

fp myiogamous

fp cf. psychogamous (in Recent times also ornithogamous)

mf cf. melittogamous

fp,mf anemogamous

fp, $m$ ditto

fp possibly entomogamous

mf cantharogamous 
The possible main new development in the Eocene is the definite establishment of psychogamy. Whether also phalaenogamy occured already cannot be established, but the fossil record of the Lepidoptera (table 5-3) suggests a later Tertiary origin. Many new genera of which the Recent representatives are psychogamous appear in the Eocene. They appear in unrelated taxa which indicates that the specialization for longer-tongued insects was completed in different ways and that the specialization to long-haustellate higher Lepidoptera was definitely established in the lower Eocene in the Caryophyllales (Phaeoptilum), Ericales (Leucopogon), Myrtales (Barringtonia) and Santalales (Loranthaceae). In the middle and upper Eocene differentiation of psychogamy can be traced: Malvales (Malvaceae); Santalales (further differentiation in the Loranthaceae) and Rubiales (Rubiaceae). The differentiation of the psychogamy indicates the presence of trumpet-shaped flowers (e.g. in Rubiaceae) and to some degree longer tube-shaped flowers.

The establishment and differentiation of melittogamy is illustrated by many genera. Whether, however, this development was already accompanied by the development of gullet-shaped flowers is questionable. Because of the specialization for strong higher bees (forcing their way into the flower) the origin of this flower type will be of a later date in the Tertiary.

The appearance of the Capparidaceae, here more certain than in the Cenomanian (see section 7.3), may indicate that the stiped ovaries were already present (the stiped ovaries can be considered an adaptation against injury by visiting beetles or other mandibulate insects).

The definite presence of Malpighiaceae (Banisteria and Brachypteris) may indicate the earliest oil-producing flowers. This would mean that Vogel (1974) is correct in estimating the time of origin of oil-producing flowers to be in the older Tertiary: Brachypteris type pollen is known from slightly earlier than the middle Eocene (Muller, 1981).

If Ficus in the Eocene was already pollinated by fig wasps, then a form of euphilic flowers or inflorescences may have been present, possibly already of a more specialized kind.

In the angiosperm differentiation traced in the Eocene the following new apomorphies of the transformation series mentioned in section 7.3 may have been established:

- genuine melittogamy (already mentioned in the Paleocene);

-obligatory psychogamy (already mentioned in the Maestrichtian end Paleocene);

-euphilic inflorescences in wasp pollination (19), perhaps already somewhat further specialized (20);

-trumpet-shaped flowers (30);

- stiped ovaries (45);

-possible earliest oil-producing flowers. 


\section{Oligocene}

Differentiation of new lower angiosperm taxa is about the same as in the Eocene. The stratigraphical appearance of the genera and presumed pollen types of species are listed in table 7-5.

Table 7-5. Stratigraphical appearance of angiosperm fossils comparable to extant families, genera or species with their possible pollination system in the Oligocene. This includes records of Daghlian et al. (1980), Frederiksen (1973) with regard to quantities of pollen grains. The families are arranged according to Takhtajan (1980).

Abbreviations: $\mathrm{fp}=$ fossil pollen; $\mathrm{mf}=$ macrofossil(s); between brackets means that there is question of a pending case.

\section{CANELLACEAE}

\section{Pleodendron \\ MONIMIACEAE \\ Laurelia type \\ LAURACEAE \\ Lindera}

BERBERIDACEAE

Berberis type

\section{Mahonia \\ Odostemon \\ RANUNCULACEAE \\ Clematis}

\section{Ranunculus \\ ULMACEAE \\ Pteroceltis \\ FAGACEAE \\ Quercus type \\ NYCTAGINACEAE \\ Mirabilis type \\ THEACEAE \\ Stewartia \\ Eurya \\ Gordonia lasianthus type PENTAPHYLLACEAE Pentaphylax}

MARCGRAVIACEAE Marcgravia/Norantea type (fp) entomogamous

fp, mf entomogamous

mf flowers in Baltic amber: nonspecialized entomogamous

mf entomogamous, with some specialization for longer-tongued insects

$(\mathrm{mf})$ ditto

(mf) ditto

mf entomogamous, with some specialization for longer-tongued insects (in Recent times also ornithogamous; possible prephase)

mf ditto

$\mathrm{mf}$ cf. anemogamous

fp,mf anemogamous

fp possibly psychogamous/ phalaenogamous (sphingogamous)

mf entomogamous with possible specialization for longer-tongued insects

mf ditto

fp ditto

$\mathrm{mf}$ flower in Baltic amber: entomogamous, possibly with some specialization for somewhat longer-tongued insects

fp cf. psychogamous/phalaenogamous (in Recent times chiropterogamy and ornithogamy occur; possible prephase) 
Table 7-5 continued

CLUSIACEAE

Pentadesma butyracea type

FLACOURTIACEAE

Casearia type

\section{VIOLACEAE}

Corynostylis type

\section{CUCURBITACEAE}

Sicyos type

\section{ERICACEAE}

\section{Vaccinium}

SAPOTACEAE

\section{Sideroxylon}

\section{Dipholis \\ Sapocites}

MYRSINACEAE

Myrsinopsis

\section{Berendtia}

Pleiomeropsis

Suttonia type

DIPTEROGARPACEAE

Dipterocarpus

Monotes type

BOMBACACEAE

Durio type

Cullenia type

Bombax

EUPHORBIACEAE

Antidesma

Statzia

THYMELAEACEAE

Gonystylus type

BRUNELLIACEAE

\section{Brunellia type}

HYDRANGEAGEAE

Stephanostemon

\section{Adenanthemum}

Deutzia fp cf. entomogamous with possible specialization for longer-tongued insects

fp pollen type occurs in several genera of the family: $c f$. melittogamous

(fp) cf. melittogamous, possibly psychogamous

fp pollen type occurs in Sicyos and Sechium: non-specialized entomogamous

mf melittogamous

mf fossil flowers: non-specialized entomogamous

$\mathrm{mf}$ ditto

mf ditto

$\mathrm{mf}$ flowers in Baltic amber: non specialized entomogamous to anemogamous

mf ditto

$\mathrm{mf}$ fossil flowers: anemogamous/entomogamous

fp anemogamous

fp non-specialized entomogamous

mf entomogamous

fp entomogamous, psychogamous (in Recent times ornithogamous and chiropterogamous; possible prephase)

fp ditto

mf ditto

$\mathrm{mf}$ flower in Baltic amber: entomogamous

$\mathrm{mf}$ fossil flower: entomogamous

fp entomogamous, specialized for longer-tongued insects

(fp) cf. anemogamous

mf flowers in Baltic amber: entomogamous, specialized for longer-tongued insects

$\mathrm{mf}$ ditto

mf anther in Baltic amber: as preceding 


\section{ROSACEAE}

Spiraea

Sibiraea

Quillaja

Crataegus

Pyrus

Cotoneaster

Cydonia

Amelanchier

Rhaphiolepis

Rubus

Prunus

Amygdalus

CHRYSOBALANACEAE

Parastemon type

FABACEAE/MIMOSOIDEAE

Fillaeopsis type

Amblygonocarpus type

Prosopis juliflora type

Leucaena type

Albizia type

Inga type

FABACEAE/CAESALPINIOIDEAE

Tamarindus type FABACEAE/PAPILIONOIDEAE

Caragana

Pterocarpus

CONNARACEAE

Rourea type

PODOSTEMACEAE SONNERATIACEAE/ LYTHRACEAE

PUNICACEAE

ONAGRACEAE

Hauya

Boisduvallia mf non-specialized entomogamous (incl. of somewhat longer-tongued insects)

$\mathrm{mf}$ ditto

$\mathrm{mf}$ fossil flower: ditto, some tendency to melittogamy

mf non-specialized entomogamous with tendency to (sapro)myiogamy

mf entomogamous with some specialization for longer-tongued insects

$\mathrm{mf}$ non-specialized entomogamous with tendency to specialized wasp pollination

$\mathrm{mf}$ entomogamous (incl. of longertongued insects)

mf ditto

mf cf. entomogamous

mf entomogamous (incl. of longertongued insects)

$\mathrm{mf}$ ditto

$\mathrm{mf}$ entomogamous, more specialized for longer-tongued insects

fp entomogamous, possibly specialized for longer-tongued insects

fp further differentiation of melittogamy/psychogamy

fp ditto

fp ditto

fp ditto

fp ditto

mf ditto

$\mathrm{mf}$ cf. melittogamous

mf melittogamous

$\mathrm{mf}$ ditto

mf flower in Baltic amber: non-

specialized entomogamous

mf cf. non-specialized entomogamous

$\mathrm{fp}$, mf entomogamous

(mf) entomogamous, specialized for longer-tongued insects (in Recent times also ornithogamous; possible pre-phase)

fp specialized for longer-tongued insects, mainly bees and bumblebees (in Recent times also sphingogamous) fp ditto 
Table 7-5 continued

\section{Fuchsia type}

Jussieua champlainensis type TRAPACEAE

Trapa

RUTACEAE

Zanthoxylum ZYGOPHYLLACEAE

Zygophyllum

Guaiacum

Porliera

BALANITACEAE

Balanites

MELIACEAE

cf. Trichilio

Guarea

ANACARDIACEAE

Campnosperma type

Pistacia

Parishia

SAPINDACEAE

Koelreutia

HIPPOCASTANEACEAE

Aesculus type

ERYTHROXYLACEAE

Erythroxylum

OXALIDACEAE

Oxalis type

GERANIACEAE

Geranium

Erodium

VOCHYSIACEAE

cf. Vochysia

APIACEAE

Chaerophyllum

CELASTRACEAE

Microtropis type

Peritassa type

Campylostemon type

Hippocratea type SANTALACEAE

Osyris

\section{RUBIACEAE}

Faramea

Mitragyne type

Macrosphyra

ASCLEPIADACEAE

Tacazzia type fp ditto (in Recent times also ornigamous)

fp ditto

mf entomogamous

(fp) non-specialized entomogamous

mf non-specialized entomogamous

mf cf. non-specialized entomogamous

mf ditto

mf cf. non-specialized entomogamous

fp entomogamous

fp ditto

fp cf. non-specialized entomogamous

mf ditto

mf ditto

mf entomogamous

(fp) melittogamous

mf non-specialized entomogamous, to some extent specialized for longertongued insects

(fp), mf entomogamous, specialized for longer-tongued insects

mf pollinated by longer-tongued insects to melittogamous

mf ditto

mf cf. melittogamous

mf non-specialized entomogamous

fp cf. entomogamous

fp ditto

fp ditto

fp ditto

$\mathrm{mf}$ flower remain in Baltic amber: non-specialized entomogamous

fp cf. non-specialized entomogamous to psychogamous

fp ditto

$\mathrm{mf}$ ditto

$\mathrm{mf}$ flower: entomogamous

fp entomogamous 


\section{OLEACEAE}

Olea type

CAPRIFOLIACEAE

Lonicera type

BORAGINACEAE

Tournefortia bicolor type

LAMIACEAE

Ajuginicula smithi

SOLANACEAE

Solanites

\section{BIGNONIACEAE}

cf. Catalpa

ACANTHACEAE

Acanthus

GOODENIACEAE

Scaevola type

ASTERACEAE

Tubiflorae type

ALISMATACEAE

Alisma

Sagittaria

HYDROCHARITACEAE

Hydrocharis

DRACAENACEAE

cf. Dracaena

JUNCACEAE

Juncus

Luzula

ZINGIBERACEAE

ARECACEAE

Oncosperma type

Chamaerops

Sabal

PANDANACEAE

cf. Freycinetia fp entomogamous

fp psychogamous/melittogamous

fp entomogamous, specialized for longer-tongued insects, probably Lepidoptera

mf melittogamous, possible gulletshaped flowers

mf fossil inflorescence: entomogamous, specialized for longer-tongued insects

mf melittogamous

mf melittogamous

fp melittogamous/psychogamous

fp entomogamous, specialized for longer-tongued insects

mf myiogamous

$\mathrm{mf}$ mainly myiogamous

mf fossil inflorescence: entomogamous, specialized for longer-tongued insects

mf cf. psychogamous/phalaenogamous

mf anemogamous, or still entomogamous

$\mathrm{mf}$ ditto

mf melittogamous/psychogamous

fp cf. anemogamous

mf anemogamous

mf entomogamous

mf entomogamous (in Recent times also ornithogamous and chiropterogamous; prephases possible)

The main development is the established differentiation of melittophilous flowers, accompanied by the establishment of the earliest probably faintly gullet-shaped flowers. Specialization from melittogamy to real bumblebee flowers may have developed during the Oligocene. Prephases of both ornithogamy and chiropterogamy may have been present. A possibly new 
development is the adaptation of flowers to larger nocturnal and crepuscular pollinators, in this period resulting in phalaenophilous and possibly already sphingophilous flowers.

In the angiosperm differentiation traced in the Oligocene the following new apomorphies of the transformation series mentioned in section 7.3 may have been established:

- specialized melittogamy, possibly already euphilic bumblebee flowers (19);

- possible early, faintly gullet-shaped flowers $(31,32)$;

- phalaenogamy (12), possibly already sphingogamy;

- prephases of ornithogamy and chiropterogamy (15-17).

\section{Miocene}

The differentiation indicated by the angiosperm fossils in the Miocene is of about the same rate as in the Oligocene and Eocene. The stratigraphical appearance of genera and presumed pollen types of species are listed in table 7-6.

Table 7-6. Stratigraphical appearance of angiosperm fossils comparable to extant families, genera or species with their possible pollination system in the Miocene. The families are arranged according to Takhtajan (1980).

Abbreviations: $\mathrm{fp}$ - fossil pollen; $\mathrm{mf}=$ macrofossil(s); between brackets means that there is question of a pending case.

ANNONACEAE

Miliusa type

HERNANDIACEAE

Gyrocarpus

RANUNCULACEAE

Thalictrum type

Batrachium

HAMAMELIDACEAE

Parrotia type

BUXACEAE

Buxus type

LEITNERIACEAE

Leitneria type

PORTULACACEAE

Portulaca type

CHENOPODIACEAE

Sarcobatus type

POLYGONACEAE

Polygonum californicum type fp entomogamous, cf. cantharogamous

mf cf. entomogamous

fp entomogamous/anemogamous

mf entomogamous with some specialization

for longer-tongued insects

fp cf. entomogamous

fp entomogamous/anemogamous

$\mathrm{mf}$ anemogamous

fp pollen type occurs in the Recent

Portulaca, Neopaxia, Montia,

Talinella, Talinum: non-

specialized entomogamous

fp cf. entomogamous

fp entomogamous (anemogamy cannot be excluded) 
Coccoloba
Rumex

\section{PLUMBAGINACEAE}

Aegialitis type

Armeria type

\section{CLUSIACEAE}

Calophyllum type

CISTACEAE

Helianthemum

BRASSICACEAE

"Cruciferae" type

ERICACEAE

Arctostaphylos type

cf. Arbutus

cf. Ledum

cf. Menziesa

cf. Gaylussacia

STYRACACEAE

Halesia

Durania

Styrax

PRIMULACEAE

Samolus valerandi type STERCULIACEAE

Pterospermum type

Fremontia

Kleinhovia

DIPTEROCARPACEAE

Shorea albida type BOMBACACEAE

Rhodognaphalon type

Camptostemon type

DICHAPETALACEAE

Tapura ivorense type

Dichapetalum barteri type

THYMELAEACEAE

Phaleria type

DROSERACEAE

Drosera

Dionaea

FABACEAE/MIMOSOIDEAE

Desmanthus type

FABACEAE/CAESALPINIOIDEAE

Eperua type

Cercis

$\mathrm{mf}$

fp cf. entomogamous

fp anemogamous (entomogamy cannot be excluded)

fp entomogamous

fp entomogamous, specialized for longer-tongued insects

fp entomogamous

fp non-specialized entomogamous

fp entomogamous

mf melittogamous

$\mathrm{mf}$ melittogamous

mf entomogamous, possibly more specialized for longer-tongued insects

$\mathrm{mf}$ entomogamous

mf non-specialized entomogamous

mf entomogamous, specialized for longer-

tongued insects

$\mathrm{mf}$ ditto

mf ditto

fp non-specialized entomogamous

fp psychogamous/phalaenogamous

fp non-specialized entomogamous

(fp) ditto

fp entomogamous

fp entomogamous, cf. specialized for longer-tongued insects

fp ditto

fp entomogamous

fp ditto

fp psychogamous

fp entomogamous

fp ditto

fp entomogamous, specialized for longertongued insects

fp entomogamous, specialized for longertongued insects (possibly chiropterogamy) non-specialized entomogamous 
Table 7-6 continued

\begin{tabular}{|c|c|c|}
\hline Hymenaea type & fp & $\begin{array}{l}\text { entomogamous, somewhat specialized for } \\
\text { longer-tongued insects }\end{array}$ \\
\hline FABACEAE/PAPILION & DEAE & \\
\hline $\begin{array}{l}\text { cf. Vigna } \\
\text { CONNARACEAE }\end{array}$ & fp & melittogamous \\
\hline Cnestis type & mf & entomogamous \\
\hline $\begin{array}{l}\text { Connarus type } \\
\text { NEPENTHACEAE }\end{array}$ & $\mathrm{mf}$ & ditto \\
\hline $\begin{array}{l}\text { Nepenthes } \\
\text { CRYPTERONIACEAE }\end{array}$ & fp & entomogamous \\
\hline $\begin{array}{l}\text { Dactylocladus type } \\
\text { LYTHRACEAE }\end{array}$ & $\mathrm{fp}$ & cf. anemogamous \\
\hline Cuphea type & $f p$ & $\begin{array}{l}\text { polllinated by longer-tongued insects: } \\
\text { myiogamous, melittogamous, psychogamous }\end{array}$ \\
\hline Lythrum & $\mathbf{f p}$ & ditto \\
\hline $\begin{array}{l}\text { Lagerstroemia type } \\
\text { SONNERATIACEAE }\end{array}$ & $\mathrm{fp}$ & ditto \\
\hline Sonneratia caseolaris & fp & entomogamous \\
\hline $\begin{array}{l}\text { S. alba } \\
\text { COMBRETACEAE }\end{array}$ & fp & ditto \\
\hline Lumnitzera littorea type & fp & entomogamous, possibly ornithogamous \\
\hline $\begin{array}{l}\text { Combretum type } \\
\text { ONAGRACEAE }\end{array}$ & $\mathrm{fp}$ & ditto \\
\hline $\begin{array}{l}\text { Ludwigia } \\
\text { RHIZOPHORACEAE }\end{array}$ & fp & non-specialized entomogamous \\
\hline $\begin{array}{l}\text { Combretocarpus type } \\
\text { LECYTHIDACEAE }\end{array}$ & fp & cf. entomogamous \\
\hline Planchonia type & (fp) & cf phalaenogamous/chiropterogamous \\
\hline Barringtonia type & (fp) & phalaenogamous/chiropterogamous \\
\hline $\begin{array}{l}\text { Gustavia type } \\
\text { MELIACEAE }\end{array}$ & (fp) & cf. ditto \\
\hline $\begin{array}{l}\text { Cedrela type } \\
\text { ANACARDIACEAE }\end{array}$ & $\mathrm{mf}$ & entomogamous \\
\hline $\begin{array}{l}\text { Melanorrhoea beccarii type } \\
\text { SAPINDACEAE }\end{array}$ & fp & cf. entomogamous \\
\hline Prometia & $\mathrm{fp}$ & (cf.) entomogamous \\
\hline Allophylus type & fp & ditto \\
\hline Paullinia type & fp & ditto \\
\hline Serjania & fp & ditto \\
\hline $\begin{array}{l}\text { Nephelium } \\
\text { MALPIGHIACEAE }\end{array}$ & mf & ditto \\
\hline Byrsonima type & fp & $\begin{array}{l}\text { entomogamous, cf. with tendency to } \\
\text { melittogamy }\end{array}$ \\
\hline $\begin{array}{l}\text { POLYGALACEAE } \\
\text { Xanthophyllum } \\
\text { CORNACEAE }\end{array}$ & $\mathrm{fp}$ & entomogamous \\
\hline $\begin{array}{l}\text { Cormus } \\
\text { ARALIACEAE }\end{array}$ & (fp) & non-specialized entomogamous \\
\hline $\begin{array}{l}\text { Acanthopanax } \\
\text { APIACEAE }\end{array}$ & $\mathrm{mf}$ & non-specialized entomogamous \\
\hline Eryngium & $\mathrm{fp}$ & non-specialized entomogamous \\
\hline $\begin{array}{l}\text { Daucus } \\
\text { ICACINACEAE }\end{array}$ & $\mathrm{mf}$ & ditto \\
\hline Stemonurus & fp & non-specialized entomogamous \\
\hline
\end{tabular}


Table 7-6 continued

BALANOPHORACEAE

\section{Balanophora type \\ RUBIACEAE}

Morelia type

Morinda type

Scyphiphora type

Timonius type

Alibertia type

Borreria type

Ixora type

Rubia type

Terebania type

APOCYNACEAE

Alstonia type

Dyera type

Trachomitum type

ASCLEPIADACEAE

Periploca type

OLEACEAE

Phillyrea

CAPRIFOLIACEAE

Sambucus type

VALERIANACEAE

\section{DIPSACACEAE}

Scabiosa type

Dipsacus type

LOASACEAE

Mentzelia

POLEMONIACEAE

Gilia filiformis type

BORAGINACEAE

Cordia subcordata type

Symphytum type

\section{LAMIACEAE}

Salvia

SCROPHULARIACEAE

Pauzlonia

PLANTAGINACEAE

Plantago (several types)

Littorella

LENTIBULARIACEAE

Utricularia minor type ACANTHACEAE

Justicia type

Trichantera type

Asystasia type

Hygrophila type

ASTERACEAE

Liguliflorae type fp entomogamous, cf. myiogamous

fp entomogamous, specialized for longertongued insects

fp ditto

fp ditto

fp ditto

fp ditto

fp ditto

fp ditto

fp non-specialized entomogamous

fp entomogamous

fp entomogamous

fp ditto

fp ditto

fp myiogamous

fp entomogamous

$\mathrm{mf}$ non-specialized entomogamous

(fp) entomogamous, specialized for longertongued insects

fp entomogamous, specialized for longer-

tongued insects

fp ditto

mf myiogamous/melittogamous

fp entomogamous, cf. melittogamous

fp melittogamous/ornithogamous (upper Miocene)

fp melittogamous

fp melittogamous

mf melittogamous

mf entomogamous/anemogamous

$\mathrm{mf}$ cf. anemogamous

fp myiogamous/cf. melittogamous

fp entomogamous, specialized for longertongued insects

fp ditto (possibly chiropterogamous)

fp ditto

fp ditto

fp less specialized entomogamous than Tubiflorae (see Oligocene) 
Table 7-6 continued

\begin{tabular}{|c|c|c|}
\hline $\begin{array}{l}\text { Ambrosia type } \\
\text { Artemisia type } \\
\text { NAJADACEAE }\end{array}$ & $\begin{array}{l}\mathrm{fp} \\
\mathrm{fp}\end{array}$ & $\begin{array}{l}\text { anemogamous } \\
\text { anemogamous, cf entomogamous }\end{array}$ \\
\hline $\begin{array}{l}\text { cf. Naja } \\
\text { LILIACEAE }\end{array}$ & $\mathrm{mf}$ & hydrogamous \\
\hline $\begin{array}{l}\text { Tulipa type } \\
\text { DIOSCOREACEAE }\end{array}$ & fp & non-specialized entomogamous \\
\hline $\begin{array}{l}\text { cf. Rajana type } \\
\text { FLAGELLARIACEAE }\end{array}$ & $\mathrm{fp}$ & cf. anemogamous \\
\hline $\begin{array}{l}\text { Flagellaria type } \\
\text { ARECACEAE }\end{array}$ & $\mathrm{fp}$ & cf. anemogamous \\
\hline Nenga & fp & anemogamous, cf. entomogamous \\
\hline Sclerosperma & $\mathrm{fp}$ & cf. anemogamous \\
\hline Elais & $\mathrm{fp}$ & ditto \\
\hline Eugeissona minor & fp & ditto \\
\hline$E$. insignis type & $\mathrm{fp}$ & ditto \\
\hline Calamis gracilis type & fp & cf. entomogamous \\
\hline Korthalsia rigida type & $\mathrm{fp}$ & cf. anemogamous \\
\hline Arenga & $\mathrm{fp}$ & ditto \\
\hline $\begin{array}{l}\text { Phytelephas } \\
\text { ARACEAE }\end{array}$ & $\mathrm{mf}$ & cf. anemogamous/entomogamous \\
\hline $\begin{array}{l}\text { Spathyphyllum type } \\
\text { Orontium }\end{array}$ & $\begin{array}{l}\mathrm{fp} \\
\mathrm{mf}\end{array}$ & $\begin{array}{l}\text { (sapro-)entomogamous (small insects) } \\
\text { inflorescence: cf. sapro-entomogamous }\end{array}$ \\
\hline
\end{tabular}

The main development in entomogamy in the Miocene is the specialization within the complex of melittogamy leading to the definite gullet-shaped flowers.

Genuine chiropterogamy (including anthophilous bats) may have been established in the Miocene. The Eperua type pollen from the lower Miocene of Guyana may indicate either the presence of chiropterogamous flowers (the Recent $E$. falcata is chiropterogamous) or a floral, possibly phalaenogamous phase, as do Hymenaea, the Barringtonia type and the Trichantera type.

Ornithogamy (including anthophilous birds) may have been developed in the upper Miocene. Possibilities are found in the fossil pollen of the taxonomically unrelated Combretum type, Barringtonia type and Cordia subcordata type and Lumnitzera littorea type.

Spathyphyllum may represent perfume flowers from which visiting male insects obtain perfumes possibly necessary for being accepted by the females for copulation (Dodson \& Frymire, 1961; Vogel, 1966, 1966a, 1966b, 1967; Faegri \& Van der Pijl, 1980).

In the angiosperm differentiation traced in the Miocene, the following new apomorphies of the transformation series mentioned in section 7.3 may have been established:

- definite gullet-shaped flowers $(31,32)$;

-chiropterogamy (17); 
-ornithogamy $(15,16)$;

- possible perfume flowers.

\section{Pliocene}

The fossil record of new angiosperm genera and species does not add new apomorphies of the transformation series mentioned in section 7.3 (see table 7-7).

Table 7-7. Stratigraphical appearance of angiosperm fossils comparable to extant genera and species with their possible pollination system in the Pliocene. The families are arranged after Takhtajan (1980).

Abbreviations: $\mathrm{fp}=$ fossil pollen; $\mathrm{mf}=$ macrofossil(s); between brackets means that there is question of a pending case.

MYRISTICACEAE

Virola type

MENISPERMACEAE

Cocculus

RANUNCULACEAE

Ficaria

MORACEAE

Cercopia type

NYCTAGINACEAE

Abronia type

PORTULACACEAE

Claytonia type

POLYGALACEAE

Calligonum

CISTACEAE

Cistus

CAPPARACEAE

Cralaeva

BRASSICACEAE

Draba venosa

\section{RESEDACEAE}

Reseda

\section{ERICACEAE}

Calluna type

Bruckenthalia type

Pieris

Kalmia

PRIMULACEAE

Lysimachia type

PITTOSPORACEAE

Pittosporum fp entomogamous

mf cf. entomogamous

mf non-specialized entomogamous

fp entomogamous

mf psychogamous

fp non-specialized entomogamous

fp cf. entomogamous

fp entomogamous

fp cf. ornithogamous/chiropterogamous

mf entomogamous, more or less specialized for longer-tongued insects

fp entomogamous, to some degree specialized for longer-tongued insects

fp entomogamous, specialized for longer-tongued insects, mainly melittogamous

fp entomogamous/anemogamous

mf entomogamous, specialized for

longer-tongued insects

mf entomogamous

mf non-specialized entomogamous

fp,mf entomogamous, cf. psychogamous 
Table $7-7$ continued

ROSACEAE

Filipendula type

Sanguisorba officinalis

fp non-specialized entomogamous

fp entomogamous, more or less specialized for longer-tongued insects/ anemogamous

Comarum $\mathrm{mf}$

Potentilla fruticosa $\quad \mathrm{mf}$

entomogamous, specialized for

longer-tongued insects

Prunus laurocerasus

$\mathrm{mf}$

FABACEAE/PAPILIONOIDEAE

Indigofera

Astragalus

LYTHRACEAE

Decodon type

PUNICAGEAE

Punica

fp

non-specialized entomogamous

entomogamous, to some degree specialized for longer-tongued insects

RUTACEAE

cf. Haplophyllum

STAPHYLEACEAE

Staphylea

(fp) psychogamous

mf entomogamous, psychogamous, ornithogamous

fp cf. entomogamous

fp,mf entomogamous, specialized for longer-tongued insects, possibly myiogamous (as in $S$. pinnata)

\section{SAPINDACEAE}

Dodonaeo

HOUMERIACEAE

Humeria type

GERANIACEAE

Pelargonium echinatum type

GARRYACEAE

Garrya masoni

APIACEAE

Ferulago/Opopanax/Petroselinum

Selinum type

Poecedanum moebii

RHAMNACEAE

Frangula type

RUBIACEAE

Canthium type

cf. Galium

GENTIANACEAE

cf. Gentiana

fp anemogamous

fp cf. non-specialized entomogamous

fp psychogamous, sphingogamous, possibly ornithogamous

mf cf. entomogamous, possibly to some degree anemogamous

fp non-specialized entomogamous

fp ditto

mf ditto

fp non-specialized entomogamous

fp entomogamous

fp non-specialized entomogamous

fp non-specialized entomogamous to melittogamous (incl. bumblebee flowers) or psychogamous, or combination of the latter two

cf. Menyanthes

mf entomogamous, specialized for longer-tongued insects

VALERIANACEAE

Valeriana cf. officinalis

mf entomogamous, specialized for

longer-tongued insects 
Table $7-7$ continued

CONVOLVULACEAE

Calystegia type

POLEMONIACEAE

Polemonium type

LAMIACEAE

Mentha type

Melissa elegans

Ajuga antiqua

CALLITRICHACEAE

Callitriche

SOLANACEAE

Physalis

SCROPHULARIACEAE cf. Hebe

PEDALIACEAE

Trapella antennifera type OROBANCHACEAE

Cistanche type

CAMPANULACEAE

Wahlenbergia type

ASTERACEAE

Cirsium type

cf. Taraxacum

SCHEUCHZERIACEAE

Scheuchzeria palustris

LILIACEAE

Androcymbium

Lilium speciosum type

POACEAE

Bambusa fp entomogamous, specialized for longer-tongued insects to psychogamous

fp entomogamous, specialized for longer-tongued insects to melittogamous

fp entomogamous, specialized for

longer-tongued insects

$\mathrm{mf}$ melittogamous

mf ditto

(fp) anemogamous to entomogamous or hydrogamous

$\mathrm{mf}$ entomogamous, specialized for longer-tongued insects, to melittogamous

fp cf. entomogamous, specialized for longer-tongued insects

$\mathrm{mf}$ hydrogamous or hydrocleistogamous

fp melittogamous, cf. bumblebee flowers

(fp) entomogamous, specialized for longer-tongued insects

fp entomogamous, specialized for longtongued insects

mf entomogamous, specialized for longer-tongued insects

$\mathrm{mf} \quad \mathrm{cf}$. anemogamous

fp cf. entomogamous

fp psychogamous

mf anemogamous

\subsubsection{Quaternary}

As in the Pliocene in the Quaternary the fossil record of new angiosperm genera and species also does not add new apomorphies to the transformation series mentioned in section 7.3 (see table 7-8). 
Table 7-8. Stratigraphical appearance of angiosperm macrofossils comparable to extant genera and species and their possible pollination system. The families are arranged after Takhtajan (1980).

ARISTOLOCHIACEAE

Asarum europaeum PHYTOLACCACEAE

Phytolacca americana CACTACEAE

Mamillaria tuberculosa DATISCACEAE

Datisca glomerata FOUQUERIACEAE

Fouqueria splendens ERICACEAE

Erica

\section{EMPETRACEAE}

Empetrum nigrum SAXIFRAGACEAE Saxifraga oppositifolia

ROSACEAE

Dryas octopetala

Prunus padus

BALSAMINACEAE

Impatiens capensis

ELAEAGNACEAE

Hippophae

OLEACEAE

Syringa

POLEMONIACEAE

Phlox cf. sibirica

HYDROPHYLLACEAE

Eriodictyon californicum BORAGINACEAE Myosotis

\section{LAMIACEAE}

Lycopus

Stachys

Teucrium

SCROPHULARIACEAE

Verbascum nigrum

\section{ASTERACEAE}

\section{Senecio}

Inula

Achillea sapromyogamous

non-specialized entomogamous

cf. melittogamous

cf. entomogamous

ornithogamous

variously entomogamous, specialized for longtongued insects (bumblebee flowers, psychogamy) to anemogamous

anemogamous to entomogamous

entomogamous, specialized for longer-tongued insects

entomogamous, specialized for longer-tongued insects

non-specialized entomogamous

melittogamous, hoverfly flowers to possibly ornithogamous

anemogamous

entomogamous, specialized for long-tongued insects

entomogamous, psychogamous

cf. entomogamous

entomogamous, specialized for somewhat longer-tongued insects

entomogamous, specialized for longer-tongued insects

melittogamous

ditto

entomogamous, specialized for longer-tongued insects

non-specialized entomogamous, slightly specialized for longer-tongued insects ditto

ditto 


\subsubsection{Some remarks on the fossil record of the Angiospermae}

The preceding compilations of the fossil record of the Angiospermae clearly demonstrate that the expectation mentioned in the beginning of this section, that fossil pollen mainly represents anemophilous flowers, only has to be considered quantitatively. The totals and ratio's in table 7-9 demonstrate that in qualitative, stratigraphical pollen analysis more types of zoogamous, mainly entomophilous, flowers are found than anemophilous flowers.

Table 7-9. Absolute numbers and ratio's of pollination systems represented by fossil pollen and macrofossils. A: totals; B: fossils found exclusively either as pollen or macroremains.

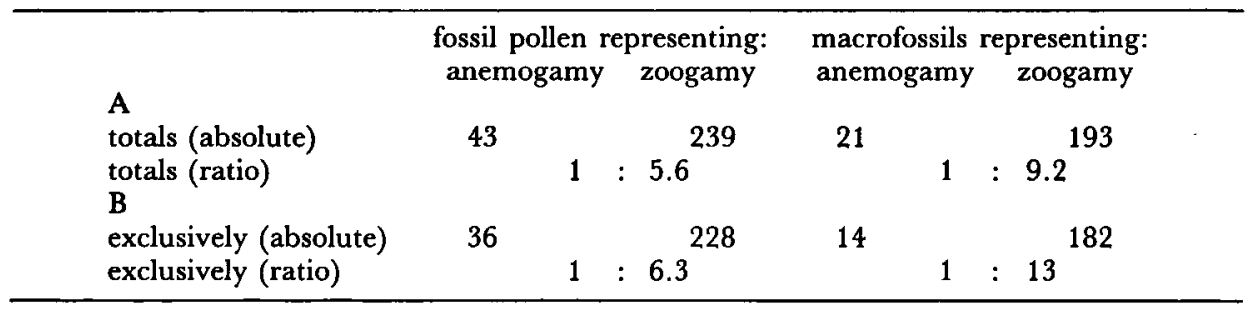

It is correct that fossil pollen representing zoophilous, mainly entomophilous, flowers in quantitative, stratigraphical pollen analysis is rare and that it occurs irregularly in time. Macrofossils more often represent zoophilous, mainly entomophilous, flowers than does fossil pollen (as expected at the beginning of this section).

Comparison of the distribution of anemogamy and entomogamy among the species of the central European flora (table 7-10) with the worldwide angiosperm fossils representing these pollination systems, demonstrates a considerable discrepancy.

Table 7-10. Absolute numbers and ratio of pollination systems in the central European flora.

\begin{tabular}{lclc}
\hline & anemogamous & entomogamous \\
totals absolute & 658 & 2610 \\
ratio & 1 & $:$ & 3.9 \\
\hline
\end{tabular}

This discrepancy may have several causes:

-the distribution of the pollination systems in the world's angiosperm flora differs from that of the central European one;

-morphological differentiation in zoophilous pollen is more extensive than in anemophilous pollen, i.e. taxa of lower rank are more easily identifiable; -zoophilous pollen is more persistent than anemophilous pollen, i.e. it fossilizes better.

The first may be mainly the case. Whitehead (1969) mentioned that anemogamy is the dominant means of pollination in environments such as the 
northern deciduous forests. It is notoriously infrequent in tropical rain forest and becomes progressively more significant with increasing latitude. In this respect Endress (1977) should also be consulted about the predominant position of the Fagales in the vegetation of temperate regions.

It would be interesting to carry out pollen analyses in Recent peats or lakes and compare the results with the angiosperm flora present in the vicinity of these sites particularly with regard to the pollination systems, more or less in the way of the research of Salski (1976a) to the frequency of the species of Lepidoptera of a certain area, caught in the resin of Pinus in that area (about $1 \%$; see section 5.5). Literature of pollen analysis in recent peat is available, but publications providing the complete desired information, however, seem to be rare.

\subsection{Phases in the evolutionary development of angiosperm pollination}

\section{Earliest fossil record}

At the end of the Albian a fair differentiation of angiosperm flowers must have existed. Anemophilous flowers most probably were present and the differentiation of reticulate and otherwise sculptured pollen indicates a taxonomically widespread presence of entomophilous flowers. The presence of anemophilous flowers may have included already unconspicuous flowers and reduction of floral size, perianth, number of stamens and number of ovules per stigma (carpel). The differentiation of entomogamy may have included more obligatory beetle pollination (beetles being the most diversified potential pollinators in the Lower Cretaceous) and some sapro-entomogamy (presence of potential pollinators such as Psychodidae throughout the Cretaceous). Both pollination systems indicate the presence of more hemiphilic flowers or inflorescences. Dish- to bowl-shaped and actinomorphic (and possibly already pleomorphic flowers, in connection with non-specialized entomophily), and brush-shaped flowers or inflorescences probably were present already: the first in connection with beetle pollination and the second at any rate in the flowers or inflorescences both pollinated by wind and indiscriminate insect visitors (as in the Clavatipollenites-Ascarina lineage, see Muller, 1984).

The presence of taxonomically diversified taxa may indicate an early origin of the Angiospermae. Particularly the presence of fossil pollen (already comparable to extant taxa) representing entomophilous flowers indicates that these flowers geographically had a wide and rather dense distribution. Apomorphous anemophilous pollination systems in the Albian (comparable to those in Recent taxa) indicate a long history since the origin of the angiosperm flowers as hypothesized in section 7.1.

The angiosperm differentiation at this time also suggests the presence of protogyny (necessary for successful differentiation of species with hermaphroditic 
flowers, both in entomophilous and anemophilous pollination systems), and unisexual flowers (necessary for the differentiation of species in which the flowers failed to become protogynous). The latter may have led already to dioecious plants. The pollination systems mentioned do not require other floral colours than greenish, yellow(ish) and white or whitish.

The angiosperm fossil record of the Lower Cretaceous and its presumed representation of pollination systems indicate a very early, probably Jurassic, origin of the Angiospermae. Since the upper Triassic (bisporangiate gymnosperm reproductive structures), selective pressures favouring "dcuble fertilization" were functional. As has been mentioned, the origin(s) of the Angiospermae must have exhibited a very limited diversity and thus, in geographical distribution (bisporangiate conditions of their predecessors), even though it might have been polyphyletic. Then, the fossil record is also very restricted in stratigraphy. More extensive pollen or spore analyses of Jurassic sediments would be interesting, probably particularly in those of the Antarctic (so far, no pollen or spore analyses are known from this continent). Because, however, the origin(s) of the Angiospermae must have taken place under entomogamous conditions (most probably exclusively pollen-feeding insects as pollinators), the search for fossil remains (fossil pollen) can be directed. It is hypothesized that the earliest fossil pollen of the Angiospermae may be found in fossil, anthophilous insects. Research on these aspects in Jurassic fossil insects may clear much of the origin of the Angiospermae.

\section{Differentiation and nectar production}

At the beginning of the Upper Cretaceous the taxonomical differentiation of the Angiospermae becomes established. In the Cenomanian (last period of fern-gymnosperm dominance) many fossils are known, more or less comparable to extant taxa, and in the Turonian the ecological breakthrough of the Angiospermae (ascendancy of angiosperm fossils, particularly fossil pollen) was established. The differentiation is much accelerated by the (probable) appearance of nectar, which gave rise to specialization of flowers for pollination by longer-tongued insects (more obligatory fly-pollinated flowers, leading to temporary, obligatory myiogamy). The flowers with exposed nectar probably were non-specialized entomophilous, with apocritan wasps having a considerable part in pollination.

\section{The influence of longer-tongued insects}

In the Coniacian-Santionian-Campanian mainly the anemogamy diversified rapidly (the record of fossil pollen indicates strong diversification of the Hamamelidae with the appearance of Fagales, Betulales, Juglandales). Differentiation of entomogamy possibly already led to flowers pollinated by flies and bees (or their predecessors) and flowers pollinated by flies and but- 
terflies/moths (or their predecessors). With regard to these presumed pollination systems, blue or bluish floral colours may have become functional.

In the Maestrichtian the fossil pollen indicates a climax in taxonomical diversification for many extant Angiospermae. Among the fossil pollen found in this period, most represent entomophilous flowers. The presence of so many types of entomophilous pollen indicates that the entomogamous plants geographically were very widespread and densely distributed. The earliest psychophilous flowers possibly were present in this period.

\section{Earliest melittogamy and certain presence of psychophilous flowers}

With the beginning of the Tertiary (Paleocene) melittophilous flowers were established (compare Crepet \& Taylor (1985): flag-shaped flower) and the diversification mentioned in the Maestrichtian was continued. In the middle Eocene the presence of psychophilous flowers was established. A trumpetshaped flower (with a narrow, elongated corolla tube and a rim of some type that can serve as an alighting platform) is mentioned by Crepet (1979) from this period (IUPC P 2226) and the definite establishment of long-haustellate Papilionoidea is mentioned by Durden \&ose (1978) from the same period. Crepet (1979) also mentioned several types of corolla indicating melittophily: a bilateral symmetrical flower (IUPC LK 2246); a bell-shaped, sympetalous corolla (with shallow, rounded lobes and a small connate calyx: UCPC W16b); and a brush-shaped mimosoid spike (IUPC W 2316), which, besides by bees, also may have been pollinated by Lepidoptera.

The amazingly rich fossil flower flora of the middle Eocene Claiborne Formation (ancient mud stream area?) consists of several hundreds of fossil flowers and inflorescences. Crepet (1979) selected only those types which can be included in the Recent pollination syndromes (see Faegri \& Van der Pijl, 1980) and found, in addition to the types already mentioned above: diversified anemogamy (both inflorescences and a single flower); cantharogamy (several types resembling Recent flowers of several genera of the "Parietales"; in the system of Takhtajan (1980) classified in the Dillenidae); and definite sapromyiogamy (spadices of Acoreae (Crepet, 1979) and aroid leaves of the Recent Philodendron (Dilcher \& Daghlian, 1977), indicating that the Araceae must have been already rather modern in the middle Eocene).

The definite establishment of psychogamy implies the presence of cryptantherous flowers with entirely concealed nectar, while the basis may have been laid for functional red or red-mixed floral colours.

\section{The final diversification of pollination systems}

In the Oligocene-Miocene-Pliocene the developments mentioned in the preceding periods continued (Muller (1984) mentioned many pollen grains 
representing herbaceous plants). In the Oligocene phalaenogamy and possibly already sphingogamy were established. From about the middle Tertiary onwards, ornithogamy and chiropterogamy (compare section 7.3) could develop and were established, inclusive of anthophilous birds and bats, respectively, in the (upper) Miocene.

The main earliest evolutionary developments in angiosperm pollination are illustrated schematically in fig. 7-5. 


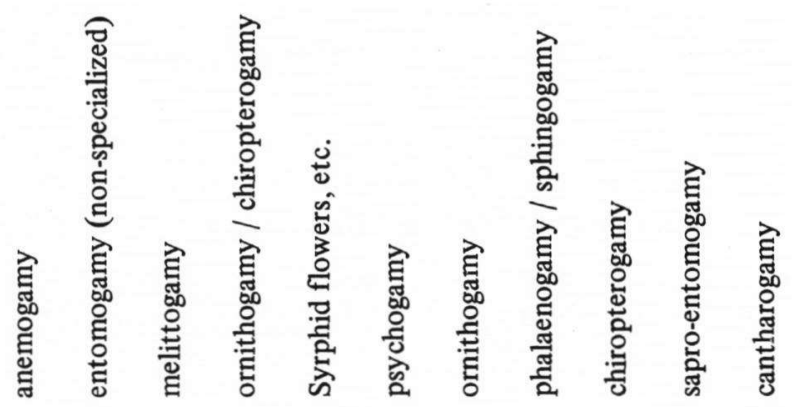

\begin{tabular}{|lr|}
\hline Pliocene & 5 \\
\hline upper Miocene & 11 \\
\hline middle Miocene & 15 \\
\hline lower Miocene & 22.5 \\
\hline & \\
\hline Oligocene & \\
\hline upper Eocene & 44 \\
\hline middle Eocene & 50 \\
\hline lower Eocene & 55 \\
\hline Paleocene & \\
\hline Maestrichtian & 69 \\
\hline Campanian & 77 \\
\hline Santonian & 84 \\
\hline Coniacian & 88 \\
\hline Turonian & 95 \\
\hline Cenomanian & 100 \\
\hline Albian & \\
\hline Aptian & \\
\hline Barremian \\
\hline
\end{tabular}

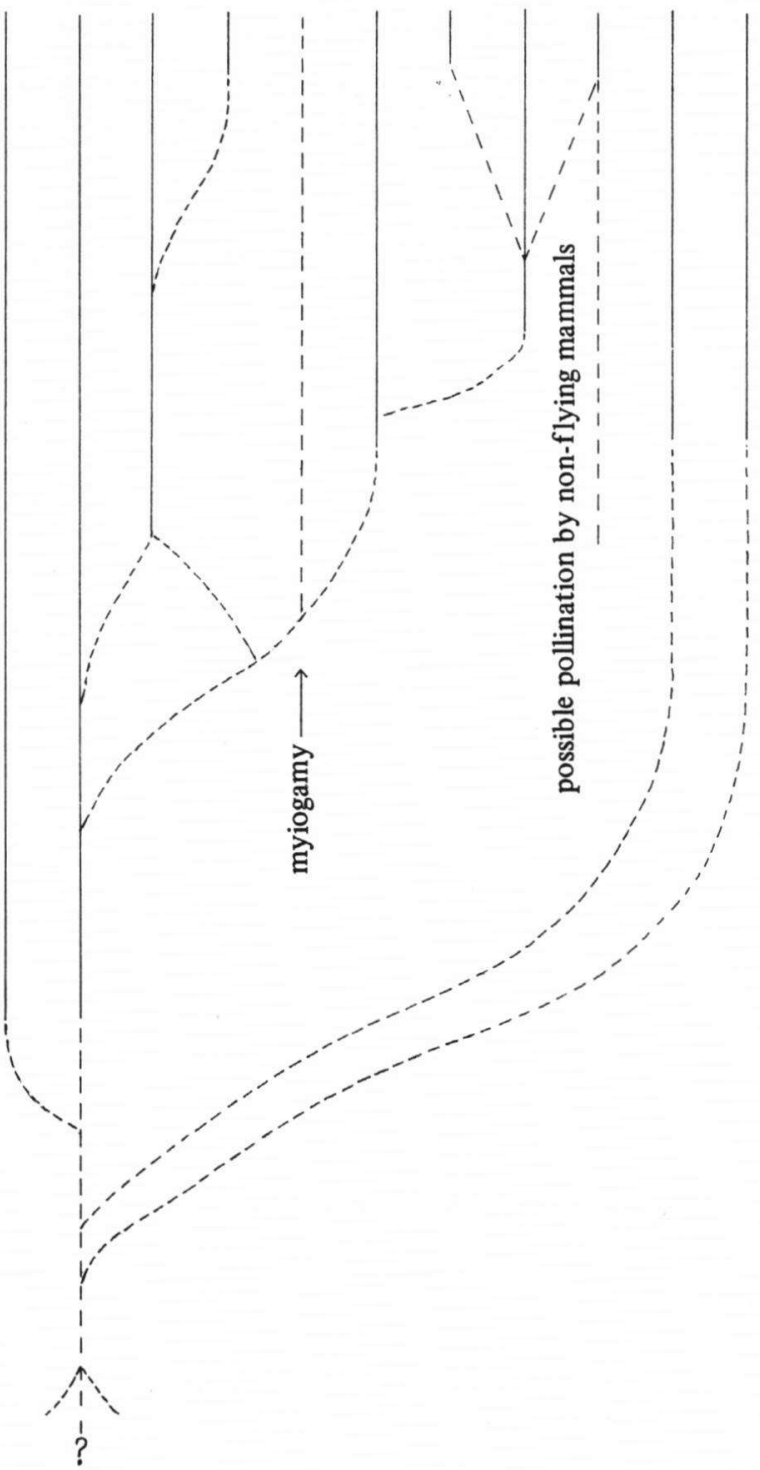

Fig. 7-5. Basic scheme of the evolutionary developments of angiosperm pollination; only the earliest differentiations are illustrated, leading to the Recent obligatory pollination types. 


\section{SUMMARY AND CONCLUSIONS}

In the introduction and chapter 2 the incentives and way of reasoning are given for the description of an evolutionary basis of pollination ecology. Starting from the until recently rather anecdotical character of the study of pollination ecology as a whole, and in the absence of large-scale correlations of flowerecologically important character states with angiosperm and insect phylogeny (in the sense of Hennig, 1966), an attempt is made to derive directed evolutionary lines (transformation series) of floral character states.

Because the fossil record of flowers is very restricted and the study of angiosperm phylogeny in the sense of Hennig (1966) is only at its very beginning, the only possibilities to achieve this, can be based on the comparatively well-known fossil history of insects and insect phylogeny, the least anecdotically compiled survey of insect visits to flowers, whether resulting in pollination or not, by Knuth (1898a and 1899) as far as it concerns the central European area (most thoroughly known area concerning insect fauna and angiosperm flora), and the fossil record of extant angiosperm taxa.

The insect visits to flowers are correlated with the pollination-ecologically important floral character states as they are found in Hegi (1906-1931; 1963, etc.; 1966, etc.) and Knuth (1898a and 1899) by statistical analyses on an extensive data base. These analyses, based on a geographically restricted area, are correlated with the evolution of insect-feeding (and corresponding morphology) based on insect phylogeny and fossil record. These correlations require two presuppositions: "horizontal" uniformitarianism (Recent insect behaviour and physiology in taxa of lower rank are supposed to be rather constant over the world); and "vertical" uniformitarianism (as it is used in historical geology). The results of these correlations form a series of functionally and stratigraphically/phylogenetically directed floral transformation series, dated by the fossil record of insects. The transformation series are compared with the fossil record of extant Angiospermae (for only a very minor part consisting of fossil flowers), requiring the possibility of spiral reasoning by the process of reciprocal illumination. The global scheme of the way of reasoning is illustrated in fig. 2-1.

It is argued that the approach to describe evolutionary developments of pollination starting from insect fossil history and phylogeny is allowed, because in the course of evolution of insect-flower relationships, entomophilous flowers are more dependent on insect character states for (cross-)pollination, than insects are on floral character states for feeding. Free-living insects form an 
essential part of the environment of the "sessile" entomophilous flowers. New developments in entomophilous floral morphology are entirely dependent on the presence of corresponding insect character states. Only in case of success the, from that moment on more restricted (specialized), insect-flower relationships give rise to genuine co-evolution of anthophilous insects and entomophilous flowers.

In chapter 3 the material and statistical methods are described, in addition to some prospects of this study in building a more refined survey, up to an analysis on the basis of extensive pollen analyses on the loads of the integuments and contents of the digestive tracts of central European Cetoniinae, Lepturinae and Cerambycinae of which the results are presented in the appendix.

In chapter 4 a survey is given of the feeding-habits of the adult insects included in the present study as mentioned in Knuth (1898a and 1899) and of their relatives, giving a systematically complete survey of the feeding-habits of Coleoptera, Hymenoptera, Lepidoptera and Diptera (with some remarks on anthophilous insects of other orders), with stress on the taxa in which anthophily developed. The main conclusion of this survey can be that of many families the feeding-habits were not found in the more general entomological literature, and also in more specialized literature the feeding-habits in many cases are imperfectly known.

Chapter 5 deals with the correlation of the anthophilous feeding-habits of insects with their phylogeny and fossil record. The correlations are restricted to the insect orders in which the main anthophilous insects occur: Coleoptera, Hymenoptera, Lepidoptera and Diptera.

Comparison of the monophyletic Holometabola with their sister-group the Paraneoptera indicates that the original feeding-habits of both larvae and adult insects of the former were saprophagous and/or fungivorous in moist vegetable debris and similar substances (as already suggested by Tillyard, 1926).

In describing the possible sister-group relationships within the Holometabola a non-pollination ecological conclusion is made: it is concluded that, if feeding on the blood of warm-blooded animals can be considered a synapomorphy in the Siphonaptera (fleas), they could not have originated earlier than in the Triassic (up to now, presumed origin of the Mammalia and Aves, see Romer, 1966); this is in contrast to Hennig (1981) who placed the origin of this order in the late Permian.

In discussing the correlations of the feeding-habits of the taxa of lower rank with their fossil record and phylogeny within the orders mentioned above, the following conclusions are drawn. 


\section{Coleoptera}

The habitat of the earliest Coleoptera most probably was that under the (loose) bark of trees. This habitat formed the selective pressure which favoured the adaptive development of elytra from the forewings. The earliest Coleoptera (Ommadidae) may have fed on reproductive structures or flowers as early as the lower Permian. In the upper Triassic this type of feeding must have been established, because all polyphagan series were present in that time (may be only some are of lower Jurassic origin). During the Jurassic the Polyphaga in which anthophily developed radiated considerably and in the upper Jurassic they were fairly well-differentiated (see tables 5-1 and 7-1). During the Cretaceous the differentiation of these beetles had a much slower rate, but, regarding the rather extensive differentiation in the upper Eocene to lower/middle Oligocene, at the end of the Cretaceous the origin may have laid of many (stem-groups) of families.

The following reconstruction of relationships between anthophilous Coleoptera and reproductive structures and/or flowers can be made. After a fairly rapid radiation during the upper Triassic and Jurassic, in the Cretaceous only few developments took place, but correlated with the ecological break-through of the Angiospermae in the Upper Cretaceous, the differentiation rate increased again.

Because it is not known when the origin of the Angiospermae has to be placed in the geological time scale (see below), in table 7-1 the stratigraphical appearance of extant insect taxa in which anthophily developed is given from the upper Triassic to the Lower Cretaceous.

\section{Hymenoptera}

The original feeding-habits of the Hymenoptera most probably were fungivorous. The habitat originally may have been decaying vegetable debris, but the Symphyta s.str. most probably lived in crevices of bark and under (loose) bark. The latter habitat probably formed the selective pressure which favoured the adaptive development of the cenchri, providing the possibility of fixing the wings in crawling under bark.

The evolutionary developments towards and within hymenopteran anthophily were correlated with those in the maternal care and social behaviour.

The earliest Hymenoptera (Xyelidae) may have fed on reproductive structures and/or flowers as early as the Triassic. The extant families of the Symphyta s.str. in which anthophily developed, differentiated from about the lower/middle Jurassic onwards and were definitely established in the upper Jurassic (see tables 5-2 and 7-1). In the Lower Cretaceous the earliest Apocrita 
appeared (Ichneumonoidea) and in the Upper Cretaceous an extensive differentiation of wasp families, in which, mainly nectarivorous, anthophily developed, can be observed (table 5-2). The differentiation of the Apoidea was about completed in the upper Eocene to lower/middle Oligocene and this may mean that the earliest Apoidea or their direct predecessors were already present in the uppermost Cretaceous.

The following reconstruction of relationships between Hymenoptera and reproductive structures and/or flowers can be made. After a fairly rapid differentiation in the Jurassic of the Symphyta s.str., only some differentiations in the Apocrita, in which anthophily developed, took place in the Lower Cretaceous, followed by an increased differentiation after the ecological breakthrough of the Angiospermae and of the nectarivorous (aculeatan) wasps in the Upper Cretaceous. Probably in the same time the Apoidea originated and differentiated very rapidly during the (uppermost Cretaceous and) early Tertiary. The stem-group of the Bombinae and Euglossinae must have been present in the upper Eocene to lower/middle Oligocene.

In correlating the feeding-habits with the phylogeny and fossil record of the Aculeata s.str. a pollination-ecologically interesting character state was met in the Bradynobaenidae. Although no feeding-habits were found for this family, the pinnate setae of its subfamily Typhoctinae may indicate close relationships with flowers (parallel evolution of setae as in Apidae). The morphology of the Bradynobaenidae urgently requires further research into their feeding-habits and behaviour.

\section{Lepidoptera}

When the Lepidoptera definitely originated within the Amphiesmenoptera (Lepidoptera + Trichoptera) is not known, but the earliest, mandibulate, certain Lepidoptera were present in the lower Cretaceous (Micropterigidae) and probably their predecessors were already present in the upper Jurassic. The Micropterigidae most probably fed on pollen in those times.

The Ditrysia were very differentiated in the middle Tertiary. This differentiation (see table 5-3), particularly that of the Papilionoidea, indicates a much earlier origin. It is suggested that after the mandibulate, pollen-feeding phase, the development of a longer haustellum induced a rapid differentiation of the higher Lepidoptera after the ecological break-through of the Angiospermae in the Upper Cretaceous, and mainly took place in the uppermost Cretaceous and early Tertiary.

\section{Diptera}

The earliest probably pollen-feeding Diptera are found in the Bibionomorpha which were present in the upper Triassic (whether Tipulomorpha, 
Psychodomorpha and Culicomorpha also had relationships with reproductive structures and/or flowers in that time, or only developed nectarivorous anthophily from the Upper Cretaceous onwards, is not known).

A rather rapid differentiation of Diptera, in which anthophily developed, can be traced in the Jurassic (see tables 5-4 and 7-1). During the Cretaceous new differentiations in dipteran anthophily hardly took place, but the extensive established differentiation of Brachycera in the upper Eocene to lower/middle Oligocene indicates a much earlier origin.

It can be suggested that after the ecological break-through of the Angiospermae the anthophilous, mainly nectarivorous Brachycera differentiated rapidly in the uppermost Cretaceous and first half of the Tertiary.

Chapter 5 is concluded with a survey of the stratigraphical appearance of the insect taxa in which anthophily developed.

In chapter 6 the statistical analyses of the central European flower visits of insects and their association with floral character states are carried out. The differentiated survey of the correlation of the feeding-habits with the phylogeny and fossil record is narrowed to insect taxa of higher rank: Coleoptera, Diptera, Lepidoptera and Hymenoptera (section 6.1). The last order is divided into two groups, viz. the Apoidea and non-apoid Hymenoptera on the basis of their different morphology and (in many cases) behaviour (Apoidea being nearly obligatory anthophilous). Generalized special morphological character states are indicated for the insect groups (lengths of mouth parts).

The interdependence of insects and floral character states is correlated with the results of chapter 5 (correlation of feeding-habits with the phylogeny and fossil record of the insect taxa in which anthophily developed).

With regard to the complex of facultative and obligatory pollination types (section 6.2), it is concluded that the more specialized insect-flower relationships developed during the latest Cretaceous and became finally established in the middle Tertiary (possibly with the exclusion of more specialized pollination by beetles, which may have evolved earlier). The earliest Angiospermae, then, most probably were non-specialized entomogamous, depending at their time of origin, on pollination by Coleoptera, Diptera and non-apoid Hymenoptera (Symphyta).

Comparison of the frequencies of obligatory pollination types within the complex of facultative and obligatory ones, indicates that bees and butterflies reached the highest degree of specialization of insect-flower relationships as far as it concerns the central European area (section 6.2.2).

With regard to the obligatory pollination (section 6.2.2), corresponding with 
the pollination syndromes, it can be stated that obligatory myiophilous flowers (not sapromyiophilous) with some depth effect may have existed from about the middle Cretaceous onwards and gave rise to melittophilous and psychophilous flowers in the (uppermost Cretaceous and) early Tertiary, while at the same time the obligatory form disappeared. Phalaenophilous flowers developed later in the Tertiary.

In the blossom-pollinator relationships (section 6.3) the following can be suggested. Allophilic flowers occurred in the earliest Angiospermae. Hemiphilic flowers may have originated in the late Cretaceous, giving rise to euphilic flowers in the early Tertiary.

As regards the development of flower types (section 6.4) it can be stated that actino- or already pleomorphic flowers occurred in the early Cretaceous. From about the middle Cretaceous somewhat stereomorphic flowers, particularly with regard to pollination by longer-rostrate flies, developed, and may have given rise to zygomorphic flowers. Stronger zygomorphic and stereomorphic flowers became functional during the early and middle Tertiary.

Among the earliest Angiospermae the following blossom classes (section 6.5) may have been present: inconspicuous entomophilous blossoms, dish- to bowlshaped blossoms and possibly some type of brush-shaped blossoms (the last ones not specialized for longer-tongued insects). From about the middle Cretaceous developments towards bell- and funnel-shaped blossoms were possible. In the late Cretaceous possibly more trumpet- and tube-shaped blossoms may have become functional and developed during the early Tertiary. Gullet-shaped blossoms are of later Tertiary origin. Flag-shaped blossoms are known from the late Paleocene.

As regards the single flower as a pollination unit versus (small-flowered) inflorescences (section 6.6) it is argued that the most plesiomorphous entomogamous Angiospermae had single flowers as pollination units (considering only the size of the flowers with regard to the size of their potential pollinators; the flowers were arranged in inflorescences, see section 7.1) and the development of small-flowered inflorescences took place under the selective pressure of ovule damage by larger, mandibulate, partly anthophagous pollinators, through plants or large inflorescences with small flowers, dependent on pollination by minute insects. The more compact inflorescences are adapted to pollination by larger and stronger-flying pollinators with the advantage of some spreading of the small one- or few-ovuled ovaries. The development of small-flowered plants and inflorescences could have taken place very early in the evolution of the angiosperm flowers. 
The developed or rudimentary perianth (section 6.7) cannot be correlated to certain insect groups. Absence of perianth parts is mainly characteristic for anemophilous flowers.

With regard to floral colours (sections 6.8.1 and 2) a comparison is also made between the taxa of lower rank by reciprocal averaging. In the comparisons the colour vision of insects is also included. One of the results of the analyses is, that in all insect groups the most plesiomorphous, anthophilous representatives mainly visit yellow (and white) flowers. The most plesiomorphous angiosperm floral colour most probably indeed was yellow (this may be supported by floral biochemistry). The total result consists of the following transformation series:

- from (green) yellow to white: very early in angiosperm evolution;

-from white to blue and blue-mixed colours: starting in the late Cretaceous;

-from yellow or white to red and red-mixed colours: starting in the late Cretaceous;

-from blue or blue-mixed to red and red-mixed colours and vice versa: from the late Cretaceous onwards.

It generally can be stated that floral colours in the course of angiosperm evolution fanned out from the middle of the spectrum towards the extremes; towards the short wave-lengths in connection with pollination by higher Apoidea and Lepidoptera; towards the longer wave-lengths in connection with pollination by certain taxa of Lepidoptera and, later, birds.

Cryptantherous flowers (section 6.9) may have been present from the late Cretaceous onwards, perhaps sapro-entomophilous inflorescences excluded.

In the numbers of stamens per flower (section 6.10) the following developments could have taken place. The earliest Angiospermae most probably had many stamens. In conjunction with the developments towards smallflowered plants and inflorescences, reduction of the numbers may have occured very early in the evolution of the angiosperm flowers. Considering that obligatory anemophilous flowers have only very few stamens per flower, this can be regarded as an apomorphous condition. In larger flowers in the second half of the Cretaceous the stamens could become reduced in numbers, in connection with specialization of the pollination.

With regard to the position of the ovaries (section 6.11), it can be stated that the selective pressure (mandibulate, anthophagous insect visitors, mainly beetles) favouring the development of half- to entirely inferior ovaries existed from the very origin of the Angiospermae and was probably completed very early. 
In the number of ovules per stigmatic surface (mostly corresponding with the carpel) (section 6.12), the number of ovules increases with an increase of the specialization of the pollination. The earliest entomogamous Angiospermae probably had few ovules per carpel. Reduction to one took place in the development to small-flowered inflorescences and anemogamy. Increase in specialized pollination types probably started in the Upper Cretaceous and early Tertiary in connection with specialized longer-tongued pollinators.

As regards nectar presence and position (section 6.13) it appeared that it cannot be suggested on the basis of the statistical analysis whether the earliest Angiospermae had pollen or nectar-containing flowers. It is demonstrated that beetles in many cases (also) feed on pollen on nectar-containing flowers (see also the tables in the appendix). In the position of the nectar the following transformation series exists: from free by way of half-concealed to entirely concealed nectar.

In the variation in time between receptivity and dehiscence (section 6.14.1) it is demonstrated that anemophilous flowers most often are protogynous, although this is also common among entomophilous flowers. Facultative and obligatory homogamy is mostly found in the obligatory pollination types. Protandry appears to be almost exclusively restricted to entomophilous flowers, but it requires adjacent developments to guide visiting insects over the flower or inflorescence by colours and/or odour and nectar, to optimalize the chance of cross-pollination.

It is argued that a gymnospermous sister group of the Angiospermae most probably was protandrous, because of the fact that, in case of endosperm proliferation before fertilization, the simultaneous presence of pollen and endosperm in hermaphroditic, entomophilous reproductive structures has to be minimalized to avoid insect injury to the endosperm. In the case of homogamy and protogyny too much endosperm would be present simultaneously with the pollen, and mandibulate insect visitors (beetles and possibly also symphytan wasps) would easily feed both on pollen and proteinrich endosperm. In order to avoid endosperm injury, the simultaneous presence of endosperm and pollen must have included a minimum quantity of the first and have lasted as short as possible. This circumstance can only occur in protandrous conditions. Moreover protandry representing the most logical sequence of ripening of the end of a stem, the simultaneous presence of pollen and endosperm, given the insects present in those times, must have prohibited the development of absolute homogamy and protogyny (avoiding too much "advertized" endosperm in entomophilous, hermaphroditic conditions).

Because protandry, however, requires adjacent "guiding''-developments, which obviously did not take place in the Gymnospermae, a selective pressure 
on the hermaphroditic reproductive structures, favouring cross-pollination, favoured the development of unisexual flowers (with a good chance to become anemogamous), and another selective pressure led to the development of "double fertilization" in which the endosperm only starts proliferation after fertilization. Once established, the "double fertilization" opened the way for the development of homogamy and protogyny.

The formation of stigmatic surfaces can be considered an adaptation to avoid fertilization-decreasing pollen droplet-feeding by, also non-mandibulate, insects (flies).

Analysis of the protandry in several families of the central European area, particularly in the Apiaceae, indicated that this type of dichogamy easily leads to the development of unisexual flowers, as so to avoid too much selfpollination. Protandrous flowers more often are self-incompatible than are protogynous ones.

Protandry appears to be more characteristic for unspecialized entomophilous pollination types, than for specialized ones (creating second order herkogamy in the former; in the more specialized flowers, particularly in melittophilous ones herkogamy is present morphologically).

The presupposition of this section was that unspecialized, mandibulate, injurious insect visitors may have formed the selective pressure favouring the development of second order herkogamy. The analysis does not support this. Dichogamy is developed under the selective pressure of optimalizing crosspollination, in protandry easily leading to unisexual flowers.

Absolute homogamy (section 6.14.2) more often occurs in specialized insectflower relationships than in unspecialized ones. In the latter case it may induce the development of unisexual flowers (but to a lesser degree than does protandry). In more specialized pollination types it may have induced development of heterostyly, and under unfavourable pollination conditions it easily led to cleistogamy.

In the developments towards dicliny (section 6.15) the following difference between anemogamous and entomogamous species is hypothesized. The difference of directability of the pollen vectors led to an enlarged chance of development of monoecy under protandrous/homogamous, anemogamous conditions and of dioecy under similar entomogamous conditions.

The abundance of hermaphroditic protogynous flowers in anemogamy requires extension of the definition of the syndrome of anemophily: "unisexual flowers, in case of monoecy protogynous, or protogynous hermaphroditic flowers", in stead of solely "unisexual flowers".

In section 6.16 the preceding evolutionary developments are outlined in a series of functionally and stratigraphically/phylogenetically directed transformation series. 
Chapter 7 deals with the reconstruction of the evolutionary developments in pollination ecology.

In hypothesizing the theoretical model of the earliest angiosperm flowers (section 7.1) by considering the plesiomorphous states of many of the transformation series, added with some comparative-morphologically derived ones, the following conclusions were drawn. The earliest angiosperms most probably had the following character states. The pollen flowers were arranged in inflorescences, most probably leafy cymes, and were of intermediate size. They were hermaphroditic, protandrous and allophilic, non-specialized entomophilous, pollinated by beetles, symphytan wasps and oligoneuran (possibly mainly bibionomorphan) and possibly asiliform flies. Their general appearance was dish- to bowl-shaped, paleomorphic. The optical attractant was formed by the stamens and discoloured upper leaves (to some degree already perianth-like); the floral colours most probably were yellow and white. The many stamens were arranged in bundles which represented compound sporangiophores, bundles being formed in a phyllotactic spiral, continuing that of the floral envelopes. The stamen filaments were short. The gynoecium consisted of probably many superior, petiole-like stiped, at anthesis not entirely closed, carpels, which were infolded cupules with sessile stigmas. Each carpel contained a few ovules in a laminar or submarginal position. Double fertilization was present.

The basic synapomorphy of the Angiospermae is the double fertilization and it strongly indicates an entomophilous, hermaphroditic origin. The indication of a selective pressure favouring the development of double fertilization, may favour the possibility of a polyphyletic origin of the Angiospermae. But the restricted possibilities of hermaphroditism in their predecessors and the probable uniqueness of this development, may indicate monophyly.

In the food supply for insect visitors it is hypothesized that in first instance the fertile parts (being the most attractive for insect visitors) provided food in the following transformation series:

1) from plain stigma to stigma with glandular warts;

2) from stamens to staminodes;

3) from plain stamens to stamens with glandular bodies at the base of the filament;

4) from plain stamens to stamens with glandular bodies at the apex of the connective;

5) from plain staminodes to staminodes with glandular bodies;

6) from stamens with glandular bodies to staminodes with the same;

The staminodes with glandular bodies occasionally may have given rise to tepals and petals with nectaries. 
In increasing the attraction of the flowers, laminar stamens were derived from stamens with a slender filament and by reduction of the upper leaves. The laminar stamens gave rise to tepals by way of laminar staminodes. This means that there more probably is question of sterilization of laminar stamens, than of the reverse.

In the remarks on the origin of the Angiospermae (section 7.2) it is concluded that there may be possibilities of temporary presence of hermaphroditic reproductive structures in the Bennettitales (demonstrated) and Gnetales (most probably). In the Pentoxylales these are not known.

The development of double fertilization is functionally explainable, and thereby it is less probably a development according to the "economy principle".

The probable entomogamy of the earliest Angiospermae may include that the "upland" theory is superfluous, because entomophilous pollen is quantitatively rare in stratigraphical pollen analysis.

In section 7.3 the apomorphies of the transformation series mentioned in section 6.16 are approximately dated on the basis of the fossil record and phylogeny of the insect taxa in which anthophily developed. Added is the dating of ornithophilous and chiropterophilous pollination types, based on the fossil record of birds and bats in which anthophily developed, respectively.

In section 7.4 the fossil record of extant angiosperm taxa is correlated with the dated apomorphies in section 7.3. For each taxon an estimation is made of the pollination type, based on the presence of extant insect taxa in which anthophily developed in the period in which the angiosperm taxon appeared, and on the basis of the type of fossils (macrofossils or fossil pollen) and the abundance of the fossil pollen. The types of angiosperm fossils may form an indication of the pollination type of the flowers they represent. There are three possibilities:

1) if in a period macrofossils are present and fossil pollen of the same taxon is not found in stratigraphical pollen analysis, or does not occur in some abundance (pollen not originating from the macrofossils), there is a major chance that the fossils represent entomophilous (or otherwise zoophilous) flowers; 2) if in a period both macrofossils and in considerable quantities fossil pollen of the same taxon are found (pollen not originating from the macrofossils), there is a major chance that the fossils represent anemophilous flowers;

3 ) if only stratigraphical pollen is found in considerable quantities, it most probably represents anemophilous flowers. 
Analysing the survey of fossils of extant angiosperm taxa at the end of this section, it is concluded that fossil pollen representing entomophilous flowers in quantitative, stratigraphical pollen analysis is rare and occurs irregularly in time (qualitatively, however, more entomophilous than anemophilous pollen types are found). Macrofossils qualitatively more often represent entomophilous than anemophilous flowers.

Pollen morphology also can give an indication of the pollination type: sculptured, tectate (and sticky) pollen mostly is entomophilous and psilate, and atectate (dry) pollen mostly is anemophilous. With regard to the pollination type, it is suggested that entomophilous pollen is longer on its way from locule to stigma, than is anemophilous pollen, and therefore more urgently needs a protective layer of "pollenkitt" to avoid desiccation; at the same time it functions as adhering agent to the body of the pollen vector. It is suggested that the columellate sculpture of the exine keeps the protective "pollenkitt" equally distributed over the pollen surface, and that the combination of sculpture and "pollenkitt" has a function in itself in the relation of adhering to the body of the pollen vector and the deposition on the stigmatic surface.

Because recent investigations indicate the presence of columellate pollen in as early as the Triassic and because also in gymnosperms evidence for relicts of columellae is found, and the earliest angiosperms most probably were entomogamous, it is suggested that the earliest angiosperm flowers had columellate pollen, which would mean that atectate, psilate pollen (as e.g. in the Degeneriaceae) has to be regarded as apomorphous.

The correlation of the extant angiosperm taxa with the above mentioned elements indicates the following appearance of floral character states in the stratigraphical periods:

\section{Barremian-Albian}

-anemophilous flowers, including possibly already inconspicuous, green flowers with reduced perianth, few stamens and a reduced number of ovules per stigma (carpel); the presence of this apomorphous pollination type and its corresponding probable character states indicate a much earlier origin of the Angiospermae;

- some more obligatory beetle pollination;

- possible sapro-entomogamy;

- somewhat hemiphilic flowers are possible (in connection with more obligatory beetle pollination);

- possible haplomorphic flowers;

-actino- and pleomorphic flowers;

-probable (partial) sympetaly; 
-dish- to bowl-shaped blossoms;

-brush-shaped blossoms (not specialized for longer-tongued insects);

-small-flowered inflorescences;

-yellow and white floral colours;

-reduction of the numbers of stamens per flower in connection with smallflowered entomophilous inflorescences;

-reduction of numbers of ovules per stigma (carpel) in connection with smallflowered inflorescences;

-possible protogyny;

- possible unisexual flowers.

\section{Cenomanian-Turonian}

-early more obligatory myiogamy;

- more obligatory cantharogamy;

- early more obligatory wasp pollination;

- earliest somewhat stereomorphic and possibly zygomorphic flowers (e.g. margin flowers of small-flowered inflorescences);

- earliest possible bell- to funnel-shaped blossoms;

- larger solitary flowers;

- possibly some blue and blue-mixed colours in connection with early more obligatory myiogamy;

- peri- and epigyny;

- nectar-containing flowers with open nectar.

\section{Coniacian-Santonian-Campanian}

- possible very early pollination by Apoidea or their direct predecessors (bee pollination) and early butterfly pollination;

- possible presence of fly- and bee-pollinated flowers;

- possible presence of fly- and butterfly-pollinated flowers.

\section{Maestrichtian}

- possible earliest psychogamy;

- some early function of red- and red-mixed floral colours;

-euphily;

- possible presence of pollination by non-flying mammals.

\section{Paleocene}

- obligatory melittogamy;

-more obligatory psychogamy;

-earliest zygomorphic solitary flowers;

- earliest flag-shaped flowers;

-earliest cryptanthery;

- complete concealment of the nectar. 


\section{Eocene}

- genuine melittogamy;

-obligatory psychogamy;

- euphilic inflorescences in (fig) wasp pollination, perhaps already somewhat more specialized;

-trumpet-shaped blossoms;

-stiped ovaries;

-possible earliest oil-producing flowers.

\section{Oligocene}

- specialized melittogamy, possibly already euphilic bumblebee flowers:

- possible early faintly gullet-shaped blossoms;

- phalaenogamy, possibly already sphingogamy.

\section{Miocene}

- definite gullet-shaped blossoms;

- possible early chiropterogamy;

- possible ornithogamy;

- possible perfume flowers.

In the Pliocene and Quaternary the developments mentioned went on, but no new developments were traced.

Comparison of the world-wide number of fossils of extant angiosperm taxa with the Recent central European flora indicates a lower frequence of anemophilous flowers in the former than in the latter. Causes suggested for this discrepancy are:

-the distribution of the pollination types in the world's angiosperm flora differs from that in the central European one;

- morphological differentiation in entomophilous pollen is more extensive than in anemophilous pollen, i.e. taxa of lower rank more easily identifiable; -entomophilous pollen is stronger than anemophilous pollen, i.e. it fossilizes better.

Most evidence points towards the first, because anemogamy is rare in tropical environments and towards higher latitudes it becomes increasingly abundant.

In section 7.5 the phases in the evolutionary development of angiosperm pollination are outlined.

In the earliest angiosperm evolution up to the beginning of the Upper Cretaceous, entomogamy differentiated slowly and gave rise to anemogamy. In the Upper Cretaceous myiogamy existed in an obligatory state, giving rise to melittogamy and psychogamy in the uppermost Cretaceous and early Ter- 
tiary. Melittogamy may partly have originated from less specialized entomophilous pollination types in these times. Psychogamy may have given rise to phalaenogamy in the upper Eocene or early Oligocene and (somewhat) later sphingogamy developed. In about the middle Tertiary ornithogamy could be derived from either melittogamy or psychogamy-sphingogamy. In about the same time, or somewhat later, chiropterogamy may have developed from melittogamous and phalaenogamous flowers. Both ornithogamy and chiropterogamy, inclusive of anthophilous birds and bats respectively, may have been established in upper Miocene or early Pliocene. Sapro-entomogamy and cantharogamy may be of very early origin.

There are many indications that the Angiospermae are much older than the time of their stratigraphical appearance in the Barremian-Aptian suggests. Before this period the Angiospermae most probably were entomogamous, which means that their pollen has to be searched for in fossil anthophilous insects. The implications and possibilities of this kind of pollen analysis have been demonstrated by the author in fossil insects in Baltic and Dominican amber.

If the earliest Angiospermae were geographically restricted in their distribution, it will be very interesting to explore Antarctic layers of pre-Cretaceous origin for their pollen contents. 


\section{PROSPECTS OF RESEARCH WITH REGARD TO EVOLU- TIONARY DEVELOPMENTS IN POLLINATION ECOLOGY}

As has been demonstrated in this study, the research into evolutionary developments in pollination ecology is an integration of several fields of natural science:

- morphology, phylogeny and systematics of anthophilous animals;

- paleontology of anthophilous animals (part of phylogeny);

- physiology, ethology and ecology of anthophilous animals;

- morphology (inclusive of anatomy and palynology), phylogeny and taxonomy of angiosperms;

- paleobotany and -palynology (part of phylogeny);

-ecology of angiosperms with regard to phylogeny;

- population dynamics for understanding micro-evolution.

It is not possible for one person to cover all these fields of biology, so that the study of the evolutionary developments in pollination ecology requires cooperation of several specialists. This study gives a more or less "overall" view of the field, but it is compiled from incomplete surveys. This means that the results may be falsified or completed. Each falsification or completion will illuminate the whole.

The described transformation series aim to bundle flower ecological observations. Separate observations can be checked against their place in several transformation series for the background of the phylogeny of either the angiosperm taxon concerned or the insect taxon involved. Thus, correlation of floral biology with the phylogeny of the taxa involved (including morphological, anatomical, ecological, physiological aspects, in the case of animals also ethology, and in the case of plants also biochemistry) forms the basis for a proper understanding of the evolutionary developments in pollination ecology by a continuous process of reciprocal illumination.

In organizing symposia and congresses the aspects of co-operation should be stressed by inviting specialists of the fields around pollination ecology. Flower ecologists should interest other scientists for pollination ecology, both descriptive and experimental, because pollination ecology is part of natural history, not only as a "scientia amabilis", but also as a serious part of biology, based on modern developments in several fields. May this study contribute in some way to the required co-operation. 


\section{ACKNOWLEDGEMENTS}

Prof. dr. St. Vogel (Institut für Spezielle Botanik, Johannes Gutenberg Universität, Mainz) and Dr. M.C.F. Proctor (Department of Biology, University of Exeter) critically read the manuscript and in stimulating discussions they provided important suggestions for completing the study. I wish to thank them very much for their valuable support.

I am very grateful to Dr. A.C. van Bruggen for his stylistic suggestions and to Dr. W. van Heel for editing the manuscript for the Leiden Botanical Series.

Miss E.E. van Nieuwkoop and Mr. J. van Os prepared the tables and figures. I am much indebted to them, particularly because of the rapidity with which they completed this work.

This study was financially supported by the Dutch Organazation for the Advancement of pure Research (Z.W.O.), grant no. 82-70. The same organization supported the publication in the Leiden Botanical Series, grant no. 82-70D. 


\section{APPENDIX}

\section{Results of pollen analyses on the loads of the integuments and contents of the digestive tracts of Cetoniinae, Cerambycinae and Lepturinae}

In order to get an idea how flower visits of various beetle species correspond with each other, extensive pollen analyses were carried out in the loads of the integuments (outer surface of the insect's body) and contents of the digestive tracts. The results of these pollen analyses are part of Willemstein (1978). In this appendix the results are arranged in correspondence with the nectar presence and position (tables 1. free nectar; 2. nectar half-concealed; 3. nectar entirely concealed; and 4 . pollen flowers). The numbers are the numbers of beetle specimens on or in which considerable amounts of the pollen of the plant species mentioned were found.

Table 1. Pollen contents of Coleoptera (Cetoniinae, Cerambycinae and Lepturinae) which visited flowers with free nectar, expressed in numbers of specimens.

Abbreviations: $t=$ total of demonstrated visits by pollen analysis; $d$ - pollen present in the digestive tract; $i=$ pollen present on the integument; $|\mathrm{i}|,|\mathrm{d}|=\mathrm{i}$ and $\mathrm{d}$ exclusively.

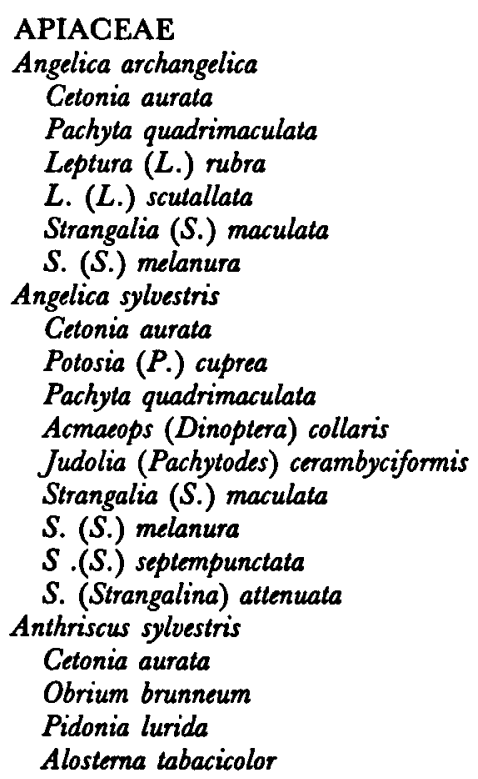

Angelica archangelica

Cetonia aurata

Pachyta quadrimaculata

Leptura (L.) rubra

$L$. (L.) scutallata

Strangalia (S.) maculata

$S .(S$.) melanura

Cetonia aurata

Potosia (P.) cuprea

Pachyta quadrimaculata

Acmaeops (Dinoptera) collaris

Judolia (Pachytodes) cerambyciformis

Strangalia $(S$.$) maculata$

$S$.(S.) septempunctata

S. (Strangalina) attenuata

nthriscus sylvestris

Cetonia aurata

Obrium brunneum

Alosterna tabacicolor

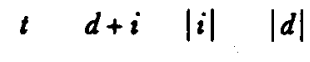

$\begin{array}{llll}3 & 3 & - & - \\ 1 & 1 & - & - \\ 1 & - & 1 & - \\ 3 & - & 3 & - \\ 4 & 2 & 2 & - \\ 1 & 1 & - & - \\ 5 & 1 & 3 & 1 \\ 1 & - & 1 & - \\ 1 & - & - & 1 \\ 1 & - & 1 & - \\ 1 & - & - & 1 \\ 1 & - & 1 & - \\ 1 & - & 1 & - \\ 1 & - & - & 1 \\ 1 & - & 1 & - \\ 2 & 2 & - & - \\ 2 & 1 & - & 1 \\ 2 & 2 & - & - \\ 2 & 2 & - & -\end{array}$


Leptura (Vadonia) lurida

L. (L.) maculicomis

L. (L.) inexpectata

Apium graveolens

Cetonia aurata

Strangalia (S.) melanura

Berula erecta

Acmaeops (Dinoptera) collaris

Chaerophyllum aureum

Oxythyrea funesta

Cetonia aurata

Obrium brunneum

Molorchus (Caenoptera) minor

Gaurotes virginea

Acmaeops (Dinoptera) collaris

Alosterna tabacicolor

Leptura (Vadonia) livida

L. (L.) sanguinolenta

Judolia (Pachytodes) cerambyciformis

Strangalia (S.) nigra

Chaerophyllum hirsutum

Cetonia aurata

Potosia ( $P$.) angustata

Acmaeops (Dinoptera) collaris

Grammoptera nuficomis

Alostema tabacicolor

Judolia (Pachytodes) cerambyciformis

Strangalia (S.) maculata

$S$. (S.) nigra

Daucus carota

Cetonia autata

Potosia ( $P$.) cuprea

Obrium brunneum

Molorchus (Caenoptera) minor

Evodinus interrogationis

Acmacops (Dinoptera) collaris

Pidonia lurida

Grammoptera ruficomis

Leptura (Vadonia) livida

L. (L.) maculicomis

L. (L.) scutellata

Judolia (Pachytodes) cerambyciformis

Strangalia (S.) maculata

$S$. (S.) melanura

S. (S.) bifasciata

$S$. (S.) septempunctata

S. (Strangalina) attenuata

Foeniculum vulgare

Leptura (L.) maculicornis

Strangalia $(S$.) melanura

Heracleum mantegazzianum

Cetonia aurata

Strangalia (S.) maculata

Heracleum sphondylium 
Cetonia aurata

Potosia (P.) cuprea

$P$. (P.) fieberi

Obrium brunneum

Evodinus interrogationis

Gaurotes virginea

Acmaeops (Dinoptera) collaris

Pidonia lurida

Leptura (Vadonia) livida

$L$. (L.) sanguinolenta

L. (L.) maculicomis

L. (L.) dubia

Judolia (Pachytodes) cerambyciformis

Strangalia $(S$.) aurulenta
$S$. (S.) maculata
S. (S.) melanura
$S$. (S.) nigra
$S$. (S.) septempunctata
S. (Strangalina) attenuata

Myrrhis odorata

Potosia (P.) cuprea

Obrium brunneum

Clytus arietis

Gaurotes virginea

Acmaeops (Dinoptera) collaris

Leptura (L.) maculicornis

L. (L.) sanguinolenta

L. (L.) dubia

Judolia (Pachytodes) cerambyciformis

Strangalia (S.) maculata

S. (S.) melanura

Pastinaca sativa

Oxythyrea funesta

Cetonia aurata

Gaurotes virginea

Alosterna tabacicolor

Leptura (Vadonia) livida

L. (L.) maculicornis

L. (L.) sanguinolenta

L. (L.) dubia

Strangalia $(S$.$) maculata$

$S$. (S.) melanura

$S .(S$.$) nigra$

Peucedanum cervaria

Gaurotes virginea

Peucedanum oreoselinum

Strangalia (S.) aurulenta

$S$. (S.) maculata

S. (S.) melanura

Pimpinella saxifraga

Cetonia aurata

Potosia (P.) fieberi

Pachyta quadrimaculata

Leptura (Vadonia) livida 
L. (L.) maculicomis

L. (L.) scutellata

L. (L.) dubia

Judolia (Pachytodes) cerambyciformis Strangalia (S.) aurulenta

$S$. (S.) maculata

$S$. (S.) melanura

S. (S.) bifasciata

$S$. (S.) septempunctata

S. (Strangalina) atlenuala

Sanicula europea

Strangalia (S.) maculata

CAPRIFOLIACEAE

Sambucus ebulus

Cetonia aurata

Leptura (L.) scutellata

Strangalia $(S$.) maculata

$S$. (S.) melanura

CORNACEAE

\section{Cornus mas}

Leptura (L.) maculicomis

Cornus sanguinea

Oxythyrea funesta

Cetonia aurata

Potosia $(P$.) angustata

$P$. (P.) cuprea

Stenopterus rufus

Evodinus interrogationis

Gaurotes virginea

Acmaeops (Dinoptera) collaris

Grammoptera ruficomis

Leptura (L.) dubia

$L$. (L.) inexpectata

Strangalia (S.) maculata

RHAMNACEAE

Frangula alnus

Acmaeops (Dinoptera) collaris

Leptura (L.) maculicomis

$L$. (L.) inexpectata

Judolia (Pachytodes) cerambyciformis

Strangalia $(S$.) nigra

RUBIACEAE

Galium

Obrium brunneum

Leptura $(L$.$) scutellata$

Strangalia $(S$.) maculata

$S$. $(S$.$) melanura$

$S$. (S.) bifasciata

TILIACEAE

Tilia platyphyllos

Cetonia aurata

Pachyta quadrimaculata

Strangalia (S.) maculata

$S$. $(S$.$) melanura$

Totals

$\begin{array}{rrrr}3 & 3 & - & - \\ 4 & 2 & 2 & - \\ 4 & 1 & 3 & - \\ 1 & - & - & 1\end{array}$

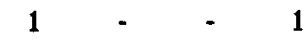

$\begin{array}{rrrr}2 & - & 2 & - \\ 48 & 31 & 16 & 1 \\ 1 & - & 1 & - \\ 1 & - & 1 & - \\ 1 & - & - & 1 \\ 1 & - & - & 1 \\ 1 & - & - & 1 \\ 2 & 2 & - & - \\ 2 & 1 & - & 1 \\ 4 & 4 & - & - \\ 1 & 1 & - & - \\ 1 & - & - & 1\end{array}$

$\begin{array}{llll}6 & 1 & - & 5 \\ 5 & 3 & 2 & - \\ 1 & - & 1 & - \\ 1 & 1 & - & - \\ 2 & - & - & 2\end{array}$

$\begin{array}{llll}1 & - & - & 1 \\ 1 & - & - & 1 \\ 2 & - & - & 2 \\ 2 & - & - & 2 \\ 3 & 1 & 2 & -\end{array}$ 
Table 2. Pollen contents of Coleoptera (Cetoniinae, Cerambycinae and Lepturinae) which visited flowers with half-concealed nectar, expressed in numbers of specimens.

Abbreviations: $t$ - total of visits demonstrated by pollen analysis; $d=$ pollen found in the digestive tract; $i=$ pollen found on the integument; $|\mathrm{i}|,|\mathrm{d}|=\mathrm{i}$ and $\mathrm{d}$ exclusively.

\author{
BRASSICACEAE \\ Armoracia rusticana \\ Acmaeops (Dinoptera) collaris \\ Leptura (L.) maculicomis \\ Strangalia (S.) maculata \\ $S$. (S.) nigra \\ CAPRIFOLIACEAE \\ Vibumum lantana \\ Cetonia aurata \\ Grammoptera ruficomis \\ Vibumum opulus \\ Oxythyrea funesta \\ Cetonia aurata \\ Potosia ( $P$.) angustata \\ $P$. (P.) cuprea \\ Obrium brunneum \\ Stenopterus rufus \\ Rhagium (R.) bifasciatum \\ Gaurotes virginea \\ Acmaeops (Dinoptera) collaris \\ Pidonia lurida \\ Alosterna tabacicolor \\ Leptura (Vadonia) livida \\ L. (L.) sanguinolenta \\ L. (L.) maculicomis \\ Judolia (Pachytodes) cerambyciformis \\ Strangalia (S.) bifasciata \\ $S$. (S.) nigra \\ POLYGONACEAE \\ Polygonum alpinum \\ Cetonia aurata \\ Potosia (P.) cuprea \\ Leptura (Vadonia) livida \\ Strangalia (S.) nigra \\ RANUNCULACEAE \\ Ranunculus acris \\ Oxythyrea funesta \\ Cetonia aurata \\ Potosia (P.) cuprea \\ Strangalia (S.) melanura \\ $S$. (S.) nigra \\ ROSACEAE \\ Crataegus \\ Acmaeops (Dinoptera) collaris \\ Judolia (Pachytodes) cerambyciformis \\ Crataegus laevigata \\ Cetonia aurata \\ Obrium brunneum \\ Crataegus monogyna \\ Cetonia aurata
}

$\begin{array}{llll}t & d+i & |i| & |d|\end{array}$

$\begin{array}{llll}5 & 4 & 1 & - \\ 1 & 1 & - & - \\ 1 & - & - & 1 \\ 1 & - & - & 1\end{array}$


Table 2 continued:

Grammoptera ruficornis

Sorbus aria

Oxythyrea funesta

Cetonia aurata

Spiraea vanhouttei

Gaurotes virginea

Totals

$$
t \quad d+i \quad|i| \quad|d|
$$

$\begin{array}{rrrr}1 & 1 & - & - \\ 1 & 1 & - & - \\ 27 & 26 & - & 1 \\ \frac{2}{200} & \frac{1}{120} & \frac{-}{56} & \frac{1}{24}\end{array}$

Table 3. Pollen contents of Coleoptera (Cetoniinae, Cerambycinae and Lepturinae) which visited flowers with entirely concealed nectar, expressed in numbers of specimens.

Abbreviations: $t$ - total of visits demonstrated by pollen analysis; $d=$ pollen found in the digestive tract; $i=$ pollen found on the integument; $|i|,|d|=i$ and $d$ exclusively.

\section{APIACEAE}

Eryngium campestre

Cetonia aurata

Obrium brunneum

Leptura (L.) cordigera

Strangalia (S.) nigra

ASTERACEAE

Achillea millefolium

Oxythyrea funesta

Cetonia aurata

Stenopterus rufus

Pachyta quadrimaculata

Evodinus interrogationis

Acmaeops (Dinoptera) collaris

Lepturia (Vadonia) livida

L. (L.) maculicornis

L. (L.) scutellata

L. (L.) sanguinolenta

Strangalia (S.) maculata

$S$. (S.) melanura

$S$. (S.) bifasciata

$S$. (S.) septempunctata

S. (Strangalina) attenuata

Centaurea macroptilon

Strangalia $(S$.) maculata

$S$. (S.) melanura

Chrysanthemum leucanthemum

Oxythyrea funesta

Leptura (Vadonia) livida

L. (L.) maculicomis

L. (L.) sanguinolenta

Strangalia (S.) maculata

$S$. (S.) melanura

S. (S.) bifasciata

$t \quad d+i \quad|i| \quad|d|$

Cirsium

Leptura (L.) cordigera

Strangalia $(S$.) septempunctata

$\begin{array}{llll}5 & 2 & 3 & - \\ 2 & 2 & - & - \\ 2 & 1 & - & 1 \\ 1 & 1 & - & -\end{array}$

$\begin{array}{rrrr}2 & - & - & 2 \\ 2 & - & 1 & 1 \\ 1 & 1 & - & - \\ 1 & - & 1 & - \\ 1 & - & - & 1 \\ 2 & 1 & 1 & - \\ 2 & 1 & - & 1 \\ 4 & 3 & - & 1 \\ 4 & - & 3 & 1 \\ 1 & - & - & 1 \\ 4 & 4 & 3 & 7 \\ 3 & 3 & 2 & 18 \\ 3 & 1 & - & 2 \\ 1 & 6 & - & 5 \\ 1 & - & 1 & -\end{array}$

3 - $\quad 3$

$5 \quad-\quad-5$

$\begin{array}{llll}5 & 1 & 2 & 2\end{array}$

$\begin{array}{llll}1 & 1 & -\end{array}$

$\begin{array}{llll}6 & 5 & - & 1\end{array}$

$\begin{array}{llll}3 & 2 & 1 & -\end{array}$

$\begin{array}{llll}2 & 1 & 1\end{array}$

$53 \quad 3 \quad 2$

22 -

$\begin{array}{llll}1 & - & - & 1\end{array}$ 
Cirsium arvense

Oxythyrea funesta

Cetonia aurata

Leptura (L.) sanguinolenta

Strangalia $(S$.) maculata

$S$. (S.) melanura

Cirsium palustre

Oxythyrea funesta

Echinops

Oxythyrea funesta

\section{Leontodon}

Leptura (L.) cordigera

Strangalia $(S$.) maculata

S. (Strangalina) attenuata

Leontodon hispidus

Oxythyrea funesta

Cetonia aurata

Potosia (P.) cuprea

Gaurotes virginea

Leptura (L.) maculicornis

$L$. (L.) sanguinolenta

Strangalia $(S$.) melanura

Matricaria inodora

Leptura $(L$.) sanguinolenta

Strangalia (S.) maculata

$S$. (S.) melanura

$S$. (S.) septempunctata

S. (Strangalina) attenuata

Stenactis

Stenopterus rufus

Stenactis trichosa

Leptura (L.) maculicomis

Strangalia (S.) maculata

$S$. (S.) melanura

$S$. (S.) septempunctata

CAMPANULACEAE

Jasione montana

Oxythyrea funesta

CAPRIFOLIACEAE

Lonicera periclymenum

Cetonia aurata

CARYOPHYLLACEAE

Silene

Oxythyrea funesta

DIPSACACEAE

Knautia arvense

Oxythyrea funesta

Evodinus interrogationis

Gaurotes virginea

Acmaeops (Dinoptera) collaris

Leptura (L.) maculicomis

$L$. (L.) sanguinolenta

L. (L.) dubia

Strangalia (S.) maculata

$\begin{array}{llll}2 & - & - & 2 \\ 2 & - & - & 2 \\ 1 & 1 & - & - \\ 5 & 2 & - & 3 \\ 8 & 1 & - & 7\end{array}$

$1 \quad-\quad 1$

$1 \quad-\quad-1$

$1 \quad-\quad-1$

1 - 1 -

$\begin{array}{llll}41 & 22 & 5 & 14\end{array}$

$12 \quad 1 \quad 11 \quad-$

$3-3=$

$2-2$ -

$1 \quad-11 \quad 1 \quad-$

$\begin{array}{llll}8 & 6 & 1 & 1\end{array}$

$1 \quad-\quad-\quad 1$

$4 \quad-\quad-4$

$\begin{array}{llll}18 & 11 & 1 & 6\end{array}$

$\begin{array}{llll}3 & 2 & - & 1\end{array}$

1

$1 \quad-\quad-1$

$2 \quad-\quad-2$

$\begin{array}{lll}31 & 6 & -\end{array}$

$\begin{array}{llll}2 & 1 & - & 1\end{array}$

11

1

1

$1-\quad-1$

$1 \quad-\quad-1$

$2 \quad-\quad-2$

$2 \quad-\quad 2$

4 - $\quad 4$

$1 \quad-\quad-\quad 1$

1 - $\quad-1$ 
Table 3 continued:

\section{LAMIACEAE \\ Mentha}

Strangalia (S.) melanura

\section{LILIACEAE}

Lilium bulbiferum

Cetonia aurata

ROSACEAE

Rubus

Cetonia aurata

Clytus arietis

Rhagium (Hargium) mordax

Acmaeops (Dinoptera) collaris

Gramoptera ruficornis

Leptura (L.) maculicornis

$L$. (L.) sanguinolenta

Judolia (Pachytodes) cerambyciformis

Strangalia (S.) maculata

$S$. (S.) melanura

$S$. (S.) nigra

$S .(S$.$) septempunctata$

VALERIANACEAE

Valeriana officinalis

Strangalia (S.) melanura

\section{VIOLACEAE}

Viola lutea

Oxythyrea funesta

Totals

$$
t \quad d+i \quad|i| \quad|d|
$$

$1 \quad-1$

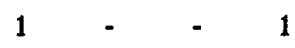

$\begin{array}{llll}6 & - & 4 & 2\end{array}$

$\begin{array}{llll}6 & 1 & - & 1\end{array}$

$1 \quad-\quad-\quad 1$

$1 \quad-\quad-1$

$1 \quad-\quad-\quad 1$

$3 \quad-\quad 2 \quad 1$

$3 \quad-\quad 1 \quad 2$

$1 \quad-\quad-1$

$3-3$ -

$1 \quad-\quad-\quad 1$

$1 \quad-\quad-1$

$1-\quad-1$

$1 \quad-\quad-\quad 1$

$\frac{3}{318} \frac{-}{98} \frac{-}{57} \frac{3}{163}$

Table 4. Pollen of nectarless flowers in the digestive tracts of Coleoptera (Cetoniinae, Cerambycinae and Lepturinae), expressed in numbers of beetle specimens in which the pollen was found.

$\begin{array}{lr}\text { CAPRIFOLIACEAE } & \\ \text { Sambucus nigra } & 2 \\ \text { Oxythyrea funesta } & 81 \\ \text { Cetonia aurata } & 1 \\ \text { Potosia (P.) angustata } & 4 \\ P .(P .) \text { cuprea } & 2 \\ \text { Molorchus (Caenoptera) minor } & 2 \\ \text { Stenopterus rufus } & 3 \\ \text { Gaurotes virginea } & 8 \\ \text { Acmaeops (Dinoptera) collaris } & 2 \\ \text { Pidonia lurida } & 48 \\ \text { Grammoptera nuficomis } & 3 \\ \text { Alosterna tabacicolor } & 3 \\ \text { Leptura (Vadonia) lurida } & 4 \\ \text { L. (L.) maculicornis } & 1 \\ \text { L. (L.) scutellata } & 1 \\ \text { L. (L.) sanguinolenta } & 4 \\ \text { L. (L.) dubia } & 2 \\ \text { L. (L.) inexpectata } & 7 \\ \text { Judolia (Pachytodes) cerambyciformis } & \end{array}$


Table 4 continued:

Strangalia (S.) maculata

$S$. (S.) melanura

$S$. (S.) bifasciata

S. (S.) nigra 7

PLANTAGINACEAE

Plantago media

Oxythyrea funesta

41

Cetonia aurata

Potosia (P.) cuprea $\quad 7$

Gaurotes virginea $\quad 7$

Acmaeops (Dinoptera) collaris $\quad 7$

Grammoptera ruficomis 1

Leptura (L.) maculicomis 3

Strangalia $(S$.$) maculata 1$

S. (S.) melanura 1

$S$. (S.) bifasciata 2

POACEAE

Gaurotes virginea

Acmacops (Dinoptera) collaris

Strangalia $(S$.$) melanura \quad 1$

POLYGONACEAE

Rumex

Cetonia aurata

ROSACEAE

Aruncus diocus

Gaurotes virginea

Grammoptera ruficomis

Filipendula ulmaria

Oxythyrea funesta

Acmaeops (Dinoptera) collaris 3

Leptura $(L$.) maculicomis 3

Judolia (Pachytodes) cerambyciformis 1

Strangalia $(S$.$) maculata \quad 2$

$S$. $(S$.) melanura 5

Filipendula vulgaris

Strangalia (S.) maculata $\quad 2$

Rosa

Grammoptera ruficomis $\quad 8$

Rosa arvensis

Stenopterus rufus 1

Rosa canina

Oxythyrea funesta 1

Cetonia aurata $\quad 11$

Stenopterus rufus 1

Acmaeops (Dinoptera) collaris 1

Leptura (L.) inexpectata

Judolia (Pachytodes) cerambyciformis 4

PINACEAE

Pinus mugo

Cetonia aurata

$\frac{22}{426}$ 


\section{REFERENCES}

Allenspach, V., 1973. Cerambycidae. Insecta Helvetica Catalogus 3 Coleoptera. Schweizerischen Entomologischen Gesellschaft, Zurich.

ANTONOVICs, J., 1968. Evolution in closely adjacent plant populations. V. Evolution of selffertility.-Heredity 23: 219-238.

-, 1976 . The nature of limits to natural selection.-Ann. Missouri bot. Gdn 63: 224-247.

Antonovics, J. and A.D. Bradshaw, 1970. Evolution in closely related adjacent populations VIII. Clinal patterns at a mine boundery.-Heredity 25: 349-362.

Arber, E.A.N. and J. PARKIN, 1907. On the origin of angiosperms. - J. Linn. Soc. (Bot). 38: $29-80$.

Argus, G.W., 1974. An experimental study of hybridization and pollination in Salix (willow).-Can. J. Bot. 52: 1613-1619.

ARNOLdI, L.V. and V.V. Zherichin, 1977. Rhynchota in Ponomarenko 1977.

Auber, L., 1965. Atlas des Coléoptères de France, Belgique, Suisse I, Éditions N. Boubee, Paris.

- - 1966. Ibid II.

Autrum, H. and H. STUMPF, 1953. Elektrophysiologische Untersuchungen über das Farbensehen von Calliphora. - Z. vergl. Physiol. 35: 71-104.

AXELROD, D.I., 1952. A theory of angiosperm evolution.-Evolution 6: 29-59.

- - 1960. The evolution of flowering plants. In. S. Tax (Ed.), Evolution after Darwin The evolution of life. University of Chicago Press, Chicago. pp. 227-305.

-, 1966 . Origin of deciduous and evergreen habits in temperate forests. - Evolution 20: 1-15.

- -, 1970. Mesozoic paleogeography and early angiosperm history.-Bot. Rev. 36: 277-319.

Badgley, H.E., C.A. Fleschner and J.C. Hall, 1955. The biology of Spilocornis preticornis Banks (Neuroptera: Coniopterygidae).-Psyche, Camb. 62: 75-81.

BAILEY, I.W. and C.G. NAST, 1945. The comparative morphology of the Winteraceae VII. Summary and conclusions. - J. Arnold Arbor. 26: 37-47.

BaILEY, I.W. and B.G.L. SWAmy, 1951. The conduplicate carpel of dicotyledons and its initial trends of specialization.-Am. J. Bot. 38: 373-379.

BAIRD, A.M., 1938. A contribution to the life history of Macrozamia reidlei.-J. Proc. R. Soc. West Aust. 25: 153-175.

BAKER, H.G., 1955. Self-incompatibility and establishment after "long-distance" dispersal.-Evolution 9: 347-349.

,-- 1959 . Reproductive methods as factors in speciation in flowering plants. Cold Spring Harbor Symposium Quant. Biol. 24: 177-190.

-, 1961 . The adaptation of flowering plants to nocturnal and crepuscular pollinators. $-Q$. Rev. Biol. 36 (1): 64-73.

- , 1966. The evolution, functioning and breakdown of heteromorphic systems. I. The Plumbaginaceae. - Evolution 20: 349-368.

- - 1967. Support for Baker's law-as a rule.-Evolution 21: 853-856.

BAKER, H.G. and P.O. HURD Jr., 1968. Intrafloral ecology.-A. Rev. Ent. 13: 385-414.

Balthasar, V., 1963. Monographie der Scarabaeidae und Aphodiidae der palearktischen und orientalischen Region. Vol. I. Tschechoslowakischen Akademie der Wissenschaften, Prague.

Bannister, M.H., 1965. Variation in the breeding system of Pinus radiata. In H.G. Baker and G.L. Stebbins (Eds). The genetics of colonizing species. Academic Press, London and New York. pp. 353-372.

BARBIER, M., 1970. Chemistry and biochemistry of pollens. In L. Reinhold and J. Linschitz (Eds.).-Progress in Phytochemistry, Vol. 2. Wiley, London. pp.1-34. 
Bateson, P., 1978. Sexual imprinting and optimal outbreeding.-Nature, Lond. 273: 659-660.

Baumann, E., 1978. Rennfliegen (Diptera: Phoridae) als Blütenbesucher. Kritische Sichtung der Literatur. - Flora, Jena 167: 301-314.

BAWA, K.S. and P.A. OPLER, 1975. Dioecism in tropical forest trees.-Evolution 29: 167-179.

BECK, C.B., 1976. Origin and early evolution of angiosperms: a perspective. In C. B. Beck (Ed.). Origin and early evolution of angiosperms. Columbia University Press, New York and London. Pp 1-10.

BELL, C.R., 1971. Breeding systems and floral biology of the Umbelliferae or Evidence for specialization in unspecialized flowers. In V.H. Heywood (Ed.) The biology and chemistry of the Umbelliferae. Academic Press, London. pp. 93-107.

BENGTsson, B.O., 1978. Avoiding inbreeding: at what cost?-J. theor. Biol. 73: 439-444.

BENNET, A.W., 1883. On the constancy of insects in their visits to flowers.-J. Linn. Soc. (Zool.) 17: 175-185.

Benson, R.B., 1945. Classification of the Pamphiliidae (Hymen, Symphyta).-Proc. R. ent. Soc. Lond. 14 (3-4): 25-33.

Berner, U., 1942. Das Einsammeln von Pollen windblütiger Pflanzen durch die Honigbiene und seine biologische Bedeutung.-Biologia gen. 15: 340-343.

Bierzychudek, P., 1981. Pollinator limitation of plant reproductive effort.-Amer. Nat. 117: 838-842.

Bino, R.J. and A.D.J. MeEuse, 1983. Nectaries in a species of Ephedra.-Acta bot. neerl. 32(4):341 (abstract).

Bischoff, H., 1927. Biologie der Hymenopteren, Julius Springer, Berlin.

BLAIR, K.G., 1943. Scolytidae from the Wealden formation.-Ent. mon. Mag. 69:59-60.

BOOTHROYD, L.E., 1930. The morphology and anatomy of the inflorescence and flower of the Platanaceae. - Am. J. Bot. 17: 678-693.

Brandl, P., 1981. Bruchidae, in Freude et al. 1981 pp. 7-22.

BrantJeS, N.B.M., 1976. Riddles around the pollination of Melandrium album (Mill.) Garcke (Caryophyllaceae) during the oviposition by Hadena bicruris Hufn. (Noctuidae, Lepidoptera). I-II. - Proc. K. ned. ak. Wet. Ser. C. 79: 1-12; 127-141.

-, 1978 . Sensory responses to flowers in night-flying moths. In A.J. Richards (Ed.), The Pollination of Flowers by Insects. Academic Press, London pp. 13-19.

Brantjes, N.B.M. and J.A.A.M. Leemans, 1976. Silene otites (Caryophyllaceae) pollinated by nocturnal Lepidoptera and Mosquitoes.-Acta bot. neerl. 25 (4): 281-295.

BRITTON, E.B., 1970. Coleoptera in C.S.I.R.O. The Insects of Australia. Melbourne University Press, Melbourne. pp. 495-621.

Brock, J.P., 1971. A contribution towards an understanding of the morphology and phylogeny of the Ditrysian Lepidoptera. - J. nat. Hist. 5: 29-102.

BROTHERS, D.J., 1975. Phylogeny and classification of the Aculeate Hymenoptera, with special reference to Mutillidae.-Univ. Kans. Sci. Bull. 50: 483-648.

BRUES, C.T., 1937. Superfamilies Ichneumonoidea, Serphoidea, and Chalcidoidea in F.M. Carpenter and J.W. Folsom et al. (Eds), Insects and arachnids from Canadian Amber.Univ. Toronto Stud. geol. Ser., 40: 27-44.

BuRkILL, I.H., 1897. Fertilization of spring flowers on the Yorkshire coast.-J. Bot. Lond. 35: $92-99 ; 138-145 ; 184-189$.

Burmeister, F., 1970. Coleoptera in Stresemann, 1970. pp. 208-463.

BURTT, B.L., 1961. Compositae and the study of functional evolution.-Trans. bot. Soc. Edinb. 39: 216-232.

Butovitsch, V., 1939. Zur Kenntnis der Paarung, Eiablage und Ernährung der Cerambyciden.-Ent. Tidskr. 60 (3-4): 206-258.

Caillol, H., 1914. Catalogue des Coléoptères de Provence.-Soc. linn. de Provence, Marseille.

CAMMerloher, H., 1931. Blütenbiologie. Bornträger, Berlin.

CAMP, W.H., 1947. Distribution patterns in modern plants and problems of ancient dispersals.-Ecol. Monogr. 17:159-183. 
Canright, J.E., 1952. The comparative morphology and relationships of the Magnoliaceae. I. Trends of specialization in the stamens.-Am. J. Bot. 39:484-497.

- - 1953. The comparative morphology and relationships of the Magnoliaceae II. Significance of the pollon.-Phytomorphology 3: 355-365.

- 1955 . The comparative morphology and relationships of the Magnoliaceae IV. Wood and nodal anatomy. - J. Arnold Arbor. 36: 119-140.

- , 1960. Comparative morphology and relationships of the Magnoliaceae III. Carpels. Am. J. Bot. 47: 145-155.

Carleuist, S., 1966. The biota of long-distance dispersal IV. Genetic systems in the flora of oceanic islands.-Evolution 20: 433-455.

Chase, V.C. and P.H. Raven, 1975. Evolutionary and ecological relationships between Aquilegia formosa and A. pubescens (Ranunculaceae), two perennial plants. - Evolution 29: 474-486.

Chesters, K.I.M., F.R. Gnauck and N.F. Hughes, 1967. Angiospermae. In W.B. Harland et al. (Eds). The Fossil Record. Geological Society, London pp. 269-288.

Christenson, L.D. and R.H. Foote, 1960. Biology of fruit flies.-A. Rev. Ent. 5: 171-192.

Clements, F.E. and F.L. Long, 1923. Experimental Pollination: an outline of the ecology of flowers and insects. Washington, D.C. Carnegie Institute of Washington. No. 336.

Cockerell, T.D.A., 1909. Descriptions of Hymenoptera from Baltic amber.-Schr. phys.oekon. Ges. Königsb. 50: 1-20.

- -, 1909a. Some additional bees from Prussian amber. - Ibid. 50: 21-25.

Conen, A.D., 1975. Peats of the Okefenokee swamp-marsh complex.-Geoscience and Man, 11: $123-131$.

Colless, D.H. and D.K. McAlPine, 1970. Diptera in C.S.I.R.O. 1970. pp. 656-740.

Common, I.F.B., 1970. Lepidoptera in C.S.I.R.O. 1970: pp. 765-866.

- - 1975. Evolution and classification of the Lepidoptera.-A. Rev. Ent. 20: 183-203.

CoRBET, S.A., 1970. Insects on Hogweed flowers: a suggestion for a student project.-J. biol. Educ. 4: 133-143.

Corbet, S.A., J. Beament and D. Eisikowitch, 1982. Are electrostatic forces involved in pollen transfer? -Plant, Cell and Environment 5: 125-129.

Corner, E. J. H., 1940. Wayside trees of Malaya. Singapore.

-, 1964. The life of plants. Weidenfeld and Nicolson, London.

- - 1966. The natural history of Palms. Weidenfeld and Nicolson, London.

Cornet, B., 1980. Tropical late Triassic monosulcate and polyaperture angiospermid pollen and their morphological relationship with associated auriculate polyplicate pollen.-Abstr. 5th. Int. Palynol. Conf. Cambridge, p. 91.

- - 1981. Recognition of pre-Cretaceous angiosperm pollen and its relationship to fossil polyplicate pollen.-Abstr. Proc. 12th Annual Meeting A.A.S.P. Palynol. 5: 212-213.

Couderc, H., 1980. Biologie florale de quelques espèces du genre Anthyllis L. et notamment de l' A. montana L. - Bull. Soc. bot. Fr. 127: 139-149.

Couderc, H. and R. Gorenflot, 1978. Adaptation de la fleur entomophile de l' Anthyllis vulneraria L. a l' autogamie.-Bull. Soc. bot. Fr. 125: 369-378.

Craighead, F.G., 1921. Hopkins host-selection principle as related to certain Cerambycid beetles.-J. agric. Res. 1921.

- , 1923. North American cerambycid larvae.-Bull. Dep. Agric. Can. ent. Brch. 27 (N.S.) Pp. 238.

CRAmer, J.M., A.D.J. Meeuse and P.A. Theunissen, 1975. A note on the pollination of nocturnally flowering species of Nymphaea.-Acta bot. neerl. 24 (5-6) : 489-490.

CRANE, R.R., 1985. Phylogenetic analysis of seed plants and the origin of angiosperms.Ann. Missouri bot. Gdn. 72: 716-793.

--, 1985a. Phylogenetic relationships in seed plants.-Cladistics 1 (4): 329-348.

CREPET, W.L., 1972. Investigations of North American cycadeoids: pollination mechanisms in Cycadeoidea.-Am. J. Bot. 59: 1048-1056.

- - 1979. Some aspects of the pollination biology of middle Eocene Angiosperms.-Rev. Paleobot. and Palynol. 27: 213-238.

- , 1979a. Insect pollination: a paleontological perspective.-BioScience 29 (2): 102-108. 
- , 1981. The status of certain families of the Amentiferae during the middle Eocene and some hypotheses regarding the evolution of wind pollination in dicotyledonous angiosperms. In K.J. Niklas (Ed.) Paleobotany, Paleoecology and Evolution, Vol. 1. Praeger, New York.

CREPET, W.L. and C.P. Daghlian, 1980. Castaneoid inflorescences from the middle Eocene of Tennessee and the diagnostic value of pollen (at the subfamily level) in the Fagaceae. Amer. J. Bot. 67: 739-757.

Crepet, W.L. and D.L. Dilcher, 1977. Investigations of angiosperms from the Eocene of North America: a mimosoid inflorescence.-Amer. J. Bot. 64: 714-725.

Crepet, W.L., D.L. Dilcher and T.W. Potter, 1974. Eocene angiosperm flowers.Science, N.Y. 185: 781-782.

Crepet, W.L. and D.W. TAYlor, 1985. The diversification of the Leguminosae: First fossil evidence of the Mimosoideae and Papilionoideae.-Science, N.Y. 228: 1087-1089.

Croneuist, A., 1968. The evolution and classification of flowering plants. Houghton Mifflin Company, Boston, etc.

- , 1971. Introductory botany, 2nd. ed. Harper and Row, New York.

- , 1981. An integrated system of classification of flowering plants. Columbia University Press, New York.

CRowson, R.A., 1954. The natural classification of the families of Coleoptera. Reprint 1967.

E. W. Classey Ltd., Hampton, Middlesex.

- , 1960. The phylogeny of Coleoptera.-A. Rev. Ent. 5: 111-134.

- 1981 . The biology of the Coleoptera. Academic Press, London etc.

Crowson, R.A., W.D.I. Rolfe, J. Smart, C.D. Waterston, E.C. Willey and R.J. Wootton, 1967. Arthropoda: Chelicerata, Pycnogonida, Palaeoisopus, Myriapoda and Insecta. In W.B. Harland et al. (Eds). The fossil record. Geological Society, London, pp. 499-534.

Cruden, R.W. and S.H. Hermann-Parker, 1977. Temporal dioecism: an alternative to dioecism?-Evolution 31: 863-866.

CRUden, R.W. and K.G. Jensen, 1979. Viscin threads, pollination efficiency and low pollenovule rates. -Am. J. Bot. 66 (8): 875-879.

C.S.I.R.O., 1970. The insects of Australia, Melbourne University Press, Melbourne.

CURTIS, J., 1883. Farm insects: being the natural history and economy of the insects injurions to the field crops of Great Britain and Ireland. John van Voorst, London.

Cymorek, S., 1969. Lyctidae in Freude et al., 1969. pp 8-12.

- 1969 a. Bostrychidae. ibid. pp 13-25.

DADD, R.H., 1973. Insect nutrition: current devolopments and metabolic implications.-A. Rev. Ent. 18: 381-420.

Daghlian, C.P., W.L. Crepet and T. Delevoryas, 1980. Investigations of Tertiary angiosperms: a new flora including Eomimosoidea plumosa from the Oligocene of Eastern Texas.-Amer. J. Bot. 67: 309-320.

Dahl, E. and E. HADAc, 1940. Maur som blomsterbestövere.-Nyt. Mag. Naturvid. 81: 46-48.

DAHLGREN,R.M.T., S. ROSENDAL-JENSEN and B.J.NIELSEN, 1981. A revised classification of the angiosperms with comments on correlation between chemical and other characters. In D.A. Young and D.S. Seigler (Eds), Phytochemistry and angiosperm phylogeny. Praeger Publishers, New York. pp 149-204.

Darwin, C., 1876. The effects of cross and self fertilization in the vegetable kingdom. John Murray, London.

DaumanN, E., 1930. Das Blütennektarium von Magnolia und die Futterkörper in der Blüte von Calycanthus.-Planta 11: 108-116.

- , 1935. Die systematische Bedeutung des Blütennektariums der Gattung Iris.-Beih. bot. Zentralbl. 53B: 525-625.

- , 1966. Pollenkitt, Bestäubungsart und Phylogenie.-Novit. bot. Univ. carol. pragensis 1966: 19-28.

-

- , 1972. Zur Blütenmorphologie und Bestäubungsökologie von Mercurialis L. - Preslia 44: 308-315. 
-—, 1975. Ein rudimentaeres Blütennektarium und unterschiedliche Pollenkittreste bei der Rüstler (Ulmus).-Preslia 47: 14-21.

Daumer, K., 1956. Reizmetrische Untersuchung des Farbensehens der Bienen.-Z. vergl. Physiol. 38: 413-478.

- , 1958. Blumenfarben, wie sie die Bienen sehen.-Z. vergl. Physiol. 41: 49-110.

Davis, P.H. and V.H. HeYwood, 1963. Principles of angiosperms taxonomy. Oliver Boyd, Edinburgh and London.

De Gunst: see Gunst, de

De Jong: see Jong, de

Demelt, C. von, 1966. Biologie der mitteleuropäischen Bockkäfer (col. Cerambycidae) unter besonderer Berücksichtigung der Larven. In F. Dahl (Ed.) Die Tierwelt Deutschlands und der angrenzenden Meeresteile 52(2) Bockkäfer oder Cerambycidae I., vii, 1-115.

DEXTER, J.S., 1913. Mosquitoes pollinating orchids.-Science N.Y. 37: 867.

Diels, L., 1916. Käferblumen bei den Ranales und ihre Bedeutung für die Phylogenie der Angiospermen.-Ber. deutsch. Bot. Ges. 34: 758-774.

Dilcher, D.L., 1979. Early angiosperm reproduction: an introductory report.-Rev. Paleobot. and Palynol. 27: 291-328.

Dilcher, D.L. and C.P. DaGhlian, 1977. Investigations of angiosperms from the Eocene of southeastern North America.-Am. J. Bot. 64: 526-534.

Dodson, C.H., 1975. Coevolution of orchids and bees. In L.E. Gilbert and P. Raven (Eds). Coevolution of animals and plants. Univ. Texas Press, Austin. pp. 91-97.

Dodson, C.H. and G.P. Fyrmire, 1961. Preliminary studies in the genus Stanhopea.-Ann. Missouri bot. Gdn 48: 137-171.

Downes, J.A., 1958. The feeding habits of biting flies and their significance in classification.-A. Rev. Ent. 3: 249-266.

Doyle, J.A., 1969. Cretaceous angiosperm pollen of the Atlantic costal plain and its evolutionary significance.-J. Arnold Arbor. 50: 1-35.

$-\ldots, 1973$. The monocotyledons: their evolution and comparative biology V. Fossil evidence on early evolution of the monocotyledons.-Q. Rev. Biol. 48: 399-413.

Doyle, J.A., P. Biens, A. Doerenkamp and S. Jardine, 1977. Angiosperm pollen from the pre-Albian lower Cretaceous of equatorial Africa.-Bull. Cent. Explor. Elf-Aquitaine 1: 451-473.

Doyle, J.A., M. van CAMPo and B. Lugardon, 1975. Observations on exine structure of Eucommiidites and Lower Cretaceous angiosperm pollen.-Pollen Spores 17: 429-486.

Doyle, J.A. and L.J. Hickey, 1976. Pollen and leaves from the mid-Cretaceous Potomac Group and their bearing on early angiosperm evolution. In C.B. Beck (Ed.). Origin and early evolution of angiosperms. Columbia University Press, New York and London. pp. 139-206.

DOYLE, J.D., 1945. Developmental lines in pollination mechanisms in the Coniferales.Scient. Proc. R. Dubl. Soc. N.S. 24: 43-62.

Dronamraju, K.R., 1960. Selective visits of butterflies to flowers; a possible factor in sympatric speciation.-Nature, Lond. 186: 178.

Dufay, C., 1961. Étude de phototropisme des Noctuides (Lepidopt.). Réactions de Noctua pronuha $L$. en présence de deux sources lumineuses de même intensite.-C.R. Paris 252: 1866-1869.

Durden, C.J. and H. Rose, 1978. Butterflies from the Middle Eocene. The earliest occurrence of fossil Papilionoidea (Lepidoptera). - The Pearce-Sellards Series No. 29. Texas Memorial Museum.

EAMES, A.J., 1952. Relationships of Ephedra.-Phytomorph. 2: 79-104.

- , 1961. Morphology of the angiosperms. McGraw-Hill, New York, Toronto, Londen.

Eckstein, K. and V. Butovitsch, 1931. Breitrag zur Kenntnis der Fauna der Kiefernkahlschläge.-Z. angew. Ent. 1931 (non vidi).

Ehrendorfer, F., 1971. Systematik und Evolution: Spermatophyta, Samenpflanzen. In Strasburger. Lehrbuch der Botanik fur Hochschulen. Fischer, Stuttgart.

- -, F., 1973. Liste der Gefasspflanzen Mitteleuropas, 2nd Ed. Gustav Fischer, Stuttgart.

- - 1976. Evolutionary significance of chromosomal differentiation patterns in gymnosperms and primitive angiosperms. In C. B. Beck (Ed.). Origin and early evolution of angiosperms. Columbia University Press, New York and London. pp.220-240. 
EICHLER, A.W., 1878. Blüthendiagramme II. Leipzig.

Elvers, I., 1980. Pollen-eating Thricops flies (Diptera, Muscidae) on Arrhenaterum pubescens and some other grasses. - Bot. Notiser 133: 49-52.

ENDRESS, P.K., 1977. Evolutionary trends in the Hamamelidales-Fagales group. - Plant Syst. Evol. Suppl. 1: 321-347.

ERLANSON, E.W. and F.J. Hermann, 1928. The morphology and cytology of perfect flowers of Populus tremuloides.-Pap. Mich. Acad. Sci. 8: 97-110.

ERMisch, K., 1969. Mordellidae (60. Breitrag zur Kenntnis der Mordelliden), in Freude et al. 1969. pp. 160-196.

Evans, G., 1975. The life of beetles. George Allen \& Unwin Ltd, London.

Evans, H.E. and M.J.W. Eberhard, 1970. The wasps, The University of Michigan Press, Ann Arbor.

Evers, A.M.J., 1979. Malachiidae in Freude et al. 1979: 53-69.

FAEGRI, K., 1965. Reflections on the development of pollination systems in African Proteaceae.-J. S. Afr. Bot. 31: 133-136.

FAeGri, K. and J. Iversen, 1964. Textbook of pollen analysis. Munksgaard, Copenhagen.

FAEGRI, K. and L. van der PuJ, 1980. The principles of pollination ecology, 3rd revised ed. Pergamon Press, Oxford etc.

FEGHNER, G.H., 1972. Development of the pistillate flower of Populus tremuloides following controlled pollination.-Can. J. Bot. 50: 2503-2509.

,-- 1976 . Development of unpollinated ovules of quaking aspen.-Proc. N. E. For. Tree Improv. Conf. 23: 121-128.

Frankie, G.W., 1975. Tropical forest phenology and pollinator plant evolution. In. L.E. Gilbert and P. Raven (Eds). Coevolution of animals and plants. Univ. Texas Press, Austin. pp. 192-209.

FREDERIKSEN, N.O., 1973. New mid-Tertiary spores and pollen grains from Mississippi and Alabama.-Tulane Studies in Geol. and Paleontol. 10: 65-86.

FreE, J.B., 1970. Insect pollination of crops. Academic Press London and New York.

FreUDE, H., 1969. Ptinidae in Freude et al. 1969 pp. 60-74.

- , 1971. Silphidae in Freude et al. 1971. pp. 190-201.

- 1971 a. Rhysodidae in Freude et al. 1971. pp. 93-94.

-, 1976 . Adephaga I. Carabidae in Freude et al. 1976. pp. 7-285.

Freude, H., K. W. Harde and G. A. Lohse (Eds), 1964. Die Käfer Mitteleuropas, Vol.4. Goecke Evers, Krefeld.

- , 1965. Ibid. Vol. 1.

- , 1966. Ibid. Vol. 9.

- , 1967. Ibid. Vol. 7.

- , 1969. Ibid. Vol. 8.

- , 1971. Ibid. Vol. 3.

- , 1974. Ibid. Vol. 5.

- , 1976. Ibid. Vol. 2.

- , 1979. Ibid. Vol. 6.

-, 1981. Ibid. Vol. 10.

FRIIS, E.M., 1983. Upper Cretaceous (Senonian) floral structures of Juglandalean affinity containing Normapolles pollen.-Rev. Paleobot. Palynol. 39: 161-188.

FRIIS, E.M. and A. SKARBY, 1982. Scandianthus gen. nov., angiosperm flowers of Saxifragalean affinity from the Upper Cretaceous of Southern Sweden.-Ann. Bot. 50: 569-583.

Frisch, K. von, 1914. Der Farbensinn und Formensinn der Biene.-Zool. Jahrb. Abt. allg. Physiol. Thiere 35: 1-182.

Froebe, H.A., 1971. Inflorescence structure and evolution in Umbelliferae. In V.H. Heywood (Ed.). The biology and chemistry of the Umbelliferae. Acad. Press, London. Suppl. 1 to Bot. J. Linn. Soc. Vol. 64. pp 157-178.

Fuchs, G.V., 1974. Die Gewinnung von Pollen und Nectar bei Käfern.-Natur Mus., Frankf. 104 (2): 45-54.

Funk, D.T., 1970. Genetics of black walnut. U.S. Department of Agriculture For. Serv. Res. Pap. WO-10. 
Fuersch, H., 1967. Coccinellidae, in Freude et al. 1967. pp. 227-278.

Galil, J., 1973. Topocentric and ethodynamic pollination. In. N.B.M. Brantjes (Ed.) Pollination and dispersal. Publication of the Department of Botany, University of Nijmegen. pp. 85-100.

Geisthardt, M., 1979. Lampyridae in Freude et al. 1979: 9-14.

- , 1979a. Drilidae, ibid 51-53.

Gibbs, P.E., J. Semir and N:D. da Gruz, 1977. Floral biology of Talauma ovata St. Hil. (Magnoliaceae).-Cienc. Cult. S Paulo 29: 1436-1441.

Gilber T, L.E., 1972. Pollen feeding and reproductive biology of Heliconus butterflies. - Proc. natn. Acad. Sci. U.S.A. 69: 1403-1407.

Gilbert, L.E. and P. Raven., 1975. Coevolution of animals and plants. Univ. Texas Press, Austin.

Goldsmith, T. and G.D. Bernard, 1974. The visual system in insects. In M. Rockstein (Ed.), The physiology of insects. II. 2nd Ed. Academic Press, London pp. 165-272.

Goodwin, T. W., 1952. Comparative biochemistry of carotenoids. Chapman and Hall, London.

- , 1958. Carotenoids. In W. Ruhland et al. (Eds). Encyclopedia of plant physiology Vol.X. The metabolism of secondary plant products. Springer, Berlin, etc.

- , 1965. Distribution of carotenoids. In T.W. Goodwin (Ed). Chemistry and biochemistry of plant pigments. Academic Press, London and New York.

- - 1966. The Carotenoids. In T. Swain (Ed). Comparative phytochemistry. Academic Press, London and New York.

- , 1976. Distribution of carotenoids. In T.W. Goodwin (Ed). Chemistry and biochemistry of plant pigments. Academic Press, London and New York. pp. 225-261.

Goot, V.S. van der, and R.A.J. GrabandT, 1970. Some species of the genera Melanostoma, Platycheirus and Pyrophaena (Diptera, Syrphidae) and their relation to flowers. - Ent. Ber. Amst. 30 (7): 135-143.

Goplen, B.P. and S.A. Brandt, 1975. Alfalfa flower colour associated with differential seed set by leafcutter bees. -Agr. J. 67: 804-806.

Gothan, W. AND H. Weyland, 1973. Lehrbuch der Palaobotanik, 3rd Ed. Akademie Verlag, Berlin.

GotTSBERger, G., 1967. Blütenbiologische Beobachtungen and brasilianischen Malvaceeen I.-Öst. bot. Z. 114 .

- , 1970. Beitrage zur Biologie von Annonaceen-Blüten. - Öst. bot. Z. 118: 237-279.

- , 1972. Blütenbiologische Beobachtungen an brasilianischen Malvaceen II. Ö̈st. bot. Z. 120: 439-509.

,-- 1974 . The structure and function of the primitive angiosperm flower. - Acta. bot. neerl. 23: 461-471.

,-- 1977 . Some aspects of beetle pollination in the evolution of flowering plants. - Pl. Syst. Evol. Suppl. 1: 211-226.

- , 1977a. A cantarofilia em Talauma ovata. - XXVIII Congr. Nac. Bot., Belo Horizonte, Minas Gerais, 23-30 Jan. 1977. Abstr. Sessao Tecnica II, 14.

GotTsberger, G. and O.R. Gottlieb, 1980. Blue flowers and phylogeny.-Revta. brasil. Bot. 3: 79-83.

- , 1981. Blue flower pigmentation and evolutionary advancement.-Biochemical Systematics and Ecology 9 (1): 13-18.

GotTsberger, G., I. Silberbauer-Gottsberger and F. Ehrendorfer, 1980. Reproductive biology in the primitive relic angiosperm Drimys brasiliensis (Winteraceae). - Pl. Syst. Evol. 135: 11-39.GRANT, K.A., 1966. A hypothesis concerning the prevalence of red coloration in California hummingbird flowers.-Am. Nat. 100: 85-97.

GRANT, V., 1949. Pollination systems as isolating mechanisms in angiosperms.-Evolution 3: 82-97.

- 1950. The protection of ovules in flowering plants.-Evolution 4: 179201.

- 1 1951. The fertilization of flowers. -Scient. Am. 184: 52-56.

- , 1963. The origin of adaptations. Columbia University Press, New York. 
Grant, V. and K.A. Grant, 1965. Flower pollination in the Phlox family. Columbia University Press, New York and London.

- -, 1968. Hummingbirds and their flowers. Columbia University Press, New York.

Greenacre, M.J., 1984. Theory and applications of correspondence analysis. Academic Press, London.

Grensted, L. W., 1946. An assemblage of Diptera on Cow-parsnip. - Entomologist's mon. Mag. 82:180.

Griffiths, G.C.D., 1972. The phylogenetic classification of Diptera Cyclorrhapha, with special reference to the Structure of the male postabdomen. Series Entomologica vol. 8. Junk, The Hague.

Grinfeld, E.K., 1973. Anthophilous evolution of the Apoidea.-Vestn. Leningr. univ. Ser. biol. 28: 7-15.

Gunst, J.H. de, 1978. De Nederlandse lieveheersbeestjes. -Wetenschappelijke Mededelingen K.N.N.V. 125. Hoogwoud pp. 120.

HABIB, D., 1970. Middle Cretaceous palynomorph assemblages from clays near the Horizon Beta deep sea.-Micropaleontology 16: 345-379.

Hagerup, O., 1943. Myre-bestövning.-Bot. Tidskr. 46: 116-123.

,- 1950 . Thrips pollination in Calluna.-Danske Vidensk. Selskab., Biol. Meded. 18: 1-16.

Hallier, H., 1901. Über die Verwandtschaftsverhaltnisse der Tubifloren und Ebenalen, den polyphyletischen Ursprung der Sympetalen und Apetalen und die Anordnung der Angiospermen überhaupt. Vorstudien zum Entwurf eines Stammbaums der Blütenpflanzen.-Abh. Geb. Naturw., Hamburg 17: 1-112.

- , 1912. L'origine et le système phyletique des Angiospermes exposés a l'aide de leur arbre genéalogique.-Archs. neerl. Sci., ser.2, 1: 146-234.

Hamilton, A.G., 1897. On the fertilization of Eupomatia laurina R.Br.- Proc. Linn. Soc. N. S. Wales 22: 48-55.

HAMmen, T. van der, 1963. A palynological study on the Quaternary of British Guiana.Leid. geol. Meded. 29: 126-168.

Hammen, T. van der, and E. Gonzales, 1960. Upper Pleistocene and Holocene climate and vegetation of the Sabana de Bogota (Colombia, South America).-Leid. geol. Meded. 25: 261-315.

Hammen, T. van der, T.A. WiJMstra and W.H. Zagwijn.,1971. The floral record of the late Cenozoic of Europe. In K.K. Turekian (Ed.). The late Cenozoic glacial ages. Yale Univ. Press, Newhaven. pp. 391-424.

Hannemann, H.J., 1968. Lepidoptera in Urania Tierreich Insecten. Urania Leipzig. pp. 518-604.

HaRde, K.W., 1966. Cerambycidae, in Freude et al. 1966. pp. 7-94.

- , 1979. Buprestidae in Freude et al. 1979 pp. 203-230.

HARPER, J.L., 1957. Biological Flora of the British Isles. Ranunculus acris, R. repens, R. bulbosus. -J. Ecol. 45: 289-342.

HaUPT, H., 1950. Die Käfer aus der eozanen Braunkohle des Geiseltales. Geologica, Berlin 6.

Hawkes, J.G. and P. SMITH, 1965. Continental drift and the age of angiosperm genera.Nature, Lond. 207: 48-50.

HEGI, G., 1906-1931. Illustrierte Flora von Mittel Europa, Ed.1. Lehmann, München.

- 1936 etc. Ibid Ed. 2.

- 1966 etc. Ibid Ed. 3.

HeinRICH, B., 1976. The foraging behaviour of individual bumblebees.-Ecol. monogr. 46: 105-128.

Heiser, C.B., 1962. Some observations on pollination and compatibility in Magnolia.-Proc. Indiana Acad. Sci. 72: 259-266.

Hennig, W., 1966. Phylogenetic systematics. University of Illinois Press, Urbana.

- -, 1969. Die Stammesgeschichte der Insekten. Waldemar Kramer, Frankfurt am Main.

- , 1981. Insect Phylogeny. Translated and edited by A. C. Pont, with revisionary notes of D. Schlee. John Wiley Sons, Chichester.

Hepburn, H. R., 1969. The proventriculus of Mecoptera.-J. Georgia Ent. Soc., 4: 159-167. $-1,1969 \mathrm{a}$. The skeleto-muscular system of the Mecoptera: the head.-Kans. Univ. Sci. Bull., 48: 721-765. 
Herngreen, G.F.W., 1973. Palynology of Albian-Cenomanian strata of borehole 1-QS-1MA, State of Maranhao, Brazil.-Pollen Spores 15: 515-555.

HertZ, M., 1929. Die Organisation des optischen Feldes bei der Biene I. - Z. vergl. Physiol., 8: 693-748.

- 1930 . Ibid. II- Ibid 11: 107-145.

- -, 1931. Ibid. III- Ibid 14: 629-647.

- -, 1935. Zur Physiologie des Formen- und Bewegungssehens II. Auflösungsvermogen des Bienenauges und opmotorische Reaktion.-Z. vergl. Physiol. 21: 579-603.

HESLOP-HARRISON, J., 1958. Ecological variation and ethological isolation.-Uppsala arsskr. 6: $150-158$.

Hess, D., 1983. Die Blüte. Ulmer, Stuttgart.

Hesse, M., 1979. Entwicklungsgeschichte und Utrastruktur von Pollenkitt und Exine bei nahe verwandten entomo- und anemophilen Angiospermen: Polygonaceae.-Flora 168: 558-577.

- - 1980. Entwicklungsgeschichte und Utrastruktur von Pollenkitt und Exine bei nahe verwandten entomophilen und anemophilen Angiospermensippen der Alismataceae, Liliaceae, Juncaceae, Cyperaceae, Poaceae und Araceae.-PI. Syst. Evol. 134: 229-267.

Heukels, H. and S.J. van OOSTsTrOOM, 1973. Flora van Nederland, 17th Ed. WoltersNoordhoff, Groningen.

HeYwoon, V.H., 1973. Taxonomy and ecology. Academic Press, London.

- , 1978. Flowering plants of the world. Oxford University Press, Oxford, London, Melbourne.

Hickey, L.J. and J.A. Doyle, 1977. Early Cretaceous fossil evidence for Angiosperm evolution.-Bot. Rev. 43: 1-104.

HIEPKO, P., 1965. Vergleichend-morphologische und entwicklungsgeschichtliche Untersuchungen über das Perianth bei den Polycarpicae, I. Teil.-Bot. Jb. 84: 359-426.

- -, 1965a. Das zentrifugale Androeceum von Paeonia.-Ber. Dt. bot. Ges. 77: 427-435.

Hilrsalmi, H., 1969. Trientalis europea L. A study of reproductive biology, ecolgy and variation in Finland.-Ann. bot. Fenn. 6: 119-173.

HILL, C.R. and P.R. CRANE, 1982. Evolutionary cladistics and the origin of angiosperms. In K. A. Joysey and A. E. Friday (Eds.). Problems of phylogenetic reconstruction. Systematic Association Spec. Vol. No. 21. Academic Press, London and New York, pp. 269-361.

Hocking, B., 1960. Northern biting flies.-A. Rev. Ent. 5: 135-152.

- - 1975. Ant-plant mutualism : evolution and energy. In L.E. Gilbert and P.H. Raven (Eds.). Coevolution of Animals and Plants. University of Texas Press, Austin and Londen. pp. 78-90.

HODEK, I., 1973. Biology of Coccinellidae, with keys for identification of larvae by coauthors G.I. Savoiskaya and B.Klausnitzer. Prague, Czechoslovak Acad. Sci. Dr. W. Junk N.V., The Hague.

Holloway, B.A., 1976. Pollen-feeding in hover-flies (Diptera-Syrphidae). - N. Z. J. Zool. 3: 339-350.

Hoтchkiss, A.T., 1958. Pollen and pollination in the Eupomatiaceae.-Proc. Linn. Soc. N. S. W. 83: 86-91.Hughes, N.F., 1976. Palaeobiology of angiosperm origins. Cambridge Univ. Press, Cambridge.

- , 1976a. Cretaceous paleobotanic problems. In C.B.Beck (Ed). Origin and early evolution of angiosperms. Columbia Univ. Press, New York and London pp. 11-22.

Hughes, N.F. and J. SMart, 1967. Plant-insect relationships in Paleozoic and later time. In W.B. Harland (Ed). The fossil record. Geological Society, London pp. 107-117.

Hull, D.L., 1967. Certainty and circularity in evolutionary taxonomy.-Evolution 21: 174-189.

- -, 1979. The limits of cladism.-Syst. Zool. 28: 416-440.

ILSE, D., 1928. Über den Farbensinn der Tagfalter.-Z. vergl. Physiol. 8: 658-692.

- , 1941. The colour vision of insects. - Proc. R. phil. Soc. Glasg. 65: 98-112.

- , 1949. Colour discrimination in the Dronefly Eristalis tenax.-Nature, Lond. 163: 255.

ILSE, D. and V.G. Vaidya, 1956. Spontaneous feeding response to colours in Papilio demoleus L.-Proc. Indiana Acad. Sci., 43: 23-31. 
IMMS, A.D., 1957. A general textbook of entomology 9th. edition. Revised by O.W. Richards and R.G. Davies. Methuen. London.

JACOBS, W. and M. RENNER, 1974. Taschenlexikon zur Biologie der Insekten, mit besonderer Berücksichtigung mitteleuropäischer Arten. Gustav Fischer, Stuttgart.

Jan du Chene, R.E., M.S. Ongike and M.A. Sowumni, 1978. Some new Eocene pollen of the Ogwashi-Asabe Formation, South-eastern Nigeria.- Rev. esp. Micropaleont. 10: 285-322.

Janssens, A., 1960. Coléoptères lamellicornes, Faune de Belgique. Institut royal des Sciences naturelles de Belgique, Brussels.

JANZEN, D.H., 1966. Coevolution of mutualism between ants and acacias in Central America.-Evolution 20: 249-275.

JARDine, S., 1967. Spores a expansions en forme d'étateres du Cretace moyen d'Afrique accidentale.-Rev. Palaeobotan. Palynol. 1 (1-4): 235-258.

Jones, C.E. and S.L. BuchmanN, 1974. Ultraviolet floral patterns as functional orientation cues in Hymenopterous pollination systems.-Anim. Behav. 22: 481-485.

JoNG, R. de, 1980. Some tools for evolutionary and phylogenetic studies.-Z. zoöl. Syst. Evolutionsf., 18 (1): 1-23.

Just, T., 1948. Gymnosperms and the origin of angiosperms. - Bot. Gaz. 110: 91-103.

Kaplan, S.M. and D.L. Mulcahy, 1971. Mode of pollination and floral sexuality in Thalictrum.-Evolution 25: 659-668.

Karrer, P. and E. Junker, 1950. Carotenoids. Elsevier Publishing Company Inc., New York, etc.

KASZAB, Z., 1969. Tenebrionidae in Freude et al., 1969. pp. 229-264.

- , 1969a. Lagriidae, ibid. pp. 213-215.

- , 1969b. Alleculidae, ibid. pp. 215-229.

- 1969 c. Oedemeridae, ibid. pp. 79-92.

-, 1969 d. Meloidae, ibid. pp. 118-134.

-, 1969 e. Anthicidae, ibid. pp. 106-118.

KAUFFELD, N.M. and E.L. SORENSEN, 1971. Interrelations of honeybee preference of alfalfa clones and flower color, aroma, nectar volume and sugar concentration.-Kansas Agr. and Exp. Station. Res. Publ. No 163: 1-14.

KAY, Q.O.N., 1978. The role of preferential and assortative pollination in the maintenance of flower colour polymorphisms. In A.J. Richards (Ed). The pollination of flowers by insects. Academic Press, London. pp 175-190.

Kelner-Pillault, S., 1969. Abeilles fossiles ancèstres des apides sociaux. Proceedings of the Sixth Congress of the International Union for the Study of Social Insects, Bern, 1969, pp. 85-93.

KEMP, E.M. and W.K. HARRIS, 1977. The palynology of early Tertiary sediments, Ninetyeast Ridge Indian Ocean.-Palaeont. Ass. London, spec. Papers Palaeont. No. 19: 1-69.

KeVAN, P.G., 1972. Insect pollination of high arctic flowers.-J. Ecol. 60: 831-847.

-, 1972a. Floral colors in the high arctic with reference to insect relation and pollination.Can. J. Bot. 50: 2289-2316.

- - 1973. Parasitoid wasps as flower visitors in the Canadian high arctic.-Anz. Schädlingsk. 46: 3-7.

- , 1978. Floral coloration, its colorimetric analysis and significance in anthecology. In A.J.Richards (Ed). The pollination of flowers by insects. Academic Press, London. pp. 51-78.

Kincaid, T., 1963. The ant-plant, Orthocarpus pusillus Bentham.-Trans. Am. microsc. Soc. 82 (1): 101-105.

KinzelbaCH, R.K., 1971. Morphologische Befunde an Facherflüglern und ihre phylogenetische Bedeutung (Insecta: Strepsiptera). - Zoologica, Stuttg. 41: 119/120, 1-256.

KirChNer, O., 1886. Neue Beobachtung über die Bestäubungseinrichtungen einheimischer Pflanzen. Progr. d. 68. Jahresfeier d. Kgl. Wurttemb. landwirtsch. Akademie Hobenheim, Stuttgart. - Bot. Zbl. 31 (non vidi).

- - 1911. Blumen und Insecten, ihre Anpassungen aneinander und ihre gegenseitige Abhängigkeit. B.G.Teubner's Verlag, Leipzig. 
KLAUS, W., 1979. Zur entwicklungsgeschichtlichen Bedeutungs triadischer, angiospermiden Pollenapertur- und Strukturanlagen.-Beitr. Palaeontol. Österr. 6: 135-177.

KNOLL, F., 1921. Insecten und Blumen. Experimentale Arbeiten zur Vertiefung unserer Kenntnisse über die Wechselbeziehungen zwischen Pflanzen und Tiere II. Bombylius fuliginosus und die Farbe der Blumen.-Abh. zoöl.-bot. Ges. Wien, 12: 17-119.

- - 1925. Lichtsinn und Blütenbesuch des Falters von Deilephila livornica. Z Z. vergl. Physiol 2: $329-380$.

- , 1926. Die Arum-Blütenstande und ihre Besucher (Insecten und Blumen IV).-Abh. zoöl.-bot. Ges. Wien 12: 379-481.

- , 1926a. Insecten und Blüten.-Abh. zoöl.-bot Ges. Wien. 12: 1-646.

- - 1927. Über Abendschwärmer und Schwärmerblumen. - Ber. Dt. bot. Ges. 45: 510-518.

-—, 1935. Über den Scharmflug der Maskenbienen (Prosopis).-Biologia gen. 11: 115-154.

- , 1956. Die Biologie der Blüte. Springer, Berlin.

KNUTH, P., 1898. Handbuch der Blütenbiologie I. Engelmann, Leipzig.

- , 1898a. Ibid II 1.

- 1899 . Ibid II 2.

- 1904 . Ibid III 1.

-, 1905 . Ibid III 2.

Komarov, V.L., 1949. Introduction to botany. Sovetskaya Nauka (in Russian) (non vidi).

- , 1961. The origin of Plants. - Acad. Sci. U.S.S.R., Leningrad. (in Russian) (non vidi).

Königsmann, E., 1976. Das phylogenetische System der Hymenoptera. Teil 1: Einführung, Grundplanmerkmale, Schwestergruppe, und Fossilfunde.-Dt. Ent. Z. (N.F.) 23: 253-279.

- , 1977. Ibid. Teil 2: Symphyta. -Dt. ent. Z. (N.F.) 24: 1-40.

- , 1978. Ibid. Teil 3: Terebrantes. (Unterordnung Apocrita).-Dt. ent. Z. (N.F.) 25: 1-55.

- , 1978a. Ibid. Teil 4: Aculeata (Unterordnung Apocrita). -Dt. ent. Z. (N.F.) 25: 365-435.

KrassiLOV, V.A., 1973. Mesozoic plants and the problem of angiosperm ancestry.-Lethaia 6: $163-178$.

- , 1975. Dirhopalostachyaceae.- a new family of proangiosperms and its bearing on the problem of angiosperm ancestry,-Palaeontographica (B) 153: 100-110.

- - 1977. The origin of angiosperms.-Bot. Rev. 43: 143-176.

KRISTENSEN, N.P., 1975. The phylogeny of the hexapod "orders". A critical review of recent accounts.-Z. zoöl. Syst. Evolut.-forsch. 13: 1-44.

- - 1976. Remarks on the family-level phylogeny of butterflies (Insecta, Lepidoptera, Rhopalocera).-Z. zoöl. Syst. Evolut.-forsch. 14 (1): 25-33.

Krugman, S.L., W.I. Stein and D.M. Schmitr, 1974. Seed biology. U.S. Department of Agriculture Handbook 450: 5-40.

Kugler, H., 1929. Blütenökologische Untersuchungen an Bryonia dioica Jacq.-Flora N.F. 24: $94-118$.

- - 1930. Blütenökologische Untersuchungen mit Hummeln. Der Farbsinn der Tiere; Die optische Bindung in der Natur; das Saftmalproblem.-Planta 10 (2): 229-280.

$-\frac{-}{1931 . ~ B l u ̈ t e n o ̈ k o l o g i s c h e ~ U n t e r s u c h u n g e n ~ m i t ~ H u m m e l n ~ I I . ~ Z u r ~ " B l u m e n s t e t i g k e i t " ~ d e r ~}$ Hummeln.-Ber. Dt. bot. Ges. 49 (8): 424-432.

- - 1932. Blütenokologische Untersuchungen mit Hummeln III. Das Verhalten der Tiere zu Duftstoffen, Duft und Farbe.-Planta 16 (2): 227-276.

- - 1932a. Ibid IV. Der Duft als chemischer Nahfactor bei duftenden und duftlosen Blüten.-Ibid. 16 (3): 534-553.

- -, 1933. Ibid V. Der Blüteneinbruch von Bombus terrester L.-Planta 19 (2): 279-298.

- , 1933a. Ibid VI. Die Reichweite der optischen Fernanlockung.-Planta 19 (4): 781-789.

- , 1935. Ibid VII. Die Anlockung von "Neulingen" durch Blüten. - Planta 23 (5): 692-714.

--, 1943. Hummelblumen. Ein Beitrag zum Problem der "Blumenklassen" auf experimenteller Grundlage.-Ber. dt. bot. Ges. 60 (1): 128-134.

- -, 1943a. Hummeln als Blütenbesucher. Ein Beitrag zur experimentellen Blütenökologie.-Ergeb. Biol. 19: 143-323.

- , 1947. Hummeln und die UV-Reflexion an Kronblattern.-Naturw. 34 (10): 315-317.

-, 1950. Hummeln und Hummelblumen. Ein Beitrag zur experimentellen Blütenökologie.-Naturw. Rundsch. 1950 (6): 269-273. 
-—, 1950a. Der Blütenbesuch der Schlammfliege (Eristalomyia tenax). -Z. vergl. Physiol. 32: 328-347.

,-- 1951 . Blütenfarbung und Insecten bestäubung.-Ber. phys.-med. Ges. Wurzburg. N.F.

66: 28-41.

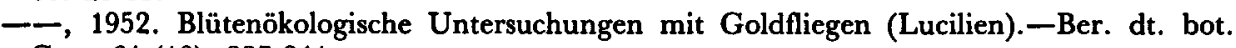
Ges., 64 (10): 327-341.

- , 1955. Zum Problem der Dipterenblumen.-Öst. bot. Z. 102 (4/5): 529-541.

- , 1956. Über die optische Wirkung von Fliegenblumen auf Fliegen.-Ber. dt. bot. Ges. 69: 387-398.

- , 1961. Experimental studies on the behaviour of flower-visiting insects in relation to the characters of flowers. - Recent Advances in Botany. University of Toronto Press, Toronto. pp. 60-64.

--, 1963. UV-Musterungen auf Blüten und ihr Zustande kommen.-Planta 59: 296-329.

- , 1966. UV-Male auf Blüten.-Ber. Dt. Bot. Ges. 76 (2): 57-70.

- , 1970. Blütenökologie. Gustav Fischer Verlag, Stuttgart.

- , 1971. Zur Bestäubung grossblumiger Datura-Arten.-Flora, Jena 160: 511-517.

- 1971 a. UV-Musterungen bei Alpenblumen.-Jahrb. Vereins zum Schutze der Alpenpflanze und -Tiere e.v. 36: 61-65.

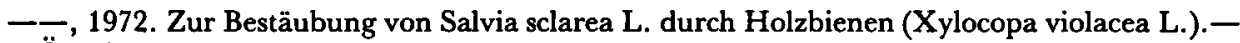
Öst. bot. Z. 120: 77-85.

-—, 1977. Zur Bestäubung mediterraner Frühjahrsblüher.-Flora, Jena 166: 43-64.

- -, 1979. Zur Bestäubung von Echinops ritro L. - Ber. Dt. Bot. Ges. 92: 637-643.

KüHN, A., 1927. Über den Farbsinn der Bienen.-Z. vergl. Physiol. 5: 762-800.

KüHN, A. and F. PoHL, 1924. Zum Nachweis des Farbenunterscheidungsvermogens der Bienen.-Naturwissenschaften 12: 116-118.

Kuyten, P.J., 1978. Revision of the Indo-Australian species of the genus Phaeochrous Costelnau, 1840 (Coleoptera: Scarabaeidae, Hybosotinae), with notes on the African species.-Zoöl. Verh. No. 165.

KWAK, M.M., 1977. Pollination ecology of five hemiparasitic, large-flowered Rhinanthoideae with special reference to the pollination behaviour of nectar-thieving, short-tongued bumblebees. - Acta. bot. neerl. 26: 97-107.

$-1,1978$. Pollination, hybridization and ethological isolation of Rhinanthus minor and $R$. serotinus (Rhinanthoideae; Scrophulariaceae) by bumblebees (Bombus Latr.).-Taxon 27: 145-158.

- , 1979. Effects of bumblebee visits on the seed set of Pedicularis, Rhinanthus and Melampyrum (Scrophulariaceae) in the Netherlands. - Acta bot. neerl. 28: 177-195.

,-- 1979 a. Maintenance of species integrity in sympatrically occurring Rhinanthus minor and R. serotinus in the Netherlands.-Oecologia 41: 1-9.

- - 1979b. Variation in Rhinanthus (Rhinanthoideae; Scrophulariaceae) in relation to bumblebee pollination. In L.J. Musselman, A.D. Worsham and R.E. Eplee (Eds). Proceedings of the Second Symposium on parasitic weeds. North Carolina State University, Raleigh, N.C. pp. 48-58.

,$-- 1979 \mathrm{c}$. The role of bumblebees in the pollination and variation of some Rhinanthoideae (Scrophulariaceae). Thesis, University of Groningen

Lakatos, I., 1976. The methodology of scientific research programmes. Philosophical Papers Vol. 1. Cambridge University Press, Cambridge etc.

Lanjouw, J., P.A. Florschütz, K.U. Kramer, A.M.W. Mennega, A.C. de Roon, F.A. Staffleu, 1968. Compendium van de Pteridophyta en Spermatophyta. A.Oosthoek's Uitgeversmaatschappij, Utrecht.'

LARsSon, S.G., 1978. Baltic Amber- a palaeobiological study. Entomonograph Vol. 1. Scandinavian Science Press. Klampenborg.

Lebart, L., A. MORINEAu and K.M. WARWICK, 1984. Multivariate descriptive statistical analysis. John Wiley and Sons, New York.

Leereveld, H., A.D.J. Meeuse and P. Stelleman, 1976. Anthecological relationship between reputedly anemophilous flowers and syrphid flies II. Plantago media L. - Acta bot. neerl. 25: 205-211. 
LeLEJI, O.I., 1973. Apparent preference by bees for different colours in cowpeas (Vigna sinensis (L.) Savi ex Hassk.). - Euphytica 22: 150-153.

Lepage, M. and R. Boch, 1968. Pollen lipids attractive to honey-bees.-Lipids. 3: 530-534. LEPPIK, E.E., 1957. A new system for classification of flower types.-Taxon 6: 64-67.

- , 1957a. Evolutionary relationships between entomophilous plants and anthophilous insects. - Evolution 11: 466-481.

- , 1971. Paleontological evidence on the morphogenic development of flower types. Phytomorph. 21: 164-174.

-, 1974 . Evolutionary interactions between rhododendrons, pollinating insects and rust fungi (Preliminary Report).-Q. Bull. Am. Rhodod. Soc. 28: 70-89.

LEvin, D.A., 1969. The effect of corolla colour and outline on interspecific pollen flow in Phlox.-Evolution 23: 444-455.

Levin, D.A. and W.W. ANDerson, 1970. Competition for pollinators between simultaneously flowering species.-Am. Nat. 104: 455-467.

LEwIs, D., 1942. The evolution of sex in flowering plants.-Biol. Rev. 17: 46-67.

LiNcK, O., 1949. Fossile Bohrgänge (Anobichnidium simile n.g., n.s.p.) an einem Keuperholz.-N. Jb. Mineral. Geol. Pal., 1949 (B): 180-185.

LLOyD, D.G., 1979. Some reproductive factors affecting the selection of self-fertilization in plants. -Am. Nat. 113: 67-79.

-, 1980 . Demographic factors and mating patterns in angiosperms. In O.T. Solbrig (Ed.). Demography and evolution in plant communities. Blackwell's, Oxford. pp 67-88.

LoHSE, G.A., 1964. Staphylinidae I (Micropeplinae bis Tachyporinae) in Freude et al. 1964.

- , 1967. Cryptophagidae, in Freude et al. 1967. pp. 110-158.

- , 1969. Anobiidae, in Freude et al. 1969. pp. 27-59.

- 1971 . Hydrophilidae, in Freude et al. 1971. pp. 127-156.

-, 1979 . Melyridae in Freude et al. Vol 6. 1979. pp. 69-83.

- , 1979a. Cleridae, ibid, pp. 84-97.

- , 1979b. Elateridae, ibid, pp. 103-185.

- 1 1979c. Eucnemidae, ibid, pp. 187-200.

- , 1979d. Dascillidae, ibid, pp. 249-250.

- , 1979e. Helodidae, ibid, pp. 250-263.

-, 1979f. Eucinetidae, ibid, pp. 264.

- , 1979g. Dermestidae, ibid, pp.304-326.

- , 1979h. Throscidae, ibid, pp. 201-203.

LOEw, E., 1895. Einführung in die Blütenbiologie, auf historischer Grundlage. Duemmlers, Berlin.

MachatschKe, J. W., 1969. Scarabaeidae, in Freude et al. 1969. pp. 266-366.

MAcior, L.W., 1968. Pollination adaptation in Pedicularis groenlandica.-Am. J. Bot. 55: 927-932.

- -, 1968a. Pollination adaptation in Pedicularis canadensis.-Am. J. Bot. 55: 1031-1035.

- -, 1969. Pollination adaptation in Pedicularis lanceolata. - Am. J. Bot. 56: 853-859.

- , 1970. The pollination ecology of Pedicularis in Colorado._Am. J. Bot. 57: 716-728.

- , 1971. Co-evolution of animals and plants; systematic insights from plant-insect relationships.-Taxon 20: 17-28.

- , 1973. The pollination ecology of Pedicularis on Mount Rainier.-Am. J. Bot. 60: 863-871.

- - 1974. Behavioral aspects of coadaptations between flowers and insect pollinators.-Ann. Missouri bot. Gdn 61: 760-769.

- , 1975. The pollination ecology of Pedicularis (Scrophulariaceae) in the Yukon Territory.-Am. J. Bot. 62: 1065-1072.

- - 1977. The pollination ecology of Pedicularis (Scrophulariaceae) in the Sierra Nevada of California.-Bull. Torrey bot. Club. 104: 148-154.

Mägdefrau, K., 1968. Paläobiologie der Pflanzen, 4th Ed. Fischer, Jena.

MalysheV, S.I., 1968. Genesis of the Hymenoptera and the phases of their evolution. (Translation from Russian edition of 1966 and somewhere altered, edited by O.W. Richards and Boris Uvarov). Methuen, London. 
Manning, A., 1956. The effect of honey-guides.-Behaviour 9: 114-139.

MARTYNOV, A.V., 1937. The wings of the termites in relation to the phylogeny of this and neighbouring groups of insects.-Acad. Sci. U.S.S.R., pp. 83-1447. (In Russian).

MAYR, E., 1947. Ecological factors in evolution.-Evolution 1: 263-288.

MCAlpine, J.F., 1973. A. fossil ironomyiid fly from Canadian amber. (Diptera: Ironomyiidae). -Can. Ent. 105: 105-111.

McAlpine, J.F. and J.E.H. Martin, 1966. Systematics of Sciadoceridae and relatives with descriptions of two new genera and species from Canadian amber and erection of family Ironomyiidae (Diptera: Phoroidea). -Can. Ent. 98: 527-544.

MCGREGOR, S.E., 1976. Insect pollination of cultivated crop plants. Agricultural Handbook No. 496. Agricultural Research Service. U.S. Dept. of Agriculture. Washington D.C.

Meeuse, A.D.J., 1965. Angiosperms- past and present.-Advg. Front. Pl. Sci. 11: 1-228.

- 1 1972. Sixty-five years of theories of the multiaxial flower.-Acta Biotheor. 21: 167-202.

- , 1974. Floral evolution and emended anthocorm theory. In T.M. Varghese (Ed). International Bio-Sci. Monograph I. Hissar, New Delhi. pp. 1-188.

- $1975 \mathrm{a}$. Origin of the angiosperms-problem or inaptitude?-Phytomorphology 25: 373-379.

- , 1977. Coincidence of characters and angiosperm phylogeny.-Phytomorphology 27:314-322.

- , 1978. Entomophily in Salix: theoretical considerations. In A.J. Richards (Ed). The pollination of flowers by insects. Academic Press, London. pp. 47-50.

-, 1979 . Why are the angiosperms so successful? $\mathrm{A}$ morphological, ecological and phylogenetic approach I and II.-Proc. K. ned. akad. Wet. (C) 82: 343-369.

- , 1979a. The significance of the Gnetatae in connection with the early evolution of the angiosperms. In P.K.K. Nair (Ed). Glimpses in plant research 4. Vikas Publishing House, New Delhi pp. 62-73.

- - 1982. Ecological aspects of Phylogenetic approaches to taxonomic Classification. In K.A. Joysey and A.E. Friday (Eds). Problems of Phylogenetic reconstruction. Academic Press, London and New York. pp. 257-268.

MeEuse, B.J.D., 1961. The story of pollination. Ronald, New York.

Melville, R., 1962. A new theory of the angiosperm flower. I. The gynoecium.-Kew Bull. 16: $1-50$.

-, 1963 . A new theory of the angiosperm flower. II. The androecium.-Kew Bull. 17: 1-63.

- - 1983. Glossopteridae, Angiospermidae and the evidence for angiosperm origin. - Bot. J. Linn. Soc. 86: 279-323.

Menzel, R., 1971. Über den Farbsinn von Paravespula germanica F. (Hymenoptera): ERG und selektive Adaptation. -Z. vergl. Physiol. 75: 86-104.

Michener, C.D., 1964. Evolution of the nests of bees.-Am. Zoologist. 4 (2): 227-239.

- , 1969. Comparative social bahaviour of bees.-A. Rev. Ent. 14: 299-342.

Mildenhall, D.C., 1978. Cranwellia costata n. sp. and Podosporites erugatus n. sp. from middle Pliocene (? early Pleistocene) sediments, South Island, New Zealand.-J. R. Soc. N.Z. 8: 253-274.

Mrldenhall, D.C. and Y.M. Crosbie, 1979. Some porate pollen from the upper Tertiary of New Zealand.-N.Z. Jl Geol. Geophys. 22: 499-508.

MJOBERG, E., 1905. Biologiska och morfologiska studier ofver Farons insect fauna.-Arkiv for Zoologi., 1905.

Moнr, K. H., 1966. Chrysomelidae, in Freude et al. 1966. pp. 95-280.

Molisor, A., 1936. Neue Beobachtungen und Versuche mit Grabwespen VIII.-Biol. Zentralbl., 1936 (non vidi).

- , 1937. Versuche betreffend die "Rotblindheit" solitärer Bienen.-Verh. zoöl. bot. Ges. Wien 86: 125-139.

- , 1937a. Zur vergleichende Psychologie der akuleaten Hymenopteren, auf experimenteller Grundlage.-Biol. gen., 1937 (non vidi).

MORERE, J.L., 1971. Nutrition des insectes. Le carotène: substance indispensable pour la nutrition de Plodia interpunctella (Lep. Pyralidae). - C. r. Acad. Sci., Paris, Ser. D. 272: 2229-2231. 
Moseley, M.F. Jr., 1958. Morphological studies in the Nymphaeaceae. I. The nature of the stamens.-Phytomorphology 8: 1-29.Mound, L.A., B.S. Heming and J.M. Palmer, 1980. Phylogenetic relationships between the families of recent Thysanoptera (Insecta). Zool. J. Linn. Soc. 69: 111-141.

MÜLLER, H., 1873. Die Befruchtung der Blumen durch Insekten und die gegenseitigen Anpassungen beider. Engelmann, Leipzig.

- 1881 . Alpenblumen, ihre Befruchtung durch Insecten und ihre Anpassungen an dieselben. Leipzig, Verlag von Wilhelm Engelmann.

Muller, J., 1970. Palynological evidence on early differentiation of Angiosperms.-Biol. Rev. 45: 417-450.

- , 1981. Fossil pollen records of extant Angiosperms.-Bot. Rev. 47 (1): 1-142.

- , 1984. Significance of fossil pollen for angiosperm history.-Ann. Missour bot. Gdn 71: 419-443.

NaIR, P.K.K., 1979. The palynological basis for the triphyletic theory of angiosperms.Grana palynol. 18: 141-144.

Norvick, M.S. and D. Burger, 1976. Palynology of the Cenomanian of Bathurst Island, Northern Territory, Australia.-Bur. Miner. Res. Geol. Geophys. Bull. 151: 1-119.

OldRoyd, H., 1964. The Natural History of Flies. Weidenfeld and Nicolson, London. OzEnda, P., 1952. Remarques sur quelques interprétations de l'étamine.Phytomorphology 2: 225-231.

Paramonov, S.J., 1953. A review of Australian Nemestrinidae (Diptera).-Aust. J. Zool. 1: 242-290.

Parenti, L.R., 1980. A phylogenetic analysis of the land plants.-Biol. J. Linn. Soc. 13: 225-242.

Parkin, J., 1914. The evolution of the inflorescence.-J. Linn. Soc. (Bot.) 42: 511-553.

- 1 1952. The unisexual flower -a criticism. - Phytomorphology 2: 75-79.

- -, 1955. A plea for a simpler gynoecium.-Phytomorphology 5: 46-57.

Parmenter, L., 1952. Flies at Ivy-bloom.-Entomologist's Rec. J. Var. 64: 90-91.

- , 1957. Flies (Diptera) and their relations with Plants. - Lond. Nat. 37: 115-125.

Paulian, R., 1943. Les Coléoptères, Formes, moeurs, rôle. Payot, Paris.

Paulus, H.F., 1979. Nosodendridae in Freude et al. 1979: 327-328.

- , 1979a. Byrrhidae, ibid 328-350.

Pedersen, M.W. and F.E. Todd, 1949. Selection and tripping in alfalfa clones by nectar collecting honey bees. - Agr. J. 41:247-249.

Peez, A. von, 1967. Lathridiidae in Freude et al., 1967. pp. 168-190.

- 1971 . Liodidae in Freude et al., 1971. pp. 243-265.

Pennell, F.W., 1948. The taxonomic significance of an understanding of floral biology.Brittonia 6: 301-308.

Pervukhina, N.V., 1967. The pollination of the primary Angiosperms and the evolution of modes of pollination. (In Russian). - Bot. Z. (Moscow) 52: 157-188. (non vidi).

Picard, F., 1929. Coléoptères Cerambycidae. Faune de France 20. Paris.

PijL, L. van der, 1953. On the flower biology of some plants from Java.-Ann. Bogor. 1: 77-99.

,-- 1954 . Xylocopa and flowers in the Tropics. I-II.-Proc. K. ned. akad. Wet. Ser. C. 57: 413-423; 541-551; 552-562.

$-\frac{1}{4}, 1960$. Ecological aspects of flower evolution. I. Phyletic evolution.-Evolution 14: 403-416. $-\frac{1}{44-59}$.
. Ecological aspects of flower evolution. II. Zoophilous flower classes.-Evolution 15:

$-\frac{1}{6}, 1966$. Ecological aspects of fruit evolution.-Proc. K. ned. Akad. Wet. (Ser. C) 69: $597-640$.

$-\frac{1}{-1969}$. Evolutionary action of tropical animals on the reproduction of plants.-Biol. J. Linn. Soc. 1: 85-92.

Pirozinski, K.A., 1976. Fossil fungi.-A. Rev. Phytopathol. 14: 237-246.

Poddubmayer-Arnoldi, V., 1960. Study of fertilization in the living material of some angiosperms.-Phytomorphology 10: 185-198. 
Poloschenzeff, P., 1929. Zur Biologie von Spondylis buprestoides L. -Russk. ent. Oborz. 23.

- , 1931. Die wichtigsten schädlichen Kiefern-Insekten und ihre forstliche Bedeutung. Mitt. Leningr. forsttechn. Akad. 1 (38).

Ponomarenko, A.G., 1977. Mesozoic beetles (in Russian). Nauka publishing house, Moscow.

Porsch, O., 1904. Die Anlockungsmittel der Blumen im Lichte neuerer Forschung.-Mitt. naturw. Ver. Wien. 2 (4-7): 25-53.

-, 1956. Windpollen und Blumeninsekt.-Öst. bot Z. 103: 1-18.

Porter, C.L., 1959. Taxonomy of flowering plants. Freeman, San Fransisco and London.

Prance, G.T. and A.B. ANDERsen, 1976. Studies of the floral biology of neotropical Nymphaeaceae 3.-Acta amazonica 6 (2): 163-170.

Prance, G.T. and J.R. Arias, 1975. A study of floral Biology of Victoria amazonica (Poepp.). Sowerby (Nymphaeaceae). -Acta amazonica 5 (2): 109-139.

Prance, G.T., A.E. Prance and J.R. Arias, 1975. A biologia floral de Victoria amazonica (Poepp.). Sowerby (Nymphaeaceae).-Cienc. Cult. S Paulo 27: 1293-1297.

Prantl, K., 1887. Beiträge zur Morphologie und Systematik der Ranunculaceen.-Bot. J. 9: 359-372.

Price, M.V. and N.M. WAser, 1979. Pollen dispersal and optimal outcrossing in Delphinium nelsoni.-Nature, Lond. 277: 294-297.

Proctor, M.C.F., 1978. Insect pollination syndromes in an evolutionary and ecosystemic context. In A.J. Richards (Ed). The pollination of insects. Academic Press, London. pp. 105-116.

- , in press. Pollination. In B. King (Ed.), Reproductive biology. George Allen and Unwin, London (1987?).

Proctor, M. and P. Yeo, 1973. The pollination of flowers. Collins, London.

Purseglove, J.W., 1972. Tropical crops. Monocotyledones Vol. 2. Wiley, New York.

Radford, A.E., W.C.Dickison, J.R. MASey and C.R. Bell, 1974. Vascular Plant Systematics, Harper and Row, New York etc.

Rasnicijn, A.P., 1972. Pereponcatokrylye nasekomye Praeaulacidae iz pozdnej jury Karatau.-Paleont. z., 1972 (1): 70-87.

- , 1975. Vyssie pereponcatokrylye mezozoja. - Tr. Paleont. Inst., 147:1-134.

-, 1980 . Proiskhozhdeniye $\mathrm{i}$ evolyutsiya pereponchatokrylykh.-Tr. Paleont. Inst. A.N. SSSR, 174: 1-191.

Rattray, G., 1913. Notes on the pollination of some South African cycads.-Trans. R. Soc. South Africa 3: 259-270.

RAvEN, P., 1972. Why are bird-visited flowers predominantly red?-Evolution 26: 674 .

- , 1973. Evolution of subalpine plant groups in New Zealand.-N.Z. J1 Bot. 11: 177-200.

Raven, P.H., R.F. Evert and H.Curtis, 1976. Biology of Plants. Worth publishers, New York.

Reitter, E., 1908. Fauna Germanica Vol. I. K.G. Lutz'Verlag, Stuttgart.

- , 1909. Ibid Vol. 2.

- , 1911. Ibid. Vol. 3.

- - 1912. Ibid. Vol. 4.

- , 1916. Ibid. Vol. 5.

Richards, O.W., 1962. A revisional study of the masarid wasps (Hymenoptera, Vespoidea). Trustees of the British Museum (Natural History), London.

Richards, O.W. and R.G. Davies, 1977. Imm's general textbook of entomology, 2 Vols, 10th Ed., Chapman and Hall, London.

Ricketr, H.W., 1944. The classification of inflorescences.-Bot. Rev. 10: 187-231.

RIEK, E.F., 1953. Fossil mecopteroid fossils from the Upper Permian of New South Wales. Rec. Aust. Mus. 23: 55-87.-, 1955 . Fossil insect from Triassic beds at Mt. Crosby, Queensland.-Aust. J. Zool., 3 (4): 654-691.

-, 1970 . Hymenoptera in C.S.I.R.O. The Insects of Australia. Melbourne Univ. Press., Melbourne. pp. 867-959.

- , 1970a. Neuroptera in C.S.I.R.O. 1970, pp. 472-494. 
Romer, A.S., 1966. Vertebrate Paleontology. The University of Chicago Press, Chicago and London.

Romero, E.J. and L.J. Hickey, 1976. A fossil leaf of Akaniaceae from Paleocene beds in Argentina.-Bull. Torrey bot. Club 103: 126-131.

Ross, H.H., 1955. The evolution of the insect orders.-Ent. News, 66: 197-208.

RotschilD, H., 1975. Remarks on carotenoids in the evolution of signals. In L.E. Gilbert and P.H. Raven (Eds.). Coevolution of Animals and Plants. Univ. of Texas Press, Austin and London. pp. 20-50.

ROUleAU, E., 1981. Guide to the generic names appearing in the Index Kewensis and its fifteen supplements. Jules Chatelain Inc., Cowanville, Canada.

SAmpSON, F.B., 1974. A new pollen type in the Winteraceae.-Grand 14: 11-15.

SAVIDGE, J.P., 1976. The angiosperm flower and related structures. In M.A. Hall. (Ed). plant structure, function and adaptation. The Macmillan Press, London and Basingstoke. pp. 326-378.

SCHEMSKe, D.W., 1980. The evolutionary significance of extrafloral nectar production by Costus woodsonii (Zingiberaceae): an experimental analysis of ant protection.-J. Ecol. 68: 959-967.

Schemske, D.W., M.F. Willson, M.N. Melampy, L.J. Miller, L. Verner, K.M. SCHEMSKe and L.B. BeST, 1978. Flowering ecology of some spring woodland herbs.Ecology 59: 351-366.

Schicha, E., 1967. Morphologie und Function der Malachiiden-mundwerkzeuge unter besonderer Berücksichtigung von Malachius bipustulatus L. (Coleopt., Malacodermata).Z. Morph. Ökol. Tiere 60: 376-433.

SCHLEE, D., 1977. Florale und extraflorale Nectarien sowie Insektenkot als Nahrungsquelle für Chironomidae. -Imagines (und andere Diptera).-Stuttg. Beitr. Naturk. (A), 300, pp. 16.

SChLEe, D. and H.G. Dietrich, 1970. Insektenführender Bernstein aus der Unterkreide des Libanon.-Neues Jahrb. Geol. Palaeont. 1970: 40-50.

Schlegtendal, A., 1934. Beitrag zum Farbensinn der Arthropoden._Z. vergl. Physiol. 20: 545-581.

Schmiedeknecht, O., 1930. Die Hymenopteren Nord- und Mitteleuropas. 2nd. Ed. Gustav Fischer, Jena.

SCHOIJEN, T.H., 1916. Beretning om skadeinsekter og plantesygdommer: land och havebruket 1915. Kristiania 1916. (Ref.: Rev. appl. Entom. 1916).

Schremmer, F., 1941. Versuche zum Nachweis der Rotblindheit von Vespa rufa.-Z. vergl. Physiol. 28: 457-466.

- - 1953. Blütenbiologische Beobachtungen an Labiaten.-Öst. bot. Z. 100: 8-24.

- , 1959. Blütenbiologische Beobachtungen in Istrien.-Öst. bot. Z. 106: 177-202.

Schuster, J.C., 1974. Saltatorial Orthoptera as common visitors to tropical flowers.Biotropica 6: 138-140.

SChuster, R.M., 1976. Plate tectonics and its bearing on the geographical origin and dispersal of angiosperms. In C.B. Beck (Ed.) Origin and early evolution of angiosperms. Columbia University Press, New York and London. pp 48-138.

Schwarzbach, M., 1950. Das Klima der Vorzeit. Eine Einführung in die Palaoklimatologie, Enke, Stuttgart.

Schweitzer, H.J., 1977. Die Raeto-Jurassischen Floren des Iran und Afghanistans, 4. Die Raetische Zwitterblüte Irania hermaphroditica nov. spec. und ihre Bedeutung für die Phylogenie der angiospermen.-Palaeontographica (B), 161: 98-145.

SHARP, D., 1895. Insects. Vol. I. Dover Plublications Inc. New York 1970.

- - 1899. Ibid. Vol. 2.

SHAw, R.C., 1962. The biosystematics of Scrophularia in western North America.-Aliso 5: 147-148.

Skalski, A.W., 1976. Les lepidopteres fossiles de l'ambre.-Linneana belgica, 6(7): 154-169. - , 1976a. Ibid (2ième partie), - Ibid 6(8): 195-208.

-, $1976 \mathrm{~b}$. Ibid (3ième partie et fin), - Ibid 6(9): 221-233.

Solbrig, O.T. and R.C. Rollins, 1977. The evolution of autogamy in species of the mustard genus Laevenworthia.-Evolution 31: 265-281 
Sole de Porta, N., 1971. Algunos generos nuevos de polen procedentes de la Formacion Guaduas (Maastrichtiense- Paleoceno) de Colombia.-Studia Geol., Salamanca 2: 133-143. SPORNE, K.R., 1965. The morphology of gymnosperms. Hutchinson, London.

,- 1971 . The mysterious origin of flowering plants. Oxford Biology Readers no. 3. Oxford University Press, London.

- - 1974. The morphology of angiosperms. Hutchinson, London.

SPORNKRAFT, K., 1967. Nitidulidae, in Freude et al., 1967. pp. 20-77.

SpRENGel, C.K., 1793. Das entdeckte Geheimnis der Natur im Bau und in der Befruchtung der Blumen. Facsimile- Reprint Mayer and Mueller, Berlin (1893).

STebrins, G.L., 1950. Variation and evolution in plants. Columbia University Press, New York.

-, 1951. Natural selection and differentiation in angiosperm families.-Evolution 5: 299-324.

-, 1974. Flowering plants, evolution above the species level. The Belknap Press of Harvard University Press, Cambridge, Massachusetts.

SteENIS, C.G.G.J., 1972. The mountain flora of Java. E.J. Brill, Leiden.

- , 1976. Autonomous evolution in plant and animal evolution.-Garden's Bull. (Singapore) 29: 103-126.

Steffan, A.W., 1979. Dryopidae in Freude et al., 1979. pp. 265-294.

Steinbach, G., 1970. Hymenoptera in Stresemann, 1970. pp. 158-207.

Stelleman, P., 1978. The possible role of insect visits in pollination of reputedly anemophilous plants, exemplified by Plantago lanceolata and Syrphid flies. In: A.J. Richards (Ed.), Pollination of flowers by insects. Academic Press, London. pp. 41-46.

,-- 1981 . Anthecological relations between reputedly anemophilous flowers and Syrphid flies. $V$. Some special aspects of the visiting of Plantago media and P. lanceolata by insects. - Beitr. Biol. Pfl. 55: 157-167.

- , 1982. De betekenis van de biotische bestuiving bij Plantago lanceolata. Thesis, Amsterdam.

Stelleman, P. and A.D.J. Meeuse, 1976. Anthecological relations between reputedly anemophilous flowers and Syrphid flies I. The possible role of Syrphid flies as pollinators of Plantago.-Tijdschr. Ent. 119: 15-31.

Steward, F.C., 1964. Plants at work. Principles of Biology Series. Addison-Wesley Publishing Company, Reading, Massachusetts.

Stoffers, A.L., C. Kalkman, F.A. Stafleu and H.C.D. de Wit, 1982. Compendium van de Spermatophyta. Bohn, Scheltema \& Holkema, Utrecht and Antwerpen.

Straka, H., 1975. Pollen- und Sporenkunde. Fischer Stuttgart.

Strassburger, E., 1967. Lehrbuch der Botanik. 26th Ed. revised by D. von Denffer, k. Mägdefrau, W. Schumacher and F. Firbas. Fischer, Stuttgart.

Stresemann, E. (Ed.), 1969. Exkursionsfauna von Deutschland. II/2. Volk und Wissen, Volkseigener Verlag, Berlin (E).

-

STruWe, G., 1972. Spectral sensitivity of the compound eye in butterflies (Heliconius).-J. comp. Physiol. 79: 191-196.

- , 1972a. Spectral sensitivity of single photoreceptors in the compound eye of a tropical butterfly (Heliconius numata). -J. comp. Physiol. 79: 197-201.

Sussman, R.W. and P.H. Raven, 1978. Pollination by lemurs and marsupials: an archaic coevolutionary system.-Science, N.Y. 200: 731-736.

Swanson, B.G.L. and S.H. SOHMER, 1976. The biology of Podophyllum peltatum L. (Berberidaceae), the may apple. II. The transfer of pollen and success of sexual reproduction.-Bull. Torrey bot. Club 103: 223-226.

SwiHart, C.A., 1971. Colour discrimination by the butterfly Heliconius charitonius Linn.Anim. Behav. 19: 156-164.

TAkHtajan, A., 1959. Die Evolution der Angiospermen. Fischer, Jena.

- , 1969. Flowering plants, origin and dispersal. Oliver and Boyd, Edinburgh.

- , 1980. Outline of the classification of flowering plants. (Magnoliophyta).-Bot. Rev. 46: 225-359. 
ThIEN, L.B., 1974. Floral biology of Magnolia.-Am. J. bot. 61: 1037-1045.

-, 1976 . The pollination of Drimys sect. Tasmannia.-J. bot. Soc. Amer., meeting 21-26 aug. 1976, abstr.: 20-21.

ThIEN, L.B. and F. UTECH, 1970. The mode of pollination in Habenaria obtusata (Orchidaceae).-Am. J. Bot. 57: 1031-1035.

Thiessen, D.D. and B. GregG, 1980. Human assortative mating and genetic equilibrium: an evolutionary perspective. - Ethol. Sociobiol. 1: 111-140.

Thomson, J.D. and S.C.M. BARRETT, 1981. Temporal variation of gender in Aralia hispida Vent. (Araliaceae).-Evolution 35: 1094-1107.

ThORNE, R.F., 1981. Phytochemistry and angiosperm phylogeny, a summary statement. In D.A. Young and D.S. Seigler (Eds). Phytochemistry and angiosperm phylogeny. Praeger Publishers, New York. pp. 233-295.

TiffNeY, B.H., 1981. Diversity and major events in the evolution of land plants. In K.J. Niklas (Ed), Paleobotany, Paleoecology and Evolution. Praeger Press, New York. pp. 193-220.

Tillyard, R.J., 1926. Kansas Permian insects. Part VIII. The order Mecoptera.-Am.J. Sci. (5) 11: 133-164.

Tinbergen, N., B.J.D. Meeuse, L.K. Boerema and W.W. Varossieau, 1942. Die Balz des Samfalters Eumenis (Satyrus) semele L.-Z. Tierpsychol. 5.

Troll, W., 1930. Organisation und Gestalt im Bereich der Blüte. Springer, Berlin.

- , 1964. Infloreszenzen, Typologie und Stellung im Aufbau des Vegetationskörpers. Vol. I. Fischer, Jena.

- - 1969. Ibid. Vol. II2.

TuCKer, S.C. and E.M. Gifford Jr., 1966. Carpel development in Drimys Lanceolata.Am. J. Bot. 53: 671-678.

Uphof, J.C.Th., 1933. Die nordamerikanischen Arten der Gattung Asimina.-Mitt. dt. dendrol. Ges. 45: 61-76.

VALENTINE, D.H., 1975. The taxonomic treatment of polymorphic variation.-Watsonia 10: 385-390.

VAN Der Goot: see GoOt, van der.

VAN Der Hammen: see Hammen, van der.

VAN Der Pijl: see Pijl, van der.

Velenovsky, J., 1904. Vergleigende Studien über die Salix-Blüte.-Beih. bot. Zbl. 17 (1): 123-128.

VOGEL, S., 1950. Farbwechsel und Zeichnungsmuster bei Blüten.-Öst. bot. Z. 97 (1): 44-100.

- - 1954. Blütenbiologische Typen als Elemente der Sippengliederung. Botanische Studien Heft 1. Fischer Jena.

-—, 1961. Die Bestäubung der Kesselfallen-Blüten von Ceropegia.-Beitr. Biol. Pfl. 36: 159-237.

- , 1966. Pollination neotropischer Orchideen durch duftstoffhöselnde PrachtbienenMännchen.-Naturw. 53: 181-182.

- , 1966a. Parfümsammelnde Bienen als Bestäuber von Orchideen und Gloxinia.—Öst. bot. Z. 113: 302-361.

,$-- 1966 \mathrm{~b}$. Scent organs of orchid flowers and their relation to insect pollination. Proc. 5th World Orchid Conf., Long Beach. pp 253-259.

- , 1967. "Parfümblumen" und Parfümsammelnde Bienen._Umsch. Wiss. Techn. 67: 327.

- , 1969. Flowers offering fatty oil instead of nectar.-Abstr. XI. Internat. Bot. Congress, Seattle 1969, 229.

- , 1971. Ölproduzierende Blumen, die durch ölsammelnde Bienen bestäubt werden.Naturwiss. 58: 58 .

,-- 1972 . Blütenökologie.-Fortschr. Bot. 34: 443-457.

- , 1973. Fungus gnat flowers and fungus mimesis. In N.B.M. Brantjes and H.F. Linskens (Eds) Pollination and Dispersal. Department of Botany, University of Nijmegen. 
- - 1974. Ölblumen und ölsammelnde Bienen.-Acad. Wiss. u. Lit., math.-naturw. Kl., Trop. u. Subtrop. Pflanzenwelt 7.

- -, 1978. Pilzmückenblumen und Pilzmimeten, 1. Teil.-Flora, Jena 167: 329-366.

- , 1978a. Ibid., 2. Teil. -Flora, Jena 167: 367-398.

- , 1978b. Evolutionary shifts from reward to deception in pollen flowers. In A.J. Richards

(Ed.) The pollination of flowers by insects. Linnean Society Symposium Series No. 6, Academic Press. London etc. pp 89-96.

- , 1980. Florengeschichte im Spiegel blütenökologischer Erkenntnisse. Rhein-westf. Akad. Wiss., Vorträge N 291. Westd. Verlag, Opladen.

- , 1984. The diascia flower and its bee-an oil-based symbiosis in Southern Africa. - Acta. bot. neerl. 33 (4): 509-518.

- , 1986. Ölblumen und ölsammelnde Bienen, Zweite Folge.-Acad. Wiss. u. Lit., mathnaturw. Kl. Trop. u. Subtrop. Pflanzenwelt 54.

Vogel, St., Ch. Westerkamp, B. Thiel and K. Gessner, 1984. Ornothophilie auf den Canarischen Inseln. - Pl. Syst. Evol. 146: 225-248.

VoGT, H., 1967. Phalacridae, in Freude et al. 1967. pp. 158-166.

VuYCK, L., 1922. Over de betrekkingen tusschen bloemen en hommels in Nederland.-Ned. kruidk. Arch. 1922: 1-52.

Wagenitz, G., 1975. Blütenreduktion als ein zentrales Problem der AngiospermenSystematik.-Bot. Jahrb. Syst. 96: 448-470.

Walker, J.W., 1971. Pollenmorphology, phytogeography and phylogeny of the Annonaceae.-Contr. Gray Herb., Harv. 202: 1-130.

-, 1974 . Comparative pollenmorphology and phylogeny of the Ranalean complex. In C.B. Beck (Ed). Origin and early evolution of angiosperms. Columbia University Press, New York and London, pp. 241-299.

$-\longrightarrow, 1974 \mathrm{a}$. Aperture evolution in the pollen of primitive angiosperms. -Am. J. Bot. 61 (10): $1112-1136$.

Walker, J.W. and I.J. Skvarla, 1975. Primitively columellaless pollen: a new concept in the evolutionary morphology of angiosperms. - Science, N.Y. 187:445-447.

WALKER, J.W., G.J. BrenNeR and A.G. WALKer, 1983. Winteraceous pollen in the lower Cretaceous of Israel: early evidence of magnolialean angiosperm family.-Science, N.Y. 220: 1273-1275.

WALKeR, M.V., 1938. Evidence of Triassic Insect in the petrified forest national Monument, Arizona.-Proc. U.S. nat. Mus. 85: 137-141.

Waltace, B., 1958. The role of heterozygosity in Drosophila populations.-Proc. Tenth. Int. Congr. Genet. 1: 408-419.

WARNKe, G., 1934. Geruchsorgane der Lamellicornier.-Zoöl. Anz., 108/109.

Wasmann, E.S.J., 1918. Totale Rotblindheit der kleinen Stubenfliege (Homalomyia canicularis).-Biol. Zbl. 38 (non vidi).

WATERKEYN, L., 1954. Études sur les Gnetales. I. Le strobile femelle, l'ovule et la graine de Gnetum africanum Welw. - Trav. biol. Inst. Carnoy Ser. XI, No. 60, pp. 105-146, 11 plates.

WEBB, C.J., 1979. Breeding systems and the evolution of dioecy in New Zealand apioid Umbelliferae.-Evolution 33 (2): 662-672.

Weberling, F. 1981. Morphologie der Blüten und der Blütenstände. Ulmer, Stuttgart.

WEBSTER, N., 1971. Webster's new twentieth century dictionary of the English language. Revised by the publisher's editorial staff under the general supervision of J.L. McKechnie. The World Publishing Company, Cleveland and New York.

Werth, E., 1949. Zum Begriff der Hummelblumen.-Naturforsch. Ges. Augsburg 2.

WhEeler, W.M., 1921. A study of some social beetles in British Guyana and of their relations to the ant-plant. Tachigalia, Zoologica, N.Y. 3: 35-134.

WhitehEAD, D.R., 1969. Wind pollination in the angiosperms: evolutionary and environmental considerations.-Evolution 23: 28-35.

Whitehouse, H.L.K., 1950. Multiple-allelomorph incompatibility of pollen and style in the evolution of the angiosperms. - Ann. bot. N.S. 14: 199-215.

WIEBES, J.T., 1979. Co-evolution of figs and their insect pollinators.-A. Rev. Ecol. Syst. 10: 1-12. 
- - 1982. The phylogeny of the Agaonidae (Hymenoptera, Chalcidoidea).-Neth. J. Zoöl. 32(3): 395-411.

WILCOX, J.R. and K.A. TAFT, 1969. Genetics of yellow-poplar (Liriodendron). U.S. Department of Agriculture For. Serv. Res. Pap. WO-6.

WillemSe, M.T.M., 1985. Pollenkitt: a glue?-Acta bot. neerl. 34 (1): 132-133.

Willemse, M.T.M. and S.A. Reznickova, 1980. Formation in the anther of Lilium 1. Development of the pollen wall. - Acta bot. neerl. 29: 127-140.

Willemstein, S.C., 1975. Carapa guianensis. Ligna Orbis, Royal Tropical Institute, Amsterdam.

- - , 1978. List of flowers visited by Cetoniidae (Coleoptera) and Central European Cerambycinae and Lepturinae (Col., Cerambycidae) based on historical and pollen analytical research. Rijksherbarium, Leyden.

- , 1978a. Preliminary results of a pollen analysis of insects enclosed in Baltic amber. Abstracts of the joint annual meeting of the Palaeontologische Gesellschaft and the Paleontological Association, Maastricht 9.25th-10.1th, p 33. (abstract).

- 1980 . Pollen in tertiary insects. Acta. bot. neerl. 29 (1): 57-58. (abstract).

Williams, G.C., 1975. Sex and evolution. Princeton University Press, Princeton N.J.

Willis, J.C., 1966. A dictionary of the flowering plants and ferns, 7th ed., revised by H.K. Airy Shaw. University Press, Cambridge.

Willis, J.C. and I.H. BurkilL, 1985. Flowers and insects in Great Britain. I.-Ann Bot. 9: 227-273.

- 1903 . Ibid. II.-Ann. Bot. 17: 313-349.

- , 1903a. Ibid. III.-Ann. Bot. 17: 539-570.

-, 1908. Ibid. IV.-Ann. Bot. 22: 603-1908.

Willson, M.F., 1981. On the evolution of complex life cycles in plants: a review and ecological perspective.-Ann. Missouri bot. Gdn. 68: 275-300.

Willson, M.F. and N. BURLEY, 1983. Mate choice in plants, tactics, mechanisms and consequences. Princeton University Press, Princeton, N.J.

Willson, M.F. and D.W. Schemske, 1980. Pollinator limitation, fruit production, and floral display in pawpaw (Asimina trilobata). - Bull. Torrey bot. Club 107: 401-408.

Willson, M.F., L.J. Miller and B.J. Rathake, 1979. Floral display in Phlox and Geranium: adaptive aspects.-Evolution 33: 52-63.

Wilson, E.O., 1971. The insect societies. The Belknap Press of Harvard University Press, Cambridge, Massachusetts.

WinTON, L.L., 1968. Fertilization in forced quaking aspen and cottonwood.-Silv. Genet. 17: 20-21.

WIT, H.C.D. de, 1963. De wereld der planten. Hogere planten Vol. 1. Gaade, The Hague. - , 1965. Ibid. Vol. 2.

Wrtzgall, K., 1971. Histeridae. In Freude et al. 1971. pp. 156-189.

WODEhOUSE, P.R., 1935. Pollen grains: their structure, identification, and significance in science and medicine. McGraw-Hill, New York.

Woittiez, R. and M.T.M. WillemSE, 1979. Sticking of pollen on stigmas: the factors and a model.-Phytomorphology 29: 57-63.

Wootron, R.J., 1986. Paleontology and phylogeny. In the Hymenopterist's Handbook, 2nd revised and edited by C.R. Betts and D. d'A-Laholey. In press.

Yoshimoto, C.M., 1975. Cretaceous chalcidoid fossils from Canadian amber.-Can. Ent. 107: 499-528.

Zechmeister, L., 1932. Carotinoide höherer Pflanzen. In G. Klein (Ed.) Handbuch der Pflanzenanalyse. Spezielle Analyse Teil 2. Organische Stoffe II. Springer, Vienna. pp. 1239-1350. 


\section{INDEX}

Abdera 58

Abderina 58

Abinothum 50

Abroma 38

Abronia 338

Abutilon 323

Acacia 83, 324

Acanthaceae 332, 336

Acanthoceridae 15

Acanthopanax 335

Acanthus 332

Acartophthalmidae 38, 39, 107, 108

Acer 199, 305

A. ambonyense 305

A. campestre 305

Aceraceae 267, 305

Achillea 39, 212, 341

A. millefolium 370

Acmaeops (Dinoptera) collaris 365, 366, 367, 368, $369,370,371,372,373$

Aconitum 251, 252, 267

Acoreae 345

Acroceridae 34, 102

Acrocomya 318

Acromyrmex 83

Acroptera 103, 177

Actinidia 323

Actinidiaceae 323

actinomorphic 129, 133, 235, 287, 298

Aculagnathidae 19

Aculeata s.lat. 74, 75, 108, 110, 169, 170

Aculeata s.str. 74, 76, 78, 84, 85

Adeliini 58

Ademosynidae 48

Adenandra 305

Adenanthemum 329

Adenanthera 324

Adephaga 13, 21, 48

Aderidae 19

Adonis 267

Aegeriidae 27, 94

Aegerioidea 94

Aegialitis 334

Aegopodium podagraria 214

Aeolothripidae 43

Aesculus 331

Aethusa cynapium 215

Agaonidae 2, 24, 72, 73, 278, 303
Agaristidae 30

Agathiphagidae 30, 90

Agavaceae 32, 317

Agave 317

Agathis 90

Aglais urticae 164

Aglycyderidae 21

Agnathus 59

Agonoxenidae 28

Agriotypidae 23

Agromyzidae 37, 107

Agromyzoinea 106, 107

Agrostemma 213

Ailanthus 324

Ajuga 213

A. antiqua 340

Ajuginicula smithi 332

Alangiaceae 320,325

Alangium 320, 325

Alastor 81

Albian 293

Albizia 330

Alcea 259

A. rosea 259

Aldrovanda 324

A. visiculosa 225

Aleochara 14

Alibertia 336

Alisma 297, 332

Alismataceae 224, 307, 332

Allamanda 306

Allecula 58

Alleculidae 18, 58, 299

Alleculinae 58, 190

Allionia 309

A. incarnata 309

Allium 261

Allocorynus 21, 63, 277

Allocotidus 71

Allodaphe cupulifera 277

Allomerus 83

allophilic 4, 125, 234

allotropic 5

Allophylus 335

Alnites grandiflora 303

Alnus 176, 190, 303, 309

Alosterna tabacicolor 365, 366, 367, 369, 372

Alsinoideae 199 


\section{Alstonia 336}

Althaea cannabina 259

Alucitidae 30

Alyxia 306, 320

A. reinwardtii 306

Amaranthaceae 313, 314

Amaranthus spinosus 314

Amaryllidaceae 261

Amaryllis belladonna 164

Amatidae 30

Amblygonocarpus 330

Amblyoponini 82

Amborellaceae 266

Ambrosia 337

Amelanchier 330

"Amentiferae" 262, 264, 268

Amiseginae 77, 78

Ammi majus 214

amorphic 129

Amorphophallus 13

Ampelopsis 326

Amphiesmenoptera 89

Amphipyra pyramidea 163

Ampulicidae 25, 85

Ampulicimorpha 77

Amygdalus 330

Amylotheca 325

Anacardiaceae 267, 305, 319, 331, 335

Anacardium occidentale 83

Anacolosa 316

Anaspis 18

Anatria 103

Anatriata 103

Anaxagorea 312

Anaxyelidae 66, 69

Ancyluris 94

Andrena 253, 259

A. argemonis 254

A. bucephala 87

A. florea 162, 172

Andrenidae 25, 85, 87, 171, 172, 174, 257

Androcymbium 340

androdioecy 227, 237, 289

androecium 269

Andromeda 303

andromonoecy 227, 237, 289

Androsace vilaliana 226

Anemone 199, 251, 252

A. narcissiflora 252

A. nemorosa 252

anemophily/-gamy $4,112,237,298,342$

Anethum graveolens 215

Angelica archangelica 215, 365

A. palustris 215

A. sylvestris 215, 365

angio-ovuly 210
Angiospermae 45, 271ff, 280, 281

Anisopodidae 32, 101, 110, 300

Anisotomidae 13. 14

Anisoxya 58

Annesleya 310

Annona 249, 312

A. crassiflora 312

A. cf glabra 249

Annonaceae 1, 217, 248, 266, 268, 269, 312, 322,333

Annonaspermum gilbediensis 312

Anobiidae 17, 51, 56, 175, 190, 295

Anomologidae 28

Anomopterellidae 72

Anoploderminae 61

Antennaria 213

Anthelidae 30

Anthericum 261

Anthicidae 17, 18, 19, 58, 59

Anthicini 60

Anthidium 121

Anthobium 14

Anthocoridae 40

anthocyanines 149,176,177, 178, 179

Anthomyiidae 38, 106

Anthomyzidae 39, 107, 312

Anthomyzoinea 106, 107

Anthophagus 14

Anthophora pilipes 254

Anthophoridae 25, 85, 87, 171, 172, 178

Anthophytes 275, 277, 280, 282

Anthoxanthum odoratum 291

Anthrax 257

Anthreninae 17, 56

Anthrenus 56

Anthribidae $2051,59,63,175$

Anthriscus cerefolium 216

A. sylvestris 216, 365

Anthyllis 213

A. cytisoides 213

Antidesma 329

Antirrhinum 260

Anybia 93

Aphodiinae 54

Aphodiites 48

Aphodius 15, 54

Aphyllanthes 262

Apiaceae 1, 23, 28, 37, 39, 40, 95, 187, 192 , $199,203,212,213 \mathrm{ff}, 231,247,256,267$, $316,320,325,331,335,339,365,370$

Apidae 25, 86, 87, 108

Apinae 108, 171, 172

Apini 86, 108

Apioceridae 34, 102

Apioideae 231

Apionidae 21, 51, 63, 64 
Apis 65, 86, 87, 254

A. mellifera $65,87,113,118,124,161,162$, $252,253,254,255,259,314$

Apium graveolens 214, 366

A. inundatum 214

A. nodiflorum 214

Apocrita 23ff, 66, 67, 69, 70ff, 169, 174, 175

Apocynaceae $260,306,320,326,336$

Apoidea 1, 10, 25, 76, 78, 79, 84, 85, 86, 87, $111,124,149,161 \mathrm{ff}, 171 \mathrm{ff}, 174,176,178$, $299,300,305,307,308,311,314,315,316$, 320,321

Apterogyninae 79

Aquifoliaceae 306

Aquilegia 1, 129, 252, 267

Arabidopsis thaliana 217

Arabis caerula 224

A. pumila 217

Araceae 14, 39, 50, 99, 107, 276, 337, 345

Araecerus 63

Aralia 305

Araliaceae 305, 306, 335

Araliaephyllum crassinerve 305

Araucariaceae 90

Arbutus 334

Arceuthobium 325

Archecoleoptera 46, 47

Archepyris minutus 77

Archexyela 42

A. crosbyi 64, 67

Archihesperinus 101

Archipleciomima 101

Archisphex 75, 85

A. crowsoni 85

Architendipedidae 97, 98, 100

Architendipes tshernouskyi 100

Architipula radiata 97, 98

Archostemata 13, 21, 47, 48, 52, 282

Arctiidae 29

Arctostaphylos 334

Arcyon 13

Areca 318

A. ipot 318

Arecaceae 307, 318, 320, 326, 332, 337

Arenaria 213

A. balearica 257

A. biflora 257

A. ciliata 257

A. serpyllifolia 257

Arenga 337

Argemone 253, 254

A. hispida 254

A. platyceras 254

Argidae 22, 67, 68

Argynis pandora 258

Argyresthiidae 93
Argyresthites 92

Arisaema triphyllum 198, 199

Aristolochia clematitis 32

Aristolochiaceae 341

Armeria 258, 334

Armoracia rusticana 369

Arnica 212

Aronicum 212

Arrhenophanidae 27

Artabotrys 248

Artematopidae 50

Artemisia 212, 237, 337

Arum 13, 18, 32, 37, 38, 99, 145

Aruncus 255

A. dioicus 218, 373

Arundo 310

Asarum curopaeum 341

Ascarina 293, 294

A. lucida 293

Ascarinopsis 294

Aschiza 35, 169, 177, 178

Asclepiadaceae 193, 331, 336

Ascomycetes 14

Aseminae 60, 61

Asilidae 34, 102

Asiliformia 102, 110, 175, 177

Asiloidea 34, 111

Asimina 249, 312

A. pygmea 312

A. speciosa 312

A. trilobata 199, 248, 312

Asparagus 262

Asphodelus 261

Asteiidae 39, 107

Asteioidea 35, 39

Astelia 326

Aster 212

Asteraceae 37, 40, 57, 95, 133, 138, 187, 188, $192,193,201,203,210,212,224,256,267$. $332,336,240,341,370$

Asterales 177

Astragalus 339

Astrantia major 214

A. minor 214

Asystasia 336

Atetha 14

Athamanta cretensis 215

Atomaria 57

Atomariinae 52

Atriata 103

Atrichopogon 32, 100

Atta 83

Attageninae 56

Attagenus 56

Attelabidae 21, 63, 64, 277

Attini 83 
Auchenorrhyncha 45

Augochlora 254

Aulacidae 23, 72

Aulacigastridae 39, 107

Aulacogaster 72

Aulacus 72

Aulacoscelinae 62

Aulacoscelis 62

Auplopus 79

Australimyzidae 107

Australimyzoinea 106, 107

Austrobaileya 270

Austrobaileyaceae 265, 268

autogamy 4, 223

Avena sativa 225

Avicennia 326

Axiidae 29

Axymyiidae 33, 100

\section{Bactris 307}

Baissodidae 75

Balanitaceae 331

Balanites 331

Balanophora 336

Balanophoraceae 336

Ballota 213

Balsaminaceae 224, 341

Bambusa 340

Banisteria 325, 327

Baoris mathias 164

Barclayaceae 265

Baronia brevicollis 94

Barremian 293

Barringtonia 327, 335, 337

B. racemosa 324

Beryconus 71

Bataceae 315

Batis argillocola 315

bat-pollinated flowers 234

Batrachium 253, 333

bee-pollinated flowers 112, 233, 284, 311

bees 1,111

beetle-pollinated flowers 112, 233, 284, 298

Belidae 21, 51, 63

Bellidiastrum 212

Bellis 212

bell-shaped blossom 133, 235, 287, 308

Belonogaster 81

Bennettitales 48, 50, 144, 262, 270, 273, 276, 277, 280, 281, 283

Berberidaceae 217, 218, 266, 268, 296, 328

Berberis 199, 328

Berendita 329

Berginus 19

Berula erecta 214, 366

Beta 40, 314
Bethylidae 76, 77, 78

Bethyloidea 23, 26, 74, 75, 76, 78, 85

Bethylonymidae 75

Betonica 213

Betula 22, 64, 176, 309

Betulaceae 303, 309, 313, 319, 322

Betulales 308, 344

Bibio 110

B. pomonae 32

Bibionidae 32, 101, 110, 295, 300

Bibionomorpha 32, 97, 99, 100, 282

Bibionomorpha s.str. 97, 100, 101

Bignoniaceae 326, 332

Biphyllidae 19

bird-pollinated flowers 234

Bittacidae 95

Blasticotomidae 22, 68, 70

Blastobasidae 28

Blephariceridae 33, 99, 209

Blephariceroidea 99,145

Blepharoceridae 33

blossom classes $133 \mathrm{ff}, 235,245$

blossom-pollinator relationships $125 \mathrm{ff}, 234$, 244

Boisduvallia 315, 330

B. cleistogama 315

Boletophagini 58

Boletophagus 58

Bombacaceae 303, 304, 323, 329, 334

Bombax 303, 329

B. virginensis 303

Bombinae 25, 86, 87, 108, 148, 162, 171, 172, 178, 295

Bombus 86, 162, 253, 256

B. agrorum 125, 254, 258, 259

B. californicus 254,255

B. hortorum 254, 258, 259

B. lapidarius 254

B. lapponicus 258

B. mastrucatus 125

B. pratorum 254

B. rajellus 254

B. terrestris 125, 251, 254, 255

Bombycidae 30

Bombycoidea 30, 94, 172

Bombyliidae 34, 102, 111, 120, 126, 169, 175, $177,201,259,260$

Bombylius 120

B. fuliginosus 159, 160

Boraginaceae 326, 332, 336, 341

Borboropsidae 107

Borreria 336

Bostrychidae 17, 51, 56

Bostrychiformia 17, 51, 55, 56

Bostrychoidea 17, 55, 56, 174, 175

bowl-shaped blossom 133, 235 
Brachycera 33ff, 97, 99, 101, 102, 108, 110, 169,177

Brachygaster 72

Brachypteris 325, 327

Brachyspectridae 16,55

Brachystegia 324

Brachytarsus 63

Braconidae 23, 71, 74, 108, 284

Bradynobaenidae 76, 78, 79

Bradynobaeninae 79

Brahmaeidae 30

Brassicaceae 199, 217, 224, 256, 296, 334, 338,369

Braulidae 38

Brenthidae 21, 63, 64

Bromeliales 177

Bromus secalinus 226

Brownlowia 319

Bruchela 63

Bruchidae 20, 51, 60, 61, 62, 175, 278

Bruckenthalia 338

Brunella 213

Brunellia 329

Brunelliaceae 329

brush-shaped blossom 134, 235, 288, 298

Bryonia dioica 162, 172

Bubbia 270

Buettneria 323

Bulbocodium 262

bumblebees 2, 111

Bupleurum 217, 325

B. falcatum 214

$B$. longifolium 214

$B$. ranunculoides 214

B. stellatum 214

B. tenuissimum 214

Buprestidae 15, 50, 55, 157, 174

Buprestoidea 15, 55, 166, 167, 174

Bursera 325

Burseraceae 325

Butomaceae 269, 317

Butomus umbellatus 317

butterfy-pollinated flowers 112, 233, 285, 311

Buxaceae 308, 322, 333

Buxus 333

Byrrhidae 15, 50

Byrrhoidea 15

Byrsomina 335

Byturidae 19, 57, 299

\section{Caccobius 15}

Cactaceae 341

Coesalpinia 304, 324

Caesalpiniaceae - Caesalpinioideae

Caesalpinioideae 193, 304, 315, 319, 321, $324,330,334$
Calamintha 213

Calamis gracilis 337

Calamus longisteus 320

Calanthe veitchii 198

Calendula 212

Calicurgus 79

Callidulidae 30

Calliduloidea 30

Calligonum 338

Calliphora 160

C. erythrocephala 160,168

Calliphoridae 38, 106

Callitrichaceae 340

Callitriche 340

Calluna 338

C. vulgaris 40, 255

Calobatidae 106

Calophyllum 334

Calpocalyx 324

Caltha 39, 251, 252, 266, 267

C. palustris 176, 222

Calycanthaceae 265, 268

Calycanthus 268, 270

Calyptratae 106

Calystegia 340

Camellidae 105

Cameolium 50

Camillidae 38, 105

Campanian 308

Campanulaceae 212, 213, 340, 371

Campanulales 177

Campichoetidae 105

Campnosperma 331

Camptostemon 334

Campylostemon 331

Canaceidae 38

Cananga odorata 248, 269

Canangium 312

Canbeya 253

Canellaceae 266, 328

Cantharidae 16, 55, 190

Cantharis tristis 55

Cantharoidea 15, 16, 55

cantharophily/-gamy 119, 233, 284, 299, 307, 318,345

Canthium 339

Capparales 177

Capparidaceae 236, 245, 288, 323, 327, 338

Capparites cynphylloides 288

Caprifoliaceae 217, 218, 256, 267, 306, 332, $336,368,369,371,372$

Capsella bursa-pastoris 217, 222

Capsicum frutescens 83

Car 63

Carabidae 21

Carabus 159 
Caragana 330

Carapa 319, 321

Carconites 277

Cardamine amara 217

Cardiophorinae 55

Cardiospermum 325

Carduus 256

Carex 90, 310, 326

C. clarkii 310

Carlina 256

Carludovica 326

Carnidae 37, 107, 108

carotenoids $149,176,177,178,179$

Carpinus 319

Carpophagus 62

Carpophilus pallipennis 254

Carposinidae 30

Carthaeidae 30

Carum carvi 214

Carya 319

Caryocar 322

Caryocaraceae 322

Caryophyllaceae 188, 199, 212, 213, 224, $257,267,268,371$

Caryophyllales 327

Casearia 329

Cassia 324

Cassidinae 62

Castanea 308, 309

Castniidae 30

Castnioidea 30, 94, 95

Catalpa 332

Catopsila pyranthe 164

Catostemma 323

Caucalis platycarpos 216

Cavognathidae 51

Cecidomyiidae $32,101,110$

Cedrela 335

Celastraceae 267, 316, 325, 331

Celastrophyllum 297

Celastroxylon celastroides 316

Celastrus 325

Celonophamia taimyria 77

Celosieae 314

Celits 302

Celyphidae 37,105

Cenomanian 300

Centaurea 256

C. macroptilon 370

Centrolepidaceae 320

Centunculus minimus 226

Cephalanthus 326

Cephaloidae 19

Cephidae 22, 70

Cephoidea 22, 66, 69, 70

Cephus 70
Cerambycidae 20, 51, 60, 61, 113, 175, 190 , 307

Cerambycinae 20, 60, 61, 202, 365ff

Ceraphronoidea 70

Cerastium 213, 257, 258

C. alpinum 257

C. arvense 224,257

C. cerastoides 224

C. diffusum 224

C. glomeratum 224, 257

C. latifolium 257

C. semidecandrum 224

C. uniflorum 257

Ceratonia 324

Ceratophyllaceae 322

Ceratophyllum 322

Ceratopogonidae 31, 32, 100, 105, 110

Ceratozamia longifolia 277

Cerbera 306

Cerceris 85

Cercidiphyllaceae 302

Cercidiphyllum 269, 302

C. japonicum 302

Cercis 334

Cercophanidae 30

Cercopia 338

Ceropegia 38, 107

Cerophytidae 16, 52

Cerylonidae 19

Cetonia 14, 15

C. aurata $55,124,190,365,366,367,368$, $369,370,371,372,373$

Cetoniinae 14, 15, 54, 69, 113, 175, 202, 245, $246,251,280,365 f f$

Chaerophyllum 331

C. aromaticum 216

C. aureum 216, 366

C. bulbosum 216

C. hirsutum 216, 366

C. temulum 216

Chaetosomatidae 18

Chalcididae 24

Chalcidoidea 24, 71, 72, 73, 74

Chamaemyiidae 37, 105

Chamaemyioinea 105

Chamaenerium 315

Chamaerops 332

Chaoboridae 100

Chelidonum 253, 254

C. majus 254

Chenopodiaceae 190, 313, 314, 333

Chenopodium 314

Chironomidae $31,32,100,110$

Chironomoidea 97, 100, 145

Chironomus 32, 100

Chiroptera 286 
chiropterophily/-gamy 182, 234, 286, 318, 333,337

Chiropteromyzidae 107

chi-square tests 11

Chloranthaceae 266, 293, 294, 298

Chloranthus 294

chlorophylls 149,176

Chloropidae 38, 39, 107, 108, 295

Chomelia 326

choripetalous 235

Choristidae 45

Choristotanyderus nanus 97

Chrysanthemum leucanthemum 370

Chrysididae 24, 76, 77, 78, 82, 111, 284, 299

Chrysidoidea 24, 169

Chrysobalanaceae 330

Chrysobalanoideae 256

Chrysobalanus 324

Chrysomela fastuosa 157, 158, 159, 167

Chrysomelidae 20, 51, 60, 61, 62, 166, 167, $190,295,299,307$

Chrysomelinae 62

Chrysomeloidea 17, 20, 51, 56, 62, 68

Chrysopolomidae 28

Chrysosplenium oppositifolium 39

Chyphotinae 79

Chyromyidae 37, 107

Cicadina 77

Cicuta maculata 203

C. virosa 214

Ciidae 19

Cimberis 20, 63

Cimbicidae 22, 68

Cinnamomum 313

Circaea 315

C. lutetiana 315

Cirsium 213, 256, 340, 370

C. arvense 371

C. palustre 371

Cissus 326

Cistaceae 225, 257, 334, 338

Cistanche 340

Cistus 257, 338

C. hirsutus 257

C. incanus 257

C. ladanifer 257

C. monspeliensis 257

C. salviifolius 257

Citrophyllum 304

Cladochorista 42, 64

Cladothrix cryptantha 314

Clambidae 15, 50, 52

Clarkia 315

Classopollis 293

Clavatipollenites 293, 294

C. , hughesii 294
Clavatipollenites-Ascarina complex 293, 294, 343

Clavicornia 57, 58

Claytonia 338

cleistogamy 223, 237, 289

Clematis 252, 253, 267, 328

C. alpina 252,267

C. cirrhosa 252, 267

C. flammula 267

C. integrifolia 252, 267

C. panos 253

C. recta 252,267

C. vectensis 253

C. vitalba 252, 267

C. viticella 252

Cleptes 77

Cleptidae 76, 77

Cleridae 18, 52, 56

Cleroidea 17, 18, 52, 56

Clethra 314

Clethraceae 314

Clinopodium 213

Clusiaceae 322, 329, 334

Clusiaphyllum 323

Clusiidae 37, 39, 107

Clytrinae 62

Clytus arietis 61, 367, 372

Cnemospathidae 107

Cnestis 335

Cnidium dubium 215

Coccidae 19, 63

Coccidotrophus socialis 19

Coccinellidae 18

Coccoloba 334

Cocculus 338

Cochylidae 27

Coelopidae 37, 107

Coenomyiidae 34

Coerebidae 285

co-evolution 4

Colchicum 262

Coleophoridae 28

Coleoptera 10, 12ff, 41, 43, 45ff, 64, 108, 110, $111,157 \mathrm{ff}, 167 \mathrm{ff}, 174,175,177,210,276$, $282,295,299,300$

Coleorrhyncha 45

Collembola 39, 295

Colletes 162

Colletidae 25, 87, 171, 172, 174

colour vision in insects $157 \mathrm{ff}$

colours $148 \mathrm{ff}, 236,288$

Colutea 304

Colydiidae 18, 19

Comarum 339

Combretaceae 324, 335

Combretocarpus 335

Combretum 335, 337 
Coniacian 308

Coniferae 46

Coniferales 1, 60, 63, 64, 67, 68, 69, 273, 274,275

"Coniferophytes" 209

conifers 273

Conioselinum tataricum 215

Conium maculatum 214

Connaraceae 330,335

Connarus 335

Cononotidae 20, 59

Cononotus 59

Conopidae 35, 36, 108

Conopoidea 36

Consolida 252, 267

Convallaria 262

Convolvulaceae 225, 326, 340

Copromorphidae 30

Copromorphoidea 30, 93

Coptis 251, 252, 270

C. trifoliata 252

Cordaitidae 275

Cordia subcordata 336, 337

Cordyluridae 312

Coriaria 315

Coriariaceae 266, 315

Corizoneura 120

Cornaceae 325, 335, 368

Cornus 26, 335

C. mas 368

C. sanguinea 368

Coronaria 213

correspondence analysis 11

Corrigiola litoralis 224

Corydalis 199

Corylophidae 19

Corylus 190, 313

Corymbiferae 212, 213

Corynocarpaceae 265

Corynostylis 329

Cosmopterigidae 28, 93

Cossidae 30

Cossoidea 30, 94

Cotoneaster 330

Cotula 212

Cowania 255

Crabro 85

Cramptonomyiidae 101

Crassulaceae 323

Crataegus 199, 330, 369

C. laevigata 369

C. monogyna 369

Crataeva 338

Cremifanniidae 107

Crena 324

Cretabythus sibiricus 78
Cretacaeiporites scabratus 297

Cretavaniidae 72

Cretavidae 84

Cretavus 75, 85

C. sibiricus 75, 84

Cretodryinus zherichini 75, 76, 77

Cretonanophyes 51

Cretosphex incertus 85

Crithmum maritimum 215

Crocus 261

Crossocerus 85

"Cruciferae" 334

Crudia 319, 321

cryptanthery $180 \mathrm{ff}, 288,321$

Crypteroniaceae 335

Crypterorrhynchinae 278

Cryptocephalinae 20, 51, 62, 63

Cryptochetidae 38, 105

Cryptophagidae 18, 52, 57, 189

Cryptopleurum 13

Cleniopus 58

Ctenolophon 316

C. engleri 316

C. parvifolius 316

Ctenolophonaceae 316

Cucubalus 213

Cucujidae 19, 51

Cucujiformia 17ff, 21, 51, 56ff, 167

Cucujoidea 17, 18, 56, 57, 58, 299

Cucurbitaceae 323, 329

Culicidae 31, 100, 110

Culicoidea 100, 145, 244

Culicoides 32, 100

Cullenia 329

Culicomorpha 31, 97, 99, 100

Cunoniaceae 319,321

Cupaniopsis 310

Cupedidae 21, 45, 50

Cupedoidea 174, 175

Cuphea 335

Curatella 250

Curculionidae 20, 51, 63, 64, 166, 175, 190 $278,295,311$

Curculionoidea 17, 20,51, 56, 63

Curiosivespa curiosa 75,81

C. magna 75,81

Curtonotidae 38, 105

Cuscuta epithymum 225

C. europea 225

Cuterebidae 106

Cyathea dealbata 21

Cyathocalyx 248

Cycadaceae 62

Cycadales 60, 62, 276

Cycadeoidea 50, 209, 210, 262, 278, 281

Cycadeoideaceae 262, 278 
cycads 273,277

Cycas 21, 276, 277

C. circinalis 276

Cyclamen purpurascens 226

Cyclandra 250

Gyclanthaceae 326

Cyclanthus 326

Cyclocephala 15

Cyclorrhapha 33, 35ff, 102, 103, 169, 300

Cyclotornidae 28

Cydonia 330

Cylindrotomidae 97, 99

Cymbalaria muralis 261

Cymodocea 317

Cymodoceaceae 317

Cynareae 213, 256

Cynipidae 23, 73

Cynipoidea 23, 71, 72, 73

Cyperaceae 217, 218, 310, 311, 326

Cyphomymex 83

Cypripedium 129

C. insigne 198

Cypselosomatidae 36, 106

Cyrilla 323

Cyrillaceae 323

Czekanowskiales 144, 282

Dacnonypha 26, 30, 90, 91, 278

Dactylocladus 335

Dahlia 212

Dalbergia 304

Daphnandra 296

Daphne mezereum 218, 222

Dascillidae 15, 50, 54, 174, 175

Dascilloidea 15, 50, 52, 54

Dashyela 32

Dasyceridae 14, 56

Dasytes obscurus 56

Dasytidae 16

Dasytinae 108

Datisca glomerata 341

Datiscaceae 341

Datura 163

Daucus 335

D. carota 216,366

Davilla rugosa 250

Decodon 339

Degeneria 269, 270, 271

Degeneriaceae 265, 268, 293, 296

Deilephia 163

D. livornica 163

Delia brassicae 160

Delphinium 252, 267

Dendrobium nobile 198

Dendromecon 253

Dermestes 17, 56
Dermestidae 17, 51, 52, 56, 190, 245, 285, 295

Dermestinae 56

Dermestoidea 17, 55, 56, 166, 167

Derodontidaè 17,190

Desmanthus 334

Deuterophlebiidae 33, 99

Deutzia 329

Diabrotica 20

Diachromus germanus 21

Dianthus 213, 258, 259

D. armeria 258

D. barbatus 258

D. carthusianorum 258

D. deltoides 258

D. monspessulanus 258

D. plumarius 258

D. superbus 258

D. sylvestris 258

Diaperini 58

Diapriidae s.lat. 70

Diastata 105

Diastatidae 38, 105

Dicaeidae 285

Dichapetalaceae 334

Dichapetalum barteri 334

dichogamy 204ff, 236, 268

dicliny $227 \mathrm{ff}, 237,268$

Dicruridae 285, 286

Dictamnus 260

Dictyoptera 39

Didymelaceae 319

Didymeles 319

Dielocerus 67

Dierama 318

Digitalis 260

Dillenia 250, 322

D. indica 250

D. suffruticosa 250

Dilleniaceae 250, 268, 296, 297, 322

Dillenidae 296, 297, 308, 345

Dillenioideae 250

Dillenites 250

Diloba caeruleocephala 29

Dinapsidae 70

Dineutes 159

Diodyrrhinchus 20, 63

dioecy 227, 237, 289

Dionaea 334

Dioon edule 276

Diopsidae 36, 107

Diopsioinea 106, 107

Dioscoreaceae 337

Dipholis 329

Dipladenia 306

Diplopeltis 325 
Diptera 10, 30ff, 41, 64, 87, 89, 95ff, 108, dystropic 4 $111,159 \mathrm{ff}, 168 \mathrm{ff}, 174,175,177,210,282$, $295,300,305$

Dipterocarpaceae 40,329, 334

Dipterocarpus 329

Dircaea 58

Discolomidae 19

dish-shaped blossom 133, 235

Disteniinae 61

Distichia 218

Ditrysia 27ff, 90, 92, 172

Dixidae 32, 100

Dodonaea 339

Dolichandrone 326

Dolichopidae 34, 102, 103

Donaciinae 20, 51, 62, 63, 299

Dorcadion 61

Doronicum 212

Dorylinae 84

"double fertilization" $210 \mathrm{ff}$

Douglasiidae 27

Draba venosa 338

Dracaena 332

Dracaenaceae 332

Dracocephalum 213

Dracunculus 13, 17, 37

Drepanidae 29, 285

Drepananthus 312

Drilidae 16, 55

Drimys 248, 270, 271, 294, 295

D. axillaris 294

D. brasiliensis $247,295,296$

D. lanceolata 247

Drosera anglica 225

D. intermedia 225

D. rotundifolia 225

Droseraceae 225, 324, 334

Drosera 334

Drosophila 312

Drosophilidae 38, 105, 106

Drosophiloidea 38, 105

Dryadinae 255

Dryas 255

D. octopetala $255,257,341$

Dryinidae 76, 77, 78

Dryomyzidae 36, 37, 39, 107

Dryopidae 16

Dryopoidea 16, 55

Dufourea 87

Durania 334

Durio 329

Echinocarpus 323

Echinophora 325

E. spinosa 216

Echinops 256, 371

E. ritro 19

Echium plantagineum 218

Eichhornia 326

Elacatidae 19

Elachistidae 28, 93

Elaeagnus 326

Elaeagnaceae 326, 341

Elaeocarpaceae 323

Elaeocarpus 323

Elacodendron 325

Elais 337

Elateridae 16, 48, 50, 51, 52, 55, 174, 190 307

Elateriformia 15ff, 50, 55

Elateroidea $15,16,55,174$

Electrapis 85

$E$. meliponoides 86

Electrocephus stralendorfii 70

Elleschodes hamiltoni 311

Elmidae 16

Embiidae 75, 78

Embolemidae 76, 77, 78

Embolemus 77

Empedidae 102, 103, 300

Empediformia 102, 103, 175

Empedinae 102, 300

Empedioidea 111

Empetraceae 314, 341

Empetrum nigrum 341

Empididae 34, 102, 175, 249, 257

Empidinae 34

Empidoidea 34

Encephalartos 277

Encyrtidae 24

Endomychidae 19

Endromidae 30

entomodomy 9

entomogamy /-phily 9, 112ff, 237, 342

Eocene 321

Eomimosoidea 324

Eophyllocerus 54

Eotillini 79

Epacridaceae 314, 323

Epacridicarpum 323

Epeolus auriginea 254

$E$. enavata 254

E. menuacha 254 
Epermeniidae 27, 28

Eperua 334, 337

E. falcata 337

Ephedra 209, 272, 280

E. aphylla 280

Ephedraceae 280

Ephedrites 280

Ephydridae 38, 105, 106

Epilobium 315

Epinephele janira 258

Epinomeuta 92

Epiplemidae 29

Epipompilus 79

Epipyropidae 28

Episyron 79

Eranthis 251, 252, 267, 269

Eremoneura 102

Eriades 121

Erica 341

E. tetralix 40

Ericaceae 247, 303, 314, 322, 329, 334, 338, 341

Ericales 303, 314, 327

Ericipites 314

Erigeron 212

Eriocraniidae 30, 91, 278

Eriocranioidea 30, 278

Eriodictyon californicum 341

Eristalis 160

$E$. nemorum 259

E. tenax 160,259

Erodium 331

E. cicutarium 259

E. malacoidea 259

Erotylidae 19, 57

Erycinidae 29

Eryngium 204, 335

E. campestre 214,370

E. maritimum 214

E. yuccifolium 203

Erythopalum 320, 321

Erythrochiton 324

Erythronium 262

Erythroxylaceae 331

Erythroxylum 331

Escalloniaceae 323

Eschscholzia 253, 254

E. californica 254

E. lobbii 253

E. mexicana 254

Ethmiidae 28

Eucalyptus 37, 310, 324

Eucinetidae 15, 48, 50

Eucinetoidea 52

Eucinetiformia 50, 52, 54

Eucnemidae 16
Eucommia 319

Eucommiaceae 319

Eugeissona insignis 337

E. minor 337

Euglossinae 86, 108

eulectic 5

Eulophidae 24, 73

Eumecoptera 95

Eumenes 81

Eumenidae 25, 77, 80, 82

Eumolpinae 62

Eunausibius wheeleri 19

Euodynerus 81

Euonymus 199, 316, 325

E. japonicus 316

E. variegatus 316

Euparagia 81

Euparaginae 81, 82

euphilic 5, 125, 234, 287, 318, 327

Euphorbiaceae 237, 323, 329

Euphoria sepulchralis 259

Euphrasia 260

Eupomatia 311

E. bennettii 311

E. laurina 311 .

Eupomatiaceae 265, 311

Eupteleaceae 322

Eupterotidae 30

Eurya 328

Eurychoromyiidae 105

Eurygnathomyiidae 108

Euryinae 22

Eurytomidae 24, 73

Eusphalerum 14, 50

eutropic 5

Evania 72

Evanigaster 72

Evaniidae 23, 72

Evanioidea 23, 71, 72, 169

Evaniops 72

Evodinus interrogationis $366,367,368,370,371$

Exeretoneura tertia 111

Exoporia 90, 92

Fabaceae 62, 188, 212, 213, 225, 260, 267, $304,315,319,324,330,334,339$

Fabales 177

Faboideae - Papilionoideae

facultative pollination types 10

Fagaceae 190, 308, 309, 328

Fagales 308, 309, 344

Fagara 324

Fagopyrum esculentum 222

Falcaria vulgaris 214

Fallugia 255

Fannia canicularis 160 
F. scalaris 106

Fanniidae 106

Faramea 331

Fedtschenkiinae 84

Fergusoninidae 37

ferns 68

Ferulago 339

Ficaria 338

Ficophyllum 297, 302

Ficoxylon 302

Ficus 2, 24, 72, 73, 74, 145, 303, 322, 327

Fideliidae 25, 87

Figitidae 23

Filago 212

F. minima 224

Filipendula 237, 256, 339

F. ulmaria 373

$F$. vulgaris 373

Fillaeopsis 330

Fissistigma 249

Flacourtiaceae 297, 323, 329

Flagellaria 337

Flagellariaceae 337

flag-shaped blossom 134, 235, 288, 321, 345

flavones $149,176,177,178,179$

floral colours 148ff, 236, 288

flower types $129 \mathrm{ff}, 235$

fly-pollinated flowers $112,233,311$

Foeniculum vulgare 215, 366

Forcipomyia 32, 100

Formica 83

Formicidae 25, 78, 82, 83, 84, 295

Formicoidea 25, 76, 78, 82, 169

Forsythia intermedia 176

F. viridissima 225

Fothergilla 313

Fouqueria splendens 341

Fouqueriaceae 341

Foveomorphomonocolpites humbertoides 249, 312

Fragaria 199, 218, 255

Frangula 339

$F$. alnus 368

Fraxinus 310

Fremontia 334

Freycinetia 332

Fritillaria 262

Fuchsia 182, 236, 315, 331

F. macrostemma 315

Fumana 257

$F$. ericoides 257

F. procumbens 257

F. thymifolia 257

Fumaria 199

Fumariaceae 253, 266, 296

funnel-shaped blossom 133, 235, 287, 288, 308
Gagea 261

G. lutea 225

Galanthus nivalis 261

Galeobdolon 213

Galeopsis 213

G. speciosa 124

Galerucinae 20, 51, 62, 63

Galium 339, 368

G. uliginosum 226

G. verum 176

Gardenia 326

Garrya masoni 339

Garryaceae 339

Gasterophilidae 39, 106

Gasteruptiidae 23, 72

Gasteruptionidae 72

Gaurotes virginea $366,367,368,369,370,371$ 372,373

Gavia 100

Gayellinae 82

Gaylussacia 334

Gelechiidae 28, 93, 278

Gelechioidea 28, 93

Genista 199

G. prostrata 225

Gentiana 339

Gentianaceae 225, 339

Gentianales 177

Gentianella campestris 225

G. tenella 225

Geometridae 29, 164

Geometroidea 29, 94, 172, 178, 286

Georyssidae 13

Geotrupes 51

G. silvaticus 158, 159, 166

Geotrupidae 15, 50, 51, 54

Gephyrapollenites 248

Geraniaceae 259, 267, 331, 339

Geraniales 177

Geranium 331

G. columbinum 259

G. dissectum 259

G. lucidum 259

G. molle 259

$G$. pratense 259

G. pyrenaicum 259

G. robertianum 259

G. rotundifolium 259

G. sanguineum 259

G. sylvaticum 259

Germaraphis 85

Geum 217, 222, 255

G. reptans 218

Gigasiricidae 69

Gilia filiformis 336

Ginkgo 209, 273 
Ginkgoales 275, 282

Gladiolus 261

Glaphyra 246

Glaphyrinae 15, 54, 55, 246

Glaucium 253, 254

Glaux maritima 83

Glechoma 213

Gleditschia 304, 324

Glendotricha olgae 94

Glephyrapollenites 294

Globicornis 56

Glossata 90

Glossinidae 106

Glossophaga 286

Glossopteridae 275

Glyptapis 85

Glyphipterigidae 27

Gnaphalium 212

Gnetaceae 280

Gnetales 264, 267, 269, 272, 273, 274, 276, $279,280,281,283$

Gnetidae 272

Gnetum 209, 272

G. africanum 279

G. gnemon 279

Gnophria quadra 258

Gomortegaceae 265

Gonepteryx rhamni 164

Goniothalamus 248, 269, 312

Gonodera 58

Gonystylus 329

Goodeniaceae 332

Gordonia axillaris 322

G. lasianthus 328

Gorytes 85

Gossypium herbaceum 259

Gracillariidae 27, 92

Grammoptera ruficomis 366, 368, 369, 370, 372, 373

Gratiola officinalis 261

Grewia 323

Grubbiaceae 303

Gryllotalpa 84

Guaiacum 331

Guarea 331

Guatteria olivaeformis 269

Guevina 317

gullet-shaped blossom 134, 235, 288, 333, 337

Gunnera 304

Gunneraceae 304

Gustavia 335

Guttiferoxplon 323

Gymnadenia 199

Gymnochares 79

Gymnospermae 70, 209ff, 264, 271, 276, 278, 283 gynodioecy $227,237,289$

gynoecium 270

gynomonoecy 227, 237, 289

Gypsophila 213

Gyrocarpaceae 265

Gyrocarpus 333

Habenaria obtusata 32

Halesia 334

half-inferior ovary 188, 236

Halictidae $25,87,171,172,174,246,256$, 257,261

Halictus 162, 250, 254, 259

H. zonulus 255

Hallomenus 58

Haloragaceae 304, 318, 324

Haloragis 324

Halticinae 62

Hamamelidaceae 296, 302, 313, 333

Hamamelidae 288, 296, 344

Hamamelis 313

H. virginiana 313

Haplocnemus pini 56

H. tarsalis 56

haplomorphic 129, 287, 298

Haploneuron 79

Haplophyllum 339

Harpalinae 21

Harpobittacus 95

Hauya 315, 330

Hebe 340

Hedera 305

H. helix 306

Hedycaryoxylon 313

Hedyosmum 293, 294

Helcomyzidae 37

Heleomyzidae 37, 107

Heleomyzoidea 37

Helianthemum 39, 199, 257, 334

Helianthus anuus 149

Helichrysum 212

Helicia 317

Heliconiinae 29, 164

Heliconius 29

H. charitonius 164

H. erato 164

H. numata 164

H. sara 164

Heliodinidae 27

Heliozela 26

Heliozelidae 26

Helleboreae 251

Helleborites 253

Helleborus 251, 253, 267, 269

H. niger 252

Helminthidae 16 
Helodidae 15, 50

Helodinidae 93

Helophorinae 51

Helopini 58

Helopus 58

Heloridae 70

Heloridae s.lat. 70

Helosciomyzidae 107

Helotidae 19

Hemerocallis 262

hemilectic 5

Hemipeplidae 19

hemiphilic 5, 125, 234, 287, 298

Hemiptera 39, 45, 276, 278, 295

Hemislemma 250

hemitropic 5

Hepatica 251, 252

Hepialidae 26

Hepialoidea 26, 92

Heracleum lanatum 203

H. mantegazzianum 366

$H$. sphondylium 32, 216, 366

herkogamy 237

hermaphroditism 227, 237

Hernandiaceae 265, 333

Hemiaria glabra 224

Hesperiidae 28, 94, 111, 164

Hesperis lineola 258

Hesperioidea 28

Heterodactyla 102

Heterogynidae 28

Heteromera 52, 57, 58

Heteromyzidae 106

Heteroneura 90

Heteroptera 278

Heteropteroidea 45

Hibbertia 250, 268, 269

H. tetandra 250

Hibiscoxylon niloticum 314

Hibiscus 182, 236, 259, 314, 323

$H$. lasiocarpus 259

$H$. liliiflorus 259

H. rosa-sinensis 259

H. schizopetalus 259

H. trionum 259

Himantandra 269

Himantandraceae 265, 268

Hippoboscidae 39, 106

Hippocastaneaceae 267, 331

Hippocratea 331

Hippophae 341

Hippuridaceae 326

Hirmoneura 111

Hispinae 62

Histeridae 13, 50

Histeroidea 13
Hohenhackeria 325

Holcoborus 51

Holodisceae 255

Holodiscus 255

Holometabola 41, 43, 45

Holosteum 213

H. umbellatum 224

Holostilpna 63

Homalisidae 16, 55

Homoeodactyla 102, 175, 177

homogamy 204, 219ff, 236, 289

Homogyne 212

Homoptera 45, 77

Honckenya 213

Hoplia 14, 15

Hopliinae 14, 54, 175

Hordeum distichon 225

H. vulgare 225

Horminium 213

Hornschuchia 248

Hottonia palustris 222, 226

Houmiriaceae 325, 339

Humeria 339

Humulus 190

Hunnemania 253

Hyacinthus 262

Hyblaeidae 28

Hybosoridae 51

Hydnora 15

Hydnoraceae 15

Hydraenidae 13, 48, 50

Hydrangeaceae 329

Hydrellia 38

Hydrocharis 332

Hydrocharitaceae 326, 332

Hydrochidae 13

Hydrocopridae 20

Hydrocotyle 316, 325

H. vulgaris 214

hydrogamy 4

Hydrophilidae 13, 14, 50

Hydrophiloidea 13

Hydrophyllaceae 225, 341

Hygrophila 336

Hymenaea 85, 290, 335, 337

Hymenalia 58

Hymenoptera 10, 21ff, 41, 43, 64ff, 87, 108 $111,282,295,299$

Hypecoum 253, 254

H. pendulum 225

Hypericaceae 225

Hypericum 199, 269

H. humifusum 225

Hyperoscelidae 101

Hypocera 103, 104, 177

Hypochoeris radicata 40 
Hypocleptes 77

Hypodermatidae 106

Hypolaena laterifolia 320

Hypsidae 30

Ibaliidae 23

Icacinaceae $306,320,325,335$

Ichneumonidae 23, 74, 108

Ichneumonoidea 23, 74, 169, 174, 284

Ilex 199, 306

I. opaca 306

1. scudderi 306

Illecebrum verticillatum 224

Illiciaceae 265, 268, 312

Illiciales 296

Illicium 312

Impatiens 212

I. capensis 341

I. noli-tangere 224

inconspicuous blossoms 134

Incurvariidae 26

Incurvariina 90,92

Incurvarioidea 26

Indigofera 339

inferior ovary 188, 236

Inga 330

Inopeplidae 19

Inula 212, 341

Iodes 320

Irania hermaphroditica 209, 282

Iriartea 326

Iridaceae $120,261,317,318$

Iris $1,261,317$

Ironomyiidae 103

Isomira 58

Isopyrum 251, 267

Ixora 336

\section{Jasione montana 371}

Johannesteijsmannia 307

Judolia (Pachytodes) cerambyciformis 365, 366, $367,368,369,372,373$

Juglandaceae $68,303,319$

Juglandales 308,344

Juglans 118, 303

Juncaceae 217, 218, 225, 247, 332

Juncus 332

J. bufonius 225

$J$. capitatus 225

$J$. effusus 225

$J$. pygmacus 225

Jussieua 315

$J$. champlainensis 331

Justicia 336

Kadsura 269, 322
Kalmia 338

Karavitidae 70

Karumiidae 16

Kickxia spuria 261

Kielmeyera 323

Kingdoniaceae 265

Kleinhovia 334

Knautia arvense 371

Koelreuteria 331

Korthalsia rigida 337

Kotujellidae 72

Lacosomidae 30

Lactoridaceae 266

Laena 58

Lagerstroemia 335

Lagria 58

Lagriidae 18, 58, 59, 299

Lagriinae 58

Lamiaceae 212, 213, 225, 296, 310, 332, 336, $340,341,372$

Lamiales 177

Lamiinae 20, 60, 61

Lamium 199, 213

L. amplexicaule 225

Lampyridae 16,55

Languriidae 19,57

Lantana camara 164

Lapeyrousia fabricii 120

Laprosticti 54

Lardizabalaceae 266, 267

Laserpitium latifolium 216

L. prutenicum 216

L. trilobum 216

Lasiocampidae 30

Lasiopetalum bracteatum 320

Lathridiidae 18, 52

Lathyrus setifolius 225

Lauraceae 265, 266, 301, 313, 328

Laurales 293

Laurelia 328

Laurophyllum 313

Laurus 313

L. nobilis 313

Lauxaniidae 36, 37, 39, 105

Lauxanioidea 105

Lauxanioinea 105

Lavandula 213

Lecythidaceae 324, 335

Lebachia 273, 274

Lebachiaceae 273, 274

Ledum 334

Leitneria 333

Leitneriaceae 333

Lemna 320

Lemnaceae 320 
Lemoniidae 30

Lentibulariaceae 336

Leontodon 371

L. hispidus 246, 371

Lepidoptera 10, 26ff, 41, 64, 87ff, 95, 108, $111,163 \mathrm{ff}, 172 \mathrm{ff}, 174,176,178,295,299$, $308,327,343$

Leptidae 33

Leptinidae 14

Leptoceridae 40

Leptofoenidae 73

Leptonycteris 286

Leptospermum 34, 95

Leptura (L.) cordigera 370,371

L. (L.) dubia $367,368,371,372$

L. (L.) inexpectata $366,368,372,373$

L. (L.) maculicornis $366,367,368,369,370$, $371,372,373$

L. (L.) rubra 365

L. (L.) sanguinolenta $366,367,369,370,371$, 372

L. (L.) scutellata $365,366,368,370,372$

L. (Vadonia) livida 366, 367, 369, 370

L. (V.) lurida 366,372

Lepturinae $20,60,61,202,365 \mathrm{ff}$

Leucaena 330

Leucojum aestivum 261

L. vernum 261

Leucopogon 323, 327

Leucospermum 317

Leucospinae $24,73,74$

Libytheidae 29

Liguliflorae 213, 336

Ligusticum mutellina 215

L. mutellinoides 215

Ligustrum subtile 310

Liliaceae 225, 261, 267, 317, 326, 337, 340, 372

Liliacidites 297

Liliales 177

Liliopsida 293, 294, 297

Lilium 262

L. bulbiferum 372

L. speciosum 340

Limacodidae 28

Limnobiidae 97, 99

Limosella aquatica 226

Limulodidae 14

Linaceae $267,316,325$

Linaria 199, 226, 260, 261

L. alpina 260

L. organifolia 261

L. striata 261

L. vulgaris 261

Lindera 328

Lindleya 255
Linum 222, 325

Liodidae 14

Liopini 61

Liopteridae 23

Liquidambar 302

Liriodendron 245, 269

L. tulipifera 199, 245, 246, 265, 266, 269

L. tulipiferoides 246

Liriodendroipollis 246

Lisponema 75

L. singularis 85

Listera ovata 39

Litchi chinensis 83

Litthosiinae 30

Littorella 336

Lloydia 199

Loasaceae 268, 336

Loboscelidae 76,77

Loganiaceae 326

Lolium perenne 291

Lonchaeidae 37, 105

Lonchaeoidea 105

Lonchoglossa 286

Lonchoptera 103

Lonchopteridae 35, 103, 300

Lonchopteroidea 35

Lonicera 256, 332

L. alpigena 256

L. caerulea 256

L. caprifolium 124, 256

L. nigra 256

L. periclymenum 256, 371

L. xylosteum 256

Lophocoronidae 30

Loranthaceae 190, 325, 327

Loranthus elegans 325

Loriinae 285

Loxoceridae 106

Lucanidae 15, 50, 54

Lucilia 160

Ludwigia 315, 335

L. alternifolia 315

Lumnitzera littorea 335, 337

Luronium natans 224

Luzula 332

L. nivea 14

Lycaena icarus 258

Lycaenidae 29, 94, 111

Lychnis chalcedonica 163

Lycidae 16, 55

Lycopodium 291

Lycopus 213, 310, 341

Lyctidae 17, 56

Lyctus 56

Lygaeidae 278

Lygaeoidea 278 
Lyginopteridatae $\mathbf{2 7 5}$

Lymantriidae 29

Lymexylidae 17, 43

Lymexyloidea 17, 51

Lyonetiidae 27, 92

Lysimachia 87, 338

Lythraceae 225, 324, 330, 335, 339

Lythrum 335

L. salicaria 222

$L$. thesoides 225

Lytta 59

Macrodactylus subspinosus 246

Macroglossum 163, 258

M. stellatarum 163, 258

Macromeris 79

Macropis 87

Macrosphyra 331

Macroxyelinae 68

Macrozamia mackenzi 276, 277

M. reidlei 276

Maestrichtian 311

Magnolia 129, 245, 246, 301

$M$. amplifolia 246

$M$. glauca 246

$M$. grandiflora 217

$M$. lacoeana 246

$M$. macrophylla 246

Magnoliaceae 243, 245, 265, 266, 268, 269, 270,301

Magnoliaestrobus gilmouri 246

Magnoliales 177

Magnoliidae 266, 267, 293, 294, 295, 298

Magnoliopsida 293, 294

Magnolipollis 301

$M$. graciliexinus 246

$M$. megafiguratus 246

Mahonia 328

Majanthemum 262

Malachiidae 16, 307

Malachiinae 108

Malachium 213

Malmea 249, 312

Malpighiaceae 325, 327, 335

Malva 259

M. alcea 259

M. moschata 259

$M$. neglectis 225

$M$. rotundifolia 259

$M$. sylvestris 259

Malvaceae 1, 177, 225, 259, 267, 314, 323, 327

Malvales 327

Malvanae 308

Mamillaria tuberculosa 341

Manduca 163
Maniltoa grandiflora 319

Maniola jurtina 164

Manningia 192, 308

Mansonia 323

Marcgravia 328

Marcgraviaceae 328

Masaridae 25, 80, 81, 82, 111, 177, 284, 299

Masarinae 80, 81, 82, 299

Mastixia 325

Matricaria inodora 371

Mauritia 320

Maytenus 325

Meconella 253

Mecoptera 40, 41, 42, 43, 45, 64, 67, 87, 89, $95,97,282$

Mecopteroidea 41, 43, 64, 87, 89, 97

Medicago sativa 162,172

medullosans 277

Megachile 121, 124

M. circumcincta 124

M. pacifica 162,172

Megachilidae 25, 77, 85, 87, 162, 171, 172, 178

Megachiroptera 286

Megalodontes 22

Megalodontidae 21, 69

Megalodontoidea 21, 69

Megaloptera 41, 46

Megalopygidae 28

Megalyridae 70

Megalyroidea 23, 25

Megamerinidae 36, 107

Megathymidae 28

Megatominae 56

Megistorhynchus longirostris 102, 120

Melampyrum 260

Melandrium 213

Melandryidae 19, 58, 59, 299

Melanorrhoea beccarii 335

Meliaceae 319, 321, 325, 331, 335

Meligethes 260

Meliosma 325

Meliosmaceae 266

Meliphagidae 285

Melipona bipunctata 250

Meliponini 85, 108, 295

Melissa 213

$M$. elegans 340

Melittidae 25, 87, 171, 172

melittophily/-gamy 119, 234, 285, 286, 321, $327,333,345$

Mellinus 85

Meloidae 18, 58, 59

Melolontha 14

Melolonthinae 14, 54, 175, 246

Melyridae 16, 18, 56, 108, 190 
Melyrinae 108

Mengea 256

Menispermaceae 265, 296, 297, 322, 338

Menispermum 322

Mentha 213, 310, 340, 372

Mentzelia 336

Menyanthes 339

M. trifoliata 222, 225

Menziesa 334

Mercurialis 118, 204, 267

Meropeidae 95

Merophysiidae 19

Merremia macrocalyx 326

Merycidae 20

Mesaulacinus oviformis 70

Mesocephalus sibiricus 70

Mesocephus 66

Mesochelorus muchini 70

Mesodascilla 54

Mesohelophorus 51

Mesolyda 69

Mesoserphidae 71

Metachandidae 28

Metarbelidae 30

Metroxena 21, 63

Meum athamanticum 215

Michelia 245, 246

Micraulacus 72

Microchiroptera 286

micro-entomophilous 105

Microlepidoptera 90

Micromalthidae 21

micromyophilous 105

Micromalthus 51, 52

Micropezidae 36, 106

Micropezoidea 36

Micropezoinea 106

Micropterigidae 26, 90, 92, 108, 110, 176, 278, 285

Micropterix 113

M. calthella 176

Microptysma 42, 64

Microptysmodes 42, 64

Microstigmus 85

Microtropis 331

Milichiidae 38, 107, 108

Milusia 333

Mimeso 85

Mimosa 304

Mimosoideae 260, 304, 324, 330, 334

Mindidae 107

Minuartia 213

Miocene 333

Mirabilis 309, 328

M. longiflora 309

Miridae 40
Mitragyne 331

Mnesarchaeidae 30, 92

Mnesarchaeoidea 92

Moehringia 213

Moenchia erecta 224

Mollinedia 313

Molorchus (Caenoptera) minor 366, 372

Momipites fragilis 303

Moneses 260, 267

M. uniflora 260

Monimiaceae 265, 266, 296, 313, 319, 328

Monimiopsis 319

Monnina 320, 321

monoecy $227,237,289$

Monomachidae 70

Monommidae 19

monophilic 125, 234

Monotes 329

Monotropa hypopitys 260

Monotrysia 26, 92

Monotrysia s.str. 92

Montia 333

$M$. fontana 226

Moraceae 302, 322, 338

Mordella 59

Mordellidae 18, 51, 58, 59, 175, 245, 295, 307

Mordellistena 59

$M$. pentas 18

Morelia 336

Morinda 336

Mormotomyiidae 39, 107

moth-pollinated flowers 112, 233, 285

Musca 160

Muscicapidae 285, 286

Muscidae 35, 38, 106, 124, 168, 249, 257, $259,260,312$

Muscoidea 38, 105, 106, 111

Mutillidae 24, 76, 78, 84, 85, 284, 299

Mycetochara 58

Mycetocharoides 58

Mycetophagidae 19

Mycetophilidae 32, 101, 110, 145, 282, 300

Mycetofiliformia 101

Mycteridae 19, 58

Mydaidae 34, 102

Mymaridae 24, 73

Mymarommidae 73

Myoglossata 90

myophily/-gamy 118, 124, 233, 234, 285, 307

Myosotis 341

Myosoton aquaticum 224

Myosurus 251, 252

Myrica 309

M. gale 309

Myricaceae 309

Myriophyllum 319 
Myristica 322

Myristicaceae 266, 322, 338

Myrmeciinae 82, 83

myrmecochory 9

myrmecodomy 9,83

myrmecogamy 9

myrmecophily 83

myrmecophylaxis 9, 83

myrmecophytes 83

Myrmica rubra 83

Myrmiciidae 69

Myrmicinae 83

Myrothamnaceae 302

Myrothamnus 302

Myrrhis odorata 216, 367

Myrsinaceae 329

Myrsinopsis 329

Myrtaceae 310, 318, 324

Myrtales 177, 308, 327

Myrtophyllum 297

Myxophaga 13, 21, 48

Naja 337

Najadaceae 326, 337

Nannochoristidae 89, 95, 97

Nannolepidoptera 92

Narcissus 129, 261

$N$. jonquilla 261

$N$. odorus 261

$N$. poeticus 261

$N$. polyanthus 261

$N$. primulus 261

$N$. pseudo-narcissus 261

$N$. tazetta 261

$N$. triandrus 261

$N$. triflorus 261

Narthecium 237, 261

N. ossifragum 176

Nasturtium officinale 224

Necrophorus 14

nectar 199ff, $265 \mathrm{ff}, 289$

Nectariniidae 285

Necydalis 61

Negastriinae 55

Nelumbites 301

Nelumbo 302, 322

Nelumbonaceae 302,322

Nematinae 67

Nematocera $31 \mathrm{ff}, 97,108,110,169,175$

Nemestrinidae $34,102,108,110,111,120$, $121,141,175,177,182,284,285,300$

Nemognatha 18

Nemonychidae 20, 51, 63, 175

Nemophila maculata 225

Nemuaron 296

Nenga 337
Neolepidoptera 90

Neopaxia 333

Neopseustidae 30, 91

Neopseustina 90, 91

Neottiophilidae 37, 108

Nepenthaceae 335

Nepenthes 335

Nepeta 213

Nephelium 335

Nepticulidae 26

Nepticuloidea 26, 92

Neriidae 36, 106

Nerium 260, 306

$N$. oleander 306

Neuroptera 40, 41

Neuropteroidea 41, 43, 46, 64, 282

Nigella 251, 267, 269

Nipanioxylon 277

Nitidulidae 18, 57, 145, 166, 175, 295

Noctuidae 29, 30, 163, 164, 172

Noctuoidea 29, 94, 178, 286

Nolidae 30

Nomada 255

non-apoid Hymenoptera 10, 111, 160ff, $169 \mathrm{ff}, 174,175,177$

Norantea 328

Nosodendridae 15

Nothiothaumidae 95

Nothofagus 308

Nothomymecia 82

Nothybidae 36, 106

Nothyboidea 105, 106

Notocyphus 79

Notodontidae 94

Notoxini 60

Nuphar 265

Nyctaginaceae 309, 322, 328, 338

Nycteribiidae 39

Nycterimorpha speiseri 111

Nymphaea 15, 129, 302

Nymphaeaceae 62, 265, 266, 268, 301

Nymphaeales 177

Nymphalidae 29, 94, 111, 164

Nymphalis io 164

N. polychlorus 164

Nymphomyiidae 33, 99

Nypa 307

Nyssa 316, 320

Nyssaceae 316, 320

obligatory pollination types 10

Obrium brunneum 365, 366, 367, 368, 369, 370

Ochnaceae 322

Ochodaeinae 54

Odiniidae 37, 39, 107, 108

Odontopus sexpunctatus 280 
Odostemon 328

Oecophoridae 28, 93

Oedemera 59

Oedemeridae $18,58,59,190$

Oenanthe aquatica 215

O. fistulosa 215

Oenothera 315

O. hookeri 164

Oestridae 39, 106

oil-collecting bees 2

oil-producing flowers 2, 327

Olacaceae 320, 321

Olax 320, 321

Olea 332

Oleaceae 225, 310, 316, 317, 332, 336, 341

Olibrus 57

Oligocene 328

"Oligoneura" 108, 169, 175

oligophilic 125, 234

Oligophryne fungivoroides 101

Omaliinae 14, 50, 52

Omalium 14

Ommadidae 45, 48, 50

Ommadinae 45

Omophlinae 58

Omophlus americanae 58

Omophrominae 21

Onagraceae 193, 315, 330, 335

Oncoba 323

Oncosperma 332

Onthophagus 15

Ooperiglyptus 48

Opatrini 58

Operophtera (Cheimatobia) brumata 164, 172

Ophrys 148

Opiselleipon 48

Opomyzidae 37, 107

Opomyzoidea 37

Opopanax 339

Opostegidae 27

Oppenheimiella baltica 104

Orchidaceae 192, 193

Orchidales 177

orchids 1

Origanum 213

Oriolidae 285, 286

Orlaya grandiflora 216

Omithogalum 262

ornithophily/-gamy 4, 182, 234, 285, 333, 337, 338

Orobanchaceae 340

Orontium 337

Orrhodia vaccinii 163

Orthilia 260, 267

O. secunda 260

Orthocarpus pusillus 83
Orthoptera 39

Orthorrhapha 33ff, 169, 175, 177

Orthosia circellaris 163

O. lota 163

Orussidae 23, 69

Osmia 121, 162, 253, 255

Osphya 59

Ostrya 322

Osyris 331

Otitidae 36, 108

Oxalidaceae 225, 260, 267, 296, 331

Oxalis 331

O. acetosella 225,260

O. corniculata 225,260

O. deppei 225

O. dillenii 260

O. fontana 260

O. pes-caprae 260

Oxybelus bellus 255

O. uniglumis 255

Oxychirotidae 28

Oxychloe 218

Oxycorynidae 21, 50, 63, 175

Oxycorynus 21, 63

Oxymitra 248

Oxytelus 14

Oxytenidae 30

Oxythyrea funesta $246,366,367,368,369,370$ $371,372,373$

Pachyneuridae 33, 100

Pachypleurum alpinum 215

Pachysandra 308

Pachyta quadrimaculata 365, 367, 368, 370

Pachytodes 20

Paeonia 251, 268, 269

P. albiflora 251

$P$. arborea 251

P. brownii 251

$P$. californica 251

$P$. daurica-corallina complex 251

$P$. delavayi 251

$P$. officinalis 251

$P$. ovata 251

$P$. suffrutescens 251

Paeoniaceae 251, 268

Palaeohemerobiidae 42

Palacoplecia 101

Palaeopyrochroa crowsoni 58

Palaeosetidae 26

Palaeotendipes alexii 100

Palaeovespa 82

Paleocene 319

Paleognathus 54

paleomorphic 129, 287

Palloptera 108 
Pallopteridae 37,108

Palorus 58

Palpomyia 100

Pamphiliidae 22, 68, 69

Pandanaceae 307,332

Pandanus tectoria 307

Pangonia 120

Panorpa 40

$P$. communis 95

Panorpidae 95

Pantophthalmidae 34

Panurgus 162

Papaver 199, 253, 254, 322

$P$. alpinum 253, 255, 257

$P$. argemone 253

P. dubium 253

P. hybridum 253

P. lecoqii 253

$P$. nudicaule 253

$P$. orientale 253

$P$. pictum 254

P. pinnatifidum 253

$P$. radicatum 253

P. rhaeticum 253

P. thoeas 149, 253

$P$. sendineri 253

$P$. somniferum 253, 254

Papaveraceae 225, 253, 255, 266, 267, 268, 296, 322

Papaverales 177

Papaverites 254

Papilio demoleus 164

$P$. machaon 164

Papilionidae 29, 94, 95, 111, 164, 172

Papilionoidea 29, 94, 95, 109, 164, 172, 178, 285, 311, 345

Papilionoideae 260, 299, 304, 319, 321, 324, $330,335,339$

Paradisea 262

Paragenia 79

Parandra 60, 61

Parandrexis 60

Paraneoptera 43, 45

Parapamphilus 66, 69

Parasabatinca aftimarca 90

Parastemon 256, 330

Paratrichoptera 42, 87, 97, 282

Paravespula 161

$P$. germanica 161

Pardalotidae 285

"Parietales" 345

Parietaria 217

Paris 262

Parishia 331

Parkic 324

Parnassia 199
Paroryssidae 66, 69

Parrotia 333

Parthenocissus 326

Passaleucus 85

Passalidae 15

Passandridae 19

Passeres 286

Passeriformes 286

Passiflora 323

Passifloraceae 323

Pastinaca sativa 203, 215, 367

Patosia 218

Paullinia 335

$P$. pinnata 305

Pauwlonia 336

Pedaliaceae 340

Pedicularis 2, 260

Pelargonium 260

P. echinatum 339

Pelecinidae 70

Pelecorhynchidae 33, 102

Pelecorhynchus 34

Pelecotoma 59

Pelliciera 322

Pellicieraceae 322

Peltidae 51

Pennantia corymbosa 306

Pentaclethra macrophylla 324

Pentadesma butyracea 329

Pentaphylaceae 328

Pentaphylax 328

Pentoxylales 277, 280

Pentoxylon 277, 283

Peperomiaceae 266

Pepsis 79

perfume flowers 337,338

Perga lewisi 67

Pergidae 22, 67, 68

Perginae 68

perianth types $133 \mathrm{ff}, 268$

actinomorphic 133

bilabiate 134

calceolate 134

campanulate 133

carinate 134

coronate 133

cruciform 133

globose 133

infundibular 133

papilionaceous 134

personate 134

saccate 134

salverform 134

unguiculate 134

urceolate 133

Perimylopidae 20 
Periploca 336

Periscelidae 39, 106

Periscelididae 106

Perissomma fusca 100

Perissommatidae 33, 100

Peritassa 331

Peritaxia hispida 254

Permotanyderus ableptus 97

Permotipula patricia 97

Permosialis 42

Perothopidae 16

Petasites 213

Petraea 326

Petroselinum 339

P. crispum 214

Peucedanites nordenskioldi 316

Peucedanum 320

$P$. alsaticum 215

P. cervaria 215,367

P. estruthium 215

$P$. officinale 215

$P$. oreoselinum 215,367

P. palustre 215

$P$. venetum 215

Phaeochrous 15

Phaeomyiidae 107

Phaeoptilum 322, 327

Phalacridae 18, 57, 190, 299

Phalacrus 58

phalaenophily/-gamy 119, 234, 286, 327, 333

phanaerogamy 237

Phaleria 334

Phaloniidae 27

phaneranthery $180 \mathrm{ff}$

Pharaxonothini 52, 57

Phasmatodea 77

Phellodendron 324

Phengodidae 16

Philepittidae 286

Philia febrilis 101

Philinae 60, 61

Phillyrea 336

Philodendron 345

Philorinum 14

Phlaeophagus 277

Phlebotominae 31, 99

Phlebotomus minutus 31

Phloeophilidae 18

Phloetrya 58

Phlox 163, 199

$P$. divaricata 199

$P$. cf sibirica 341

Phora 104

Phoridae 35, 103, 104, 249, 300

Phormiaceae 326

Phormium 326
Phoroidea 35, 103

Phragmites 310

Phthiraptera 43

Phycosecidae 19

Phyllocnistidae 27, 92

Phyllopertha 14, 15

Phyllostomatidae 286

Phyllostomus 286

Phymatidae 39

Physalis 340

Physocarpus 255

Physoptilidae 28

Phytelephas 307, 337

Phytidae 19, 58

Phytocreme microcarpa 306

Picea excelsa 55, 56, 190

Phytolacca americana 341

Phytolaccaceae 341

Pidonia lurida 365, 366, 367, 369, 372

Pieridae 29, 94, 111, 164, 172

Pieris (Ericaceae) 338

Pieris (butterfly) 164

P. brassicae 164,258

P. napi 258

P. rapae 258

Pilocarpus 324

Pimpinella major 214

P. saxifraga 214,367

Pinaceae 373

Pinicae 273, 275

Pinus 17, 20, 22, 59, 63, 109, 176, 291, 293 343

P. cembra 60,190

P. mugo 55, 190, 373

P. sylvestris $56,58,190,209$

Piophilidae 37, 108

Piper 301

Piperaceae 266, 301

Piperites tuscalooensis 301

Pipunculidae 35, 104, 111

Pison 85

Pisonia 309

P. cauliflora 309

Pistacia 331

Pittoecus 75

Pittosporaceae 338

Pittosporum 338

Planchonia 335

Plantaginaceae 336, 373

Plantago 190, 237, 336

$P$. media 113, 373

Platanaceae 296, 302

Platanus 270, 302

Platea 320

Platycarya 319

Platypezidae 35, 104, 313 
Platypezidea 103, 104

Platystemon 253, 254

Platystethus 14

Platystomatidae 36, 108

Plecoptera 39

Plectrotarsidae 87

Pleiomeropsis 329

Pleiostigma 312

Pleodendron 328

pleomorphic 129, 235, 287, 298

Plerandra pickeringii 305

Pleuronerinae 68

Pleurospermum 325

P. austriacum 214

Pleurosticti 54

Pliocene 338

Ploceidae 285, 286

Plumariidae 24, 76, 78

Plumbaginaceae 1, 334

Plumbaginales 177

Plumerioideae 306

Plusia gamma 258

Plutellidae 92

Poaceae 225, 226, 310, 320, 340, 373

Poales 177

Podalirius 259

$P$. occidentalis 254

Podophyllum peltatum 199

Podostemaceae 330

Poecedanum moebii 339

Polemoniaceae 1, 336, 340, 341

Polemoniales 177

Polemonium 340

P. caeruleum 95

Polistes 81

Polistinae 81

pollination syndromes $3,118 \mathrm{ff}, 233,234$

pollination types $112 \mathrm{ff}, 233,240$

pollinia 193

polyads 193

Polyalthia 249, 250

$P$. laterifolia 248

Polybia 81

Polycarpon tetraphyllum 224

Polygala 226

Polygalaceae 226, 320, 321, 325, 335, 338

polygamy $227,237,289$

Polygonaceae 226, 269, 319, 333, 369, 373

Polygonatum 262

Polygonum 135

P. alpinum 369

$P$. aviculare 226

$P$. californicum 333

P. hydropiper 226

$P$. minus 226

P. mite 226
$P$. persicaria 226, 319

"Polyneura" 108, 169, 175

Polyphaga 13, 48, 49, 52, 167

polyphilic 125,234

Polyporina cribraria 313

Polystiche 250

Pomoideae 256

Pompilidae 24, 79, 80

Pompiloidea 24, 76, 78, 79, 82

Pompilopterus ciliatus 78

Pompilus 79

Ponerinae 82, 84

Pontederiaceae 326

Pontia 67

Populus 118, 176, 190, 232, 303

Porana 326

Porliera 331

Portulaca 333

$P$. grandiflora 226

P. oleracea 226

Portulacaceae 226, 333, 338

Posidonia 317

Posidoniaceae 317

Potamogetonaceae 320

Potamogeton 320

Potentilla 199, 217, 255

$P$. anserina 255

$P$. erecta 176

P. fruticosa 255,339

$P$. tridentata 255

Potentilleae 255

Potentillinae 255

Potosia 14, 15

$P$. (P.) angustata $366,368,369,372$

$P$. (P.) cuprea $365,366,367,368,369,371$, 372,373

P. (P.) fieberi 367

Praeaulacidae 71, 72

Praeaulacinus 72

Praeaulacites 72

Praeaulacon 72

Praeaulacops 72

Praeaulacus 72

Praepapilio colorado 94

$P$. gracilis 94

Praepapilioninae 94

Precis almama 164

Primula 222, 261

P. integrifolia 261

$P$. minima 261

$P$. veris 149

Primulaceae 226, 261, 334, 338

Primulales 177

Priochilus 79

Priocnemis 79

Prioninae 60, 61 
Priophora canadambra 103

Pristaulacus 72

Prochrysis succinalis 77

Procleptes 75, 77

Proctotrupidae 70

Proctotrupoidea 23, 26, 70, 77

Prodoxidae 26, 92

Progymnospermae 275

Prolyda 69

Prometia 335

Propalticidae 20

Proscelinae 62

Proseuca 102

Prosopanche 63

Prosopis (wasp) 121, 162

Prosopis juliflora (Fabaceae) 330

Protallactoneura 101

protandry 204ff, 236, 289

Protamisega 77

Protea 317

Proteaceae 1, 317

Proteales 177

Protempidae 102

Protempis antennuata 102

Proterhinidae 21

Proteroscarabaeus 51

Proteroscelio 71

Protimaspis 73

Protoatherospermoxylon 313

Protobrachyceron liasinum 101

Protocoleoptera 46, 47

Protocucujidae 20, 57

Protodiptera 97

protogyny 204ff, 236, 289, 299

Protolbiogaster 97, 98, 101

Protomecoptera 95

Protomphrale martynovi 102

Protopolybia 81

Protorhyphus 97, 98

$P$. turanicus 101

P. stigmatcus 101

Prototheoridae 26

Prunoideae 256

Prunus 188, 330

$P$. laurocerasus 339

$P$. padus 341

Psammochares 79

Pselaphidae 14

Psen 85

Pseudarbelidae 27

Pseudima frutescens 305

Pseudococcus bromeliae 19

Pseudomyrmex 83

Pseudomyzidae 36, 106

Pseudoprosopis sericeus 324

Pseudosiricidae 66
Pseudowintera 247, 248, 267, 294, 295

Pseudowinterapollis 248, 294, 295

P. couperi 248, 294

P. wahooensis 248,294

Psilatricolporites undulatus 256

Psilidae 36, 106

Psittacidae 285, 286

Psocodea 43

Psocoptera 43

Psychidae 27, 92

Psychoda 99

Psychodidae 31, 99, 105, 110, 145, 343

Psychodinae 31

Psychodoidea 99, 209

Psychodomorpha 31, 97, 99

Psychomyiidae 87

psychophily/-gamy $119,234,285,286,318$, 321,327

Ptelea 324

Pteridospermae 275

Pteridospermales 275, 276, 280, 282

Pterocallidae 108

Pterocarpus 330

Pteroceltis 328

Pterogeniidae 20

Pterolonchidae 28

Pteromalidae 24, 73

Pterospermum 334

Pterothysanidae 30

Ptiliidae 14

Ptilodactylidae 50

Ptinidae 17, 56, 190

Ptinus dubius 17, 56

Ptychopteridae 31, 99

Ptychopteroidea 99

Pulicaria 212

Pulmonaria officinalis 222

Pulsatilla patens 267

$P$. pratensis 267

$P$. vernalis 267

P. vulgaris 267

Punctioratipollis ludwigi 253

Punica 339

Punicaceae 330, 339

Purshia 255

Pycnanthus 322

Pyralidae 28, 286

Pyraloidea 28, 94, 172, 178

Pyrgotidae 36, 108

Pyrochroidae 19, 58

Pyroideae 304

Pyrola 260, 267

P. media 260

P. minor 260

$P$. rotundifolia 260

Pyrolaceae 260, 267 
Pyrus 256, 304, 330

qualitative analysis 10

quantitative analysis 10

Quasimus 55

Quaternary 340

Quercus 59, 328

Quillaja 255, 256, 330

Q. saponaria 255

Quilajeae 255

Quintinia 323

\section{Rajana 337}

Randia 326

Ranunculaceae $251,266,267,268,328,333$, 338,369

Ranunculales 177

Ranunculidae 296

Ranunculus 199, 251, 252, 253, 269, 328

$R$. acer 176

$R$. acris 176,369

$R$. alsimaefolius 251

$R$. auricomus 176

$R$. bulbosus 176

$R$. flammula 251

$R$. ovaliformis 253

$R$. repens 176

Raphanus raphanistrum 160, 162, 164

Raphidiidae 40

Raphidioptera 41

Ratardidae 30

reciprocal averaging 11

reciprocal illumination 7

Reseda 270, 338

$R$. odorala 134

Resedaceae 256, 338

Restio subverticillatus 318

Restionaceae 318, 320

Reveesia 319, 320

Rhaetofungivora 101

Rhaetofungivorella 101

Rhaetofungivoroides 101

Rhaetomyia 97, 98

$R$. necopinata 100

Rhagionidae 33, 102, 175

Rhagium 20

R. (R.) bifasciatum 60, 190, 369

$R$. (Hargium) mordax 372

Rhamnaceae 267, 339, 368

Rhamnus 28, 199

Rhaphiolepis 330

Rhetus 94

Rhinanthus 260

Rhinotoridae 107

Rhipiceroidea 16

Rhipidius 59
Rhipiphoridae 19, 58, 59

Rhipiphorus 59

Rhizophagidae 19

Rhizophora 324

Rhizophoraceae 324, 335

Rhodocera rhamni 258

Rhododendron 2, 322

Rhodognaphalon 334

Rhoiptelea 309

Rhoipteleaceae 309

Rhopalocera 28, 29, 172, 178

Rhopalosoma 79

Rhopalosomatidae 24, 76, 78, 79

Rhus 319

$R$. canadensis 305

$R$. glabra 305

R. powelliana 305

Rhyphidae 32

Rhysodidae 21

Ribes 222

Richardiidae 36,108

Rigidella 318

Riodina 94

Riodinae 94

Riodinella nympha 94

Riodini 94

Rivellia 36

Rollinia 248

Romneya 253, 254

$R$. coulteri 254

Ropalomeridae 37, 39, 107

Roproniidae 70

Rosa $199,267,373$

$R$. arvensis 373

$R$. canina 373

$R$. hilliae 256

Rosaceae 217, 255, 267, 304, 324, 330, 339, $341,369,372,373$

Rosales 177

Rosidae 296, 297

Rosoideae 256

Rourea 330

Rousettus 286

Rubia 336

Rubiaceae 226, 256, 267, 326, 327, 331, 336, 339,368

Rubiales 177,327

Rubus 134, 330, 372

$R$. chamaemorus 217

$R$. fruticosus 176

$R$. idaeus 134

Rumex 334, 373

Ruppia 320

Ruppiaceae 320

Ruta 260

Rutaceae 260, 267, 304, 305, 324, 331, 339 
Rutelinae 14, 54, 175

Sabal 332

Sabiaceae 265, 325

Sachyanthus 325

Sacoglossis 325

Sagina 213, 257, 259

S. apetala 224, 257

S. nodosa 224,257

S. procumbens 224,257

S. saginoides 224

Sagittaria 332

Sagrinae 62

Sahnia 277

Salicaceae 278, 280, 296, 303

Salix 134, 146, 147, 232, 249, 267, 277, 279, $280,283,296,303$

S. bebbiana 232

S. discolor 232

S. lucida 232

S. petiolaris 232

Salpingidae 19

Salsola 314

Salvia 129, 213, 310, 336

S. glutinosa 124

Sambucus 28, 267, 336

S. australis 237

S. ebulus 199, 368

S. nigra 199, 372

Samolus valerandi 334

Sanguisorba 190, 199, 218, 222, 339

S. officinalis 256

Sanicula europea 214,368

S. marilandica 203

Santalaceae 331

Santalales 327

Santonian 308

Sapindaceae 305, 310, 325, 331, 335, 339

Sapindales 177

Sapindopsis brevifolia 305

Saponaria 213

S. villosa 125

Sapotaceae 303, 329

Sapotacites 303, 329

sapro-entomophily/-gamy $234,245,285,298$, 343

sapromyiophily/-gamy 119, 234

Saprosites 54

Sapygidae 24, 76, 78, 84

Sarauia 322

Sarcandra 293, 294

Sarcobatus 333

Sarcophaga 160

Sarcophagidae 38, 106, 312

Sargentodoxaceae 265

Sarothamnus 199
Sarothriidae 17

Sassafras 301,313

S. officinale 301

Satureja 213

Saturniidae 30

Saxifraga 199, 212, 275

S. oppositifolia 341

Saxifragaceae 341

Scabiosa 336

Scaevola 332

Scandianthus 308

Scandix pecten-veneris 216

Scaphidiidae 14

Scarabaeidae 14, 15, 48, 50, 51, 55, 84, 189 301

Scarabaeinae 54

Scarabaeiformia 14ff, 50, 52ff, 54, 166, 174 175

Scarabaeoidea 14, 51, 52, 54

Scatophagidae 38, 106

Scatopsidae 33, 101, 110, 295

Scenopinidae 34, 102

Schefflera digittata 306

Scheuchzeria palustris 340

Scheuchzeriaceae 340

Schisandra 312

Schisandraceae 266, 269, 312, 322

Schizophora 35ff, 103, 104, 105, 168, 177, $178,300,313$

Schuurmansia 322

Sciadoceridae 35, 103, 104

Sciadophora bostoni 103

Sciaridae 33, 101, 295

Scilla bifolia 262

$S$. hyacinthoides 261

S. italica 262

S. peruviana 261

S. verna 262

Sciomyzidae $36,37,107$

Sciomyzoidea 36

Sciomyzoinea 106, 107

Scirpus 326

Scleranthus annuus 224

Sclerogibbidae 74, 75, 78

Sclerosperma 337

Scolebythidae 76,78

Scolia 80

S. thoracica 309

Scoliidae 24, 76, 78, 80, 82, 177, 284, 299

Scolioidea 24, 84, 169, 170, 177

Scolytidae 19, 51, 278

Scopellosoma satellitia 163

Scraptia pseudofusculosa 59

Scraptiidae 19, 58, 59, 299, 307

Scrophularia $218,226,260$

S. nodosa 161 
Scrophulariaceae 226, 260, 336, 340, 341

Scrophulariales 177

Scutellaria 213

Scydmaenidae 14, 50, 51, 52

Scyphiphora 336

Scythridae 28

Scythrididae 93

Scythropites 93

Secale cereale 226

Sechium 329

Securidaca bombacopsis 325

Sedum 323

Selinum 339

S. carvifolia 215

Sematuridae 29

Senecio 28, 212, 341

Sepsidae 36, 37, 39, 107

Sepsis 37

Sepulcidae 69

Serjania 305, 335

Serratula 213

Serropalpidae 58

Serropalpus 58

Seseli annuum 215

S. hippomarathrum 215

$S$. libanotis 215

Shorea albida 334

Sibiraea 330

Sicyos 329

Sideroxylon 329

Sierolomorphidae 76, 78

Silaum silaus 215

Silene 213, 257, 258, 259, 371

S. acaulis 257

S. ameria 258

S. longiflora 258

S. nutans 258

S. otites 32,258

S. rupestris 258

S. saxifraga 258

S. vulgaris 258

Silphidae 13, 14, 50

Silvanidae 19, 57

Silvanus 57

Simarubaceae 324

Simuliidae $31,32,100,105,110$

Sinapis arvense 224

Sindora 315

Sinosirex 66

S. gigantea 69

Sinosiridae 69

Sintor 63

Siparuna 313

Siphonaptera 41, 43, 89, 95, 97

Siphonia 39

Siricidae 23, 69
Siricoidea 21, 23, 67, 69

Sisyrinchium 261

Sium latifolium 214

S. suave 203

Smicripidae 20, 57

Smilacaceae 307

Smilax 307

S. kansana 307

Solanaceae 326, 332, 340

Solanites 332

Solanum 199

S. dulcamara 237

Soldanella 261

S. alpina 261

S. montana 261

S. pusilla 261

Solidago 212

Somatiidae 37, 106

Sonneratia alba 335

$S$. caseolaris 335

Sonneratiaceae 330, 335

Sorbaria 255

Sorbus aria 370

Spathyphyllum 337

Spercheidae 13

Spergula 213

S. arvensis 224

$S$. morisonii 224

S. pentandra 224

Spergularia 213

S. rubra 224

Spermatophyta $271 \mathrm{ff}$

Sphaeritidae 13

Sphaeroceridae 37, 39, 107

Sphecidae 25, 85, 161, 259, 317

Sphecoidea 25, 76, 78, 84, 85, 169, 170, 177, $299,300,305$

Sphecoidea s.lat. 84,85

Sphecoidea s.str. 85

Sphecomyrma 75

S. freyi 75

Sphecomyrminae 84

Sphindidae 19, 57

Sphingidae 29, 141, 163, 234, 259, 287

Sphingoidea 29, 94, 172, 178, 286

sphingophily/-gamy 182, 234, 286, 333

Spicatae 250

Spiraea 255, 330

$S$. vanhouttei 370

Spiraeeae 255

Spiraeoideae 255, 256

spiral reasoning 7

Stachys 341

Staphylea 339

Staphyleaceae 339

Staphylinidae 13, 14, 50, 174, 189, 245, 285 
Staphyliniformia 13ff, 50, 52, 166, 174

Staphylinoidea $13,50,52,54$

Stathmopodidae 28, 93

Statira $\mathbf{5 8}$

Statirinae 58

Statzia 329

Stelechocarpus 249

S. burakol 249

Stellatopollis 297

S. barghoomii 296

Stellaria 213

S. media 224

Stelopolybia 81

Stemonurus 335

Stenactis 212, 371

S. trichosa 371

Stenogaster micans 81

S. depressigaster 81

Stenogastrinae 81

Stenomidae 28

Stenopsychodes 87

Stenopterus rufus 368, 369, 370, 371, 372, 373

Stephanidae 70

Stephanostemon 329

Sterculia 323

Sterculiaceae 319, 320, 323, 334

stereomorphic $129,235,287,308$

Sternorrhyncha 45

Stewartia 328

Stigmaphronidae 71

Stigmellidae 26

Stigmelloidea 26

Stipa pennata 225

stiped ovary 236, 245, 288, 327

Strangalia 20

S. (S.) aurulenta $365,367,368$

S. (S.) bifasciala $366,368,369,370,373$

S. (S.) maculata $365,366,367,368,369,370$, $371,372,373$

S. (S.) melanura $365,366,367,368,369,370$, $371,372,373$

S. (S.) nigra $366,367,368,369,370,372,373$

$S$. (S.) quadrifasciata 61

$S$. (S.) septempunctata $365,366,367,368,370$, 371,372

S. (Strangalina) attenuata $365,366,367,368$, 370,371

Stratiomyidae $33,34,102,175$

Stratiotes 326

Streblidae 39

Strepsimanidae 28

Strepsiptera 41, 43, 46, 64, 282

Streptocarpus 262

Strophandria 69

Strumigenis 83

Strychnos 326
Sturiella (Sturianthus) langeri 209, 241, 262, 278, 281

Styloceras 322

Stylogastridae 108

Styracaceae 334

Styrax 334

Subularia aquatica 224

Suriane 325

Suttonia 329

Swertia 199

Sylvacoleus 46

Sylviidae 285, 286

Symmocidae 93

sympetaly $235,287,298$

Symphonia globulifera 323

Symphoricarpus 256

Symphyta $21 \mathrm{ff}, 23,66 \mathrm{ff}, 108,110,117,169$, $174,175,210$

Symphyta s.str. $66,67,69,70$

Symphytum 336

Symplocaceae 314

Symplococarpon 310

Symplocos 314

Synagris 81

S. comuta 81

Synapis 87

Syntellidae 13

Syntexidae 23, 69

Syringa 341

Syringogastridae 107

Syrphidae $35,104,110,111,141,177,178$, $201,249,254,257,259,260,295,312$

Syrphidea 103, 104, 105, 126, 313

Syrphoidea 35, 111, 113, 300

Systropha 87

Tabanidae 33, 102, 120, 175, 285

Tabaniformia 102

Tabanoidea 33

Tacazzia 331

Tachigalia paniculata 19

Tachinidae 38, 39, 106, 124, 312

Tachiniscidae 36,108

Taeniapteridae 106

Taeniothrips atratus 40

$T$. ericae 40

T. vulgatissimus 40

Taimyrisphex 75

T. pristinus 85

Talauma ovata 301

Talinella 333

Talinum 333

Tamarindus 330

Tanychora 74

Tanychorella 71, 74

Tanyderidae 31, 99 
Tanyderophryne 98

T. multinervis 99

Tanygnathus 50

Tanypezidae 36, 106

Tanypezoidea 36

Tanypezoinea 106

Tapura ivorense 334

Taraxacum 340

T. officinale 224

Tasmannia 248, 270, 271, 294, 295, 296

Taxidae 275

Tegeticula yuccasella 92

Telegeustidae 16

Telephoridae 16, 190

Tenebrionidae 18, 51, 58, 175, 190, 195

Tenthredinidae 21, 22, 68, 69, 259

Tenthredinoidea $22,67,68,77$

Tephritidae 36,108

Tephritoidea 36

Tephritoinea 106, 107, 108

Teratomyzidae 39,106

Terebania 336

"Terebrantes" 70, 108

Terminalia 324

Termitoxeniidae 103

Ternstroemieae 310

Ternstroemioxylon dachelense 309

Ternstroemites harwoodensis 309

Tethinidae 38, 107

Tetracampidae 73

Tetracentraceae 296

Tetracera 250

T. masuiana 250

Tetraceroideae 250

tetrads 193

Tetralonia 162

Tetraphaleridae 48,50

Tetrapus mayri 74

Tetrastigma 326

Tetratomidae 19, 58

Teucrium 213, 341

Thalictrum 134, 190, 231, 251, 252, 253, 333

$T$. aquilegifolium 134

Thaumaleidae $32,97,100$

Theaceae $309,310,322,328$

Thecosomata 106

Theobroma 83

T. cacao 320

Therevidae 34, 102, 175

Thlaspi arvense 224

Thoninia 325

Thorictidae 17

Thricops 106

Thrips flavus 40

T. fuscipennis 40

T. major 40
Thyatiridae 29

Thymelaeaceae $217,323,329,334$

Thymus 213

Thynninae 84

Thyreophoridae 108

Thyrididae 28

Thyris fenestrella 28

Thysanoptera 40, 43, 295

Tilia 319

T. platyphyllos 368

Tiliaceae $319,323,368$

Timonius 336

Timyridae 28

Tineidae 26, 27, 28, 92

Tineodidae 28

Tineoidea 27, 92, 93, 172, 174

Tiphia 84

Tiphiidae 24, 76, 78, 84, 246, 284, 299

Tipula 31

Tipulidae 31, 97, 99, 110

Tipuloidea 97, 99

Tipulomorpha 31, 97, 99, 100, 209

Tischeriidae 26

Tofieldia 261,317

Toona 325

Tordylium maximum 216

Torilis japonica 216

Tortricidae 27, 94

Tortricoidea 27, 93, 94, 172

Torymidae 24, 73

Tournefortia bicolor 332

Tozzia 260

Trachomitum 336

Trachymyrmex 83

Trapa 331

Trapaceae 331

Trapella antennifera 340

tree fern 46

Triboliini 58

Tribolium 58

Trichantera 336, 337

Trichiinae 14, 54, 175

Trichilia 331

Trichius 14, 15

Trichoceridae 31, 97, 99

Trichogrammatidae 24,73

Trichophthalma 111

T. bivittata 111

T. calabyi 111

T. lutea 111

Trichoptera 40, 41, 64, 87, 89, 90, 95

Trichospermum 323

Trictenotomidae 20

Trientalis europea 199

Trigona iridipennis 277

Trigonalidae 70 
Trigonaloidea 23, 25

Trimenia 297, 301

Trimeniaceae 266, 301

Trinia glauca 214

Trinodes 56

Trinodinae 56

trioecy 227, 237, 289

Trisema 250

Triumfetta 323

Trixagidae 16, 55

Trixoscelidae 107

Trochilidae 285, 286

Trochilus colubris 259

Trochodendraceae 296

Trogidae 15

Trogossitidae 18, 56

Trollius 251, 267

Tropideres 63

Tropinota 14, 15

trumpet-shaped blossom 134, 235, 288, 327, 345

Trypetidae 108

Tshekardocoleus 42, 46, 64

Tuberaria guttata 225

tube-shaped blossom 134, 235, 287, 321, 327

Tubiflorae 212, 213, 332

Tulipa 262, 337

Tunica 213

Turdidae 285, 286

Turgenia latifolia 216, 222

Turonian 300

Tussilago 213

Typha latifolia 320

Typhaceae 318,320

Typhoctinae 79

Typhoctini 79

Typhonium trilobatum 14

Tyria jacobaeae 30

\section{Ulidiidae 108}

Ulmaceae $68,302,313,322,328$

Ulmus 117, 190, 204, 267, 313

U. glabra 117,118

$U$. laevis 118

U. minor 118

Uloma 58

Ulomini 58

Umbellales 177

uniformitarianism 6

unisexual flowers 299

Unona 248

Uraniidae 29

Urtica 190

Urticaceae 322

Utricularia minor 336

Uvaria 248
Vaccaria 213

Vaccinium 329

Vaccinioideae 303

Valeriana 199

$V$. (cf) officinalis 339,372

Valerianaceae 256, 267, 336, 339, 372

Valgus 14, 15

Valginae 15,54

Vanessa cardui 164

$V$. urticae 258

Vanhorniidae 70

Vanilla 199

V. fragrans 199

Vantanea 325

Vardekloeftia 279

Variimorda fasciata 18

Veneblesia collurium 56

Veratrum 261

Verbascum 260

V. nigrum 341

Verbena 199

Verbenaceae 296, 326

Veronica 260, 261

V. agrestis 226

V. alpina 261

$V$. anagallis 261

$V$. arvensis 226, 261

$V$. beccabunga 261

V. chamaedrys 261

$V$. hederifolia 226, 261

$V$. montana 261

$V$. officinalis 261

$V$. peregrina 226

$V$. persica 226, 261

$V$. polita 226

V. serpyllifolia 226,261

V. spuria 261

V. triphyllos 226, 261

Vespa 81, 82, 260

V. rufa 161

Vespidae 25, 80, 81, 82, 295

Vespinae 81

Vespoidea $25,76,78,80,169,170,177,305$

Vibumum 218, 256, 306

V. grewiopsium 306

V. lantana 369

V. opulus 369

Vicia sativa 225

V. villosa 124

Victoria 15

V. amazonica 269

Vigna 335

$V$. sinensis 162

Vinca 260,306

Viola 199

V. biflora 226 
V. canina 226

$V$. cucullata 226

$V$. eliator 226

V. hirta 226

$V$. lutea 372

V. mirabilis 226

V. persicifolia 226

V. reichenbachiana 226

$V$. rupestris 226

V. suavis 226

Violaceae 226, 329, 372

Violales 177

Virola 338

Viscaceae 325

Viscaria 213

Viscum 325

Vitaceae 267, 326

Vitex 326

Vitis 134, 326

$V$. vinifera 222

Vochysia 331

Vochysiaceae 331

Volucella bombylans 258

$V$. zonaria 35

Wahlenbergia 340

Walchia 46

wasp-pollinated flowers $112,233,284,307$, 327

wasps $10,110,111,300$

Weinmannia 319, 321

Welwitschia 209, 264, 272

W. bainesii 279

Welwitschiaceae 279

Wielandiella 262, 278

W. angustifolia 278

Wielandiellaceae 262, 278

Williamsonia 278

W. gigas 279

W. harrisiana 279

W. hildae 279

W. sewardiana 279

Williamsoniaceae 262, 278

Williamsoniella 209, 278, 281

W. coronata 270,278

W. lignieri 278

Winteraceae 243, 247, 266, 267, 268, 294, $295,296,298$

Xanthium 213 xanthophylls 149, 176, 177, 179

Xanthophyllum 335

Xenoglossa 259

Xiphydriidae 23, 69

$X$ yela julii 22, 64

Xyeliciinae 68

Xyelidae 22, 64, 67, 190

Xyelinae 22, 64, 67, 68

Xyeloidea 22, 66, 67

Xyelotomidae 66, 68

Xyelya 69

Xyelydidae 69

Xylocopa 121, 165

$X$. valga 124

$X$. violacea 125

Xylopia 249, 312, 322

Xylocopiaecarpum 249

Xylomyidae 34, 102

Xylophagidae 34

Xyloryctidae 28

Yponomeutidae 27, 92

Yponomeutoidea 27, 92, 93

Yucca 92

Yucca moth 26, 92

Zabrinae 21

Zamia 63

Zanthoxylum 324, 331

Zauscheria 315

Zelkowa 322

Zeugloptera 26, 89, 90, 278

Zingiberaceae 332

Zingiberales 177

Zizia aurea 203

Zopheridae 19

Zoraptera 43

Zostera 317

Zosteraceae 317

Zosteropidae 285

Zygaena 258

Z. camiolica 258

$Z$. lonicerae 258

Z. trifolii 258

Zygaenidae 28

Zygaenoidea 28, 94

Zygogynum 247

zygomorphic 129, 235, 287, 308, 321

Zygophyllaceae 331

Zygophyllum 331 